University of Louisville

ThinkIR: The University of Louisville's Institutional Repository

$12-2004$

\title{
Probing the properties of the second coordination sphere of biologically relevant metal complexes using amide function.
}

Lionel E. Cheruzel 1976-

University of Louisville

Follow this and additional works at: https://ir.library.louisville.edu/etd

\section{Recommended Citation}

Cheruzel, Lionel E. 1976-, "Probing the properties of the second coordination sphere of biologically relevant metal complexes using amide function." (2004). Electronic Theses and Dissertations. Paper 241. https://doi.org/10.18297/etd/241

This Doctoral Dissertation is brought to you for free and open access by ThinkIR: The University of Louisville's Institutional Repository. It has been accepted for inclusion in Electronic Theses and Dissertations by an authorized administrator of ThinkIR: The University of Louisville's Institutional Repository. This title appears here courtesy of the author, who has retained all other copyrights. For more information, please contact thinkir@louisville.edu. 
PROBING THE PROPERTIES OF THE SECOND COORDINATION SPHERE

OF BIOLOGICALLY RELEVANT METAL COMPLEXES USING AMIDE

FUNCTIONALIZED IMIDAZOLE LIGANDS AND OTHER HYDROGEN

BONDING MOIETIES

By

Lionel E. Cheruzel

\begin{abstract}
A Dissertation
Submitted to the Faculty of the

Graduate School of the University of Louisville

In Partial Fulfillment of the Requirements

For the Degree of

Doctor of Philosophy
\end{abstract}

Department of Chemistry

University of Louisville

Louisville, Kentucky

December, 2004 
PROBING THE PROPERTIES OF THE SECOND COORDINATION SPHERE

OF BIOLOGICALLY RELEVANT METAL COMPLEXES USING AMIDE

FUNCTIONALIZED IMIDAZOLE LIGANDS AND OTHER HYDROGEN

BONDING MOIETIES

By

Lionel E. Cheruzel

French Engineer Degree, Ecole Nationale Superieure de Chimie de Montpellier, 2000

A Dissertation Approved on

By the following Dissertation Committee:

Dissertation Director 


\section{ACKNOWLEDGEMENTS}

The author would like to gratefully acknowledge the invaluable assistance of his advisor, Dr. Robert M. Buchanan; no one has done more to make this dissertation possible. His leadership, critiques, insight and support were only a small part of his contribution, and the author will always remember the five years under his guidance with much fondness and gratitude. The author also would like to thank the members of his committee; Drs. Grapperhaus, Noble, Taylor and Trent. He would like to express his

deepest gratitude to Dr. Mark S. Mashuta for his valuable insights and assistance during crystallography training. His gratitude is further extended to Dr. Sara E. Edison and Dr. Michael J. Baldwin from the University of Cincinnati for their help in Raman data collection. The author also would like to acknowledge the assistance of talented research assistants from the University of Louisville; Ned Smith in Dr. William M. Pierce‘s laboratory at the department of Pharmacology for providing ESI-MS spectra and also Rodica B. McCoy from the Engineering School for her help in the acquisition of TGA and DSC data as well as powder diffraction measurements. The author would like to express his appreciation to Dr. Maxim S. Pometum and Dr. Richard J. Wittebort for their collaboration in the solid-state NMR experiments as well as Dr. Anton S. Petrov and Dr. George R. Pack for their continual help in theoretical calculations. The expertise of Dr. Neal J. Stolowich in NMR spectroscopy was also invaluable. 
The author has other personal acknowledgements. The most important is to his family, parents Christian and Danièle, grandmother Cathy, and sister Elodie Cheruzel whose moral support, patience and encouragement have made this work a success; to Anna and Alexander Tchernatinsky for their friendship; and to his lab mates Elizabeth A. Romaine-Schmidt, Brian C. Frye, Leland L. Civils, Phillip D. Bauer and a special thanks to Matthew R. Cecil for his great assistance and friendship.

The author would like to personally thank Dr. Florence M. Brunel for her genuine support and friendship during these years. The author is deeply indebted to Mr. Allan M. Steinberg who made the author's stay in Louisville memorable. Finally, warm thoughts go out to Carrie "Biquette" Turner.

This work would not have been possible without the financial support of the Graduate School and the University of Louisville in a teaching assistantship position and the National Science Foundation (Grant No. CHE-0328406), and the Kentucky Science and Engineering Foundation (Grant No. KSEF-275-RDE-003) grants. The generous grant from the Brown Cancer Center and the Chemistry Department provided further support in developing the author's expertise in X-ray crystallography. 
A la mémoire de mes deux grands-pères, Humbert Dolla et Pierre Chéruzel, qui me manquent beaucoup. 


\begin{abstract}
PROBING THE PROPERTIES OF THE SECOND COORDINATION SPHERE OF BIOLOGICALLY RELEVANT METAL COMPLEXES USING AMIDE FUNCTIONALIZED IMIDAZOLE LIGANDS AND OTHER HYDROGEN BONDING MOIETIES

Lionel E. Cheruzel

December, 2004
\end{abstract}

This dissertation deals with various imidazole compounds with emphasis on hydrogen bond interactions and weaker intermolecular forces. New amide functionalized polyimidazole metal binding pockets are able to form intramolecular six-membered hydrogen bonded rings with apical ligands bonded to the metal. The design of such ligands has been successful in the stabilization and characterization of mononuclear $\mathrm{Cu}-$ $\mathrm{OH}$ and $\mathrm{Cu}-\mathrm{OOH}$ species. The end-on $\mathrm{Cu}-\mathrm{OOH}$ species was characterized by $\mathrm{UV}$-visible (band at $365 \mathrm{~nm}$ with $\left.\varepsilon=1500 \mathrm{M}^{-1} \mathrm{~cm}^{-1}\right)$, EPR, ESI-MS and Raman spectroscopy $\left(v_{\mathrm{O}-\mathrm{O}}=\right.$ $854 \mathrm{~cm}^{-1}$ which shifts by $46 \mathrm{~cm}^{-1}$ upon ${ }^{18} \mathrm{O}$ substitution).

Simple imidazole ligands were synthesized by general Mannich-type reactions. The ligand $\mathrm{L}^{\mathrm{Et}, \mathrm{Me}}\left(\mathrm{L}^{\mathrm{Et}, \mathrm{Me}}=4,4^{\prime}\right.$-methylene-bis(2-ethyl-5-methylimidazole)) stabilizes late divalent first row transition metal complexes in 1:1 and 2:1 ligand-to-metal ratios. N-H--$\mathrm{Cl}$ hydrogen bonds stabilize supramolecular assemblies with interesting chloride 
arrangements. The $\left[\mathrm{Co}\left(\mathrm{L}^{\mathrm{Et}, \mathrm{Me}}\right)_{2}\right] \mathrm{Cl}_{2}$ crystallizes in the monoclinic space group $\mathrm{C} 2 / \mathrm{c}, \mathrm{Z}=$ 12, with lattice dimensions of $\mathrm{a}=28.684(5) \AA, \mathrm{b}=25.247$ (5) $\AA, \mathrm{c}=13.393$ (2) $\AA$ and $\beta$ $=110.743(4)^{\circ}$. Its crystal structure displays tubular channels with internal dimensions of $8.43 \times 3.75 \AA^{2}$ with $\operatorname{Co}(\mathrm{II})$ atoms facing each other within the channel. The study also includes crystal structures of nitroimidazole synthons used in amide ligand synthesis, which demonstrate the importance of weak C-H---O(nitro) hydrogen bonding in stabilizing supramolecular assemblies. The compound, (bis(1-methyl-imidazol-2yl)methyl)((1-methyl-4-nitroimidazol-2-yl)methyl)amine, and boric acid co-crystallize in the monoclinic space group $\mathrm{P} 2{ }_{1} / \mathrm{n}, \mathrm{Z}=4$, lattice dimensions $\mathrm{a}=$ 15.7997(18) $\AA, b=8.2540(9) \AA, c=27.530(3) \AA$ and $\beta=92.861(2)^{\circ}$. The resulting supramolecular structure contains bundled antiparallel imidazole-boric acid coils and boric acid filled one-dimensional channels.

A variety of imidazole hydrates has been characterized that illustrates many of the fundamental properties of water. Important forms of water have been isolated within imidazole hosts: one-dimensional water chains and also water clusters with four-, fiveand six-membered hydrogen bonded water rings. These forms of water are thought to play crucial roles in biological systems by participating in protein structure, function, hydration and recognition and in the transport of protons or water molecules. 


\section{TABLE OF CONTENTS}

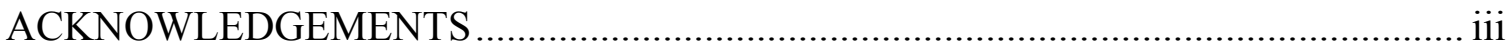

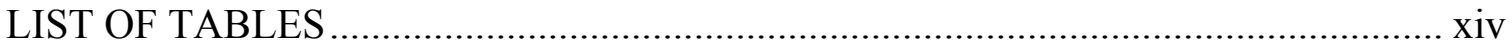

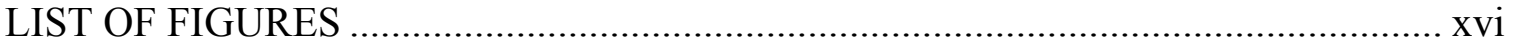

LIST OF COMPOUNDS AND NOMENCLATURE ............................................... xxiii

\section{CHAPTER}

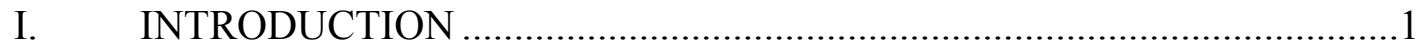

II. EXPERIMENTAL SECTION ............................................................. 18

A. Physical Measurements.......................................................... 18

1. Differential Scanning Calorimetry...................................18

2. Elemental Analysis ......................................................19

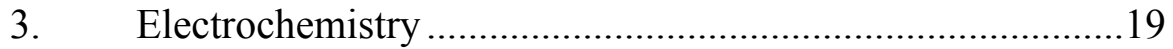

4. Electronic Spectroscopy ….......................................20

5. Electron Paramagnetic Resonance....................................20

6. Infrared Spectroscopy ............................................. 21

7. Resonance Raman Spectroscopy ....................................22

8. Mass Spectrometry …...............................................23

9. Melting Point ...................................................................23

10. Nuclear Magnetic Resonance Spectroscopy .......................23

11. Thermogravimetry Analysis ............................................24

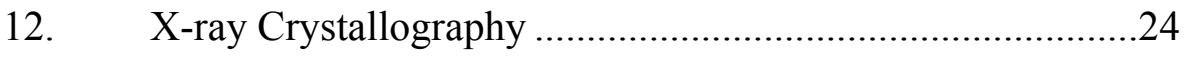

B. Chemical Reagents ................................................................ 26

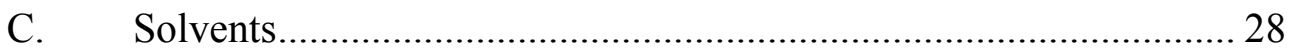


III. BIDENTATE IMIDAZOLE LIGANDS

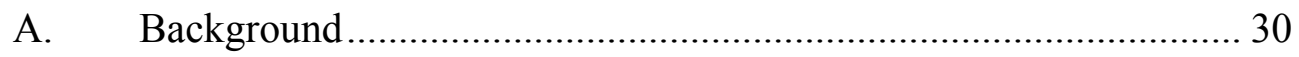

B. Synthesis and Characterization of Bis-imidazole Ligands ............... 33

1. $\quad 4,4^{\prime}$-Methylene-bis(2-ethyl-5-methyl-imidazole) ...................33

2. 4,4'-Methylene-bis(2,5-dimethyl-imidazole).........................33

C. Mono-adduct Complexes of $\mathrm{Cu}(\mathrm{II}), \mathrm{Ni}(\mathrm{II}), \mathrm{Co}(\mathrm{II})$ and $\mathrm{Zn}(\mathrm{II})$ with 4,4'-Methylene-bis(2-ethyl-5-methyl-imidazole) (1).........................33

1. Synthesis of the Mono-adduct Metal Complexes ...................33

2. Characterization of the Mono-adduct Metal Complexes......34

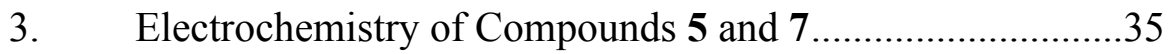

4. Evaluation of the Crystal Structures of the Mono-adduct

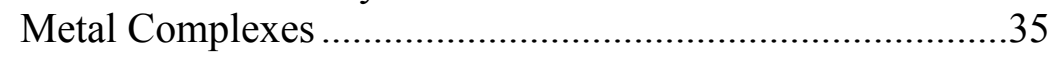

5. Solid-state Packing Diagrams of the Mono-adduct Metal Complexes

D. Bis-adduct Complexes of $\mathrm{Cu}(\mathrm{II}), \mathrm{Ni}(\mathrm{II}), \mathrm{Co}(\mathrm{II})$ and $\mathrm{Zn}(\mathrm{II})$ with $4,4^{\prime}$

-Methylene-bis(2-ethyl-5-methyl-imidazole) ................................... 40

1. Synthesis of the Bis-adduct Metal Complexes ………….......41

2. Characterization of the Bis-adduct Metal Complexes ...........42

3. Evaluation of the Crystal Structures of

Compounds 8 and 9

4. Solid-state Packing of Compound 8

5. Square Planar Complexes of $\left[\mathrm{M}\left(\mathrm{L}^{\mathrm{Et}, \mathrm{Me}}\right)_{2}\right] \mathrm{Cl}_{2}$

where $\mathrm{M}=\mathrm{Cu}, \mathrm{Ni}$

6. Five-coordinate Complexes of $\left[\mathrm{M}\left(\mathrm{L}^{\mathrm{Et}, \mathrm{Me}}\right)_{2} \mathrm{Cl}\right] \mathrm{Cl}$ where $\mathrm{M}=\mathrm{Cu}, \mathrm{Ni}$ .48

7. EPR Characterization of $\mathrm{Cu}(\mathrm{II})$ Complexes …………….......51

E. Reactivity Scheme for the $\mathrm{Ni}(\mathrm{II})$ Complexes ................................... 54

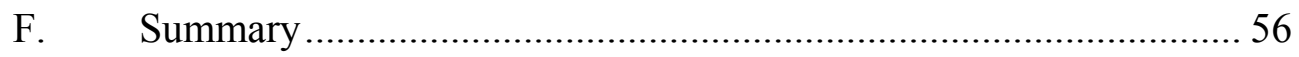


IV. SYNTHESIS OF NOVEL AMIDE FUNCTIONALIZED IMIDAZOLE TRIPODS

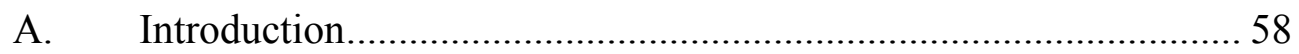

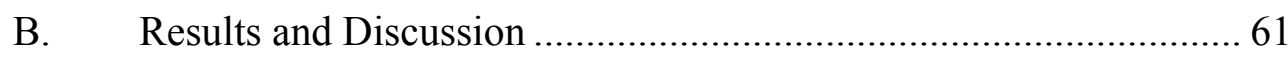

1. Synthesis of the 1-Methyl-4-nitro-imidazol-2carboxaldehyde Synthon (15).

2. Synthesis of Amide Functionalized Imidazole Tripods, L1 and $\mathbf{L} 2$

3. Synthesis of 1-Methyl-4-pivaloylamido-imidazole-2carboxaldehyde (26)

4. New Synthetic Strategy for Preparing Amide-functionalized

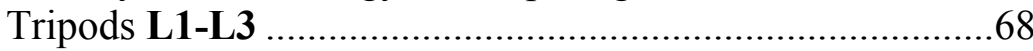

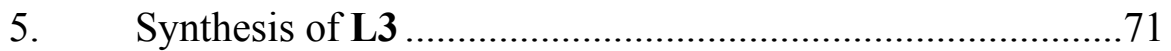

6. ${ }^{1} \mathrm{H}$ NMR Spectra of L1-3 _....................................................

7. Versatility of the Synthetic Strategy ......................................73

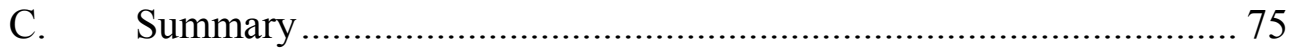

D. Experimental Section ................................................................ 76

V. METAL COMPLEXES OF THE NOVEL AMIDE FUNCTIONALIZED

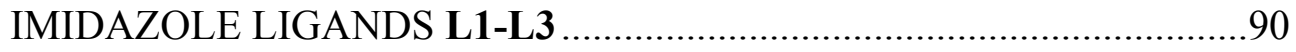

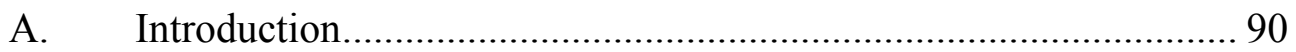

B. Iron(III) Complex of L1 (35) .................................................... 91

C. Synthesis, Structure and Properties of $\mathrm{Cu}$ (II) Complexes of $\mathbf{L 2}$..... 95

1. Synthesis and Characterization of the $\mathrm{Cu}(\mathrm{II})$ complexes of

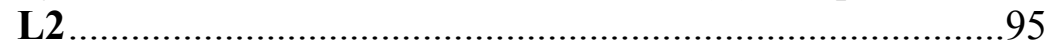

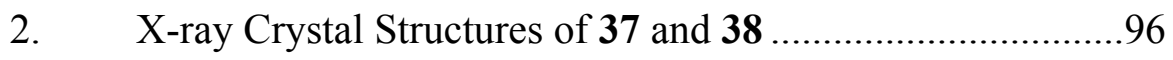

3. $\quad$ EPR Characterization of Compounds $\mathbf{3 7}$ and $\mathbf{3 8} \ldots \ldots \ldots \ldots \ldots . . . .100$

D. Synthesis and Characterization of $[\mathrm{Cu}(\mathbf{L} 2) \mathrm{OH}] \mathrm{ClO}_{4}(\mathbf{3 9}) \ldots \ldots \ldots . . .102$

E. Synthesis and Characterization of $\left[\mathrm{Cu}(\mathbf{L 2}) \mathrm{N}_{3}\right] \mathrm{ClO}_{4}(\mathbf{4 0}) \ldots \ldots \ldots \ldots . . .106$ 
F. Summary of the EPR Parameters for the $\mathrm{Cu}(\mathrm{II})$

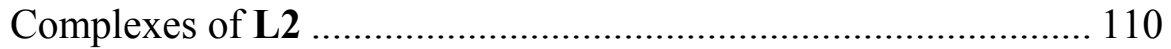

G. Crystal Structure of the L2 Ligand .............................................. 111

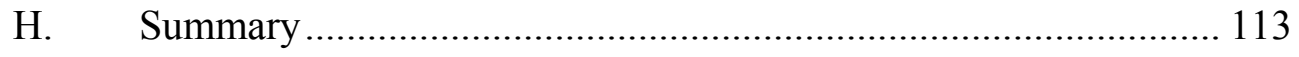

VI. SUPRAMOLECULAR ASSEMBLIES OF NITROIMIDAZOLE COMPOUNDS AND BORIC ACID TEMPLATING AGENT..................115

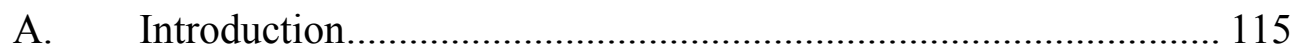

B. Synthesis and Characterization of Nitro and Tripodal Imidazole Compounds ............................................................................ 119

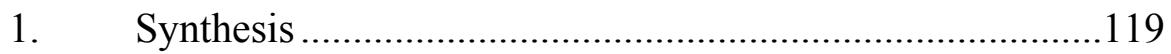

2. Characterization of Compounds 41 and $42 \ldots \ldots \ldots \ldots \ldots \ldots \ldots \ldots . . . . .120$

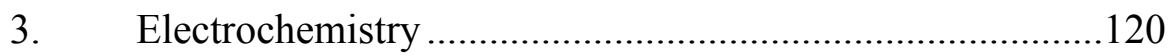

C. Crystal Structure of 2-Hydroxymethyl-1-methyl-4-nitro-imidazole

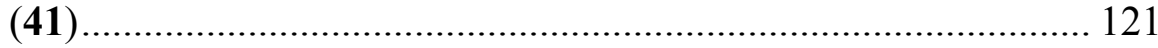

D. Crystal Structure of 1-Methyl-4-nitroimidazole-2-carboxaldehyde

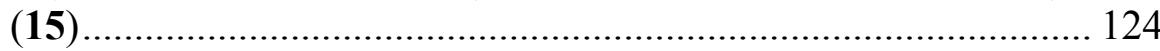

E. Crystal Structure of 1-Methyl-4-nitroimidazole-2-carboxylic acid

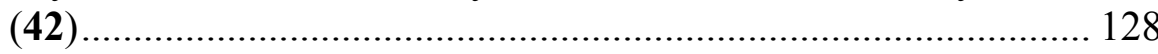

F. Crystal Structure of 1-Methyl-4-nitroimidazole-2-acetal (21) ...... 131

G. Summary of the Nitroimidazole Study .......................................... 133

H. Evaluation of the Crystal Structure of

Tmima:boric acid (1/1) (43) ...................................................... 134

I. Evaluation of the Crystal Structure of Compound 16 : boric acid

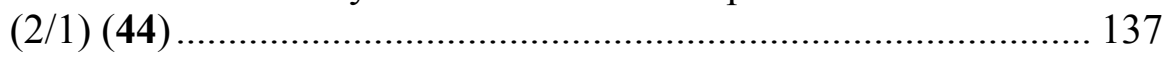

VII. REACTIVITY OF CU(II) COMPLEXES WITH $\mathrm{H}_{2} \mathrm{O}_{2} \ldots \ldots \ldots \ldots \ldots \ldots \ldots \ldots \ldots \ldots . . . . . . . . . . . .144$

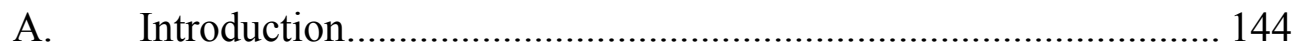

B. Reactivity of Compounds $\mathbf{1 3}$ and $\mathbf{1 4}$ with Hydrogen Peroxide ..... 148

1. UV-vis Characterization ................................................... 148

2. Reactivity of the LEt,Me Ligand ..................................... 150 
3. EPR Characterization

C. Isolation and Characterization of a Mononuclear $\mathrm{Cu}-\mathrm{OOH}$ Species with the L2 Ligand, (45)....................................................... 154

1. $\quad \mathrm{UV}$-vis Characterization of $[\mathrm{Cu}(\mathbf{L 2}) \mathrm{OOH}]^{+} \ldots \ldots \ldots \ldots \ldots \ldots . . . . . . . .155$

2. $\quad$ EPR Characterization of $[\mathrm{Cu}(\mathbf{L 2}) \mathrm{OOH}]^{+} \ldots \ldots \ldots \ldots \ldots \ldots \ldots \ldots . . . \ldots \ldots$

3. Resonance Raman Characterization of $[\mathrm{Cu}(\mathbf{L 2}) \mathrm{OOH}]^{+} \ldots 157$

4. ESI-MS Characterization of $[\mathrm{Cu}(\mathbf{L 2}) \mathrm{OOH}]^{+} \ldots \ldots \ldots \ldots \ldots \ldots . . . . . .158$

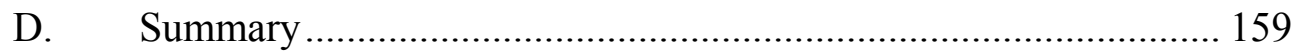

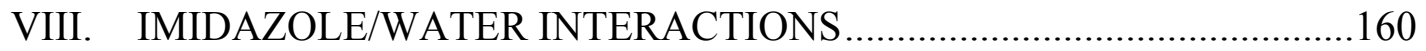

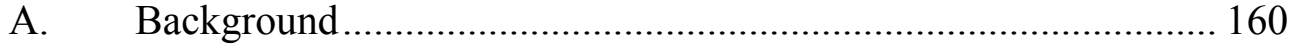

B. Synthesis of the Imidazole Ligands ........................................... 164

C. Synthesis and Characterization of Compounds 46-51 ................ 165

1. (Bis(2-ethyl-5-methylimidazol-4-yl)methyl)((1methylimidazol-2-yl)methyl)amine (46)

2. N,N-Bis(2-ethyl-5-methylimidazol-4-methyl) glycine (47) 166

3. $\quad \mathrm{N}, \mathrm{N}, \mathrm{N}^{\prime}, \mathrm{N}^{\prime}$-Tetrakis((2-ethyl-5-methylimidazolyl-4-) methyl)ethylene diamine (48).

4. $\quad \mathrm{N}, \mathrm{N}, \mathrm{N}^{\prime}, \mathrm{N}^{\prime}-$ Tetrakis((2,5-dimethylimidazolyl-4-) methyl)ethylene diamine (49)

D. X-ray Crystallographic Analysis of Compounds 46 and 47

Monohydrates . 168

E. Extended Hydrate Structures .................................................... 172

F. Evaluation of the Crystal Structure of Compound 1................... 177

G. Evaluation of the Crystal Structures of Compounds 48 and 49 .... 179

H. Arrangement of Waters in Compound 48 ............................... 184

1. Chair-like Conformation of the Six-membered Water Ring (O2, O3, O5, O2', O3', O5'). 
2. Four-membered Water Ring (O3, O4, O3', O4') .189

I. Analysis of the Crystal Structure of Compound 49 192

1. Five-membered Water Ring A (O1, O2, O4, O5, O9).......194

2. Five-membered Water Ring B (O9, O5, O6, O3, O12).....197

3. Six-membered Water Ring $\mathrm{C}$

$(\mathrm{O} 2, \mathrm{O} 3, \mathrm{O} 6, \mathrm{O} 11, \mathrm{O} 10, \mathrm{O} 4)$........................................200

4. Fourteen-membered Water Ring .....................................203

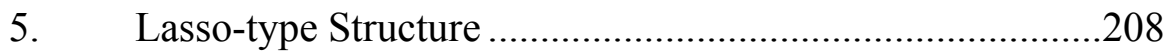

6. Sixteen-membered Water Ring.......................................210

7. Seventeen-membered Water Ring ..................................212

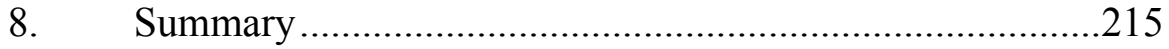

J. Thermogravimetric Analyses (TGA) and Differential Scanning Calorimetry (DSC) Studies ................................................... 216

K. Powder X-ray Diffraction Study............................................ 219

L. $\quad$ Solid-state ${ }^{2} \mathrm{H}$ NMR Spectroscopy ......................................... 220

1. Crystal Structure of 4(5)-Methyl-2-phenylimidazole .........221

2. Reorientational Behavior of the Water Molecules in the Solid-state .222

M. Solid-state ${ }^{17} \mathrm{O}$ NMR Experiment ......................................... 225

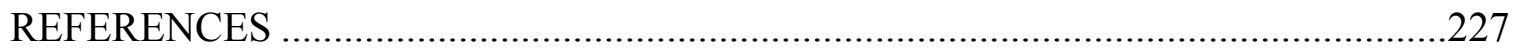

APPENDIX

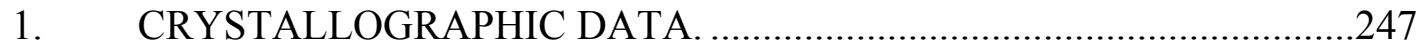

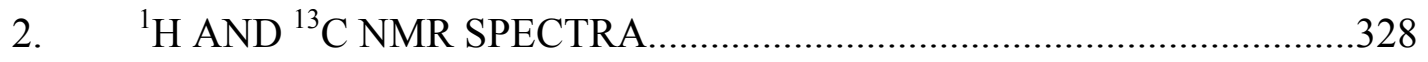

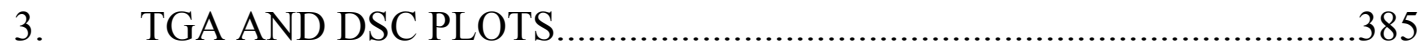

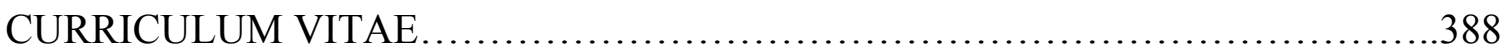




\section{LIST OF TABLES}

\section{TABLE}

1. UV-visible transitions for the series of $\mathrm{MLCl}_{2}$ complexes .............................34

2. ESI-MS mass units and elemental analyses of the $\mathrm{MLCl}_{2}$ complexes ............34

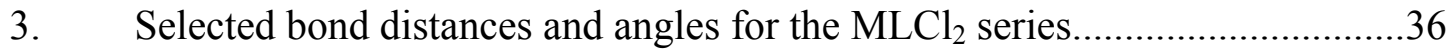

4. UV-visible transitions for the series of $\mathrm{ML}_{2} \mathrm{Cl}_{2}$ complexes.........................42

5. ESI-MS mass units and elemental analyses of the bis-adduct complexes.......43

6. Selected bond distances and angles for compounds 8 and 9 .......................44

7. Selected bond distances and angles for compounds $\mathbf{1 0}$ and $\mathbf{1 1} \ldots \ldots \ldots \ldots \ldots \ldots . . . . . . . .47$

8. Selected bond distances and angles for compounds $\mathbf{1 2}$ and $\mathbf{1 3} \ldots \ldots \ldots \ldots \ldots \ldots \ldots . . . . . . . . .50$

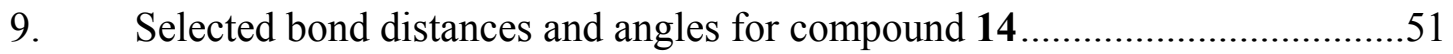

10. EPR parameters of $\mathrm{Cu}(\mathrm{II})$ complexes of $\mathbf{1}$ in frozen methanol solution..........54

11. Bond distances and angles of iron(III) complexes of tmima and $\mathbf{L 1}$..............93

12. Bond distances and angles for compounds $\mathbf{3 7}$ and $\mathbf{3 8}$ and other related $\mathrm{Cu}(\mathrm{II})-\mathrm{Cl}$ complexes with tripodal pyridine ligands ................................98

13. Selected bond distances and angles for compound $\mathbf{3 9}$ and other related $\mathrm{Cu}-\mathrm{OH}$ complexes......................................................................... 104

14. Bond distances and angles for compound $\mathbf{4 0}$ and other related $\mathrm{Cu}-\mathrm{N}_{3}$

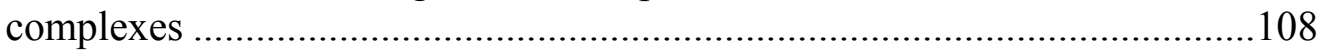

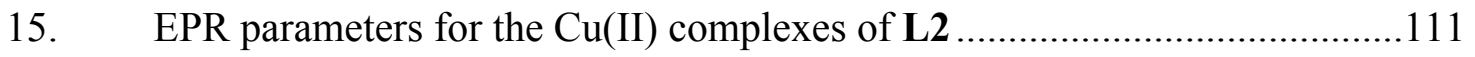

16. $E_{1 / 2}$ potentials for the series of nitroimidazole compounds ........................121

17. Summary of all the resonance Raman $v(\mathrm{O}-\mathrm{O})$ vibrations for mononuclear $\mathrm{Cu}(\mathrm{II})-\mathrm{OOH}$ complexes 158

18. Selected O---O separations and O-H---O angles for compounds $\mathbf{2}$ and $\mathbf{5 2} \ldots 175$ 
19. Selected O---O separations and O---O---O, O-H---O angles for the sixmembered water rings

20. Selected O---O separations and O---O---O, O-H---O angles for the fourmembered water ring with two wingtip water molecules

21. Selected O---O separations, O---O---O and O-H---O angles for ring A.........196

22. Selected O---O separations, O---O---O and O-H---O angles found in ring $\mathrm{B}$

23. Selected O---O separations, O---O---O and O-H---O angles in the six -membered water ring $\mathrm{C}$

24. Selected O---O separations, O---O---O and O-H---O angles found in the lasso-type structure

25. Selected O---O separations, O---O---O and O-H---O angles found in the fourteen-membered water ring.

26. Selected O---O separations, O---O---O and O-H---O angles found in the sixteen-membered water ring.....

27. Selected O---O separations, O---O---O and O-H---O angles found in the seventeen-membered water ring.

28. TGA experiment results illustrating the weight lost corresponding to the lost of water molecules for all hydrate compounds

29. DSC results showing the dehydration temperatures and the corresponding hydrogen bond strength per water molecule for all hydrated compounds.....218 


\section{LIST OF FIGURES}

\section{FIGURE}

1. Representation of the histidine amino acid ............................................

2. Representations of imidazole and pyrrole based drugs.................................

3. Illustration of structural metalloenzyme active site ..................................6

4. Illustrations of Copper proteins and their reactions with dioxygen ..................

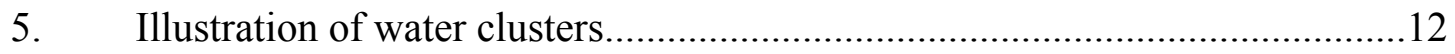

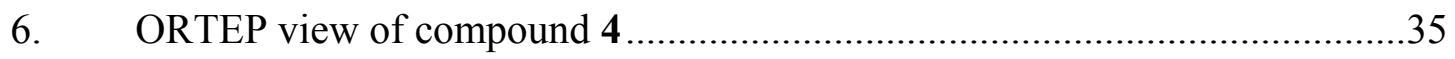

7. Hydrogen bonding interactions between imidazole $\mathrm{N}-\mathrm{Hs}$ and $\mathrm{Cl}$ bonded to the metal in compounds $\mathbf{3}, \mathbf{5}$ and $\mathbf{6}$

8. Packing diagram of compound $\mathbf{5}$ showing the hydrogen-bonded assemblies of tapes along the crystallographic c axis

9. Packing diagram of the compound $\mathbf{3}$ showing the $3-\mathrm{D}$ hydrogen bonding network

10. Hydrogen bonding interactions between imidazole $\mathrm{N}-\mathrm{Hs}$ and $\mathrm{Cl}$ bonded to the metal found in the packing arrangement of 4

11. ORTEP view of compound 7.

12. ORTEP views of the cationic portions of compounds 8 and 9

13. Packing diagram of the chlorine atoms in the $\mathrm{Co}\left(\mathrm{L}^{\mathrm{Et}, \mathrm{Me}}\right)_{2}$ that forms a parallelepiped box with a diamond pattern on the faces

14. Arrangement of the Co atoms in compound 8 showing the potential reaction chamber. The green spheres represent the chlorine atoms encapsulating the inorganic cation.

15. ORTEP view of the two independent cationic portions of $\mathbf{1 0}$, as well as the hydrogen bonding interactions between imidazole N-Hs and the outer sphere chlorine and water molecules 
16. Discrete cluster of four water molecules and four chlorine atoms stabilized in the lattice of the compound $\mathbf{1 0}$

17. ORTEP view of the cationic portion of compound 13 .................................49

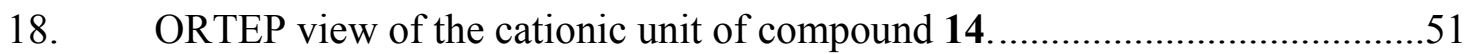

19. $\quad$ EPR spectra of crystalline samples of compounds 5 and 7 .........................52

20. EPR spectra of frozen methanolic solution of compounds 5, 7, 13 and $\mathbf{1 4}$

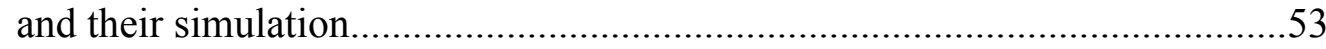

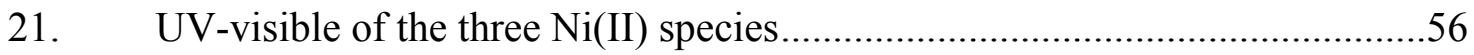

22. Novel metal binding pockets based on the polyimidazole tripod ligand, tmima, illustrating the amide pendant capable of forming the intramolecular six-membered hydrogen bonds, L1-3 ......................................60

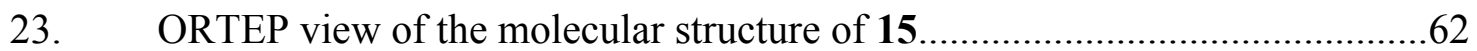

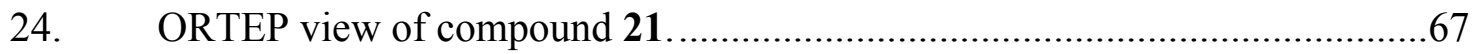

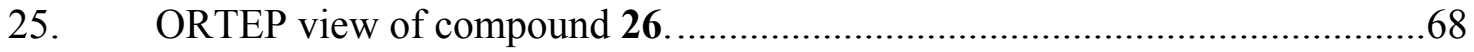

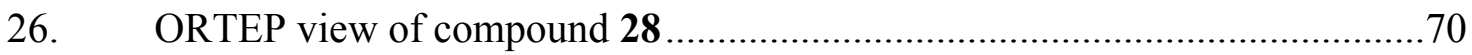

27. ${ }^{1} \mathrm{H}$ NMR spectra of the amide functionalized imidazole tripods L1-3 …........72

28. ORTEP view of the cationic portion of compound 35 ...............................92

29. ORTEP view of the cationic portion of compound 38 .................................

30. Capped-stick top-view representations of $[\mathrm{Cu}(\mathbf{L 2}) \mathrm{Cl}]^{+},[\mathrm{Cu}(\mathbf{L 3}) \mathrm{Cl}]^{+}$and $[\mathrm{Cu}(\text { tppa }) \mathrm{Cl}]^{+}$

31. EPR spectra of frozen solutions of $\mathbf{3 7}$ and $\mathbf{3 8}$

32. ORTEP view of the cationic portion of compound $\mathbf{3 9}$

33. Experimental and simulated X-band EPR spectra of a frozen methanolic solution of $\mathbf{3 9}$

34. Theoretical and experimental isotopic distribution obtained from ESI-MS experiment for $\mathrm{m} / \mathrm{z}$ of $[\mathrm{Cu}(\mathbf{L} 2) \mathrm{OH}]^{+}$and $[\mathrm{Cu}(\mathbf{L} 2) \mathrm{OMe}]^{+} \ldots \ldots \ldots \ldots \ldots \ldots \ldots \ldots \ldots . . . . . . . . . . .106$

35. ORTEP view of the cationic portion of $\mathbf{4 0}$ 107 
36. Top-view of capped-stick representations of $\left[\mathrm{Cu}(\mathbf{L} 2) \mathrm{N}_{3}\right]^{+}$and $\left[\mathrm{Cu}(\mathrm{Hbppa}) \mathrm{N}_{3}\right]^{+}$indicating the twisting of the rings in the latter compound...

37. Experimental and simulated X-band EPR spectra of a frozen methanolic solution of compound $\mathbf{4 0}$

38. ORTEP view of the $\mathbf{L} 2$ ligand hydrogen bonded to a water molecule

39. Capped-stick representation of the intermolecular interaction present in the crystal structure of $\mathbf{L} \mathbf{2}$

40. ORTEP view of compound $\mathbf{4 1}$

41. Capped-stick representation of compound $\mathbf{4 1}$ illustrating the intermolecular forces present in the crystal structure

42. Illustration of the herringbone pattern found in the packing arrangement of 41

43. ORTEP view of compound $\mathbf{1 5}$.

44. Capped-stick representation of the tetrameric unit of compound $\mathbf{1 5}$ illustrating the weak intermolecular forces present in the packing diagram such as C-H---O, C-H---N, $\pi$-stacking

45. Illustration of the $\mathrm{C}=\mathrm{O}---\mathrm{N}$ and the point-to-face $\pi$-stacking interactions in 15

46. Packing diagram of the tetrameric units of compound $\mathbf{1 5}$

47. ORTEP view of compound $\mathbf{4 2}$

48. Illustration of the interactions present in the crystal structure of compound 42 including strong and weak C-H---O hydrogen bond interactions.

49. Packing diagram of compound $\mathbf{4 2}$ illustrating the $\pi$-stacked layers

50. ORTEP view of compound $\mathbf{4 1}$

51. Illustration of the $\mathrm{C}-\mathrm{H}---\mathrm{O}$ interactions present in the crystal structure of 41.

52. ORTEP view of the two molecular components of 43

53. Packing diagram of 43, displaying the hydrogen bonding interaction between imidazole rings and boric acid molecules, and the $\pi-\pi$ stacking interactions between imidazole rings containing atom $\mathrm{N} 2$ 
54. ORTEP view of the three molecular components of $\mathbf{4 4}$

55. Views of the complementary antiparallel coils of 44, as well as the capped -stick representation and space filling model of the side-by-side coils resulting from hydrogen bonding and $\pi-\pi$ stacking interactions projected along the crystallographic a axis.

56. Closest interatomic contacts between $\pi$-stacked imidazole molecules associated with rings $\mathrm{F}$ and $\mathrm{C}, \mathrm{A}$ and $\mathrm{E}, \mathrm{A}$ and $\mathrm{F}$

57. Weak intermolecular hydrogen bonding contacts between nitro group oxygens and imidazole ring hydrogens.

58. Closest interatomic contacts between $\pi$-stacked imidazole molecules associated with rings $\mathrm{B}$ and $\mathrm{B}, \mathrm{D}$ and $\mathrm{D}$

59. Packing diagram of $\mathbf{4 4}$ projected along the crystallographic bc plane showing the intermolecular hydrogen bonding and parallel $\pi-\pi$ stacking interactions between neighboring interlocked coiled units

60. UV-visible spectrum of the proposed $\left[\mathrm{Cu}(\mathrm{III})_{2}\left(\mu-\mathrm{O}_{2}\right)\left(\mathrm{L}^{\mathrm{Et}, \mathrm{Me}}\right)_{2}\right] \mathrm{Cl}_{2}$ species..149

61. UV-vis spectra of the further reaction of compounds $\mathbf{1 3}$ and $\mathbf{1 4}$ with $\mathrm{H}_{2} \mathrm{O}_{2}$ consistent with the oxidation of the ligand and the generation of an organic radical

62. Representation of the molecular structure of lophine

63. EPR spectra of the starting $\mathrm{Cu}$ (II) complex, 13, and the organic radical generated by the addition of excess hydrogen peroxide

64. UV-visible spectra of the starting material compound $\mathbf{3 6}$ and its peroxo species generated by the addition of alkyl and hydroperoxide.....

65. EPR spectra of frozen methanol solution of compound $\mathbf{3 6}$ and compound 45 and their simulations...... 156

66. Resonance-Raman spectra of $\mathrm{Cu}(\mathbf{L 2})(\mathrm{OOH})$ and $\mathrm{Cu}(\mathbf{L 2})\left({ }^{18} \mathrm{O}^{18} \mathrm{OH}\right) \ldots \ldots \ldots . . .157$

67. Theoretical and experimental mass ions for $[\mathrm{Cu}(\mathbf{L 2}) \mathrm{OOH}]^{+} \ldots \ldots \ldots \ldots \ldots \ldots \ldots . . . . . . .158$

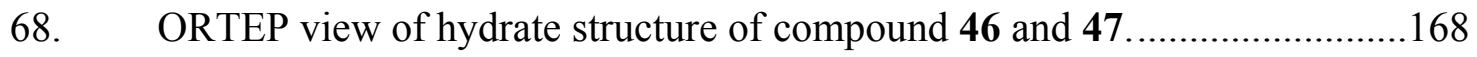

69. Illustration of the network of hydrogen bonds between water molecules and imidazole nitrogens found in the packing diagram of compound 46.....169

70. Capped-stick representation of the dimeric structure of compound $47 \ldots \ldots . .170$ 
71. Capped-stick representation of the supramolecular assembly resulting from the interactions of dimers of compound 47.

72. ORTEP views of the molecular structures of compounds $\mathbf{5 2}$ and $\mathbf{2}$.............173

73. Packing representations viewed down the water channel of compound $\mathbf{5 2}$ and $\mathbf{2}$ are shown. In addition, hydrogen-bonding representations illustrating the nanostructure of the water chains of $\mathbf{5 2}$ and $\mathbf{2}$ are shown with each channel oriented along the horizontal axis of the illustration........174

74. Closest interatomic contacts between imidazole molecules associated with the water channel and weak intermolecular interactions between adjacent channels

75. ORTEP view of compound 1

76. Side- and top-views of the one-dimensional strong hydrogen bonded arrangements of compound 1

77. Packing arrangement of the one dimensional chains of $\mathrm{L}^{\mathrm{Et}, \mathrm{Me}}$ and their intermolecular hydrogen bonding with symmetry related chains...................178

78. ORTEP views of the hydrates of compounds 48 and 49 ............................180

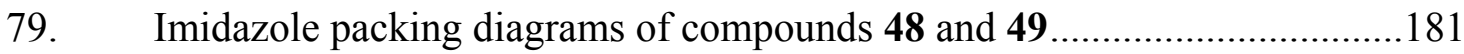

80. Four-helix bundle of the Influenza A M2 domain .........................................182

81. His-Trp $\pi$-stacking from the PDB coordinates; imidazole arrangements found in both compounds that interact with two structural waters.

82. Water organization in compound 48. Clusters of six water molecules in a distorted chair conformation are confined in an hourglass-like channel and isolated from each other by hydrophobic barriers composed of the ethyl groups

83. Illustration of the six-water cluster of compound $\mathbf{4 8}$ with the positionally disordered water molecule $(\mathrm{O} 4 / \mathrm{O} 5)$.

84. Ball-and-stick representations of the six-membered water ring found in 48

85. Ball-and-stick representations of the four-membered water ring with two wingtip water molecules found in $\mathbf{4 8}$

86. Organization of water molecules in compound 49 showing the twodimensional layer of water molecules 
87. Ball-and-stick representation of the fused five- and six- membered ring observed in the crystal structure of compound 49

88. Ball-and-stick representations of one of the five-membered ring observed in the crystal structure of compound $\mathbf{4 9}$

89. Illustration of the point defects in ice-like structures associated with water hydrogens

90. Ball-and-stick representations of the second five-membered ring observed in compound 49 .

91. Capped-stick representation of the point-to-face $\pi$ stacked interaction between water molecule, $\mathrm{O} 12$, and the imidazole ring containing $\mathrm{N} 8$

92. Ball-and-stick representations of the six-membered water ring $\mathrm{C}$ observed in compound 49.

93. Supramolecular packing of the hydrate lattice encapsulating the polyimidazole compound $\mathbf{4 9}$

94. Ball-and-stick representations of the fourteen-membered water ring found in the crystal structure of compound $\mathbf{4 9}$

95. Ball-and-stick representation of the incomplete 6-4-6 water rings in compound 49

96. Ball-and-stick representations of the lasso-type structure found in compound 49

97. Capped-stick representation of the pi-stack interaction between the water molecule and the imidazole ring

98. Ball-and-stick representations of the sixteen-membered water ring found in the crystal structure of compound $\mathbf{4 9}$

99. Ball-and-stick representations of the seventeen-membered water ring found in the crystal structure of compound 49 ...........................................213

100. Typical TGA plot illustrated for compound 2 ..............................................

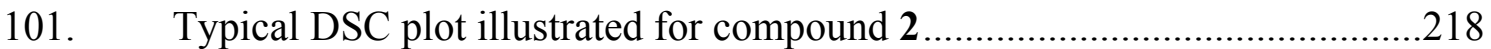

102. X-ray powder diffractogram of hydrated, dehydrated and rehydrated compound 2

103. ORTEP view of 4(5)-methyl-2-phenylimidazole 
104. Capped-stick representations of side and top view of the hydrogen bonding chain of 4(5)methyl-2-phenylimidazole in the solid-state

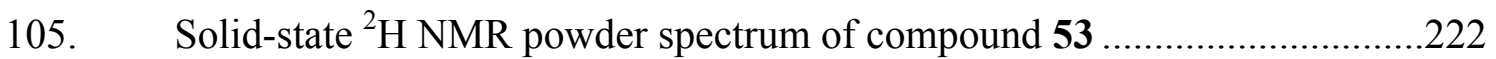

106. Solid-state ${ }^{2}$ H NMR powder spectrum of compound 47 ............................223

107. Solid-state ${ }^{2} \mathrm{H}$ NMR powder spectra of compound $\mathbf{5 2}$ and compound 2 ......224

108. ${ }^{2} \mathrm{H}$ solid-state NMR spectra for compounds 48 and 49 consistent with a slow reorientational dynamic behavior of the water molecules in the

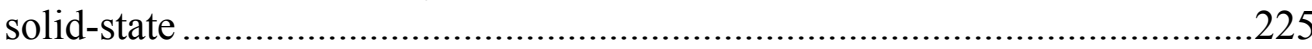

109. Solid-state ${ }^{17} \mathrm{O}$ NMR powder spectrum for both compound $\mathbf{2}$ and $\mathbf{4 8}$ indicating the exchange of ${ }^{17} \mathrm{O}$ water vapor with lattice water in the solid-state 


\section{LIST OF COMPOUNDS AND NOMENCLATURE}

\section{COMPOUND}

1

2

3

4

5

6

7

8

9

10

11
4,4'-Methylene-bis(2-ethyl-5-methylimidazole) $\left(\mathrm{L}^{\mathrm{Et}, \mathrm{Me}}\right)$

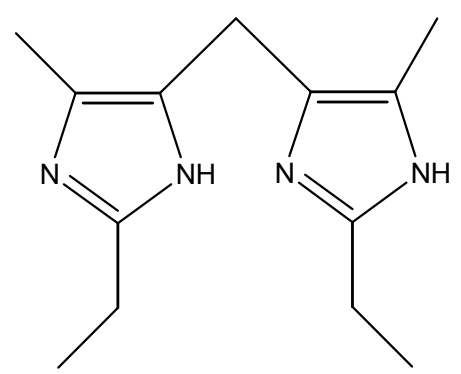

4,4'-Methylene-bis(2,5-dimethylimidazole) $\left(\mathrm{L}^{\mathrm{Me}, \mathrm{Me}}\right)$

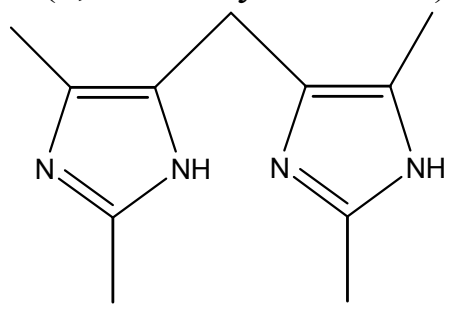

$\mathrm{Co}\left(\mathrm{L}^{\mathrm{Et}, \mathrm{Me}}\right) \mathrm{Cl}_{2}$
$\mathrm{Ni}\left(\mathrm{L}^{\mathrm{Et}, \mathrm{Me}}\right) \mathrm{Cl}_{2}$
$\mathrm{Cu}\left(\mathrm{L}^{\mathrm{Et}, \mathrm{Me}}\right) \mathrm{Cl}_{2}$
$\mathrm{Zn}\left(\mathrm{L}^{\mathrm{Et}, \mathrm{Me}}\right) \mathrm{Cl}_{2}$
$\mathrm{Cu}\left(\mathrm{L}^{\mathrm{Me}, \mathrm{Me}}\right) \mathrm{Cl}_{2}$
$\mathrm{Co}\left(\mathrm{L}^{\mathrm{Et}, \mathrm{Me}}\right)_{2} \mathrm{Cl}_{2}$
$\mathrm{Zn}\left(\mathrm{L}^{\mathrm{Et}, \mathrm{Me}}\right)_{2}\left(\mathrm{ClO}_{4}\right)_{2}$
$\mathrm{Ni}\left(\mathrm{L}^{\mathrm{Et}, \mathrm{Me}}\right)_{2} \mathrm{Cl}_{2}$
$\mathrm{Cu}\left(\mathrm{L}^{\mathrm{Et}, \mathrm{Me}}\right)_{2}\left(\mathrm{PF}_{6}\right)_{2}$


12

13

14

15

16

17

18

19
$\left[\mathrm{Ni}\left(\mathrm{L}^{\mathrm{Et}, \mathrm{Me}}\right)_{2} \mathrm{Cl}\right] \mathrm{Cl}$

$\left[\mathrm{Cu}\left(\mathrm{L}^{\mathrm{Et}, \mathrm{Me}}\right)_{2} \mathrm{Cl}\right] \mathrm{Cl}$

$\left[\mathrm{Cu}\left(\mathrm{L}^{\mathrm{Et}, \mathrm{Me}}\right)_{2} \mathrm{ClO}_{4}\right] \mathrm{ClO}_{4}$

1-Methyl-4-nitroimidazole-2-carboxaldehyde

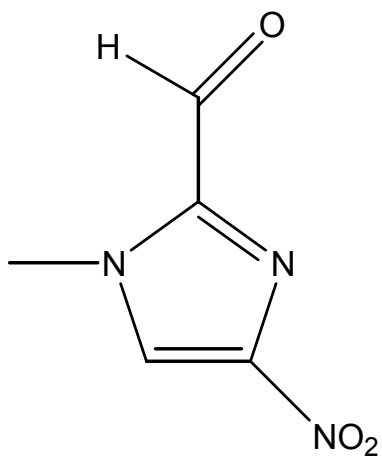

((1-Methyl-4-nitroimidazole-2-yl)methyl)bis((1methylimdazole-2-yl)methyl)amine

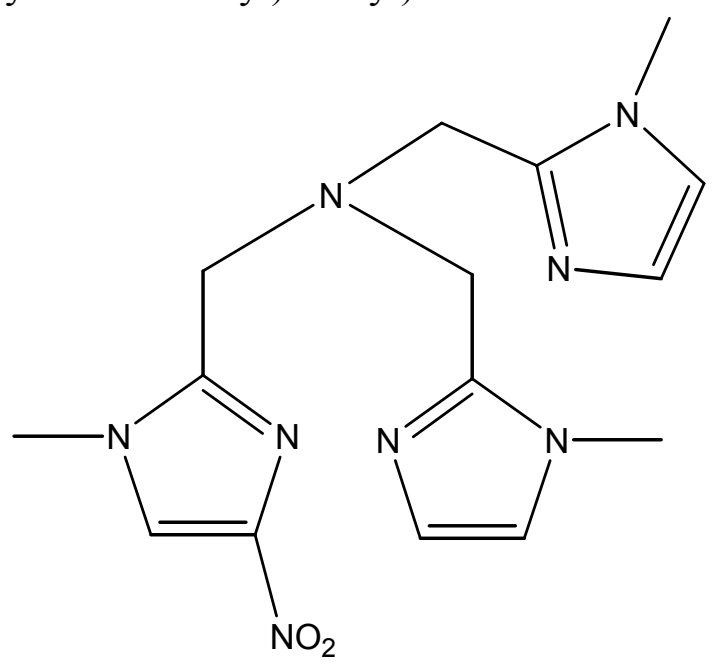

((4-Amino-1-methylnitroimidazole-2-yl)methyl)bis((1methylimdazole-2-yl)methyl)amine

(1-Methyl-4-nitroimidazole-2-yl)methyl(1methylimidazole-2-ylmethyl)amine

(Bis(1-methyl-4-nitroimidazole-2-yl)methyl)((1methylimdazole-2-yl)methyl)amine 


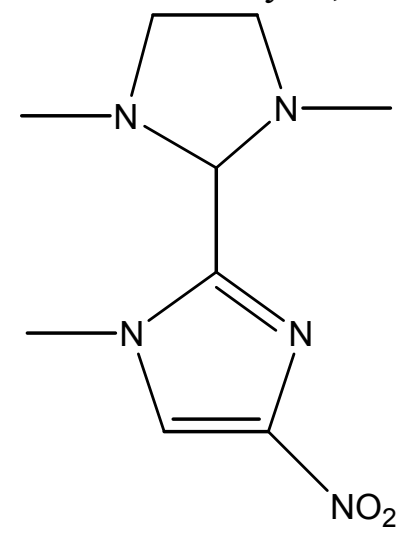

1-Methyl-4-nitroimidazole-2-carboxaldehyde acetal

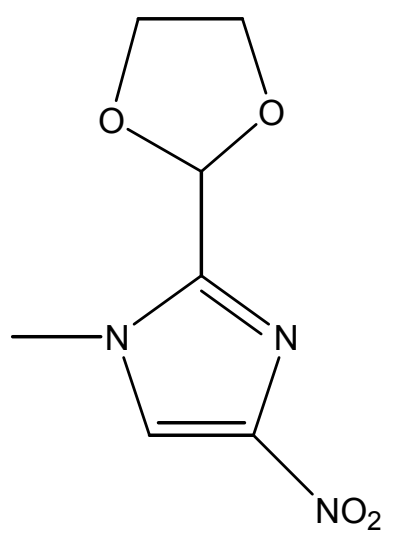

22

23

24

25

26
4-Amino-1-methylimidazole-2-yl-1,3-imidazolidine

4-Amino-1-methylimidazole-2-carboxaldehyde acetal

1-Methyl-4-pivaloylamidoimidazole-2-yl-1,3-imidazolidine

1-Methyl-4-pivaloylamido-imidazole-2-carboxaldehyde acetal

1-Methyl-4-pivaloylamido-imidazole-2-carboxaldehyde

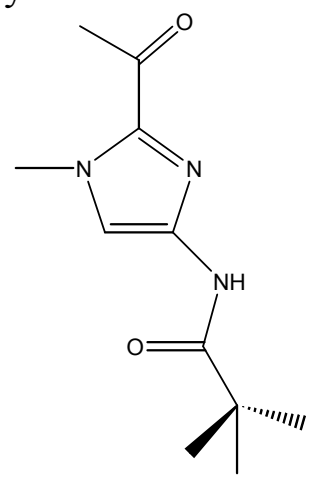


(1-Methyl-4-pivaloylimidazole-2-yl)methyl(1methylimidazole-2-ylmethyl)amine

28

29

30

31

32

33

34

L1, L2, L3

35

36
1-Methyl-4-pivaloylamido-imidazole-2-oxime

1-Methyl-4-pivaloylamido-imidazole-2-aminomethyl hydrochloride salt

Bis(1-methyl-4-pivaloylimidazole-2-yl)methyl)amine

4-N-Acetyl-DL-phenylalanide(1-methylimidazole-2carboxaldehyde acetal

4-(1-Methylimidazole-2-yl)(1-methyl-imidazole-2carboxaldehyde acetal) imine

4-Benzamido-1-methylimidazole-2-carboxaldehyde acetal

4-Furamido-1-methylimidazole-2-carboxaldehyde acetal

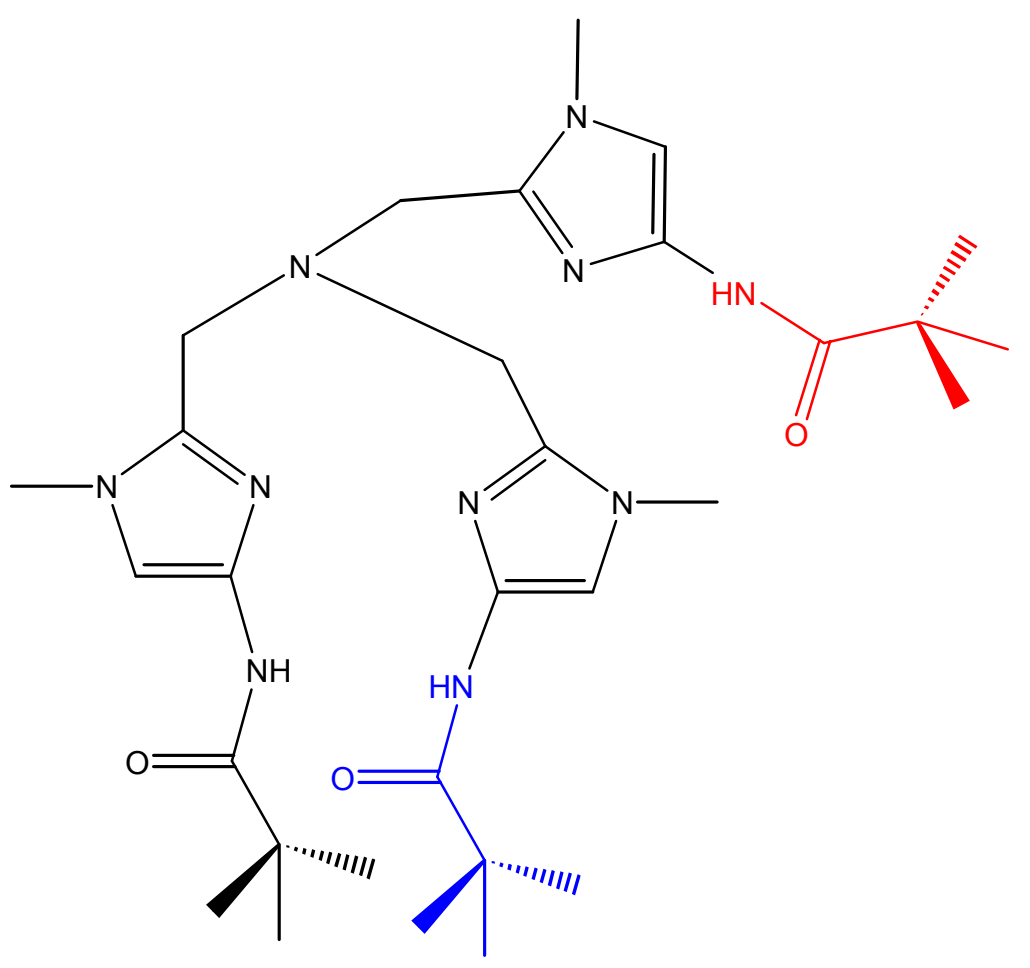

$\left[\mathrm{Fe}(\mathbf{L 1}) \mathrm{Cl}_{2}\right]^{+}$

$[\mathrm{Cu}(\mathbf{L 2})]\left(\mathrm{ClO}_{4}\right)_{2}$ 
$\left[\mathrm{Cu}(\mathbf{L 2}) \mathrm{N}_{3}\right]^{+}$

41

42

43

44

45

46

47

48

49

50

51

52

53
2-Hydroxymethyl-1-methyl-4-nitroimidazole

1-Methyl-4-nitroimidazole-2-carboxylic acid

Tmima : boric acid $(1 / 1)$

Compound 16 : boric acid (2/1)

$[\mathrm{Cu}(\mathbf{L 2}) \mathrm{OOH}]^{+}$

Bis(2-ethyl-5-methylimidazole-4-methyl)(1methylimidazole-2-yl)methyl)amine

N,N-Bis(2-ethyl-5-methylimidazole-4-methyl) glycine

$\mathrm{N}, \mathrm{N}, \mathrm{N}^{\prime}, \mathrm{N}^{\prime}$-Tetrakis(2-ethyl-5-methylimidazole-4-methyl) ethylene diamine

$\mathrm{N}, \mathrm{N}, \mathrm{N}^{\prime}, \mathrm{N}^{\prime}$-Tetrakis(2,5-dimethylimidazole-4-methyl) ethylene diamine

N,N-Bis(2-ethyl-5-methylimidazole-4-methyl)ethanol amine

N,N-Bis(2,5-dimethylimidazole-4-methyl)ethanol amine

1-Methylimidazole-4-carboxaldehyde

4(5)-Methyl-2-phenylimidazole 


\section{CHAPTER I}

\section{INTRODUCTION}

This study will evaluate the structures and properties of a series of imidazole compounds. Results from these studies are relevant to several fundamental aspects of the chemistry of imidazole compounds, such as: their importance as models for histidine residues found in the active sites of metalloenzyme, their use in stabilizing novel supramolecular solid-state assemblies via hydrogen bond and $\pi$-stack interactions, and their general utility in coordination chemistry and molecular recognition studies. These properties and other related topics will be discussed throughout the following chapters.

Histidine is one of the most versatile amino acids found in nature and plays many critical roles in biological systems. It is the second most frequently encountered amino acid in enzyme active sites (Varfolomeev, S. D. \& Gurevich, K. G., 2001) and possesses several unique properties resulting from its imidazole ring pendant (Figure 1).

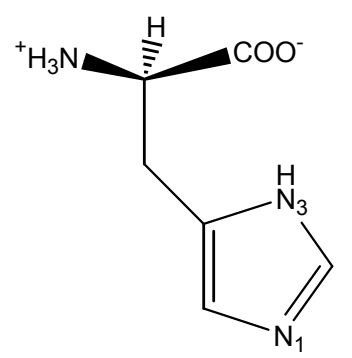

Figure 1. Representation of the histidine amino acid.

This dissertation conforms to the style and formatting of the University of Louisville Graduate School dissertation guidelines. 
The 1,3 diazole ring possesses features similar to both pyrrole and pyridine (Sundberg, R. J. \& Martin, R. B., 1974). The pyrrole nitrogen, designated N3, carries the hydrogen atom which is often found to be hydrogen bonded within enzyme active sites. The pyridine nitrogen, designated N1, also participates in bonding through its lone pair with various Lewis acids (e.g. metal ions, $\mathrm{M}^{\mathrm{n}+}$, and protons). Also, histidine is an amphoteric species, and, at physiological $\mathrm{pH}$, is found in its neutral form $(\mathrm{pKa}=6.0)$.

Recently, interest in imidazole chemistry has been motivated, in part, by the synthesis of purine bases found in DNA (Jain, M. L. et al., 2001) and by the synthesis of drugs; e.g. the nitroimidazole compound, metronidazole (Mendz, G. L. \& Megraud, F., 2002), and analogs of the naturally occurring drugs, distamycin and netropsin, to mention a few (Hawkins, C. A. et al., 2000; Kopka, M. L. et al., 1997; Yang, X. L. et al., 1999). Metronidazole has been used for forty years in the treatment of anaerobic protozoan and bacterial infections. Its mode of action is unclear but is thought to involve its interaction with DNA upon reduction of its nitro group and the formation of free radicals. On the other hand, dystamycin, netropsin and some of their imidazole analogs have shown antiviral and oncolytic activities and act by blocking the template function of DNA by binding to specific nucleotide sequences in the minor groove of DNA.

Several compounds have been synthesized by Dervan (Hawkins, C. A. et al., 2002) and others (Nguyen, B. et al., 2002; O'Hare, C. C. et al., 2002) to exploit their use as DNA sequence targeting agents. Similar approaches have been used in fundamental studies related to molecular recognition; e.g. protein-protein interaction and protein-small molecule interactions, and in supramolecular chemistry. 


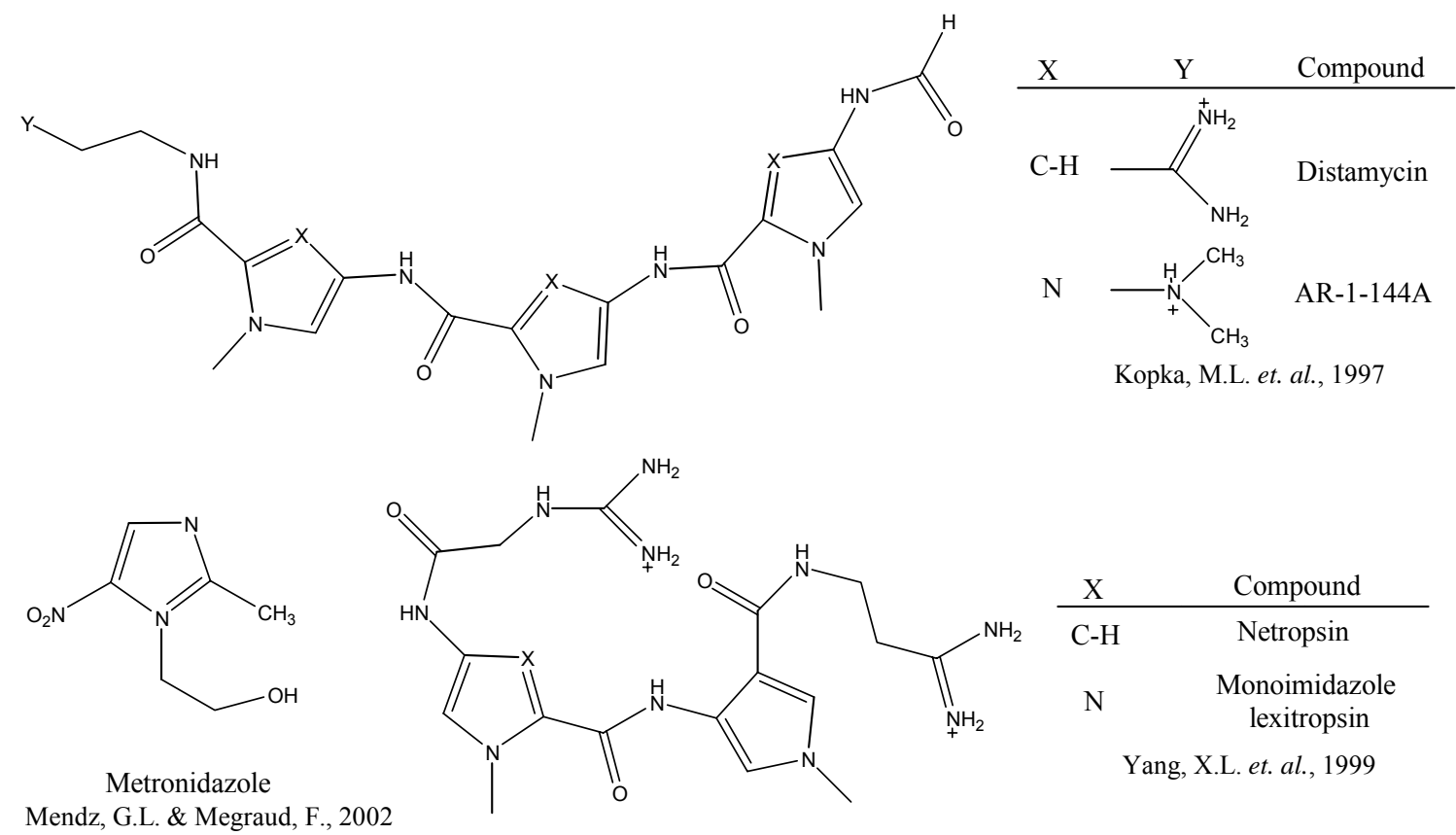

Figure 2. Representations of imidazole and pyrrole based drugs.

In the realm of supramolecular chemistry, weak intermolecular forces present in the solid-state structures of small molecules are receiving increasing attention. Overall, supramolecular chemistry can be viewed as the study of molecular information stored at the molecular level in the structural features. This information is then conveyed to the supramolecular level in the form of molecular recognition and self-assembly via weak intermolecular forces (Lehn, J. M., 1990). The systematic study of the interactions found in crystal structures and the continuous identification of supramolecular synthons are the basis for the rational design of supramolecular assemblies (Desiraju, G. R., 1995). It is worth noting that there has been limited use of imidazole compounds in supramolecular chemistry and this is the focus in part of this study (see Chapters III and VI).

Hydrogen bonds are one of the most important non-covalent interactions associated with molecular recognition (Krische, M. J. \& Lehn, J. M., 2000). They are directional and their strength, selectivity and complementary can be tuned. In addition to 
the traditional $\mathrm{X}-\mathrm{H}---\mathrm{Y}$ hydrogen bond $(\mathrm{X}, \mathrm{Y}=\mathrm{N}, \mathrm{O}, \mathrm{F})$, weaker hydrogen bonds involving $\mathrm{X}=\mathrm{C}, \mathrm{O}, \mathrm{N}$ and $\mathrm{Y}=\mathrm{O}, \mathrm{N}, \mathrm{Cl}, \mathrm{M}-\mathrm{Cl}$ atoms have been determined to play a crucial role in the stabilization of solid-state structures (Brammer, L. et al., 2001; Desiraju, G. R., 1996). To some extent, interests in these weak interactions have stimulated the evaluation of different small molecules as building blocks for supramolecular assemblies (see Chapters III and VI). Furthermore, the concepts of supramolecular chemistry have far-reaching impacts on the field of drug discovery and material sciences, where the same intermolecular forces are known to be present.

The imidazole ring has many of the same structural features that may be useful in the general area of molecular recognition and supramolecular chemistry. It can form strong hydrogen bonds with donors and acceptors, and the aromaticity of its ring facilitates formation of $\pi$-stacking interactions with other imidazole or aromatic compounds. In addition, the hydrogen bonding properties of imidazoles in both solid and liquid states have been of interest as electrolytes in fuel cells for the conduction of ions (Munch, W. et al., 2001). Because proton conduction occurs between hydrogen bonded molecules, solid-state fuel cells have used imidazoles as both a water substitute and an electrolyte.

Both properties of histidine, its ability to form hydrogen bonds and to interact with Lewis acids, are exploited in metalloenzyme active sites and have been the focus in many active site modeling studies (Cheruzel, L. E. et al., 2002; Collman, J. P. et al., 2004; Driessen, W. L. et al., 2003). It is recognized that protein function is closely related to its three-dimensional structure. In the realm of molecular recognition, the structure of proteins is viewed to conform to the shape of their biological targets (e.g. receptors and 
small molecules). For example, enzymes are proteins that perform complex biochemical reactions. The function of the enzyme, as well as its selectivity, is linked to the structure of its active site. The active site is often defined as a cavity within the protein architecture where the desired substrate docks. The strength of the docking process is controlled by the complementarity of the size and shape of the substrate and cavity. In general, enzymes contain specific amino acids in their active sites that in some cases participate directly in the catalytic process. The general structure of metalloenzyme active sites can be divided further into two parts: the primary coordination sphere that contains a metal binding site and a second coordination sphere that can participate in substrate stabilization and functionalization (Karlin, S. et al., 1997).

The same weak intermolecular forces that govern substrate recognition in the second coordination sphere of metalloenzyme active sites are also observed in protein/protein and protein/ligand interactions. These intramolecular forces include ion pairing (electrostatic), hydrophobic/hydrophilic interactions, hydrogen bond, host-guest interactions, $\pi$-stacking and Van der Waals interactions. While substantial advances continue to be made through direct studies of complex biological systems, additional significant contributions have come from small molecule modeling studies. Therefore the evaluation of the intermolecular forces found in small molecule systems is relevant to our understanding of the properties of complex biological systems, as long as those model systems possess key structural and electronic features found in these natural systems. 


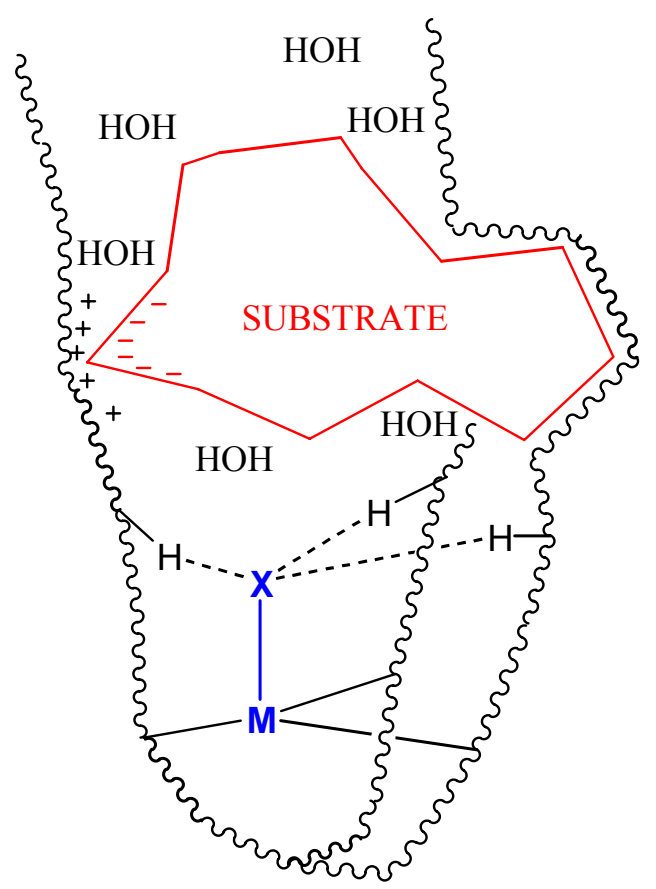

Figure 3. Illustration of structural metalloenzyme active site.

In modeling the second coordination sphere of metalloenzymes, investigators have used small molecules containing hydrogen bonding amide pendant groups to stabilize apically coordinated ligands. Studies usually have employed a tripodal ligand framework capable of forming thermodynamically stable intramolecular six-membered hydrogen bonding rings with apical ligands. While Einaga and coworkers (Harata, M. et al., 1998b) have developed a tripodal pyridine-based ligand to stabilize unstable and reactive intermediates, such as mononuclear hydroperoxo species bonded to a copper atom. Borovik and coworkers (Gupta, R. et al., 2002; MacBeth, C. E. et al., 2001) have developed urea-based tripods for the stabilization of high-valence metal-oxo or metalhydroxo species. Prior to the study described herein, none of the previous investigations have utilized biologically relevant imidazole ligands containing properly oriented amide functionalized pendants (see Chapters III and V). 
Copper and iron are generally considered to govern the field of dioxygen chemistry (Holm, R. H. et al., 1996b). Copper active sites can reversibly bind dioxygen and store it as in hemocyanin (Solomon, E. I. et al., 1994). Also copper-containing enzymes utilize dioxygen to functionalize substrates. In the case of galactose, amine and catechol oxidases, the reduction of oxygen to hydrogen peroxide is coupled to the oxidation of substrates (Klinman, J. P., 1996). For dopamine ß-oxygenase, peptidylglycine monooxygenase and tyrosinase, the peroxide-copper species generated by the reduction of dioxygen is used in the hydroxylation of substrates (Klinman, J. P., 1996; Solomon, E. I. et al., 1996). Finally, specific copper metalloenzymes perform the fundamental four-electron reduction of dioxygen to water coupled to substrate oxidation (laccase and ascorbate oxidase) (Solomon, E. I. et al., 1996), or proton pumping (cytochrome c oxidase) (FergusonMiller, S. \& Babcock, G. T., 1996) (Figure 4).

Depending on the number of metal centers, the copper enzymes can be categorized further in three subfamilies (Solomon, E. I. et al., 2001). The first group includes mononuclear species that require cofactors to perform the reduction of dioxygen coupled to substrate oxidation (galactose, amine oxidase). The non-coupled binuclear copper enzymes constitute the second class of proteins. Their metal centers are not magnetically coupled and are located further than $11 \AA$ apart. Meanwhile, oxygen reduction is thought to occur at only one copper center. A putative $\mathrm{Cu}-\mathrm{OOH}$ species is proposed to be responsible for the $\mathrm{C}-\mathrm{H}$ atom abstraction from the substrate followed by - OH hydroxylation, formed by homolytic cleavage of the bound peroxide O-O bond (Chen, P. \& Solomon, E. I., 2004). 
Protein

Mononuclear copper

Amine

Oxidase

(AmO)

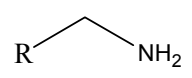

Galactose

Oxidase

(GO)

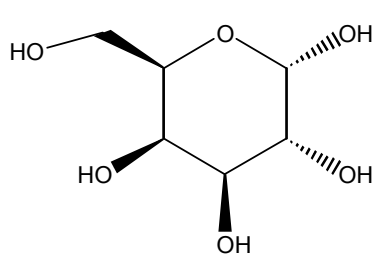

\section{Mononuclear copper}

\section{(GO)}

Catalytic reaction

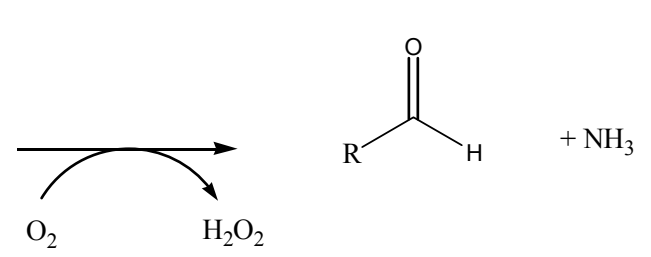

Non-coupled binuclear copper

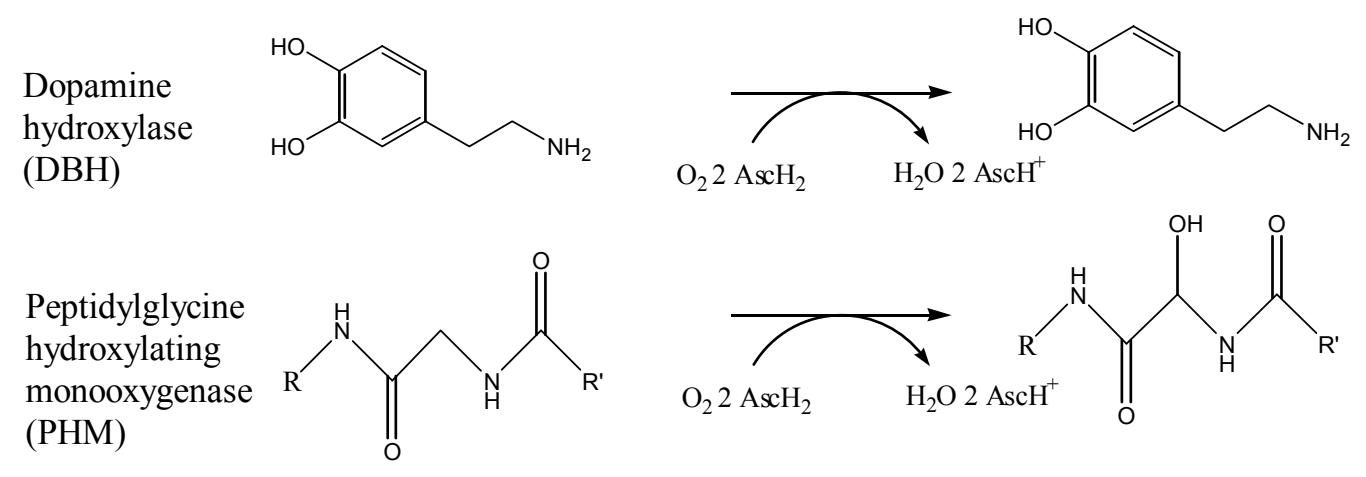

Coupled binuclear copper

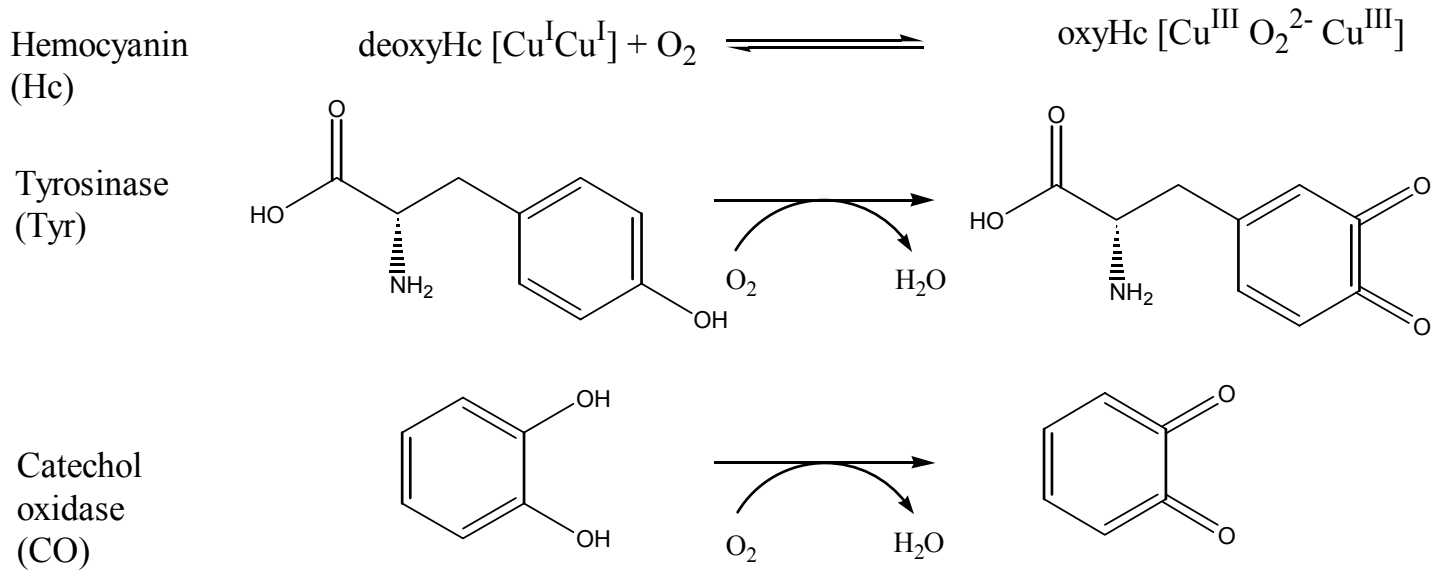

Trinuclear copper clusters

Laccase (LC), Ascorbate oxidase (AO), Ceruloplasmin (Cp) /FET3, Bilirubin oxidase (BO)

Figure 4. Illustrations of Copper proteins and their reactions with dioxygen (adapted from (Solomon, E. I. et al., 2001)). 
Finally, the trinuclear copper cluster found in laccase and ascorbate oxidase constitutes the third member of the family of copper metalloenzymes that utilize dioxygen. Modeling these copper active sites has been challenging and continues to be the focus of an active area of research in bioinorganic chemistry.

It is often recognized that the area of copper biochemistry began with the report in 1992 of a structural model for oxy-hemocyanin by Kitajima et al. (Kitajima, N. et al., 1992). Since Kitajima's report, many studies have focused on $1: 1$ and $2: 1$ copper/dioxygen model compounds, as well as structural models of laccase, as reported by Cole et al. (Cole, A. P. et al., 1996). To date, only five mononuclear $\mathrm{Cu}-\mathrm{OOH}$ species have been characterized, and only two of them by X-ray crystallography (Chen, P. et al., 2000; Wada, A. et al., 1998). On the other hand, 2:1 Cu/ $\mathrm{O}_{2}$ species have been investigated more intensely. This is due to the fact that the $\mathrm{Cu}_{2} \mathrm{O}_{2}$ units are the more thermodynamically favored species (Que, L. \& Tolman, W. B., 2002). Mechanistic studies using fast-quenching methods on a model complex have established that an endon hydroperoxo mononuclear copper(II) intermediate is formed first during the course of the reaction between $\mathrm{Cu}(\mathrm{II})$ and $\mathrm{H}_{2} \mathrm{O}_{2}$, which rapidly reorganizes to form a side-on peroxo copper(II) species. Adding an additional $\mathrm{Cu}(\mathrm{II})$ center generates the more stable $\mu-\eta^{2}: \eta^{2}$-peroxodicopper(II) species (Osako, T. et al., 2002).

Specific spectroscopic features have been identified for each species from these studies. However, there are still more mechanistic details of $\mathrm{Cu}-\mathrm{OOH}$ species that need to be elucidated before a complete understanding of the reaction of $\mathrm{Cu}(\mathrm{II})$ with $\mathrm{H}_{2} \mathrm{O}_{2}$ can be understood fully. Therefore, the development of new systems containing biologically relevant ligands that can stabilize apically coordinated $\mathrm{OOH}$, unstable and reactive 
species, through intramolecular hydrogen bonding is critical to the understanding of $\mathrm{Cu} / \mathrm{O}_{2}$ chemistry and the mechanism of $\mathrm{O}-\mathrm{O}$ bond cleavage.

Interestingly, in many of the enzyme systems described above, active sites often contain structural waters or occulted water molecules that can participate in the enzyme mechanism. The presence of active site waters are thought to be important to the structure of the metalloproteins and in some instances, water is involved directly in the chemistry of the metalloprotein. A number of recent studies have evaluated the participation of active site water molecules in the catalysis via molecular dynamic simulation studies. Most notable are the studies by Christianson and coworkers who have simulated the participation of water chains in the active site of Carbonic Anhydrase V (Jude, K. M. et al., 2002). Carbonic Anhydrase V is a zinc metalloenzyme that performs the catalytic conversion of $\mathrm{CO}_{2}$ to the benign carbonate anion. The reaction mechanism involves the deprotonation of a water molecule coordinated to the zinc atom. The resulting hydroxide group reacts with $\mathrm{CO}_{2}$ to produce the carbonate anion. Christianson and coworkers have successfully demonstrated that the proton generated during the reaction is shuttled away from the active site via a one-dimensional channel of hydrogen-bonded water molecules. This study will examine the structures and properties of novel water structures in the solid-state (see Chapter VIII).

Water is a remarkable molecule and its hydrogen bond interactions are responsible for its unique properties in both solid and liquid states (Stillinger, F. H., 1980). Water can form four hydrogen bonds arranged in a tetrahedral arrangement, where two hydrogens are donated to neighboring waters and two lone pairs form hydrogen bonds with additional neighboring oxygen atoms. Such interactions result in the 
formation of many complex water clusters of different sizes and shapes (e.g. pentamers, hexamers but also icosahedral and dodecahedral water structures) (Ludwig, R., 2001).

Compared to more typical liquids, water has higher boiling and freezing points, a higher specific heat capacity, and facilitates the fast mobility of protons in its liquid form. Surprisingly, there are still no accurate models that correctly describe all forty one unusual properties listed below (Chaplin, M. F., 2000; Stillinger, F. H., 1980).

\section{Forty one unusual properties of water ${ }^{\text {(a) }}$}

1. An unusual high boiling point $\left(100^{\circ} \mathrm{C}\right)$

2. An unusual high melting point $\left(0^{\circ} \mathrm{C}\right)$

3. An unusual high critical point $\left(374^{\circ} \mathrm{C}\right)$.

4. Solid water exists in a wide variety of stable (and metastable) crystal and amorphous structures.

5. Proton and hydroxide ion mobilities are anomalously fast in an electric field.

6. An unusual high surface tension (72.75 $\mathrm{mJ} / \mathrm{m}^{2}$ ).

7. $\mathrm{D}_{2} \mathrm{O}$ and $\mathrm{T}_{2} \mathrm{O}$ differ significantly from $\mathrm{H}_{2} \mathrm{O}$ in their physical properties.

8. The dielectric constant is high and behaves anomalously with temperature.

9. X-ray diffraction shows an unusually detailed structure.

10. Heat of vaporization. $(40.7 \mathrm{~kJ} / \mathrm{mol})$

11. High viscosity. $(0.89 \mathrm{cP})$

12. Water shrinks on melting.

13. High density that increases on heating.

14. The number of nearest neighbors increases on melting.

15. The number of nearest neighbors increases with temperature.

16. Pressure reduces its melting point.

17. Pressure reduces the temperature of maximum density.

18. Large viscosity increase as the temperature is lowered.

19. Viscosity decreases with pressure (at temperature below $\left.33^{\circ} \mathrm{C}\right)$.

20. Low compressibility $\left(0.46 \mathrm{GPa}^{-1}\right)$.

21. Compressibility drops as temperature increases.

22. Low thermal expansivity $\left(0.00021 /{ }^{\circ} \mathrm{C}\right)$

23. Water's thermal expansivity reduces increasingly (becoming negative at low temperature).

(a) Adapted from the following website www.martin.chaplin.btinternet.co.uk
24. Speed of sound increases with temperature (maximum at $73{ }^{\circ} \mathrm{C}$ ).

25. High specific heat capacity $(\mathrm{Cv}$ and $\mathrm{Cp}, 4.18$ $\mathrm{Jg}^{-1} \mathrm{~K}^{-1}$ )

26. Water has about twice the specific heat capacity of ice or steam.

27. Specific heat capacity $(\mathrm{Cp})$ has a minimum.

28. NMR spin-lattice relaxation is very small at low temperatures.

29. Solutes have varying effects on properties such as density and viscosity.

30. Solutions are not ideal.

31. Supercooled water has two phases and a second critical point at about $-91^{\circ} \mathrm{C}$.

32. Liquid water is easily supercooled.

33. Hot water freezes faster than cold water (the Mpemba effect).

34. The refractive index of water has a maximum value just below $0^{\circ} \mathrm{C}$.

35. The solubilities of non-polar gases in water decrease with increasing temperature to a minimum and then rise.

36. At low temperatures, the self-diffusion of water increases as the density and pressure increase.

37. The thermal conductivity of water rises to a maximum at about $130^{\circ} \mathrm{C}$ and then falls.

38. The heat of fusion of water with temperature exhibits a maximum at $-17^{\circ} \mathrm{C}$.

39. Under high pressure water molecules move further away from each other with increasing pressure.

40. The electrical conductivity of water rises to a maximum at about $230^{\circ} \mathrm{C}$ and then falls.

41. Warm water vibrates longer than cold water. 
Substantial evidence comes from the fact that water molecules form infinite hydrogen bond networks with localized and structurally complex clusters.

For example, thirteen polymorphs of ice have been classified based on the variation of size of their water cluster and hydrogen bond patterns. While in the liquid phase, in addition to the hexameric ring, dodecahedral (Graziano, G., 1998; Sobott, F. et al., 1999) as well as icosahedral structures (Chaplin, M. F., 2000) also have been detected.

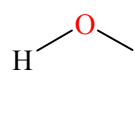

$$
\text { o---o }
$$

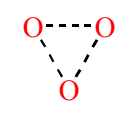

$$
\text { trimer }
$$
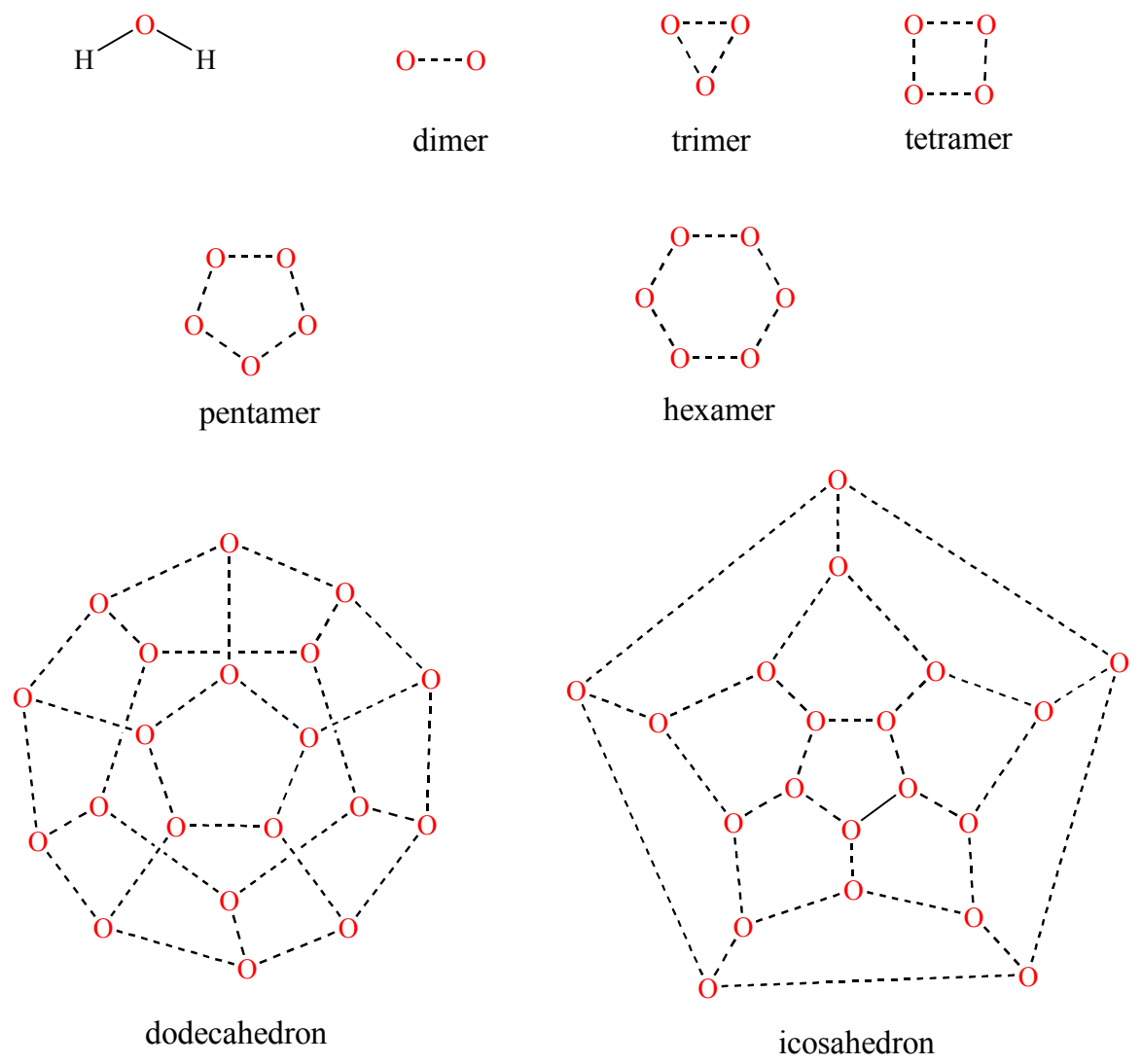

Figure 5. Illustration of water clusters.

Recent reviews have described the structural relationship between liquid, supercooled and low-density amorphous ice and the characterization of both experimental and computationally-generated small water clusters thought to be present in bulk water (Mishima, O. \& Stanley, H. E., 1998). 
Currently, there are several different theories that explain the properties of water, all based on the differences in hydrogen bonding interactions between water molecules. Some investigators have claimed that the unusual properties of water are due to the nonbonded interactions of water molecules within a fully hydrogen-bonded water network (Speedy, R. J., 1997). Others have proposed that competition between bonded and nonbonded water interactions is important (Tanaka, H., 1998). Significant bendings of the hydrogen bonds are also thought to contribute to these anomalies (Cho, C. H. et al., 1997). Finally, some of these properties have been explained by the presence of equilibria between pentameric, hexameric and dodecahedral water arrays in the liquid phase (Dougherty, R. C. \& Howard, L. N., 1998). Very few of these structures have actually been observed. Rather, they have been deduced from various physical measurements or computer simulation models (Ludwig, R., 2001).

Water has also been found to play an important role in the structures of proteins and their folding. Indeed, proteins lose activity when water molecules are removed. There are different ways that water contributes to the structure of proteins. Waters buried within protein architecture are found to play an important role in stabilizing the protein structure by forming strong hydrogen bonds, either with amino acid side chains, or with backbone amide bonds (Parker, M. J. \& Clarke, A. R., 1997; Sreenivasan, U. \& Axelsen, P. H., 1992). Within enzyme active sites, networks of hydrogen-bonded water molecules are usually found to play both structural and catalytic roles as described above for Carbonic Anhydrase V. On the other hand, a layer of water molecules on or near the protein surface constitutes an indispensable hydration shell for the protein function (Modig, K. et al., 2004). This layer is found to be an integral component of the protein structure and has 
properties different from the bulk water. The surface waters are ordered and show slow dynamic behavior compared to the bulk water (Bhattacharyya, S. M. et al., 2003). The ordering is related to the fact that water molecules can hydrogen-bond to polar groups at the surface of the protein. In the case of hydrophobic groups, they have been shown to promote the formation of clathrate structures, especially pentameric structures (Cameron, I. L. et al., 1997b). In addition, surface clusters of water molecules are found to participate in protein/protein interactions and recognition (Pal, S. K. \& Zewail, A. H., 2004; Pardanani, A. et al., 1998; Zhao, L. et al., 2004), and are likely important in other molecular recognition functions in biological systems.

There are other forms of water that occur in solids and biological systems that are less well understood (Hummer, G. et al., 2001). These are assemblies of water that are organized in one-dimensional chains. Many fundamental biological processes appear to depend on the unique properties of water chains (Cukierman, S., 2000; Jude, K. M. et al., 2002; Kandori, H., 2000; Lanyi, J. K., 2000; Law, R. J. et al., 2000; Zaslavsky, D. \& Gennis, R. B., 2000; Zhong, Q. F. et al., 1998). For example, water chains may assist in proton translocation through membranes by functioning as "proton wires" (Decoursey, T. E., 2003). Such behavior is illustrated by the membrane protein gramicidin A (gA) (Cukierman, S., 2000) where protons are envisioned to either hop along a single file chain of waters according to the Grotthuss relay mechanism (Agmon, N., 1995), or migrate as $\mathrm{H}_{9} \mathrm{O}_{4}{ }^{+}$(Eigen, M., 1963) or $\mathrm{H}_{5} \mathrm{O}_{2}{ }^{+}$(Zundel, G. \& Metzger, H., 1967) ionic water clusters. In addition, water chains appear to be important for the proton pathways in the cytochrome b6f complex of plant chloroplast thylakoid membrane and mitochondrial ATPase (Futai, M. et al., 2000), and carbonic anhydrase II (Jude, K. M. et al., 2002), as 
well as in redox proteins such as cytochrome oxidase (Wikstrom, M. et al., 2003), bacteriorhodopsin (Lanyi, J. K., 2000), and the photosynthetic reaction center of Rhodobacter sphaeroides (Xu, Q. et al., 2004). Water chains are also found in membrane aquapores, and are important to the function of the nicotinic receptor M2 $\delta$ (Law, R. J. et al., 2000) as well as the influenza A M2 virus (Wang, J. F. et al., 2001).

Little is known of the structural constraints required in stabilizing 1-D water chains (see Chapter VIII). In 1991, Peter Agre (2003 Nobel Prize in Chemistry) discovered that water is transported efficiently through red blood cell membranes and renal proximal tubulures by a membrane protein known as aquaporin 1 (AQP1) (Preston, G. M. et al., 1992). Since that time, Agre and others have characterized a family of aquaporin water channels in both plants and humans. The human genome is known to encode more than $10 \mathrm{AQP}$ genes and their defects lead to diseases that include nephrogenic diabetes insipidies, congenital cataracts and Sjørgens syndrome (Agre, P. et al., 2002). The specific function of AQPs is its exceptional water permeability $\left(3 \times 10^{9}\right.$ molecules/monomer per second), while at the same time preventing the exchange of ions and protons ("proton wires") (Pohl, P. et al., 2001). In addition, water molecules are thought to be hydrogen bonded and transported along single file chains.

As with the transport of water by AQPs, the translocation of $\mathrm{H}^{+}$across cell membranes is highly regulated by channel gates. For example, in the M2 influenza A virus, the channel gate is formed by four closely spaced histidine residues (one residue from each of the four bundled-helices) that are presumed to participate directly in proton "shuttling" through the channel constriction, or indirectly by regulating the dimension of the hour-glass shaped channel constriction disrupting the water chain (Wang, C. et al., 
1995). Also, pH-regulation is thought to be important to the function of the influenza virus. The $\mathrm{M} 2$ ion channel regulates $\mathrm{H}^{+}$transport to the virion interior which weakens the interaction between matrix proteins and the ribonucleoprotein core (Wang, C. et al., 1993).

Globally, this study will describe many of the characteristic features of imidazole compounds that are of importance to the design of more biologically relevant metal binding pockets, as well as to the diverse fields of supramolecular chemistry and molecular recognition. More precisely, this study has four objectives:

i) The rational design of novel amide functionalized imidazole metal binding pockets which can form intramolecular six-membered hydrogen bonds with various apical ligands bonded to different metals. These systems will eventually contain molecular recognition features (future studies). Three novel imidazole tripods (L1-L3) were synthesized in the study that contain amide pendants in the 4-position of the imidazole ring(s). The synthesis was achieved via the formation of nitroimidazole compounds. The reduction of the nitro group generates an unstable amine that was acylated in-situ to yield the desired amido imidazole derivatives.

ii) The evaluation of the coordination chemistry of the amide functionalized polyimidazole tripods through the isolation and the characterization of ferric and cupric complexes. Their properties are compared to the unfunctionalized and structurally related polyimidazole complexes and their pyridine analogs. Several studies focused on the properties of $\mathbf{L 2}$ and its three $\mathrm{Cu}(\mathrm{II})$ complexes containing apically bonded $\mathrm{Cl}^{-}, \mathrm{OH}^{-}$and $\mathrm{N}_{3}{ }^{-}$ligands. This part of the study resulted in the full characterization of a reactive and unstable mononuclear $\mathrm{Cu}-\mathrm{OOH}$ species of the $\mathbf{L 2}$ ligand. This $\mathrm{Cu}-\mathrm{O}_{2}$ adduct was fully 
characterized by UV-visible, EPR and Raman spectroscopy, as well as by ESI mass spectrometry.

iii) The supramolecular chemistry of two series of imidazole compounds was examined to evaluate the weak intermolecular forces that govern their solid-state assembly. The first group of imidazole compounds is composed of metal complexes of a novel bidentate imidazole ligand. Both mono- and bis-adduct complexes of divalent late first-row transition metals were characterized. The second group was used to evaluate the weak $\mathrm{C}-\mathrm{H}---\mathrm{O}$ hydrogen bonds present in the crystal structures of five nitroimidazole derivatives.

iv) The study of the hydrogen bonding properties of imidazole compounds with other small molecules, e.g. boric acid and water. Two polyimidazole tripods crystallize with boric acid and display interesting 2-D and 3-D supramolecular assemblies. In the case of water/imidazole interactions, six hydrated imidazole structures were studied, which lead to the characterization of two novel 1-D water chains, as well as, unique water clusters. These clusters are composed of four-, six-, fourteen-, sixteen- and seventeenmembered water rings, and of ribbons of fused five- and six-membered water rings. In addition, the influence of the imidazole compounds on the water arrangement is discussed. 


\section{CHAPTER II}

\section{EXPERIMENTAL SECTION}

\section{A. Physical Measurements}

The following physical methods have been used to characterize the compounds described herein: X-ray crystallography, solid-state ${ }^{2} \mathrm{H}$ and ${ }^{17} \mathrm{O}$ NMR, IR, Thermogravimetric Analysis (TGA), Differential Scanning Calorimetry (DSC) and elemental analyses provide useful information about the solid-state properties of the compounds. Electron paramagnetic resonance, ${ }^{1} \mathrm{H}$ and ${ }^{13} \mathrm{C}$ nuclear magnetic resonance, resonance Raman, electronic spectroscopy and cyclic voltammetry were used to study the properties of compounds in solution.

\section{Differential Scanning Calorimetry}

Hydrated samples were analyzed by Differential Scanning Calorimetry (DSC) on a Universal V2.5H TA instrument. Typically, the samples were first equilibrated to $30^{\circ} \mathrm{C}$ and then heated at a rate of $1^{\circ} \mathrm{C} / \mathrm{min}$ in flowing $\mathrm{N}_{2}$. Crystals of the samples were removed from their storage solution and dried on filter paper prior to analysis. In addition, from the overall enthalpy change, strength of the hydrogen bonds could be deduced. 


\section{Elemental Analysis}

Elemental analyses were performed by Midwest Microlab, LTD., Indianapolis, Indiana. Determinations of the percent carbon, hydrogen and nitrogen have been performed for all solid compounds.

\section{Electrochemistry}

Cyclic voltammetry has been used to study the electrochemical properties of selected compounds. Oxidation and reduction potentials of these compounds illustrate the accessibility of redox active states. Voltammetric measurements were conducted using a PAR 173 potentiostat, a PAR 175 universal programmer, a PAR digital coulometer and a Houston Instruments $2000 \mathrm{X}-\mathrm{Y}$ plot recorder. Electrochemical experiments were performed in either dry acetonitrile or methanol under an inert nitrogen atmosphere with tetra-butylammonium perchlorate as the supporting electrolyte. The three-electrode cell set-up consisted of a $\mathrm{Ag} / \mathrm{AgCl}$ reference electrode, a platinum coil auxiliary electrode and a glassy-carbon working electrode. The platinum coil was cleaned before use with concentrated nitric acid and further rinsed with water and acetone. The glassy carbon electrode was polished on the microcloth disk wetted with alumina polish prior to use. All redox potentials were referenced against the ferrocene/ferrocinium redox potential $\left(\mathrm{E}_{1 / 2}=+0.44 \mathrm{~V}\right.$ versus $\mathrm{Ag} / \mathrm{AgCl}$ in acetonitrile) externally (Gagne, R. R. et al., 1980).

The reversibilities of the redox processes were established according to standard procedures (Bard, A. J. \& Faulkner, L. R., 1980). A one-electron process is considered reversible if the peak-to-peak separation of the redox wave is $0.059 \mathrm{~V}$, and if the cathodic to anodic peak current ratio (ipc/ipa) is equal to unity. For any deviations from these 
conditions, the one-electron process is considered quasi-reversible where peak-to-peak separation of the redox waves are greater than $0.059 \mathrm{~V}$, but less than $0.15 \mathrm{~V}$. Peak-to-peak separations exceeding $0.15 \mathrm{~V}$ were considered irreversible. An electron process can be coupled to a chemical reorganization in an irreversible process (EC mechanism).

\section{Electronic Spectroscopy}

Photoexcitation of electrons between various states in metal complexes gives rise to characteristic electronic spectra, and therefore provides valuable information about the electronic structure of the molecules and the types of ligands bonded to the metal (Que, L., 2000). For example, the copper complexes with dioxygen intermediates have fingerprint electronic absorptions that have been intensely studied and well characterized. In this study, electronic spectra between 200 and $900 \mathrm{~nm}$ were recorded on a Cary 50 Bio Spectrophotometer. Values of $\lambda_{\max }$ are reported in $\mathrm{nm}$ units and the extinction coefficients, $\varepsilon$, from the Beer's law are expressed in units of $\mathrm{M}^{-1} \mathrm{~cm}^{-1}$.

\section{Electron Paramagnetic Resonance}

Electron Paramagnetic Resonance (EPR) spectroscopy is useful in probing the environment of a paramagnetic center and the study evaluates the interaction of the paramagnetic center with an applied magnetic field. An important feature obtained from the study is the $g$ factor, also called the spectroscopic splitting factor, which has a value of 2.0023 for a free electron. Electrons in metal systems usually exhibit different $g$ values depending on their environments. The overall magnetic moment is correlated to the gfactor and its three tensors $g_{x}, g_{y}, g_{z}$ reflecting the anisotropy of the system. The following are four extreme cases illustrating different conditions of anisotropy: 
i) If $g_{x}=g_{y}=g_{z}$, the magnetic moment is independent of orientation, then the system is isotropic and a single sharp EPR signal is obtained. The paramagnetic model can be represented as a sphere.

ii) If $g_{x}=g_{y}<g_{z}$, the spectrum is said to be axial with a minor feature at lower fields ( $g_{z}$ equal to $\left.g_{/ /}\right)$and a major feature at higher fields $\left(g_{x}=g_{y}\right.$, equal to $\mathrm{g} \perp$ ).

iii) If $g_{x}=g_{y}>g_{z}$, the spectrum is also axial but the features are inverted with the major feature observed at lower fields $\left(g_{x}=g_{y}\right.$, equal to $\left.g \perp\right)$.

iv) If $g_{x} \neq g_{y} \neq g_{z}$, the spectrum has now three major features associated with the three unique g-tensors. The spectrum is said to be rhombic.

X-band $(9.03 \mathrm{GHz})$ EPR spectra were recorded on a Varian Associates E-109 spectrometer. The magnetic field was calibrated using a Varian E-500 NMR Gauss meter. An insert dewar filled with liquid nitrogen was used for low temperature experiments (77K). EPR spectra were simulated using WINEPR SimFONIA Program V 1.25.

\section{Infrared Spectroscopy}

This technique has been used to probe the vibrational modes occurring in the infrared spectral region. Antisymmetric stretching and deformation modes, which produce large dipole changes dominate the IR spectrum. It is therefore a useful tool for identifying characteristic stretching frequencies associated with amide and carbonyl bonds. Infrared spectra were recorded on a Mattson Galaxy series 5000 FTIR using the Diffuse Reflectance Infrared Fourier Transform Spectra (DRIFTS) mode. The solid samples were prepared by mixing solid analyte samples in a dried $\mathrm{KBr}$ matrix. For 
solution samples, a film of the analyte was deposited by slow evaporation on a $\mathrm{Ag} / \mathrm{AgCl}$ plate. FTIR spectra were processed on an IBM-PC using the software program FIRST.

\section{Resonance Raman Spectroscopy}

While IR active modes require a change in the dipole moment associated with the corresponding vibration bending or stretching actions, Raman scattering depends on the changes in the dipole moment induced by the photon. Therefore, symmetric bond stretching vibrations, associated with large polarizability changes, dominate the Raman spectrum. Raman spectroscopy has been used to characterize $\mathrm{Cu}-\mathrm{O}$ and $\mathrm{O}-\mathrm{O}$ stretches associated with copper-peroxides species (Henson, M. J. et al., 2003).

The Raman data collection was performed in collaboration with Dr. Sara E. Edison and Dr. Michael Baldwin at the University of Cincinnati. A SPEX $14040.85 \mathrm{~m}$ double spectrometer equipped with a liquid $\mathrm{N}_{2}$ cooled $13.6 \mathrm{~mm}$ back-thinned SPEX Spectrum-1 CCD chip detector was used to collect Raman spectra. Raman scattering was excited by the $488.0 \mathrm{~nm}$ line of a Coherent $10 \mathrm{~W}$ Sabre Ar ion laser. A $200 \mathrm{~mW}$ power was used to excite the sample because at higher power settings, samples were found to photodecompose. The scattered light was directed through a Kaiser Optical Systems Holographic SuperNotch filter. Raman shifts were calibrated against the appropriate Raleigh scattering line. A methanol solution of the sample to be analyzed was cooled in a capillary tube to approximately $-100{ }^{\circ} \mathrm{C}$ by a liquid nitrogen chilled stream of $\mathrm{N}_{2}$ gas blown through a quartz EPR-type cooling tube (Bruker Instruments). Resulting spectra were four-point baseline corrected using GRAMS/32 (v5.22). Multiple spectra were averaged to improve the signal-to-noise ratios. 


\section{Mass Spectrometry}

The Electrospray Ionization Mass Spectroscopy (ESI-MS) experiments were performed on a Micromass Mass Spectrometer Electrospray Triple Quadrupole Quattro LCZ by Mr. Ned Smith and Dr. William Pierce, Jr., at the Biomolecular Mass Spectrometry Core Laboratory at the University of Louisville.

\section{Melting Point}

The melting points of all organic compounds were recorded on a Thomas Hoover capillary melting point apparatus that was calibrated with benzoic acid $\left(120-121^{\circ} \mathrm{C}\right)$.

10. Nuclear Magnetic Resonance Spectroscopy

a) Solid-state ${ }^{2} \mathrm{H}$ and ${ }^{17} \mathrm{O} \mathrm{NMR}$

${ }^{2} \mathrm{H}$ NMR spectra were recorded on a home-built NMR spectrometer using a home-built double-resonance ${ }^{1} \mathrm{H}-{ }^{2} \mathrm{H} /{ }^{17} \mathrm{O}$ probe, where the channel can be switched between the ${ }^{2} \mathrm{H}(76.05 \mathrm{MHz})$ and ${ }^{17} \mathrm{O}(67.20 \mathrm{MHz})$ frequencies by addition of extra capacitance. Recycle delays were used at various times depending on temperature to avoid saturation of spectrum. Samples were recrystallized from deuterated methanol and deuterium oxide for the ${ }^{2} \mathrm{H}$ experiment. Samples recrystallized from ${ }^{16} \mathrm{O}$ water were exposed to ${ }^{17} \mathrm{O}$ water vapor for five days prior to conducting ${ }^{17} \mathrm{O}$ NMR measurements. Typical water exchange conditions were as follows: $40 \mathrm{mg}$ of crystals were inserted into $4 \mathrm{~mm}$ glass tubes with $50 \mu \mathrm{L}$ of ${ }^{17} \mathrm{O}$ water on the other side of the tube, and the tubes were sealed with epoxy glue. 


\section{b) Solution NMR}

${ }^{1} \mathrm{H}$ and ${ }^{13} \mathrm{C}$ NMR spectra were recorded on a three-channel Bruker UnityInova $500 \mathrm{MHz}$ spectrometer complete with pulse-field gradient capability. The chemical shifts of diamagnetic compounds were recorded as ppm units relative to internal TMS standard. FIDs obtained from the Bruker AMX 500 spectrometer were transferred to a SUN station, and processed using the software program WIN-NMR.

\section{Thermogravimetry Analysis}

The samples were analyzed by thermogravimetry (TGA) on a Universal V2.5H TA instrument. The samples were first equilibrated to $30^{\circ} \mathrm{C}$ and then heated at a rate of $1{ }^{\circ} \mathrm{C} / \mathrm{min}$ in flowing $\mathrm{N}_{2}$. Crystals of the samples were removed from their storage solution and dried on filter paper prior to analysis. The data shows a weight-loss for each sample consistent with the percentage of water molecules observed crystallographically.

\section{X-ray Crystallography}

X-ray crystallography has been used to characterize many of the inorganic complexes as well as organic compounds and hydrated samples. The following describes typical experimental conditions used for mounting crystals and data collection. A single X-ray quality crystal was mounted on a $0.05 \mathrm{~mm}$ CryoLoop with Paratone oil for collection of X-ray data on a Bruker SMART APEX CCD diffractometer. The SMART (Bruker Advanced X-ray Solutio, I., 2001b) software package (v 5.625) was used to acquire frame $\omega$-scan exposures of data at $100 \mathrm{~K}$ to a $2 \theta_{\max }=56.44^{\circ}$ using monochromated Mo Ka radiation $(0.71073 \AA)$ from a sealed tube and a monocapillary. Frame data were processed using SAINT (Bruker Advanced X-ray Solutio, I., 2001a) (v 
6.22) to determine final unit cell parameters. Independent reflections were then corrected for absorption using SADABS (Sheldrick, G. M., 1997a) (v 2.02). The structure was solved by either direct or Patterson methods and refined by least-squares methods on $\mathrm{F}^{2}$ using SHELXL-97 (Sheldrick, G. M., 1997b) incorporated into the SHELXTL (Sheldrick, G. M., 1997b) (v 6.12) suite of programs. In general, all non-hydrogen atoms were refined anisotropically. Hydrogen atoms on carbon atoms were placed in their geometrically generated positions and refined as a riding model. Hydrogen atoms on oxygen or nitrogen were usually located by difference maps and refined isotropically. The final anisotropic full matrix least-squares refinement on $F^{2}$ for all variables converged at the specified $R_{1}$ and $\mathrm{wR}_{2}$ values with GOF values less than 1.04.

Note: certain organic groups and large counterions can rotate or translate freely in the crystal lattice even at low temperatures. This is often the case with ethyl, tert-butyl groups, perchlorate anions, and even, in this particular study, hydrogen and oxygen atoms of water molecule. In the case of such disorders, the atoms involved in the motion are modeled as positionally disordered and their occupancy factors are divided between the respective positions. In the case of the water studies conducted in Chapter VIII, the hydrogen atoms were located by difference maps and their positions were fixed to their corresponding oxygen atoms using the DFIX commands. Disordered perchlorate anions were modeled using SAME and SADI commands. In two cases, where the solvent molecule was disordered and could not be modeled, the SQUEEZE option was used (Vandersluis, P. \& Spek, A. L., 1990). The SQUEEZE program creates a new reflection file where the disordered solvent contribution is subtracted from the observed data. This option should be used with caution. 


\section{B. Chemical Reagents}

Acetic acid (Fisher Scientific, $\mathrm{FW}=60.05, \mathrm{BP}=118^{\circ} \mathrm{C}, \mathrm{d}=1.049$ ), reagent grade, used as received.

Ammonium nitrate (Fisher Scientific, $\mathrm{FW}=80.0, \mathrm{MP}=440{ }^{\circ} \mathrm{C}$ ), reagent grade, used as received.

Cobalt(II) chloride, hexahydrate (Fisher Scientific, FW = 237.92), reagent grade, used as received.

Copper(II) chloride, dihydrate (Fisher Scientific, $\mathrm{FW}=170.50$ ), reagent grade, used as received.

Copper(II) perchlorate, hexahydrate (Alfa, FW $=370.53$ ), reagent grade, used as received.

$\mathbf{N}, \mathbf{N}^{\prime}$-Dimethylethylenediamine (Aldrich, $\mathrm{FW}=88.15, \mathrm{BP}=119^{\circ} \mathrm{C}, \mathrm{d}=0.827$ ), reagent grade, used as received.

2, 4(5)-Dimethylimidazole (Lancaster, $\mathrm{FW}=96.13, \mathrm{MP}=78^{\circ} \mathrm{C}$ ), reagent grade, used as received.

1,2-Ethanedithiol (Aldrich, $\mathrm{FW}=94.20, \mathrm{BP}=144{ }^{\circ} \mathrm{C}, \mathrm{d}=1.123$ ), reagent grade, used as received.

2-Ethyl-4(5)-methylimidazole (Lancaster, $\mathrm{FW}=110.16, \mathrm{MP}=52{ }^{\circ} \mathrm{C}$ ), reagent grade, used as received.

Ethyleneglycol (Aldrich, FW = 62.07), reagent grade, used as received.

Ethylenediamine (Aldrich, $\mathrm{FW}=60.10, \mathrm{BP}=118{ }^{\circ} \mathrm{C}, \mathrm{d}=0.899$ ), reagent grade, used as received.

Formaldehyde solution ( 37 wt. $\%$ in water, $F W=30.03, d=1.09$ ), reagent grade, used as received.

Hydrochloric acid (Aldrich, $\mathrm{FW}=36.46, \mathrm{BP}>100^{\circ} \mathrm{C}, \mathrm{d}=1.2$ ), reagent grade, used as received.

Hydrogen chloride gas was generated by adding sulfuric acid dropwise to a saturated solution of sodium chloride in hydrochloric acid.

Hydrogen peroxide (Aldrich, 3 or $30 \%(\mathrm{w} / \mathrm{w}), \mathrm{FW}=34.01, \mathrm{~d}=1$ ), reagent grade, used as received.

Hydroxylamine hydrochloride (Fisher, $\mathrm{FW}=69.49^{\circ} \mathrm{C}, \mathrm{MP}=159^{\circ} \mathrm{C}$ ), reagent grade, used as received. 
Hydrazine, monohydrate (Aldrich, $\mathrm{FW}=50.06, \mathrm{BP}=120.1^{\circ} \mathrm{C}, \mathrm{d}=1.032$ ), reagent grade, used as received.

Iron(III) chloride (Alfa, FW = 162.20), anhydrous, reagent grade, used as received.

Magnesium sulfate (Aldrich, $\mathrm{FW}=120.37$ ), anhydrous, reagent grade, used as received.

1-Methylimidazole (Aldrich, $\mathrm{FW}=82.11, \mathrm{BP}=198{ }^{\circ} \mathrm{C}, \mathrm{d}=1.030$ ), reagent grade, used as received.

Ni(II) chloride, hexahydrate (Fisher Scientific, $\mathrm{FW}=237.71$ ), reagent grade, used as received.

Nitric Acid (Aldrich, ACS reagent fuming 99.5\%, FW =63.01, $\mathrm{d}=1.52$ ), reagent grade, used as received.

${ }^{18} \mathrm{O}$ labeled hydrogen peroxide (Icon Isotopes, $90 \%{ }^{18} \mathrm{O}, 0.5 \mathrm{~g}$ ), reagent grade, used as received.

Palladium on activated carbon (Aldrich, Pd content $10 \%$ and $5 \%$ ), reagent grade, used as received with the precaution of adding the reagent under inert atmosphere.

Pivaloyl chloride (Aldrich, $\mathrm{FW}=120.58, \mathrm{BP}=105^{\circ} \mathrm{C}, \mathrm{d}=0.979$ ), reagent grade, used as received.

Potassium hydroxide (Aldrich, $\mathrm{FW}=56.11$ ), reagent grade, used as received.

Sodium azide (Aldrich, 99.99\%, FW =65.01), reagent grade, used as received.

Sodium bicarbonate (Aldrich, $\mathrm{FW}=84.01$ ), reagent grade, used as received.

Sodium borohydride (Aldrich, $\mathrm{FW}=37.83, \mathrm{MP}>300^{\circ} \mathrm{C}$ ), reagent grade, used as received.

Sodium cyanoborohydride (Aldrich, $95 \%, \mathrm{FW}=62.84, \mathrm{MP}<242{ }^{\circ} \mathrm{C}$ ), reagent grade, used as received.

Sodium perchlorate (Alfa, $95 \%, \mathrm{FW}=122.44$ ), reagent grade, used as received.

Sulfuric Acid (Aldrich, ACS reagent 98.0\%, FW = 98.08, d = 1.84), reagent grade, used as received.

Tetra-N-butylammonium perchlorate (TBAP) (Eastman Chemicals, $\mathrm{FW}=341.92$, MP $=213{ }^{\circ} \mathrm{C}$ ), reagent grade, used as received.

p-Toluenesulfonic acid (Lancaster, $98 \%, \mathrm{FW}=190.72$ ), reagent grade, used as received. 
Triethylamine (Aldrich, 99.5\%, $\mathrm{FW}=101.19, \mathrm{BP}=88.8{ }^{\circ} \mathrm{C}, \mathrm{d}=0.726$ ), reagent grade, used as received.

Zn(II) chloride (Aldrich, 98\%, $\mathrm{FW}=136.30, \mathrm{MP}=293{ }^{\circ} \mathrm{C}, \mathrm{d}=2.910$ ), reagent grade, used as received.

Zn(II) perchlorate, hexahydrate (Aldrich, 99\%, $\mathrm{FW}=372.36$ ), reagent grade, used as received.

C. Solvents

Acetone (Aldrich, $\mathrm{BP}=56^{\circ} \mathrm{C}$ ), reagent grade, used as received.

Acetic acid (Aldrich, BP $=118^{\circ} \mathrm{C}$ ), reagent grade, used as received.

Acetonitrile (Aldrich, BP $=82^{\circ} \mathrm{C}$ ), anhydrous, reagent grade, used as received.

Benzene (Aldrich, $\mathrm{BP}=80^{\circ} \mathrm{C}$ ), anhydrous, reagent grade, used as received.

Chloroform (Aldrich, $\mathrm{BP}=61^{\circ} \mathrm{C}$ ), reagent grade, used as received.

Chloroform-d $\mathbf{d}_{\mathbf{1}}$ (Cambridge Isotope Laboratory), NMR grade, 99.9\%, used as received.

Dichloromethane (Aldrich, $\mathrm{BP}=41^{\circ} \mathrm{C}$ ), reagent grade, used as received.

Dimethyl sulfoxide (Aldrich, $\mathrm{BP}=189^{\circ} \mathrm{C}$ ), reagent grade, used as received.

Dimethyl sulfoxide-d $\mathbf{d}_{\mathbf{6}}$ (Cambridge Isotope Laboratory), NMR grade, 99.5\%, used as received.

1,4-Dioxane (Aldrich, $\mathrm{BP}=101^{\circ} \mathrm{C}$ ), anhydrous, reagent grade, used as received.

Diethylether (Aldrich, $\mathrm{BP}=35^{\circ} \mathrm{C}$ ), anhydrous, reagent grade, used as received.

Ethanol (Aldrich, $\mathrm{BP}=78^{\circ} \mathrm{C}$ ), reagent grade, used as received.

Ethylacetate (Aldrich, BP $=77^{\circ} \mathrm{C}$ ), reagent grade, used as received.

Hexanes (Curtin Matheson Scientific, BP $=69^{\circ} \mathrm{C}$ ), reagent grade, used as received.

Methanol (Aldrich, $\mathrm{BP}=65^{\circ} \mathrm{C}$ ), reagent grade, used as received.

Methanol-d $\mathbf{d}_{4}$ (Cambridge Isotope Laboratory), NMR grade, 99.5\%, used as received.

Tetrahydrofuran (Aldrich, $\mathrm{BP}=66^{\circ} \mathrm{C}$ ), reagent grade, purified by distillation from sodium shavings and benzophenone. 
Toluene (Aldrich, BP $=111^{\circ} \mathrm{C}$ ), reagent grade, used as received. 


\section{CHAPTER III}

\section{BIDENTATE IMIDAZOLE LIGANDS}

\section{A. Background}

Ligands containing imidazole moieties have been of particular interests as mimics for metalloenzyme active sites (Holm, R. H. et al., 1996b; Lipscomb, W. N. \& Strater, N., 1996). In the case of copper and zinc containing metalloenzyme active sites, the metal is often found to be bound to two or more histidine residues. Hence, the development of bidentate imidazole ligands is of interest in modeling metalloenzyme active sites. Metal complexes of bidentate ligands have also been used in catalysis and polymerization. There are examples of second- and third-row transition metal complexes, e.g. Rh (Elgafi, S. et al., 1999), Ru (Elgafi, S. et al., 1997), with bidentate imidazole ligands that have found use in catalytic hydrogenation reactions. $\mathrm{Cu}(\mathrm{II})$ (Liu, C. L. et al., 1999) and Pt(II) (Bloemink, M. J. et al., 1996) complexes of bidentate imidazole ligands have also been used as DNA binders. On the other hand, $\mathrm{Cu}(\mathrm{II})$ complexes of bidentate ligands having azole rings have been used in the coupling of imidazoles with arylboronic acid (Collman, J. P. et al., 2001) and chiral bidentate ligands as catalysts for enantioselective reactions (Thorhauge, J. et al., 2002). Incorporation of imidazole moieties in the ligand framework is often difficult (Bhalla, R. et al., 1997). Therefore, the imidazole moiety has often been substituted by pyridine or pyrazole compounds in model studies (Kitajima, N. \& Morooka, Y., 1994; Tyeklar, Z. \& Karlin, K. D., 1989). 
Recently, the intrinsic properties of imidazole as either a hydrogen bond donor or acceptor, and the potential of its $\pi$ stacking ability have been recognized as a useful building block in supramolecular chemistry (Desiraju, G. R., 1995). The simple 2,2'biimidazole ligand and its resulting metal complexes have been shown to form novel supramolecular assemblies (Tadokoro, M. \& Nakasuji, K., 2000). Other structural motifs, such as $\mathrm{M}-\mathrm{Cl}$ units, have been used successfully to stabilize supramolecular assemblies. Brammer and coworkers (Brammer, L. et al., 2001) have established that the M-Cl unit, as well as $\mathrm{Cl}^{-}$ions, can be used as supramolecular synthons (Desiraju, G. R., 1995). In coordination chemistry and ligand design, an understanding and control of the stoichiometry of ligand/metal ratios and the metal coordination environments are crucial to the resulting structure of compounds. This is also the case in the supramolecular assemblies where a rational design of building blocks and an understanding of the supramolecular forces dictating the assembly are required.

With this in mind, we have investigated the properties of 4,4'-methylene-bis(2ethyl-5-methylimidazole) (Shikoku Chemicals Corp., 2004) and a series of its metal complexes in 1:1 and 2:1 ligand-to-metal ratio with $\mathrm{MCl}_{2}$ salt. It is worth noting that similar bidentate ligands with different azole rings and their metal complexes have been reported; for example: bis(imidazole-2-yl)methane (2-BIM) (Abuskhuna, S. et al., 2004) and its derivatives (Place, C. et al., 1998), 2,2'-dipyridylmethane (Manzur, J., 1986), 2,2'dibenzimidazolemethane (Elgafi, S. et al., 1999), 4,4'-dipyrazolylmethane (Broomhead, J. A. et al., 1998) and dipyrromethane (Novak, A. et al., 2002).

This study evaluates the interactions between the ligand backbone N-Hs, M-Cl unit and chloride ions and their resulting solid-state supramolecular assemblies 
containing both 1:1 and 2:1 ligand-to-metal ratios. In the mono-adduct series, the ability of the $\mathrm{MLCl}_{2}$ complexes to be used as building blocks for supramolecular assemblies was investigated (Navarro, J. A. R. \& Lippert, B., 2001). All metal complexes have distorted tetrahedral coordination geometries and yet, their hydrogen bonding patterns are different. The bis-adduct series has revealed the flexibility of the bulky ligand to accommodate various environments around the metal, and in several cases (e.g. Co(II) and $\mathrm{Ni}$ (II) structures) the compounds display interesting packing of the chloride ions and extended imidazole $\mathrm{N}-\mathrm{H}$ hydrogen bonds to inter-lattice chloride ions producing structures potentially relevant to the biological ion channels (Hille, B., 1992). In addition, chloride ions have also been observed to interact with receptors (Kavallieratos, K. et al., 1999) and have been used as templating agents for supramolecular assemblies (Fleming, J. S. et al., 1998; Vilar, R. et al., 1998).

Described herein is the synthesis and the characterization of metal complexes of simple bis-imidazole compounds prepared by a general procedure based on a well-known Mannich-type reaction (Scheme 1). Metal complexes of the bis-coupled ligands 4,4'methylene-bis-(2-ethyl-5-methylimidazole) $\quad\left(\mathrm{L}^{\mathrm{Et}, \mathrm{Me}}\right)$ (1) and 4,4'-methylene-bis-(2,5dimethylimidazole) $\left(\mathrm{L}^{\mathrm{Me}, \mathrm{Me}}\right)$ (2) were characterized by elemental analyses, ESI-MS spectrometry, X-ray crystallography, UV and EPR spectroscopy.
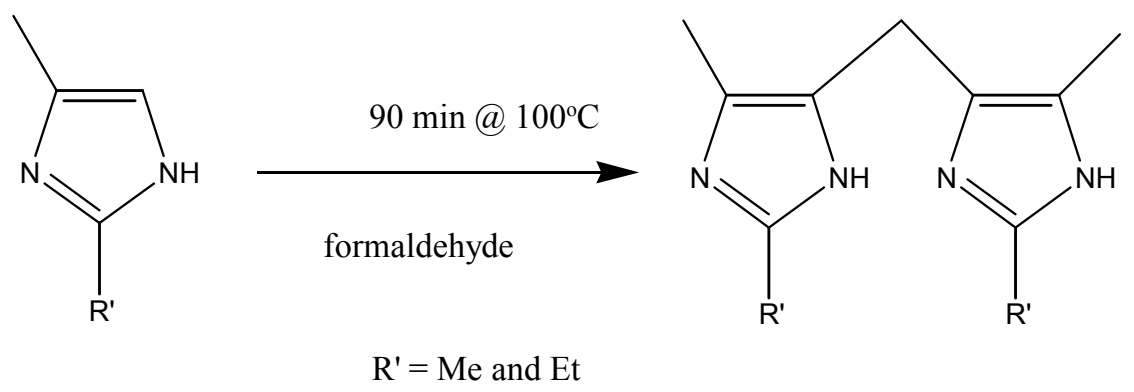

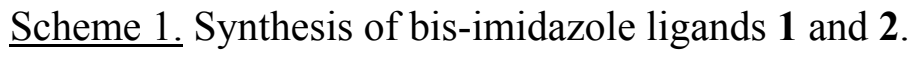


B. Synthesis and Characterization of Bis-imidazole Ligands

Both ligands (1 and 2) were prepared following a published procedure (Shikoku Chemicals Corp., 2004) and isolated in 60\% yield as a white powder.

1. $\quad 4,4^{\prime}$-Methylene-bis(2-ethyl-5-methyl-imidazole), $\mathrm{L}^{\mathrm{Et}, \mathrm{Me}}(\mathbf{1})$ $\mathrm{MP}>260{ }^{\circ} \mathrm{C} ;{ }^{1} \mathrm{H}$ NMR $\mathrm{CD}_{3} \mathrm{OD} \delta=3.57\left(2, \mathrm{~s},-\mathrm{CH}_{2}-\right), 2.49\left(4, \mathrm{q},-\mathrm{CH}_{2}-\right), 1.90(6, \mathrm{~s}$, $\left.-\mathrm{CH}_{3}\right), 1.07\left(6, \mathrm{t},-\mathrm{CH}_{3}\right) .{ }^{13} \mathrm{C}$ NMR $\mathrm{CD}_{3} \mathrm{OD}, \delta=148.1(\mathrm{C} 2), 127.8(\mathrm{C} 4), 125.9(\mathrm{C} 5), 22.1$ $\left(-\mathrm{CH}_{2}-\right), 21.6\left(-\mathrm{CH}_{2}-\right), 12.2\left(-\mathrm{CH}_{3}\right), 9.3\left(-\mathrm{CH}_{3}\right)$. ESI-MS m/z $233.33\left(\mathrm{M}+\mathrm{H}^{+}\right)$; Anal. Calcd for $\mathrm{C}_{13} \mathrm{H}_{20} \mathrm{~N}_{4}: \mathrm{C}, 67.21 ; \mathrm{H}, 8.68 ; \mathrm{N}, 24.12$. Found $\mathrm{C}, 66.84 ; \mathrm{H}, 8.33 ; \mathrm{N}, 23.97$.

2. $\quad 4,4^{\prime}$-Methylene-bis(2,5-dimethyl-imidazole), $\mathrm{L}^{\mathrm{Me}, \mathrm{Me}}(\mathbf{2})$ $\mathrm{MP}>260{ }^{\circ} \mathrm{C} ;{ }^{1} \mathrm{H}$ NMR $\mathrm{CD}_{3} \mathrm{OD} \delta=3.72\left(2, \mathrm{~s},-\mathrm{CH}_{2}-\right), 2.25\left(6, \mathrm{~s},-\mathrm{CH}_{3}\right), 2.01(6, \mathrm{~s},-$ $\left.\mathrm{CH}_{3}\right) .{ }^{13} \mathrm{C} \mathrm{NMR} \mathrm{CD} \mathrm{CD}_{3} \mathrm{OD} \delta=142.3(\mathrm{C} 2), 127.8(\mathrm{C} 4), 125.9(\mathrm{C} 5), 35.1\left(-\mathrm{CH}_{2}-\right), 12.1$ ($\left.\mathrm{CH}_{3}\right)$, $9.2\left(-\mathrm{CH}_{3}\right)$; ESI-MS m/z $205.35\left(\mathrm{M}+\mathrm{H}^{+}\right)$; Anal. Calcd for $\mathrm{C}_{11} \mathrm{H}_{16} \mathrm{~N}_{4}: \mathrm{C}, 64.68 ; \mathrm{H}$, 7.89; N, 27.43. Found C, 64.33; H, 7.59; N, 27.53.

C. Mono-adduct Complexes of $\mathrm{Cu}(\mathrm{II}), \mathrm{Ni}(\mathrm{II}), \mathrm{Co}(\mathrm{II})$ and $\mathrm{Zn}(\mathrm{II})$ with 4,4'-Methylene -bis(2-ethyl-5-methyl-imidazole) (1)

1. Synthesis of the Mono-adduct Metal Complexes

In an equimolar ratio, a solution of $\mathrm{MCl}_{2}$ salt in methanol was added slowly to a methanol solution containing the appropriate bis-imidazole ligand. Layering of the methanol solution with ether yielded suitable X-ray quality crystals overnight after slow diffusion. The yields for the reaction ranged from $40 \%$ for the Ni complex to $78 \%$ for the Co complex. 


\section{Characterization of the Mono-adduct Metal Complexes}

The $\mathrm{MLCl}_{2}$ compounds were analyzed by X-ray crystallography, ESI mass spectrometry, elemental analysis and UV-visible spectroscopy. The following nomenclature has been adopted: $\mathrm{Co}\left(\mathrm{L}^{\mathrm{Et}, \mathrm{Me}}\right) \mathrm{Cl}_{2}(\mathbf{3}), \mathrm{Ni}\left(\mathrm{L}^{\mathrm{Et}, \mathrm{Me}}\right) \mathrm{Cl}_{2}(\mathbf{4}), \mathrm{Cu}\left(\mathrm{L}^{\mathrm{Et}, \mathrm{Me}}\right) \mathrm{Cl}_{2}$ (5), $\mathrm{Zn}\left(\mathrm{L}^{\mathrm{E}, \mathrm{Me}}\right) \mathrm{Cl}_{2}(\mathbf{6})$ and $\mathrm{Cu}\left(\mathrm{L}^{\mathrm{Me}, \mathrm{Me}}\right) \mathrm{Cl}_{2}$ (7). In subsequent Chapters, compounds are assigned sequential numerical representations that will be used throughout the dissertation.

The UV-visible measurements were conducted on methanol solutions of the metal complexes, with the exception of the $\mathrm{Ni}$ complex, where a mixture of $\mathrm{CH}_{2} \mathrm{Cl}_{2} / \mathrm{MeOH}$ $(5 \%)$ was used. The characteristic bands for each compound are summarized below in Table 1.

Table 1. UV-visible transitions for the series of $\mathrm{MLCl}_{2}$ complexes.

\begin{tabular}{cccc}
\hline Compound & \multicolumn{3}{c}{$\lambda$ in $\mathrm{nm}\left(\varepsilon{\left.\text { in } \mathrm{M}^{-1} \mathrm{~cm}^{-1}\right)}\right.$} \\
\hline $\mathbf{3}$ & $320(1000)$ & $580(815)$ & \\
$\mathbf{4}$ & $324(140)$ & $531(80)$ & $980(50)$ \\
$\mathbf{5}$ & $283(4815)$ & $368(205)$ & $680(185)$ \\
$\mathbf{6}$ & $270(4542)$ & $378(180)$ & $719(132)$ \\
\hline
\end{tabular}

ESI-mass spectrometry and elemental analyses were performed on crystalline samples and the results are presented in Table 2.

Table 2. ESI-MS mass units and elemental analyses of the $\mathrm{MLCl}_{2}$ complexes.

\begin{tabular}{|c|c|c|c|}
\hline Compound & ESI-MS [M-Cl] $]^{+}$ & \multicolumn{2}{|c|}{ Elemental analysis } \\
\hline & & Calc. & Found \\
\hline 3 & 326.1 & C $43.11 \%$; H $5.57 \%$ N $15.47 \%$ & C $43.00 \%$; H $5.53 \%$ N $15.39 \%$ \\
\hline 4 & 325.1 & C $43.14 \%$; H $5.57 \%$ N $15.48 \%$ & C $42.96 \%$; H $5.63 \%$ N $15.42 \%$ \\
\hline 5 & 330.1 & C $42.57 \%$; H $5.50 \%$ N $15.28 \%$ & C $42.31 \%$; H $5.29 \%$ N $15.23 \%$ \\
\hline 6 & 302.1 & C $39.00 \% ;$ H $4.76 \%$ N $16.54 \%$ & С $39.33 \%$; H $4.93 \%$ N $16.49 \%$ \\
\hline 7 & 331.1 & C $42.36 \%$; H $5.47 \%$ N $15.20 \%$ & C $42.09 \%$; H $5.87 \%$ N $15.09 \%$ \\
\hline
\end{tabular}




\section{Electrochemistry of Compounds $\mathbf{5}$ and $\mathbf{7}$}

The two $\mathrm{Cu}(\mathrm{II})$ compounds, 5 and 7, display quasi-reversible one-electron voltammetry with $\mathrm{E}_{1 / 2}$ values of $0.00 \mathrm{~V}$ and $0.02 \mathrm{~V}$ (versus $\mathrm{Ag} / \mathrm{AgCl}$ in $\mathrm{CH}_{3} \mathrm{CN} / \mathrm{TBAP}$ ), respectively. The electrochemistry of the other compounds displays irreversible electrochemical behavior.

4. Evaluation of the Crystal Structures of the Mono-adduct Metal Complexes

A series of divalent late first-row transition metal complexes of $\mathbf{1}$ has been synthesized. All four of the metal complexes used in this study crystallize with one ligand and two chlorine atoms attached to the central metal atom, as illustrated in Figure 6 . The coordination environment around the metal can be best described as distorted tetrahedral.

Table 3 summarizes the selected bond distances and angles for all complexes.

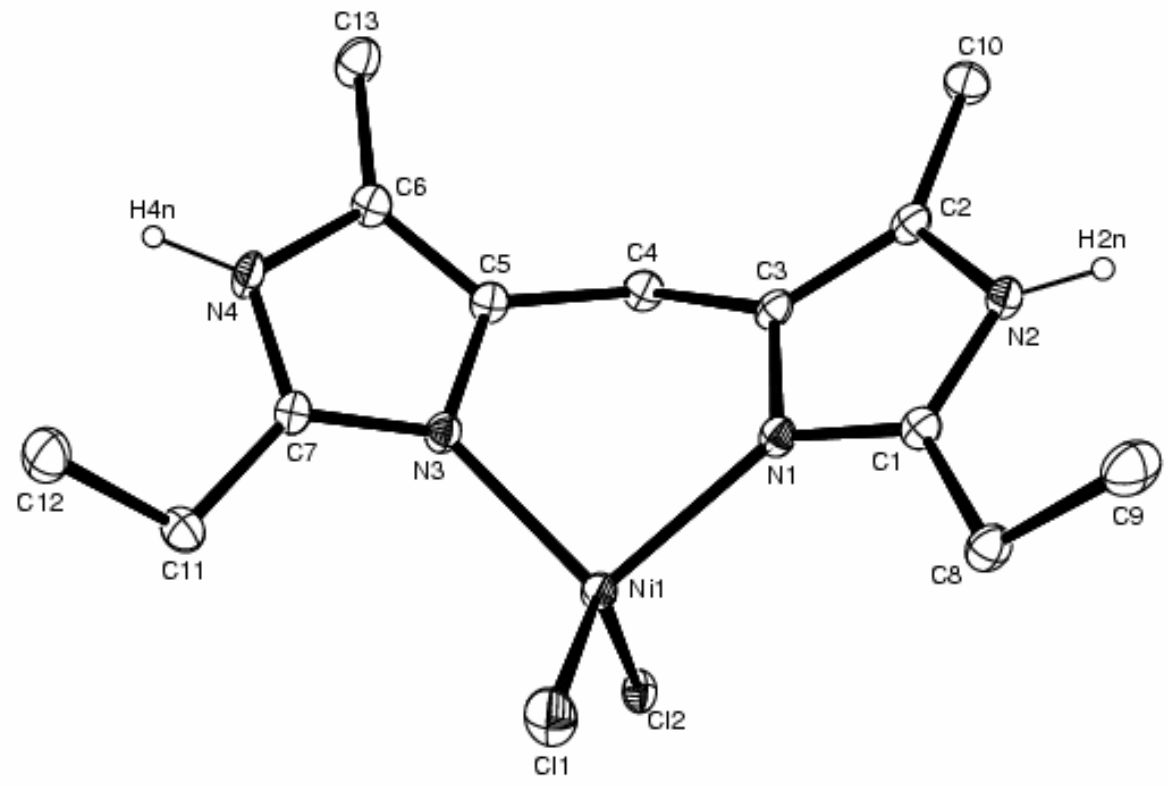

Figure 6. ORTEP view of compound 4. Ellipsoids drawn at $40 \%$ probability. Hydrogen atoms have been omitted for clarity. 
The main distortion from ideal tetrahedral geometry in these complexes results from the pinched nature of the ligand that imposes a constrained N-M-N angle of about 94. In all complexes, the bond distances and angles associated with the ligand are normal and consistent with other reported imidazole compounds (Chen, S. et al., 1994; Riggio, I. et al., 2001). The M-N bond distances are consistent with other imidazole M-N bond distances (Table 3). Similar agreement is observed for the M-Cl bond distances with the exception of the Ni complex, 4 . This discrepancy can be rationalized by looking at the packing diagram of compound $\mathbf{4}$, see discussion below.

Table 3. Selected bond distances and angles for the $\mathrm{MLCl}_{2}$ series.

\begin{tabular}{cccccc}
\hline Compound & $\mathbf{3}$ & $\mathbf{4}$ & $\mathbf{5}$ & $\mathbf{6}$ & $\mathbf{7}$ \\
\hline Distance $(\AA)$ & & & & & \\
M-N1 & $2.005(4)$ & $2.037(3)$ & $1.949(4)$ & $2.019(5)$ & $1.928(2)$ \\
M-N3 & $2.015(4)$ & $1.949(2)$ & $1.938(4)$ & $2.007(5)$ & $1.972(2)$ \\
M-Cl1 & $2.2747(14)$ & $2.0691(9)$ & $2.2228(19)$ & $2.236(3)$ & $2.3506(8)$ \\
M-Cl2 & $2.2478(14)$ & $2.3551(9)$ & $2.2805(18)$ & $2.2721(3)$ & $2.1930(8)$ \\
& & & & & \\
Angles $\left({ }^{\circ}\right)$ & & & & & \\
N1-M-N3 & $95.00(15)$ & $94.90(1)$ & $93.82(16)$ & $96.1(2)$ & $93.47(9)$ \\
N1-M-C11 & $108.89(15)$ & $107.39(7)$ & $126.03(12)$ & $114.9(2)$ & $97.29(7)$ \\
N1-M-C12 & $115.60(13)$ & $107.17(7)$ & $108.46(16)$ & $108.9(2)$ & $135.47(7)$ \\
N3-M-C11 & $108.90(14)$ & $109.05(8)$ & $109.06(16)$ & $115.2(2)$ & $113.80(7)$ \\
N3-M-C12 & $116.68(13)$ & $105.25(8)$ & $117.18(17)$ & $109.3(2)$ & $111.52(7)$ \\
Cl1-M-Cl2 & $110.65(5)$ & $128.09(4)$ & $102.97(6)$ & $111.34(9)$ & $104.66(3)$ \\
\hline
\end{tabular}

The crystal structures of all four complexes appear to be remarkably similar, and their packing diagrams can be divided into two different groups, depending on the hydrogen bonding interactions involving the imidazole $\mathrm{N}-\mathrm{Hs}$ and the coordinated chlorine atoms. 
5. Solid-state Packing Diagrams of the Mono-adduct Metal Complexes

For the $\mathrm{Co}, \mathrm{Cu}$ and $\mathrm{Zn}$ complexes, 3, 5 and $\mathbf{6}$ respectively, both chlorine atoms are hydrogen-bonded to the imidazole N-Hs associated with symmetry related molecules (Figure 7), and display an average Cl---N separation of $3.256 \AA$ and N-H---Cl angle of $164.31^{\circ}$. This is consistent with other weak hydrogen bonding interactions.

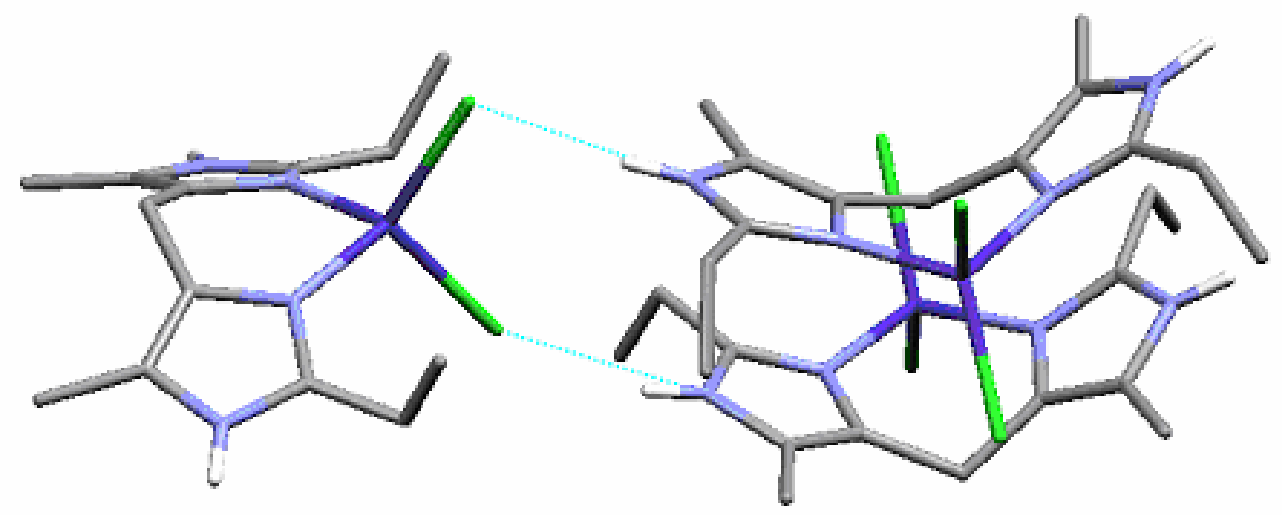

Figure 7. Hydrogen bonding interactions between imidazole $\mathrm{N}-\mathrm{Hs}$ and $\mathrm{Cl}$ (green) bonded to the metal in compounds $\mathbf{3}, \mathbf{5}$ and $\mathbf{6}$. Hydrogens on methyl and methylene have been omitted for clarity.

For compound 5, similar interactions create a 2-D layered structure (Figure 8) (MacDonald, J. C. et al., 2000) not found in the two other complexes, which contain discrete molecules interacting with each other through the hydrogen bonds (Figure 9). 


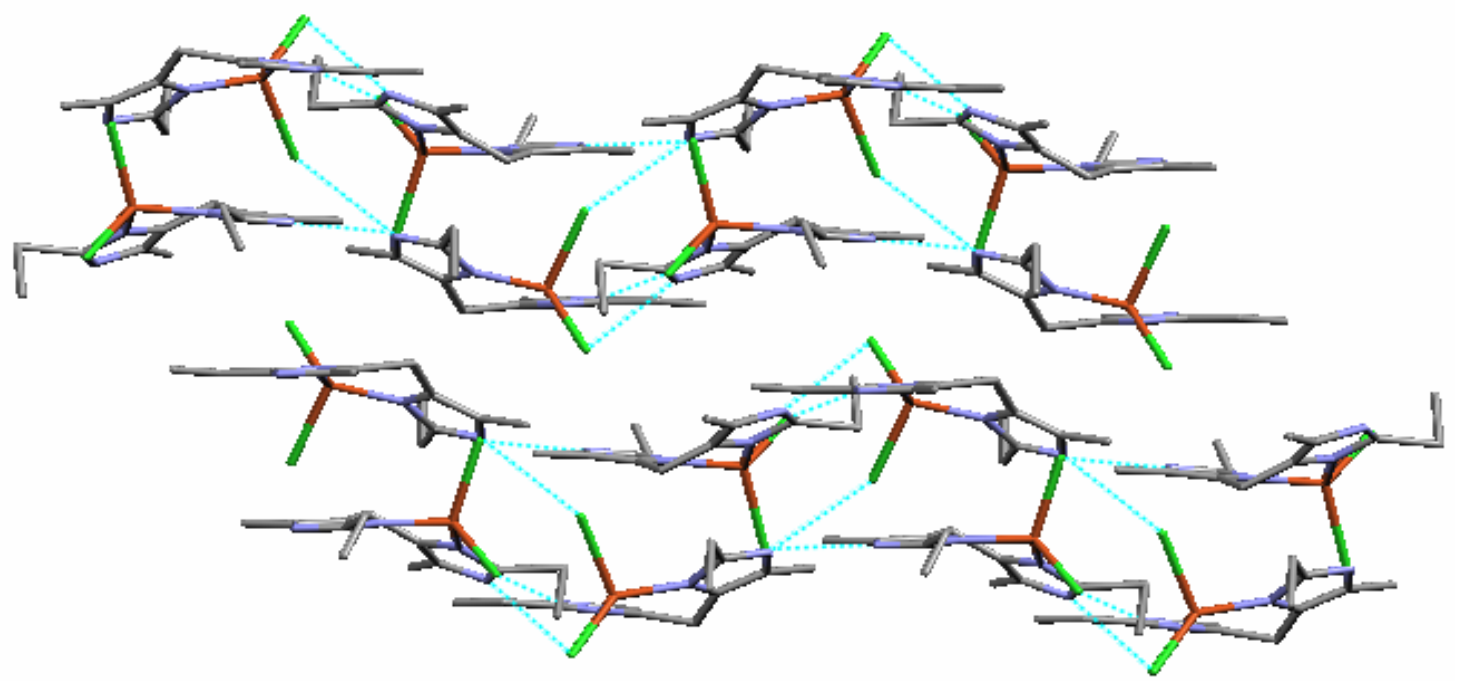

Figure 8. Packing diagram of compound 5 (Cu: orange, $\mathrm{Cl}$ : green, $\mathrm{N}$ : blue, $\mathrm{C}$ : grey) showing the hydrogen-bonded (baby blue) assemblies of tapes along the crystallographic c axis. Hydrogen atoms have been omitted for clarity.

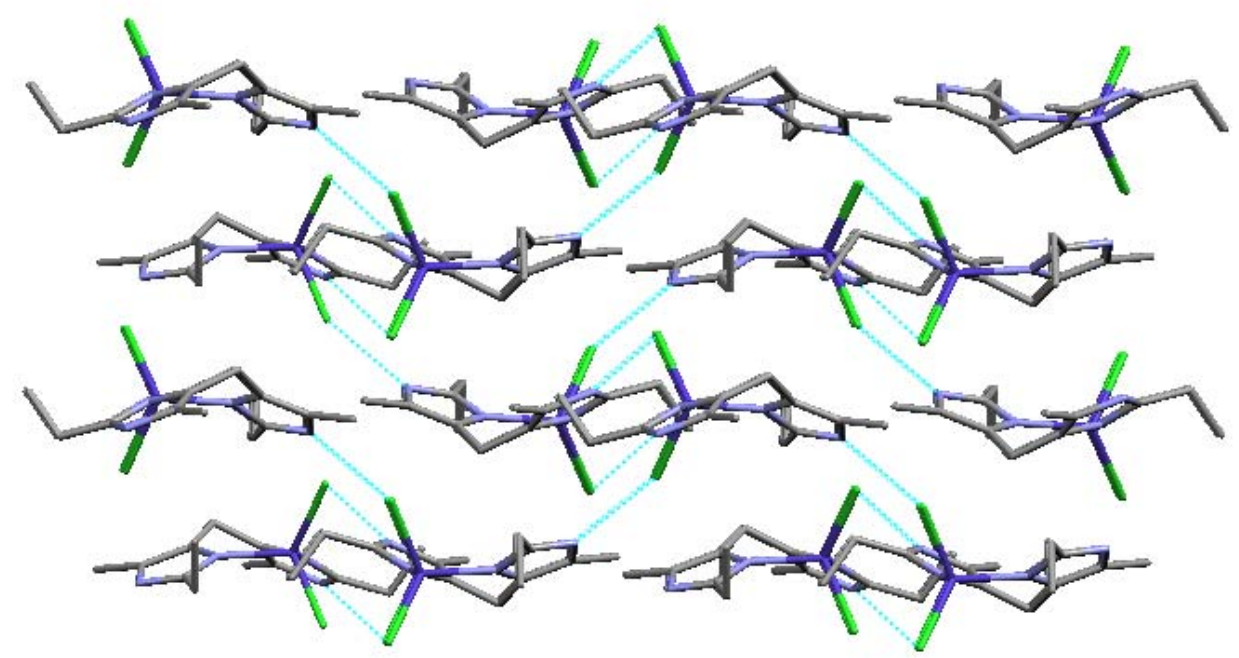

Figure 9. Packing diagram of the compound $\mathbf{3}$ (Co: dark blue, Cl: green, N: blue, C: grey, $\mathrm{H}$ : white) showing the 3-D hydrogen bonding network.

The Ni(II) complex of $\mathbf{1}$, compound $\mathbf{4}$, contains a different packing arrangement with one of the chlorine atoms involved in bifurcated hydrogen bonding interactions with two imidazole N-Hs from symmetry related molecules (average Cl---N separation of $3.319 \AA$ and $\mathrm{N}-\mathrm{H}---\mathrm{Cl}$ angle of $142.99^{\circ}$ ) (Figure 10). Such bifurcated hydrogen bonding 
was not observed by Brammer (Brammer, L. et al., 2001). In addition, the second chlorine atom is oriented towards one of the methylene hydrogen atoms (H4a) with a Cl--C4 separation of $3.279 \AA$ and a $\mathrm{Cl}---\mathrm{H} 4 \mathrm{a}-\mathrm{C} 4$ angle of $135.1^{\circ}$. The differences of packing arrangements observed in compound $\mathbf{4}$ may be due to different orientations of the ethyl groups in the solid-state. In fact, in the $\mathrm{Ni}(\mathrm{II})$ complex, the ethyl chains are pointing away from the chlorine atoms, which allow the chlorine atom to interact with the methylene hydrogen atom, H4a.

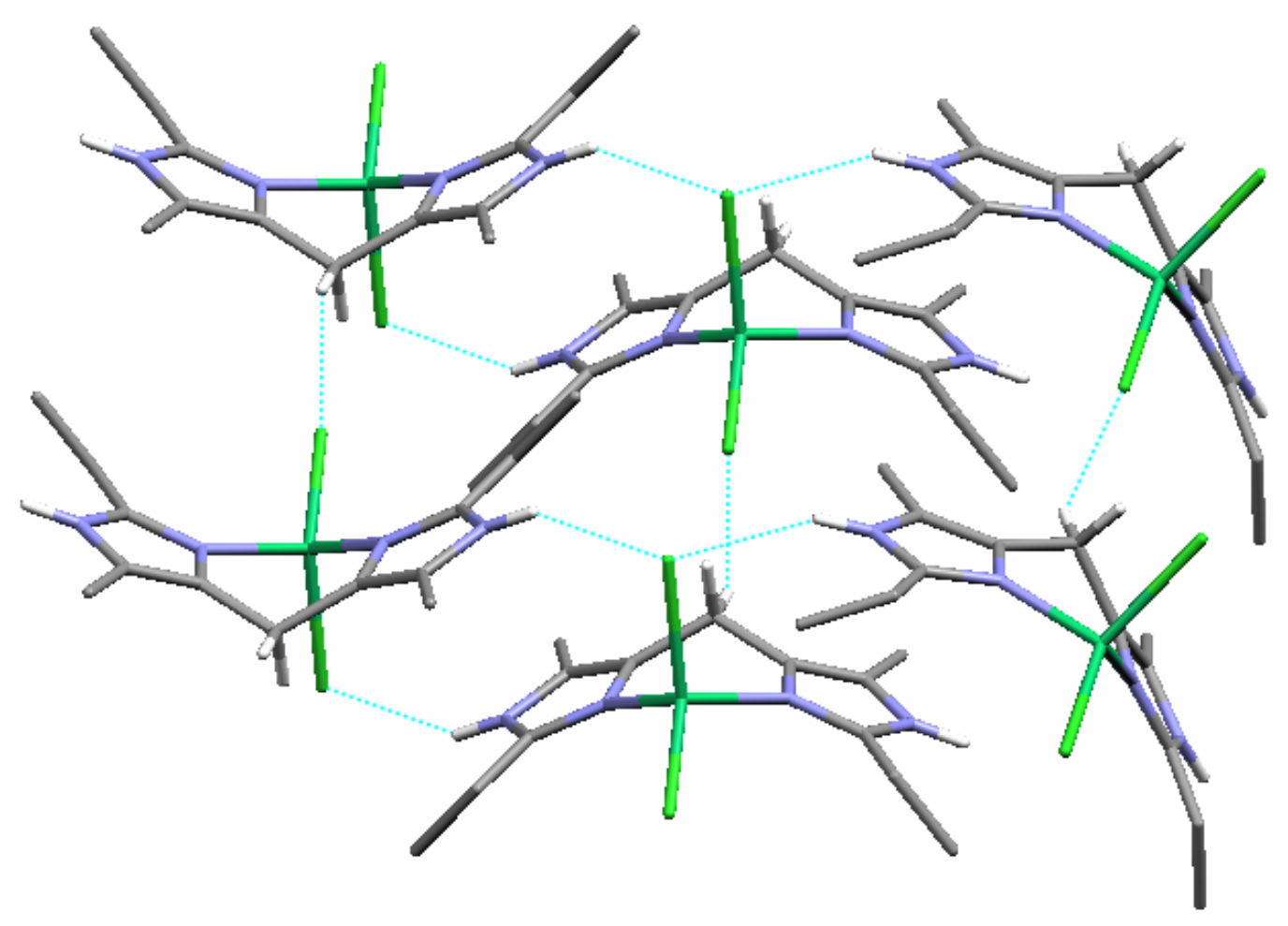

Figure 10. Hydrogen bonding interactions between imidazole $\mathrm{N}-\mathrm{Hs}$ and $\mathrm{Cl}$ (green) bonded to the metal found in the packing arrangement of 4 . Hydrogens on methyl and methylene from the ethyl chains have been omitted for clarity. 
This observation is further substantiated by the packing arrangement of the $\mathrm{CuL}{ }^{\mathrm{Me}, \mathrm{Me}^{-}} \mathrm{Cl}_{2}$ complex (7) where the 2-position ethyl groups have been replaced with less bulky methyl groups (Figure 11). The coordination environment of 7 is distorted tetrahedral.

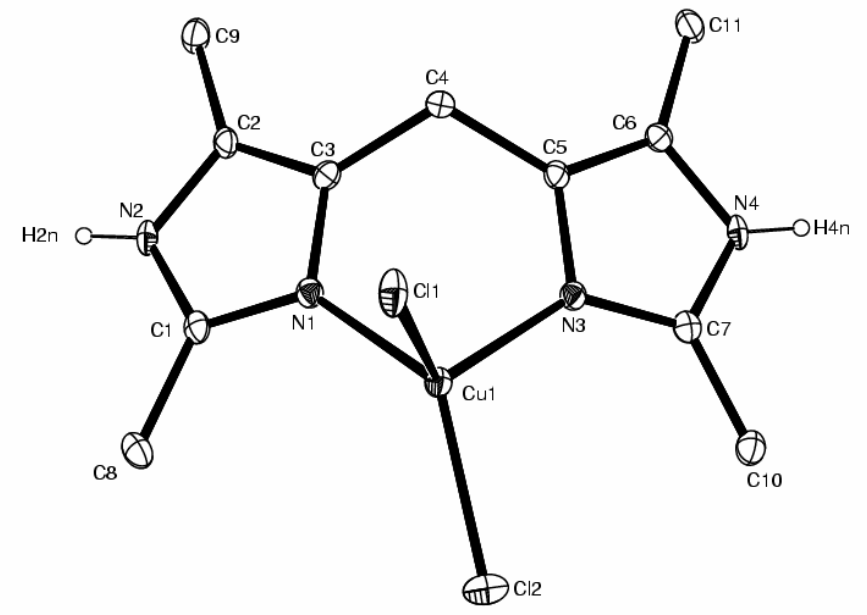

Figure 11. ORTEP view of compound 7. Methyl and methylene hydrogens have been omitted for clarity.

The $\mathrm{Cu}-\mathrm{N}(\mathrm{Im})$ distances are normal and consistent with compound 5 (Table 3). However, the two $\mathrm{Cu}-\mathrm{Cl}$ distances are different by $0.16 \AA$. One of the chlorine atoms, $\mathrm{Cl1}$, is involved in a bifurcated hydrogen bonding interaction, and $\mathrm{Cl} 2$ is weakly interacting with a methylene hydrogen atom of the ligand (Cl2---C4 separation of $3.499 \AA$ and $\mathrm{Cl} 2---\mathrm{H} 4 \mathrm{a}-$ $\mathrm{C} 4$ angle of $112.74^{\circ}$ ). Interestingly, this $\mathrm{Cu}(\mathrm{II})$ complex has a packing arrangement similar to compound 4 (Figure 11). As with compound 4, the weak hydrogen bonding interactions observed in the structure of compound 7 are consistent with those reported by Brammer and coworkers (Brammer, L. et al., 2001).

D. Bis-adduct Complexes of $\mathrm{Cu}(\mathrm{II}), \mathrm{Ni}(\mathrm{II}), \mathrm{Co}(\mathrm{II})$ and $\mathrm{Zn}(\mathrm{II})$ with 4,4'-Methylene -bis(2-ethyl-5-methyl-imidazole)

This study involves metal complexes of $\mathbf{1}$ with ligand-to-metal stoichiometries of 2:1. Four- and five-coordinate metal compounds of $\mathbf{1}$ are reported below. Co(II) and 
$\mathrm{Zn}(\mathrm{II})$ complexes of $\mathbf{1}$ are isolated as four-coordinate complexes $\mathrm{M}\left(\mathrm{L}^{\mathrm{Et}, \mathrm{Me}}\right)_{2} \mathrm{X}_{2}$, compounds $\mathbf{8}$ and $\mathbf{9}$, and have distorted tetrahedral geometry. The $\mathrm{Ni}(\mathrm{II})$ and $\mathrm{Cu}(\mathrm{II})$ complexes, on the other hand, stabilize four-coordinate square planar complexes, compounds $\mathbf{1 0}$ and 11, respectively, as well as five-coordinate distorted trigonal bipyramidal complexes of general formula $\left[\mathrm{M}\left(\mathrm{L}^{\mathrm{Et}, \mathrm{Me}}\right)_{2} \mathrm{Cl}\right] \mathrm{Cl}$, compounds $\mathbf{1 2}$ and $\mathbf{1 3}$, respectively.

\section{Synthesis of the Bis-adduct Metal Complexes}

These compounds were prepared in two different ways: (i) by the reaction of the appropriate molar ratio of ligand to the metal salt, or (ii) by adding an extra equivalent of 1 to a methanol solution of the corresponding $\mathrm{ML}^{\mathrm{Et}, \mathrm{Me}} \mathrm{Cl}_{2}$ complex.

\section{Compound 13}

\section{Method A}

For example, $\left[\mathrm{Cu}\left(\mathrm{L}^{\mathrm{Et}, \mathrm{Me}}\right)_{2} \mathrm{Cl}\right] \mathrm{Cl}(\mathbf{1 3})$ was synthesized by reacting $1.00 \mathrm{~g}(4.26 \mathrm{mmol})$ of the $\mathrm{L}^{\mathrm{Et}, \mathrm{Me}}$ ligand in $5 \mathrm{~mL}$ of $\mathrm{MeOH}$ with $0.33 \mathrm{~g}(1.94 \mathrm{mmol})$ of $\mathrm{CuCl}_{2}$ in $2 \mathrm{~mL}$ of $\mathrm{MeOH}$. After slow vapor diffusion of ether into the methanol solution, $0.86 \mathrm{~g} \mathrm{(74 \% )}$ of $\mathbf{1 3}$ were isolated overnight as green plates of X-ray crystallography quality.

\section{Method B}

Compound $\mathbf{1 3}$ was also isolated by adding $0.45 \mathrm{~g}(1.95 \mathrm{mmol})$ of $\mathbf{1}$ in $2 \mathrm{~mL}$ of $\mathrm{MeOH}$ to a methanolic solution $(3 \mathrm{~mL})$ containing $0.65 \mathrm{~g}(1.77 \mathrm{mmol})$ of the mono-adduct compound 7. The slow diffusion of ether vapors into the methanolic solution yielded 0.69 $\mathrm{g}(65 \%)$ of $\mathbf{1 3}$ as green plates.

This latter strategy was successful for the $\mathrm{Co}, \mathrm{Ni}, \mathrm{Cu}$ complexes, but could not be

employed for preparing the $\mathrm{Zn}$ complex because the $\mathrm{Zn}\left(\mathrm{L}^{\mathrm{Et}, \mathrm{Me}}\right) \mathrm{Cl}_{2}$ is too insoluble in 
methanol to promote further reactivity. A different approach for $\mathrm{Zn}$ was developed using the more labile perchlorate anion, which lead to the successful isolation of the bis-adduct Zn complex.

\section{Compound 9}

A methanolic solution $(2 \mathrm{~mL})$ of $0.80 \mathrm{~g}(3.00 \mathrm{mmol})$ of $\mathrm{Zn}\left(\mathrm{ClO}_{4}\right)_{2}$ was added dropwise to $1.54 \mathrm{~g}$ (6.61 mmol) of $\mathbf{1} \mathrm{in} 3 \mathrm{~mL}$ of $\mathrm{MeOH}$. Layering of the reaction solution with ether led, overnight, to the formation of $1.58 \mathrm{~g}(72 \%)$ of colorless crystals of $\mathrm{Zn}\left(\mathrm{L}^{\mathrm{Et}, \mathrm{Me}}\right)_{2}\left(\mathrm{ClO}_{4}\right)_{2}(\mathbf{9})$.

2. Characterizations of the Bis-adduct Metal Complexes

The $\mathrm{M}\left(\mathrm{L}^{\mathrm{Et}, \mathrm{Me}}\right)_{2} \mathrm{X}_{2}$ compounds, where $\mathrm{X}=\mathrm{Cl}^{-}$or $\mathrm{ClO}_{4}^{-}$, were analyzed by $\mathrm{X}$-ray crystallography, ESI mass spectrometry, elemental analysis and UV-visible spectroscopy. The UV-visible measurements were conducted using methanolic and aqueous solutions of the metal complexes. The characteristic bands for each compound are summarized below in Table 4.

Table 4. UV-visible transitions for the series of $\mathrm{ML}_{2} \mathrm{Cl}_{2}$ complexes.

\begin{tabular}{cccc}
\hline Compound & \multicolumn{2}{c}{$\lambda$ in $\mathrm{nm}\left(\varepsilon\right.$ in $\left.\mathrm{M}^{-1} \mathrm{~cm}^{-1}\right)$} & Solvent \\
\hline $\mathbf{8}$ & $450(720)$ & $560(450)$ & water \\
$\mathbf{1 0}$ & $400(140)$ & $660(100)$ & water \\
$\mathbf{1 2}$ & $425(200)$ & $620(80)$ & $\mathrm{MeOH}$ \\
$\mathbf{1 3}$ & $375(530)$ & $635(120)$ & $\mathrm{MeOH}$ \\
\hline
\end{tabular}

ESI-mass spectrometry and elemental analyses were performed on crystalline samples and the results are presented in Table 5. 
Table 5. ESI-MS mass units and elemental analyses of the bis-adduct complexes.

\begin{tabular}{|c|c|c|c|}
\hline Compound & ESI-MS & \multicolumn{2}{|c|}{ Elemental analysis } \\
\hline & & Calc. & Found \\
\hline 8 & $522.7[\mathrm{M}-\mathrm{H}]^{+}$ & C $52.35 \%$; H $7.10 \%$ N $18.79 \%$ & C $52.41 \%$; H $7.05 \%$ N $18.84 \%$ \\
\hline 9 & $528.4[\mathrm{M}-\mathrm{H}]^{+}$ & C $42.84 \%$; H $5.58 \%$ N $15.37 \%$ & C $42.78 \%$; H $5.53 \%$ N $15.31 \%$ \\
\hline 10 & $522.3[\mathrm{M}-\mathrm{H}]^{+}$ & C $52.55 \%$; H $6.78 \%$ N $18.86 \%$ & C $52.59 \%$; H $6.79 \%$ N $18.89 \%$ \\
\hline 12 & $557.2[\mathrm{M}]^{+}$ & C $52.55 \%$; H $6.78 \%$ N $18.86 \%$ & C $52.49 \%$; H $6.69 \%$ N $18.83 \%$ \\
\hline 13 & $562.5[\mathrm{M}]^{+}$ & C $52.12 \% ;$ H $6.73 \%$ N $18.70 \%$ & C $52.17 \%$; H $6.69 \%$ N $18.76 \%$ \\
\hline
\end{tabular}

3. Evaluation of the Crystal Structures of Compounds 8 and 9

Bis-adduct complexation of $\mathbf{1}$ was anticipated to stabilize distorted tetrahedral structures. In fact, the coordination environment around the $\mathrm{Co}$ and $\mathrm{Zn}$ atoms in the complexes shown below (Figure 12) are very similar. This is why spectroscopically active $\mathrm{Co}(\mathrm{II})$ ions have been used to probe the structure of metalloenzyme active sites containing Zn(II) (Maret, W. \& Vallee, B. L., 1993).

(a)

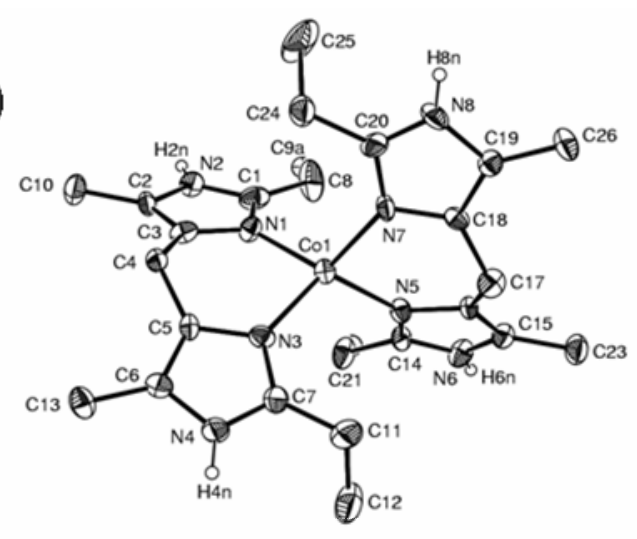

(b)

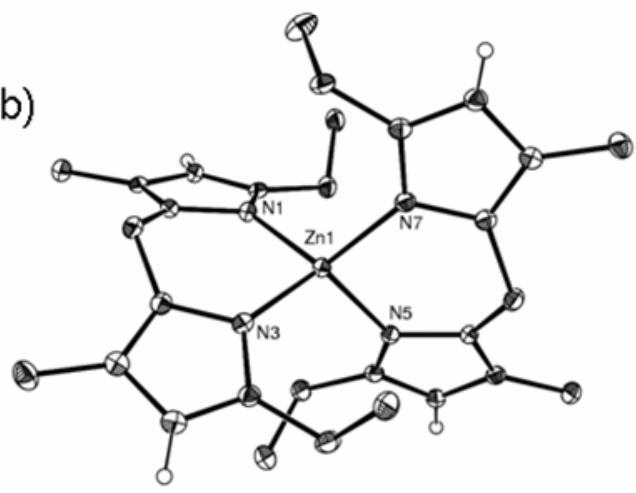

Figure 12. ORTEP views of the cationic portions of compounds 8 (a) and 9 (b). 
Table 6. Selected bond distances and angles for compounds 8 and 9.

\begin{tabular}{ccc}
\hline & $\mathrm{Co}\left(\mathrm{L}^{\mathrm{Et}, \mathrm{Me}}\right)_{2}$ & $\mathrm{Zn}\left(\mathrm{L}^{\mathrm{Et}, \mathrm{Me}}\right)_{2}$ \\
\hline distances $(\AA)^{\mathrm{a}}$ & & \\
M-N1 & $2.017(7)$ & $1.998(4)$ \\
M-N3 & $2.000(7)$ & $1.976(4)$ \\
M-N5 & $2.016(7)$ & $1.989(4)$ \\
M-N7 & $2.004(7)$ & $1.983(4)$ \\
& & \\
angles( $\left.{ }^{\circ}\right)^{\mathrm{a}}$ & & \\
N1-M-N3 & $95.0(3)$ & $96.5(2)$ \\
N1-M-N5 & $117.8(2)$ & $116.3(2)$ \\
N1-M-N7 & $116.7(3)$ & $114.0(2)$ \\
N3-M-N5 & $116.6(3)$ & $113.4(2)$ \\
N3-M-N7 & $118.5(4)$ & $121.7(2)$ \\
N5-M-N7 & $94.4(3)$ & $95.9(2)$ \\
\hline
\end{tabular}

a) There are two independent molecules in the asymmetric unit for both compounds. The distances and angles reported have been averaged.

The distances and angles associated with $\mathbf{8}$ and $\mathbf{9}$ are normal and consistent with other reported imidazole compounds (Novak, A. et al., 2002). The imidazole nitrogen-tometal distances are $2.011 \AA$ and $1.980 \AA$ for $\mathbf{8}$ and $\mathbf{9}$, respectively. For both complexes, there are two types of N-M-N angles. The first type consists of the angles imposed by the pinched nature of the ligand, e.g. N1-M-N3 or N5-M-N7, which have average values of $94.09^{\circ}$ and $96.40^{\circ}$ for $\mathbf{8}$ and $\mathbf{9}$, respectively. The second sets of N-M-N angles have average values of $117.67^{\circ}$ and $116.36^{\circ}$ for $\mathrm{Co}(\mathrm{II})$ and $\mathrm{Zn}$ (II) complexes, respectively. Even though the counterions are different for the metal complexes (e.g. $\mathrm{Cl}^{-}$versus $\mathrm{ClO}_{4}{ }^{-}$), the imidazole N-Hs are still involved in hydrogen bonding interactions with either $\mathrm{Cl}$ (average N---Cl separation of $3.137 \AA$ and $\mathrm{N}-\mathrm{H}---\mathrm{Cl}$ angle of $171.09^{\circ}$ ) for the $\mathrm{Co}$ complex, or with perchlorate $\mathrm{O}$ atoms (average N---O separations of $2.921 \AA$ and N-H--$\mathrm{O}$ of $162.85^{\circ}$ ) for the $\mathrm{Zn}$ complex. 


\section{Solid-state Packing of Compound $\mathbf{8}$}

The packing arrangement of compound $\mathbf{8}$, the bis-adduct Co(II) complex of $\mathbf{1}$, displays a unique supramolecular assembly of chlorine atoms, as illustrated in Figure 13. At first glance, the chloride anions form a parallelepiped box with dimensions of $13.8 \mathrm{x}$ $10.5 \AA^{2}$, with a diamond pattern of atoms on the long faces of the boxes (as illustrated in Figure 13). The box formed by these chlorine atoms encapsulates the inorganic cation in which the two exposed $\mathrm{Co}(\mathrm{II})$ centers face each other forming a potential reaction chamber with dimensions of $8.43 \times 3.75 \AA^{2}$ (Figure 14). Similar tubular channels have been of interest in photoelectric devices, ion exchange, molecular sieves (Kresge, C. T. et al., 1992), sensors (Xing, W. L. \& He, X. W., 1997), biomimetics, catalysts, artificial storages and templates for the synthesis of nanomaterials (Hong, B. H. et al., 2001; Meissner, R. S. et al., 1995; Son, S. U. et al., 2003).
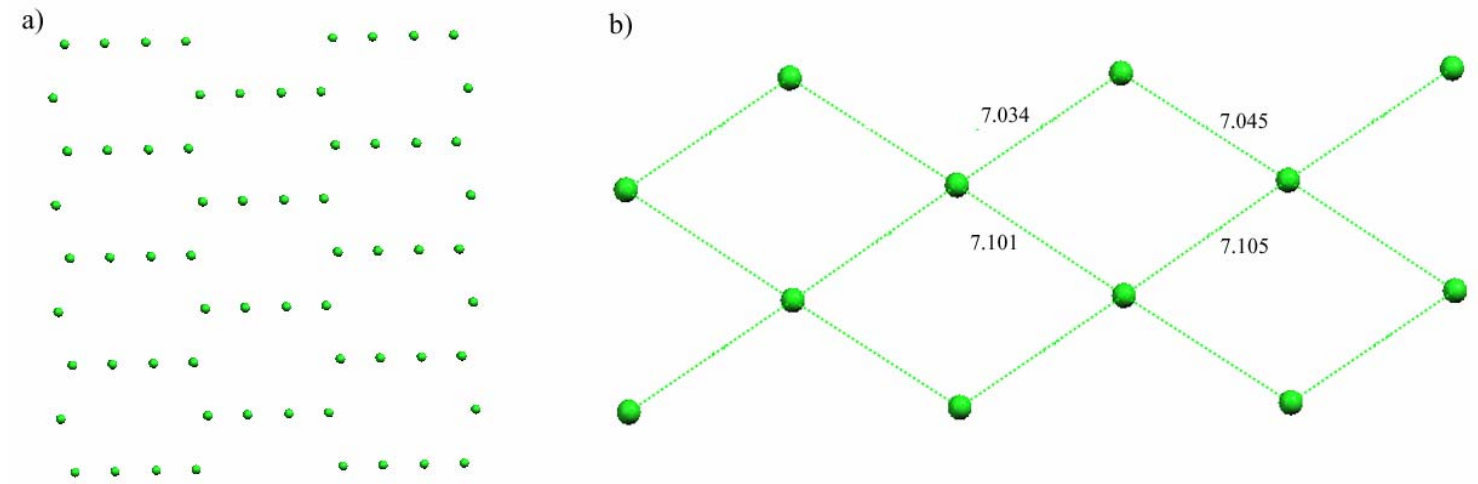

Figure 13. Packing diagram of the chlorine atoms in the $\mathrm{Co}\left(\mathrm{L}^{\mathrm{Et}, \mathrm{Me}}\right)_{2}$ that forms (a) a parallelepiped box with (b) a diamond pattern on the faces. 


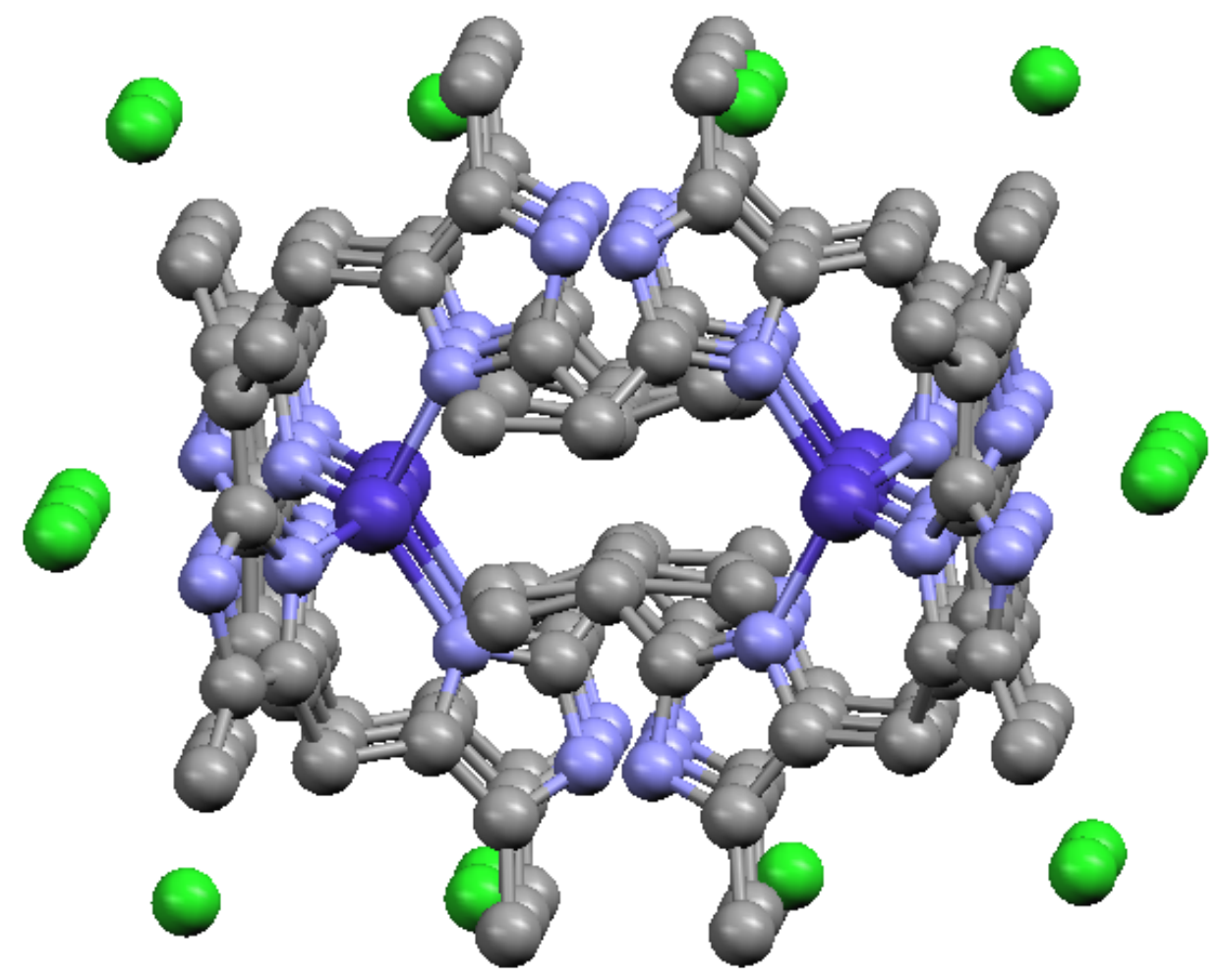

Figure 14. Arrangement of the Co (dark blue sphere) atoms in compound $\mathbf{8}$ showing the potential reaction chamber. The green spheres represent the chlorine atoms encapsulating the inorganic cation.

5. Square Planar Complexes of $\left[\mathrm{M}\left(\mathrm{L}^{\mathrm{Et}, \mathrm{Me}}\right)_{2}\right] \mathrm{Cl}_{2}$ where $\mathrm{M}=\mathrm{Cu}, \mathrm{Ni}$

Interestingly, the ethyl groups of $\mathbf{1}$ are flexible enough to accommodate square planar geometries in $\mathrm{Cu}(\mathrm{II})$ and $\mathrm{Ni}(\mathrm{II})$ complexes. The $\mathrm{Cu}(\mathrm{II})$ complex (11) (see Chapter VII, Section B) was solved and refined as an incommensurate structure which is similar to the related compound $\mathbf{1 0}$ shown in Figure 15. In both the $\mathrm{Cu}$ and Ni structures, the metal atoms were located on crystallographic special positions and therefore required that only half of each molecule be refined (because the other half of the molecule was generated by inversion symmetry). In both complexes, the bond distances and angles are normal and consistent with previously reported complexes (Table 7) (Driessen, W. L. et al., 2003). In these cases, the N1-M-N3 angles $\left(92.91^{\circ}\right.$ and $93.61^{\circ}$ for $\mathbf{1 0}$ and $\mathbf{1 1}$, 
respectively) imposed by the pinched nature of the ligand favor stabilization of square planar structures.

Table 7. Selected bond distances and angles for compounds $\mathbf{1 0}$ and $\mathbf{1 1 .}$

\begin{tabular}{ccc}
\hline & $\mathrm{Ni}\left(\mathrm{L}^{\mathrm{Et}, \mathrm{Me}}\right)_{2}$ & $\mathrm{Cu}\left(\mathrm{L}^{\mathrm{Et}, \mathrm{Me}}\right)_{2}$ \\
\hline Distances $(\AA)$ & & \\
M-N1 & $1.891(2)$ & $1.9801(18)$ \\
M-N3 & $1.896(3)$ & $1.9866(18)$
\end{tabular}

\begin{tabular}{ccc} 
Angles $\left(^{\circ}\right)$ & & \\
N1-M-N3' & $87.09(10)$ & $86.39(7)$ \\
N1-M-N1' & 180 & 180 \\
N1-M-N3 & $92.91(10)$ & $93.61(7)$ \\
\hline
\end{tabular}

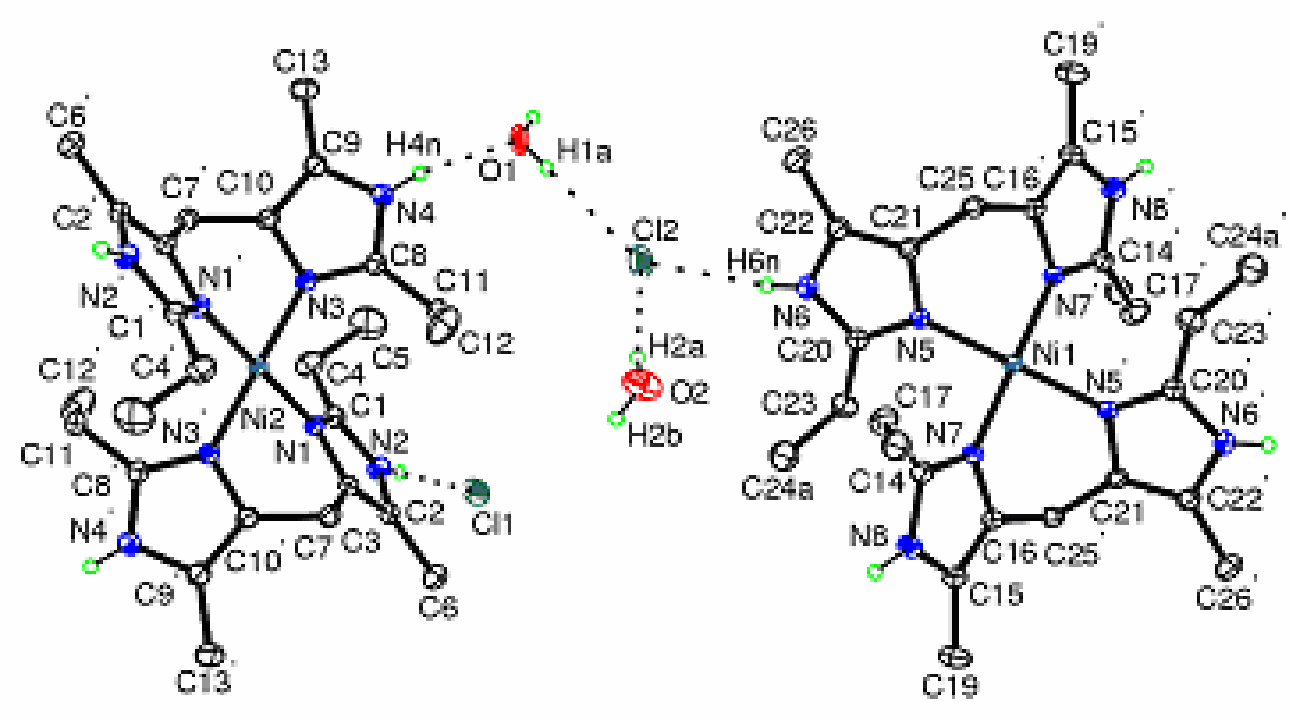

Figure 15. ORTEP view of the two independent cationic portions of 10, as well as the hydrogen bonding interactions between imidazole N-Hs and the outer sphere chlorine and water molecules.

As observed previously, both imidazole N-Hs are hydrogen bonded to either a lattice water molecule (N4---O1 separation of $2.759 \AA$ and a N4-H4N---O1 angle of $166.15^{\circ}$ ) or a chlorine counterion (average N---Cl separations of $3.148 \AA$ and N-H---Cl angle of $165.26^{\circ}$ ), which are also weakly hydrogen bonded to neighboring water 
molecules (average O---Cl separations of $3.276 \AA$ and $\mathrm{O}-\mathrm{H}---\mathrm{Cl}$ angle of $171.22^{\circ}$ ) stabilizing isolated four-water and four-chlorine units, as shown in Figure 16. Such discrete clusters have been previously observed (Infantes, L. et al., 2003) and thought to play an important role in the ion transport channel in transmembrane proteins (Dutzler, R. et al., 2002).
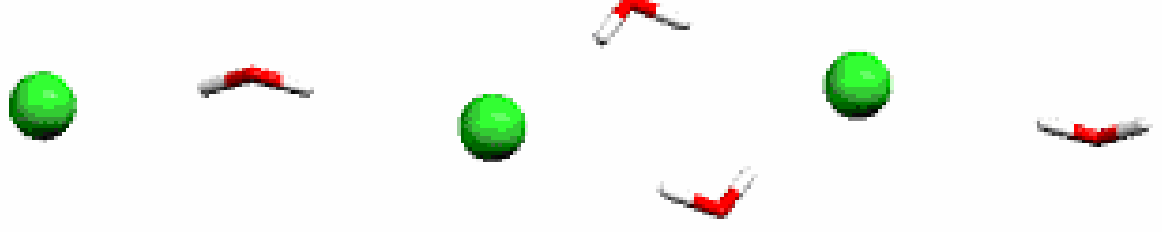

Figure 16. Discrete cluster of four water molecules (H (white); $\mathrm{O}$ (red)) and four chlorine atoms (green) stabilized in the lattice of the compound $\mathbf{1 0 .}$

6. Five-coordinate Complexes of $\left[\mathrm{M}\left(\mathrm{L}^{\mathrm{Et}, \mathrm{Me}}\right)_{2} \mathrm{Cl}\right] \mathrm{Cl}$ where $\mathrm{M}=\mathrm{Cu}, \mathrm{Ni}$

In the case of $\mathrm{Ni}$ and $\mathrm{Cu}$, five-coordinate complexes (compounds $\mathbf{1 2}$ and $\mathbf{1 3}$, respectively), were isolated containing a chlorine atom bonded to both metal atoms. The coordination environment around both metal atoms is best described as distorted trigonal bipyramidal. The geometric parameter, $\tau$, introduced by Addison et al. has been used to evaluate the coordination environment around the metal centers (Addison, A. W. et al., 1984). By definition, $\tau=(\beta-\alpha) / 60$ where $\alpha$ and $\beta$ are two basal angles $(\beta \geq \alpha)$ and has a value of 1 for an ideal trigonal bipyramidal arrangement and 0 for a square pyramidal geometry. For 12 and 13, $\tau$ values of 0.99 and 0.83 , respectively, are indicative of distorted trigonal bipyramidal arrangements around the metal atom. Both compounds 12 and 13 could be isolated but only compound 13 was fully characterized by X-ray crystallography. An incommensurate structure was obtained for compound 12. For both structures, the distorted trigonal bipyramidal geometry is defined by N1, Cl1 and N5 in the trigonal plane and N3 and N7 that occupy apical positions (Figure 17). 


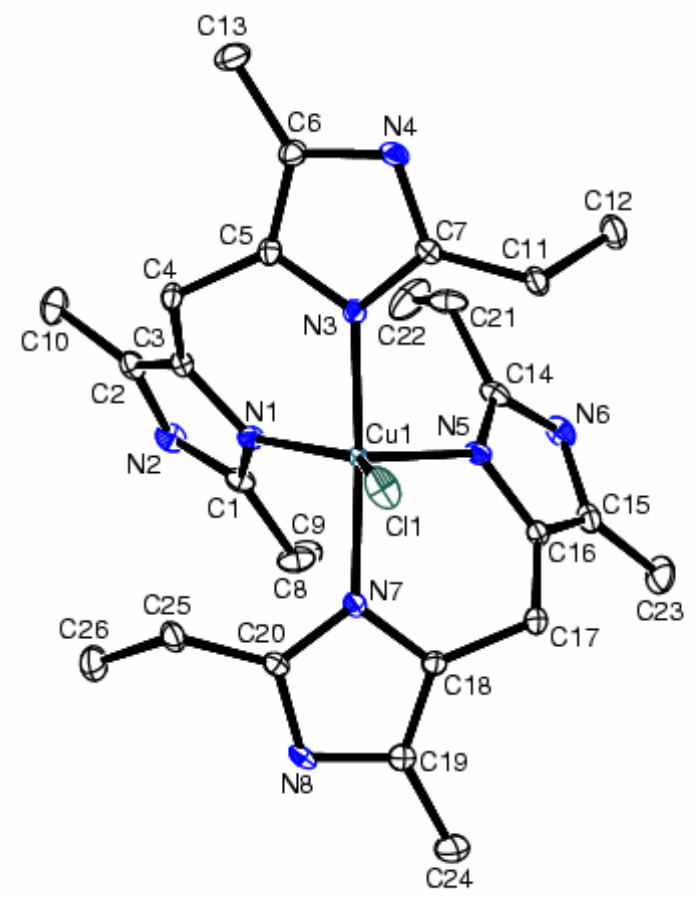

Figure 17. ORTEP view of the cationic portion of compound 13.

The average $\mathrm{N}-\mathrm{M}-\mathrm{Cl}$ bond angles are $130.7^{\circ}$ and $131.81^{\circ}$ for $\mathbf{1 2}$ and $\mathbf{1 3}$, respectively, and the N1-M-N5 angles are $86.35^{\circ}$ and $96.34^{\circ}$ for 12 and $\mathbf{1 3}$, respectively (Table 8). The N3-M-N7 angles, which include two trans imidazole nitrogens, are $166.6^{\circ}$ and $171.93^{\circ}$ for the $\mathrm{Ni}$ and $\mathrm{Cu}$ complexes, respectively. While the $\mathrm{N}-\mathrm{Ni}$ distances are uniform, normal and consistent with other $\mathrm{Ni}-\mathrm{N}$ (imidazole) distances, the $\mathrm{N}-\mathrm{Cu}$ distances are different. In particular, one of the distances (N7-Cu1) is significantly longer $(2.144 \AA)$ due to Jahn-Teller distortion.

As with previously described complexes, the imidazole N-Hs of both complexes are weakly hydrogen bonded to lattice chlorine atoms with an average $\mathrm{N}---\mathrm{Cl}$ separation of $3.149 \AA$ and N-H---Cl angle of $166.78^{\circ}$. In addition, methanol solvent molecules are also weakly hydrogen bonded to chlorine counterions (O---Cl separation of $3.123 \AA$ and O-H---Cl angle of $\left.167.17^{\circ}\right)$. 
Table 8. Selected bond distances and angles for compounds $\mathbf{1 2}$ and $\mathbf{1 3}$.

\begin{tabular}{ccc}
\hline Compound & $\mathbf{1 2}$ & $\mathbf{1 3}$ \\
\hline Distances $(\AA)$ & & \\
M-Cl1 & $2.403(3)$ & $2.382(1)$ \\
M-N1 & $2.058(7)$ & $2.073(1)$ \\
M-N3 & $2.044(7)$ & $1.977(1)$ \\
M-N5 & $2.017(7)$ & $2.144(1)$ \\
M-N7 & $2.029(7)$ & $1.977(1)$ \\
& & \\
Angles ( $\left.{ }^{\circ}\right)$ & & \\
C11-M-N1 & $153.9(2)$ & $141.26(5)$ \\
C11-M-N3 & $88.0(2)$ & $87.63(5)$ \\
Cl1-M-N5 & $107.5(2)$ & $122.36(5)$ \\
Cl1-M-N7 & $84.7(2)$ & $85.41(4)$ \\
N1-M-N3 & $88.0(3)$ & $89.51(6)$ \\
N1-M-N5 & $98.6(3)$ & $96.34(7)$ \\
N1-M-N7 & $93.7(3)$ & $93.38(6)$ \\
N3-M-N5 & $102.5(3)$ & $97.21(6)$ \\
N3-M-N7 & $166.6(3)$ & $171.93(6)$ \\
N5-M-N7 & $90.5(3)$ & $89.96(6)$ \\
\hline
\end{tabular}

Another five-coordinate $\mathrm{Cu}(\mathrm{II})$ complex of $\mathbf{1}$ was characterized as a perchlorate salt and this complex is designed as compound $\mathbf{1 4}$ (Figure 18). In this case, one perchlorate ion was found to be weakly coordinated to the copper atom $(\mathrm{Cu}---\mathrm{O} 1$ separation of $2.519 \AA$ and $\mathrm{Cu}---\mathrm{O} 3$ of $2.846 \AA$ ). In addition, the structure illustrates the flexibility of $\mathbf{1}$ to stabilize more open coordination environments. This led us to envision that the two bis-adduct copper complexes, $\mathbf{1 3}$ and 14, may be capable of binding hydrogen peroxide resulting in the formation of mono or dinuclear $\mathrm{Cu}(\mathrm{II})$ peroxide species, or even $\mathrm{Cu}(\mathrm{III})$ species (see Chapter VII).

The $\mathrm{Cu}(\mathrm{II})$ environment of $\mathbf{1 4}$ is best described as distorted trigonal bipyramidal ( $\tau$ $=0.97$, see III.4 for the definition of $\tau$ ) with N1, N5, O1 occupying equatorial positions. The average $\mathrm{N}---\mathrm{Cu}$ distance in the plane is $2.067 \AA$ and the average N-Cu1-O1 angle is $128.58^{\circ}$. The N1-Cu1-N5 angle, on the other hand, is $102.82^{\circ}$. The apical positions of the 
trigonal bipyramid are occupied by N3 and N7 (average N---Cu distance $1.950 \AA$ and the N3-Cu1-N7 angle is $166.79^{\circ}$ ) (Table 9).

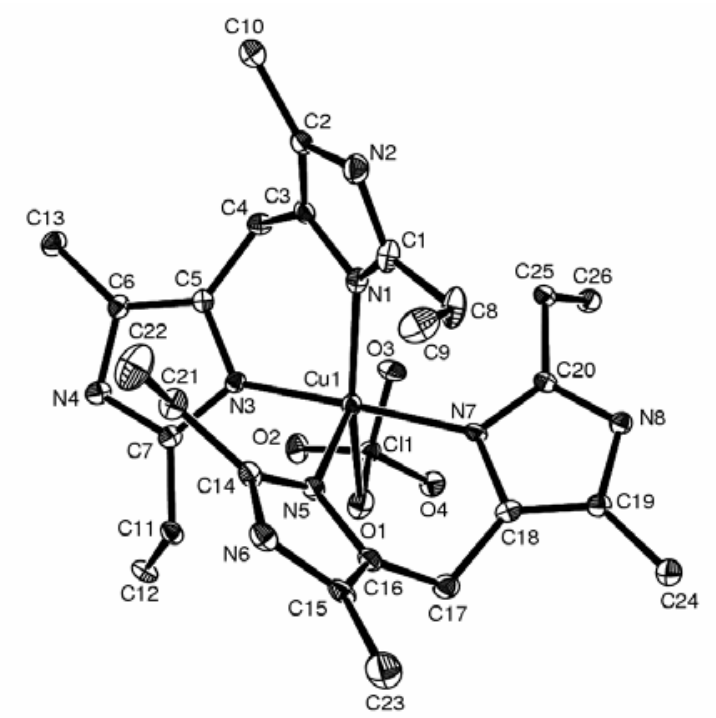

Figure 18. ORTEP view of the cationic unit of compound 14. Hydrogen atoms have been omitted for clarity.

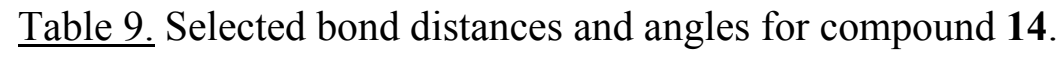

\begin{tabular}{cccccc}
\hline \multicolumn{2}{c}{ distances $(\AA)$} & \multicolumn{5}{c}{ angles $\left(^{\circ}\right)$} \\
\hline Cu1-N1 & $2.062(3)$ & N1-Cu1-N3 & $91.48(3)$ & N3-Cu1-N7 & $166.79(13)$ \\
Cu1-N3 & $1.946(3)$ & N1-Cu1-N5 & $107.82(13)$ & N3-Cu1-O1 & $84.42(11)$ \\
Cu1-N5 & $2.072(3)$ & N1-Cu1-N7 & $95.91(13)$ & N5-Cu1-N7 & $92.44(13)$ \\
Cu1-N7 & $1.953(3)$ & N1-Cu1-O1 & $153.98(11)$ & N5-Cu1-O1 & $103.17(11)$ \\
Cu1-O1 & $2.519(3)$ & N3-Cu1-N5 & $96.58(13)$ & N7-Cu1-O1 & $84.14(11)$ \\
\hline
\end{tabular}

\section{EPR Characterization of $\mathrm{Cu}(\mathrm{II})$ Complexes}

The $\mathrm{Cu}$ (II) complexes, 5, 7, 13 and 14, were studied by EPR spectroscopy, which reveals that the coordination environments observed in the crystal structures are not maintained in solution. Interestingly, the EPR spectra of crystalline samples of compounds $\mathbf{5}$ and $\mathbf{7}$ are different as are the crystal structures. The EPR spectrum of compound $\mathbf{5}$ is consistent with an axial spectrum $\left(g_{z}>g_{x}=g_{y}\right)$. On the other hand, the spectrum of 7 is characteristic of a rhombic system with $g_{z} \neq g_{y} \neq g_{x}$ (Figure 19). 


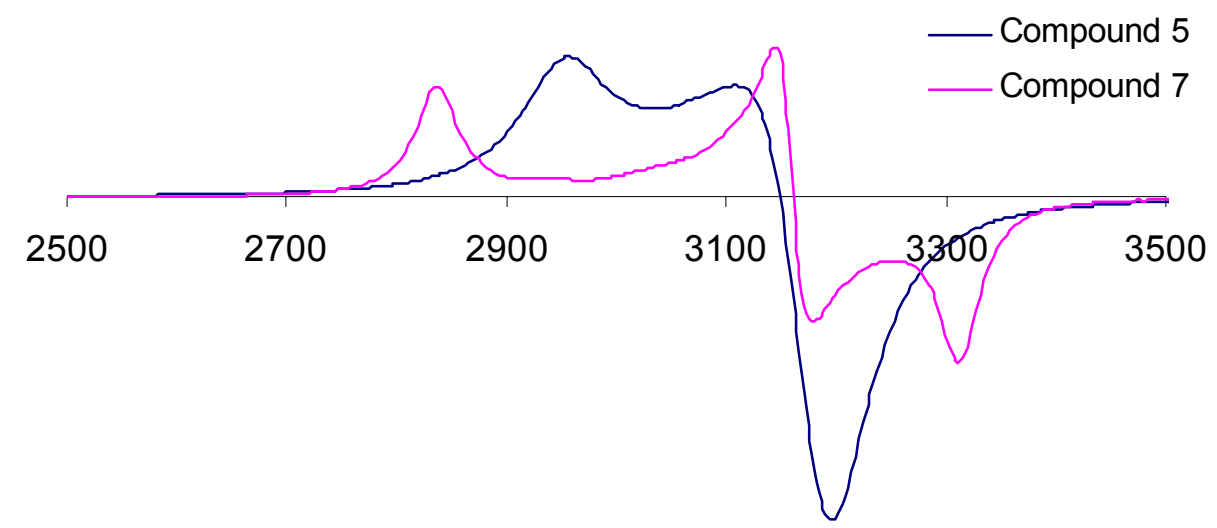

Figure 19. EPR spectra of crystalline samples of compounds 5 and 7 (frequency 9.451 $\mathrm{GHz}$, power $1 \mathrm{~mW}$, modulation amplitude $8.00 \mathrm{G}$, temperature $77 \mathrm{~K}$ ).

These results are consistent with the coordination environment observed in both crystal structures. Indeed, in compound 7, the two $\mathrm{Cu}-\mathrm{Cl}$ distances are significantly different (Table 3), a difference that results in the rhombic EPR spectrum of the crystalline sample. On the other hand, the $\mathrm{Cu}-\mathrm{N}$ distances and $\mathrm{Cu}-\mathrm{Cl}$ distances are more similar in compound $\mathbf{5}$, consistent with the axial EPR spectrum of the crystalline sample.

Figure 20 illustrates the EPR spectra of frozen methanol solutions of the four $\mathrm{Cu}(\mathrm{II})$ complexes $(\mathbf{5}, \mathbf{7}, \mathbf{1 3}$ and 14). The axial EPR spectra of 5 and $\mathbf{1 3}$ are consistent with a square pyramidal arrangement around the $\mathrm{Cu}$ atom with a $\mathrm{d}_{\mathrm{x}^{2}-\mathrm{y}^{2}}$ ground state. $(\mathrm{g} / /=2.30$ and 2.27, $\mathrm{g}_{\perp}=2.06$ and 2.08, respectively, and $\mathrm{A}_{/ /}=150 \mathrm{G}$ ). The EPR spectra of compounds $\mathbf{7}$ and $\mathbf{1 4}$ are rhombic as illustrated by the simulated magnetic parameters summarized in Table 10. The rhombicity of the EPR spectra indicates a distorted tetragonal environment in both complexes. These results seem to imply that the different coordination geometries observed in the crystal structures are not necessarily maintained in solution. 


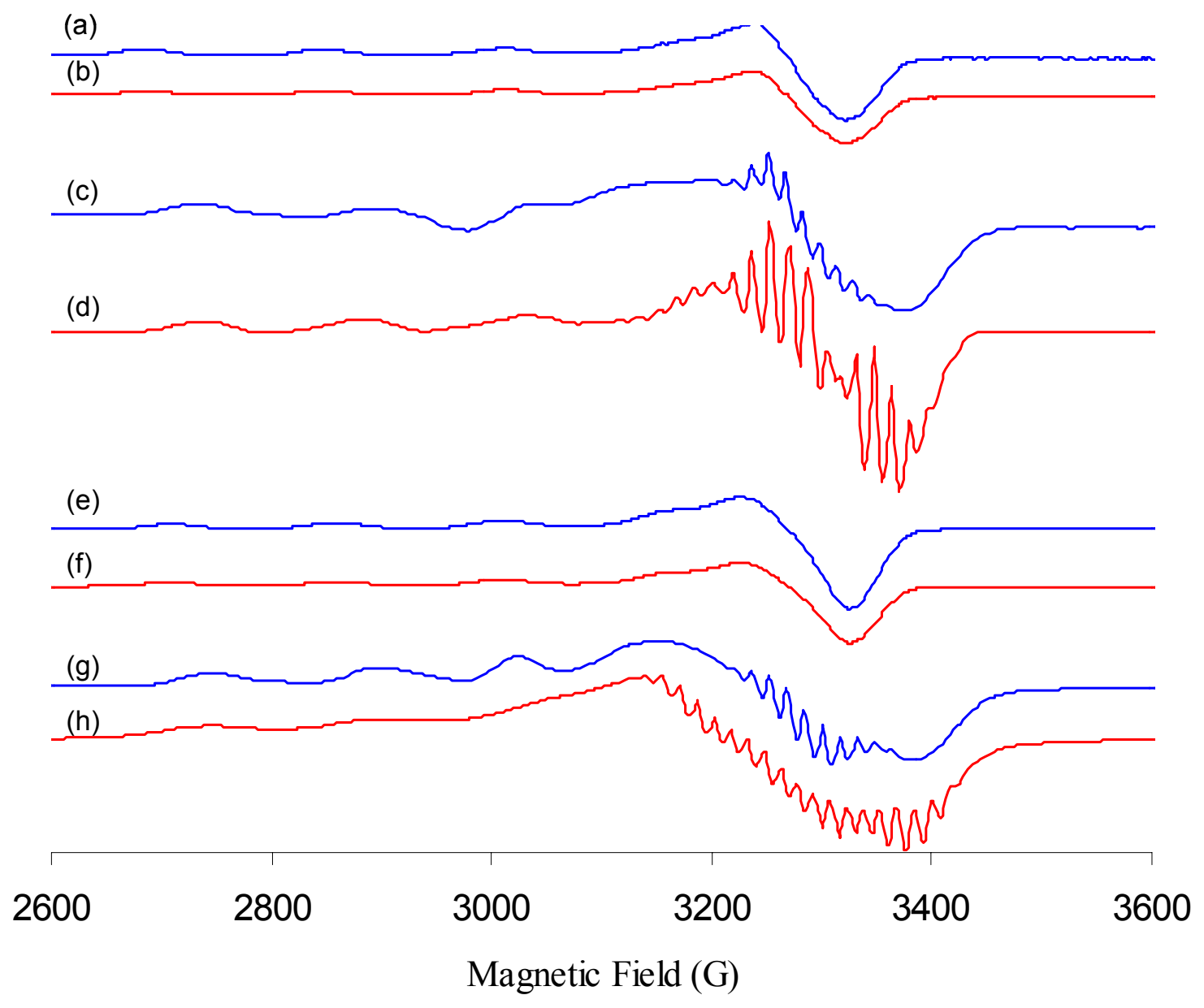

Figure 20. EPR spectra of frozen methanolic solution of compounds 5 (a), 7 (c), 13 (e) and $14 \mathrm{~g}$ ) and their simulation (b, d, f, h, respectively). (frequency 9.445 $\mathrm{GHz}$, power $1.3 \mathrm{~mW}$, modulation amplitude $10.00 \mathrm{G}$, temperature $77 \mathrm{~K}$ ). 
Table 10. EPR parameters of $\mathrm{Cu}(\mathrm{II})$ complexes of $\mathbf{1}$ in frozen methanol solution.

\begin{tabular}{|c|c|c|c|}
\hline Compound & Solvent & $\mathrm{g}$ & $\mathrm{A}\left(10^{-4} \mathrm{~cm}^{-1}\right)$ \\
\hline \multirow[t]{2}{*}{5} & $\mathrm{MeOH}$ & $\mathrm{g}_{/ /}=2.30$ & $\mathrm{~A}_{/ /}=150$ \\
\hline & & $g_{\perp}=2.06$ & $\mathrm{~A}_{\perp}=17$ \\
\hline \multirow[t]{3}{*}{7} & $\mathrm{MeOH}$ & $\mathrm{g}_{3}=2.28$ & $A_{3}=150$ \\
\hline & & $\mathrm{g}_{2}=2.09$ & $\mathrm{~A}_{2}=10$ \\
\hline & & $\mathrm{g}_{1}=2.02$ & $A_{1}=10$ \\
\hline \multirow[t]{2}{*}{13} & $\mathrm{MeOH}$ & $\mathrm{g}_{/ /}=2.27$ & $\mathrm{~A}_{/ /}=150$ \\
\hline & & $\mathrm{g}_{\perp}=2.08$ & $\mathrm{~A} \perp=17$ \\
\hline \multirow[t]{3}{*}{14} & $\mathrm{MeOH}$ & $\mathrm{g}_{3}=2.27$ & $A_{3}=155$ \\
\hline & & $\mathrm{g}_{2}=2.12$ & $A_{2}=15$ \\
\hline & & $\mathrm{g}_{1}=2.06$ & $A_{1}=60$ \\
\hline
\end{tabular}

E. Reactivity Scheme for the Ni(II) Complexes

The following reactivity (Scheme 2) has been established for compound $\mathbf{4}$, which provides some insight into the formation and stability of the three $\mathrm{Ni}(\mathrm{II})$ compounds in solution. Indeed, the purple tetrahedral mono-adduct species, compound $\mathbf{4}$, has been shown to react in solution (step 1) with an additional equivalent of $\mathbf{1}$ to generate the distorted trigonal bipyramidal species compound 12, which internally reorganizes slowly (step 2) in the presence of water to give the yellow square planar, compound 10. Each species in Scheme 2 has also been isolated and characterized independently. The interconversion between species can be readily followed by UV-visible spectroscopy because all three species have distinct electronic spectra (Figure 21). 


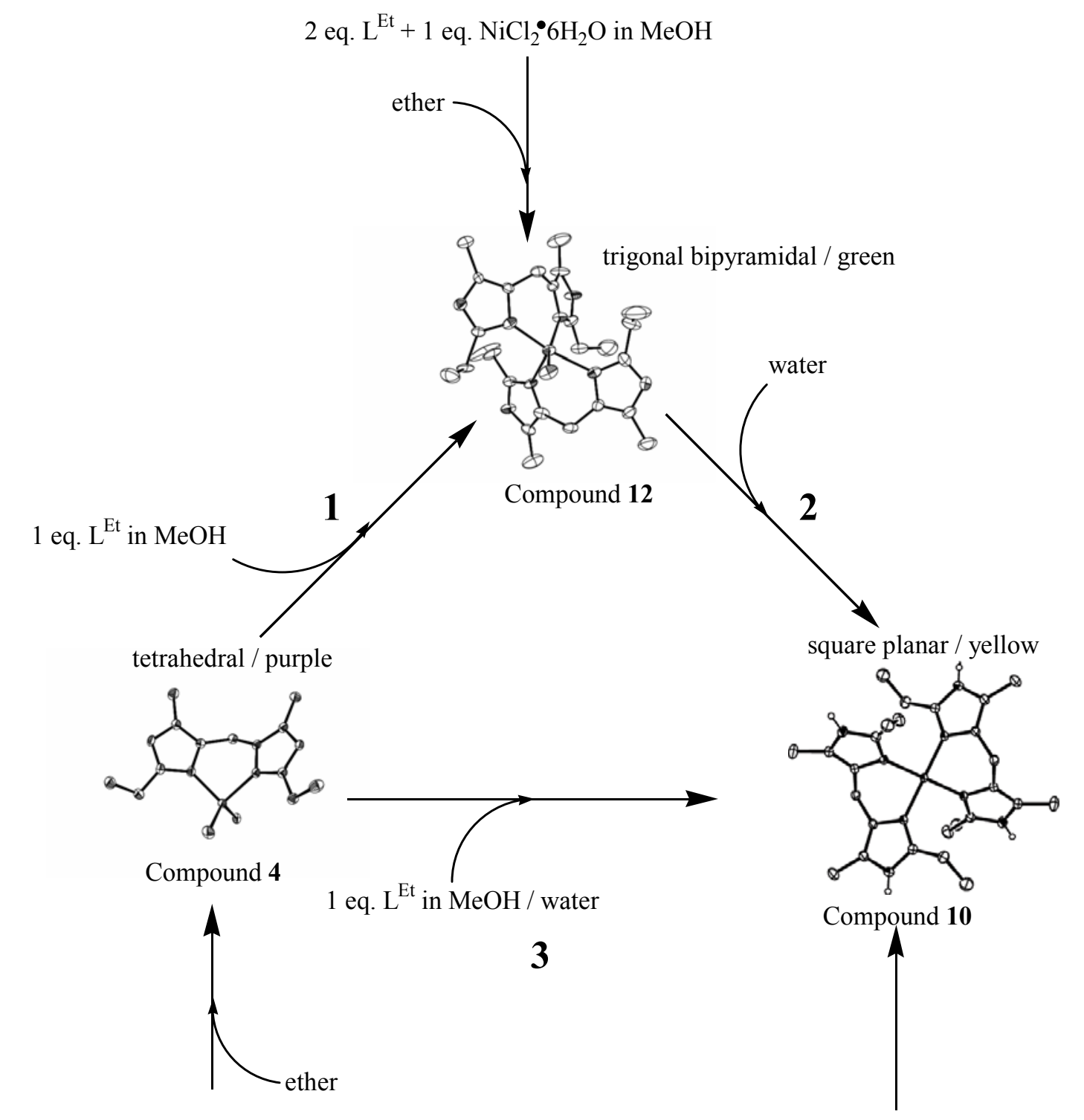

1 eq. $\mathrm{L}^{\mathrm{Et}}+1$ eq. $\mathrm{NiCl}_{2} \bullet 6 \mathrm{H}_{2} \mathrm{O}$ in $\mathrm{MeOH}$

2 eq. $\mathrm{L}^{\mathrm{Et}}+1$ eq. $\mathrm{NiCl}_{2} \bullet 6 \mathrm{H}_{2} \mathrm{O}$ in water Scheme 2. Reactivity of compound 4.

The conversion of the mononuclear compound $\mathbf{4}$ to compound $\mathbf{1 0}$ after the addition of 1 equivalent of $\mathbf{1}$, forms an intermediate trigonal bipyramidal species (12), that is likely formed via an associative mechanism (Hoss, H. \& Elias, H., 1993). Similar reactivity has also been observed for the copper complexes of $\mathbf{1}$. 


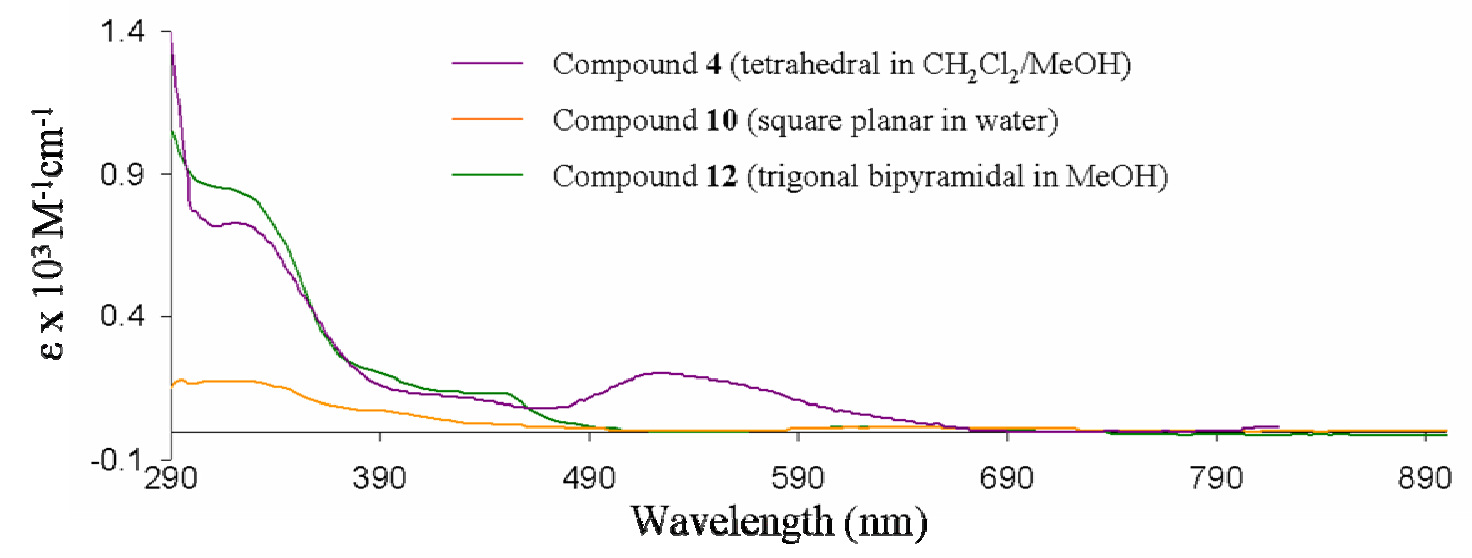

Figure 21. UV-visible of the three Ni(II) species. The spectrum color is associated with the color of the crystal for each compound.

Finally, the displacement of one chloride ligand by a different bis-imidazole in some cases leads to the formation of mixed ligand bis-adduct complexes as highlighted in Scheme 3 (Brownback, M. A. et al., 2001). Further characterizations of these metal complexes are in progress.

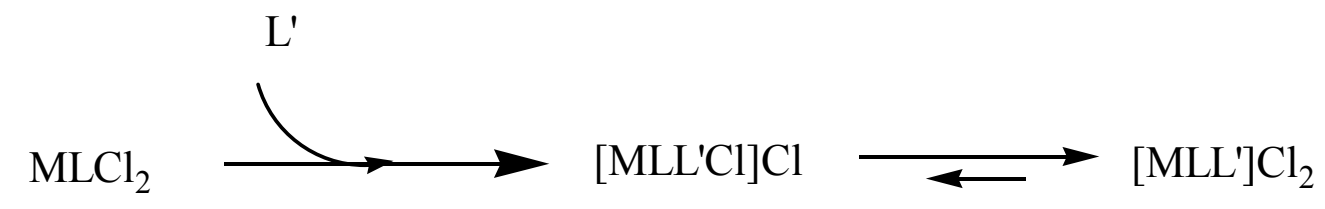

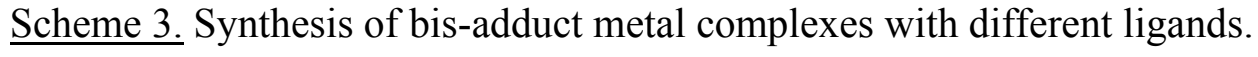

\section{F. Summary}

This study highlights the ability of new bidentate imidazole ligands to chelate metals forming either 1:1 or 2:1 ligand-to-metal complexes. The resulting compounds also have the potential of forming supramolecular assemblies stabilized by intermolecular hydrogen bonding. In most of the metal complexes, the pinched nature of the chelate angle was conserved and the N1-M-N3 angles are around $95.0 \pm 3.0^{\circ}$ (except for 12 and 13). The $\mathrm{ML}^{\mathrm{Et}, \mathrm{Me}} \mathrm{Cl}_{2}$ series of complexes have distorted tetrahedral geometries. Supramolecular assemblies in all of the complexes were dictated by hydrogen bondings 
between $\mathrm{M}-\mathrm{Cl}$ and the imidazole N-Hs. Two different types of hydrogen bonding were observed. For the $\mathrm{Co}, \mathrm{Zn}$ and $\mathrm{Cu}$ complexes, each chlorine atom is interacting with one imidazole N-H of a neighboring molecule. While for the $\mathrm{NiL}^{\mathrm{Et}, \mathrm{Me}^{2}} \mathrm{Cl}_{2}$ and $\mathrm{CuL}^{\mathrm{Me}, \mathrm{Me}} \mathrm{Cl}_{2}$ complexes, one of the chlorine atoms is involved in a bifurcated hydrogen bond with the two imidazole N-Hs. The remaining chlorine atom is hydrogen bonded to a backbone methylene hydrogen. The methylene hydrogens are likely more acidic because of the electron-withdrawing properties of the two imidazole rings. The $\mathrm{Cu}(\mathrm{II})$ complex (5) displays an interesting 2-D layered arrangement.

The bis-adduct structures in this study indicate the flexibility of the ligands to accommodate different geometries around the metal atoms; e.g. tetrahedral, trigonal bipyramidal, and even square planar geometries for $\mathrm{Ni}(\mathrm{II})$ and $\mathrm{Cu}(\mathrm{II})$ complexes. The packing diagrams of the $\mathrm{Co}(\mathrm{II})$ and square planar $\mathrm{Ni}(\mathrm{II})$ complexes display interesting structural features involving the chloride counterions. For the $\mathrm{Co}(\mathrm{II})$ complex, the chloride counterions form a parallelepiped arrangement with diamond shape pattern on each of the faces encapsulating the Co(II) complex. The two Co atoms are stacked along channels facing each other, generating a channel with dimensions of $8.43 \times 3.75 \AA^{2}$.

For the $\mathrm{Ni}(\mathrm{II})$ structure, a discrete cluster of four waters and four chlorines are trapped in the crystal lattice. Such a discrete cluster may serve as a model for ion channels found in transmembrane proteins.

Finally, a reactivity scheme was established for the Ni(II) complexes in solution. The lability of the chlorine atoms in the mono-adduct species was demonstrated, indicating that the mono-adduct species can serve as building blocks for bis-adduct complexes containing different ligands. This will be the subject of future studies. 


\section{CHAPTER IV}

\section{SYNTHESIS OF NOVEL AMIDE FUNCTIONALIZED IMIDAZOLE TRIPODS}

\section{A. Introduction}

Metalloenzymes carry out fundamental and complex reactions in biological and physiological systems (Holm, R. H. et al., 1996a). Trying to understand the mechanism, reactivity, selectivity or even the spectroscopic features of such enzymes has been a challenge throughout the years. Nevertheless, significant contributions have come from small molecule model studies (Que, L. \& Tolman, W. B., 2002; Tyeklar, Z. \& Karlin, K. D., 1989). The focus of modeling studies has mainly been to mimic the primary coordination sphere around the metal using ligands bearing pyridine (Liang, H. C. et al., 1999), imidazole (Oberhausen, K. J. et al., 1990), carboxylate (Tshuva, E. Y. \& Lippard, S. J., 2004), thioether (Tubbs, K. J. et al., 2003a) or amine (Mirica, L. M. et al., 2002) functionalities.

Recently, more importance has been attributed to the role of neighboring amino acid residues that form the so-called second coordination sphere (Karlin, S. et al., 1997) and their importance in metalloenzyme reactivity. These amino acids are involved in hydrogen bonding, donor-acceptor interactions, and possess hydrophobic or hydrophilic properties that facilitate the stabilization and selectivity of the substrates by the enzyme active site. In recent years, model studies have utilized the hydrogen bonding properties of amide pendant groups to stabilize apical ligands bonded to tripodal metal complexes 
by forming strong intramolecular six-membered hydrogen bonding rings. While Einaga and coworkers (Harata, M. et al., 1998b) have used tripodal pyridine-based ligands to stabilize unstable and reactive intermediates, such as hydroperoxide species bonded to metals, Borovik and coworkers (MacBeth, C. E. et al., 2001) have developed elegant urea-based tripods that stabilize high valence metal-oxo or metal-hydroxo compounds.

In our lab, studies have focused on the use of tris((1-methyl-imidazol-2yl)methyl)amine (tmima) (Chen, S. et al., 1994) as a model for the histidine residues found in the primary coordination sphere of metalloenzymes. The constrained nature of the metal binding pocket of tmima makes it suitable for binding various metals. This aspect of the study focused on modifying the tmima metal binding pocket to include amide pendant groups capable of stabilizing various exogenous ligands bonded to different metals. The study further illustrates the use of these specially engineered amide pendants in molecular recognition to mimic the effects of the second coordination sphere in enzymes.

Herein, we report the synthesis and characterization of a family of novel amide functionalized polyimidazole chelates, L1-3 (Figure 22). As illustrated below in Figure 22, our approach in ligand design utilized the tmima framework as a scaffold for building novel amide functionalized polyimidazole ligands L1-3. We based our synthetic strategy on modifying the tmima procedure, which utilizes reductive amination steps during the course of the synthesis. 


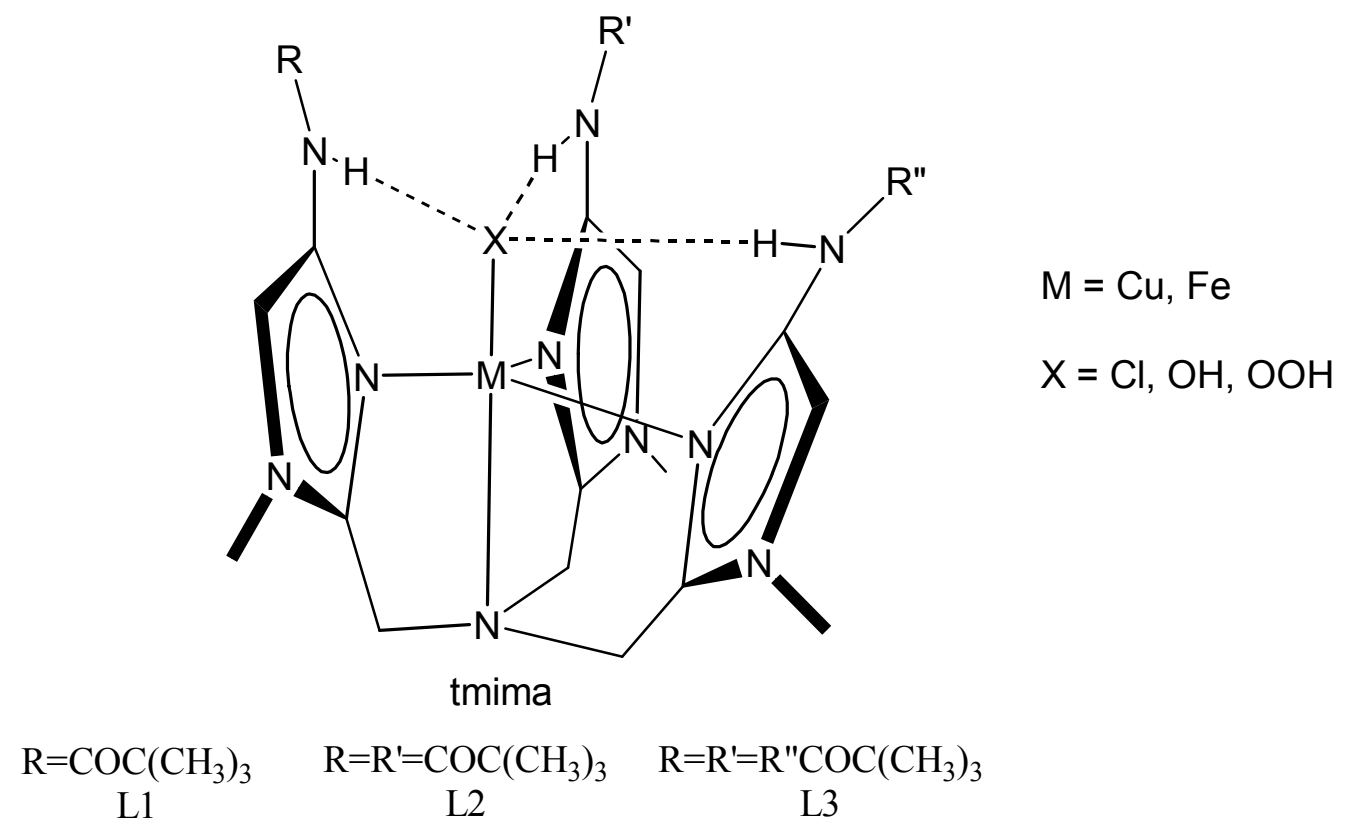

Figure 22. Novel metal binding pockets based on the polyimidazole tripod ligand, tmima, illustrating the amide pendant capable of forming the intramolecular sixmembered hydrogen bonds, L1-3.

The key step in the synthesis of the amide functionalized chelate was the introduction of the amide pendant in the fourth position of the imidazole ring. This position is crucial for the formation of intramolecular six-membered hydrogen bonding rings, as illustrated in Figure 22. This was achieved through the nitration of the synthon, 1-methylimidazol-2-carboxaldehyde, which occurs regioselectively at the fourth position. Reduction of the nitro group produced an amine that can be further acylated to generate the desired amide functionality. The following sections outline the synthetic strategies used in this study. All intermediate species were thoroughly characterized using conventional analytical and spectroscopic methods. 


\section{B. Results and Discussion}

1. Synthesis of the 1-Methyl-4-nitro-imidazol-2-carboxaldehyde Synthon (15)

A valuable synthon used in the synthesis of tmima is 1-methylimidazole-2carboxaldehyde. This compound was converted to the corresponding nitro analog, 1methyl-4-nitro-imidazole-2-carboxaldehyde (15) under nitration conditions using various sources of $\mathrm{NO}_{2}{ }^{+}\left(\mathrm{HNO}_{3} / \mathrm{H}_{2} \mathrm{SO}_{4}\right.$ or $\left.\mathrm{NH}_{4} \mathrm{NO}_{3} / \mathrm{H}_{2} \mathrm{SO}_{4}\right)$ as illustrated in Scheme 4 (Baird, E. E. \& Dervan, P. B., 1996; Jain, M. L. et al., 2001).

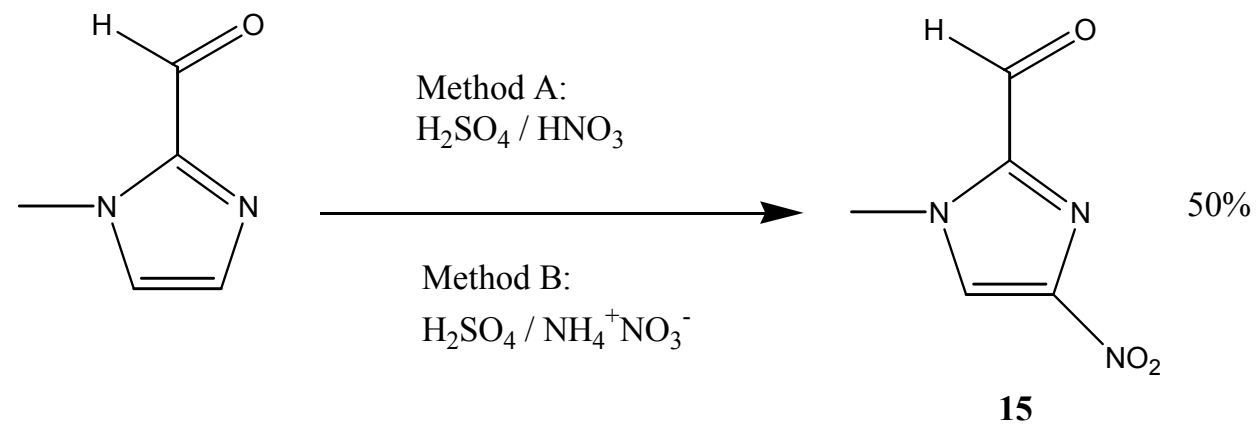

Scheme 4. Nitration of 1-Methylimidazole-2-carboxaldehyde.

The observed regiochemistry of the reaction can be rationalized by the fact that the electron-withdrawing ability of the carboxaldehyde strongly disfavored the 5-position intermediate, as illustrated in Scheme 5. Indeed, for the nitration in the fifth position, one of the resonance structures of the intermediate has a positive charge on the $\mathrm{C} 2$ carbon, which carries the electron-withdrawing carbonyl group, strongly disfavoring the formation of such an intermediate. 

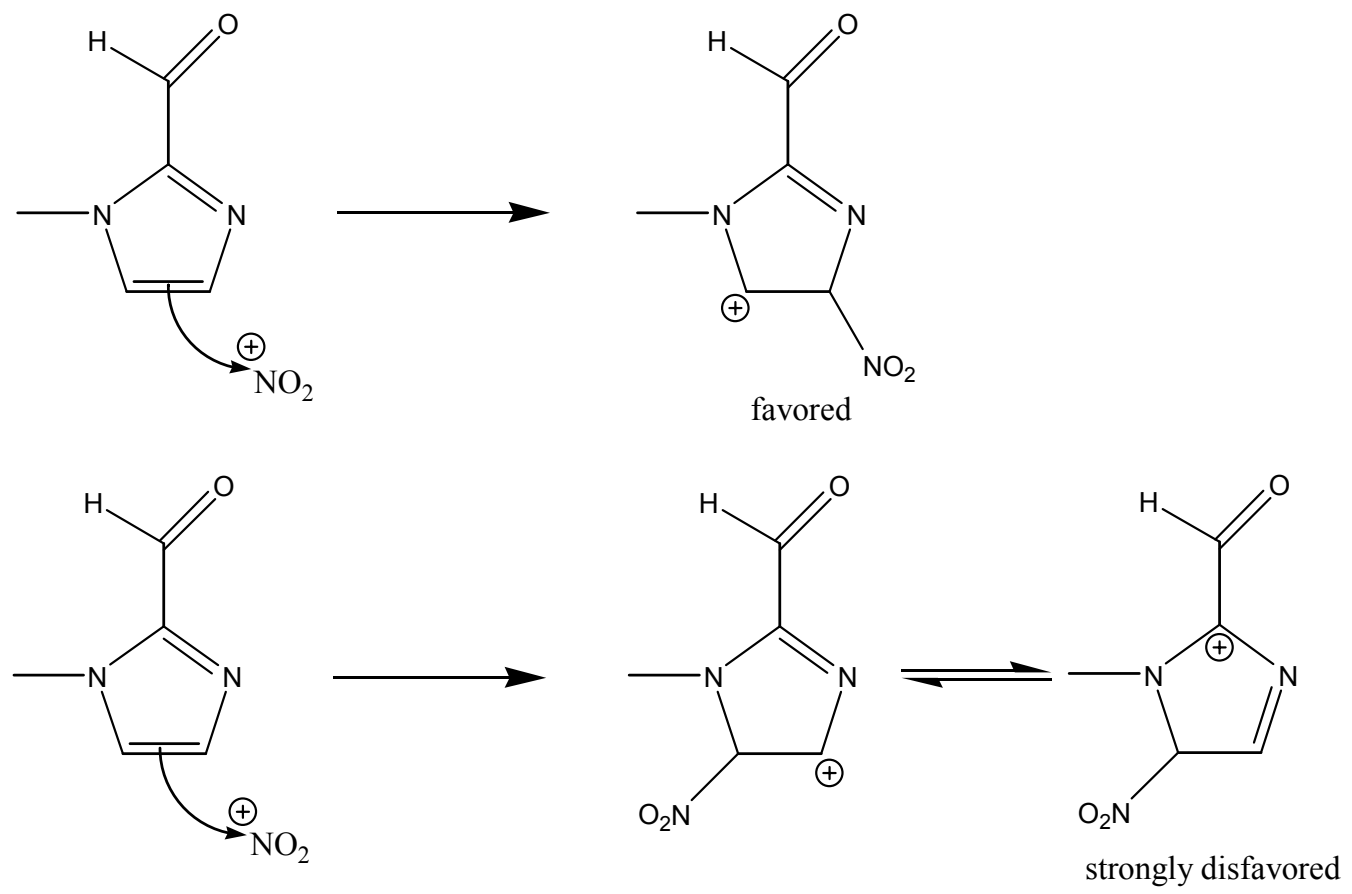

Scheme 5. Regiochemistry of the nitration of 1-methylimidazole-2-carboxaldehyde.

The regiochemistry shown above was confirmed by X-ray crystallography, clearly establishing the presence of the nitro group in the fourth position of the imidazole ring (Figure 23). For a detailed description of the crystal structure, see Chapter VI. ${ }^{1} \mathrm{H}$ and ${ }^{13} \mathrm{C}$ NMR spectra appear in Appendix 2 (Figures S5 and S6).

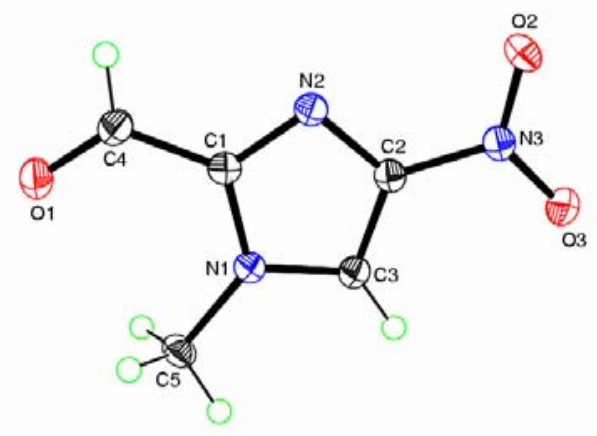

Figure 23. ORTEP view of the molecular structure of $\mathbf{1 5}$. Thermal ellipsoids are drawn at $40 \%$ probability level. 


\section{Synthesis of Amide Functionalized Imidazole Tripods, L1 and L2}

Compound $\mathbf{1 5}$ is a useful synthon for preparing amide functionalized imidazole compounds. The general synthetic strategy used to prepare the nitro functionalized tripods is shown in Scheme 6. Using a mild coupling reagent, sodium tris(acetoxy)borohydride (AbdelMagid, A. F. et al., 1996), the nitro tmima analog, compound 16, was synthesized in $60 \%$ yield and found to co-crystallize with a molecule of boric acid (see Chapter VI). The nitro group of $\mathbf{1 6}$ could not be reduced using Pd/C and $\mathrm{H}_{2}$, even though such conditions have been used to reduce nitro groups on other imidazole compounds (Lythgoe, D. J. \& Ramsden, C. A., 1994). Under these conditions, we observed the deamination of the tripodal framework (Buchman, R. et al., 1974). However, when hydrazine monohydrate was employed as a reducing agent with $\mathrm{Pd} / \mathrm{C}$, the nitro group of $\mathbf{1 6}$ could be reduced to the amino analog, compound 17, quantitatively.

The reduction of the nitro group was followed by ${ }^{1} \mathrm{H}$ NMR. The 5-position imidazole hydrogen is shifted by almost $1 \mathrm{ppm}$ upfield upon reduction. The amine intermediate was found to be unstable, as previously observed (Lythgoe, D. J. \& Ramsden, C. A., 1994) for other 4-amino imidazole compounds, and therefore was not isolated but rather acylated in-situ. The acylation reaction, however, required the use of a different solvent. While the reduction was carried out in methanol, this solvent is not suitable for acylation reactions. Therefore, the solution containing the amine was first poured into water, and then after evaporation of the methanol, the aqueous solution was extracted with dichloromethane. The organic layer was dried over magnesium sulfate and the unstable amine was then acylated to yield $\mathbf{L 1}$ in $60 \%$ yield from $\mathbf{1 6}$ (Scheme 6) 
(Harata, M. et al., 1998a) (see Appendix 2, Figures S33 and S34 for ${ }^{1} \mathrm{H}$ and ${ }^{13} \mathrm{C}$ NMR spectra).

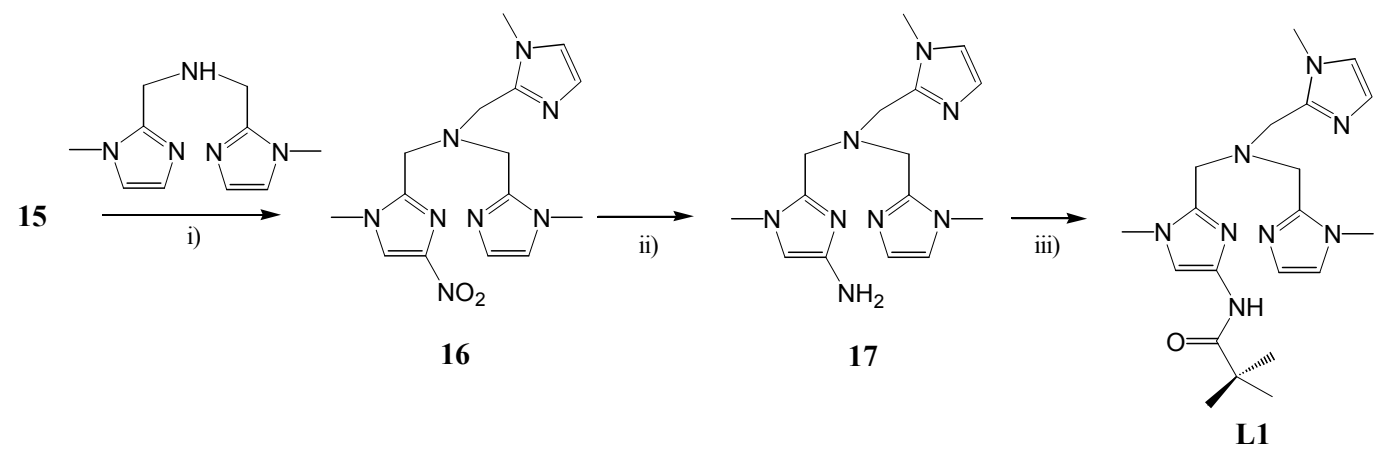

Reagents and Conditions: $\quad$ i) Dichloroethane, $\mathrm{NaHB}(\mathrm{OAc})_{3}$; ii) $\mathrm{MeOH}, 5 \% \mathrm{Pd} / \mathrm{C}, \mathrm{NH}_{2} \mathrm{NH}_{2}$;

iii) $\mathrm{CH}_{2} \mathrm{Cl}_{2},\left(\mathrm{CH}_{3}\right)_{3} \mathrm{CCOCl}$, TEA.

Scheme 6. Synthetic strategy for the synthesis of $\mathbf{L 1}$.

Following the same general approach, we were interested in synthesizing a tmima analog that possesses two nitro groups (e.g. compound 19). Based on the synthesis of bis((1-methylimidazole-2-yl)methyl)amine, bmima (Chen, S. et al., 1994), its nitro analog, 18, could be prepared by a slight modification of the original procedure. Because $\mathrm{NaBH}_{4}$ is a strong reducing agent, the Schiff base formed from the reaction of $\mathbf{1 5}$ with 2aminomethyl-1-methylimidazole was reduced at $0{ }^{\circ} \mathrm{C}$ for 30 minutes. Following general reductive amination procedures, $\mathbf{1 8}$ was reacted with $\mathbf{1 5}$ in the presence of $\mathrm{NaBH}_{3} \mathrm{CN}$ to give 19 in $65 \%$ yield (see Appendix 2, Figure S9). Under similar reductive conditions employed for $\mathbf{1 6}$, the two nitro groups could be reduced, but the very unstable diamine contributed to the poor yield of $\mathbf{L} 2$ after acylation (Scheme 7) (see Appendix 2, Figure S35 and S36 for the ${ }^{1} \mathrm{H}$ and ${ }^{13} \mathrm{C}$ NMR spectra). 
Reagents and conditions: i) $\mathrm{MeOH}, \mathrm{NaBH}_{4}$; ii) $\mathrm{NaBH}_{3} \mathrm{CN}, \mathrm{MeOH}$; iii) $\mathrm{MeOH}, \mathrm{NH}_{2} \mathrm{NH}_{2}, 5 \% \mathrm{Pd} / \mathrm{C}$; iv) $\mathrm{CHCl}_{3}, \mathrm{TEA},\left(\mathrm{CH}_{3}\right)_{3} \mathrm{CCOCl}$.

Scheme 7. Synthetic strategy for the synthesis of L2.

Following this described synthetic route, the synthesis of the tripod containing three amide pendants, L3, was envisioned to be problematic. Moreover, it allows the synthesis of only symmetrical tripods containing identical amide pendants according to the reaction sequence illustrated in Scheme 7. From a modeling perspective, it would be more interesting to design unsymmetrical tripods that mimic the second coordination sphere amino acid residues and their intrinsic properties. So, we investigated the possibility of using preformed amide functionalized synthons in the construction of different imidazole frameworks to synthesize L1-3, and some of their derivatives. Again we followed the strategy of reducing first the nitro group to the amine, followed by the acylation prior to the coupling of the aldehyde group with various amines. To do this, however, it was necessary to protect the aldehyde moiety.

3. Synthesis of 1-Methyl-4-pivaloylamido-imidazole-2-carboxaldehyde (26) Several carboxaldehyde protecting methods were investigated, such as the formation of: i) a 1,3 imidazolidine, compound $\mathbf{2 0}$ (Rao, P. \& Benner, S. A., 2001), ii) a acetal, compound 21 (Groziak, M. P. \& Wei, L. L., 1992) and iii) a thioether 
(Firouzabadi, H. et al., 2001). The thioether protecting method did not work, but the other methods were very efficient in protecting the aldehyde (Scheme 8).

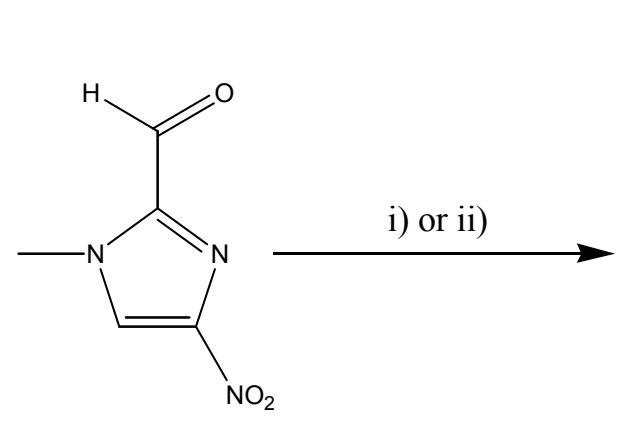

15

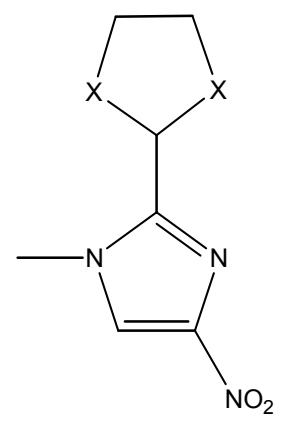

20: $\mathrm{X}=\mathrm{N}-\mathrm{Me}$

21: $\mathrm{X}=\mathrm{O}$

Reagents and conditions: i) N, N' dimethylethylenediamine, benzene; ii) ethylene glycol, toluene, $\mathrm{TsOH}$.

Scheme 8. General procedure for the protection of the carboxaldehyde moiety of $\mathbf{1 5 .}$

Both protected compounds $\mathbf{2 0}$ and $\mathbf{2 1}$ were isolated in near quantitative yields (see Appendix 2, Figure S10-S13 for ${ }^{1} \mathrm{H}$ and ${ }^{13} \mathrm{C}$ NMR spectra). The 1,3 imidazolidine compound (20) appeared to be more sensitive to acidic $\mathrm{pH}$ and moisture compared to compound 21. It is worth noting that the acetal compound, 21, was isolated as a white powder in 75\% yield. Recrystallization of compound $\mathbf{2 1}$ from acetone/hexane yielded Xray quality crystals and its structure was determined by X-ray crystallography (see Chapter VI). The structure of 21 has also been evaluated by ${ }^{1} \mathrm{H}$ NMR spectroscopy. The set of multiplets at 4.15 and 4.03 ppm observed in the ${ }^{1} \mathrm{H}$ NMR spectrum of 21 in $\mathrm{CDCl}_{3}$ (see ${ }^{1} \mathrm{H}$ NMR spectrum in Appendix 2, Figure S12) are assigned to the methylene protons of the acetal ring. Their inequivalence is attributed to the different faces of the acetal. From Figure 24, it is clear that the two hydrogens on the methylene carbon are magnetically inequivalent with respect to the methine hydrogen associated with $\mathrm{C} 5$. 


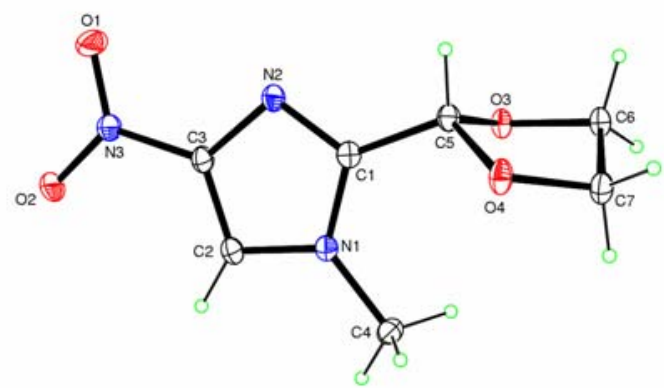

Figure 24. ORTEP view of compound 21. Ellipsoids are drawn at 35\% probability level. (See Chapter VI for more details of the solid-state packing of the compound).

Both protected nitro imidazoles could be reduced in either 1,4-dioxane or THF using $\mathrm{H} 2 / \mathrm{Pd} / \mathrm{C}$ to their corresponding amines (Rao, P. \& Benner, S. A., 2001). Once again, the reduction of the nitro group was followed by ${ }^{1} \mathrm{H}$ NMR and the signal associated with the proton adjacent to the nitro group shifted more than $1 \mathrm{ppm}$ upfield upon reduction, consistent with the change from the electron-withdrawing properties of the nitro group to the electron-donating properties of an amino group. Both protected imidazole amines were readily acylated in-situ using pivaloyl chloride to compounds $\mathbf{2 4}$ and $\mathbf{2 5}$ in 70 to $80 \%$ yields, respectively (Scheme 9).

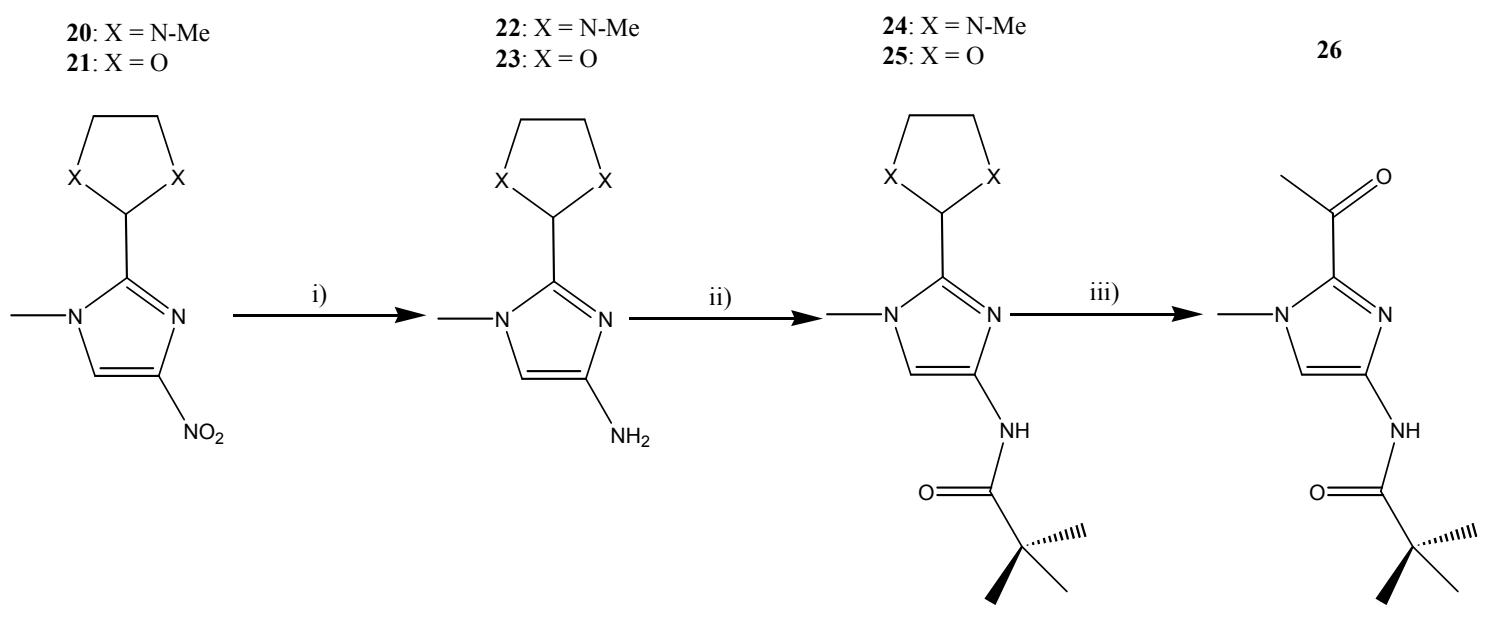

Reagents and conditions: i) 1,4-dioxane, $10 \% \mathrm{Pd} / \mathrm{C}, \mathrm{H}_{2}$; ii) $\mathrm{N}(\mathrm{Et})_{3},\left(\mathrm{CH}_{3}\right)_{3} \mathrm{CCOCl}$; iii) acetone/water $3 \mathrm{M} \mathrm{HCl}$ or reflux acetic acid.

Scheme 10. Synthetic procedure for the synthesis of $\mathbf{2 6}$. 
Compared to the previous examples (Scheme 8), involving coupled reduction/acylation reactions, this route is more efficient because both steps are done in dioxane or THF. However, with compound 20, slight deprotection of the aldehyde was observed to occur ( $20 \%$ by ${ }^{1} \mathrm{H}$ NMR). Hence, the amido compound, 24, containing the 1,3 imidazolidine group was not isolated but rather carried through to the deprotection step.

After acylation, both protected amido compounds $\mathbf{2 4}$ and $\mathbf{2 5}$ were deprotected under acidic conditions (using either $3 \mathrm{M} \mathrm{HCl}$ in acetone/water for $2 \mathrm{~h}$ or refluxing acetic acid for $4 \mathrm{~h}$ ) to yield the very useful synthon: 1-methyl-4-pivaloylamido-imidazole-2carboxaldehyde (26). Compound $\mathbf{2 6}$ was isolated as a crystalline white powder in $70 \%$ overall yield from 15. Recrystallization from acetone/hexanes yielded X-ray quality crystals (Figure 25).

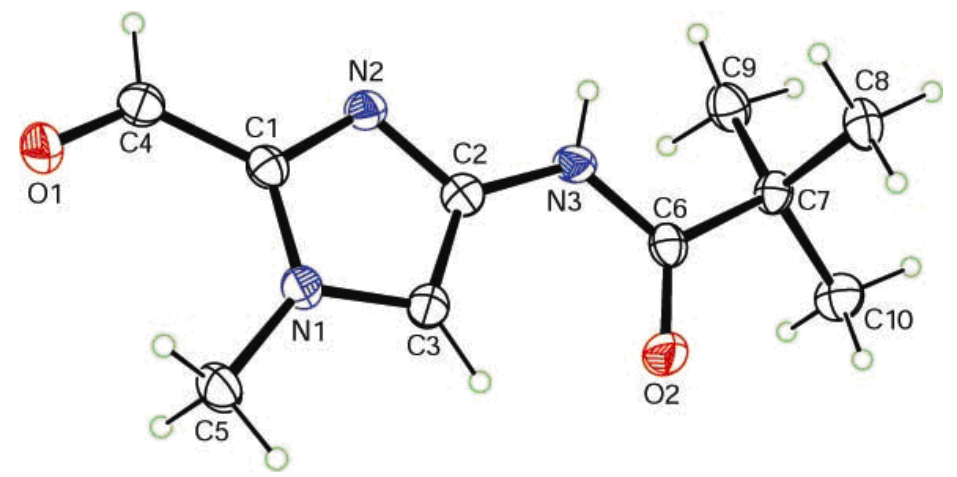

Figure 25. ORTEP view of compound 26. Ellipsoids are drawn at 40\% probability level.

Using this synthon and following the tmima synthetic procedure, the synthesis of L1-3 was found to be much more efficient (Scheme 11).

4. New Synthetic Strategy for Preparing Amide-functionalized Tripods L1L3

Under reductive amination conditions in the presence of sodium cyanoborohydride, $\mathbf{2 6}$ could be coupled to bmima to give $\mathbf{L 1}$ in $75 \%$ yield (Scheme 12). 
Based on the syntheses of bmima and its nitro analog, the amido form (27) could be synthesized in $80 \%$ yield, and even isolated as the hydrochloride salt. The addition of slightly more than one equivalent of $\mathbf{2 6}$ followed by the traditional reductive amination step with $\mathrm{NaBH}_{3} \mathrm{CN}$ gave $\mathbf{L 2}$ in $45 \%$ yield. NMR spectra of both compounds were consistent with the proposed structures (see Appendix 2, Figures S22-23, S35-36). Recrystallization of $\mathbf{L 2}$ from ethyl acetate/hexanes yielded X-ray quality crystals (for details of the crystal structure see chapter V).
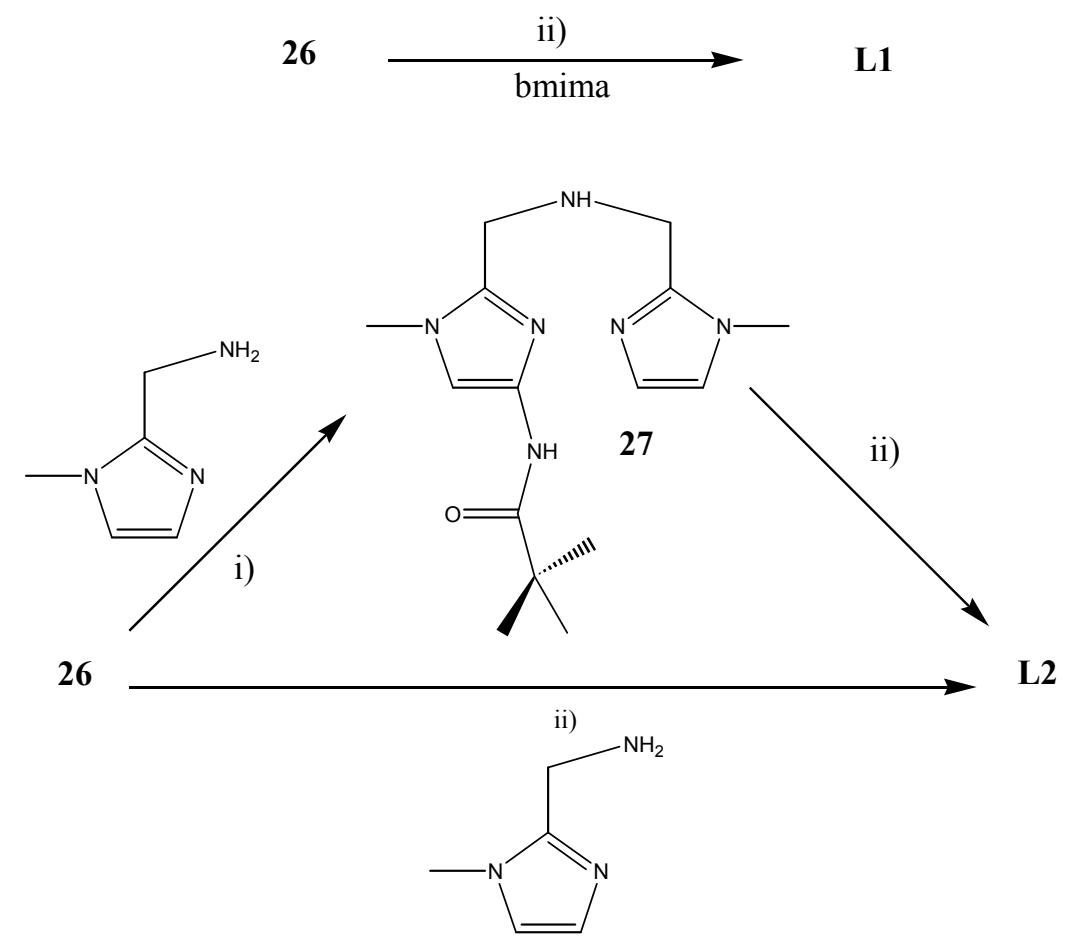

Reagents and conditions: i) $\mathrm{NaBH}_{4}, \mathrm{MeOH}$; ii) $\mathrm{NaBH}_{3} \mathrm{CN}, \mathrm{MeOH}$.

Scheme 12. New synthetic strategy for the synthesis of $\mathbf{L 1}$ and $\mathbf{L 2}$.

At this stage of the synthesis, it is possible to introduce a derivative of $\mathbf{2 6}$ with a different amide pendant group (see Section 7 in this Chapter) generating unsymmetrical derivatives of the $\mathbf{L} \mathbf{2}$ tripod.

Based on the procedure used to prepare tmima (Chen, S. et al., 1994), the aldehyde, 26, could be converted to the corresponding oxime, $\mathbf{2 8}$, very efficiently via reaction with 
hydroxylamine (Scheme 13). The oxime, 28, has been crystallized and characterized by X-ray crystallography (Figure 26) and its solution structure confirmed by ${ }^{1} \mathrm{H}$ and ${ }^{13} \mathrm{C}$ NMR (Figures S24-S25).

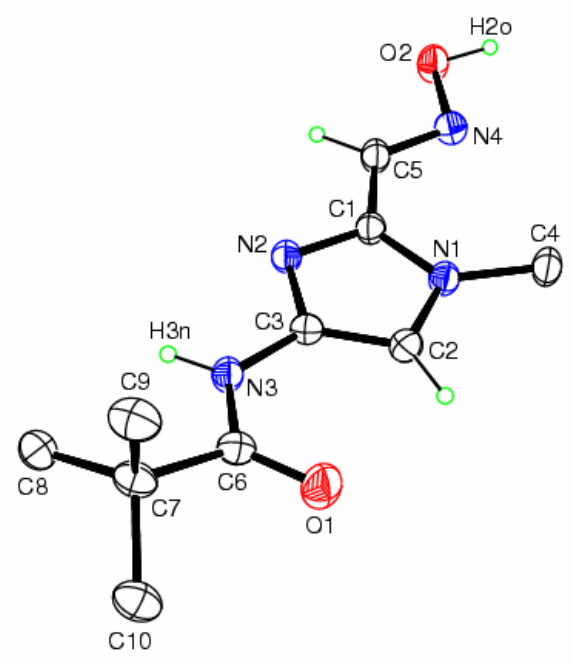

Figure 26. ORTEP view of compound 28. Ellipsoids are drawn at 40\% probability level.

The oxime was then converted to the corresponding 2-aminomethyl-1-methyl-4pivalamidoimidazole, 29, isolated and stored as the hydrochloric acid salt (Figures S26S28 for the ${ }^{1} \mathrm{H}$ and ${ }^{13} \mathrm{C}$ NMR spectra). This very useful synthon was used to synthesize L3 through the formation of a bmima analog, 30, containing two amide pendants (Scheme 14) (Figures S29, S30, S37 and S38, Appendix 2).

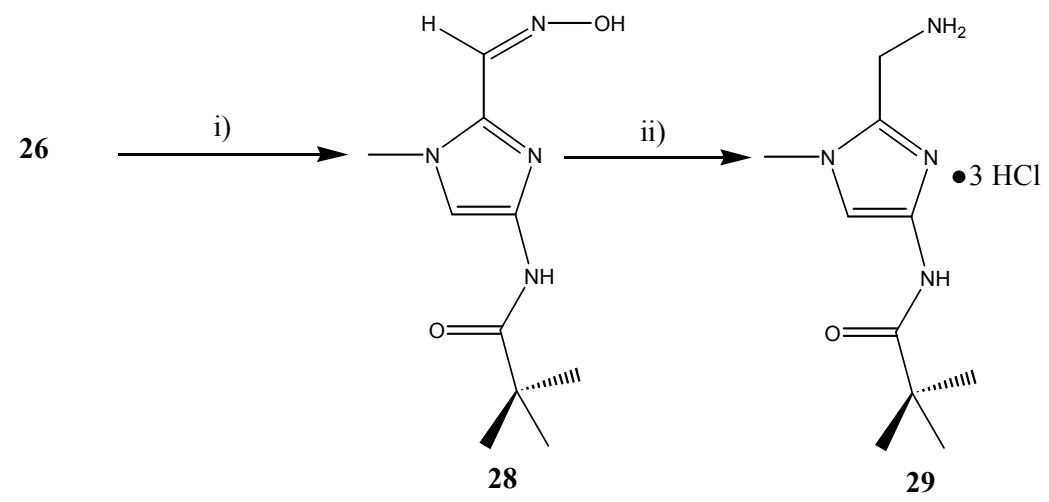

Reagents and conditions: i) $\mathrm{NH}_{2} \mathrm{OH}, \mathrm{EtOH} / \mathrm{H}_{2} \mathrm{O}$; ii) $10 \% \mathrm{Pd} / \mathrm{C}, \mathrm{H}_{2}, \mathrm{MeOH} / \mathrm{HCl}$.

Scheme 13. Synthetic procedure for the synthesis of 29. 


\section{Synthesis of $\mathbf{L 3}$}

The free base of $\mathbf{2 9}$ was reacted with one equivalent of $\mathbf{2 6}$ in methanol to generate the bmima derivative, 30, which contains two amide pendants. Compound $\mathbf{3 0}$ was then reacted with an other equivalent of $\mathbf{2 6}$ to generate the tmima derivative, $\mathbf{L 3}$, which contains three amide pendants (Scheme 14) (Figures S29, S30, S37 and S38, Appendix 2).

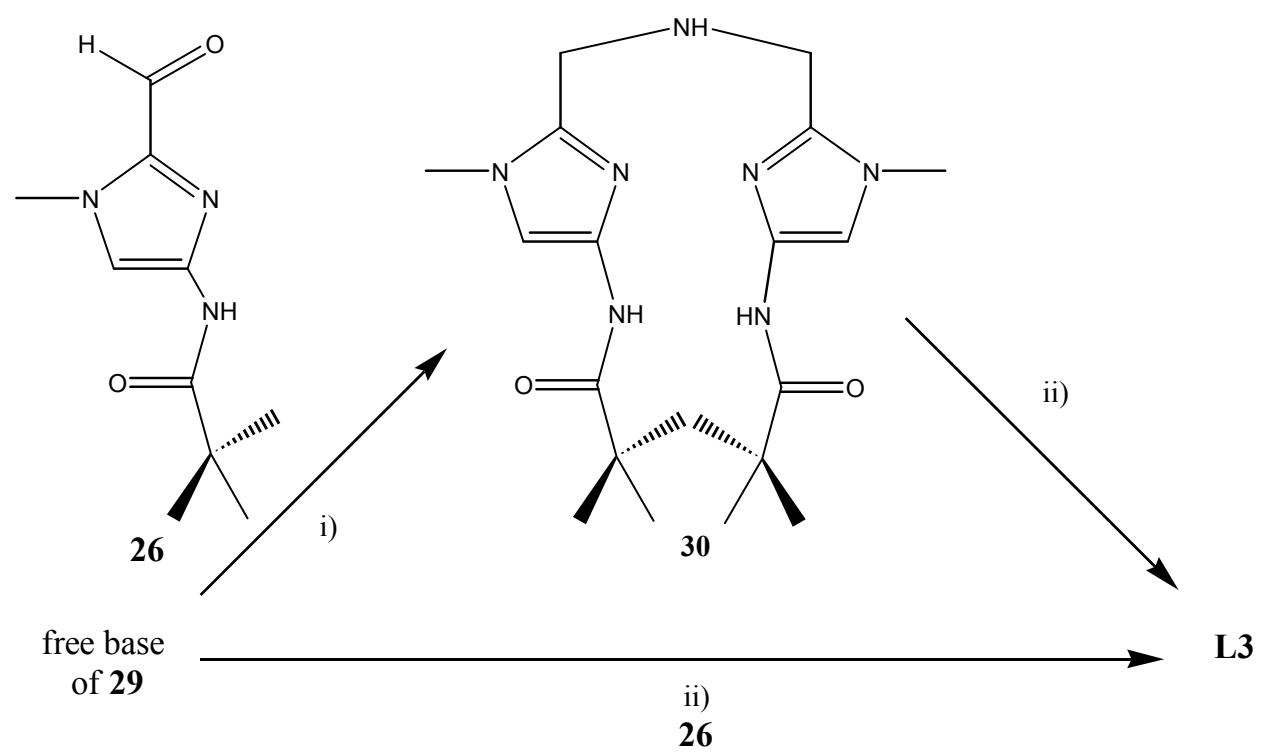

Reagents and conditions: i) $\mathrm{NaBH}_{4}, \mathrm{MeOH}$; ii) $\mathrm{NaBH}_{3} \mathrm{CN}, \mathrm{MeOH}$.

Scheme 14. Synthetic strategy for the synthesis of $\mathbf{L 3}$.

\section{6. $\quad{ }^{1} \mathrm{H}$ NMR Spectra of $\mathbf{L 1 - 3}$}

Figure 27 illustrates the stacked ${ }^{1} \mathrm{H}$ NMR spectra of the three amide functionalized polyimidazole tripods L1-3. 

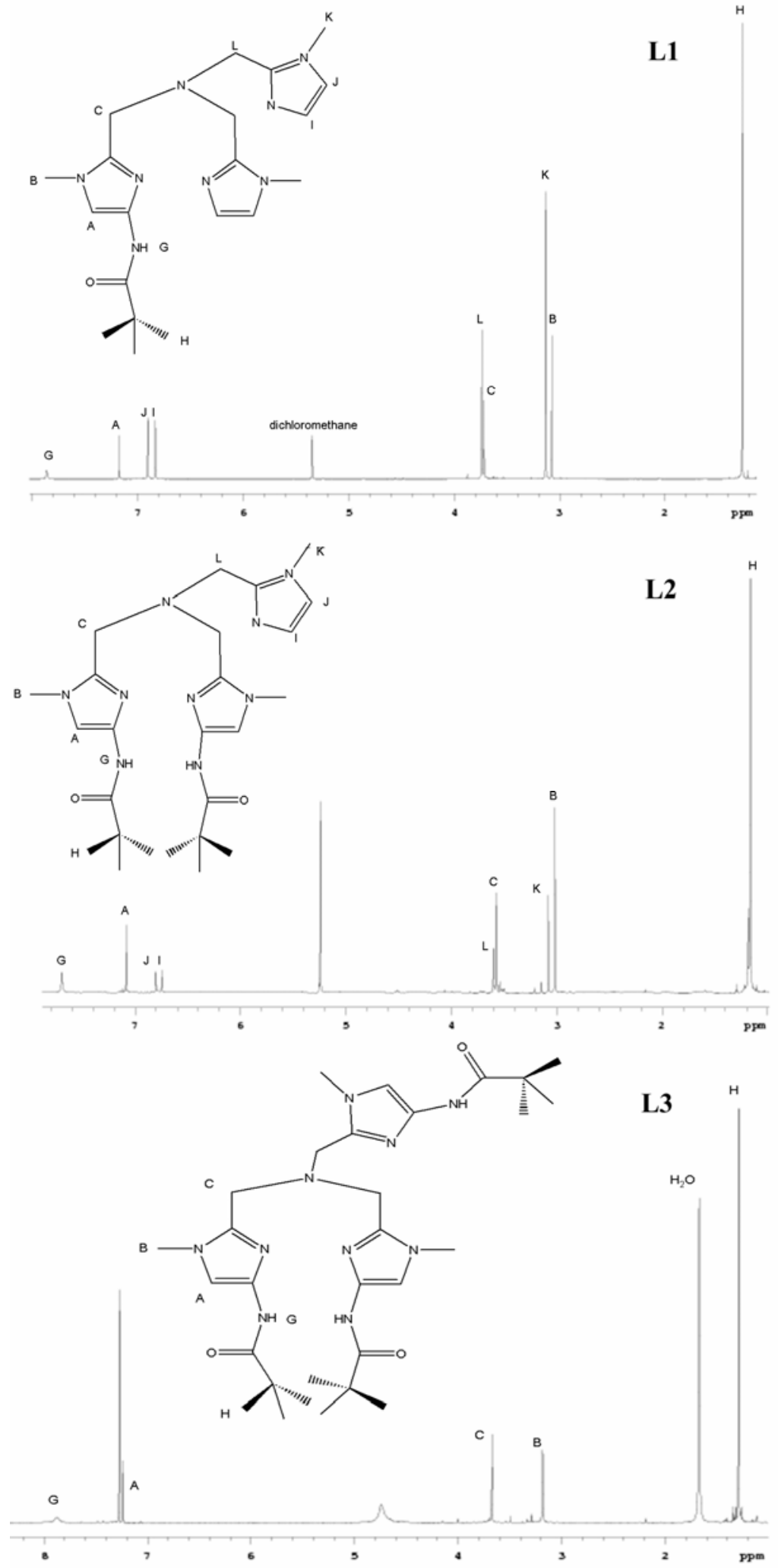

Figure 27. ${ }^{1} \mathrm{H}$ NMR spectra of the amide functionalized imidazole tripods L1-3. 
The proton assignments for $\mathbf{L} \mathbf{1}$ and $\mathbf{L} 2$ are very straightforward because the unfunctionalized imidazole protons can be used as an internal reference (Figure 27). For $\mathbf{L 1}$ and $\mathbf{L 2}$, the ratio of functionalized/unfunctionalized imidazole pendants is reflected in the ratio of the protons integration. The proton signals for $\mathbf{L 3}$ also were assigned unambiguously. However, interpretation of the ${ }^{1} \mathrm{H}$ NMR spectra of the free amine of 29 and 30 were less straightforward. Differences reside in the position of the methylene and methyl groups (see NMR spectra in Appendix 2). In the free base of 29 both methylene and methyl protons are downfield compared to $\mathbf{3 0}$ and $\mathbf{L 3}$. In the spectrum of $\mathbf{3 0}$, as well as for $\mathbf{L 3}$, both methylene hydrogens have the same chemical shift (3.62 ppm). The methyl signals of $\mathbf{L 3}$ are shifted upfield compared to $\mathbf{3 0}$ (3.22 compared to $3.35 \mathrm{ppm}$ for 30). The structures of $\mathbf{L 1}, \mathbf{L} 2$ and $\mathbf{L 3}$ were further verified by the crystallographic studies of their metal complexes (see Chapter V).

\section{Versatility of the Synthetic Strategy}

The development of a rational method for preparing amide functionalized imidazole ligands allows the possibility of further evaluating the effects of the second coordination sphere in molecular recognition. With this in mind, we initiated the creation of a library of amide imidazole synthons containing carboxaldehydes. The presence of a free amine in the fourth position allows a variety of reactions to be explored, such as: i) peptide coupling reaction, ii) reductive amination with various aldehydes, and iii) acylation with various acyl chlorides (Scheme 15). The first reaction type is very attractive because it can be used in the coupling of amino acids (and eventually peptides) to the L1-3 molecular frameworks. To further establish the feasibility of such reactions, we synthesized $\mathbf{3 1}$ by reacting the activated N-acetyl-D-phenylalanine with the free base 
of the acetal amine, 23. While standard peptide coupling reagents ( $\mathrm{DCC} / \mathrm{HOBt}$ or EDCI/DMAP in DMF) (Baird, E. E. \& Dervan, P. B., 1996) gave low yields for the coupling reaction, $\mathbf{3 1}$ was successfully synthesized using HBTU/DIEA coupling reagents after $22 \mathrm{~h}$ in $65 \%$ yield (Seio, K. et al., 2004). The synthesis of 31 and its derivatives opens new directions in the design of metal binding pockets. Introduction of amino acids or peptides to the framework of $\mathbf{2 3}$ should result in a new class of imidazole compounds with unique molecular recognition properties.
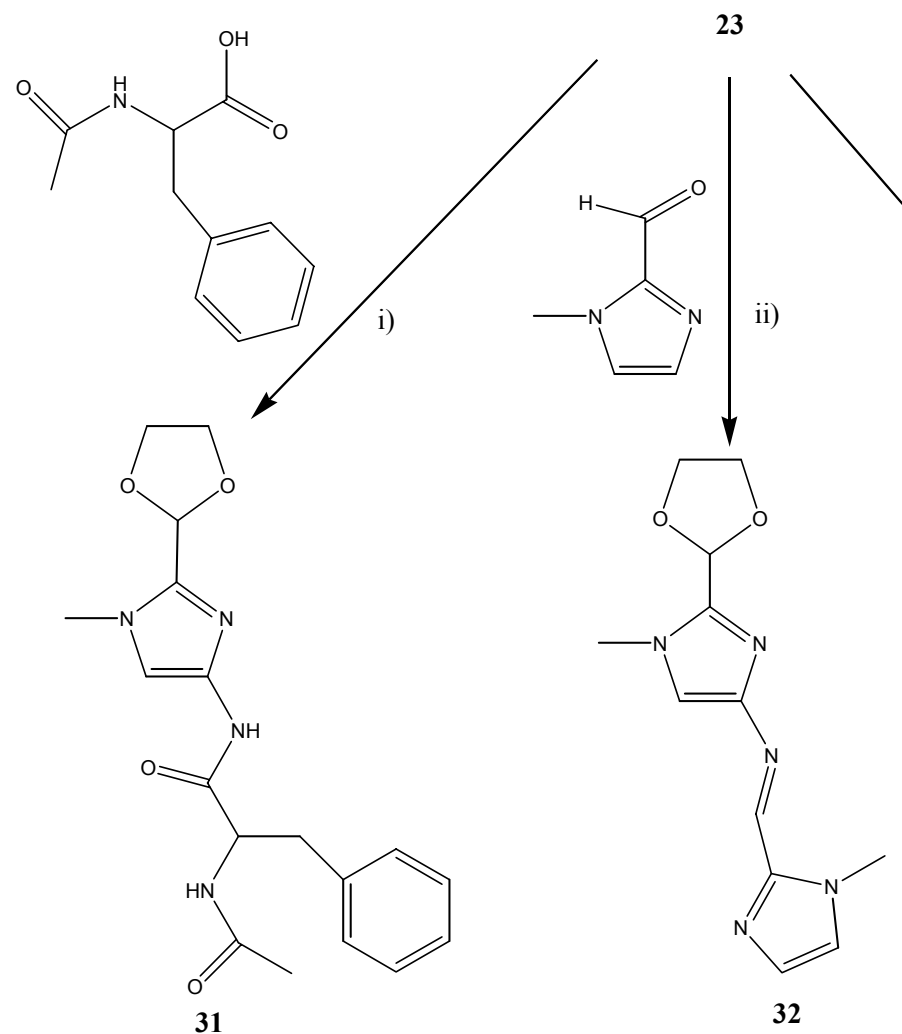

Reagents and conditions: i) HBTU, DIEA; ii) $\mathrm{MeOH}, \mathrm{NaBH}_{4}$; iii) 1,4-dioxane, TEA

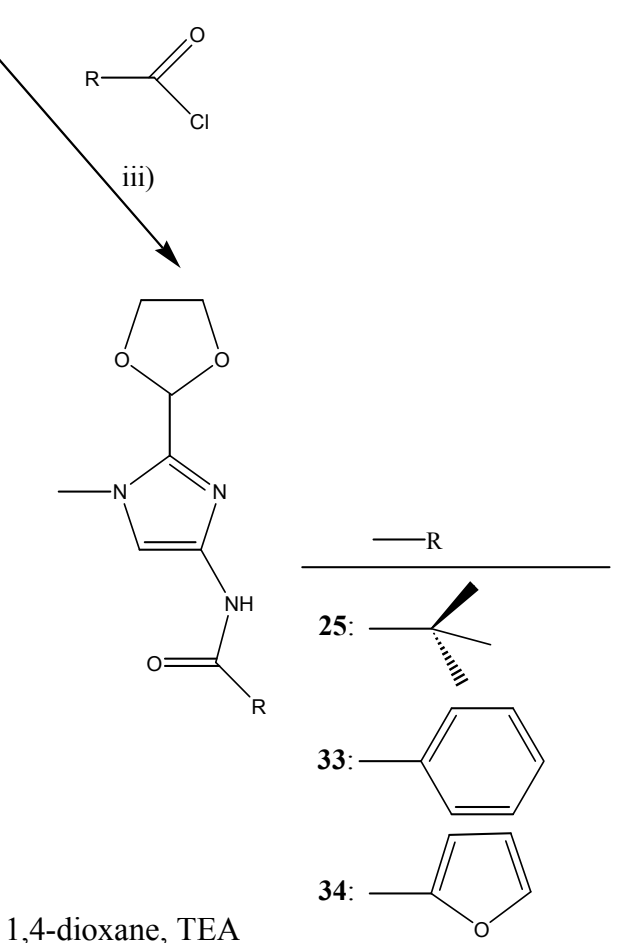
$\underline{\text { Scheme } 15}$. Versatility of the synthetic strategy.

Similarly, the acetal amine free base, 23, was reacted with 1-methylimidazol-2carboxaldehyde in methanol at room temperature for two hours to form the corresponding Schiff base compound (32). The resulting imine was found to be quite stable, probably due to the high degree of conjugation. Reduction of the Schiff base using $\mathrm{NaBH}_{4}$ or 
$\mathrm{Pd} / \mathrm{C} / \mathrm{H}_{2}$ yielded what appears to be an unstable amine that could not be isolated. These results differ from those observed for related pyridine compounds where secondary or primary amines are found to be stable (Wada, A. et al., 2004).

Finally, other commercially available acyl chloride compounds were used to generate different amide groups in the fourth position of the imidazole ring. Following the same reaction conditions used for the synthesis of $\mathbf{2 6}$, benzoyl or 2-furoyl chloride were added dropwise to a dioxane solution of $\mathbf{2 3}$ containing 1.0 eq. of triethylamine. After evaporation of the solvent and recrystallization of the crude materials, the benzamido- (33) and furamido- (34) analogs of $\mathbf{2 5}$ were isolated as pale yellow oils in $75 \%$ yield. These compounds should be very useful in future ligand design studies.

\section{Summary}

A facile methodology has been developed based on the tmima procedure to synthesize novel and versatile amide-functionalized polyimidazole metal binding pockets. In addition, the synthetic method developed herein allows the design of new metal binding pockets that can form intramolecular six-membered hydrogen bonding rings with other endogenous ligands, and may be useful in recognition studies modeling the second coordination sphere of metalloenzymes. The development of new amido imidazole synthons containing carboxaldehyde or amine functionalities permits a wide range of control over the structure and electronic properties of metal binding pockets. The molecular framework around the metal can be fine-tuned with harder or softer ligands. Another attractive aspect of this synthetic strategy is that the nitration step can be used to introduce ${ }^{15} \mathrm{~N}$ nucleus in the fourth position of the imidazole ring by using ${ }^{15} \mathrm{~N}$-labeled ammonium nitrate. After reduction and acylation, it should be possible to further probe 
the strength of the hydrogen bond between the ${ }^{15} \mathrm{~N}$ nucleus and the cis ligand bonded to the metal by ${ }^{15} \mathrm{~N}$ NMR and IR spectroscopy.

\section{Experimental Section}

\section{1-Methyl-4-nitro-imidazol-2-carboxaldehyde (15)}

\section{Method A}

To $11.0 \mathrm{~g}$ of 1-methylimidazole-2-carboxaldehyde $(100 \mathrm{mmol})$ in $62 \mathrm{~mL}$ of sulfuric acid was added $62 \mathrm{~mL}$ of concentrated nitric acid at $0{ }^{\circ} \mathrm{C}$. The solution was then heated to 100 ${ }^{\circ} \mathrm{C}$ for 50 minutes (Note: careful control of the reaction time is important). The reaction mixture was then cooled and poured into $200 \mathrm{~g}$ of ice. The blue solution was then extracted 4 times with $20 \mathrm{~mL}$ of dichloromethane. The resulting organic layer was then

dried over $\mathrm{MgSO}_{4}$ and evaporation of the solvent yielded $5.43 \mathrm{~g}$ (35\%) of a white powder.

$\mathrm{MP}=129^{\circ} \mathrm{C} ; \mathrm{IR}(\mathrm{KBr}) 1701 \mathrm{~cm}^{-1}(\mathrm{HC}=\mathrm{O}), 1543$ and $1335 \mathrm{~cm}^{-1}\left(\mathrm{NO}_{2}\right) ;{ }^{1} \mathrm{H} \mathrm{NMR} \mathrm{CDCl} \mathrm{NM}_{3}$ $\delta 9.87(\mathrm{~s}, \mathrm{H}-\mathrm{C}=\mathrm{O}), 7.90(\mathrm{~s}, \mathrm{H}-5), 4.14\left(\mathrm{~s},-\mathrm{CH}_{3}\right) ;{ }^{13} \mathrm{C} \mathrm{NMR} \delta 182.1(\mathrm{C}=\mathrm{O}), 147.5(\mathrm{C} 4)$, $140.7(\mathrm{C} 2), 125.4(\mathrm{C} 5), 36.5\left(\mathrm{~N}-\mathrm{CH}_{3}\right) ; \mathrm{ESI}-\mathrm{MS} \mathrm{m} / \mathrm{z} 155.9\left(\mathrm{M}+\mathrm{H}^{+}\right)$; Anal. Calcd for $\mathrm{C}_{5} \mathrm{H}_{5} \mathrm{~N}_{3} \mathrm{O}_{3}: \mathrm{C}, 38.70 ; \mathrm{H}, 3.25 ; \mathrm{N}, 27.10$. Found $\mathrm{C}, 38.58 ; \mathrm{H}, 3.33 ; \mathrm{N}, 26.05$.

Yields of the reaction can be improved by further extraction of the aqueous layer as follows: the $\mathrm{pH}$ of the aqueous layer was adjusted to 9 by slowly adding $\mathrm{NaOH}$ pellets. The basic solution was then extracted three times with dichloromethane. After drying and evaporating the solvent, $4.05 \mathrm{~g}$ of the starting material (1-methylimidazole-2carboxaldehyde) was recovered and was recycled. The adjusted yield for the nitration reaction was typically about $55 \%$ after multiple extractions. 


\section{Method B}

To $15.1 \mathrm{~g}$ of 1 -methylimidazole-2-carboxaldehyde $(137 \mathrm{mmol})$ in $110 \mathrm{~mL}$ of sulfuric acid was added slowly $16.4 \mathrm{~g}$ of ammonium nitrate $(205 \mathrm{mmol})$. The reaction mixture was then heated to $100{ }^{\circ} \mathrm{C}$ for $12 \mathrm{hr}$. The reaction mixture was then cooled to room temperature and poured into $300 \mathrm{~g}$ of ice. Extraction of the aqueous layer with $20 \mathrm{~mL}$ of dichloromethane followed by removal of the solvent under vacuum yielded $10.1 \mathrm{~g}$ of $\mathbf{1 5}$ $(48 \%)$ as a white powder.

\section{(Bis(1-methylimidazol-2-yl)methyl)((1-methyl-4-nitroimidazol-2-yl)methyl)amine} (16)

A solution of $0.78 \mathrm{~g}$ of (bis(1-methylimidazol-2-yl)methyl)amine (bmima) (Chen, S. et al., 1994) (3.80 $\mathrm{mmol})$ and $0.59 \mathrm{~g}$ of $15(3.80 \mathrm{mmol})$ in $25 \mathrm{~mL}$ of 1,2-dichloroethane was treated with $1.13 \mathrm{~g}$ of $\mathrm{NaBH}(\mathrm{OAc})_{3}(5.28 \mathrm{mmol})$. After $1.5 \mathrm{~h}$, the reaction mixture was quenched with $20 \mathrm{~mL}$ of saturated sodium bicarbonate solution. The solvent was removed under vacuum and the aqueous layer was extracted three times with $20 \mathrm{~mL}$ of ethyl acetate. After drying the organic layer with $\mathrm{MgSO}_{4}$, the solvent was removed under vacuum to yield $0.75 \mathrm{~g}(57 \%)$ of a pale yellow oil.

IR (film) 1503 and $1291 \mathrm{~cm}^{-1}\left(\mathrm{NO}_{2}\right) ;{ }^{1} \mathrm{H}$ NMR $\mathrm{CDCl}_{3} \delta 7.55$ (s, H-5), 6.86 (s, 2, H-5), $6.62(\mathrm{~s}, 2, \mathrm{H}-4), 3.85\left(\mathrm{~s}, 2, \mathrm{CH}_{2}\right), 3.78\left(\mathrm{~s}, 4, \mathrm{CH}_{2}\right), 3.32\left(\mathrm{~s}, 6,-\mathrm{CH}_{3}\right), 3.31\left(\mathrm{~s}, 3,-\mathrm{CH}_{3}\right) .{ }^{13} \mathrm{C}$ $\mathrm{NMR} \mathrm{CDCl}_{3} \delta 146.1\left(\mathrm{~s},{ }^{\mathrm{NO} 2} \mathrm{C}-4\right), 145.7$ (s, C-2), 145.3 (s, C-4), $145.0\left(\mathrm{~s},{ }^{\mathrm{NO} 2} \mathrm{C}-2\right), 128.2$

(s,C-5), $122\left(\mathrm{~s}, \mathrm{~s},{ }^{\mathrm{NO} 2} \mathrm{C}-5\right), 49.5\left(\mathrm{~s}, 1, \mathrm{~s},{ }^{\mathrm{NO} 2} \mathrm{CH}_{2}\right), 48.5\left(\mathrm{~s}, 2, \mathrm{CH}_{2}\right), 34.4\left(\mathrm{~s}, 1, \mathrm{~s},{ }^{\mathrm{NO} 2} \mathrm{CH}_{3}\right)$, $32.3\left(\mathrm{~s}, 2, \mathrm{CH}_{3}\right)$. HRMS calcd for $\mathrm{C}_{15} \mathrm{H}_{20} \mathrm{~N}_{8} \mathrm{O}, 345.1787\left(\mathrm{M}+\mathrm{H}^{+}\right)$, found 345.1803. 


\section{Bis(1-methylimidazol-2-yl)methyl)((4-amino-1-methylimidazol-2-yl)methyl)amine}

(17)

A degassed solution of $16(0.75 \mathrm{~g}, 2.17 \mathrm{mmol})$ in anhydrous $\mathrm{MeOH}$ was reduced with 0.8 $\mathrm{g}$ of $\mathrm{Pd} / \mathrm{C} 5 \%$ and $263 \mu \mathrm{L}(5.43 \mathrm{mmol})$ of hydrazine monohydrate. After $4 \mathrm{~h}$, the catalyst was filtered on celite and the filtrate was poured into $50 \mathrm{~mL}$ of water. After removing the methanol under vacuum, the aqueous layer was extracted three times with $15 \mathrm{~mL}$ of dichloromethane and dried with $\mathrm{MgSO}_{4}$. Because the free amine was found to be unstable, it was not isolated but rather converted into $\mathbf{L 1}$ as described below.

${ }^{1} \mathrm{H} \mathrm{NMR} \mathrm{CDCl}_{3} \delta 6.86$ (s, 2, H-5), 6.62 (s, 2, H-4), 6.05 (s, H-5), 3.85 (s, 2, $\mathrm{CH}_{2}$ ), 3.78 (s, 4, $\left.\mathrm{CH}_{2}\right), 3.32\left(\mathrm{~s}, 6,-\mathrm{CH}_{3}\right), 3.31\left(\mathrm{~s}, 3,-\mathrm{CH}_{3}\right)$.

\section{(Bis(1-methylimidazol-2-yl)methyl)((4-pivaloylamido-1-methylimidazol-2- yl)methyl)amine (L1)}

To the dichloromethane solution $(60 \mathrm{~mL})$ containing 17 was added $394 \mu \mathrm{L}(2.83 \mathrm{mmol})$ of triethylamine followed by dropwise addition of $322 \mu \mathrm{L}(2.62 \mathrm{mmol})$ of pivaloyl chloride. After stirring the solution for $2 \mathrm{~h}$, the solvent was evaporated under vacuum yielding a pale yellow oil. The residual oil was purified by column chromatography (silica gel, solvent: $\mathrm{CH}_{2} \mathrm{Cl}_{2}$ with a gradient of $\mathrm{MeOH}$ until reaching 2/1 ratio, $\mathrm{R}_{\mathrm{f}}=0.4$ ). IR (film) $3152 \mathrm{~cm}^{-1}$ (amide-NH), $1638 \mathrm{~cm}^{-1}$ (amide-C=O); ${ }^{1} \mathrm{H} \mathrm{NMR} \mathrm{CDCl}_{3} \delta 7.81$ (s, NH), $7.21\left(\mathrm{~s}, 1,{ }^{A m} \operatorname{Im}(\mathrm{H}-5)\right), 6.95$ (s, 2, $\left.\operatorname{Im}(\mathrm{H}-5)\right), 6.80$ (s, 2, $\left.\operatorname{Im}(\mathrm{H}-4)\right), 3.78$ (s, 4, $\left.\operatorname{Im}\left(\mathrm{CH}_{2}\right)\right), 3.77\left(\mathrm{~s}, 2,{ }^{\mathrm{Am}} \operatorname{Im}\left(-\mathrm{CH}_{2}\right)\right), 3.11\left(\mathrm{~s}, 3,{ }^{\mathrm{Am}} \operatorname{Im}\left(-\mathrm{CH}_{3}\right)\right), 3.05$ (s, 6, $\left.\operatorname{Im}\left(-\mathrm{CH}_{3}\right)\right), 1.29$ (s, 9, $\left.{ }^{\mathrm{Am}} \operatorname{Im}\left(-\mathrm{C}\left(\mathrm{CH}_{3}\right)_{3}\right)\right) .{ }^{13} \mathrm{C} \mathrm{NMR} \mathrm{CDCl}_{3} \delta 175.8\left(\mathrm{~s},{ }^{\mathrm{Am}} \operatorname{Im}(-\mathrm{C}=\mathrm{O})\right), 145.4(\mathrm{~s}, \operatorname{Im}(\mathrm{C} 2)), 141.2$ (s, $\left.{ }^{\operatorname{Am}} \operatorname{Im}(\mathrm{C} 4)\right), 136.3$ (s, $\left.{ }^{\operatorname{Am}} \operatorname{Im}(\mathrm{C} 2)\right), 127.7$ (s, $\left.\operatorname{Im}(\mathrm{C} 4)\right), 121.7$ (s, $\left.\operatorname{Im}(\mathrm{C} 5)\right), 109.2$ (s, $\left.{ }^{\mathrm{Am}} \operatorname{Im}(\mathrm{C}-5)\right), 53.9\left({ }^{\mathrm{Am}} \operatorname{Im}\left(-\mathrm{CH}_{2}-\right)\right), 48.9\left(\mathrm{~s}, \operatorname{Im}\left(-\mathrm{CH}_{2}-\right)\right), 39.2\left(\mathrm{~s},{ }^{\mathrm{Am}} \mathrm{Im}\left(\underline{\mathrm{N}-\mathrm{CH}_{3}}\right), 32.1 \quad(\mathrm{~s}\right.$, $\left.\operatorname{Im}\left(\mathrm{CH}_{3}\right)\right), 27.8\left(\mathrm{~s},{ }^{\mathrm{Am}} \operatorname{Im}\left(\underline{\mathrm{C}}\left(\mathrm{CH}_{3}\right)_{3},{ }^{\mathrm{Am}} \operatorname{Im}\left(\mathrm{C}\left(\underline{\mathrm{CH}}_{3}\right)_{3}\right) ; \mathrm{HRMS}\right.\right.$ calcd for $\mathrm{C}_{20} \mathrm{H}_{30} \mathrm{~N}_{8} \mathrm{O}, 399.2621$ 
$\left(\mathrm{M}+\mathrm{H}^{+}\right)$, found 399.2655; Anal. Calcd for $\mathrm{C}_{20} \mathrm{H}_{30} \mathrm{~N}_{8} \mathrm{O} \cdot \mathrm{H}_{2} \mathrm{O}: \mathrm{C}, 57.75 ; \mathrm{H}, 7.74 ; \mathrm{N}, 27.03$. Found C, 57.98; H, 7.86; N, 27.22.

((1-Methyl-4-nitroimidazol-2-yl)methyl)(1-methylimidazol-2-yl)methyl)amine (18)

An anhydrous methanol solution $(25 \mathrm{~mL})$ of $0.11 \mathrm{~g}(1.00 \mathrm{mmol})$ of 2-aminomethyl-1methylimidazole and $0.16 \mathrm{~g}(1.00 \mathrm{mmol})$ of $\mathbf{1 5}$ was refluxed for $30 \mathrm{~min}$. The reaction mixture was cooled to $0{ }^{\circ} \mathrm{C}$, and $87 \mathrm{mg}(2.30 \mathrm{mmol})$ of $\mathrm{NaBH}_{4}$ was added. The solution was stirred for an additional $30 \mathrm{~min}$ and quenched by the addition of $20 \mathrm{~mL}$ of saturated sodium bicarbonate. After evaporating the methanol, the aqueous solution was extracted three times with $15 \mathrm{~mL}$ of chloroform. The organic layer was dried over $\mathrm{MgSO}_{4}$ and evaporated under vacuum to yield $0.25 \mathrm{~g}(70 \%)$ of a pale yellow oil.

${ }^{1} \mathrm{H} \mathrm{NMR} \mathrm{CDCl}{ }_{3} \delta 7.65$ (s, $\left.{ }^{\mathrm{NO} 2} \operatorname{Im}(\mathrm{H}-5)\right), 6.96$ (s, 2, H-5), 6.82 (s, 2, H-4), 3.95 (s, 2 , $\left.{ }^{\mathrm{NO} 2} \operatorname{Im}\left(\mathrm{CH}_{2}\right)\right), 3.85\left(\mathrm{~s}, 2, \mathrm{CH}_{2}\right), 3.75\left(\mathrm{~s}, 3,{ }^{\mathrm{NO} 2} \mathrm{Im}\left(\mathrm{CH}_{3}\right)\right), 3.62\left(\mathrm{~s}, 3, \mathrm{CH}_{3}\right)$.

\section{(Bis(1-methyl-4-nitroimidazol-2-yl)methyl)((1-methylimidazol-2-yl)methyl)amine} (19)

Following the same general procedure described for 16, a dichloromethane solution (25 $\mathrm{mL})$ containing $0.16 \mathrm{~g}(0.64 \mathrm{mmol})$ of 18 with $0.10 \mathrm{~g}(0.64 \mathrm{mmol})$ of 15 in anhydrous methanol was treated with $0.14 \mathrm{~g}(2.22 \mathrm{mmol})$ of $\mathrm{NaBH}_{3} \mathrm{CN}$. After $1.5 \mathrm{~h}$, the reaction mixture was quenched and after the appropriate work-up outlined for tmima (Chen, S. et al., 1994), $0.14 \mathrm{~g}(60 \%)$ of 19 was isolated as a pale yellow oil. (Caution! Cyanide is extremely toxic, and appropriate safety precautions should be followed at the initial stage of the work-up procedure).

${ }^{1} \mathrm{H} \mathrm{NMR} \mathrm{CDCl}_{3} \delta 7.59$ (s, 2, $\left.{ }^{\mathrm{NO} 2} \operatorname{Im}(\mathrm{H}-5)\right), 6.96$ (s, 1, H-5), 6.80 (s, 1, H-4), 4.04 (s, 2, $\left.\mathrm{CH}_{2}\right), 4.05\left(\mathrm{~s}, 4,{ }^{\mathrm{NO} 2} \operatorname{Im}\left(\mathrm{CH}_{2}\right)\right), 3.77\left(\mathrm{~s}, 3, \mathrm{CH}_{3}\right), 3.76\left(\mathrm{~s}, 6,{ }^{\mathrm{NO} 2} \operatorname{Im}\left(\mathrm{CH}_{3}\right)\right)$, HRMS calcd for 
$\mathrm{C}_{15} \mathrm{H}_{19} \mathrm{~N}_{9} \mathrm{O}_{4}, 390.1638\left(\mathrm{M}+\mathrm{H}^{+}\right)$, found 390.1669.; Anal. Calcd for $\mathrm{C}_{15} \mathrm{H}_{19} \mathrm{~N}_{9} \mathrm{O}_{4}$ : C, 46.26;

H, 4.92; N, 32.38. Found C, 46.80; H, 4.86; N, 32.52.

\section{(Bis(1-methyl-4-pivalamidoimidazol-2-yl)methyl)((1-methylimidazol-2- yl)methyl)amine (L2)}

Compound $\mathbf{L} \mathbf{2}$ was prepared following the same general procedure used for L1: $0.13 \mathrm{~g}$ ( $0.33 \mathrm{mmol})$ of the pale yellow oil of $\mathbf{1 9}$ in $25 \mathrm{~mL}$ of anhydrous methanol was reduced in the presence of $0.12 \mathrm{~g}$ of $5 \% \mathrm{Pd} / \mathrm{C}$ and $0.94 \mathrm{~mL}(1.65 \mathrm{mmol})$ of hydrazine monohydrate. After $4 \mathrm{~h}$, the catalyst was filtered on celite and the methanol filtrate was poured into 50 $\mathrm{mL}$ of water. After evaporation of the methanol, the aqueous solution was extracted four times with $15 \mathrm{~mL}$ of dichloromethane. The organic layer was dried over magnesium sulfate. To the dichloromethane solution, $119 \mu \mathrm{L}(0.86 \mathrm{mmol})$ of triethylamine and $96 \mu \mathrm{L}$ (0.79 mmol) pivaloyl chloride was added slowly. After $2 \mathrm{~h}$, removal of the solvent yielded $72 \mathrm{mg}$ (43\%) of $\mathbf{L} \mathbf{2}$ as a yellow oil that could be further purified by column chromatography (silica gel, solvent: $\mathrm{CH}_{2} \mathrm{Cl}_{2}$ and gradient of $\mathrm{MeOH}(2: 1)$ ratio, $\mathrm{R}_{\mathrm{f}}=0.4$ ). IR (KBr) $3052 \mathrm{~cm}^{-1}$ (amide-NH), $1667 \mathrm{~cm}^{-1}$ (amide-C=O); ${ }^{1} \mathrm{H}$ NMR $\mathrm{CD}_{2} \mathrm{Cl}_{2} \delta 7.81$ (s, $\left.{ }^{\mathrm{Am}} \operatorname{Im}(\mathrm{N}-\mathrm{H})\right), 7.09$ (s, 2, $\left.{ }^{\mathrm{Am}} \operatorname{Im}(\mathrm{H}-5)\right), 6.80(\mathrm{~s}, 1, \operatorname{Im}(\mathrm{H}-5)), 6.75$ (s, 1, $\left.\operatorname{Im}(\mathrm{H}-4)\right), 3.60$ (s, 2, $\left.\operatorname{Im}\left(-\mathrm{CH}_{2}\right)\right), 3.57\left(\mathrm{~s}, 4,{ }^{\mathrm{Am}} \operatorname{Im}\left(\mathrm{CH}_{2}\right)\right), 3.07$ (s, 3, $\left.\operatorname{Im}\left(-\mathrm{CH}_{3}\right)\right), 3.02\left(\mathrm{~s}, 6,{ }^{\mathrm{Am}} \operatorname{Im}\left(-\mathrm{CH}_{3}\right)\right), 1.18$ (s, 18, $\left.{ }^{\mathrm{Am}} \operatorname{Im}\left(-\mathrm{C}\left(\mathrm{CH}_{3}\right)_{3}\right)\right) .{ }^{13} \mathrm{C}$ NMR $\mathrm{CDCl}_{3} \delta$ 174.1, $\left(\mathrm{s},{ }^{\mathrm{Am}} \operatorname{Im}(-\mathrm{C}=\mathrm{O})\right), 145.4(\mathrm{~s}, \operatorname{Im}(\mathrm{C} 2))$, $141.2\left(\mathrm{~s},{ }^{\mathrm{Am}} \operatorname{Im}(\mathrm{C} 4)\right), 135.5\left(\mathrm{~s},{ }^{\mathrm{Am}} \operatorname{Im}(\mathrm{C} 2)\right), 126.4$ (s, $\left.\operatorname{Im}(\mathrm{C} 4)\right), 120.8$ (s, $\left.\operatorname{Im}(\mathrm{C} 5)\right), 107.9$ (s, $\left.{ }^{\mathrm{Am}} \operatorname{Im}(\mathrm{C}-5)\right), 47.8\left(\mathrm{~s}, \operatorname{Im}\left(-\mathrm{CH}_{2}-\right),{ }^{\mathrm{Am}} \operatorname{Im}\left(-\mathrm{CH}_{2}-\right)\right), 38.0\left(\mathrm{~s},{ }^{\mathrm{Am}} \operatorname{Im}\left(\underline{\left.\mathrm{N}-\mathrm{CH}_{3}\right)}\right), 31.1\left(\mathrm{~s}, \operatorname{Im}\left(\mathrm{CH}_{3}\right)\right)\right.$, $28.9\left(\mathrm{~s},{ }^{\mathrm{Am}} \mathrm{Im}\left(\underline{\mathrm{C}}\left(\mathrm{CH}_{3}\right)_{3},{ }^{\mathrm{Am}} \operatorname{Im}\left(\mathrm{C}\left(\underline{\mathrm{C}}_{3}\right)_{3}\right) ; \mathrm{HRMS}\right.\right.$ calcd for $\mathrm{C}_{25} \mathrm{H}_{30} \mathrm{~N}_{9} \mathrm{O}_{2}, 498.3305\left(\mathrm{M}+\mathrm{H}^{+}\right)$, found 498.3311 


\section{1,3-Dimethyl-2-(4-nitro-1-methylimidazolyl)imidazolidine (20)}

A benzene solution $(50 \mathrm{~mL})$ of $1.15 \mathrm{~g}$ of $15(7.42 \mathrm{mmol})$ and $0.65 \mathrm{~g}(7.42 \mathrm{mmol})$ of $\mathrm{N}_{,} \mathrm{N}^{\prime}-$ dimethylethylenediamine was refluxed for $2 \mathrm{~h}$. Removal of the benzene under vacuum yielded $1.65 \mathrm{~g}$ of a brown solid (98\%).

$\mathrm{MP}=49-50{ }^{\circ} \mathrm{C}$; IR $(\mathrm{KBr}) 1506$ and $1338 \mathrm{~cm}^{-1}\left(\mathrm{NO}_{2}\right) ;{ }^{1} \mathrm{H} \mathrm{NMR} \mathrm{CDCl}_{3} \delta 7.72$ (s, 1, H-5), $3.93\left(\mathrm{~s}, 3, \mathrm{~N}-\mathrm{CH}_{3}\right), 3.78$ (s, 1, -CH-), 3.31 (dd, 2, $\left.\mathrm{CH}_{2}\right), 2.55$ (dd, 2, $\left.\mathrm{CH}_{2}\right), 2.25$ (s, 6, N$\left.\mathrm{CH}_{3}\right) .{ }^{13} \mathrm{C} \mathrm{NMR} \mathrm{CDCl}_{3} \delta 145.4(\mathrm{~s}, \mathrm{C} 4), 128.5$ (s, C2), 123.7 (s, C5), 86.9 (s, C-H), 53.5 $\left(\mathrm{s}, \mathrm{CH}_{2}\right), 40.1\left(\mathrm{~s}, \mathrm{~N}-\mathrm{CH}_{3}\right), 34.9\left(\mathrm{~s}, \mathrm{Im}\left(\mathrm{N}-\mathrm{CH}_{3}\right)\right)$; ESI-MS m/z $226.2\left(\mathrm{M}+\mathrm{H}^{+}\right)$; Anal. Calcd for $\mathrm{C}_{9} \mathrm{H}_{15} \mathrm{~N}_{5} \mathrm{O}_{2}$ : C, 47.99; H, 6.71; N, 31.09. Found C, 48.04; H, 6.36; N, 30.72.

\section{1-Methyl-4-nitroimidazol-2-carboxaldehyde ethylene acetal (21)}

A toluene solution $(40 \mathrm{~mL})$ of $0.57 \mathrm{~g}(3.68 \mathrm{mmol})$ of 15 with $0.92 \mathrm{~mL}(14.7 \mathrm{mmol})$ of ethylene glycol and $0.10 \mathrm{~g}(0.58 \mathrm{mmol})$ of p-toluenesulfonic acid was refluxed in a 20mL-capacity Dean-Stark trap apparatus for $4 \mathrm{~h}$. After being cooled to room temperature, the organic layer was washed three times with $20 \mathrm{~mL}$ of saturated $\mathrm{Na}_{2} \mathrm{CO}_{3}$. The basic washes were combined and extracted twice with dichloromethane. The combined organic layers were dried over $\mathrm{MgSO}_{4}$ and the solvent was removed under vacuum yielding $0.59 \mathrm{~g}(96 \%)$ of $\mathbf{2 1}$ as a white powder. Compound $\mathbf{2 1}$ was recrystallized from acetone/hexane to yield X-ray quality crystals.

$\mathrm{MP}=96-98{ }^{\circ} \mathrm{C}$; IR (KBr) 1500 and $1392 \mathrm{~cm}^{-1}\left(\mathrm{NO}_{2}\right) ;{ }^{1} \mathrm{H} \mathrm{NMR} \mathrm{CDCl}_{3} \delta 7.66(\mathrm{~s}, 1, \mathrm{H}-5)$, 5.80 (s, 1, - $\mathrm{CH}-), 4.15\left(\mathrm{dd}, 2, \mathrm{CH}_{2}\right), 4.03\left(\mathrm{dd}, 2, \mathrm{CH}_{2}\right), 3.76\left(\mathrm{~s}, 3, \mathrm{~N}_{-} \mathrm{CH}_{3}\right) .{ }^{13} \mathrm{C} \mathrm{NMR}$ $\mathrm{CDCl}_{3} \delta 146.4(\mathrm{~s}, \mathrm{C} 4), 142.0(\mathrm{~s}, \mathrm{C} 2), 123.2(\mathrm{~s}, \mathrm{C} 5), 98.7(\mathrm{~s}, \mathrm{C}-\mathrm{H}), 65.8\left(\mathrm{~s}, \mathrm{CH}_{2}\right), 35.0(\mathrm{~s}$, $\left.\mathrm{N}-\mathrm{CH}_{3}\right)$; ESI-MS m/z $200.2\left(\mathrm{M}+\mathrm{H}^{+}\right)$; Anal. Calcd for $\mathrm{C}_{7} \mathrm{H}_{9} \mathrm{~N}_{3} \mathrm{O}_{4}: \mathrm{C}, 42.21 ; \mathrm{H}, 4.55 ; \mathrm{N}$, 21.10. Found C, 42.31; H, 4.56; N, 21.08. 


\section{1,3-Dimethyl-2-(4-amino-1-methyl-imidazolyl)imidazolidine (22)}

A 1,4 dioxane solution $(25 \mathrm{~mL})$ of $20(1.75 \mathrm{~g}, 7.81 \mathrm{mmol})$ was reduced with $10 \% \mathrm{Pd} / \mathrm{C}$

( $2.83 \mathrm{~g}$ ) under $1 \mathrm{~atm}$ of $\mathrm{H}_{2}$ for $4 \mathrm{~h}$. Filtration of the catalyst on celite yielded a solution of 22. Compound 22 was too unstable to be isolated and decomposed slowly at room temperature.

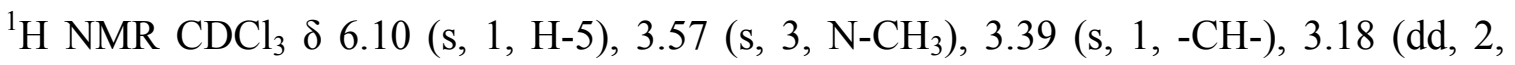
$\left.\mathrm{CH}_{2}\right), 2.41\left(\mathrm{dd}, 2, \mathrm{CH}_{2}\right), 2.09\left(\mathrm{~s}, 6, \mathrm{~N}-\mathrm{CH}_{3}\right) .{ }^{13} \mathrm{C} \mathrm{NMR} \mathrm{CD}_{2} \mathrm{Cl}_{2} \delta 145.6(\mathrm{~s}, \mathrm{C} 2), 139.0(\mathrm{~s}$, C4), 104.0 (s, C5), 87.7 (s, C-H), $53.3\left(\mathrm{~s}, \mathrm{CH}_{2}\right), 39.7\left(\mathrm{~s}, \mathrm{~N}-\mathrm{CH}_{3}\right), 33.9\left(\mathrm{~s}, \mathrm{Im}\left(\mathrm{N}-\mathrm{CH}_{3}\right)\right)$.

4-Amino-1-methyl-imidazol-2-carboxaldehyde ethylene acetal (23)

Compound 21 (0.59 g, $2.96 \mathrm{mmol})$ was dissolved in $25 \mathrm{~mL}$ of anhydrous 1,4 dioxane and treated with $0.95 \mathrm{~g}$ of $10 \% \mathrm{Pd} / \mathrm{C}$ and $1 \mathrm{~atm}$ of $\mathrm{H}_{2}$. After $4 \mathrm{~h}$, filtration of the catalyst on celite yielded $\mathbf{2 3}$ as an unstable amine that was not isolated.

${ }^{1} \mathrm{H} \mathrm{NMR} \mathrm{CDCl}_{3} \delta 6.20$ (s, 1, H-5), 5.81 (s, 1, -CH-), $4.18\left(\mathrm{dd}, 2, \mathrm{CH}_{2}\right), 4.04$ (dd, 2, $\left.\mathrm{CH}_{2}\right)$,

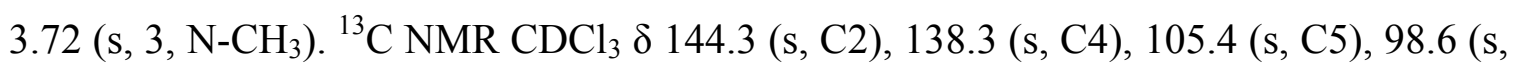
$-\mathrm{CH}-), 67.3\left(\mathrm{~s},-\mathrm{CH}_{2}-\right), 65.4\left(\mathrm{~s},-\mathrm{CH}_{2}-\right), 33.1\left(\mathrm{~s}, \mathrm{~N}-\mathrm{CH}_{3}\right)$.

\section{1,3-Dimethyl-2-(4-pivaloylamido-1-methyl-imidazolyl)imidazolidine (24)}

The unstable amine, 22, in 1,4 dioxane containing $1.41 \mathrm{~mL}$ of triethylamine $(10.2 \mathrm{mmol})$ was acylated in-situ by adding dropwise $1.05 \mathrm{~mL}(8.59 \mathrm{mmol})$ of pivaloyl chloride. A white precipitate of triethylammonium hydrochloride salt formed during the course of the reaction. After $2 \mathrm{~h}$, the precipitate was filtered and the filtrate was concentrated under vacuum to yield a crude oil of $24(0.16 \mathrm{~g}, 73 \%)$. Slight deprotection of the aldehyde was observed by ${ }^{1} \mathrm{H} \mathrm{NMR}$, hence the crude product was not isolated but rather used to prepare compound 26. 
${ }^{1} \mathrm{H} \mathrm{NMR} \mathrm{CDCl}_{3} \delta 7.98$ (s, 1, N-H), 7.55 (s, 1, H-5), 3.90 (s, 3, N-CH N, 3.42 (s, 1, -CH-), $3.18\left(\mathrm{dd}, 2, \mathrm{CH}_{2}\right), 2.19\left(\mathrm{dd}, 2, \mathrm{CH}_{2}\right), 1.45\left(\mathrm{~s}, 9, \mathrm{C}\left(\mathrm{CH}_{3}\right)_{3}\right), 1.18$ (s, 6, N-CH$)_{3}$; ESI-MS $\mathrm{m} / \mathrm{z} 279.4\left(\mathrm{M}+\mathrm{H}^{+}\right)$.

\section{4-Pivaloylamido-1-methyl-imidazol-2-carboxaldehyde ethylene acetal (25)}

The 1,4-dioxane solution $(25 \mathrm{~mL})$ of $\mathbf{2 3}$ was treated with 1.3 equivalents of triethylamine $(0.53 \mathrm{~mL}, 3.85 \mathrm{mmol})$. Over the course of ten minutes, 1.2 eq. of pivaloyl chloride $(0.46$ $\mathrm{mL}, 3.55 \mathrm{mmol}$ ) were added dropwise, generating a white precipitate. The mixture was stirred for $4 \mathrm{~h}$ at room temperature and the triethylamine hydrochloride salt was removed by filtration. The solvent was evaporated under vacuum to yield a pale yellow solid in $78 \%$ yield $(0.58 \mathrm{~g})$. The solid was recrystallized from an acetone/hexane mixture yielding a white microcrystalline powder of $\mathbf{2 5 .}$

$\mathrm{MP}=137-139{ }^{\circ} \mathrm{C} ; \mathrm{IR}(\mathrm{KBr}) 2968 \mathrm{~cm}^{-1}$ (amide-CH), $1528 \mathrm{~cm}^{-1}$ (amide-C=O); ${ }^{1} \mathrm{H}$ NMR $\mathrm{CDCl}_{3} \delta 7.95$ (s, 1, N-H), 7.30 (s, 1, H-5), 5.88 (s, 1, -CH-), 4.18 (dd, 2, $\mathrm{CH}_{2}$ ), 4.07 (dd, 2, $\left.\mathrm{CH}_{2}\right), 3.71\left(\mathrm{~s}, 3, \mathrm{~N}-\mathrm{CH}_{3}\right), 1.28\left(\mathrm{~s}, 9, \mathrm{C}\left(\mathrm{CH}_{3}\right)_{3}\right) .{ }^{13} \mathrm{C} \mathrm{NMR} \mathrm{CDCl}_{3} \delta 175.7(\mathrm{~s}, \mathrm{C}=\mathrm{O})$, 138.5 (s, C4), 136.5 (s, C2), 110.9 (s, C5), 98.3 (s, C-H), $65.5\left(\mathrm{~s}, \mathrm{CH}_{2}\right), 39.2\left(\mathrm{~s}, \mathrm{~N}-\mathrm{CH}_{3}\right)$, $33.6\left(\mathrm{~s}, \underline{\mathrm{C}}\left(\mathrm{CH}_{3}\right)_{3}\right), 27.8\left(\mathrm{~s}, \mathrm{C}\left(\underline{\mathrm{CH}}_{3}\right)_{3}\right) ;$ ESI-MS m/z $254.2\left(\mathrm{M}+\mathrm{H}^{+}\right)$; Anal. Calcd for $\mathrm{C}_{12} \mathrm{H}_{19} \mathrm{~N}_{3} \mathrm{O}_{3}: \mathrm{C}, 56.90 ; \mathrm{H}, 7.56 ; \mathrm{N}, 16.59$. Found $\mathrm{C}, 57.03 ; \mathrm{H}, 7.63 ; \mathrm{N}, 16.23$.

\section{4-Pivaloylamido-1-methyl-imidazol-2-carboxaldehyde (26)}

\section{Method A}

Compound 26 was prepared from either compound $\mathbf{2 4}$ or $\mathbf{2 5}, 0.10 \mathrm{~g}(0.36$ and $0.39 \mathrm{mmol}$, respectively) of which were dissolved in $20 \mathrm{~mL}$ of acetone and to which $30 \mathrm{~mL}$ of $3 \mathrm{M}$ $\mathrm{HCl}$ was added. The reaction mixture was stirred for $2 \mathrm{~h}$ and quenched by the addition of saturated $\mathrm{Na}_{2} \mathrm{CO}_{3}$ until the solution reached $\mathrm{pH}=10$. Evaporation of the acetone and 
extraction of the basic aqueous layer three times with $30 \mathrm{~mL}$ of dichloromethane yielded 26 in $72 \%$ (54 mg) and 78\% (65 mg) yield, respectively.

\section{Method B}

Compound 24 or 25 ( $0.10 \mathrm{~g}, 0.36$ and $0.39 \mathrm{mmol}$, respectively) was dissolved in glacial acetic acid and the solution was refluxed for $4 \mathrm{~h}$. Removal of the acetic acid under vacuum yields a crude yellow powder of 26. The solid was recrystallized from an acetone/hexane mixture yielding a white microcrystalline powder of $\mathbf{2 6}$ (66 and $74 \mathrm{mg}$, 80 and $88 \%$ yield, respectively).

$\mathrm{MP}=150-151{ }^{\circ} \mathrm{C}$; IR $(\mathrm{KBr}) 2966 \mathrm{~cm}^{-1}\left(\right.$ amide-NH), $1686 \mathrm{~cm}^{-1}(\mathrm{HC}=\mathrm{O}), 1549 \mathrm{~cm}^{-1}$ (amide-C=O); 1H NMR $\mathrm{CDCl}_{3} \delta 9.69$ (s, 1, H-C=O), 7.96 (s, 1, N-H), 7.66 (s, 1, H-5), $4.03\left(\mathrm{~s}, 3, \mathrm{~N}-\mathrm{CH}_{3}\right), 1.33\left(\mathrm{~s}, 1, \mathrm{C}\left(\mathrm{CH}_{3}\right)_{3}\right) \cdot{ }^{13} \mathrm{C} \mathrm{NMR} \mathrm{CDCl}_{3} \delta 180.9$ (s, $\left.\mathrm{H}-\mathrm{C}=\mathrm{O}\right), 176.4$ (s, amide-C=O), 139.5 (s, C4), 138.0 (s, C2), 117.5 (s, C5), 39.3 (s, N-CH$), 35.3$ (s, $\left.\underline{\mathrm{C}}\left(\mathrm{CH}_{3}\right)_{3}\right), 27.7\left(\mathrm{~s}, \mathrm{C}\left(\mathrm{C}_{3}\right)_{3}\right)$. ESI-MS m/z $210.2\left(\mathrm{M}+\mathrm{H}^{+}\right)$; Anal. Calcd for $\mathrm{C}_{10} \mathrm{H}_{15} \mathrm{~N}_{3} \mathrm{O}_{2}: \mathrm{C}$, 57.40; H, 7.23; N, 20.08. Found C, 57.37; H, 7.20; N, 19.98.

\section{(1-Methylimidazol-2-yl)methyl)((1-methyl-4-pivaloylamidoimidazol-2- yl)methyl)amine (27)}

Following the same procedure used to prepare bmima (Chen, S. et al., 1994), $0.10 \mathrm{~g}(0.91$ mmol) of 2-aminomethyl-1-methylimidazole and $0.19 \mathrm{~g}(0.91 \mathrm{mmol})$ of 26 in $25 \mathrm{~mL}$ of anhydrous $\mathrm{MeOH}$ was treated with $0.08 \mathrm{~g}(2.1 \mathrm{mmol})$ of $\mathrm{NaBH}_{4}$. Compound 27 could be isolated after the appropriate workup, as described for compound $\mathbf{1 8}$, as a pale yellow oil in $65 \%$ yield $(0.18 \mathrm{~g})$.

${ }^{1} \mathrm{H} \mathrm{NMR} \mathrm{CDCl}{ }_{3} \delta 8.05\left(\mathrm{~s},{ }^{\mathrm{Am}} \mathrm{Im}(\mathrm{N}-\mathrm{H})\right), 7.15\left(\mathrm{~s},{ }^{\mathrm{Am}} \operatorname{Im}(\mathrm{H}-5)\right), 6.88$ (s, 1, H-5), 6.77 (s, 1, H-4), $3.82\left(\mathrm{~s}, 2, \mathrm{CH}_{2}\right), 3.77\left(\mathrm{~s}, 2,{ }^{\mathrm{Am}} \operatorname{Im}\left(\mathrm{CH}_{2}\right)\right), 3.56\left(\mathrm{~s}, 3, \mathrm{~N}-\mathrm{CH}_{3}\right), 3.52\left(\mathrm{~s}, 3,{ }^{\mathrm{Am}} \mathrm{Im}(\mathrm{N}-\right.$ $\left.\left.\mathrm{CH}_{3}\right)\right), 1.21 \quad\left(\mathrm{~s}, 9,{ }^{\mathrm{Am}} \operatorname{Im}\left(\mathrm{C}\left(\mathrm{CH}_{3}\right)_{3}\right)\right) .{ }^{13} \mathrm{C} \quad \mathrm{NMR} \delta \mathrm{CDCl}_{3} 175.8(\mathrm{~s}, \mathrm{C}=\mathrm{O}), 145.9$ (s, 
$\left.{ }^{A m} \operatorname{Im}(\mathrm{C} 4)\right), 141.6(\mathrm{~s}, \operatorname{Im}(\mathrm{C} 2)), 136.2(\mathrm{~s}, \operatorname{Im}(\mathrm{C} 4)), 126.8(\mathrm{~s}, \operatorname{Im}(\mathrm{C} 5)), 121.8\left(\mathrm{~s},{ }^{\mathrm{Am}} \operatorname{Im}(\mathrm{C} 2)\right)$, $109.3\left(\mathrm{~s},{ }^{\mathrm{Am}} \operatorname{Im}(\mathrm{C} 5)\right), 44.7\left(\mathrm{~s},-\mathrm{CH}_{2}\right), 39.1\left(\mathrm{~s},{ }^{\mathrm{Am}} \mathrm{Im}\left(\mathrm{N}-\mathrm{CH}_{3}\right)\right), 33.3\left(\mathrm{~s}, \operatorname{Im}\left(\mathrm{N}-\mathrm{CH}_{3}\right)\right),(\mathrm{s}$, $\left.\underline{\mathrm{C}}\left(\mathrm{CH}_{3}\right)_{3}\right), 27.8\left(\mathrm{~s}, \mathrm{C}\left(\underline{\mathrm{CH}}_{3}\right)_{3}\right)$.

Note: The white hydrochloride salt of 27 was isolated by bubbling $\mathrm{HCl}_{(\mathrm{g})}$ through an ethanol solution of the compound for 30 minutes.

\section{4-Pivaloylamido-1-methyl-imidazol-2-oxime (28)}

An ethanol solution $(25 \mathrm{~mL})$ of $0.51 \mathrm{~g}(2.44 \mathrm{mmol})$ of $\mathbf{2 6}$ was treated with $10 \mathrm{~mL}$ of a $\mathrm{pH}$ $=10$ aqueous sodium carbonate solution containing $0.21 \mathrm{~g}(2.93 \mathrm{mmol})$ hydroxylamine hydrochloride for $2 \mathrm{~h}$. A yellow precipitate formed during the course of the reaction. Filtration of the solution yielded 28 as a yellow powder in $85 \%$ yield $(0.46 \mathrm{~g})$.

$\mathrm{MP}=210-211{ }^{\circ} \mathrm{C}$; IR $(\mathrm{KBr}) 3470 \mathrm{~cm}^{-1}(\mathrm{OH}), 2957 \mathrm{~cm}^{-1}$ (amide-NH), 1676 (oxime$\mathrm{C}=\mathrm{N}), 1551 \mathrm{~cm}^{-1}$ (amide-C=O); ${ }^{1} \mathrm{H}$ NMR $\mathrm{CDCl}_{3} \delta 8.04(\mathrm{~s}, 1, \mathrm{H}-\mathrm{C}=\mathrm{N}), 7.93(\mathrm{~s}, 1, \mathrm{~N}-\mathrm{H})$, $7.32(\mathrm{~s}, 1, \mathrm{H}-5), 3.73\left(\mathrm{~s}, 3, \mathrm{~N}-\mathrm{CH}_{3}\right), 1.20\left(\mathrm{~s}, 1, \mathrm{C}\left(\mathrm{CH}_{3}\right)_{3}\right) .{ }^{13} \mathrm{C} \mathrm{NMR} \mathrm{CDCl}_{3} \delta 176.1(\mathrm{~s}$, $\mathrm{C}=\mathrm{O}), 141.8(\mathrm{~s}, \mathrm{C} 4), 137.8(\mathrm{~s}, \mathrm{H}-\mathrm{C}=\mathrm{N}), 135.6(\mathrm{~s}, \mathrm{C} 2), 112.3(\mathrm{~s}, \mathrm{C} 5), 39.2\left(\mathrm{~s}, \mathrm{~N}-\mathrm{CH}_{3}\right)$, $35.5\left(\mathrm{~s}, \underline{\mathrm{C}}\left(\mathrm{CH}_{3}\right)_{3}\right), 27.8\left(\mathrm{~s}, \mathrm{C}\left(\underline{\mathrm{CH}}_{3}\right)_{3}\right) ;$ ESI-MS m/z $225.2\left(\mathrm{M}+\mathrm{H}^{+}\right)$; Anal. Calcd for $\mathrm{C}_{10} \mathrm{H}_{16} \mathrm{~N}_{4} \mathrm{O}_{2}$ : C, 53.56; H, 7.19; N, 24.98. Found C, 53.93; H, 7.19; N, 24.88.

2-Aminomethyl-1-methyl-4-pivaloylamido-imidazole, hydrochlorhydride salt (29)

Following the same general procedure used to prepare 1-methylimidazol-2-yl methylamine (Chen, S. et al., 1994), a methanolic/HCl solution of 28 (0.25 g, $1.11 \mathrm{mmol})$ was reduced using $10 \% \mathrm{Pd} / \mathrm{C}(27 \mathrm{mg})$ under $1 \mathrm{~atm}$ of $\mathrm{H}_{2}$. After filtration of the catalyst, the solution was stored at $-20{ }^{\circ} \mathrm{C}$ and a white powder of 29 was observed to precipitate overnight. The solid was isolated by filtration in $75 \%$ yield $(0.17 \mathrm{~g})$. 
IR (KBr) $2942 \mathrm{~cm}^{-1}$ (amide-NH), $1668 \mathrm{~cm}^{-1}$ (amide-C=O); ${ }^{1} \mathrm{H}$ NMR DMSO-d 610.78 (s, 1, N-H) 8.93 (s, 2, $\left.\mathrm{NH}_{2}\right), 7.45$ (s, 1, H-5), 4.27 (s, 2, - $\left.\mathrm{CH}_{2}-\right), 3.85$ (s, 3, $\left.\mathrm{CH}_{3}\right), 1.21$ (s, 9, $\left.\mathrm{C}\left(\mathrm{CH}_{3}\right)_{3}\right) .{ }^{13} \mathrm{C}$ NMR DMSO-d 6 $\delta 176.9(\mathrm{~s}, \mathrm{C}=\mathrm{O}), 135.6(\mathrm{~s}, \mathrm{C} 2), 132.4(\mathrm{~s}, \mathrm{C} 4), 111.2(\mathrm{~s}$, C5), $39.7\left(\mathrm{~s}, \mathrm{CH}_{2}\right), 39.7\left(\mathrm{~s}, \mathrm{~N}-\mathrm{CH}_{3}\right), 35.4\left(\mathrm{~s}, \underline{\mathrm{C}}\left(\mathrm{CH}_{3}\right)_{3}\right), 27.7\left(\mathrm{~s}, \mathrm{C}\left(\underline{\mathrm{C}} \mathrm{H}_{3}\right)_{3}\right)$. Anal. Calcd for $\mathrm{C}_{10} \mathrm{H}_{21} \mathrm{Cl}_{3} \mathrm{~N}_{4} \mathrm{O}$ : C, 37.57; H, 6.62; N, 17.13. Found C, 37.05; H, 6.64; N, 17.13.

\section{2-Aminomethyl-1-methyl-4-pivaloylamido-imidazole (free base of 29)}

The $\mathrm{pH}$ of an aqueous solution $(1 \mathrm{~mL})$ of $\mathbf{2 9}(0.15 \mathrm{~g}, 0.71 \mathrm{mmol})$ was adjusted to 11 by the addition of saturated sodium carbonate. The mixture was extracted three times with chloroform. Evaporation of the solvent under vacuum yielded a yellow oil of the free amine which was used directly to synthesize compound $\mathbf{3 0}$.

${ }^{1} \mathrm{H} \mathrm{NMR} \mathrm{CDCl}_{3} \delta 7.89$ (s, 1, N-H), 7.22 (s, 1, H-5), 3.90 (s, 2, - $\left.\mathrm{CH}_{2}-\right), 3.61$ (s, 3, N-CH$)_{3}$, $1.80\left(\mathrm{~s}, 2, \mathrm{NH}_{2}\right), 1.29\left(\mathrm{~s}, 9, \mathrm{C}\left(\mathrm{CH}_{3}\right)_{3}\right)$.

\section{Bis((1-methyl-4-pivaloylamidoimidazol-2-yl)methyl)amine (30)}

Following the procedure used to prepare $18,0.33 \mathrm{~g}(1.62 \mathrm{mmol})$ of the free amine of $\mathbf{2 9}$ was reacted with $0.33 \mathrm{~g}$ (1.62 mmol) of $\mathbf{2 6}$ in $35 \mathrm{~mL}$ of refluxing methanol for $30 \mathrm{~min}$, after which time, $0.14 \mathrm{~g}(3.68 \mathrm{mmol})$ of $\mathrm{NaBH}_{4}$ was added and the solution was stirred for $2 \mathrm{~h}$ at $0{ }^{\circ} \mathrm{C}$. The reaction was quenched with saturated sodium carbonate. Evaporation of the methanol was followed by three chloroform extractions $(20 \mathrm{~mL})$ yielding $0.51 \mathrm{~g}$ of 30 (78\% yield).

${ }^{1} \mathrm{H} \mathrm{NMR} \mathrm{CDCl}_{3} \delta 7.82(\mathrm{~s}, 1, \mathrm{~N}-\mathrm{H}), 7.21$ (s, 1, H-5), 5.32 (s, 1, N-H), $3.60\left(\mathrm{~s}, 2, \mathrm{CH}_{2}\right)$, $3.32\left(\mathrm{~s}, 3, \mathrm{~N}-\mathrm{CH}_{3}\right), 1.20\left(\mathrm{~s}, 9, \mathrm{C}\left(\mathrm{CH}_{3}\right)_{3}\right) \cdot{ }^{13} \mathrm{C} \mathrm{NMR} \mathrm{CDCl}_{3} \delta 175.7(\mathrm{~s}, \mathrm{C}=\mathrm{O}), 139.4(\mathrm{~s}$, C4), 136.2 (s, C2), 110.1 (s, C5), $53.8\left(\mathrm{~s}, \mathrm{CH}_{2}\right), 39.1$ (s, N-CH 3$), 33.4\left(\mathrm{~s}, \underline{\mathrm{C}}\left(\mathrm{CH}_{3}\right)_{3}\right), 27.7$ (s, $\left.\mathrm{C}\left(\mathrm{CH}_{3}\right)_{3}\right)$. 


\section{Tris((1-methyl-4-pivaloylamidoimidazol-2-yl)methyl)amine (L3)}

Following the procedure used to prepare L2, $0.35 \mathrm{~g}(0.87 \mathrm{mmol})$ of $\mathbf{2 6}$ was reacted with $0.18 \mathrm{~g}(0.87 \mathrm{mmol})$ of $\mathbf{3 0}$ and the reaction mixture was treated with $0.14 \mathrm{~g}(2.20 \mathrm{mmol})$ of $\mathrm{NaBH}_{3} \mathrm{CN}$. $0.34 \mathrm{~g}$ of $\mathbf{L 3}$ was isolated as a yellow oil (65\% yield) following the work-up procedure outlined for L2. (Caution! Cyanide is extremely toxic and should be handled with care).

${ }^{1} \mathrm{H} \mathrm{NMR} \mathrm{CDCl}_{3} \delta 7.85$ (s, 1, N-H), 7.24 (s, 1, H-5), 3.67 (s, 2, $\left.\mathrm{CH}_{2}\right), 3.18\left(\mathrm{~s}, 2, \mathrm{~N}-\mathrm{CH}_{3}\right)$, $1.29\left(\mathrm{~s}, 9, \mathrm{C}\left(\mathrm{CH}_{3}\right)_{3}\right) .{ }^{13} \mathrm{C} \mathrm{NMR} \mathrm{CDCl}_{3} \delta 175.8(\mathrm{~s}, \mathrm{C}=\mathrm{O}), 140.6(\mathrm{~s}, \mathrm{C} 4), 136.4(\mathrm{~s}, \mathrm{C} 2)$, 109.5 (s, C5), $49.2\left(\mathrm{~s}, \mathrm{CH}_{2}\right), 39.2\left(\mathrm{~s}, \mathrm{~N}-\mathrm{CH}_{3}\right), 32.4\left(\mathrm{~s}, \underline{\mathrm{C}}\left(\mathrm{CH}_{3}\right)_{3}\right), 27.8\left(\mathrm{~s}, \mathrm{C}\left(\underline{\mathrm{CH}}_{3}\right)_{3}\right)$; HRMS calcd for $\mathrm{C}_{30} \mathrm{H}_{48} \mathrm{~N}_{10} \mathrm{O}_{3}: 597.3984\left(\mathrm{M}+\mathrm{H}^{+}\right)$, found 597.3991.

\section{4-(N-Acetyl-D-phenylalanine)amido-1-methylimidazole-2-yl-carboxaldehyde ethylene acetal (31)}

To a $25 \mathrm{~mL}$ anhydrous DMF solution containing $2.22 \mathrm{mmol}(0.38 \mathrm{~g})$ of the free amine, 23, was added $0.44 \mathrm{mg}(3.56 \mathrm{mmol})$ of HBTU in $10 \mathrm{~mL}$ of DMF, $0.62 \mathrm{~mL}(3.36 \mathrm{mmol})$ of N,N-diisopropyletylamine, DIEA, and $0.37 \mathrm{~g}(1.78 \mathrm{mmol})$ of N-Acetyl-DLphenylalanine. The solution was then stirred at room temperature for $22 \mathrm{~h}$. The reaction mixture was then poured into $40 \mathrm{~mL}$ of water and extracted with $3 \times 25 \mathrm{~mL}$ of ethyl acetate. The organic layer was then washed with $3 \times 30 \mathrm{~mL}$ of $10 \% \mathrm{HCl}, 3 \times 30 \mathrm{~mL}$ of saturated sodium bicarbonate and $3 \times 30 \mathrm{~mL}$ of water. After drying the organic solution over magnesium sulfate, evaporation of the solvent yielded a crude yellow oil (0.42 $\mathrm{g}$, $65 \%$ yield). Recrystallization of the crude oil from a dioxane/hexanes mixture yielded a white powder of $\mathbf{3 1}$ in $70 \%$ yield $(0.29 \mathrm{~g})$.

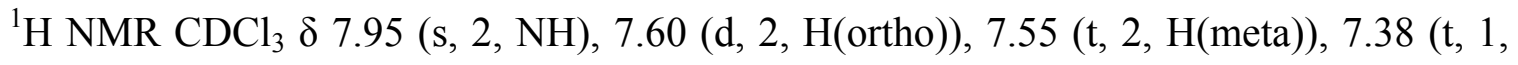
H(para)), 7.15 (s, 1, Im(H-5)), 6.18 (s, 1, - $\mathrm{CH}-), 4.18$ (s, 2, - $\left.\mathrm{CH}_{2^{-}}\right), 4.07$ (s, 2, - $\left.\mathrm{CH}_{2^{-}}\right)$, 
$3.74\left(\mathrm{~s}, 3, \mathrm{Im}\left(\mathrm{N}-\mathrm{CH}_{3}\right)\right), 2.60\left(\mathrm{~s}, 3, \mathrm{CH}_{3}\right) ;{ }^{13} \mathrm{C} \mathrm{NMR} \mathrm{CDCl}_{3} \delta 170.2(\mathrm{~s}, \mathrm{C}=\mathrm{O}), 167.9(\mathrm{~s}$, $\mathrm{C}=\mathrm{O}), 136.3(\mathrm{~s}, \operatorname{Im}(\mathrm{C} 4)), 135.4(\mathrm{~s}, \operatorname{Im}(\mathrm{C} 2)), 129.0$ (s, $\left.\mathrm{C}_{\text {ortho }}, \mathrm{C}_{\text {meta }}\right), 127.4$ (s, $\left.\mathrm{C}_{\text {para }}\right), 111.5$

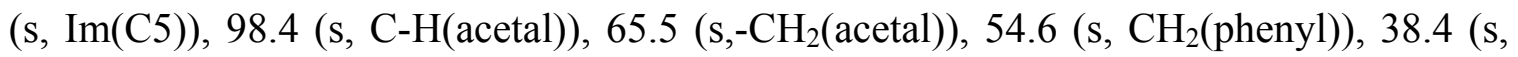
N-CH${ }_{3}$ ), 35.8 (s, C-H(phenyl)), $33.6\left(\mathrm{~s},-\mathrm{CH}_{3}\right)$; ESI-MS m/z $359.4\left[\mathrm{M}+\mathrm{H}^{+}\right]$. Anal. Calcd for $\mathrm{C}_{18} \mathrm{H}_{22} \mathrm{~N}_{4} \mathrm{O}_{4}$ : C, 60.32; H, 6.19; N, 15.63. Found C, 60.53; H, 6.13; N, 15.88.

4-N-(1'-methylimidazol-2'-methyl)(1-methyl-imidazol-2-yl carboxaldehyde ethylene acetal) imine (32)

The free acetal amine $23(\sim 0.35 \mathrm{~g}, 2.07 \mathrm{mmol})$ in $25 \mathrm{~mL}$ of methanol was reacted at room temperature for 2 hours with $0.18 \mathrm{~g}(1.66 \mathrm{mmol})$ of 1-methylimidazole-2carboxaldehyde. Evaporation of the methanol under vacuum yielded $\mathbf{3 2}$ as a pale yellow oil $(0.28 \mathrm{~g})$ in $65 \%$ yield.

${ }^{1} \mathrm{H} \mathrm{NMR} \mathrm{CDCl}_{3} \delta 9.02(\mathrm{~s}, 1, \mathrm{HC}=\mathrm{N}), 7.18\left(\mathrm{~s}, 1,{ }^{\text {Protec }} \operatorname{Im}(\mathrm{H}-5)\right), 6.97$ (s, 2, $\left.\operatorname{Im}(\mathrm{H})\right), 5.91$ (s, 1, - $\mathrm{CH}-), 4.22$ (s, 2, - $\left.\mathrm{CH}_{2}-\right), 4.07$ (s, 5, $-\mathrm{CH}_{2}-$ and $\left.\operatorname{Im}\left(\mathrm{N}-\mathrm{CH}_{3}\right)\right), 3.74$ (s, 3, ${ }^{\text {Protec }} \operatorname{Im}(\mathrm{N}-$ $\left.\left.\mathrm{CH}_{3}\right)\right) .{ }^{13} \mathrm{C}$ NMR $\mathrm{CDCl}_{3} \delta 147.5(\mathrm{~s}, \mathrm{C} 4), 144.3(\mathrm{~s}, \mathrm{C} 2), 142.1$ (s, $\left.{ }^{\text {Protec }} \mathrm{Im}(\mathrm{C} 4)\right), 141.1$ (s, $\left.{ }^{\text {Protec }} \operatorname{Im}(\mathrm{C} 2)\right), 130.3$ (s, C5), 125.0 (s, $\left.{ }^{\text {Protec }} \operatorname{Im}(\mathrm{C} 5)\right), 117.9$ (s, C=N), 99.1 (s, -CH-), 65.5 (s, - $\left.\mathrm{CH}_{2}-\right), 35.5\left(\mathrm{~s},{ }^{\text {Protec }} \mathrm{Im}\left(\mathrm{N}-\mathrm{CH}_{3}\right)\right), 33.8\left(\mathrm{~s}, \mathrm{~N}-\mathrm{CH}_{3}\right)$. ESI-MS m/z $262.31\left[\mathrm{M}+\mathrm{H}^{+}\right]$.

\section{4-Benzamido-1-methyl-imidazol-2-yl acetal (33)}

Following the procedure used to synthesize 25 , the free acetal amine $23(\sim 0.20 \mathrm{~g}, 1.18$ mmol $)$ in $25 \mathrm{~mL}$ of dioxane was treated with $132 \mu \mathrm{L}(0.95 \mathrm{mmol})$ of triethylamine and $103 \mu \mathrm{L}(0.89 \mathrm{mmol})$ of benzoyl chloride. The solution was then stirred for $2 \mathrm{~h}$ at room temperature. Evaporation of the dioxane under vacuum yielded $\mathbf{3 3}$ as a pale yellow oil $(0.16 \mathrm{~g})$ in $65 \%$ yield.

${ }^{1} \mathrm{H} \mathrm{NMR} \mathrm{CDCl}_{3} \delta 7.95$ (s, 1, NH), 7.46 (d, 2, H(ortho)), 7.44 (t, 2, H(meta)), 7.41 (t, 1, $\mathrm{H}\left(\right.$ para)), 7.19 (s, 1, Im(H-5)), 5.89 (s, 1, -CH-), 4.15 (s, 2, - $\left.\mathrm{CH}_{2^{-}}\right), 4.02$ (s, 2, - $\left.\mathrm{CH}_{2^{-}}\right)$, 
$3.68\left(\mathrm{~s}, 3, \operatorname{Im}\left(\mathrm{N}_{-}-\mathrm{CH}_{3}\right)\right) ;{ }^{13} \mathrm{C} \mathrm{NMR} \mathrm{CDCl}_{3} \delta 171.4(\mathrm{~s}, \mathrm{C}=\mathrm{O}), 138.3(\mathrm{~s}, \operatorname{Im}(\mathrm{C} 4)), 131.9$ (s, $\operatorname{Im}(\mathrm{C} 5)), 128.2$ (s, C(phenyl)), 115.2 (s, Im(C5)), 97.7 (s, -CH-), 65.6 (s, - $\left.\mathrm{CH}_{2^{-}}\right), 33.7$ (s, $\left.\mathrm{N}-\mathrm{CH}_{3}\right) ; \mathrm{ESI}-\mathrm{MS} \mathrm{m} / \mathrm{z} 274.29\left[\mathrm{M}+\mathrm{H}^{+}\right]$.

\section{2-Furamido-1-methyl-imidazol-2-yl acetal (34)}

Following the procedure used to synthesize $\mathbf{2 5}$, the free acetal amine $23(\sim 0.20 \mathrm{~g}, 1.18$ mmol) in $25 \mathrm{~mL}$ of dioxane was treated with $132 \mu \mathrm{L}(0.95 \mathrm{mmol})$ of triethylamine and 88 $\mu \mathrm{L}(0.89 \mathrm{mmol})$ of 2 -furoyl chloride. The solution was the stirred for $2 \mathrm{~h}$ at room temperature. Evaporation of the dioxane under vacuum yielded $\mathbf{3 4}$ as a pale yellow oil $(0.17 \mathrm{~g})$ in $73 \%$ yield.

${ }^{1} \mathrm{H} \mathrm{NMR} \mathrm{CDCl}{ }_{3} \delta 9.33$ (s, 1, NH), 7.48 (s,1, H(furan)), 7.38 (s, 1, H(furan)), 7.19 (s, 1, $\operatorname{Im}(\mathrm{H}-5)), 6.49$ (s, 1, H(furan)), 5.85 (s, 1, - $\mathrm{CH}-), 4.15$ (s, 2, - $\left.\mathrm{CH}_{2}-\right), 4.02$ (s, 2, - $\left.\mathrm{CH}_{2}-\right)$, $3.69\left(\mathrm{~s}, 3, \operatorname{Im}\left(\mathrm{N}_{-} \mathrm{CH}_{3}\right)\right) ;{ }^{13} \mathrm{C} \mathrm{NMR} \mathrm{CDCl}_{3} \delta 163.4(\mathrm{~s}, \mathrm{C}=\mathrm{O}), 147.6(\mathrm{~s}, \operatorname{Im}(\mathrm{C} 4)), 144.8$ (s, $\operatorname{Im}(\mathrm{C} 2)), 118.2$ (s, Im(C5)), 115.3 (s, C(furan)), 112.5 (s, C(furan)), 98.2 (s, -CH-), 65.5 (s, $\left.-\mathrm{CH}_{2}-\right), 33.7\left(\mathrm{~s}, \mathrm{~N}-\mathrm{CH}_{3}\right) ; \mathrm{ESI}-\mathrm{MS} \mathrm{m} / \mathrm{z} 264.19\left[\mathrm{M}+\mathrm{H}^{+}\right]$ 


\section{CHAPTER V}

\section{METAL COMPLEXES OF THE NOVEL AMIDE FUNCTIONALIZED IMIDAZOLE LIGANDS L1-L3}

\section{A. Introduction}

In histidine containing metalloenzyme active site modeling studies, pyridine compounds have been used extensively compared to imidazole based ligands because of their ease of preparation (Bhalla, R. et al., 1997). Even though the coordination environments around the metal centers are very similar in related imidazole and pyridine complexes, there are still subtle differences between the two ligands in the way they "fine-tune" the electronic properties of metals. In previous studies, Buchanan and coworkers established the subtle differences in $\sigma$ and $\pi$ bonding properties of tripodal ligands bearing pyridine and 1-methylimidazole substituents and their effects on the structural, electronic and redox properties of pentacoordinated $\mathrm{Cu}(\mathrm{II})$ complexes (Oberhausen, K. J. et al., 1990).

The novel amide functionalized imidazole tripods, L1-L3 (see chapter IV), offered the opportunity to probe further the effects of ligand structure on the properties of metal complexes. Thus, the structures and properties of these new ligands are compared with those of tmima, as well as with related amide functionalized pyridine ligands developed by Masuda and coworkers (Harata, M. et al., 1998b). In addition, we sought to evaluate the hydrogen bonding ability of L1-L3. 
In this study, $\mathrm{Fe}(\mathrm{III})$ and $\mathrm{Cu}(\mathrm{II})$ complexes of the amide functionalized imidazole tripods were synthesized and characterized by X-ray crystallography, EPR spectroscopy and cyclic voltammetry. The crystal structures of Fe(III) complexes of tmima and L1 were evaluated to establish the effects that the introduction of one amide pendant arm to the tmima framework has on the structure and electronic properties of the complexes (Cheruzel, L. E. et al., 2002). Studies were extended to include $\mathrm{Cu}(\mathrm{II})$ complexes of $\mathbf{L 2}$ and L3. Again, the effect of ligand modification on the structure and electronic properties of the $\mathrm{Cu}(\mathrm{II})$ complexes was examined relative to related tmima and pyridine analogs (Harata, M. et al., 1998b). In these metal complexes, chloride ions are bonded to the metal atoms in apical positions. Weak $\mathrm{N}-\mathrm{H}---\mathrm{Cl}$ hydrogen bond interactions were observed in both the $\mathrm{Fe}$ (III) and $\mathrm{Cu}(\mathrm{II})$ complexes. In the case of $\mathrm{Cu}$ (II) complexes, intramolecular hydrogen bonding was exploited further in the stabilization of mononuclear $\mathrm{Cu}(\mathrm{II})-\mathrm{N}_{3}$ and $\mathrm{Cu}(\mathrm{II})-\mathrm{OH}$ complexes of $\mathbf{L 2}$. More detailed analyses of the structure and properties of these biological relevant imidazole amide metal complexes can be found below.

\section{B. Iron(III) Complex of L1 (35)}

The iron(III) compound $\left[\mathrm{Fe}(\mathbf{L 1}) \mathrm{Cl}_{2}\right]_{2}\left[\mathrm{Fe}_{2} \mathrm{OCl}_{6}\right]$ (35) was synthesized by mixing equimolar quantities of anhydrous $\mathrm{FeCl}_{3}$ and $\mathbf{L 1}$ in ethanol. Compound 35 was prepared by layering the reaction mixture with ether. After several days, flat plate- and blockshaped orange crystals were isolated. The plate-shaped crystals $(\sim 40 \%$ yield) rapidly lose solvent molecules of crystallization at room temperature. In general, these crystals were found to be unsuitable for X-ray crystallographic analysis because of their poor diffraction quality. However, electrospray ionization mass spectrometric analysis (ESI) of 
the crystals showed an $\mathrm{m} / \mathrm{z} 524.1\left[\mathrm{M}^{+}\right]$ion signal supporting the formation of the $\left[\mathrm{Fe}(\mathbf{L 1}) \mathrm{Cl}_{2}\right]^{+}$cation. The block-shaped crystals $(\sim 20 \%$ isolated yield $)$ on the other hand, were found to be very stable at room temperature and of high quality for X-ray diffraction analysis. The counter ion of $\mathbf{3 5}$ is the well known $\left[\mathrm{Fe}_{2} \mathrm{OCl}_{6}\right]^{2-}$ ion formed presumably from the hydrolysis of residual $\mathrm{FeCl}_{3}$ present in the reaction solution (Armstrong, W. H. \& Lippard, S. J., 1985; Haselhorst, G. et al., 1993).

The coordination environment of the cationic portion of $\mathbf{3 5}$ ion is shown in Figure 28 , and the crystal structure reveals that the iron atom has a distorted octahedral geometry and is coordinated to the four nitrogen atoms of $\mathbf{L} \mathbf{1}$ and to two chlorine atoms.

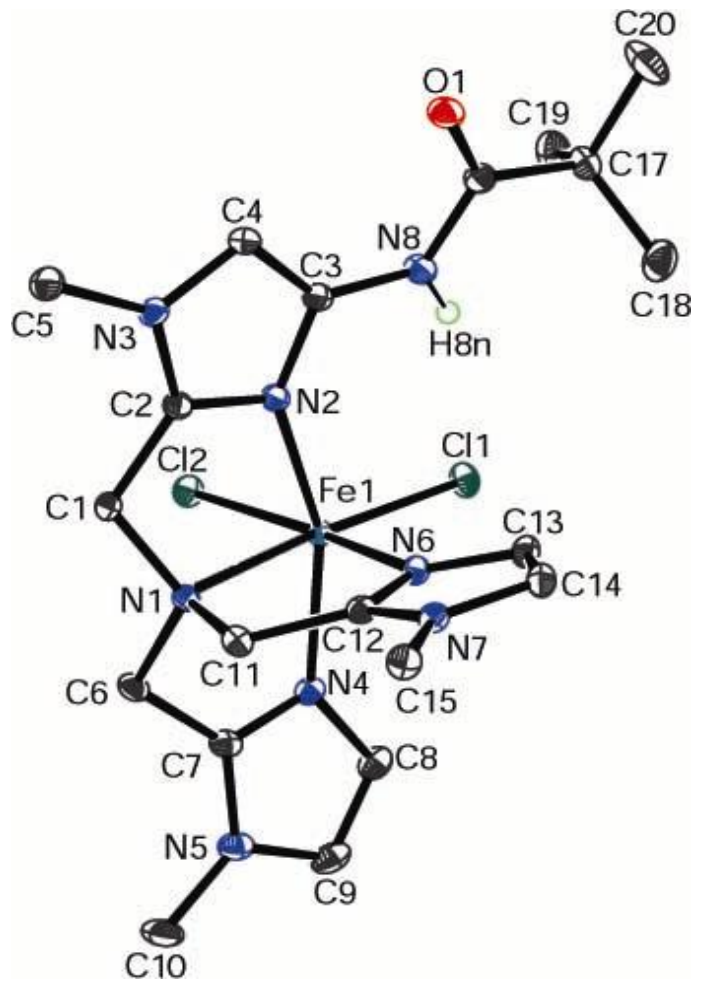

Figure 28. ORTEP view of the cationic portion of compound 35. Ellipsoids are drawn at $40 \%$ probability level. 
The $\mathrm{Fe}-\mathrm{Cl}$ bonds $(\mathrm{Fe}-\mathrm{Cl}(1) 2.2511(7), \mathrm{Fe}-\mathrm{Cl}(2) 2.3114(7) \AA)$ are similar to the bonds in [Fe(tmima) $\left.\mathrm{Cl}_{2}\right]^{+}$and other $\mathrm{Fe}(\mathrm{III})-$ imidazole complexes (Buchanan, R. M. et al., 1993; Buchanan, R. M. et al., 1994). The longest Fe-N distance (Fe-N(1) 2.323(2) $\AA)$ is associated with the tertiary amine nitrogen atom, and the remaining $\mathrm{Fe}-\mathrm{N}(\mathrm{Im})$ distances average $2.099 \AA$. Close inspection of the distances and angles of $\left[\mathrm{Fe}(\mathbf{L} \mathbf{1}) \mathrm{Cl}_{2}\right]^{+}$compared to $\left[\mathrm{Fe}(\mathrm{tmima}) \mathrm{Cl}_{2}\right]^{+}$reveals that they are remarkably similar despite the presence of the bulky tert-butylamide group of $\mathbf{L 1}$ (see Table 11).

Table 11. Bond distances and angles of iron(III) complexes of tmima and L1.

\begin{tabular}{ccc}
\hline & $\mathrm{Fe}\left(\mathrm{tmima}_{2}\right)$ & $\mathrm{Fe}(\mathbf{L} 1) \mathrm{Cl}_{2}$ \\
\hline Distance $(\AA)$ & & \\
Fe-Cl1 & $2.233(1)$ & $2.2511(7)$ \\
$\mathrm{Fe}-\mathrm{Cl} 2$ & $2.331(1)$ & $2.3114(7)$ \\
$\mathrm{Fe}-\mathrm{N} 1$ & $2.380(3)$ & $2.323(2)$ \\
$\mathrm{Fe}-\mathrm{N} 2$ & $2.076(4)$ & $2.114(2)$ \\
$\mathrm{Fe}-\mathrm{N} 4$ & $2.074(4)$ & $2.075(2)$ \\
Fe-N6 & $2.104(3)$ & $2.107(2)$ \\
& & \\
Angle $\left({ }^{\circ}\right)$ & & \\
C11-Fe-C12 & $99.55(5)$ & $100.01(3)$ \\
C11-Fe-N1 & $166.40(9)$ & $169.79(5)$ \\
C11-Fe-N2 & $108.68(12)$ & $103.88(6)$ \\
C11-Fe-N4 & $102.86(11)$ & $104.08(6)$ \\
C11-Fe-N6 & $90.92(10)$ & $92.85(6)$ \\
C12-Fe-N1 & $93.66(9)$ & $90.19(5)$ \\
C12-Fe-N2 & $87.35(11)$ & $89.18(5)$ \\
C12-Fe-N4 & $89.21(10)$ & $93.10(6)$ \\
C12-Fe-N6 & $169.50(10)$ & $165.90(6)$ \\
N1-Fe-N2 & $74.97(14)$ & $75.58(7)$ \\
N1-Fe-N4 & $73.93(13)$ & $75.60(7)$ \\
N1-Fe-N6 & $75.93(12)$ & $76.96(7)$ \\
N2-Fe-N4 & $148.41(15)$ & $151.09(8)$ \\
N2-Fe-N6 & $88.57(14)$ & $82.10(7)$ \\
N4-Fe-N6 & $89.20(14)$ & $89.32(8)$ \\
\hline
\end{tabular}

The $\mathrm{Fe}-\mathrm{Cl}$ distances as well as the $\mathrm{Fe}-\mathrm{N}$ distances are very similar in both compounds and there are only minor differences in the $\mathrm{N}-\mathrm{Fe}-\mathrm{N}$ angles between the two 
high-spin Fe(III) complexes, further supporting the similarity of the L1 and tmima chelates. The complex anion of $\mathbf{3 5}$ is $\left[\mathrm{Fe}_{2} \mathrm{OCl}_{6}\right]^{2-}$ which has been reported to crystallize with a variety of cations (Armstrong, W. H. \& Lippard, S. J., 1985; Haselhorst, G. et al., 1993). $\left[\mathrm{Fe}_{2} \mathrm{OCl}_{6}\right]^{2-}$ contains a linear $\mathrm{Fe}-\mathrm{O}-\mathrm{Fe}$ bridge $(\mathrm{Fe}-\mathrm{O}$ 1.7643(4) $\AA)$ that has a crystallographically imposed inversion symmetry.

Compound 35 contains a tert-butylamide group attached to the 4-position of one of the $\mathbf{L 1}$ imidazole pendants. As a result, L1 should have the ability to form intramolecular hydrogen bonds to ligands coordinated cis to the amide pendant. In $\mathbf{3 5}$, the $\mathrm{N}(8)---\mathrm{Cl}(1)$ separation is 3.395(2) $\AA$ (H8n-Cl1 2.55(3) $\AA$ ) and the N8-H8n-Cl1 angle is $155(3)^{\circ}$, suggesting that there is a weak hydrogen bonding interaction between H8n and Cl1 similar to those reported for amide functionalized pyridine complexes (Harata, M. et al., 1998b). The resulting six-membered ring formed by the Fe1, Cl1, H8n, N8, C3 and $\mathrm{N} 2$ atoms is nearly planar (rms deviation of the atoms in the six-membered ring is 0.0577 $\AA$ ). Compound $\mathbf{3 5}$ has been further characterized by UV-vis spectroscopy as well as by cyclic voltammetry. The UV-vis spectrum of 35 in $\mathrm{CH}_{3} \mathrm{CN}$ is very similar to the spectrum observed for $\left[\mathrm{Fe}(\mathrm{tmima}) \mathrm{Cl}_{2}\right]^{+}$. Both display strong Cl-to-Fe(III) charge-transfer transitions at $313 \mathrm{~nm}\left(\varepsilon=4200 \mathrm{M}^{-1} \mathrm{~cm}^{-1}\right)$ for 35 compared to $367 \mathrm{~nm}\left(\varepsilon=4300 \mathrm{M}^{-1} \mathrm{~cm}^{-1}\right)$ for the tmima complex. This shift in the wavelength is indicative of an increase in the Clto-Fe charge-transfer energy of $56.2 \mathrm{~kJ} / \mathrm{mol}$ probably due to the hydrogen bonding between the amide $\mathrm{N}-\mathrm{H}$ and the coordinated $\mathrm{Cl}$ atom.

Cyclic voltammetry on 35 in $\mathrm{CH}_{3} \mathrm{CN} / 0.1 \mathrm{M}$ TBAP shows quasi-reversible redox behavior. The $\mathrm{E}_{1 / 2}$ values are $+0.25 \mathrm{~V}\left(\left[\mathrm{Fe}(\mathbf{L 1}) \mathrm{Cl}_{2}\right]^{+}\right)$and $+0.05 \mathrm{~V}\left(\left[\mathrm{Fe}_{2} \mathrm{OCl}_{6}\right]^{2-}\right)$ versus $\mathrm{Ag} / \mathrm{AgCl}\left(\mathrm{Fc} / \mathrm{Fc}^{+}=+0.44 \mathrm{~V}\right)$ compared to $+0.16 \mathrm{~V}$ for $\left[\mathrm{Fe}(\mathrm{tmima}) \mathrm{Cl}_{2}\right]^{+}$and $-0.095 \mathrm{~V}$ for 
[Fe(tpa) $\left.\mathrm{Cl}_{2}\right]^{+}$in $\mathrm{CH}_{3} \mathrm{CN}$ (Kojima, T. et al., 1993). The approximate $90 \mathrm{mV}$ shift in the redox potential of $\left[\mathrm{Fe}(\mathbf{L 1}) \mathrm{Cl}_{2}\right]^{+}$compared to $\left[\mathrm{Fe}(\mathrm{tmima}) \mathrm{Cl}_{2}\right]^{+}$is attributed to the electronwithdrawing nature of the amide group.

In summary, the structural comparison between the two cationic species $\left[\mathrm{Fe}(\mathbf{L} \mathbf{1}) \mathrm{Cl}_{2}\right]^{+}$and $\left[\mathrm{Fe}(\mathrm{tmima}) \mathrm{Cl}_{2}\right]^{+}$reveals no significant differences in the bond distances and angles around the iron centers. The major deviations associated with the introduction of the amide pendant in 35 compared to $\left[\mathrm{Fe}(\mathrm{tmima}) \mathrm{Cl}_{2}\right]^{+}$were a $54 \mathrm{~nm}$ shift in the Cl-to$\mathrm{Fe}(\mathrm{III})$ charge transfer transition and a $90 \mathrm{mV}$ shift in the $\mathrm{Fe}^{\mathrm{II}} / \mathrm{Fe}^{\mathrm{III}}$ redox couple attributed to the hydrogen bonding and electron-withdrawing properties of the amide pendant. The most noteworthy aspect of this study is that the amide pendant can form thermodynamically stable six-membered hydrogen bonded rings with cis-coordinated ligands.

With these results, we further evaluated the influence of the amide pendants of $\mathbf{L} 2$ and $\mathbf{L 3}$ and compared their properties to the tmima and related pyridine ligands. $[\mathrm{Cu}(\mathbf{L} 2) \mathrm{Cl}]^{+}(\mathbf{3 7})$ and $[\mathrm{Cu}(\mathbf{L 3}) \mathrm{Cl}]^{+}(\mathbf{3 8})$ were synthesized and fully characterized by $\mathrm{X}-$ ray crystallography, cyclic voltammetry and EPR spectroscopy. In addition, the hydrogen bonding properties of $\mathbf{L} 2$ were utilized to stabilize $[\mathrm{Cu}(\mathbf{L} 2) \mathrm{X}]^{+}$complexes with $\mathrm{X}^{-}=\mathrm{OH}^{-}$, $\mathrm{N}_{3}{ }^{-}$and $\mathrm{OOH}^{-}$(see Chapter VII, Sections D and E).

C. Synthesis, Structure and Properties of $\mathrm{Cu}(\mathrm{II})$ Complexes of $\mathbf{L 2}$

1. Synthesis and Characterization of the $\mathrm{Cu}(\mathrm{II})$ complexes of $\mathbf{L 2}$

a) $\quad \mathrm{Cu}(\mathbf{L} 2)\left(\mathrm{ClO}_{4}\right)_{2}$

To $0.24 \mathrm{~g}$ ( $0.47 \mathrm{mmol})$ of $\mathbf{L} \mathbf{2}$ in $2 \mathrm{~mL}$ of methanol was added dropwise $0.17 \mathrm{~g}(0.47$ mmol) of copper(II) perchlorate hexahydrate in $1 \mathrm{~mL}$ of methanol. The green solution 
was then layered with $10 \mathrm{~mL}$ of ether and stored at $-20{ }^{\circ} \mathrm{C}$. A green precipitate of $\mathrm{Cu}(\mathbf{L 2})\left(\mathrm{ClO}_{4}\right)_{2}$ (36) formed overnight (75 \% yield). The ESI-MS spectrum of $\mathbf{3 6}$ showed two positive ions with peak clusters at $\mathrm{m} / \mathrm{z} 559.3\left([\mathrm{Cu}(\mathbf{L} 2-\mathrm{H})]^{+}\right)$and $\mathrm{m} / \mathrm{z} 659.3$ $\left(\left[\mathrm{Cu}(\mathbf{L 2}) \mathrm{ClO}_{4}\right]^{+}\right)$. The UV-vis spectrum of $\mathbf{3 6}$ displayed two transitions at $365 \mathrm{~nm}(\varepsilon=$ $\left.430 \mathrm{M}^{-1} \mathrm{~cm}^{-1}\right)$ and $765 \mathrm{~nm}\left(\varepsilon=100 \mathrm{M}^{-1} \mathrm{~cm}^{-1}\right)$.

b) $\quad[\mathrm{Cu}(\mathbf{L 2}) \mathrm{Cl}]^{+}(\mathbf{3 7})$

The $[\mathrm{Cu}(\mathbf{L 2}) \mathrm{Cl}]^{+}$complex was prepared by adding $100 \mu \mathrm{L}$ of saturated $\mathrm{NaCl}$ to a $8 \mathrm{mM}$ stock methanol solution $(2 \mathrm{~mL})$ of $\mathrm{Cu}(\mathbf{L 2})\left(\mathrm{ClO}_{4}\right)_{2}$. The green methanolic solution was then layered with ether and stored at $-20^{\circ} \mathrm{C}$. Large X-ray quality brown crystals $(4.5 \mathrm{mg})$ of $[\mathrm{Cu}(\mathbf{L 2}) \mathrm{Cl}]^{+}$(37) formed overnight (48\% yield). ESI-MS: m/z $596.4[\mathrm{Cu}(\mathbf{L 2}) \mathrm{Cl}]^{+} ; \mathrm{E}_{1 / 2}$ $=-200 \mathrm{mV}$ (versus $\mathrm{Ag} / \mathrm{AgCl})$.

c) $\quad[\mathrm{Cu}(\mathbf{L 3}) \mathrm{Cl}]^{+}(\mathbf{3 8})$

Following a similar procedure used for 36, a methanol solution $(1 \mathrm{~mL})$ of $0.06 \mathrm{~g}(0.35$ mmol) of copper chloride was added dropwise to $0.21 \mathrm{~g}(0.35 \mathrm{mmol})$ of $\mathbf{L 3}$ in $1 \mathrm{~mL}$ of methanol. Layering of the solution with ether yielded brown crystals of $[\mathrm{Cu}(\mathbf{L 3}) \mathrm{Cl}]^{+}(\mathbf{3 8})$ suitable for X-ray analysis (55\% yield). ESI-MS m/z $696.4[\mathrm{Cu}(\mathbf{L 3}) \mathrm{Cl}]^{+} ; \mathrm{E}_{1 / 2}=-87 \mathrm{mV}$ (versus $\mathrm{Ag} / \mathrm{AgCl})$.

\section{X-ray Crystal Structures of $\mathbf{3 7}$ and $\mathbf{3 8}$}

The crystal structures of $\mathbf{3 7}$ and $\mathbf{3 8}$ reveal that the coordination environments around the metal centers are best described as distorted trigonal bipyramidal with $\tau=0.94$ for both complexes with three imidazole nitrogen atoms in the equatorial plane and the tertiary amine nitrogen and chloride atoms occupying the apical positions (Figure 29). 
For the definition of $\tau$, see section III.4. The bond distances and angles in both $[\mathrm{Cu}(\mathbf{L 2}) \mathrm{Cl}]^{+}$and $[\mathrm{Cu}(\mathbf{L 3}) \mathrm{Cl}]^{+}$are normal and consistent with the $[\mathrm{Cu}(\mathrm{tmima}) \mathrm{Cl}]^{+}$analog (Chen, S. et al., 1994). However, there are slight differences in bond distances of the two complexes worth noting.

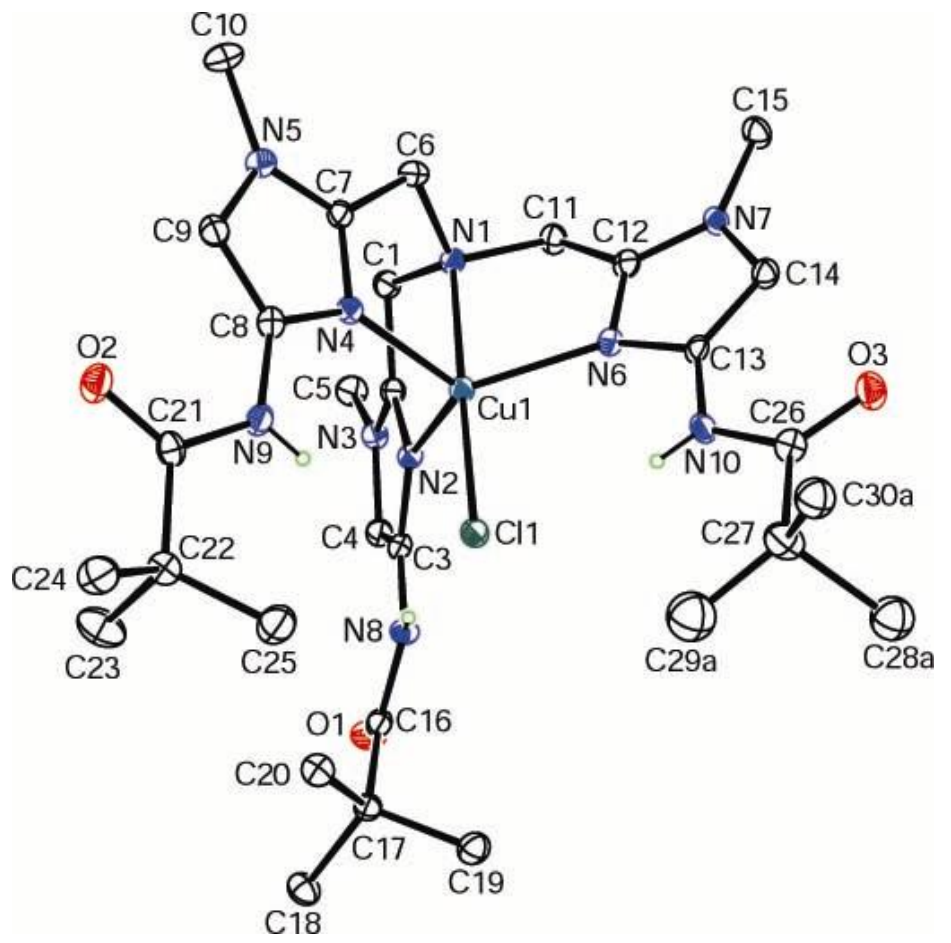

Figure 29. ORTEP view of the cationic portion of compound 38. Ellipsoids are drawn at $40 \%$ probability level. Methyl and methylene hydrogens have been omitted for clarity.

For example, the $\mathrm{Cu}-\mathrm{N} 1$ distances systematically shorten with the introduction of each amide pendant $(\mathbf{L} \mathbf{2} \rightarrow \mathbf{L 3})$ compared to tmima (Table 12). The strengthening of the $\mathrm{Cu}-\mathrm{N} 1$ bond is accompanied by the elongation of the trans $\mathrm{Cu}-\mathrm{Cl} 1$ distance $(\mathbf{L} 2 \rightarrow \mathbf{L 3})$ compared to $[\mathrm{Cu}(\mathrm{tmima}) \mathrm{Cl}]^{+}$. It appears $\mathrm{N} 1$ exerts a trans influence on the $\mathrm{Cu}-\mathrm{Cl}$ bond. For $[\mathrm{Cu}(\mathrm{tmima}) \mathrm{Cl}]^{+}$and $[\mathrm{Cu}(\mathbf{L} \mathbf{3}) \mathrm{Cl}]^{+}$, the $\mathrm{Cu}-\mathrm{N}($ imidazole) distances are reflective of an overall $\mathrm{C}_{3}$ symmetry associated with the complexes. Indeed, the $\mathrm{Cu}-\mathrm{N}$ (imidazole) distances are virtually identical in both complexes, while in the $[\mathrm{Cu}(\mathbf{L} 2) \mathrm{Cl}]^{+}$, the $\mathrm{Cu}-\mathrm{N}$ 
distances are significantly different with two distances of approximately $1.95 \AA$ and the third (Cu-N6) equal to $2.11 \AA$.

Table 12. Bond distances and angles for compounds $\mathbf{3 7}$ and $\mathbf{3 8}$ and other related $\mathrm{Cu}(\mathrm{II})-$ $\mathrm{Cl}$ complexes with tripodal pyridine ligands.

\begin{tabular}{ccccccc}
\hline & & & & $\mathrm{Cu}(\mathrm{tppa}) \mathrm{Cl}$ \\
$(\mathrm{a})$ & $\begin{array}{c}\mathrm{Cu}(\text { ebnpa)Cl } \\
(\mathrm{b})\end{array}$ & $\begin{array}{c}\mathrm{Cu}(\mathrm{pbnpa}) \mathrm{Cl} \\
(\mathrm{b})\end{array}$ \\
\hline Distance $(\AA)$ & & & & & & \\
$\mathrm{Cu}-\mathrm{N} 1$ & $2.167(3)$ & $2.140(4)$ & $2.109(5)$ & $1.955(5)$ & $2.0374(15)$ & $2.043(2)$ \\
$\mathrm{Cu}-\mathrm{N} 2$ & $2.062(3)$ & $1.963(4)$ & $2.052(5)$ & $2.138(5)$ & $2.1744(14)$ & $2.025(2)$ \\
$\mathrm{Cu}-\mathrm{N} 4$ & $2.021(4)$ & $1.945(4)$ & $2.051(5)$ & $2.313(5)$ & $2.0897(14)$ & $2.014(2)$ \\
$\mathrm{Cu}-\mathrm{N} 6$ & $2.011(2)$ & $2.106(4)$ & $2.053(5)$ & $2.149(6)$ & $\mathrm{N} / \mathrm{A}$ & $\mathrm{N} / \mathrm{A}$ \\
$\mathrm{Cu}-\mathrm{Cl} 1$ & $2.234(1)$ & $2.234(2)$ & $2.2813(17)$ & $2.206(2)$ & $2.2740(5)$ & $2.2548(8)$ \\
& & & & & & \\
Angle $\left(^{\circ}\right)$ & & & & & \\
N1-Cu-Cl1 & $177.9(1)$ & $177.99(14)$ & $178.70(16)$ & $174.88(15)$ & $171.75(4)$ & $149.82(7)$ \\
N1-Cu-N2 & $79.0(1)$ & $81.9(2)$ & $81.7(2)$ & $81.33(5)$ & $80.35(6)$ & $82.46(9)$ \\
N1-Cu-N4 & $80.1(2)$ & $80.5(2)$ & $81.3(2)$ & $77.62(5)$ & $81.12(6)$ & $82.78(9)$ \\
N1-Cu-N6 & $79.9(1)$ & $81.1(2)$ & $81.7(2)$ & $80.85(5)$ & N/A & N/A \\
N2-Cu-Cl1 & $99.6(1)$ & $98.0(2)$ & $99.58(15)$ & $100.96(14)$ & $105.84(4)$ & $98.26(7)$ \\
N2-Cu-N4 & $112.0(2)$ & $113.9(2)$ & $113.3(2)$ & $116.69(5)$ & $109.59(6)$ & $165.08(9)$ \\
N2-Cu-N6 & $116.9(1)$ & $132.4(2)$ & $121.3(2)$ & $123.75(5)$ & N/A & N/A \\
N4-Cu-Cl1 & $101.9(1)$ & $106.6(2)$ & $98.39(16)$ & $97.27(15)$ & $101.48(4)$ & $95.59(7)$ \\
N4-Cu-N6 & $121.6(1)$ & $97.8(2)$ & $119.0(2)$ & $110.66(5)$ & N/A & N/A \\
N6-Cu-Cl1 & $99.4(1)$ & $100.4(2)$ & $97.41(15)$ & $101.41(14)$ & N/A & N/A \\
\hline
\end{tabular}

(a) (Harata, M. et al., 1998b) ; (b) (Tubbs, K. J. et al., 2003b)

Interestingly, similar discrepancies in bond distances are also observed in two related pyridine complexes (Table 12). Globally, the $\mathrm{Cu}-\mathrm{N}$ (ring) distances are usually longer in pyridine compounds (weaker $\sigma$ and $\pi$ donors) compared to imidazole compounds (Chen, S. et al., 1994). Differences in the strength of the pyridine versus imidazole binding may contribute to the $0.1 \AA$ elongation of the $\mathrm{Cu}-\mathrm{N} 1$ distances in imidazole tripods compared to pyridine analogs.

The differences between the imidazole and pyridine complexes are also reflected in the structure of the complexes (Figure 30). Indeed, one of the pyridine rings is severely 
twisted in the $[\mathrm{Cu}(\mathrm{tppa}) \mathrm{Cl}]^{+}$complex. For the imidazole analogs, the ligands $\mathbf{L 2}$ and $\mathbf{L 3}$ are less twisted and $\mathbf{L} \mathbf{3}$ maintains its pseudo $\mathrm{C}_{3}$ symmetry upon complexation.
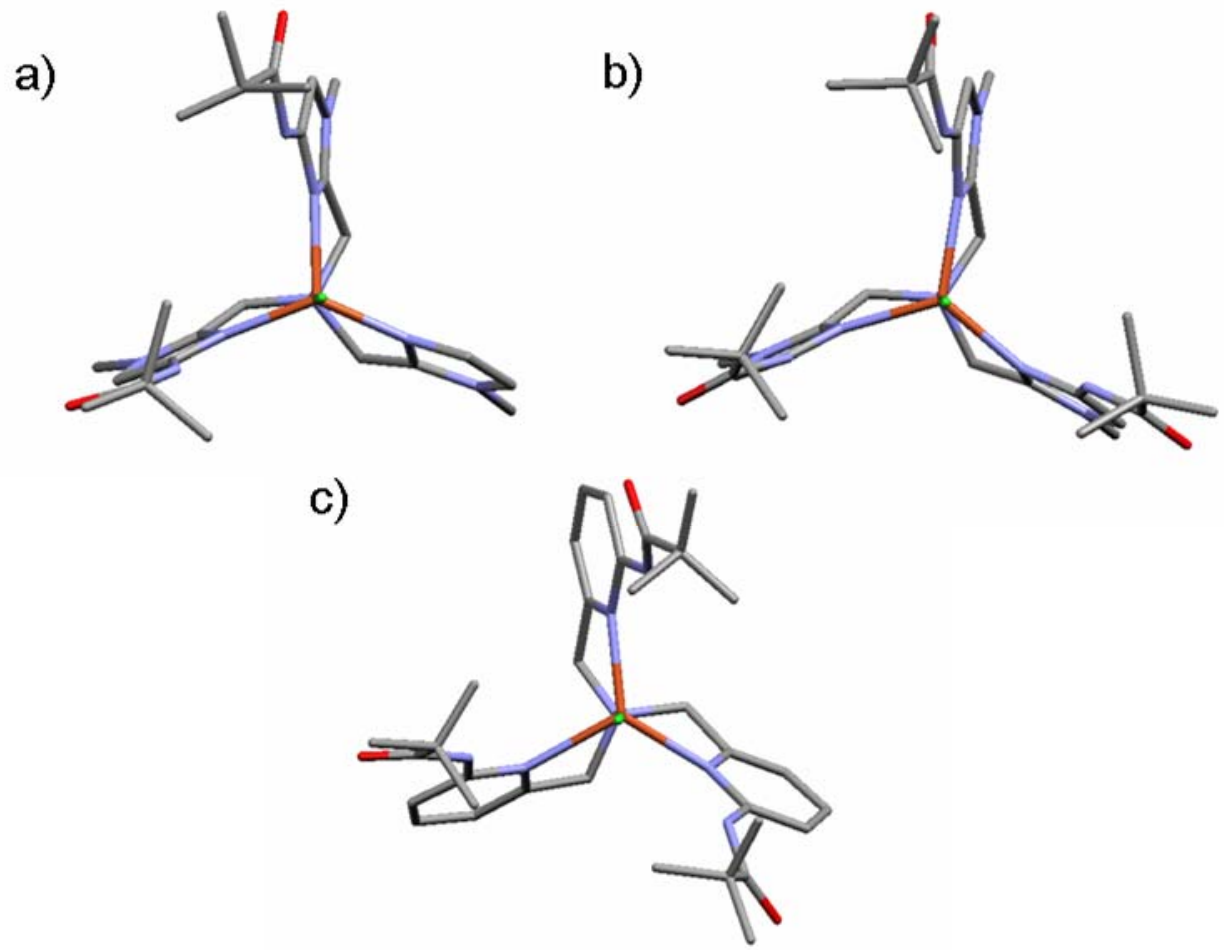

Figure 30. Capped-stick top-view representations of $[\mathrm{Cu}(\mathbf{L 2}) \mathrm{Cl}]^{+}$(a), $[\mathrm{Cu}(\mathbf{L 3}) \mathrm{Cl}]^{+}$(b) and $[\mathrm{Cu}(\mathrm{tppa}) \mathrm{Cl}]^{+}(\mathrm{c})$.

As a result of the differences between the $\mathrm{Cu}-\mathrm{N}(\mathrm{Py}), \mathrm{Cu}-\mathrm{N}(\mathrm{Im})$ and $\mathrm{Cu}-\mathrm{N}($ tert $)$ distances, the hydrogen bonding interaction between the $\mathrm{N}$ (amide) hydrogen and apically coordinated $\mathrm{Cl}$ ligand are stronger in the pyridine complexes (with larger twist angles) than in the imidazole complexes of $\mathbf{L 2}$ and $\mathbf{L 3}$. The twisting of the pyridine ligands optimized the hydrogen bondings. The average $\mathrm{N}$ (amide)---Cl separation is $2.78 \AA$ in $[\mathrm{Cu}(\text { tppa }) \mathrm{Cl}]^{+}$and $3.27 \AA$ and $3.29 \AA$ in $[\mathrm{Cu}(\mathbf{L 2}) \mathrm{Cl}]^{+}(\mathbf{3 7})$ and $[\mathrm{Cu}(\mathbf{L 3}) \mathrm{Cl}]^{+}(\mathbf{3 8})$, respectively. The slight difference in $\mathrm{N}$ (amide)---Cl separation in compound $\mathbf{3 8}$ compared to 37 can be attributed to steric hindrance of the third neighboring tert-butyl 
group of 38. The presence of three tert-butyl groups in $\mathbf{3 8}$ having near $\mathrm{C}_{3}$ symmetry increases contact distances between the amide hydrogens and the chlorine atom.

Cyclic voltammetric measurements were performed on compounds $\mathbf{3 7}$ and $\mathbf{3 8}$ in $\mathrm{CH}_{3} \mathrm{CN}$ /TBAP $(0.1 \mathrm{M})$ under inert atmosphere. Both compounds display single quasireversible one-electron redox behavior in acetonitrile. The $\mathrm{E}_{1 / 2}$ values of both complexes are -200 and $-87 \mathrm{mV}$ versus $\mathrm{Ag} / \mathrm{AgCl}\left(\mathrm{E}_{1 / 2}(\right.$ ferrocene/ferrocenium $\left.)=+0.36 \mathrm{mV}\right)$ for $\mathbf{3 7}$ and 38, respectively. The shift observed between the $E_{1 / 2}$ of the two complexes is consistent with the cathodic shift observed for the $\left[\mathrm{Fe}(\mathbf{L} \mathbf{1}) \mathrm{Cl}_{2}\right]^{+}$. However, the $\mathrm{E}_{1 / 2}$ value of $-0.165 \mathrm{~V}$ for the $[\mathrm{Cu}(\mathrm{tmima}) \mathrm{Cl}]^{+}$is in between the $\mathrm{E}_{1 / 2}$ values for $\mathbf{3 7}$ and $\mathbf{3 8}$. Interestingly, a similar trend has been observed in $\mathrm{Cu}(\mathrm{II})$-azido pyridine complexes with amine group (Wada, A. et al., 2004). It should be noted that there is more than a $400 \mathrm{mV}$ difference in the $\mathrm{E}_{1 / 2}$ value of $\mathbf{3 8}$ compared to its pyridine analog.

\section{3. $\quad$ EPR Characterization of Compounds $\mathbf{3 7}$ and $\mathbf{3 8}$}

To establish if the coordination environments observed in the crystal structures of the $\mathrm{Cu}$ (II) complexes are maintained in solution, the EPR spectra of $\mathbf{3 7}$ and $\mathbf{3 8}$ were recorded at $77 \mathrm{~K}$ as frozen solution and are shown in Figure 31 along with their respective simulated spectra. The EPR spectra are rhombic, indicative of distortion of five-coordinate geometries between square pyramidal and trigonal bipyramidal, as established recently by Garribba and coworkers (Garribba, E. et al., 2000). The magnetic parameters obtained from computer simulation are summarized in Table 15. The calculated $\mathrm{R}$ values ( 0.04 for $\mathbf{3 7}$ and 0.15 for $\mathbf{3 8}$ ) imply that both complexes have a geometry closer to square pyramidal in solution and a $\mathrm{d}_{\mathrm{x}-\mathrm{y}}^{2}{ }^{2}$ ground state. 

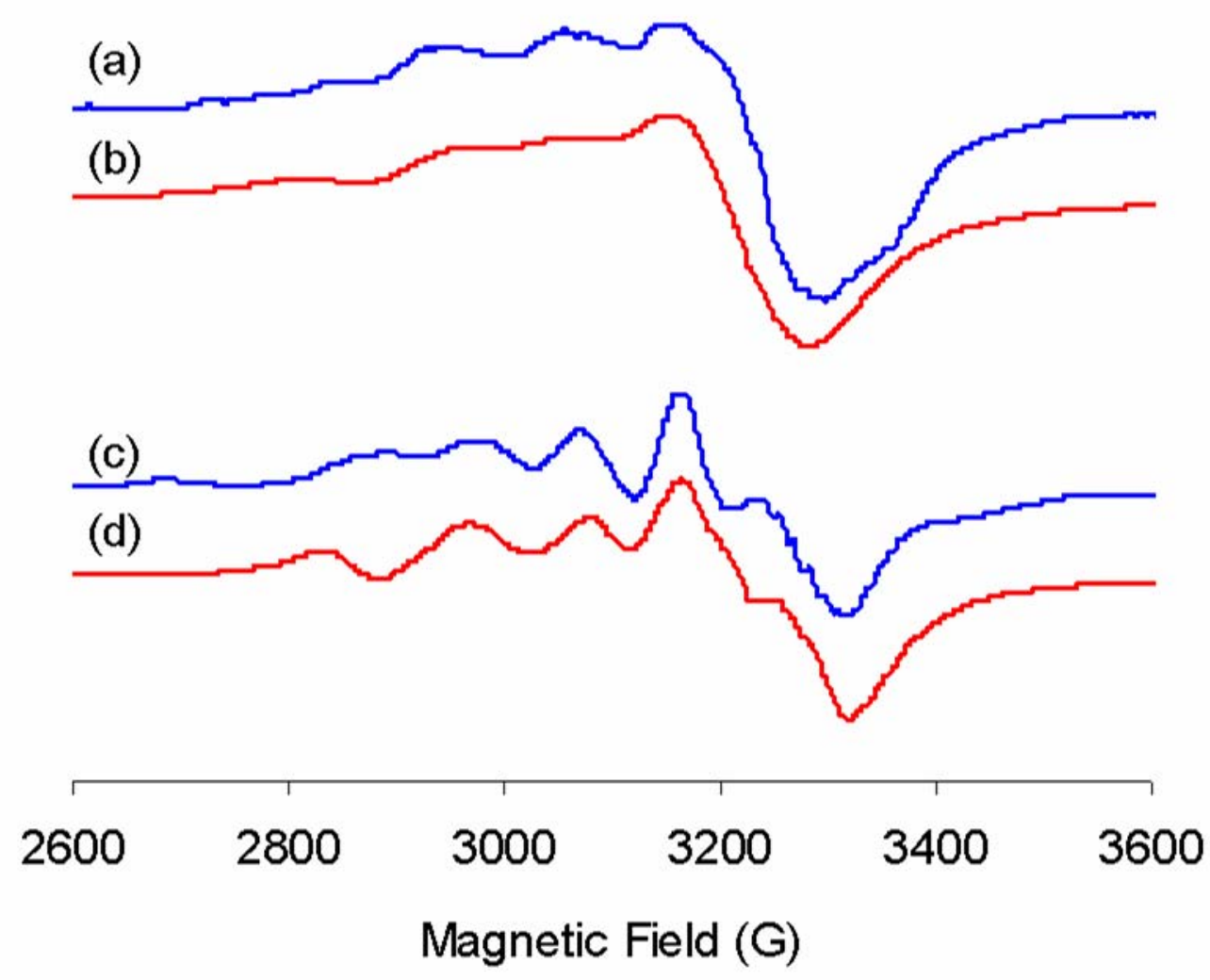

Figure 31. EPR spectra of frozen acetonitrile solutions of $\mathbf{3 7}$ and $\mathbf{3 8}$ (frequency 9.461 $\mathrm{GHz}$, power $5 \mathrm{~mW}$, modulation amplitude $10.00 \mathrm{G}$, temperature $77 \mathrm{~K}$ ).

In summary, for $\mathbf{L} \mathbf{2} \rightarrow \mathbf{L 3}$, the imidazole ring nitrogens were found to bond more strongly to $\mathrm{Cu}(\mathrm{II})$ than in the related pyridine analogs. Also, the $\mathrm{Cu}-\mathrm{N}$ (tertiary) distances of $\mathbf{L 2} \rightarrow \mathbf{L 3}$ are longer compared to their pyridine analogs. These differences can potentially result in different reactivities of the metal complexes. The additions of amide pendants do not significantly alter the coordination environment around the $\mathrm{Cu}$ atoms, but are associated with a shift of the $\mathrm{Cu}(\mathrm{I}) / \mathrm{Cu}(\mathrm{II})$ redox potentials in a manner consistent with the shift in the $\mathrm{Fe}^{\mathrm{II}} / \mathrm{Fe}^{\mathrm{III}}$ redox potential observed in the $\mathrm{Fe}$ (III) complexes of tmima and L1 (see Section B of this Chapter). 


\section{Synthesis and Characterization of $[\mathrm{Cu}(\mathbf{L} 2) \mathrm{OH}] \mathrm{ClO}_{4}(\mathbf{3 9})$}

The two $[\mathrm{Cu}(\mathbf{L 2}) \mathrm{OH}]^{+}(\mathbf{3 9})$ and $\left[\mathrm{Cu}(\mathbf{L 2}) \mathrm{N}_{3}\right]^{+}(\mathbf{4 0})$ complexes are part of the reactivity study of compound $\mathbf{3 6}$ with hydrogen peroxide (see Chapter VII). In fact, compound 39 is a proposed intermediate in the formation of the mononuclear $\mathrm{Cu}-\mathrm{OOH}$ species, and the azide anion in $\mathbf{4 0}$ has been used as a structural model of the hydroperoxo anion. There are only a few mononuclear $\mathrm{Cu}(\mathrm{II})$ hydroxide species that have been characterized crystallographically (Tubbs, K. J. et al., 2003a). This is because these compounds have a tendency to dimerize forming the $\mu-\mathrm{Cu}_{2}(\mathrm{OH})_{2}$ unit. In this study, we utilized the steric hindrance of the tert-butyl groups of the amide pendants of $\mathbf{L 2}$, as well as their hydrogen bonding ability to stabilize a mononuclear $\mathrm{Cu}(\mathrm{II})-\mathrm{OH}$ complex, $\mathbf{3 9}$.

\section{Compound 39}

Compound 39 was prepared as follows: to the $8 \mathrm{mM}$ stock methanolic solution $(2 \mathrm{~mL})$ of compound $\mathbf{3 6}$ was added $2.3 \mu \mathrm{L}(0.03 \mathrm{mmol})$ of triethylamine. Slow evaporation of the methanol yielded green X-ray quality plates (58 \% yield). The UV-vis spectrum of $\mathbf{3 9}$ display two transitions at $315 \mathrm{~nm}\left(\varepsilon=1390 \mathrm{M}^{-1} \mathrm{~cm}^{-1}\right)$ and $800 \mathrm{~nm}\left(\varepsilon=40 \mathrm{M}^{-1} \mathrm{~cm}^{-1}\right)$.

Compound 39 crystallizes in the monoclinic space group $\mathrm{P} 2{ }_{1} / \mathrm{n}$ with two independent molecules and two perchlorate anions per asymmetric unit. The crystal structure reveals a trigonal bipyramidal arrangement around the copper atom $(\tau=0.85$, see section III.4 for the definition of $\tau$ ) with the three imidazole nitrogens in the plane and the tertiary amine nitrogen and the hydroxide oxygen in apical positions (Figure 32). The $\mathrm{Cu}-\mathrm{N}(\mathrm{Im})$ distances are normal and consistent with other reported $\mathrm{Cu}-\mathrm{N}(\mathrm{Im})$ distances

(Chen, S. et al., 1994). The average $\mathrm{Cu}-\mathrm{N}(\mathrm{Im})$ distance is $0.1 \AA$ shorter than the distances of the pyridine analogs (Table 13). Data summarized in Table 13 includes other reported 
$\mathrm{Cu}-\mathrm{OH}$ complexes with ligands having pendant groups able to hydrogen bond with the $\mathrm{OH}$ group bonded to the metal. Hbppa is the pyridine analog of $\mathbf{L 2}$ and pbnpa is N-2phenylthio-ethyl-N,N-bis((6-neopentyl-amino-2-pyridyl)methyl) amine. The sulfur atom of ebnpa is derivatized with an ethyl chain instead of the phenyl ring in pbnpa. Again, the distance between the tertiary nitrogen and the copper is longer in compound $39(\mathrm{Cu}-\mathrm{N} 1$ distance of $2.189 \AA$ ) compared to the pyridine analogs.

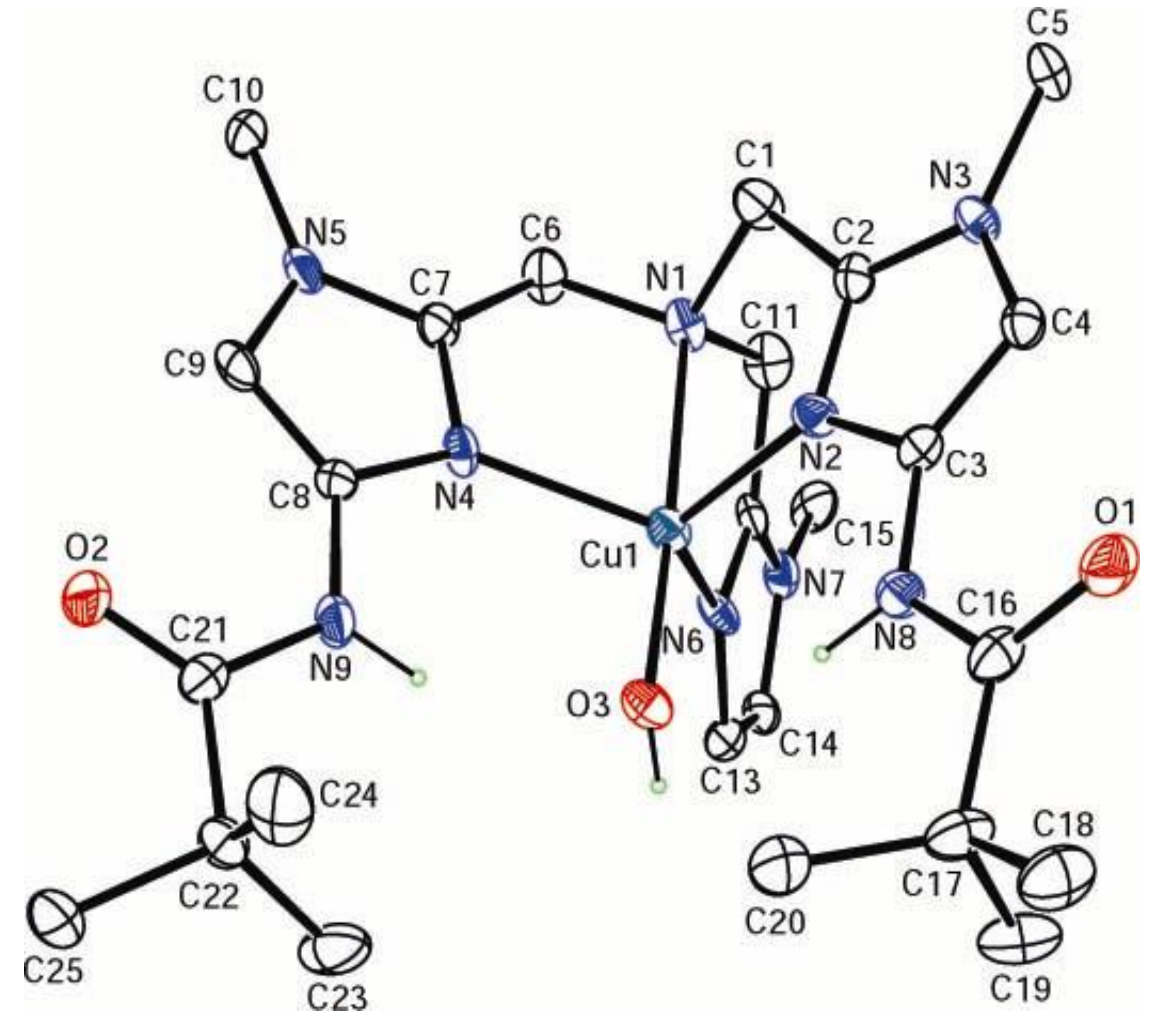

Figure 32. ORTEP view of the cationic portion of compound 39. Ellipsoids are drawn at $40 \%$ probability level. Methyl and methylene hydrogens have been omitted for clarity.

This observation is in agreement with the previous analysis between tmima and the related pyridine ligand, tpa. Interestingly, the $\mathrm{Cu}-\mathrm{OH}$ distance of 1.924(5) $\AA$ for 39 is still longer than those of other complexes (see Table 13). The trans influence of the tertiary amine should be less pronounced in $\mathbf{3 9}$ because the $\mathrm{Cu}-\mathrm{N} 1$ distance is longer than in the related pyridine complexes. In addition, the N1-Cu-O3 angle is only $173.1(2)^{\circ}$ and 
more acute than in the pyridine complexes, where the angles are closer to $180^{\circ}$. In 39 , the two amide groups of $\mathbf{L} \mathbf{2}$ are strongly interacting with the hydroxyl oxygen, O3, with average N---O separation of $2.875 \AA$ and N-H---O angle of $153.0^{\circ}$, which differ from those of the pyridine analogs (average N---O separation of $2.72 \AA$ and N-H---O angle of $\left.160^{\circ}\right)$

Table 13. Selected bond distances and angles for compound 39 and other related $\mathrm{Cu}-\mathrm{OH}$ complexes.

\begin{tabular}{|c|c|c|c|c|}
\hline & $\mathrm{Cu}(\mathbf{L} \mathbf{2}) \mathrm{OH}$ & $\mathrm{Cu}(\mathrm{Hbppa}) \mathrm{OH}(\mathrm{a})$ & $\mathrm{Cu}($ ebnpa $) \mathrm{OH}(\mathrm{b})$ & $\mathrm{Cu}($ pbnpa)OH (b) \\
\hline \multicolumn{5}{|l|}{ Distance $(\AA)$} \\
\hline $\mathrm{Cu}-\mathrm{O} 3$ & $1.924(5)$ & $1.849(5)$ & $1.8873(14)$ & $1.9038(11)$ \\
\hline $\mathrm{Cu}-\mathrm{N} 1$ & $2.189(6)$ & $1.973(6)$ & $2.0489(16)$ & $2.0469(13)$ \\
\hline $\mathrm{Cu}-\mathrm{N} 2$ & $1.990(6)$ & $2.193(5)$ & $2.1242(15)$ & $2.0357(13)$ \\
\hline $\mathrm{Cu}-\mathrm{N} 4$ & $2.032(6)$ & $2.086(6)$ & $2.0840(15)$ & $2.0449(13)$ \\
\hline $\mathrm{Cu}-\mathrm{N} 6$ & $1.985(6)$ & $2.166(6)$ & N/A & N/A \\
\hline \multicolumn{5}{|l|}{ Angle $\left(^{\circ}\right)$} \\
\hline $\mathrm{N} 1-\mathrm{Cu}-\mathrm{N} 2$ & $80.1(2)$ & $79.1(2)$ & $80.61(6)$ & $83.34(5)$ \\
\hline $\mathrm{N} 1-\mathrm{Cu}-\mathrm{N} 4$ & $79.6(3)$ & $98.0(2)$ & $82.85(6)$ & $81.12(5)$ \\
\hline $\mathrm{N} 1-\mathrm{Cu}-\mathrm{N} 6$ & $80.7(2)$ & $81.5(3)$ & $\mathrm{N} / \mathrm{A}$ & $\mathrm{N} / \mathrm{A}$ \\
\hline $\mathrm{N} 1-\mathrm{Cu}-\mathrm{O} 3$ & $173.1(2)$ & $177.4(3)$ & $177.18(7)$ & $176.41(5)$ \\
\hline $\mathrm{N} 2-\mathrm{Cu}-\mathrm{N} 4$ & $113.4(2)$ & $130.7(2)$ & $122.67(6)$ & $164.43(5)$ \\
\hline $\mathrm{N} 2-\mathrm{Cu}-\mathrm{N} 6$ & $122.6(4)$ & $113.6(2)$ & $\mathrm{N} / \mathrm{A}$ & N/A \\
\hline $\mathrm{N} 2-\mathrm{Cu}-\mathrm{O} 3$ & $96.0(2)$ & $101.1(2)$ & $96.75(6)$ & $98.43(5)$ \\
\hline N4-Cu-N6 & $115.4(2)$ & $108.9(2)$ & $\mathrm{N} / \mathrm{A}$ & N/A \\
\hline $\mathrm{N} 4-\mathrm{Cu}-\mathrm{O} 3$ & $97.0(2)$ & $98.0(2)$ & $98.83(6)$ & $97.03(5)$ \\
\hline N6-Cu-O3 & $106.2(0)$ & $96.0(2)$ & $\mathrm{N} / \mathrm{A}$ & $\mathrm{N} / \mathrm{A}$ \\
\hline
\end{tabular}

(a) (Harata, M. et al., 1998b); (b) (Tubbs, K. J. et al., 2003a)

In compound 39, the hydroxyl hydrogen is hydrogen bonded to the carbonyl oxygen of an amide pendant from the second complex of the asymmetric unit (O3---O5 separation of $3.186 \AA$ and $\mathrm{O} 3-\mathrm{H} 3 \mathrm{O}---\mathrm{O} 5$ angle of $158.24^{\circ}$ ).

EPR spectroscopy has been used to evaluate the coordination environment around the $\mathrm{Cu}$ center of compound $\mathbf{3 9}$ in frozen solution. As for compounds $\mathbf{3 7}$ and $\mathbf{3 8}$, the EPR 
spectrum of $\mathbf{3 9}$ is rhombic indicative of a distorted geometry between square pyramidal and trigonal bipyramidal (Figure 33). The magnetic parameters for the rhombic spectra were determined through computer simulation: $\mathrm{g}_{3}=2.23, \mathrm{~g}_{2}=2.04, \mathrm{~g}_{1}=2.002$ and $\mathrm{A}_{3}=$ $100, A_{2}=60, A_{1}=40$. An $R$ value of 0.2 implies a $d_{x^{2}-y^{2}}$ ground state and a geometry around the $\mathrm{Cu}(\mathrm{II})$ closer to square pyramidal in solution.

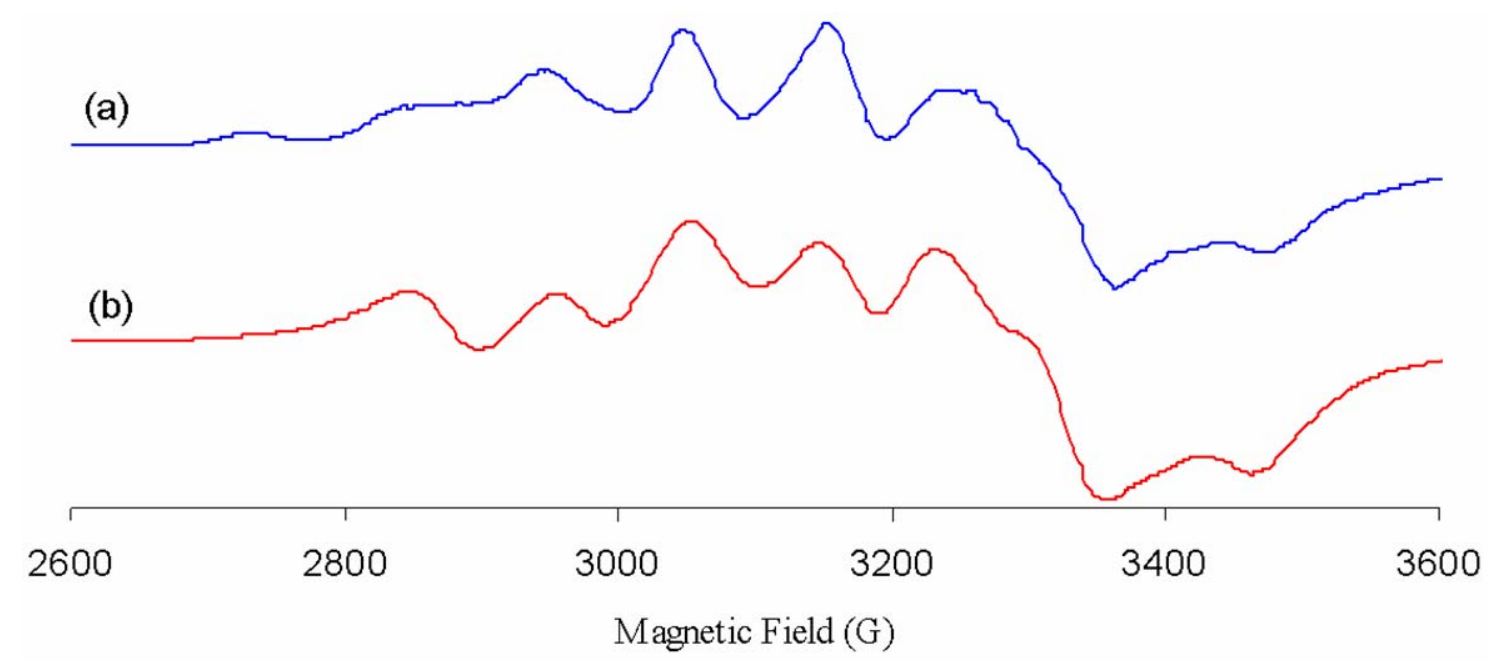

Figure 33. Experimental (a) and simulated (b) X-band EPR spectra of a frozen methanolic solution of $\mathbf{3 9}$.

The $\mathrm{Cu}-\mathrm{OH}$ species was also characterized by ESI mass spectrometry. The ESIMS spectrum of 39 in water showed only one positive ion with peak cluster at $\mathrm{m} / \mathrm{z} 577.3$, consistent with the proposed structure. But for a methanolic solution of 39, the only cationic species detected by ESI-MS was consistent with a methoxide anion bonded to the copper $\left(\mathrm{MS} \mathrm{m} / \mathrm{z} 591.3[\mathrm{Cu}(\mathbf{L} 2) \mathrm{OMe}]^{+}\right.$) (Figure 34). The $[\mathrm{Cu}(\mathbf{L} 2) \mathrm{OMe}]^{+}$species results from a ligand exchange reaction between a molecule of $\mathrm{MeOH}$ and the bound hydroxide. This reaction probably occurs during the electrospray ionization. Attempts to isolate the $[\mathrm{Cu}(\mathbf{L} 2) \mathrm{OMe}]^{+}$using different bases (Tubbs, K. J. et al., 2003a) are currently in progress. 


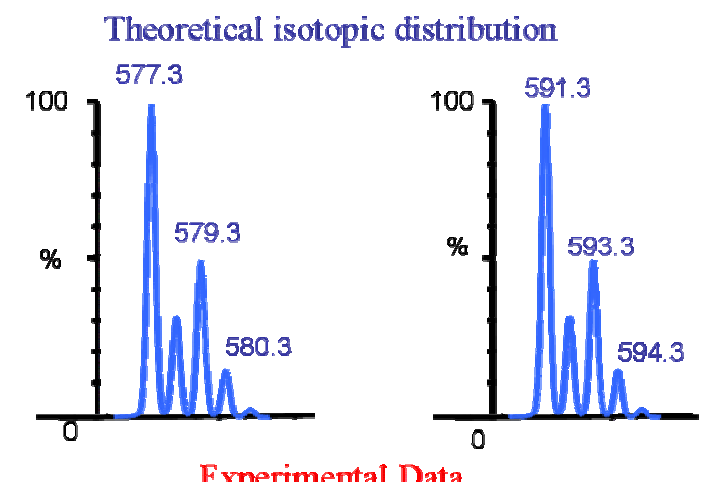

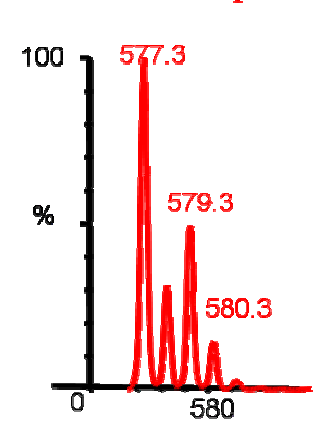

(a)

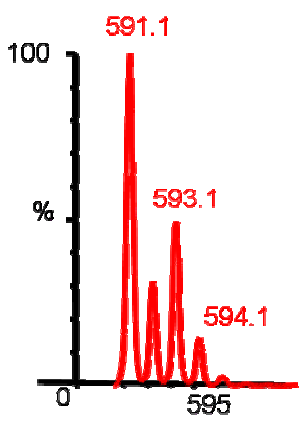

(b)

Figure 34. Theoretical and experimental isotopic distribution obtained from ESI-MS experiment for $\mathrm{m} / \mathrm{z}$ of (a) $[\mathrm{Cu}(\mathbf{L 2}) \mathrm{OH}]^{+}$and (b) $[\mathrm{Cu}(\mathbf{L} 2) \mathrm{OMe}]^{+}$.

In summary, the structure of $\mathbf{3 9}$ confirms the ability of $\mathbf{L} \mathbf{2}$ to form strong hydrogen bonds to acceptor atoms, such as oxygen, coordinated to $\mathrm{Cu}(\mathrm{II})$. In addition, the presence of the tert-butyl group prevents the thermodynamically favored dimerization of the $\mathrm{Cu}-\mathrm{OH}$ species.

E. Synthesis and Characterization of $\left[\mathrm{Cu}(\mathbf{L 2}) \mathrm{N}_{3}\right] \mathrm{ClO}_{4}(\mathbf{4 0})$

The characterization of an azido copper complex was important in the hydroperoxide study to evaluate the ability of the ligand to accept and stabilize the hydroperoxide anion. The azide ion has been used as a structural model for the hydroperoxide ion (see Chapter VII) (Solomon, E. I. et al., 1992). 


\section{Compound 40}

Compound 40 was prepared as follows: to the $8 \mathrm{mM}$ stock methanolic solution $(2 \mathrm{~mL})$ of 36 was added $10 \mathrm{mg}(0.2 \mathrm{mmol})$ of sodium azide in $0.5 \mathrm{~mL}$ of water. Layering of the solution with ether yielded dark green crystals (74 \% yield) suitable for X-ray analysis. The UV-vis spectrum of $\mathbf{4 0}$ display two transitions at $382 \mathrm{~nm}\left(\varepsilon=450 \mathrm{M}^{-1} \mathrm{~cm}^{-1}\right)$ and 700 $\mathrm{nm}\left(\varepsilon=50 \mathrm{M}^{-1} \mathrm{~cm}^{-1}\right)$. Its electrochemical behavior in acetonitrile $(0.1 \mathrm{M}$ TBAP $)$ is irreversible and different from the reversible one-electron process observed for the series of $\mathrm{Cu}$ (II)-azido complexes with pyridine ligands (Wada, A. et al., 2004).

The crystal structure of $\mathbf{4 0}$ reveals that the coordination environment around the metal is distorted trigonal bipyramidal $(\tau=0.70$, see III.4 for the definition of $\tau$ ) with the imidazole nitrogens in the plane and the tertiary amine N1 and azido N10 nitrogen atoms occupying apical positions (Figure 35).

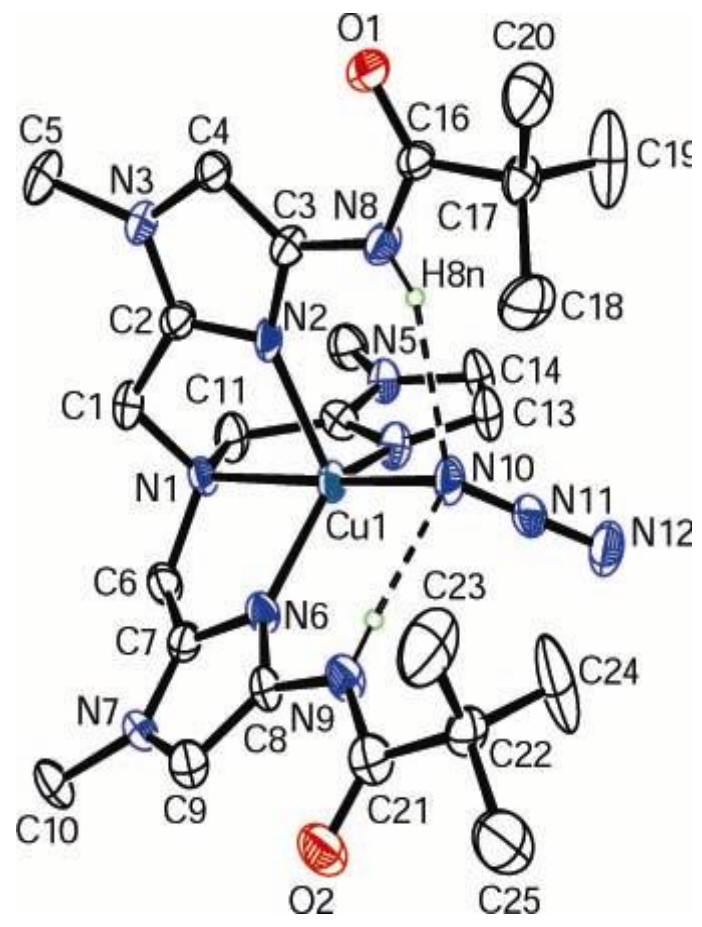

Figure 35. ORTEP view of the cationic portion of 40. Ellipsoids are drawn at $40 \%$ probability level. Methyl and methylene hydrogens have been omitted for clarity. 
All distances and angles associated with the L2 ligand are normal and similar to previously reported imidazole compounds.
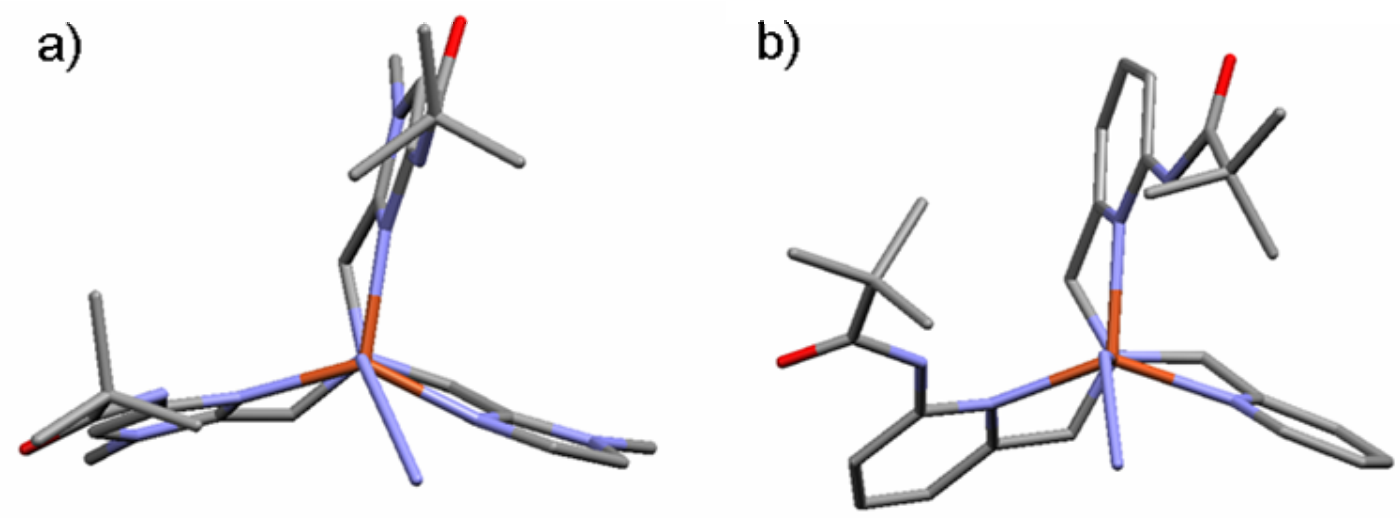

Figure 36. Top-view of capped-stick representations of $\left[\mathrm{Cu}(\mathbf{L 2}) \mathrm{N}_{3}\right]^{+}$and $\left[\mathrm{Cu}(\mathrm{Hbppa}) \mathrm{N}_{3}\right]^{+}$ indicating the twisting of the rings in the latter compound.

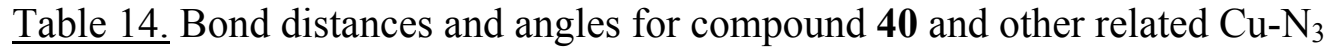
complexes.

\begin{tabular}{|c|c|c|c|}
\hline & {$\left[\mathrm{Cu}(\mathbf{L 2}) \mathrm{N}_{3}\right]^{+}$} & {$\left[\mathrm{Cu}(\mathrm{Hbppa}) \mathrm{N}_{3}\right]^{+}$(a) } & {$\left[\mathrm{Cu}(\mathrm{ebnpa}) \mathrm{N}_{3}\right]^{+}(\mathrm{b})$} \\
\hline \multicolumn{4}{|l|}{ Distance $(\AA)$} \\
\hline $\mathrm{Cu}-\mathrm{N} 1$ & $2.169(4)$ & $1.986(7)$ & $2.0214(18)$ \\
\hline $\mathrm{Cu}-\mathrm{N} 2$ & $2.058(5)$ & $2.102(7)$ & $2.0950(17)$ \\
\hline $\mathrm{Cu}-\mathrm{N} 4$ & $1.936(5)$ & $2.056(7)$ & $2.1474(19)$ \\
\hline $\mathrm{Cu}-\mathrm{N} 6$ & $1.978(5)$ & $2.218(7)$ & $\mathrm{N} / \mathrm{A}$ \\
\hline $\mathrm{Cu}-\mathrm{N} 10$ & $1.984(5)$ & $1.937(7)$ & $1.9652(19)$ \\
\hline \multicolumn{4}{|l|}{ Angle $\left(^{\circ}\right)$} \\
\hline $\mathrm{N} 1-\mathrm{Cu}-\mathrm{N} 2$ & $80.83(19)$ & $79.1(3)$ & $81.66(7)$ \\
\hline $\mathrm{N} 1-\mathrm{Cu}-\mathrm{N} 4$ & $81.52(19)$ & $83.2(3)$ & $81.31(7)$ \\
\hline N1-Cu-N6 & $81.39(19)$ & $79.7(3)$ & $\mathrm{N} / \mathrm{A}$ \\
\hline $\mathrm{N} 1-\mathrm{Cu}-\mathrm{N} 10$ & $176.0(2)$ & $175.8(3)$ & $178.33(7)$ \\
\hline N2-Cu-N4 & $106.2(2)$ & $136.8(3)$ & $112.24(7)$ \\
\hline N2-Cu-N6 & $112.6(2)$ & $110.6(3)$ & N/A \\
\hline $\mathrm{N} 2-\mathrm{Cu}-\mathrm{N} 10$ & $95.6(2)$ & $99.1(3)$ & $99.60(7)$ \\
\hline N4-Cu-N6 & $134.1(2)$ & $104.5(3)$ & $\mathrm{N} / \mathrm{A}$ \\
\hline $\mathrm{N} 4-\mathrm{Cu}-\mathrm{N} 10$ & $101.3(2)$ & $100.6(3)$ & $99.18(8)$ \\
\hline N6-Cu-N10 & $98.4(2)$ & $97.5(3)$ & N/A \\
\hline Cu-N10-N11 & $119.5(2)$ & $128.6(3)$ & $121.0(7)$ \\
\hline
\end{tabular}

(a) (Harata, M. et al., 1998b); (b) (Tubbs, K. J. et al., 2003b). 
As observed previously, the $\mathrm{Cu}-\mathrm{N} 1$ distance is longer in $\mathbf{4 0}$ than in the related pyridine complexes. Once again, the $\mathrm{Cu}-\mathrm{N} 10$ distance is longer in $\mathbf{4 0}$ compared to the pyridine complexes. The $\mathrm{Cu}-\mathrm{N}(\mathrm{Im})$ distances are normal for $\mathrm{Cu}(\mathrm{II})$ complex but they are more uniform than their pyridine analogs (Table 14). The $\mathbf{L} 2$ ligand keeps a pseudomirror plane bisecting the two amide pendants, while the pyridine analog $\left[\mathrm{Cu}(\mathrm{Hbppa}) \mathrm{N}_{3}\right]^{+}$has twisted pyridine rings (Figure 36) (Harata, M. et al., 1998b).

The azide molecule is oriented towards the empty space close to the unfunctionalized imidazole ring. This arrangement can lead to the design of adequate pendant group on the unfunctionalized imidazole arm that can interact with the terminal nitrogen atom (N12) of the azide as it has been engineered on a pyridine ligand to stabilize a $\mathrm{Cu}(\mathrm{II})$-peroxide complex (Yamaguchi, S. et al., 2003).

The two amide hydrogens are interacting with the N10 nitrogen atom of the azide molecule (average N---N10 distance of $3.094 \AA$ and N-H---N10 angle of $158.3^{\circ}$ ). Interestingly, the two azide $\mathrm{N}=\mathrm{N}$ bond distances are not crystallographically identical (N10-N11 distance of $1.210 \AA$ for $1.144 \AA$ for N11-N12), which might be a result of the hydrogen bond interactions. However, the Cu-N10-N11 angle is $119.52(3)^{\circ}$ as expected for a $\mathrm{sp}^{2}$ hybrized azide nitrogen.

As with the other $\mathrm{Cu}(\mathrm{II})$ complexes, the coordination geometry of $\mathbf{4 0}$ has been examined in solution by EPR spectroscopy. The rhombic EPR spectrum of compound $\mathbf{4 0}$ is again consistent with a distorted square pyramidal geometry around the $\mathrm{Cu}$ atom. From the computer-simulated spectrum, the following magnetic parameters were determined: $\mathrm{g}_{3}=2.25, \mathrm{~g}_{2}=2.095, \mathrm{~g}_{1}=2.055$ and $\mathrm{A}_{3}=103, \mathrm{~A}_{2}=65, \mathrm{~A}_{1}=55$. An $\mathrm{R}$ value of 0.21 indicates a $\mathrm{d}_{\mathrm{x}^{2}-\mathrm{y}^{2}}$ ground state and a geometry around the $\mathrm{Cu}$ close to square pyramidal. 


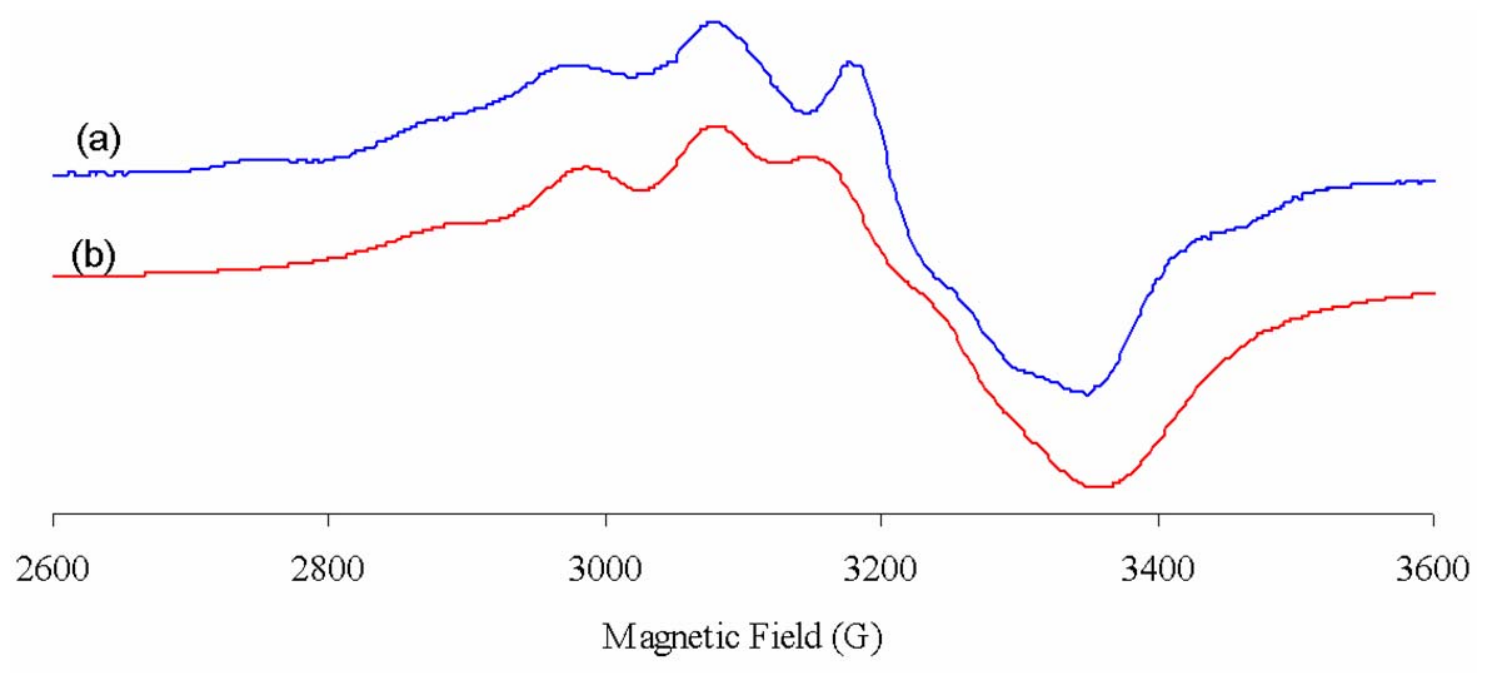

Figure 37. Experimental (a) and simulated (b) X-band EPR spectra of a frozen methanolic solution of compound $\mathbf{4 0 .}$

F. $\quad$ Summary of the EPR Parameters for the $\mathrm{Cu}(\mathrm{II})$ Complexes of $\mathbf{L 2}$

Table 15 summarizes the EPR parameters for the $\mathrm{Cu}$ (II) complexes of $\mathbf{L} 2$ studied in this chapter as well as the parameters for the mononuclear $\mathrm{Cu}-\mathrm{OOH}$ species (45) characterized in Chapter VII. Interestingly, all $\mathrm{Cu}(\mathrm{II})$ complexes display rhombic spectra and the geometry around the $\mathrm{Cu}(\mathrm{II})$ center are closer to a square pyramidal arrangement in frozen solution with $\mathrm{a} \mathrm{dx}_{\mathrm{x}}^{2} \mathrm{y}^{2}$ ground state as reflected in their respective $\mathrm{R}$ values (Garribba, E. et al., 2000). 
Table 15. EPR parameters for the $\mathrm{Cu}(\mathrm{II})$ complexes of $\mathbf{L 2}$.

\begin{tabular}{ccccc}
\hline Species & Solvent & $\mathrm{g}$ & $\mathrm{A}(\mathrm{G})$ & $\mathrm{R}$ value \\
\hline Compound 36 & $\mathrm{MeOH}$ & $\mathrm{g}_{3}=2.295$ & $\mathrm{~A}_{3}=135$ & \\
& & $\mathrm{~g}_{2}=2.10$ & $\mathrm{~A}_{2}=35$ & 0.10 \\
Compound 37 & $\mathrm{MeOH}$ & $\mathrm{g}_{1}=2.08$ & $\mathrm{~A}_{1}=15$ & \\
& & $\mathrm{~g}_{2}=2.23$ & $\mathrm{~A}_{3}=120$ & \\
& & $\mathrm{~g}_{1}=2.095$ & $\mathrm{~A}_{2}=10$ & 0.04 \\
Compound 38 & $\mathrm{CH}_{3} \mathrm{CN}$ & $\mathrm{g}_{3}=2.22$ & $\mathrm{~A}_{3}=120$ & \\
& & $\mathrm{~g}_{2}=2.085$ & $\mathrm{~A}_{2}=40$ & 0.15 \\
& & $\mathrm{~g}_{1}=2.065$ & $\mathrm{~A}_{1}=50$ & \\
Compound 39 & $\mathrm{MeOH}$ & $\mathrm{g}_{3}=2.23$ & $\mathrm{~A}_{3}=100$ & \\
& & $\mathrm{~g}_{2}=2.04$ & $\mathrm{~A}_{2}=40$ & 0.20 \\
Compound 40 & $\mathrm{MeOH}$ & $\mathrm{g}_{1}=2.002$ & $\mathrm{~A}_{1}=60$ & \\
& & $\mathrm{~g}_{3}=2.25$ & $\mathrm{~A}_{3}=103$ & \\
& & $\mathrm{~g}_{2}=2.095$ & $\mathrm{~A}_{2}=65$ & 0.26 \\
Compound 45 & $\mathrm{MeOH}$ & $\mathrm{g}_{3}=2.055$ & $\mathrm{~A}_{1}=55$ & \\
& & $\mathrm{~g}_{2}=2.065$ & $\mathrm{~A}_{3}=135$ & \\
& & $\mathrm{~A}_{2}=25$ & 0.13 \\
\hline
\end{tabular}

\section{G. Crystal Structure of the $\mathbf{L} \mathbf{2}$ Ligand}

Recrystallization of the $\mathbf{L} 2$ ligand from ethyl acetate and hexane yielded colorless X-ray quality crystals. The crystal structure of $\mathbf{L} \mathbf{2}$ contains an organic molecule and water molecule per asymmetric unit (Figure 38). The distances and angles of the organic molecule are normal and consistent with previously reported imidazole compounds. Interestingly, the $\mathbf{L 2}$ molecule adopts the paddle-wheel arrangements previously observed in the crystal structure of tmima and its derivative (see Chapter VI). The water molecule is hydrogen bonded to two imidazole rings containing N4 and N6 (N4---O3 and 
N6---O3 separations of $2.858 \AA$ and $2.781 \AA$, respectively with O3-H3BO---N4 and O3$\mathrm{H} 3 \mathrm{AO}---\mathrm{N} 6$ angles of $167.27^{\circ}$ and $174.40^{\circ}$, respectively) (Figure 39).

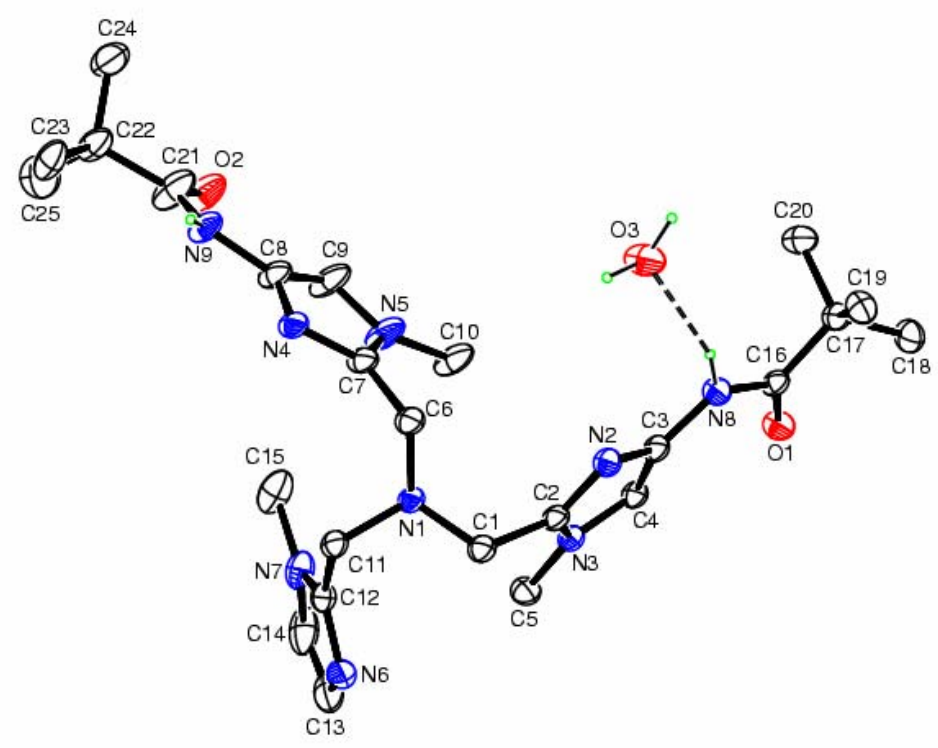

Figure 38. ORTEP view of the L2 ligand hydrogen bonded to a water molecule. Ellipsoids are drawn at $40 \%$ probability. Methyl and methylene hydrogens have been omitted for clarity.

In addition, one of the amide hydrogens, $\mathrm{H} 8 \mathrm{~N}$, is strongly hydrogen bonded to $\mathrm{O} 3$ with N8---O3 separation of $2.830 \AA$ and N8-H8N---O3 angle of $152.74^{\circ}$. The last imidazole ring containing $\mathrm{N} 2$ is weakly hydrogen bonded to the second amide hydrogen, H9N, with N2---N9 separation of $3.271 \AA$ and N9-H9N---N2 angle of $157.48^{\circ}$. Also, two symmetry related imidazole rings containing N6 are involved in a slipped $\pi$-stack interaction (Janiak, C., 2000) with the closest contact of $3.577 \AA$ between C12 and C12'. One of the carbonyl oxygens from the amide pendants is involved in a strong C-H---O hydrogen bond interaction with the methyl group of a symmetry related imidazole ring (O1---C5 separation of $3.077 \AA$ and O1---H5A-C5 angle of $\left.131.95^{\circ}\right)$. The second carbonyl oxygen, $\mathrm{O} 2$, is involved in a weaker $\mathrm{C}-\mathrm{H}---\mathrm{O}$ interactions with the methyl 
carbon, $\mathrm{C} 10\left(\mathrm{O} 2---\mathrm{C} 10\right.$ separation of $3.716 \AA$ and $\mathrm{C} 10-\mathrm{H} 10 \mathrm{~A}---\mathrm{O} 2$ angle of $\left.114.61^{\circ}\right)$.

For the discussion on C-H---O hydrogen bonding involving methyl groups and oxygen atoms, see Chapter VI.

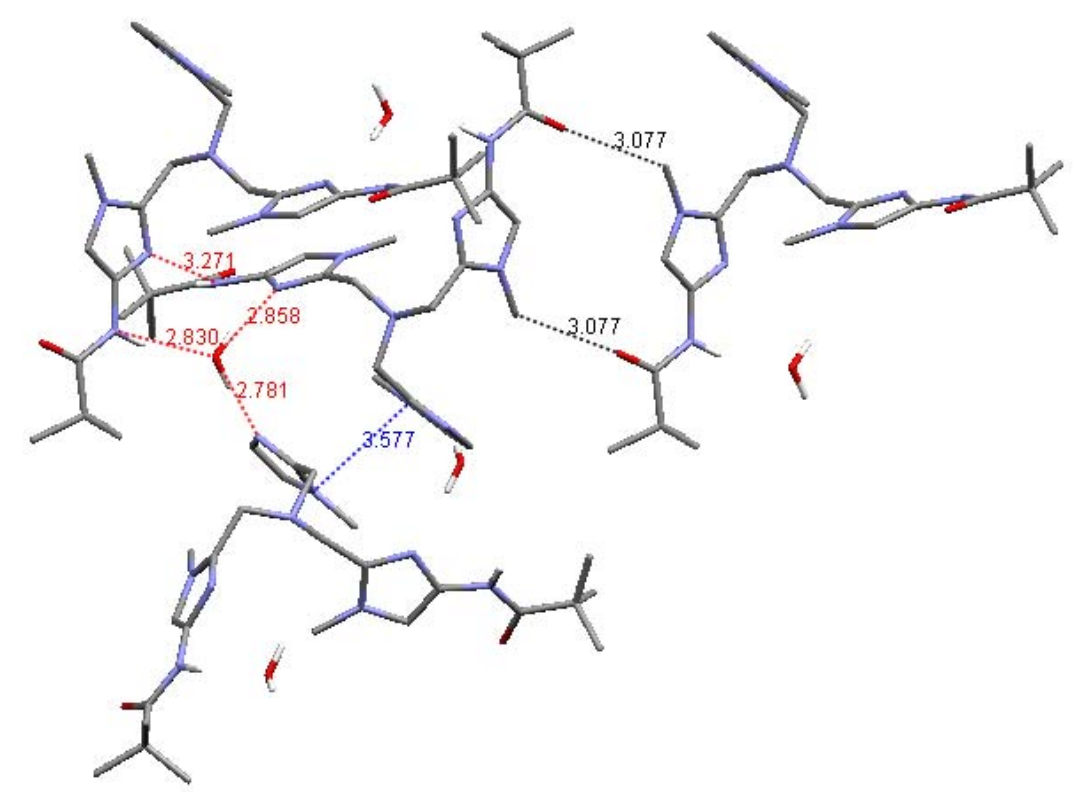

Figure 39. Capped-stick representation of the intermolecular interaction present in the crystal structure of $\mathbf{L} 2$ (hydrogen bond in red, C-H---O interaction in black, $\pi$ stacking in blue).

The hydrogen bonding interactions between imidazole and water molecules is further explored in Chapter VIII, where imidazole compounds have been found to stabilize unique water arrangements.

\section{H. Summary}

This study confirms the ability of the novel amide functionalized tripodal ligands L1-3 to form significant intramolecular six-membered hydrogen bonded rings with apical ligands $\left(\mathrm{Cl}^{-}, \mathrm{OH}^{-}, \mathrm{N}_{3}{ }^{-}\right)$bonded to the metal. Interestingly, the coordination environment around the metal is not significantly altered by the introduction of the amide groups in the 
series of L1-3 complexes compared to the tmima complexes. The most noticeable difference occurs in the tertiary amine nitrogen (N1)-to-copper distance. The Cu-N1 distance decreases with the increase of amide pendants on the ligands. The introduction of the amide groups has an effect on the electronic properties of the ligands. The electronwithdrawing ability of the amide pendants is reflected in a shift of the metal redox potential to more positive values. Recently, Masuda and coworkers reported a similar study on azido copper complexes with mono-, bis- and tris-amino substituted pyridine ligands (Wada, A. et al., 2004). The imidazole ligands are coordinating to the metal more strongly than their pyridine analogs as previously observed. As a result, the tertiary nitrogen-to-copper distances, as well as the separation between the amide nitrogen and the apical ligands are longer in the imidazole complexes. 


\section{CHAPTER VI}

\section{SUPRAMOLECULAR ASSEMBLIES OF NITROIMIDAZOLE COMPOUNDS AND BORIC ACID TEMPLATING AGENT}

\section{A. Introduction}

The self-assembly of molecular species in the solid-state via weak non-covalent interactions is a fundamental property of supramolecular chemistry (Lehn, J. M., 1990), and an important component in the synthesis and manipulation of nanoscale materials (Boncheva, M. et al., 2003). In general, solid-state supramolecular assemblies are stabilized by many of the same weak intermolecular forces thought to be involved in the stabilization of more complex biological systems, such as hydrogen bonding, hydrophobic and hydrophilic interactions, $\pi-\pi$ stacking, and electrostatic interactions between ionic groups. Therefore, a clearer understanding of the forces controlling supramolecular assemblies is not only useful in the design of new materials with unique solid-state properties, or of drugs with improved binding affinities, but may also lead to an improvement of our understanding of complex biological processes (Popot, J. L. \& Engelman, D. M., 2000). This section presents the results of a series of studies evaluating the ability of nitro derivatized imidazole compounds to function as building blocks for stabilizing supramolecular solid-state assemblies.

Interestingly, nitroimidazole compounds have been used as drugs for nearly forty years but little is known about their mode of action and pharmalogical properties. Indeed, the radiosensitizing properties of metronidazole (2-methyl-5-nitroimidazole-1-ethanol) 
have been used in the treatment of anaerobic protozoan and bacterial infections (Silvestri, R. et al., 2000). The accepted mechanism of action of metronidazole involves the reduction of the nitro group and the formation of free radicals (Tocher, J. H. \& Edwards, D. I., 1992). The reduction is thought to be effected by nitroreductase enzymes, however the nature of the affinity of metronidazole is still not clear (Crossnoe, C. R. et al., 2002).

While synthesis and characterization of nitroimidazole compounds have been known for some time, few studies to date have focused on their use in supramolecular assemblies (Galvan-Tejada, N. et al., 2002). Three types of interactions have been observed between $\mathrm{X}-\mathrm{H}(\mathrm{X}=\mathrm{C}, \mathrm{O}, \mathrm{N})$ and nitro groups as illustrated in Scheme 16. They are symmetrically bifurcated bonds (A), bicoordinated with one oxygen atom, X-H---O bonds trans to the $\mathrm{C}-\mathrm{N}$ bond (B), and monocoordinated $\mathrm{X}-\mathrm{H}---\mathrm{O}$ bonds cis to the $\mathrm{C}-\mathrm{N}$ bond (C). Robinson et al. have tried to categorize the recognition properties of the nitro group and concluded that they depend significantly on the nature of the $\mathrm{X}$ donor groups (Robinson, J. M. A. et al., 2000).

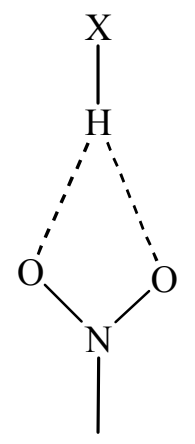

A

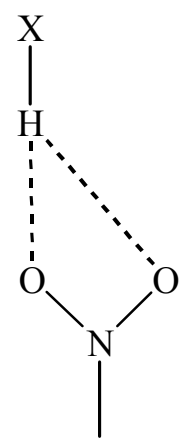

B

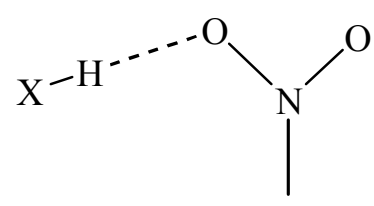

$\mathrm{C}$

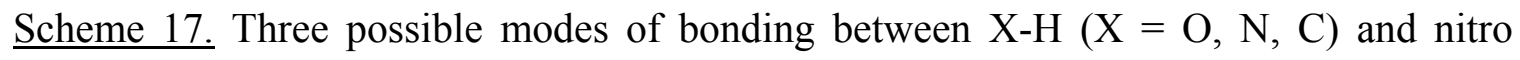
groups.

In broader analogies, Desiraju has evaluated C-H---O bonding interactions based on crystallographic data to develop a scale of C-H acidities (Desiraju, G. R., 1996). For 
C---O separations ranging from 3.0 to $4.0 \AA$ and $\mathrm{C}-\mathrm{H}---\mathrm{O}$ angles between 110 and $180^{\circ}$, C-H---O hydrogen bonding interactions are considered to be soft. They have been shown to be crucial in supramolecular assemblies and are gradually being recognized as important components of biological assemblies (Derewenda, Z. S. et al., 1995).

Another important aspect of supramolecular chemistry that has received some attention recently is the role of small molecules as templating agents in assembly formation. For example, Etter (VidenovaAdrabinska, V. \& Etter, M. C., 1995) and others (Li, Q. et al., 1999) have shown the proton donor-acceptor properties of urea to be ideal for templating the assembly of interesting two- and three-dimensional solid-state structures. Similarly, the neutral and ionic forms of boric acid have been shown in a limited number of examples to stabilize extended solid-state structures with various amines (Roy, A. et al., 2002). In addition, boric acid has been shown to have an affinity for the nitrogen atoms of the histidine imidazole ring (London, R. E. \& Gabel, S. A., 2002) and to play an important role in plant physiology (Brown, P. H. et al., 2002). More specifically, boron is thought to be critical to the stabilization of healthy cell wall structures in plants, where it is proposed to be covalently bonded to adjacent glycosyl chains.

While the importance of boron to plant biochemistry has been well established, the precise mechanism of boron uptake and its incorporation in cellular structures has not been definitively delineated and is a subject of continued debate (Brown, P. H. et al., 2002). Although passive diffusion of boric acid through cell membranes is a probable, and certainly recognized pathway, Brown and others have presented recent evidence for assisted diffusional processes via molecular chaperones (Noguchi, K. et al., 2000) or 
aquaporin-like channels (Tsukaguchi, H. et al., 1998). These latter observations are intriguing because chaperone proteins and aquaporin-like channels are known (or thought) to be involved in trafficking small molecules through cell membranes in a variety of biological systems.

Described below is a crystallographic study of a family of 1-methyl-4nitroimidazole compounds with different functional groups in the 2-position of the ring: 2-hydroxymethyl-1-methyl-4-nitroimidazole, 41, 1-methyl-4-nitroimidazole-2-carboxylic acid, 42, and the two previously characterized compounds 15 and 21 (Scheme 18). The substituents, which vary from an alcohol moiety to the two-electron oxidized carboxylic acid, are potentially useful synthons in the synthesis of more elaborate nitroimidazole drugs (Siddiqui, A. Q. et al., 1999).
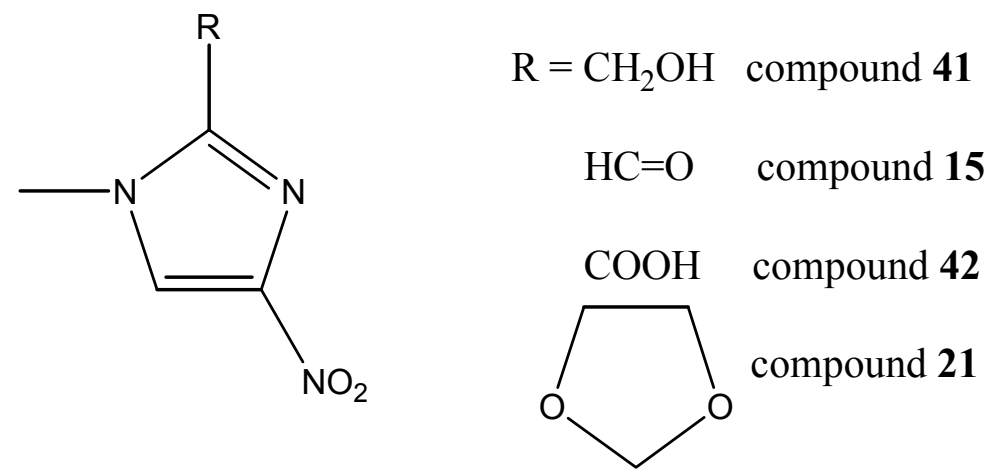

Scheme 18. Illustration of the nitroimidazole compounds used in this study.

Part of the study below illustrates the importance of the nitro group, as well as various $\mathrm{C}-\mathrm{H}---\mathrm{O}$ interactions and $\pi$ stacking, in stabilizing supramolecular assemblies. In most of these compounds, the dominant interaction is the soft hydrogen bond between the oxygen of the nitro group and the acidic $\mathrm{C}-\mathrm{H}$ hydrogen in the fifth position of the imidazole rings adjacent to the nitro group. Other acidic C-H---O interactions were identified along with a unique $\mathrm{C}=\mathrm{O}---\mathrm{N}$ interaction between a carbonyl oxygen and the 
positively charged nitrogen atom of the nitro group, as observed previously for $\mathrm{N}$-oxalyl 2,4-dinitroanilide (Yin, Z. M. et al., 2003).

In addition, this study explored the potential use of boric acid in the crystallization of heterocyclic polyamine compounds, such as the polyimidazole ligand tris((1methylimidazol-2-yl)methyl)amine (tmima) (Mashuta, M. S. et al., 2002), which like many polyimidazole compounds, is hygroscopic and does not crystallize readily using conventional crystallization methods. Boric acid was found to form strong hydrogen bonds in the solid-state with tmima and a related nitro derivative, compound $\mathbf{1 6}$, resulting in the stabilization of interesting 2-D and 3-D supramolecular assemblies.

B. Synthesis and Characterization of Nitro and Tripodal Imidazole Compounds

1. Synthesis

The synthesis and characterization of the 1-methyl-4-nitroimidazole-2carboxaldehyde (15), 1-methyl-4-nitroimidazole-2-acetal (21) and (bis(1-methylimidazol2-yl)methyl)(1-methyl-4-nitroimidazol-2-yl)methyl)amine (16) have been described previously in Chapter IV, while tris((1-methylimidazol-2-yl)methyl)amine (tmima) was prepared as described by Chen et al. (Chen, S. et al., 1994).

2-Hydroxymethyl-1-methyl-4-nitroimidazole (41) and 1-methyl-4-nitroimidazole2-carboxylic acid (42) were synthesized according to the procedure used to prepare compound 15 (Chapter IV). The only difference is for compound 41, the parent 2hydroxymethyl-1-methylimidazole was used. Compound $\mathbf{4 2}$ was isolated from the exhaustive oxidation of the carboxaldehyde group of $\mathbf{1 5}$ resulting from longer reaction times ( 2 hours instead of 50 minutes described in method A) ( $45 \%$ yield). 


\section{Characterization of Compounds $\mathbf{4 1}$ and $\mathbf{4 2}$}

Each compound was fully characterized by ${ }^{1} \mathrm{H}$ and ${ }^{13} \mathrm{C}$ NMR, ESI-MS and IR spectroscopy and elemental analysis. The characterizations of tmima and compounds $\mathbf{1 5}$, 16 and 21 have been reported elsewhere (see Chapter IV and (Chen, S. et al., 1994)).

\section{a) Compound $\mathbf{4 1}$}

$\mathrm{MP}=164-65{ }^{\circ} \mathrm{C}$; IR $(\mathrm{KBr}) 3133 \mathrm{~cm}^{-1}(\mathrm{OH}), 1549$ and $1389 \mathrm{~cm}^{-1}\left(\mathrm{NO}_{2}\right) ;{ }^{1} \mathrm{H}$ NMR $\left(\mathrm{CD}_{3} \mathrm{OD}, 500 \mathrm{MHz}\right): \delta 8.11(\mathrm{~s}, \mathrm{H}-5), 4.66\left(\mathrm{~s},-\mathrm{CH}_{2}-\right), 3.85\left(\mathrm{~s},-\mathrm{CH}_{3}\right) .{ }^{13} \mathrm{C} \mathrm{NMR} \mathrm{CD}_{3} \mathrm{OD} \delta$ 147.5 (s, C4), 148.1 (s, $\mathrm{C} 2), 122.5$ (C5), $57.9\left(\mathrm{~s},-\mathrm{CH}_{2}-\right), 32.3\left(\mathrm{~N}-\mathrm{CH}_{3}\right) ;$ ESI-MS m/z 158.0 $\left(\mathrm{M}+\mathrm{H}^{+}\right)$; Anal. Calcd for $\mathrm{C}_{5} \mathrm{H}_{7} \mathrm{~N}_{3} \mathrm{O}_{3}$ : C, 38.22; H, 4.49; N, 26.74. Found C, 38.18; H, $4.53 ; \mathrm{N}, 26.72$.

\section{b) Compound $\mathbf{4 2}$}

$\mathrm{MP}=144-46^{\circ} \mathrm{C} ; \mathrm{IR}(\mathrm{KBr}) 2868 \mathrm{~cm}^{-1}(\mathrm{OH}), 1730(\mathrm{C}=\mathrm{O}), 1554$ and $1384 \mathrm{~cm}^{-1}\left(\mathrm{NO}_{2}\right) ;{ }^{1} \mathrm{H}$ NMR ( $\mathrm{d}_{6}$-acetone, 500MHz) $\delta 8.37(\mathrm{~s}, \mathrm{H}-5), 4.17\left(\mathrm{~s},-\mathrm{CH}_{3}\right) .{ }^{13} \mathrm{C}$ NMR DMSO-d 6 $\delta 159.1$ (s, $\mathrm{COOH}), 143.2$ (s, C4), 136.2 (s, C2), 126.4 (s, C5), $36.5\left(\mathrm{~N}^{-C_{3}}\right)$; ESI-MS m/z 172.1 $\left(\mathrm{M}+\mathrm{H}^{+}\right)$; Anal. Calcd for $\mathrm{C}_{5} \mathrm{H}_{5} \mathrm{~N}_{3} \mathrm{O}_{4}: \mathrm{C}, 35.10 ; \mathrm{H}, 2.95 ; \mathrm{N}, 24.56$. Found $\mathrm{C}, 35.13 ; \mathrm{H}$, $3.01 ; \mathrm{N}, 24.52$.

\section{Electrochemistry}

The reduction potentials of the nitro groups of compounds 15, 21, 41 and 42 were determined and compared to the $\mathrm{E}_{1 / 2}$ value for metronidazole to evaluate the influence of the substituent in the 2-position on the electrochemical properties of the nitroimidazole compounds (Cavalcanti, J. C. M. et al., 2004). The electrochemical studies were carried out in dimethyl sulfoxide in the presence of $0.1 \mathrm{M}$ tetrabutylammonium perchlorate using 
a glassy carbon electrode and $\mathrm{Ag} / \mathrm{AgCl}$ reference electrode. The initial potential was set at $+0.8 \mathrm{~V}$ and the potentiostat was scanned negatively to $-0.9 \mathrm{~V}$. The scan rate was kept at $50 \mathrm{mV} / \mathrm{sec}$ throughout the experiments and the $\mathrm{E}_{1 / 2}$ values are summarized in Table 16 along with the $E_{1 / 2}$ value of metronidazole. The electrochemical reduction process is typical of nitro aromatic compounds in aprotic solvents and is consistent with the formation of a stable nitro anion radical (Barety, D. et al., 1984).

$\underline{\text { Table } 16 .} \mathrm{E}_{1 / 2}$ potentials for the series of nitroimidazole compounds.

\begin{tabular}{ccc}
\hline Compound & $\begin{array}{c}\mathrm{E}_{1 / 2} \\
\text { ( in mV versus Ag/AgCl) }\end{array}$ & \\
\hline metronidazole & -847 & $\begin{array}{c}\text { quasi-reversible } \\
\text { (Cavalcanti, J. C. M. et al., 2004) }\end{array}$ \\
$\mathbf{2 1}$ & -600 and -760 & $\begin{array}{c}\text { Irreversible (Roffia, S. et al., 1982) } \\
\text { (probable self-protonation mechanism) } \\
\text { quasi-reversible }\end{array}$ \\
$\mathbf{4 1}$ & -750 & $\begin{array}{c}\text { quasi-reversible } \\
\mathbf{4 2}\end{array}$ \\
& -750 & $\begin{array}{c}\text { irreversible (probable ECE mechanism) } \\
\text { (Barety, D. et al., 1984) }\end{array}$ \\
\hline
\end{tabular}

C. Crystal Structure of 2-Hydroxymethyl-1-methyl-4-nitro-imidazole (41)

Compound $\mathbf{4 1}$ crystallizes in the unusual centrosymmetric space group Pccn with one molecule in the asymmetric unit. An ORTEP view of the molecule is shown in Figure 40. All distances and angles in $\mathbf{4 1}$ are normal and consistent with other related imidazole compounds (Galvan-Tejada, N. et al., 2002) (Kowalski, A., 1996). From a supramolecular point-of-view, compound $\mathbf{4 1}$ forms strong hydrogen bond donor and acceptor interactions $(\mathrm{OH}$ and imidazole $\mathrm{N})$, as well as weaker hydrogen bonds between $\mathrm{C}-\mathrm{H}$ and nitro oxygen atoms. 


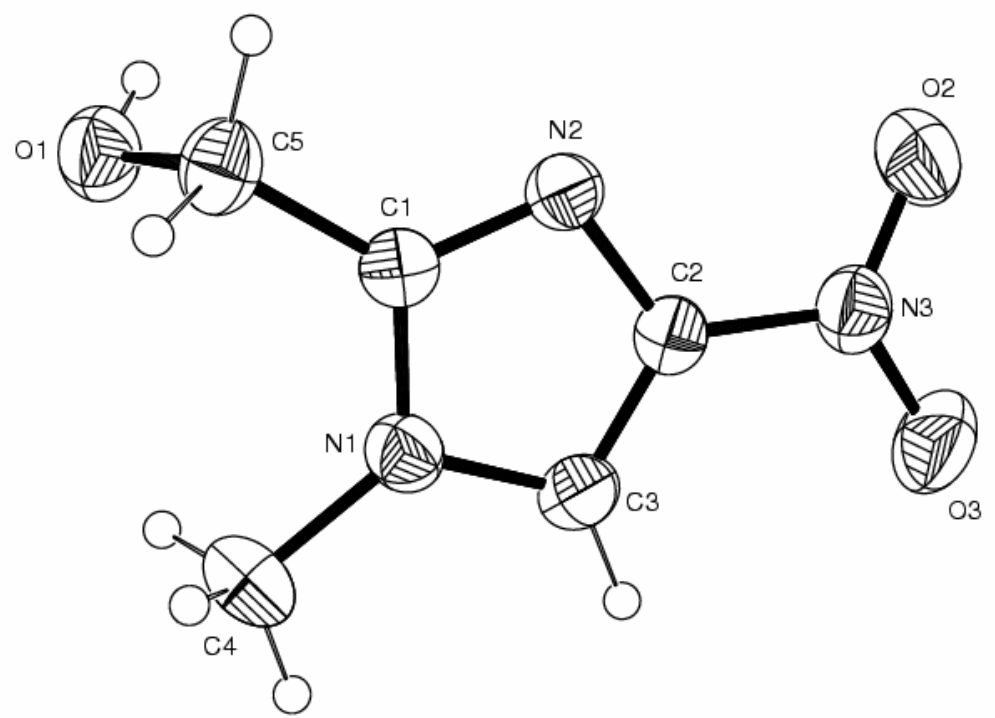

Figure 40. ORTEP view of compound $\mathbf{4 1}$, shown with $40 \%$ probability displacement ellipsoids.

As observed previously for the parent compound, 2-hydroxymethyl-1methylimidazole, the inherent strong hydrogen bond interaction (Krische, M. J. \& Lehn, J. M., 2000) involving the hydroxyl group and a symmetry related imidazole nitrogens, form V-shape dimers. These dimers interact with each other through weak hydrogen bonds via $\mathrm{C}-\mathrm{H}$ groups and hydrogen bond acceptors to form wedge-shaped layers. The layers are also stacked via $\pi$-interaction between nitro groups and neighboring imidazole rings.

Additionally, the hydroxyl hydrogen atoms form weak bifurcated hydrogen bonds between symmetry related imidazole nitrogen atoms (N2) (O1---N2 separation of 2.971 $\AA$ and $\mathrm{O} 1-\mathrm{H} 1---\mathrm{N} 2$ angle of $\left.158.12^{\circ}\right)$ and the oxygen atom, O2, of the nitro group (O1--$\mathrm{O} 2$ separation of $3.023 \AA$ and $\mathrm{O} 1-\mathrm{H} 1---\mathrm{O} 2$ angle of $128.71^{\circ}$ ). A strong type B interaction exists between the other nitro group oxygen, $\mathrm{O} 3$, and a symmetry related acidic ring hydrogen atom H3, adjacent to the nitro group. (Figure 41) (Robinson, J. M. A. et al., 2000) (C---O distance of $3.252 \AA$ and C-H---O angle of $\left.147.46^{\circ}\right)$. 


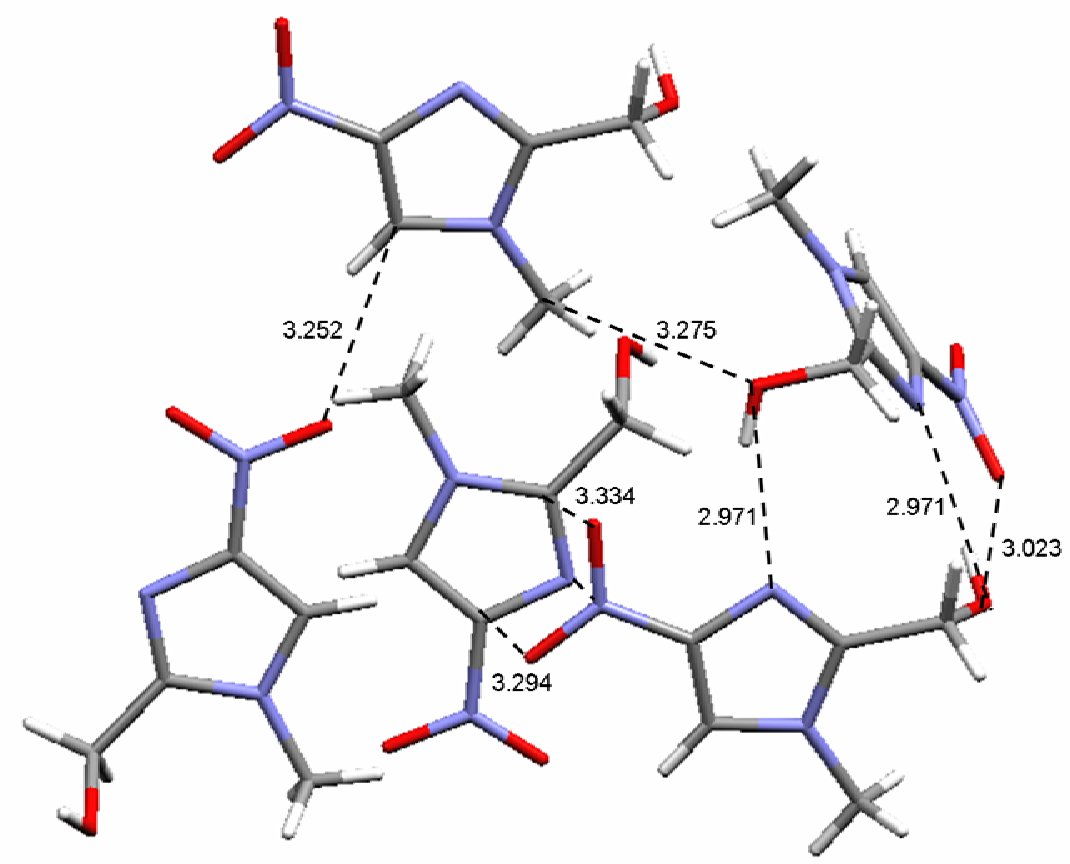

Figure 41. Capped-stick representation of compound $\mathbf{4 1}$ illustrating the intermolecular forces present in the crystal structure.

Another interaction is observed between $\mathrm{O} 1$ atom of the alcohol group and a methyl hydrogen associated with C4 attached to N1 (C---O separation of $3.275 \AA$ and C$\mathrm{H}---\mathrm{O}$ angle of $\left.106.40^{\circ}\right)$. Even though the angle is rather acute, the $\mathrm{C}-\mathrm{H}---\mathrm{O}$ interaction is still considered to be a weak interaction (Desiraju, G. R., 1996). It should be noted that methyl hydrogen atoms were calculated and not located on the difference Fourier map, so their positions are approximate and may contribute to slight alterations in the observed C$\mathrm{H}---\mathrm{O}$ angles. Along the crystallographic c axis, each layer of $\mathbf{4 1}$ is involved in slipped $\pi$ stacking (Janiak, C., 2000) between the two nitro N-O bonds and the C2-N2 bonds of the imidazole rings, with the shortest contact of $3.265 \AA$ (Figure 41). The overall packing arrangement resembles a herringbone pattern (Figure 42). 


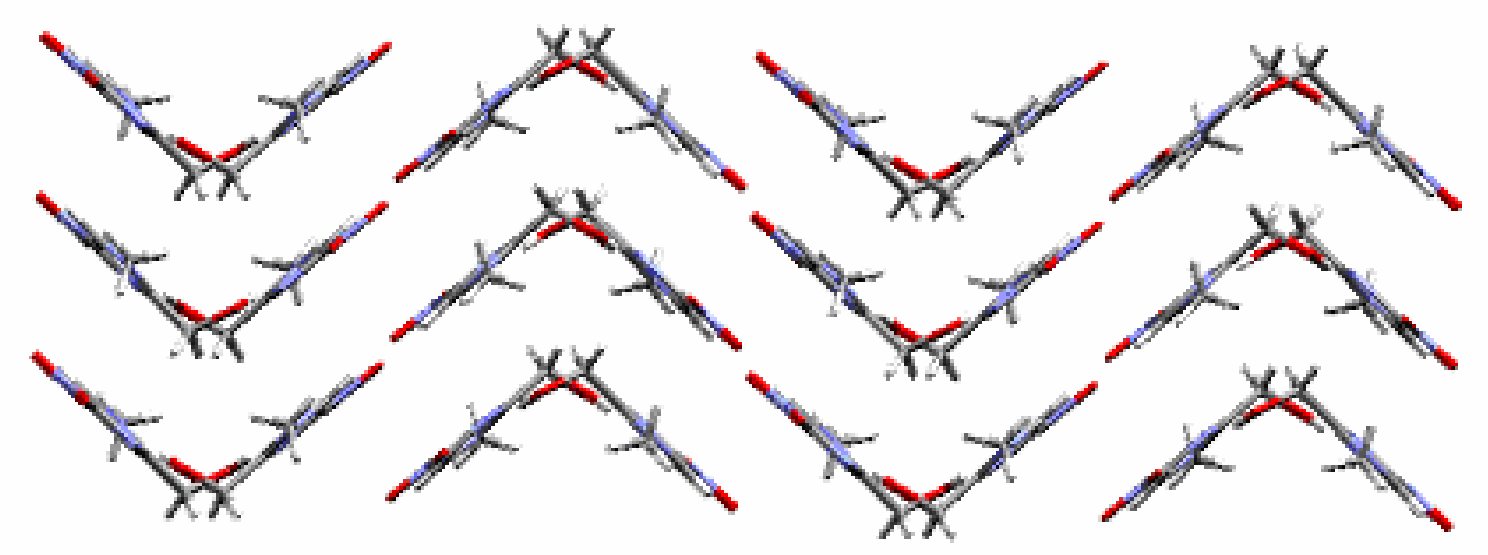

Figure 42. Illustration of the herringbone pattern found in the packing arrangement of $\mathbf{4 1}$.

D. Crystal Structure of 1-Methyl-4-nitroimidazole-2-carboxaldehyde (15)

The asymmetric unit of compound $\mathbf{1 5}$ is composed of two independent molecules. Their structures are displayed in Figure 43. All distances and angles are normal and consistent with other reported imidazole compounds (Galvan-Tejada, N. et al., 2002) (Kowalski, A., 1996). In this compound, there are no strong hydrogen bond donors. Instead, compound $\mathbf{1 5}$ possesses several potentially weak C-H donors, which in addition to $\pi$-stacking interactions stabilize the tetrameric units observed in the structure of compounds 15. Tubular channels are observed along the crystallographic a axis. The channels are joined together via $\pi$-stacking between the nitro groups and imidazole rings, as well as by unique weak $\mathrm{N}---\mathrm{O}=\mathrm{C}$ interactions between the positively charged nitrogen atoms of the nitro group and carbonyl oxygen atoms (Yin, Z. M. et al., 2003). 

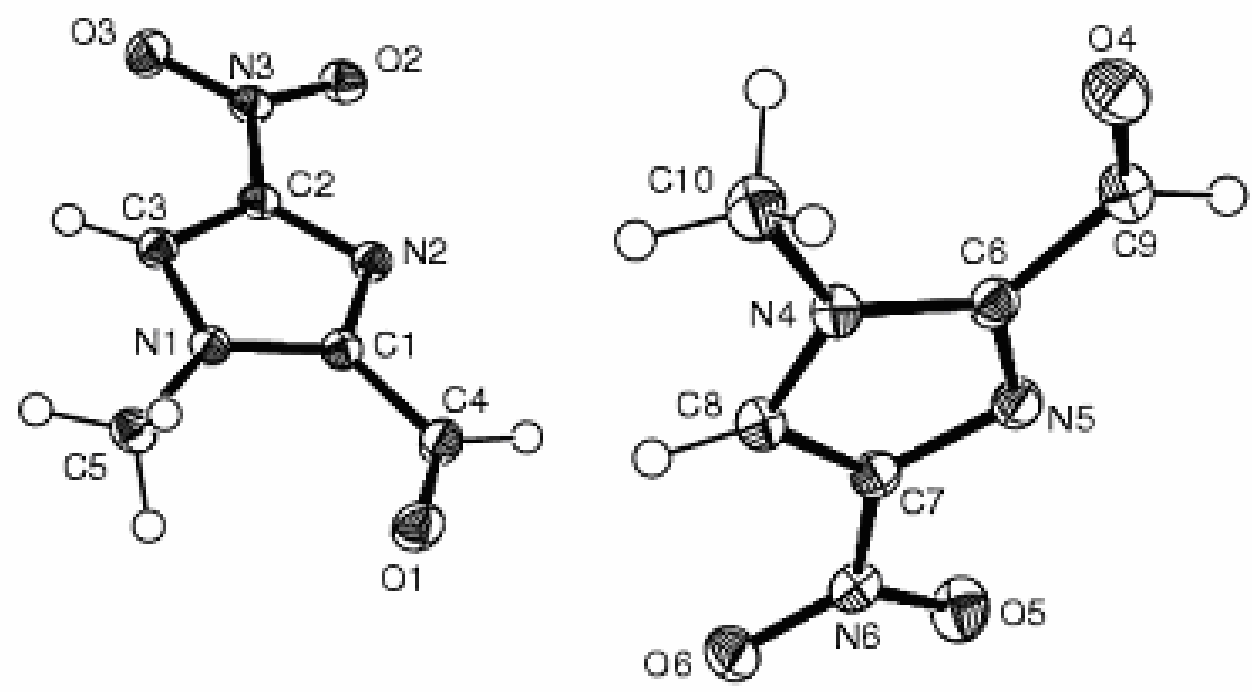

Figure 43. ORTEP view of compound 15. Ellipsoids are drawn at 40\% probability level.

The tetrameric unit of nitroimidazole molecules is composed of two weak intermolecular hydrogen bonding interactions between 5-position imidazole and methyl $\mathrm{C}-\mathrm{H}$ hydrogen and neighboring $\mathrm{N}$ (imidazole) and $\mathrm{O}$ (nitro group) atoms (Figure 44). Both 5-position imidazole ring hydrogens ( $\mathrm{H} 3$ and $\mathrm{H} 8)$ adjacent to the nitro group are involved in $\mathrm{C}-\mathrm{H}---\mathrm{X}(\mathrm{X}=\mathrm{N}$ or $\mathrm{O})$ hydrogen bonds; however in different ways. $\mathrm{H} 8$ is involved in a bifurcated hydrogen bond between the other imidazole nitrogen atom, N2, and the oxygen atom, $\mathrm{O} 2$, of the nitro group (C8---N2 and C8---O2 separations of 3.476 and $3.414 \AA$, respectively, and C8-H8---N2 and C8-H8---O2 angles of 132.99 and $127.24^{\circ}$ ). On the other hand, $\mathrm{H} 3$ is only hydrogen bonded to oxygen $\mathrm{O} 6$ of the nitro group of a neighboring molecule (C3---O6 separation of 3.323 Å and a C3-H3---O6 angle of $\left.142.95^{\circ}\right)$. Oxygen atoms ( $\mathrm{O} 6$ and $\left.\mathrm{O} 2\right)$ of different nitro groups are also interacting with methyl hydrogens (C5---O6 and C10---O2 separations of $3.480 \AA$ and $3.445 \AA$, respectively, with C5-H5A---O6 and C10-H10A---O2 angles of $154.92^{\circ}$ and $140.02^{\circ}$, respectively). 


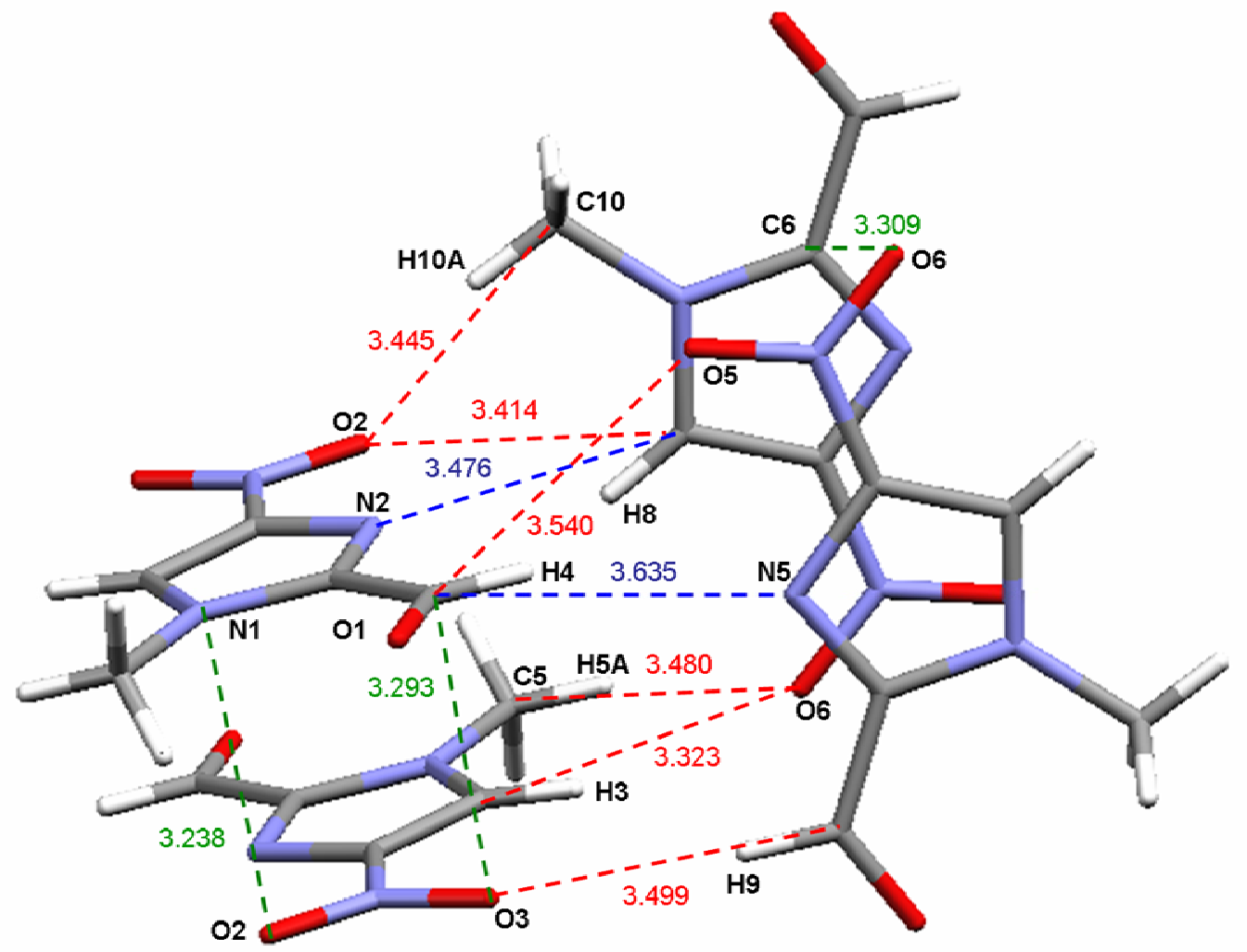

Figure 44. Capped-stick representation of the tetrameric unit of compound 15 illustrating the weak intermolecular forces present in the packing diagram such as $\mathrm{C}-\mathrm{H}---$ $\mathrm{O}$ (red), C-H---N (blue), $\pi$-stacking (green).

As mentioned above, it was anticipated that aldehyde hydrogens would be acidic according to Desiraju's crystallographic scale of acidic carbon hydrogens (Desiraju, G. R., 1996). Indeed, both aldehyde hydrogens (H4 and H9) are involved in hydrogen bonding with the imidazole nitrogen atom, N5, and with nitro oxygen atoms, O3 and O5. While O3 is interacting with the aldehyde hydrogen H9 (C9---O3 separation of $3.499 \AA$ and $\mathrm{C} 9-\mathrm{H} 9---\mathrm{O} 3$ angle of $\left.173.15^{\circ}\right), \mathrm{H} 4$ is involved in a bifurcated hydrogen bond with the imidazole nitrogen atoms, N5 (C4---N5 separation of $3.635 \AA$ and C4-H4---N5 angle of $\left.160.80^{\circ}\right)$ and $\mathrm{O} 5$ of the nitro group (C4---O5 separations of $3.540 \AA$ and C4-H4---O5 angle of $139.81^{\circ}$ ). Finally, the tetramer is composed of two sets of $\pi$-stacks involving the entire $\pi$-cloud of the conjugated nitroimidazole carboxaldehyde, with separations of 
$3.238 \AA$ and $3.252 \AA$. The tetrameric units of molecules create channels that extend along the crystallographic a axis with dimensions of $3.24 \times 3.25 \AA^{2}$. Channels are linked together through weak interactions including $\pi$-stacks and an interesting $\mathrm{C}=\mathrm{O}---\mathrm{N}$ interaction previously observed for only one other nitro compound (Yin, Z. M. et al., 2003).

Both aldehyde carbonyl oxygen atoms (O1 and $\mathrm{O} 4)$ point towards the slightly positively charged nitrogen atoms (N3 and N6) of neighboring nitro groups with C---N separations of 2.932 and $3.053 \AA$, respectively, and $\mathrm{C}=\mathrm{O}---\mathrm{N}$ angles of 164.19 and $163.86^{\circ}$, respectively (Figure 45). In addition, both carbonyl oxygen atoms $\mathrm{O} 4$ and $\mathrm{O} 1$ are involved in weak bifurcated interactions with carbon atoms of the methylated imidazole nitrogen (C5---O1 and C10----O1 separations of 3.425 and $3.202 \AA$, respectively, with C5-H5B---O1 and C10-H10A---O1 angles of 144.03 and $127.45^{\circ}$, respectively, and C5---O4 and C10----O4 separations of 3.279 and $3.578 \AA$, respectively, and $\mathrm{C} 5-\mathrm{H} 5 \mathrm{~A}---\mathrm{O} 4$ and $\mathrm{C} 10-\mathrm{H} 10 \mathrm{~B}---\mathrm{O} 4$ angles of 128.03 and $162.19^{\circ}$, respectively).

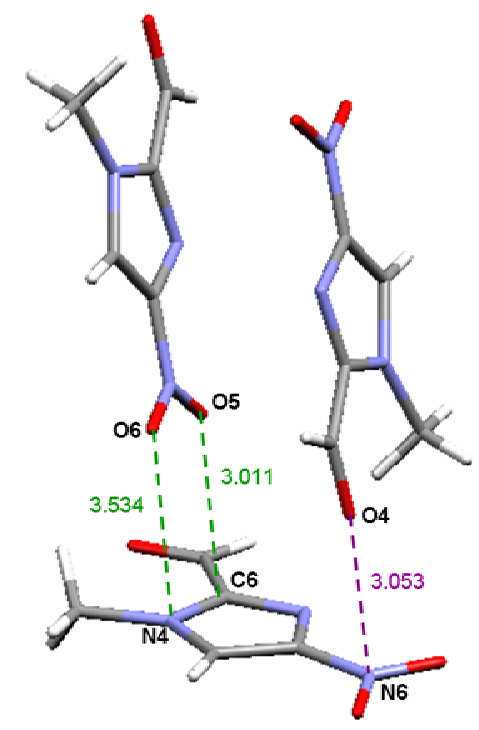

Figure 45. Illustration of the $\mathrm{C}=\mathrm{O}---\mathrm{N}$ (purple) and the point-to-face $\pi$-stacking (green) interactions in $\mathbf{1 5 .}$ 
These interactions are in the accepted range of weak C-H---O interactions, however, there are several differences worth noting. When the C---O separation is short, the angle is more acute, while for longer distances, angles are closer to $180^{\circ}$. Finally, both nitro groups form point-to-face $\pi$-stacks with imidazole ring $\mathrm{C}=\mathrm{N}$ bonds with $\mathrm{O} 3$--N1 and O5---C6 separations of 3.137 and $3.011 \AA$, respectively.

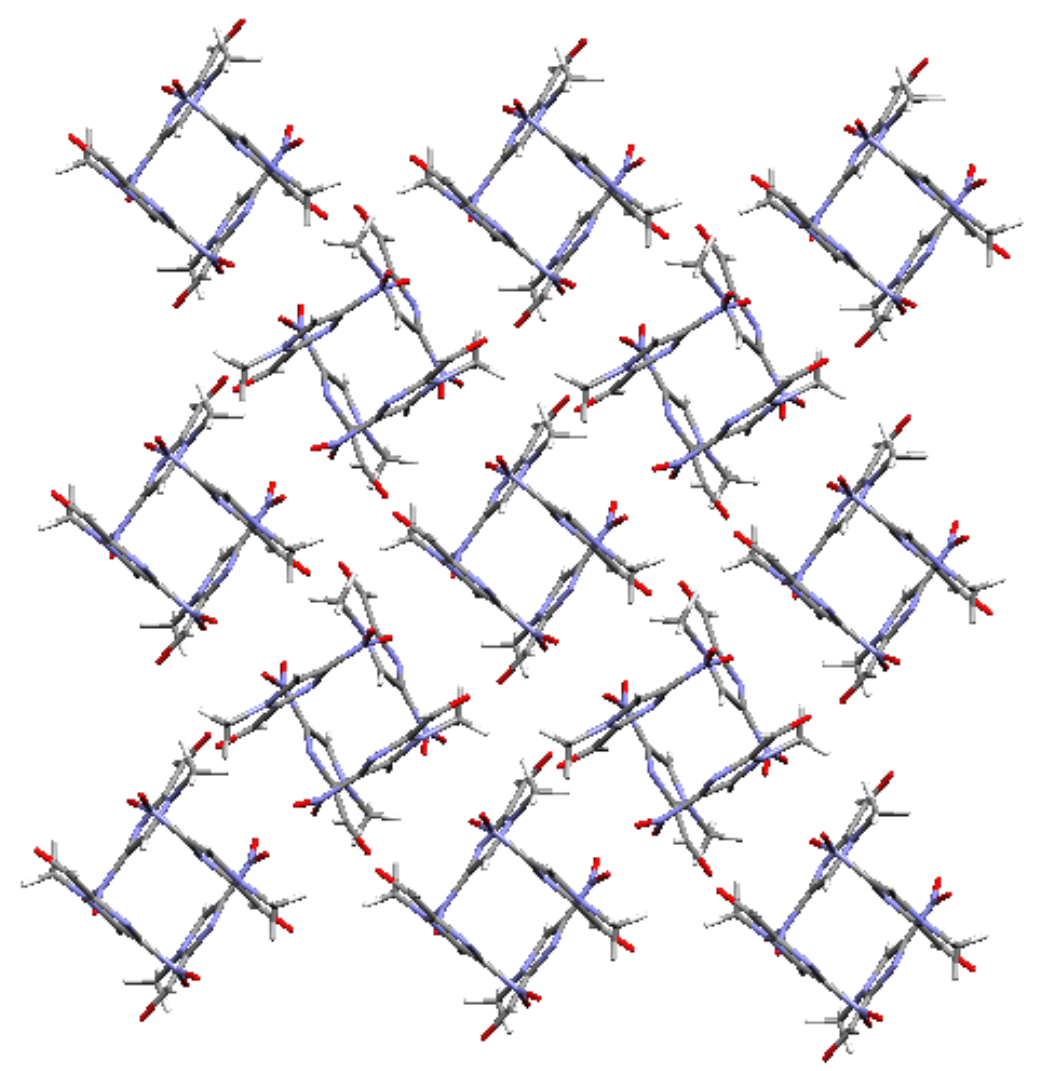

Figure 46. Packing diagram of the tetrameric units of compound 15.

E. Crystal Structure of 1-Methyl-4-nitroimidazole-2-carboxylic acid (42)

This compound crystallizes with one molecule of methanol per compound $\mathbf{4 2}$ in the asymmetric unit (Figure 47). The methanol is held tightly in a hydrophobic pocket via strong hydrogen bonds. 


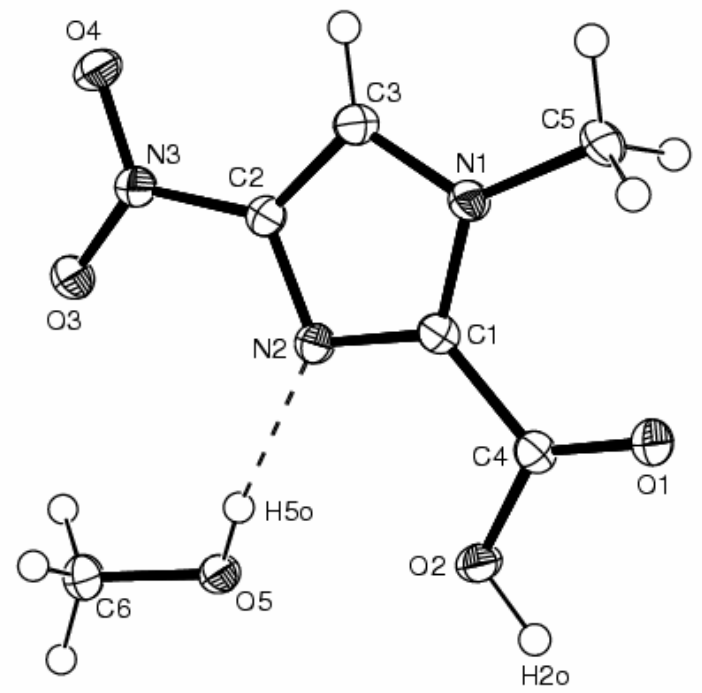

Figure 47. ORTEP view of compound 42. Ellipsoids are drawn with $40 \%$ probability level.

The carboxylic acid oxygen donor is strongly hydrogen bonded to the oxygen atom of the methanol molecule (O2---O5 separation of $2.547 \AA$ and $\mathrm{O} 2-\mathrm{H} 2 \mathrm{O}---\mathrm{O} 5$ angle of $171.38^{\circ}$ ) (see Figure 48 ). The methanol oxygen acts also as a hydrogen bond donor with the imidazole nitrogen $\left(\mathrm{O}---\mathrm{N}\right.$ separation of $2.890 \AA$ and $\mathrm{O}-\mathrm{H}---\mathrm{N}$ angle of $\left.172.43^{\circ}\right)$. The imidazole hydrogen is involved in a type $\mathrm{C}$ interaction with the nitro group of a symmetry related molecule (C3---O4 separation of 3.275 $\AA$ and C3-H3---O4 angle of $149.70^{\circ}$ ) (Figure 48). Both methyl groups from the methanol and methylated imidazole nitrogen are involved in weak hydrogen bonding with nitro and carboxylic acid groups. The methyl carbon atom, C6, of the methanol molecule is interacting with both nitro oxygen atoms in a type A interaction and with the carbonyl oxygen atoms. 


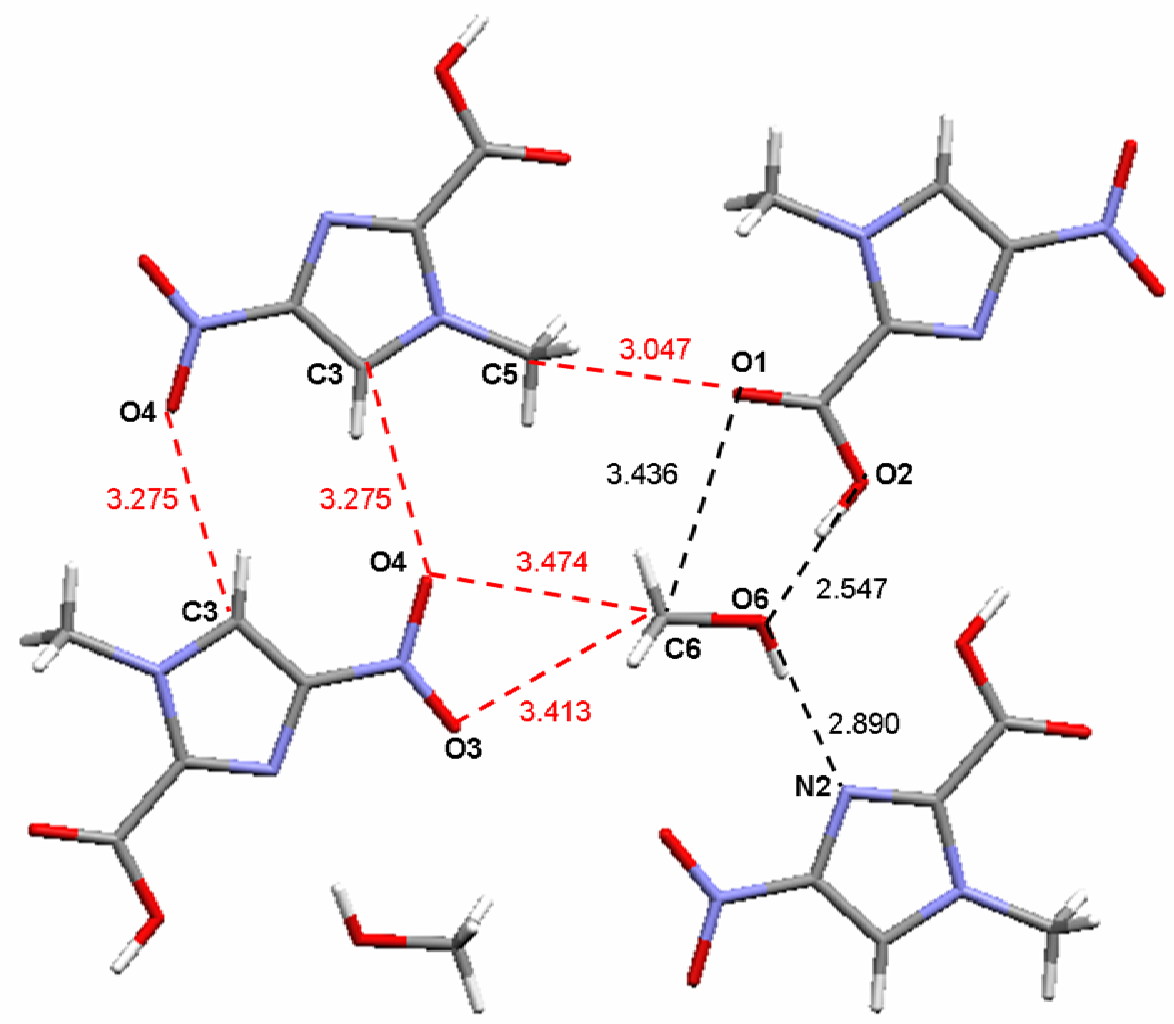

Figure 48. Illustration of the interactions present in the crystal structure of compound $\mathbf{4 2}$ including strong (black) and weak $\mathrm{C}-\mathrm{H}---\mathrm{O}$ (red) hydrogen bond interactions.

For the nitro group, the average C6---O(nitro) separation is $3.444 \AA$ and C6-H--$\mathrm{O}$ angle is $109.88^{\circ}$. For the carbonyl oxygen atom, the average C6---O1 separation is $3.436 \AA$ and $\mathrm{C} 6-\mathrm{H}---\mathrm{O} 1$ angle is $128.77^{\circ}$. O1 also interacts with the methyl group on the imidazole nitrogen (C5---O1 separation is $3.047 \AA$ and C5-H5B---O1 angle is $101.91^{\circ}$ ). Finally, the $\mathbf{4 2} \cdot \mathrm{CH}_{3} \mathrm{OH}$ units stack in layers with the closest separation between layers

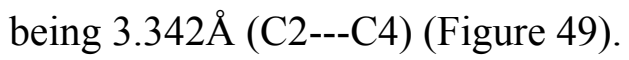




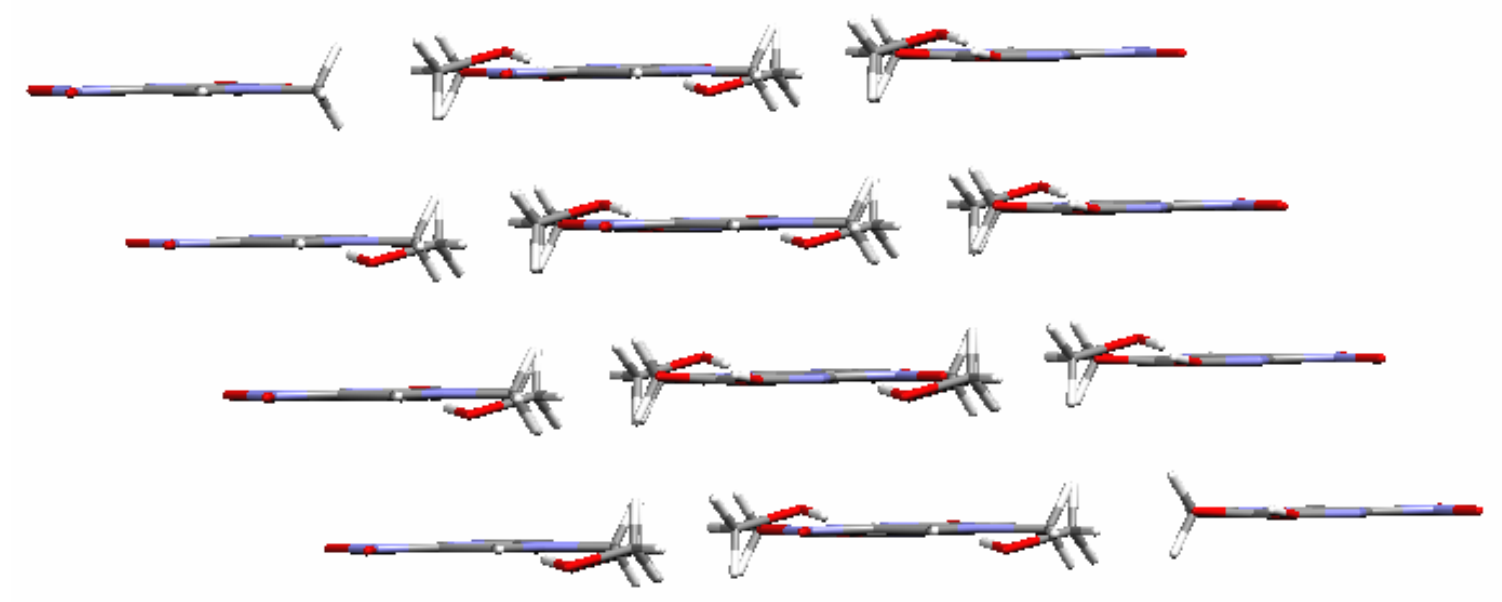

Figure 49. Packing diagram of compound $\mathbf{4 2}$ illustrating the $\pi$-stacked layers.

F. Crystal Structure of 1-Methyl-4-nitroimidazole-2-acetal (21)

Compound 21 crystallizes in the space group $\mathrm{P} 2{ }_{1} / \mathrm{c}$ with one molecule per asymmetric unit. The structure of the compound is illustrated in Figure 50.

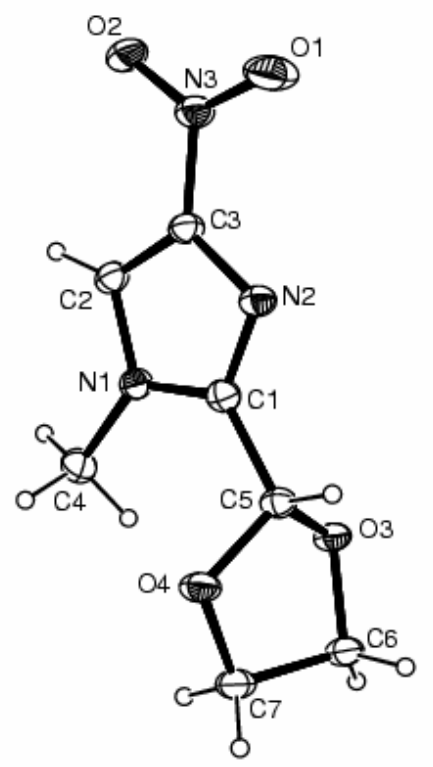

Figure 50. ORTEP view of compound 21 with ellipsoids drawn at 40\% probability level.

All distances and angles are normal and consistent with other reported imidazole compounds (Galvan-Tejada, N. et al., 2002). The solid-state structure appears to be 
stabilized by C-H---O hydrogen bonds.

Interestingly, the nitro oxygens are not interacting with the acidic hydrogen in the fifth position of the imidazole ring but rather interact with the methyl group on the imidazole nitrogen, as well as the methylene backbone of the acetal. The acidic aromatic hydrogen interacts with the more basic acetal oxygen along with the other acidic hydrogen $\mathrm{H} 5$ of the acetal ring.

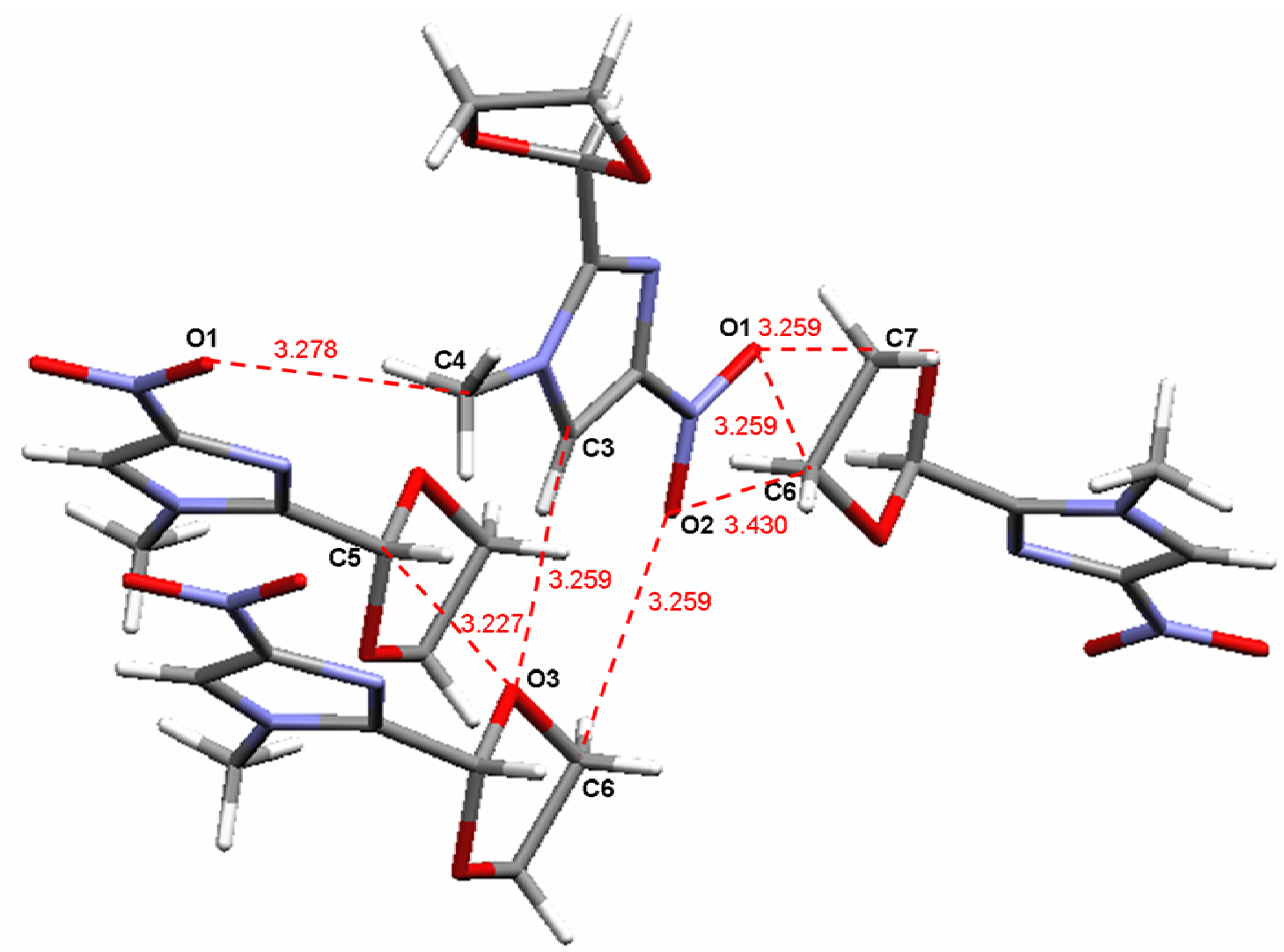

Figure 51. Illustration of the C-H---O interactions present in the crystal structure of $\mathbf{2 1}$.

The more basic $\mathrm{O} 3$ atom of the acetal interacts strongly with the $\mathrm{H} 3$ and $\mathrm{H} 5$ with C3---O3 and C5---O3 separations of 3.259 and $3.227 \AA$, respectively, and C3-H3---O3 and $\mathrm{C} 5-\mathrm{H} 5---\mathrm{O} 3$ angles of 161.91 and $137.21^{\circ}$, respectively. Both oxygen atoms of the nitro groups interact with methyl and methylene hydrogens. O1 is involved in a bifurcated hydrogen bond (type A) between the methyl group of the imidazole nitrogen 
and one of the methylene hydrogens from the acetal (O1---C4 and O1---C7 separations of 3.278 and 3.208 $\AA$, respectively, with C4-H4A---O1 and C7-H7A---O1 angles of 160.58 and $92.43^{\circ}$, respectively). The $\mathrm{O} 2$ oxygen atoms also interacts with the same methylene backbone carbon atom, C6, associated with two symmetry related molecules (the average C6---O2 separation of $3.430 \AA$ and C6-H6---O2 angle of $126.34^{\circ}$ ).

\section{G. Summary of the Nitroimidazole Study}

Even though two of the compounds contain strong hydrogen bond donors which preorganize to form molecular assemblies, the supramolecular structures in the nitroimidazole series were dominated by weak C-H---O interactions involving various acidic hydrogens and acceptor oxygens. In addition, the nitro group functionality has proved to play an important role in the architecture of the crystal structure through hydrogen bonding interactions and $\pi$-stacking, but also through a new type of $\mathrm{C}=\mathrm{O}---\mathrm{N}$ interaction that could be utilized in further rational design strategies. As Robinson noted (Robinson, J. M. A. et al., 2000), there is no dominant mode of interaction for the nitro group. Nevertheless, in this series, the nitro group has a tendency towards self-association with a 5-position acidic hydrogen adjacent on a symmetry related molecule in a type $\mathrm{C}$ interaction rather than in a bifurcated mode of bonding. The shortest C---O separations were observed between the nitro oxygens and the carbons in the fifth position of the imidazole rings. To a larger extent, the nitro group also interacts with hydrogens of the methylated imidazole ring (longer C---O distances compensated by more linear angles). The Desiraju's crystallographic scale of carbon acidity can be further expanded to include imidazole ring hydrogen as well as methyl groups attached to electron withdrawing groups (e.g. methylated imidazole nitrogen atoms and methanol). The only structure that 
does not contain any interaction between the nitro group and the ring hydrogen is the acetal structure where the acetal oxygen interacts instead with the 5-position ring hydrogen. Apparently, for hydrogens with similar acidities the stronger $\mathrm{C}-\mathrm{H}---\mathrm{O}$ interactions will involve the more basic oxygens. Finally, a potentially important interaction has been confirmed with the carbonyl oxygen pointing towards the slightly positively charged nitrogen of the nitro group. Such interactions may be of importance in biological systems and drug-protein interactions where the amide $\mathrm{C}=\mathrm{O}$ can potentially interact with nitro groups.

H. Evaluation of the Crystal Structure of Tmima: boric acid (1/1) (43)

Compound 43 crystallizes with one tmima and boric acid molecule per asymmetric unit, and the crystal structure of independent tmima and boric acid molecules are shown in Figure 52. The tmima molecule has approximated threefold symmetry with imidazole pendants oriented in a paddle-wheel arrangement around the amine nitrogen atom, N1. The imidazole C---C and C---N distances and C---C---N and C---N---C angles are normal and consistent with other imidazole compounds (Richardson, J. F. et al., 1988). The boric acid molecule, on the other hand, is planar and has local $C_{3 h}$ symmetry. The B---O distances and O---B---O angles are consistent with values reported for other boric acid structures (Andrews, S. J. et al., 1983), and all three $\mathrm{B}(\mathrm{OH})_{3}$ hydrogen atoms are involved in hydrogen bonding. 


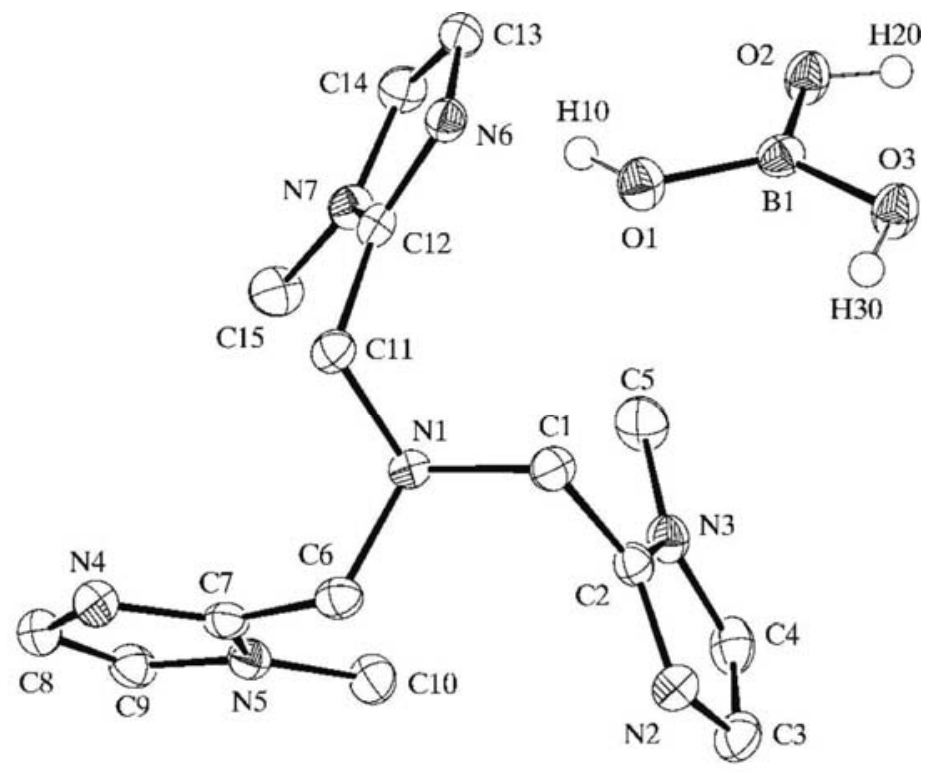

Figure 52. ORTEP view of the two molecular components of $\mathbf{4 3}$, shown with $50 \%$ probability displacement ellipsoids. Methyl and methylene hydrogens have been omitted for clarity.

The packing arrangement of $\mathbf{4 3}$ (Figure 53) shows the presence of an extended intermolecular hydrogen bonding network involving tmima and boric acid molecules which result in the formation of layers of hydrogen bonding planes projected along the crystallographic $\mathrm{b}$ and $\mathrm{c}$ axes. The layers are slightly less than one unit cell in depth, projected along the a axis, and separated by hydrophobic boundaries composed of imidazole $\mathrm{N}-\mathrm{CH}_{3}$ and ring hydrogen atoms. As illustrated in Figure 53, there are two types of hydrogen bonding interactions along the $\mathrm{b}$ and $\mathrm{c}$ axes. The first involves bonds between boric acid molecules and different imidazole pendants of neighboring tmima

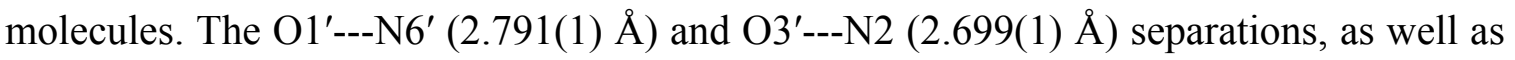
the $\mathrm{O}^{\prime}-\mathrm{H} 1 \mathrm{O}^{\prime}---\mathrm{N}^{\prime}\left(171(2)^{\circ}\right)$ and $\mathrm{O}^{\prime}-\mathrm{H}^{\prime} \mathrm{O}^{\prime}---\mathrm{N} 2\left(175(2)^{\circ}\right)$ angles, illustrate strong hydrogen bonding between different tmima pendants and boric acid molecules. A second type of hydrogen bonding occurs between symmetry related $\mathrm{B}(\mathrm{OH})_{3}$ molecules oriented along the crystallographic $2_{1}$ screw axis and related by inversion. The resulting eight- 
membered ring formed via two O-H bonds is planar, and the O2---O3' $(2.758(1) \AA)$ separations and $\mathrm{O} 2-\mathrm{H} 2 \mathrm{O}---\mathrm{O}^{\prime}\left(173(2)^{\circ}\right)$ angles indicate strong hydrogen bonding between $\mathrm{B}(\mathrm{OH})_{3}$ molecules.

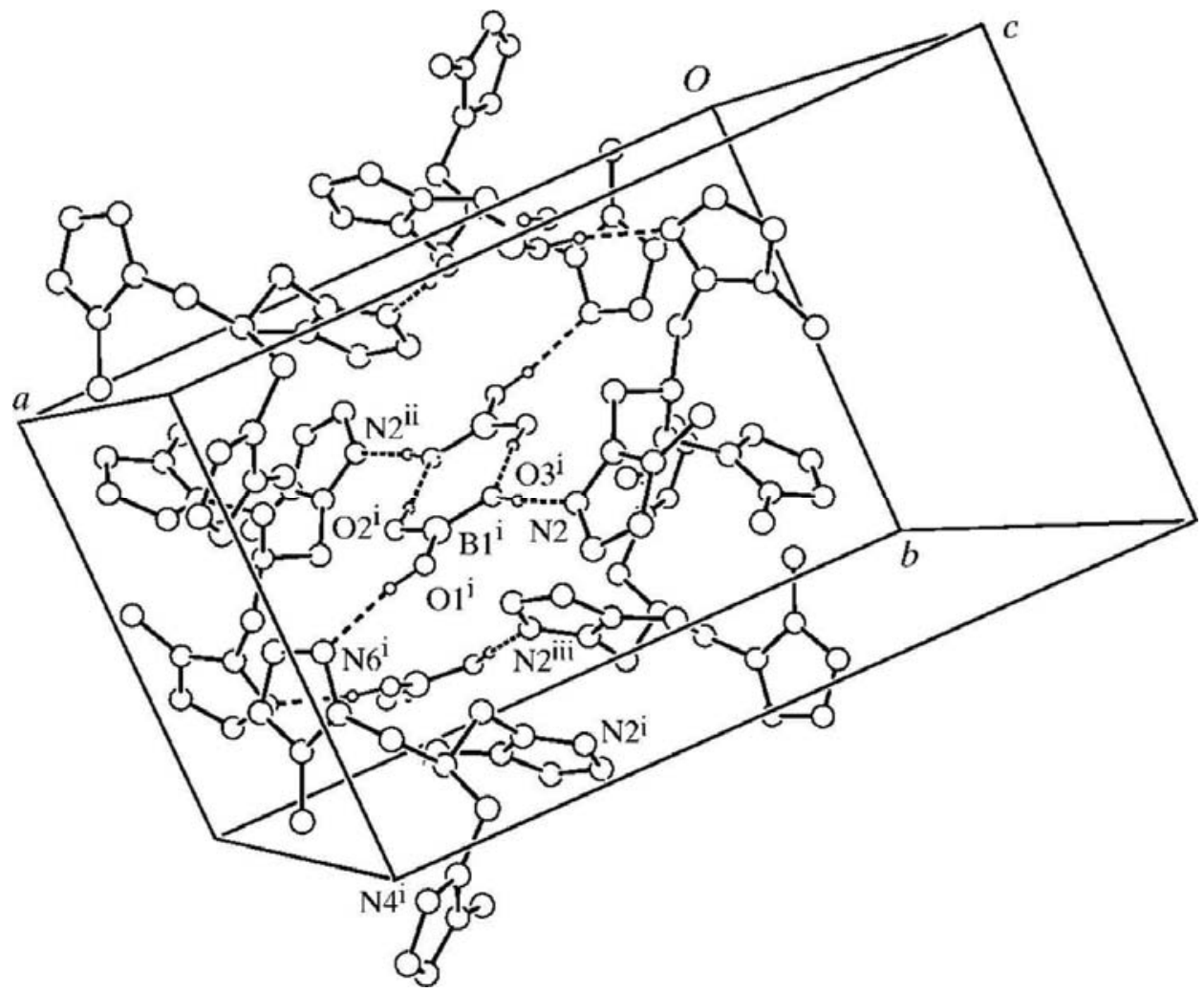

Figure 53. Packing diagram of $\mathbf{4 3}$, displaying the hydrogen bonding interaction between imidazole rings and boric acid molecules, and the $\pi-\pi$ stacking interactions between imidazole rings containing atom N2.

Figure 53 also illustrates the intermolecular $\pi$-stacking interactions between tmima molecules. Imidazole rings containing N2 form $\pi$-stacks centered around inversion centers and projected along both the $\mathrm{b}$ and $\mathrm{c}$ axes. Separation between imidazole ring centroids is $3.533 \AA$, which is indicative of strong $\pi$ - $\pi$ interactions between the imidazole rings. Curiously, the third imidazole pendant containing N4 is not involved in hydrogen bonding, nor $\pi$-stacking, but rather is oriented towards methyl groups of neighboring tmima molecules which are part of the hydrophobic boundary between hydrogen bonding layers. The closest H---H contacts between layers is $2.560 \AA$. 
To summarize, we have established the effectiveness of boric acid to induce crystallization of the polyimidazole compound tmima.

I. Evaluation of the Crystal Structure of Compound 16 : boric acid (2/1) (44)

Based on the results above for the tmima : boric acid complex (1/1) and the nitroimidazole studies, we deduced that the introduction of a nitro group in the 2-position of the imidazole ring of tmima, e.g. compound 16, should affect the interactions of this compound with boric acid molecules in the solid-state. Indeed, the co-crystallization of boric acid and $\mathbf{1 6}$ results in the formation of novel boric acid containing channels created from the association of antiparallel imidazole-boric acid coils of compound 44. The sideby-side coils are further bundled together forming a novel supramolecular structure stabilized by non-covalent interactions that include weak hydrogen bonding between imidazole ring hydrogen atoms and nitro oxygen atoms, as well as imidazole $\pi$ - $\pi$ stacking interactions between neighboring coils.

Compound 44, which contains a 2:1 nitroimidazole tripod/boric acid ratio, was crystallized by slow vapor diffusion of ether into an ethyl acetate solution of the complex, and crystallizes in the monoclinic space group $\mathrm{P} 2{ }_{1} / \mathrm{n}$ with two molecules of the nitroimidazole tripod per boric acid in the asymmetric unit (Figure 54). 


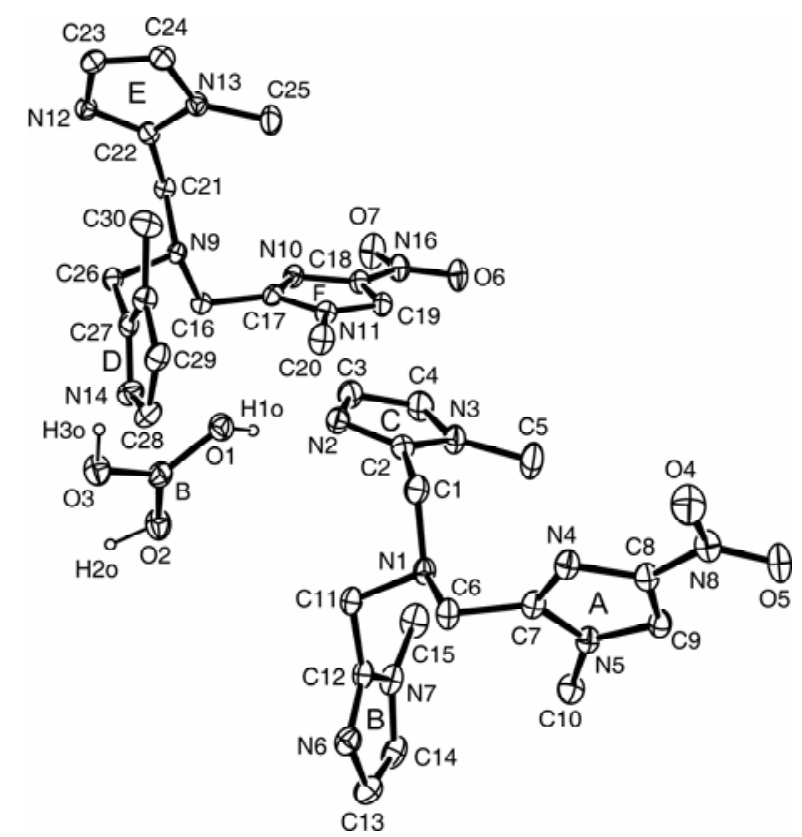

Figure 54. ORTEP view of the three molecular components of 44, shown with $50 \%$ probability displacement ellipsoids. All hydrogen atoms except those associated with the boric acid molecules have been omitted for clarity. Each individual imidazole ring has been assigned a letter from A to F.

For clarity in the discussion below, each of the unique imidazole rings in the two tripods has been assigned a letter to distinguish it from other rings. All of the imidazole groups are involved in $\pi$-stacking and three of the six imidazole pendants $(\mathrm{C}, \mathrm{D}$ and $\mathrm{E})$ are hydrogen bonded to the boric acid molecule. The bond distances and angles of the nitroimidazole tripods and boric acid molecule are consistent with those reported previously (Mashuta, M. S. et al., 2002).

Figure 55 shows views of the complementary antiparallel one-dimensional coiled components of 44 that extend along the crystallographic a axis, as well as the complementary interlocking arrangement of its side-by-side coiled structure (c and d), stabilized by hydrogen bonding interactions between imidazole and boric acid molecules and $\pi-\pi$ stacking between neighboring imidazole groups (Figure 56). 


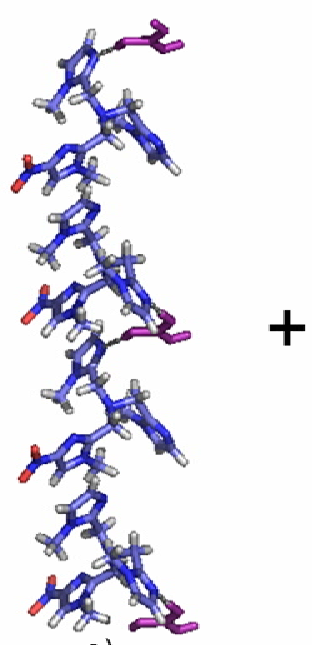

a)

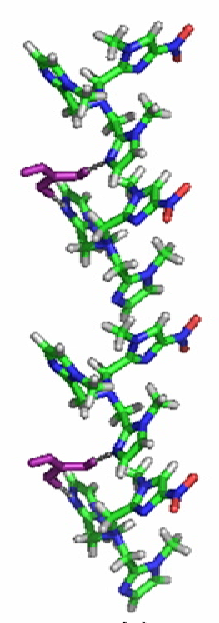

b)

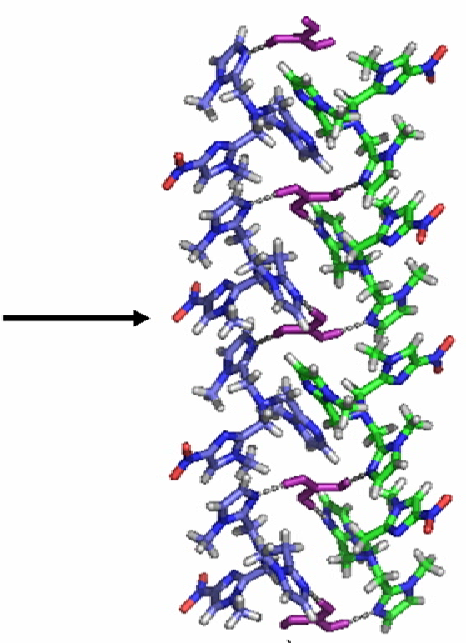

c)

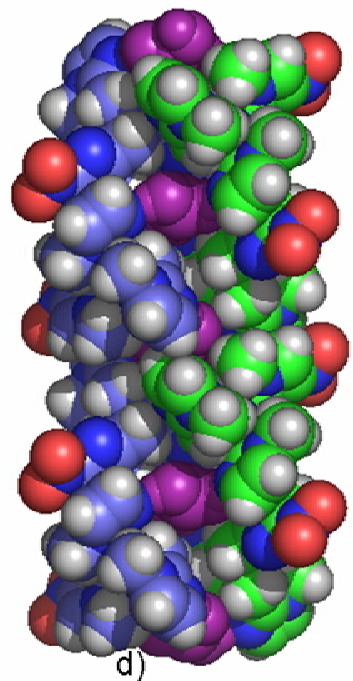

Figure 55. Views of the complementary antiparallel coils (a and b) of $\mathbf{4 4}$, as well as the capped-stick representation (c) and space filling model (d) of the side-by-side coils resulting from hydrogen bonding and $\pi-\pi$ stacking interactions projected along the crystallographic a axis.

Within each individual helix, two boric acid hydrogen atoms associated with $\mathrm{O} 1$ and $\mathrm{O} 3$ are strongly hydrogen bonded with nitrogen atoms, N2 and N14, associated with imidazole rings labeled $\mathrm{C}$ and $\mathrm{D}$ (Figure 54) resulting in N---O separations of 2.761(2) and 2.808(2) $\AA$ and N---H-O angles of 165(2) and 174(2) ${ }^{\circ}$, respectively. In addition, the turn of the coil is stabilized by $\pi-\pi$ stacks between nitro-functionalized and nonfunctionalized imidazole rings (A---E and F---C). A slipped $\pi$-stack is observed between ring $\mathrm{C}$ and the nitro group of ring $\mathrm{F}$ as reflected by the closest contact of $3.390 \AA$ (Figure 56). A strong parallel $\pi-\pi$ interaction occurs between ring $E$ and the nitro group of ring $A$ with a separation of $3.182 \AA$ (Figure 56). In addition, the two complementary coils are interlocked forming a one-dimensional side-by-side coiled structure, as illustrated in Figure 55 ( $\mathrm{c}$ and d), by a third hydrogen bond between $\mathrm{O} 2$ of the boric acid molecule and the nitrogen atom $\mathrm{N} 12$ of ring $\mathrm{E}$ with a N---O separation of 2.788(2) $\AA$ and an $\mathrm{O}-\mathrm{H}---\mathrm{N}$ angle of $170(2)^{\circ}$. 

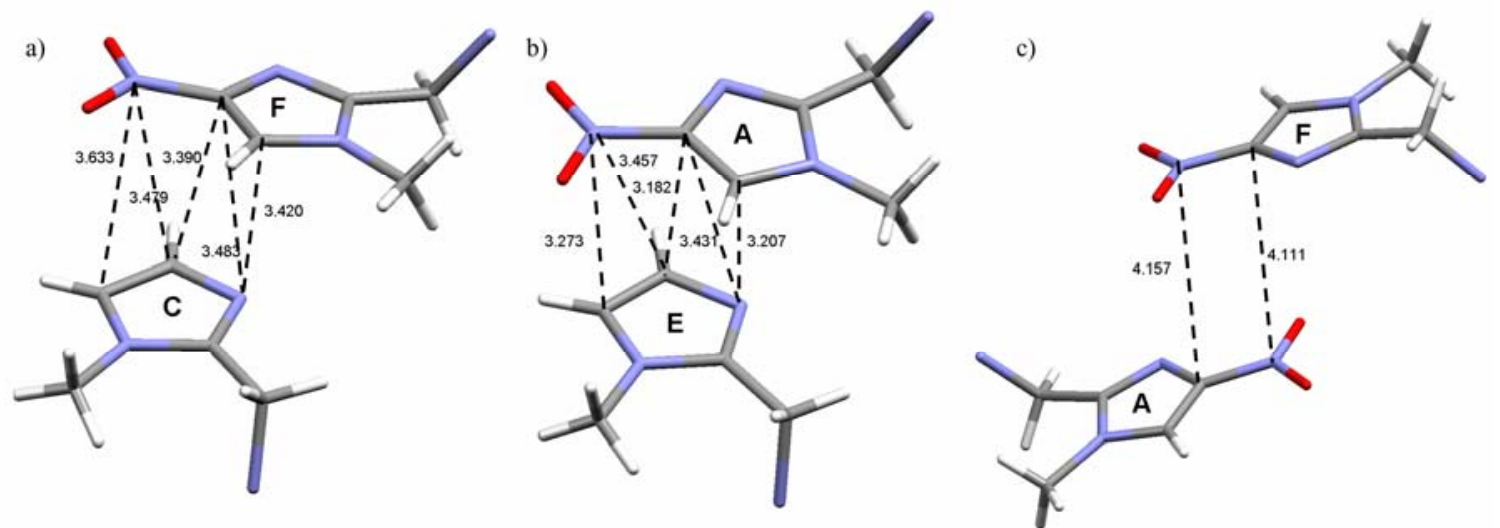

Figure 56. Closest interatomic contacts between $\pi$-stacked imidazole molecules associated with rings a) $\mathrm{F}$ and $\mathrm{C}, \mathrm{b}$ ) $\mathrm{A}$ and $\mathrm{E}, \mathrm{c}$ ) $\mathrm{A}$ and $\mathrm{F}$.

The resulting fusion of the two one-dimensional coils into a larger interlocked structure shown in Figure 55 (c and d) generates a continuous one-dimensional channel contoured around the $\mathrm{B}(\mathrm{OH})_{3}$ molecules. The boric acid molecules are stacked unsymmetrically in a continuous chain within the channel, and boron atoms are separated by 7.311 and $8.587 \AA$. The B---B---B angle between neighboring boron atoms is $167^{\circ}$. The widest dimension of the channel is approximately $2.8 \times 2.8 \AA^{2}$, ideally suited to accommodate a boric acid molecule whose molecular radius is $2.573 \AA^{3}$ (Brown, P. H. et al., 2002). The narrowest region of the channel is $2.514 \AA$ between N6 (ring B) and H1 $1 \mathrm{~b}$ associated with the methylene backbone of an imidazole tripod. In addition, Figure 55 (c and d) also shows the opposing orientation of the nitro groups on the surface of the sideby-side coiled units.

Figure 59 shows the arrangement of neighboring units bundled in the crystallographic be plane. There are several types of interactions that zip the individual units together. First, along the crystallographic $\mathrm{c}$ axis, adjacent bundles are interlocked via a weak slipped $\pi$-stack between the nitro $\mathrm{C}-\mathrm{N}$ bonds of rings $\mathrm{A}$ and $\mathrm{F}$ with a separation of $4.111 \AA$ (Figure 56). 

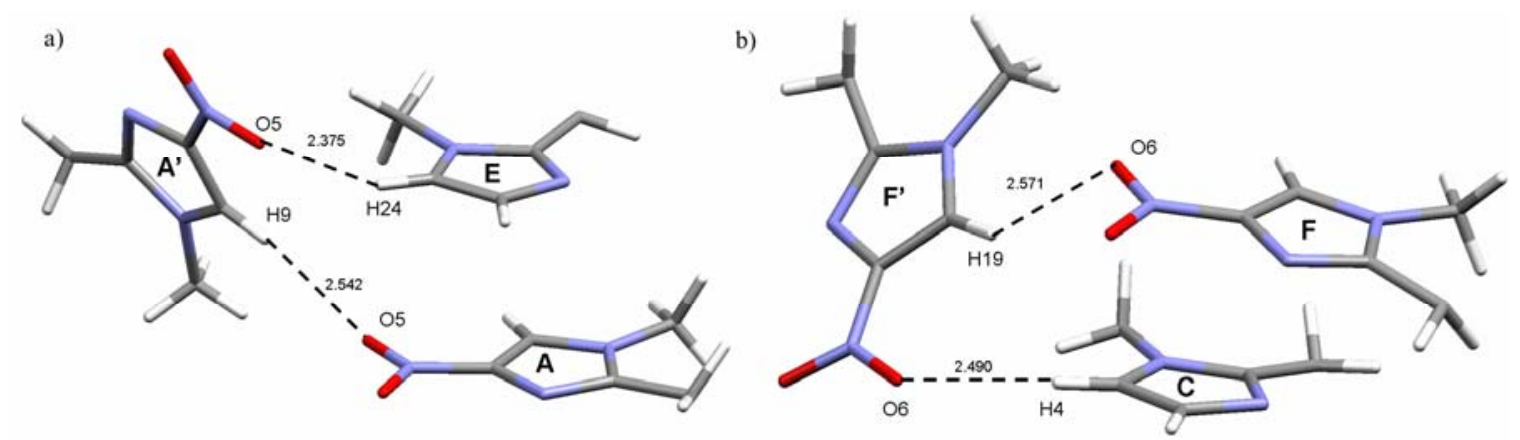

Figure 57. Weak intermolecular hydrogen bonding contacts between nitro group oxygens and imidazole ring hydrogens.

In addition, the nitro groups are weakly hydrogen bonded to symmetry related imidazole ring hydrogens associated with neighboring helices projected along the crystallographic b axis, as observed for the nitroimidazole compounds 41 and $\mathbf{4 2}$. The O5---H9" separation between imidazole A rings is $2.542 \AA$ and the O5---H9"-C9" angle is $143^{\circ}$. Similarly, the nitro group of the same A ring is directed towards $\mathrm{H} 24^{\prime \prime}$ of ring E with a O5---H24" separation of $2.375 \AA$ and an O5---H24"-C24" angle of $124^{\circ}$ (Figure 57). In the same manner, O6" of ring F is weakly interacting with H19" of the symmetry related ring F and H4" of ring C with separations of 2.571 and $2.491 \AA$ and O6---H19”C19” and O6---H4”-C4" angles of 141 and 176 , respectively (Figure 57).
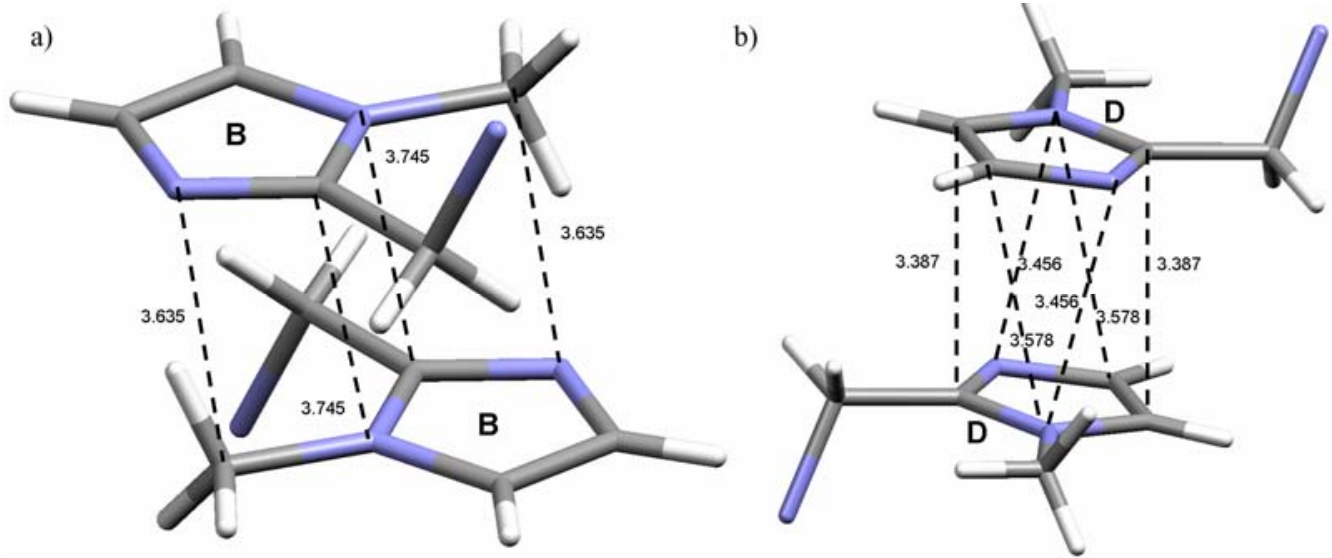

Figure 58. Closest interatomic contacts between $\pi$-stacked imidazole molecules associated with rings a) $\mathrm{B}$ and $\mathrm{B}, \mathrm{b}) \mathrm{D}$ and $\mathrm{D}$. 
The supramolecular assembly of the interlocked coils of $\mathbf{4 4}$ is further stabilized by strong parallel $\pi-\pi$ stacking of the two remaining imidazole rings, B and D, along the crystallographic b axis (Figure 58).

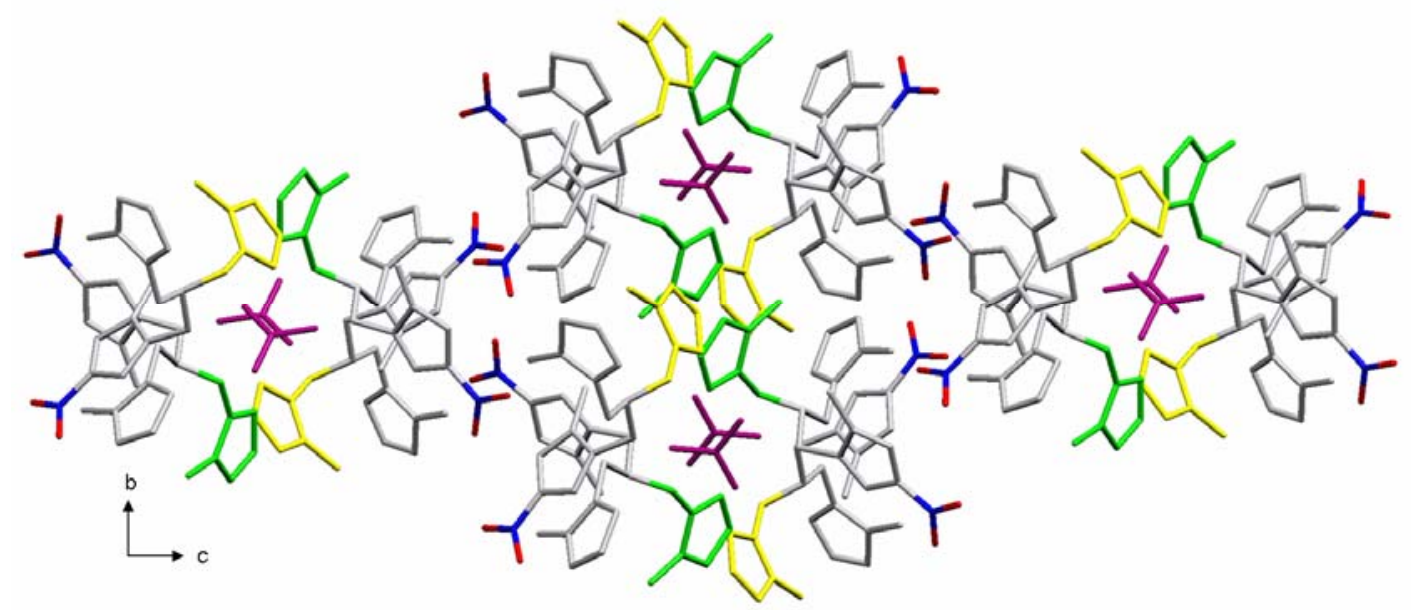

Figure 59. Packing diagram of $\mathbf{4 4}$ projected along the crystallographic be plane showing the intermolecular hydrogen bonding and parallel $\pi-\pi$ stacking interactions between neighboring interlocked coiled units. Boric acid molecules are represented in purple, weak $\pi$ interactions between imidazole nitro groups in blue $(\mathrm{N})$ and red $(\mathrm{O})$, and $\pi-\pi$ stacking between imidazole rings in green (B) and yellow (D). All hydrogen atoms have been omitted for clarity.

The shortest separation between ring B and its symmetry related neighbor is 3.426

$\AA$, while a slightly shorter separation of $3.387 \AA$ is observed between symmetry related D rings.

In conclusion, the incorporation of a nitro group in the structure of compound $\mathbf{4 4}$ alters its supramolecular architecture, compared to $\mathbf{4 3}$, from a two-dimensional to a threedimensional structure of weak intermolecular interactions. Furthermore, non-covalent interactions, such as those described above, are thought to be important in stabilizing paired helices in membranes (Choma, C. et al., 2000). In fact, Popot (Popot, J. L. \& Engelman, D. M., 2000) has noted recently that the presence of weak van der Waals contacts on the surface of complementary helices, as well as the presence of surface 
prosthetic groups, favor side-by-side helical association. The weak intermolecular interactions present in the supramolecular structure of $\mathbf{4 4}$, therefore, model the interactions responsible for stabilizing membrane bundled helices and channels (Zhang, P. J. et al., 1998) used to transport ions, water, glycerol and other small molecules. This study also supports our recent findings that weak van der Waals interactions involving imidazole compounds can lead to supramolecular assemblies containing biologically relevant water channels having novel one-dimensional water structures (Cheruzel, L. E. et al., 2003) (see Chapter VIII). 


\section{CHAPTER VII}

\section{REACTIVITY OF CU(II) COMPLEXES WITH $\mathrm{H}_{2} \mathrm{O}_{2}$}

\section{A. Introduction}

In metalloenzymes, copper and iron govern the field of dioxygen chemistry (Holm, R. H. et al., 1996b). Copper active sites can reversibly bind and store dioxygen as in hemocyanin (Solomon, E. I. et al., 1994). These species also utilize dioxygen in substrate activation. In the case of galactose, amine and catechol oxidases, the reduction of oxygen to hydrogen peroxide is coupled with substrate oxidation (Klinman, J. P., 1996). In the case of dopamine $\beta$-oxygenase, peptidylglycine monooxygenase and tyrosinase, the $\mathrm{Cu}$-peroxide species generated by the reduction of dioxygen is used in the hydroxylation of substrates (Klinman, J. P., 1996; Solomon, E. I. et al., 1996). Finally, specific copper metalloenzymes carry the fundamental four-electron reduction of dioxygen to water, coupled to substrate oxidation (laccase and ascorbate oxidase) (Solomon, E. I. et al., 1996) or to the pumping of protons through membrane (cytochrome c oxidase) (FergusonMiller, S. \& Babcock, G. T., 1996).

Depending on the number of metal centers, the copper metalloenzymes can be divided further in three sub-families (Solomon, E. I. et al., 2001). The first group includes mononuclear species that require a cofactor to perform the reduction of dioxygen coupled to substrate oxidation (e.g. galactose, amine oxidase). The non-coupled binuclear copper metalloenzymes constitute the second class. Their metal centers are not 
magnetically coupled and are located further than $11 \AA$ apart. Oxygen reduction in these species is thought to occur at only one copper center. The putative $\mathrm{Cu}-\mathrm{OOH}$ species involved is thought to be responsible for the $\mathrm{C}-\mathrm{H}$ atom abstraction from the substrate followed by $\cdot \mathrm{OH}$ hydroxylation, originating from the homolytic cleavage of the bonded peroxide O-O bond (Chen, P. \& Solomon, E. I., 2004). Finally, the trinuclear copper cluster found in laccase and ascorbate oxidase completes the family of copper metalloenzyme that utilize dioxygen.

Modeling of such copper metalloenzyme active sites has been a challenging endeavor. A report of the structural model of oxy-hemocyanin by Kitajima et al. in 1992 initiated the field of copper/dioxygen biomimetic studies (Kitajima, N. et al., 1992). Since then, studies have focused on the 1:1 and 2:1 copper/dioxygen model compounds, as well as a structural model of laccase reported by Cole et al. (Cole, A. P. et al., 1996). To date, only five mononuclear $\mathrm{Cu}-\mathrm{OOH}$ species have been characterized, and only two of them by X-ray crystallography (Chen, P. et al., 2000; Wada, A. et al., 1998). The 2:1 $\mathrm{Cu} / \mathrm{O}_{2}$ species have been more intensively investigated because $\mathrm{Cu}_{2} \mathrm{O}_{2}$ species are the more thermodynamically favored species (Que, L. \& Tolman, W. B., 2002).

Mechanistic studies using fast quenching methods have established, using model complexes, that a mononuclear end-on hydroperoxo-copper(II) is formed first, which rapidly reorganizes to generate a side-on peroxo copper(II) species. Addition of an extra $\mathrm{Cu}(\mathrm{II})$ center generates the $\mu-\eta^{2}: \eta^{2}$-peroxodicopper(II) species (Osako, T. et al., 2002). From these studies, specific spectroscopic features have been identified for each intermediate. Because of the intense peroxide-to-copper charge-transfer transition, UVvisible spectroscopy has been shown to be a powerful tool to characterize such species, as 
has resonance Raman spectroscopy. Indeed, spectra obtained by excitation of these charge-transfer transitions show $\mathrm{O}-\mathrm{O}$ stretches in regions characteristic of each species. To some extents, EXAFS spectroscopy has proved to be valuable, especially for dinuclear species where the second shell $(\mathrm{Cu}-\mathrm{Cu}$ interaction) can be effectively characterized.

For $\mathrm{Cu}-\mathrm{OOH}$ species, the peroxide-to-copper charge-transfer transition usually occurs in the $350 \mathrm{~nm}$ region with an absorption coefficient of around $1500 \mathrm{M}^{-1} \mathrm{~cm}^{-1}$. The $\mathrm{O}-\mathrm{O}$ stretch in the resonance Raman spectrum has usually been observed around 850 $\mathrm{cm}^{-1}$. For the $\mathrm{Cu}_{2} \mathrm{O}_{2}$ core, equilibrium between $\mu-\eta^{2}: \eta^{2}$-peroxodicopper(II) and the bis- $\mu$ oxo $\mathrm{Cu}(\mathrm{III})_{2}$ has been found to depend on the concentration, temperature, ligand hindrance and the coordination properties of the solvent and the counterions (Que, L. \& Tolman, W. B., 2002). Both species have spectroscopic signatures. The bis- $\mu$-oxo $\mathrm{Cu}(\mathrm{III})_{2}$ species shows two intense bands in the 300 and $400 \mathrm{~nm}$ with absorption coefficients ranging from 13000 to $25000 \mathrm{M}^{-1} \mathrm{~cm}^{-1}$. The $\mu-\eta^{2}: \eta^{2}$-peroxodicopper(II) complex exhibits one intense charge-transfer band around $350 \mathrm{~nm}\left(\varepsilon \approx 25000 \mathrm{M}^{-1} \mathrm{~cm}^{-1}\right)$ and a less intense band in the $530 \mathrm{~nm}$ region with $\left(\varepsilon \approx 2000 \mathrm{M}^{-1} \mathrm{~cm}^{-1}\right)$. The resonance Raman spectra for the latter compounds are diagnostic with the presence of a peroxide bound $\mathrm{O}-\mathrm{O}$ stretch in the $720 \mathrm{~cm}^{-1}$ region. A vibration around $510 \mathrm{~cm}^{-1}$ in the resonance Raman spectrum of the bis- $\mu$-oxo $\mathrm{Cu}(\mathrm{III})_{2}$ species has been assigned to the "breathing" mode of the diamond core. These spectroscopic features reflect the electronic differences between the two structurally similar binuclear compounds, which also results in differences in reactivity. There are still some mechanistic issues that need to be unraveled, but it is accepted that bis- $\mu$-oxo $\mathrm{Cu}(\mathrm{III})_{2}$ species are involved in substrate 
oxidation through $\mathrm{H}$-atom abstraction, where the $\mu-\eta^{2}: \eta^{2}$-peroxodicopper(II) species is presumably competent to perform oxo-transfer reactions (Taki, M. et al., 2002). Substrates can be exogenous molecules, but often the chelating ligand is oxidized during the reaction.

The synthetic $\mathrm{Cu}: \mathrm{O}_{2}$ adducts are usually generated through the exposure of copper(I) complexes with dioxygen at low temperature. However, room temperature $\mu$ $\eta^{2}: \eta^{2}$-peroxodicopper(II) complexes have been characterized recently (Kodera, M. et al., 2004). Also, the reaction of hydrogen peroxide and $\mathrm{Cu}(\mathrm{II})$ complexes have been used to generate $\mathrm{Cu}$-peroxo species. Most of the studies to date have used aprotic and non-polar solvents with amine, pyridine and pyrazole ligands. This study will focus on reactions in protic media using bis-imidazole chelates.

We have been interested in investigating the reactivity of $\mathrm{Cu}(\mathrm{II})$ model complexes with imidazole based ligands and report herein the reactivity of two $\mathrm{Cu}(\mathrm{II})$ model complexes with hydrogen peroxide and the generation of biologically relevant peroxidecopper species. The room temperature species generated by the addition of hydrogen peroxide to an aqueous solution of compounds 13 and 14 (Chapter III) produces spectroscopic features relevant to a bis- $\mu$-oxo $\mathrm{Cu}(\mathrm{III})_{2}$ species. Ligands with different coordination abilities (bi, tri and tetradentate) have been used to generate reactive $\mathrm{Cu}$ peroxide species (Que, L. \& Tolman, W. B., 2002). Equilibrium studies involving $\mu$ $\eta^{2}: \eta^{2}$-peroxodicopper(II) and bis- $\mu$-oxo $\mathrm{Cu}(\mathrm{III})_{2}$ species suggest that a bidentate ligand with strong $\sigma$-donating amine donors lacking bulky substituents is more suitable in stabilizing bis- $\mu$-oxo $\mathrm{Cu}(\mathrm{III})_{2}$. Hence, the $\mathrm{L}^{\mathrm{Et}, \mathrm{Me}}$ ligand of $\mathbf{1 3}$ and $\mathbf{1 4}$ has the desired prerequisite steric bulk. On the other hand, the rational design of ligands bearing 
intramolecular hydrogen bonding groups, mimicking the so-called second coordination sphere found in metalloenzyme active sites, have been used for the stabilization and characterization of mononuclear peroxide species. Thus, we have explored the reactivity of a $\mathrm{Cu}(\mathrm{II})$ complex of the biologically relevant imidazole $\mathbf{L 2}$ ligand, compound 36, (Chapters IV and V) with hydrogen peroxide. We were able to successfully generate and characterize a mononuclear $\mathrm{Cu}-\mathrm{OOH}$ species. The peroxide species has been fully characterized by ESI-mass spectrometry, EPR, UV-visible and resonance Raman spectroscopy.

\section{B. Reactivity of Compounds $\mathbf{1 3}$ and $\mathbf{1 4}$ with Hydrogen Peroxide}

\section{UV-vis Characterization}

The formation of $\mathrm{Cu}$-peroxide species with both $\mathrm{Cu}(\mathrm{II})$ complexes, compounds $\mathbf{1 3}$ and 14 (previously characterized in Chapter III) were investigated. The addition of hydrogen peroxide to aqueous solutions of both complexes was accompanied by an immediate color change to bright yellow. Generally, this reaction was conducted at room temperature in the following manner: to an aqueous $10^{-4} \mathrm{M}$ solution of the $\mathrm{Cu}$ (II) complex was added $1 \mu \mathrm{L}$ of $1 \mathrm{M} \mathrm{KOH}$ and $1 \mu \mathrm{L}$ of $3 \% \mathrm{H}_{2} \mathrm{O}_{2}$ in water at room temperature. The color change was followed by UV-visible spectroscopy. The UV-visible spectrum displays two intense features at $360 \mathrm{~nm}$ and $450 \mathrm{~nm}$ with $\varepsilon=13000 \mathrm{M}^{-1} \mathrm{~cm}^{-1}$ per $\mathrm{Cu}$ atom (Figure 60).

The intense features in Figure 60 could be observed at room temperature for 30 minutes, after which time they decreased in intensity indicating decomposition of the compound. These intense charge-transfer transitions are reminiscent of the bis- $\mu$-oxo $\mathrm{Cu}(\mathrm{III})_{2}$ fingerprints observed by others (Quant, L. D. et al., 2003). Because we did not 
observe loss of the $\mathrm{L}^{\mathrm{Et}, \mathrm{Me}}$ ligand during the reaction, we assumed that the two $\mathrm{L}^{\mathrm{Et}, \mathrm{Me}}$ ligands were still coordinated to the bis- $\mu$-oxo $\mathrm{Cu}(\mathrm{IIII})_{2}$ core unit. In fact, Kitagawa and coworkers reported the crystal structure of a bis- $\mu$-oxo $\mathrm{Cu}(\mathrm{III})_{2}$ with the tetradentate ligand bis-(6-methyl-2-pyridyl-methyl)(2-pyridylmethyl)amine ( $\mathrm{Me}_{2}$-tpa) where each copper center has a square planar arrangement composed of a $\mathrm{N}_{2} \mathrm{O}_{2}$ set of donors (Hayashi, H. et al., 2000). The two remaining pyridine nitrogen atoms were found to be interacting weakly (2.48 and $2.55 \AA$ ) with the copper (Hayashi, H. et al., 2000).

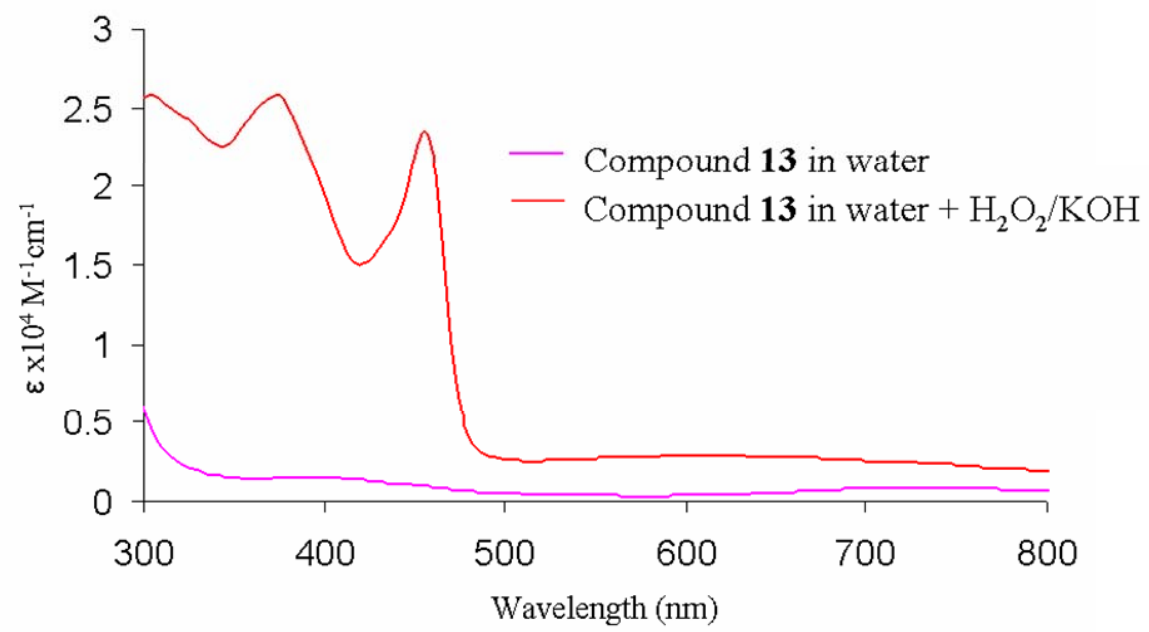

Figure 60. UV-visible spectrum of the proposed $\left[\mathrm{Cu}(\mathrm{III})_{2}\left(\mu-\mathrm{O}_{2}\right)\left(\mathrm{L}^{\mathrm{Et}, \mathrm{Me}}\right)_{2}\right] \mathrm{Cl}_{2}$ species.

The formation of the bis- $\mu$-oxo $\mathrm{Cu}(\mathrm{III})_{2}$ species was further suggested by EPR studies. The bright yellow solution produced after addition of $\mathrm{H}_{2} \mathrm{O}_{2}$ is EPR-silent, which is consistent with the formation of a diamagnetic species. These results can be interpreted as arising from the possible formation of three different species: i) two $\mathrm{Cu}(\mathrm{I})$ centers, ii) two magnetically coupled $\mathrm{Cu}(\mathrm{II})$ centers, or iii) two $\mathrm{d}^{8} \mathrm{Cu}(\mathrm{III})$ centers. To exclude the possibility of $\mathrm{Cu}(\mathrm{I})$ species in solution, we independently synthesized a $\mathrm{Cu}(\mathrm{I})$ complex of $\mathrm{L}^{\mathrm{E}, \mathrm{Me}}$ that does not display the features in the visible region of the electronic spectrum (Figure 60). In addition, the reaction of the $\mathrm{Cu}(\mathrm{I})$ complex with dioxygen does not 
generate the bright yellow solution observed above. The only compound isolated from the $\mathrm{Cu}(\mathrm{I}) / \mathrm{O}_{2}$ reaction solution was the square planar $\mathrm{Cu}(\mathrm{II})$ compound, $\left[\mathrm{Cu}\left(\mathrm{L}^{\mathrm{Et}, \mathrm{Me}}\right)_{2}\right]\left(\mathrm{PF}_{6}\right)_{2}(\mathbf{1 1})$, described in Chapter III. Attempts to identify a $\mathrm{Cu}(\mathrm{II})_{2}$-peroxide species from the reaction by resonance Raman spectroscopy were impeded because of the intense fluorescence of the sample. No discernable vibrational stretches could be detected.

2. Reactivity of the $\mathrm{L}^{\mathrm{Et}, \mathrm{Me}}$ Ligand

It is worth noting that the addition of an extra $10 \mu \mathrm{L}$ aliquot of $\mathrm{H}_{2} \mathrm{O}_{2}$ to the initial yellow solution produced an intense band at $450 \mathrm{~nm}$ with an $\varepsilon$ value of $100,000 \mathrm{M}^{-1} \mathrm{~cm}^{-1}$ (Figure 61).

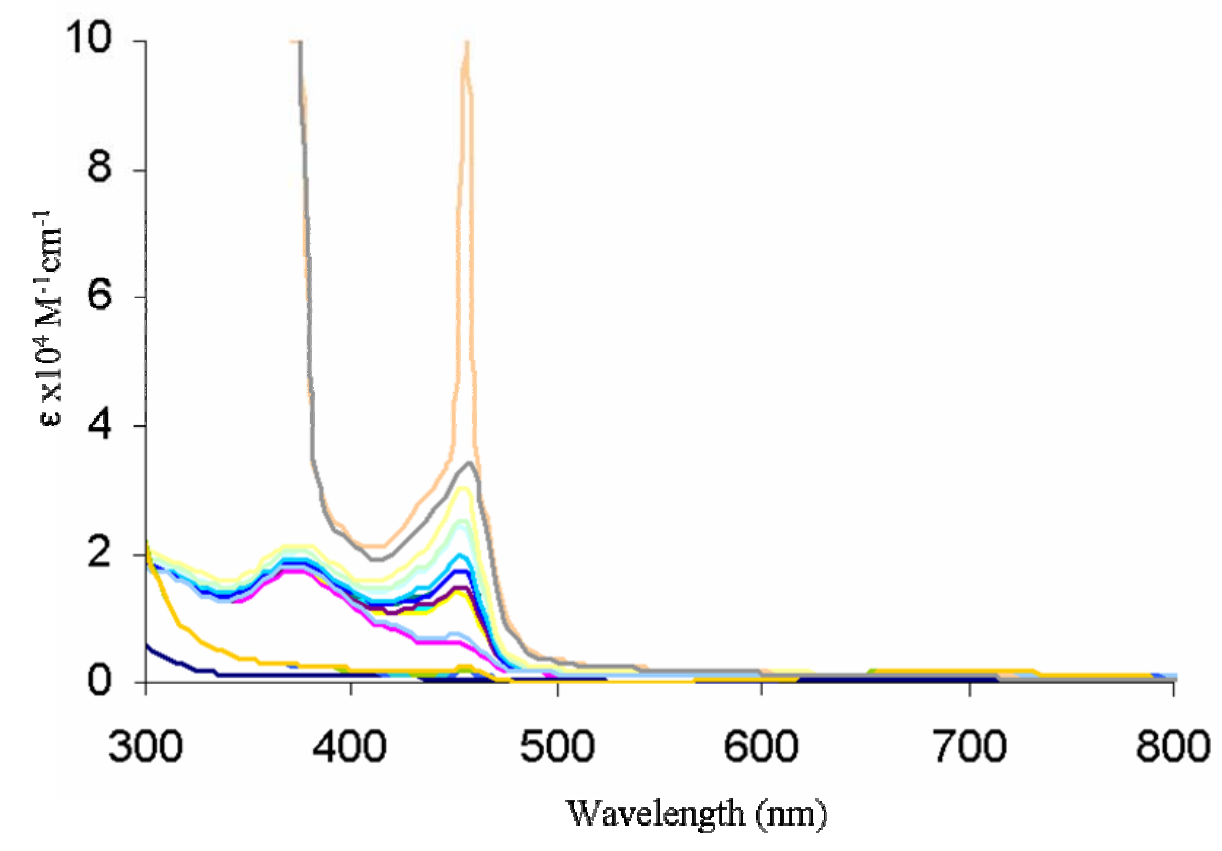

Figure 61. UV-vis spectra of the further reaction of compounds $\mathbf{1 3}$ and $\mathbf{1 4}$ with $\mathrm{H}_{2} \mathrm{O}_{2}$ consistent with the oxidation of the ligand and the generation of an organic radical. 
This band was too intense to be attributed to a ligand-to-metal charge-transfer transition associated with a bis- $\mu$-oxo $\mathrm{Cu}(\mathrm{III})_{2}$ species, but rather is indicative of an organic chromophore and suggestive of an oxidative process involving the ligand.

We then turned our attention to evaluating the reactivity of the $\mathrm{L}^{\mathrm{Et}, \mathrm{Me}}$ ligand. A related system, lophine (Hu, Z. Z. et al., 2000) shown in Figure 62, is known to chemiluminesce, although the mechanism of the process is still unclear. Lophine is a hydroperoxide trisubstituted imidazole compound (see Figure 62) (Nakashima, K., 2003) whose chemiluminescence is generated in solution in the presence of a strong base. This observation prompted us to explore the reaction of the $\mathrm{L}^{\mathrm{Et}, \mathrm{Me}}$ ligand with hydrogen peroxide. Interestingly, the intense yellow color, as well as the strong charge-transfer transition (Figure 61) were reproduced by simply reacting an aerated DMSO solution of the $\mathrm{L}^{\mathrm{Et}, \mathrm{Me}}$ with concentrated aqueous $\mathrm{KOH}$. Curiously, no color change was observed when the DMSO reaction solution was deareated, or an aerated methanolic solution was used instead. It has been shown that a superoxide anion could be generated in aerated DMSO by the addition of strong base (Qiao, X. L. et al., 2001).

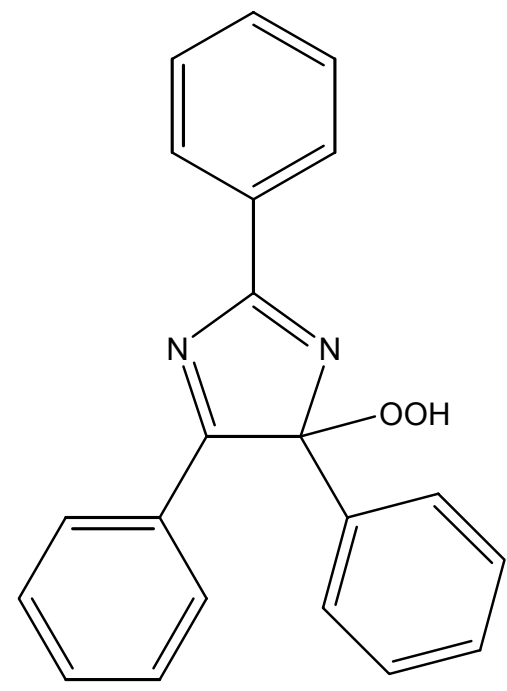

Figure 62. Representation of the molecular structure of lophine. 
Therefore, it seems reasonable that in DMSO and in the presence of superoxide anion, the $\mathrm{L}^{\mathrm{E}, \mathrm{Me}}$ ligand displays luminescence behavior similar to that of lophine, which is thought to involve the formation and degradation of a peroxide species (Hu, Z. Z. et al., 2000). It is also conceivable that similar chemistry on the ligand could occur as a result of either the intra or intermolecular attack of a copper-peroxide species on a $\mathrm{L}^{\mathrm{Et}, \mathrm{Me}}$ ligand through the cleavage of the Cu-peroxide bond (Fenton Chemistry) (Sawyer, D. T. et al., 1996).

\section{EPR Characterization}

We further characterized the reactivity of the $\mathrm{L}^{\mathrm{Et}, \mathrm{Me}}$ ligand by EPR spectroscopy, where the presence of a sharp signal at $\mathrm{g}=2.029$ is consistent with an organic radical. The EPR spectrum of the organic radical could be generated from either the reaction of the $\mathrm{Cu}$ (II) species with hydrogen peroxide or from the DMSO/KOH chemistry (Figure $63)$.

The EPR spectrum of compound $\mathbf{1 3}$ in $\mathrm{MeOH}$ at $77 \mathrm{~K}$ (blue trace) is consistent with a species having a distorted tetragonal arrangement $\left(\mathrm{g}_{/ /}=2.27, \mathrm{~g}_{\perp}=2.08, \mathrm{~A}_{/ /}=150\right.$ G) (see Chapter III). The green trace in Figure 63 results from the addition of 1:1 $\mathrm{H}_{2} \mathrm{O}_{2} /$ base to a $\mathrm{MeOH}$ solution of compound $\mathbf{1 3}$ followed by rapid freezing (intensity of the $\mathrm{Cu}$ signal decreases by $\sim 50 \%)$. Warming the solution to room temperature $(\sim 1$ minute), then rapidly freezing it to $77 \mathrm{~K}$ produced the spectrum associated with the red trace that contains an intense isotropic signal at $\mathrm{g}=2.029$ (and less than $5 \%$ of the original tetragonal copper signal). Similar spectral behavior is observed for compound $\mathbf{1 3}$ in the presence of tert- $\mathrm{BuOOH} / \mathrm{base}$ in $\mathrm{MeOH}$ at $77 \mathrm{~K}$, suggesting the isotropic signal arises from the same species, possibly a radical form of the $\mathrm{L}^{\mathrm{Et}, \mathrm{Me}}$ ligand. 
To determine if the radical species is free in solution, we recorded the EPR spectrum of $\mathrm{L}^{\mathrm{Et}, \mathrm{Me}}$ in aerated DMSO and in the presence of a base (same conditions that produce the intense band at $450 \mathrm{~nm}$ in Figure 61). The EPR spectrum in Figure 63 (red trace) shows the presence of a radical species with a $g$ value of 2.029 , which differs from the anisotropic spectrum of the superoxide ion $\left(\mathrm{g}_{/ /}=2.102, \mathrm{~g}_{\perp}=2.008\right)$ produced under the same conditions in DMSO/KOH in the absence of $\mathrm{L}^{\mathrm{Et}, \mathrm{Me}}$ (Qiao, X. L. et al., 2001). The species associated with the $g=2.029$ signal is tentatively assigned to a radical of $\mathrm{L}^{\mathrm{Et}, \mathrm{Me}}$

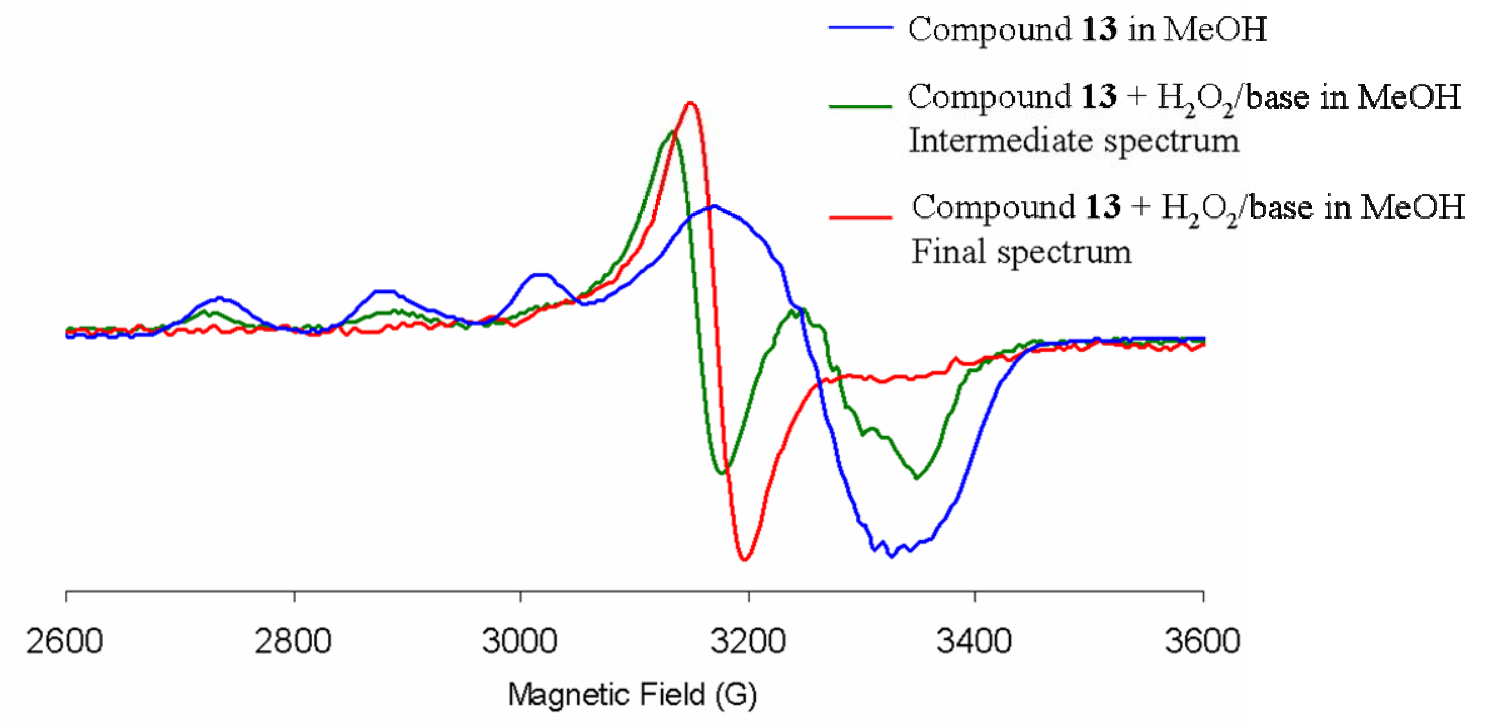

Figure 63. EPR spectra of the starting $\mathrm{Cu}(\mathrm{II})$ complex, 13, and the organic radical generated by the addition of excess hydrogen peroxide.

Similar radical species have been observed for histidine and other bis-imidazole ligands coordinated to $\mathrm{Cu}$ (and $\mathrm{Fe}$ ) in the presence of $\bullet \mathrm{OH}$ and $\bullet \mathrm{OR}$ radical (Gunther, $\mathrm{M}$. R. et al., 2002; Vandermeer, K. \& Mulder, J. J. C., 1975).

In conclusion, the addition of hydrogen peroxide to the starting compounds $\mathbf{1 3}$ or 14 generated in water, at room temperature, a peroxide-copper adduct that has the spectral features of a bis- $\mu$-oxo $\mathrm{Cu}(\mathrm{III})_{2} \mathrm{O}_{2}$ species. This species reacts further with the 
chelating ligand producing a lophine-like trisubstituted imidazole-peroxide species that undergoes chemiluminescence.

C. Isolation and Characterization of a Mononuclear $\mathrm{Cu}-\mathrm{OOH}$ Species with the $\mathbf{L 2}$ Ligand, (45)

As mentioned previously, mononuclear end-on $\mathrm{Cu}-\mathrm{OOH}$ species have been proposed as intermediates in the two non-coupled copper active sites of dopamine $\beta$ monooxygenase and peptidylglycine $\alpha$-hydroxylating monooxygenase (Klinman, J. P., 1996). Such species also have been characterized by low temperature stop-flow experiments as the precursor of binuclear Cu-peroxide species (Osako, T. et al., 2002). In the stop-flow experiment, $\mathrm{Cu}(\mathrm{II})$ complexes were reacted with hydrogen peroxide and the studies revealed a three-step process: first with the formation of an end-on hydroperoxo$\mathrm{Cu}(\mathrm{II})$ species, that reorganizes to a side-on peroxide species. This side-on peroxide species reacts further with an extra $\mathrm{Cu}(\mathrm{II})$ complex to generate the $\mu-\eta^{2}: \eta^{2}$ peroxodicopper(II) species.

In trying to generate and stabilize mononuclear end-on species, one has to deal both with their instability and their tendency to dimerize, forming the dinuclear core structures. To circumvent this, Masuda and coworkers have utilized the properties of an amido-pyridine ligand to isolate and crystallographically characterize a novel end-on hydroperoxide species (Wada, A. et al., 1998). With this in mind, we investigated the reaction of hydrogen peroxide with a $\mathrm{Cu}(\mathrm{II})$ complex, $\mathbf{3 6}$, of the biologically relevant ligand $\mathbf{L} 2$ having two amide-functionalized imidazole pendants (Chapter V). The reaction was followed by UV-visible spectroscopy, coupled with EPR to ensure the completeness 
of the reaction. In addition, the peroxide species was unambiguously characterized by resonance Raman spectroscopy and also ESI mass spectrometry.

\section{UV-vis Characterization of $[\mathrm{Cu}(\mathbf{L} 2) \mathrm{OOH}]^{+}$}

Typically, the addition of 10 eq. of $3 \% \mathrm{H}_{2} \mathrm{O}_{2}$ to a $1 \mathrm{mM}$ methanolic solution of compound 36 containing 1 eq. of base (usually $\mathrm{KOH}$ ) in methanol at $-40{ }^{\circ} \mathrm{C}$ is followed by an immediate change in color from green to yellow. The UV-visible spectrum of the green methanol solution $(1 \mathrm{mM})$ of compound 36 displays one transition at $365 \mathrm{~nm}(\varepsilon \approx$ $\left.430 \mathrm{M}^{-1} \mathrm{~cm}^{-1}\right)$ and a weak d-d transition around $765 \mathrm{~nm}\left(\varepsilon \approx 100 \mathrm{M}^{-1} \mathrm{~cm}^{-1}\right)$ (Figure 64). The addition of 1 eq. of $\mathrm{KOH}$ to this solution results in the formation of a band at $300 \mathrm{~nm}$ with an extinction coefficient $\varepsilon$ of $2500 \mathrm{M}^{-1} \mathrm{~cm}^{-1}$. Further addition of 10 eq. of either $30 \%$ or $3 \%$ aqueous $\mathrm{H}_{2} \mathrm{O}_{2}$ produced a color change of the solution from green to yellow, and the appearance of a band at $365 \mathrm{~nm}$ with an extinction coefficient of $1500 \mathrm{M}^{-1} \mathrm{~cm}^{-1}$, consistent with other reported $\mathrm{Cu}-\mathrm{OOH}$ species (Wada, A. et al., 1998). This band has been assigned to a peroxo $\pi^{*}{ }_{\sigma} \rightarrow \mathrm{Cu}$ charge-transfer transition (Chen, P. et al., 2000).

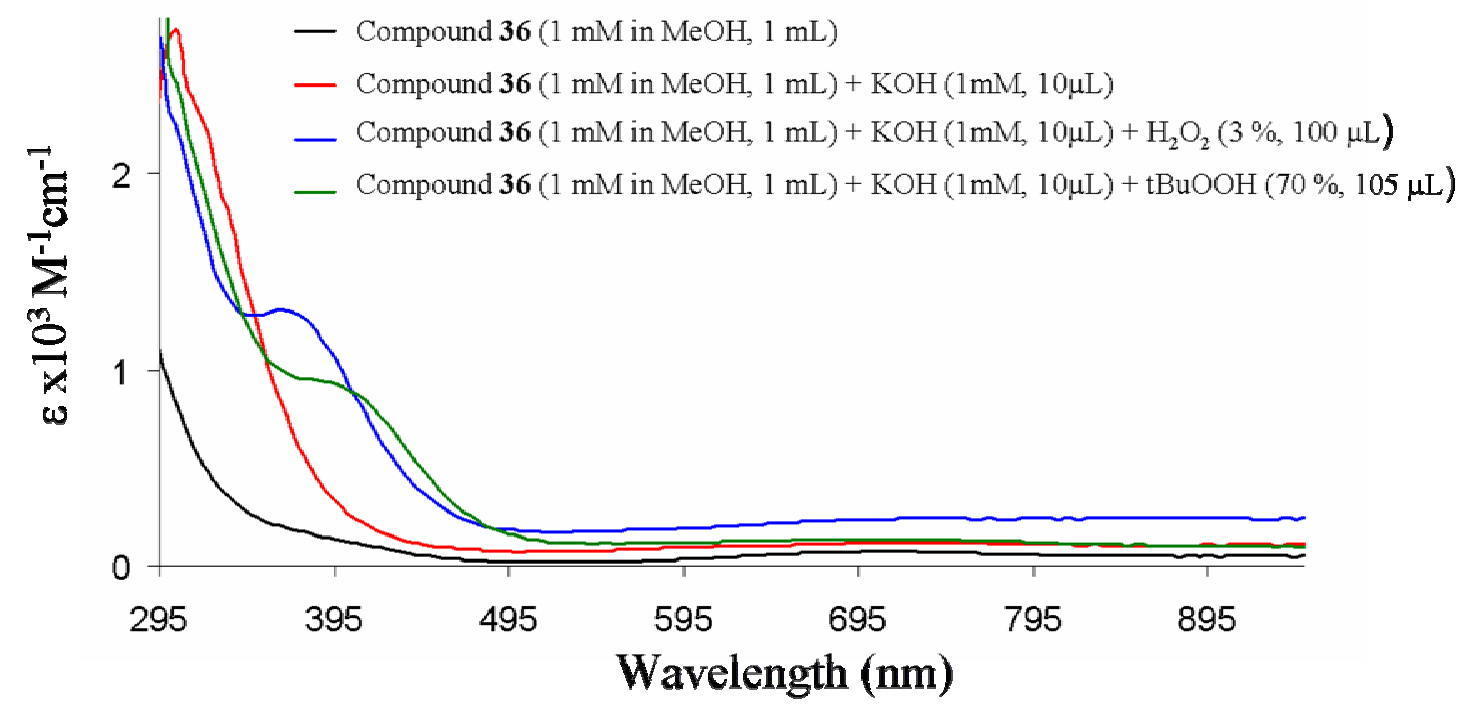

Figure 64. UV-visible spectra of the starting material compound $\mathbf{3 6}$ and its peroxo species generated by the addition of alkyl- and hydroperoxide. 
Similarly, the addition of 80 eq. of an aqueous tert-butylperoxide (70\%) to a methanol solution of 36 produced an absorption band at $395 \mathrm{~nm}\left(\varepsilon\right.$ of $\left.1000 \mathrm{M}^{-1} \mathrm{~cm}^{-1}\right)$, indicative of the formation of a tert-butylperoxo species.

\section{2. $\quad$ EPR characterization of $[\mathrm{Cu}(\mathbf{L} 2) \mathrm{OOH}]^{+}$}

UV-visible and EPR spectroscopy were used to evaluate the completeness of the reaction. After the addition of hydrogen peroxide to the reaction solution, an aliquot was withdrawn and its EPR spectrum was recorded at $77 \mathrm{~K}$. Figure 65 shows the frozen solution spectrum of the reaction mixture, which is indicative of a distorted fivecoordinate geometry. From computer simulation, the following magnetic parameters were obtained: $\mathrm{g}_{3}=2.225, \mathrm{~g}_{2}=2.065, \mathrm{~g}_{1}=2.045$ and $\mathrm{A}_{3}=135, \mathrm{~A}_{2}=25, \mathrm{~A}_{1}=60$. An $\mathrm{R}$ value of 0.13 indicates a $\mathrm{d}_{\mathrm{x}^{2}-\mathrm{y}^{2}}$ ground state and a geometry around the $\mathrm{Cu}$ close to square pyramidal.

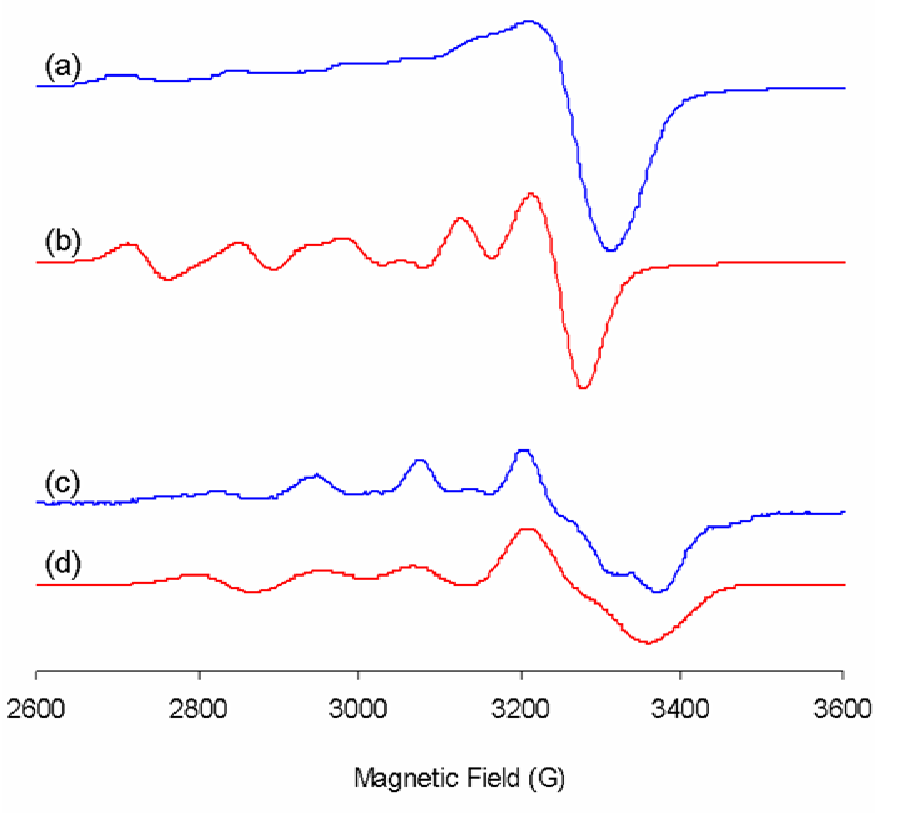

Figure 65. EPR spectra of frozen methanol solution of (a) compound $\mathbf{3 6}$ and (c) compound $\mathbf{4 5}$ and their simulations ((b) and (d), respectively). 
This spectrum differs from that of the starting material, compound 36, which also displays a rhombic spectrum with $\mathrm{g}_{3}=2.295, \mathrm{~g}_{2}=2.10, \mathrm{~g}_{1}=2.08$ and $\mathrm{A}_{3}=135, \mathrm{~A}_{2}=35$, $A_{1}=15$ (Figure 65). An $R$ value of 0.10 for this compound also indicates a $d_{x^{2}-y^{2}}$ ground state and a geometry around the $\mathrm{Cu}$ close to square pyramidal.

\section{Resonance Raman Characterization of $[\mathrm{Cu}(\mathbf{L} 2) \mathrm{OOH}]^{+}$}

Finally, the end-on hydroperoxo species was unambiguously characterized by resonance Raman spectroscopy. Excitation into the tail of the $365 \mathrm{~nm}$ charge-transfer transition (laser excitation wavelength $514.5 \mathrm{~nm}$ ) revealed a resonance-enhanced vibration at $854 \mathrm{~cm}^{-1}$ that shifted to $808 \mathrm{~cm}^{-1}\left(\Delta v=46 \mathrm{~cm}^{-1}\right)$ when ${ }^{18} \mathrm{O}$-labeled hydrogen peroxide was added (Figure 66). The region of the vibration as well as the shift upon ${ }^{18} \mathrm{O}$ exchange are consistent with an end-on hydroperoxo $\mathrm{Cu}(\mathrm{II})$ species (Wada, A. et al., 1998). Table 17 summarizes all the $v(\mathrm{O}-\mathrm{O})$ vibrations for all known hydroperoxo species and includes the position of the vibration observed in this study.

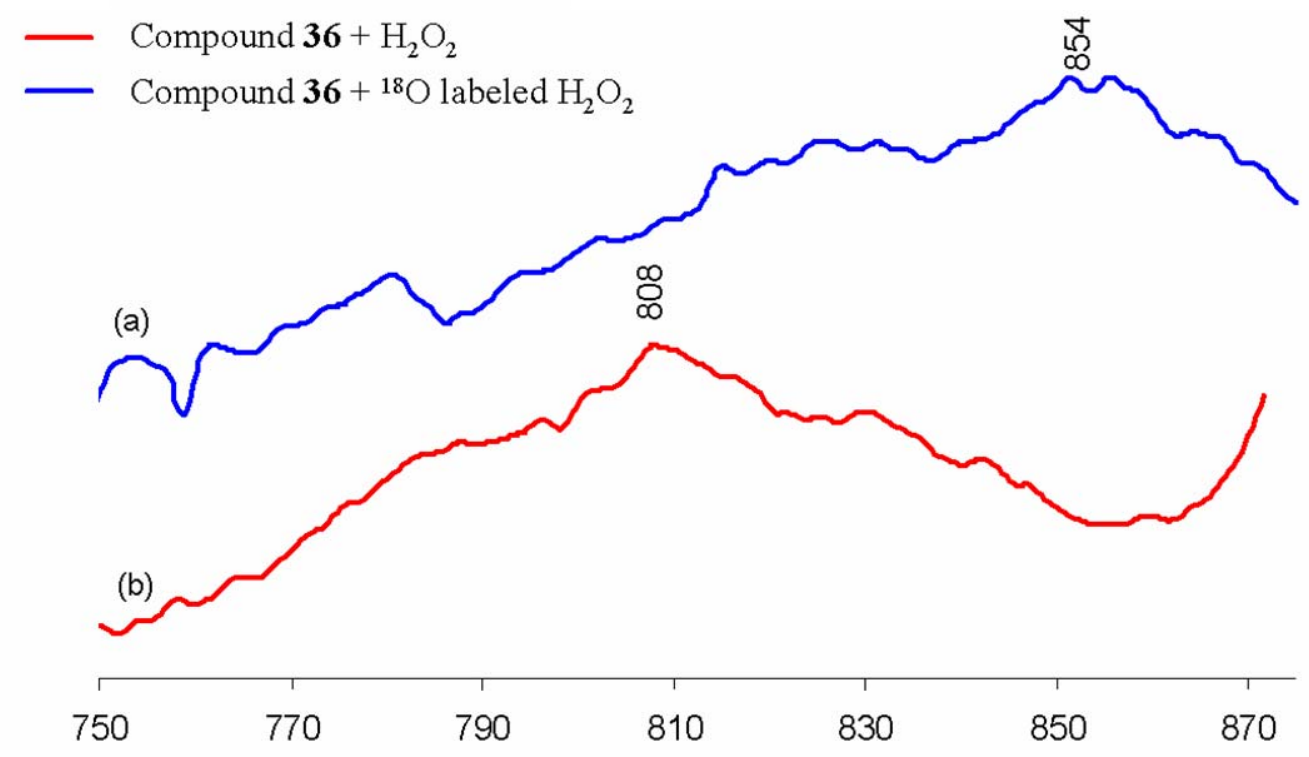

Figure 66. Resonance Raman spectra of (a) $\mathrm{Cu}(\mathbf{L 2})\left({ }^{16} \mathrm{O}^{16} \mathrm{OH}\right)$ and (b) $\mathrm{Cu}(\mathbf{L 2})\left({ }^{18} \mathrm{O}^{18} \mathrm{OH}\right)$. 
Table 17. Summary of resonance Raman $v(\mathrm{O}-\mathrm{O})$ vibrations for mononuclear $\mathrm{Cu}(\mathrm{II})-\mathrm{OOH}$ complexes.

\begin{tabular}{|c|c|c|}
\hline & $v\left({ }^{16} \mathrm{O}-{ }^{16} \mathrm{O}\right) \mathrm{cm}^{-1}$ & reference \\
\hline $\mathrm{Cu}\left(\mathrm{HB}(3-\mathrm{tBu}-5-\mathrm{iPrpz})_{3}\right)(\mathrm{OOH})$ & 843 & (Chen, P. et al., 2000) \\
\hline$\left[\mathrm{Cu}_{2}(\mathrm{bdpi})\right](\mathrm{OOH})$ & 848 & (Ohtsu, H. et al., 2001) \\
\hline$[\mathrm{Cu}(\mathrm{TEPA})](\mathrm{OOH})$ & 851 & (Osako, T. et al., 2002) \\
\hline $\mathrm{Cu}(\mathrm{L} 2) \mathrm{OOH}$ & 854 & this work \\
\hline $\mathrm{Cu}(\mathrm{bppa})(\mathrm{OOH})$ & 856 & (Wada, A. et al., 1998) \\
\hline $\mathrm{CuN}_{3} \mathrm{~S}-\mathrm{L} 1(\mathrm{OOH})$ & 881 & (Kodera, M. et al., 2001) \\
\hline
\end{tabular}

We have attempted to convert the end-on hydroperoxo species to a side-on peroxo species as established by Que's group for a Fe(III) model complex (Roelfes, G. et al., 2003). The addition of two equivalents of base to the methanol solution of $\mathrm{Cu}-\mathrm{OOH}$ did not affect the UV-visible nor the EPR spectra. It appears that the pocket generated by the L2 is too sterically hindered to accommodate a side-on peroxide species.

\section{4. $\quad$ ESI-MS Characterization of $[\mathrm{Cu}(\mathbf{L 2}) \mathrm{OOH}]^{+}$}

To further characterize the peroxide species, we utilized ESI-mass spectrometry. The yellow solution of $\mathrm{Cu}(\mathrm{II})-\mathrm{OOH}$ species displayed a cluster of peaks and a mass ion at $\mathrm{m} / \mathrm{z}$ 593.4. This species has the mass and isotopic distribution identical to the theoretical pattern predicted for $[\mathrm{Cu}(\mathbf{L 2})(\mathrm{OOH})]^{+}$(see Figure 67).

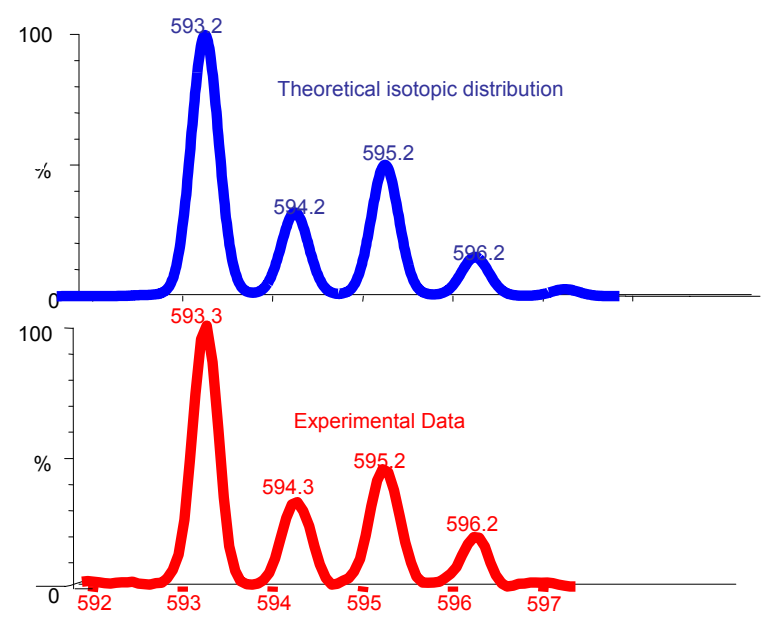

Figure 67. Theoretical and experimental mass ions for $[\mathrm{Cu}(\mathbf{L 2}) \mathrm{OOH}]^{+}$. 
From the results above, we have successfully established the formation of a mononuclear $\mathrm{Cu}(\mathrm{II})-\mathrm{OOH}$ species, stabilized by our amide functionalized imidazole ligand L2. The species was successfully characterized by UV-visible, EPR and Raman spectroscopy.

D. Summary

We investigated the reactions of hydrogen peroxide with two $\mathrm{Cu}(\mathrm{II})$ complexes containing biologically relevant imidazole ligands. The first compound displays spectroscopic features similar to those of a bis- $\mu$-oxo $\mathrm{Cu}(\mathrm{III})_{2}$ core species and was observed at room temperature and in water. The complex displayed intense chemiluminescence from the oxidization of the ligand. In the second $\mathrm{Cu}(\mathrm{II})$ complex, the bulky nature of the ligand prevents the formation of the thermodynamically favored $\mathrm{Cu}_{2} \mathrm{O}_{2}$ species. In addition, the presence of the amide functionalities of $\mathbf{L 2}$ assists in the stabilization of a biologically relevant mononuclear end-on hydroperoxide species. The compound was successfully characterized by various spectroscopic techniques. Further investigations involving the reactivity of these Cu-peroxide species with various exogenous substrates are in progress. 


\section{CHAPTER VIII}

\section{IMIDAZOLE/WATER INTERACTIONS}

\section{A. Background}

For such a simple molecule, water exhibits unusual properties (Stillinger, F. H., 1980). For example, water has numerous crystalline and amorphous polymorphs and displays a high mobility for the transport of protons (Ludwig, R., 2001). To date, studies have focused on understanding and explaining these properties at a molecular level. It has been known for a long time that water can form four hydrogen bonds arranged in a tetrahedral manner, where two hydrogens are donated to neighboring waters and two lone pairs form hydrogen bonds with additional neighboring oxygen atoms. Such interactions result in the formation of many complex water clusters of different sizes and shapes (e.g. pentamers, hexamers and also icosahedral and dodecahedral water structures).

The study of water clusters offers quantitative information about the interactions of the water at a molecular level as well as insights into the collective phenomena observed in liquid water and ice. Molecular dynamic simulations (Koga, K. et al., 2000), IR spectroscopy (Burnham, C. J. et al., 2002), X-ray crystallography and neutron diffraction (Janiak, C. et al., 2002) have been used to characterize these forms of water. Also, recent studies have focused on the various transition phases that occurred in supercooled water (Mishima, O. \& Stanley, H. E., 1998), amorphous water and ice. Interestingly, Zeng and coworkers have established that water ring sizes change during 
the liquid, amorphous and crystalline ice phase transitions in a hydrophobic slit pore (Koga, K. et al., 2000). They detected the presence of pentameric and heptameric water rings in addition to the observed hexameric structures of ice. Studies on the behavior of water molecules in hydrophobic environments have been driven in part by the importance of water/macromolecule interactions in biological systems (Papoian, G. A. et al., 2004; Teeter, M. M. et al., 2001).

Water has been found to play crucial roles in the structure and function of many biological macromolecules (Bizzarri, A. R. \& Cannistraro, S., 2002). For example, water molecules have been located in crystal structures buried within protein active sites, such as chymotrypsin (Pal, S. K. et al., 2002b) and serine proteases (Sreenivasan, U. \& Axelsen, P. H., 1992). These structural waters are conserved in many enzyme active sites and participate in the protein folding pathways. Bridging water molecules are postulated to play an important role in the formation and stabilization of helix-helix interactions in membranes (Popot, J. L. \& Engelman, D. M., 2000). In addition to structural waters, a shell of hydration at the surface of proteins is thought to be responsible for the stability and structure of the proteins (Modig, K. et al., 2004). Also, clusters of surface waters have been shown to participate in protein/protein recognition (Papoian, G. A. et al., 2003; Pardanani, A. et al., 1998; Zhao, L. et al., 2004). This shell of hydration has been found to be an integral part of the protein and the dynamic behavior of these waters is different from that of bulk-water (Bhattacharyya, S. M. et al., 2003). The surface waters have a much slower reorientational and translational dynamic behavior compared to the bulk water (Pal, S. K. et al., 2002a). 
An arrangement of water molecules that is still challenging the scientific community is one associated with proton and water transport. One-dimensional (1-D) water chain structures constitute a potentially important form of water that is poorly understood (Hummer, G. et al., 2001). Many fundamental biological processes appear to depend on the unique properties of water chains (Cukierman, S., 2000; Jude, K. M. et al., 2002; Kandori, H., 2000; Lanyi, J. K., 2000; Law, R. J. et al., 2000; Zaslavsky, D. \& Gennis, R. B., 2000; Zhong, Q. F. et al., 1998). For example, water chains may assist in proton translocation through membranes by functioning as "proton wires" (Decoursey, T. E., 2003; Tieleman, D. P. et al., 2001). Such behavior is illustrated by the membrane protein gramicidin A (gA) (Cukierman, S., 2000) where protons are envisioned (Pomes, R. \& Roux, B., 2002) to either hop along a single file chain of waters according to the Grotthuss relay mechanism, (Agmon, N., 1995) or migrate as $\mathrm{H}_{9} \mathrm{O}_{4}{ }^{+}$(Eigen, M., 1963) or $\mathrm{H}_{5} \mathrm{O}_{2}{ }^{+}$(Zundel, G. \& Metzger, H., 1967) ionic water clusters.

In addition, water chains appear to be important to the proton pathways in the cytochrome b6f complex of plant chloroplast thylakoid membrane and mitochondrial ATPase (Carrozzo, R. et al., 2004), and carbonic anhydrase V (Jude, K. M. et al., 2002), as well as in redox proteins such as cytochrome oxidase (Zaslavsky, D. \& Gennis, R. B., 2000), bacteriorhodopsin (Lanyi, J. K., 2000), and the photosynthetic reaction center of Rhodobacter sphaeroides (Xu, Q. et al., 2004). Water chains are also found in membrane aquapores, which are important to the function of the nicotinic receptor $\mathrm{M} 2 \delta_{5}(\mathrm{Law}, \mathrm{R} . \mathrm{J}$. et al., 2000) as well as the influenza A M2 virus (Zhong, Q. F. et al., 1998). Rapid translocation of $\mathrm{H}^{+}$along water chains is important in controlling proton flux in these and related systems, and the mechanism of proton conduction appears to be different from 
other ions. Recently a number of theoretical studies on proton conduction have used gramicidin A (gA) as a model system. Proton conduction through the polypeptide lined gA channel is thought to occur through a succession of hops along a single-file hydrogen bonded water chain according to the Grotthuss relay mechanism, or as ionic clusters of waters.

In 2003, Peter Agre received the Nobel Price for his discovery of the aquapore proteins that are important for the transport of water across membranes, and therefore regulate the water content within the cell (Preston, G. M. et al., 1992). Malfunction of such aquapores leads to diseases such as nephrogenic diabetes insipidies, congenital cataracts and Sjorgens syndrome (Agre, P. et al., 2002). Most AQPs have "hour-glass" shaped channels that are $\sim 20 \AA$ in length and $\sim 3-4 \AA$ in diameter (at its narrowest constriction), and are lined with hydrophobic residues (Asn-Pro-Ala motif is conserved). The specific function of AQPs is its exceptional water permeability $\left(3 \times 10^{9}\right.$ molecules/monomer per second) which simultaneously prevents the exchange of ions and protons ("proton wires") (Pohl, P. et al., 2001). In addition, water molecules are thought to be hydrogen bonded and transported through membranes along single file chains.

Another interesting water chain is thought to be present in the M2 domain of the influenza A virus and its proton-selective channel formed by four helices bundled together within membranes (Wang, J. F. et al., 2001). By controlling the proton flux, the M2 domain plays a crucial role in the dissociation of the ribonucleoprotein from the M1 virion domain which is further transported to the cell's nucleus (Wang, C. et al., 1995). The crystal structure of the M2 domain reveals a unique arrangement of four histidine 
residues which are thought to be involved in a gating process regulating the proton flux (Wang, J. F. et al., 2001).

With this in mind, we have studied and characterized a series of hydrated imidazole compounds that display interesting water arrangements. This series of compounds illustrate the main features of water interactions mentioned above, ranging from structural waters to the formation and stabilization of one-dimensional water chains as well as water clusters containing four-, five- and six-membered rings associated with imidazole organic hosts. All the compounds in this study contain biomimetic forms of amino acids. In particular, compounds 46 and 47 bear biologically relevant imidazole and carboxylic acid moieties. They have only one water molecule of hydration similar to the structural water found in many enzyme active sites. The less hindered compound $\mathbf{5 2}$ and 2 are able to stabilize one-dimensional water chains thought to occur in important biological systems. The remaining compounds 48 and 49 display interesting water clusters, which are relevant to the structure of water on the surface of proteins. These water assemblies were characterized by single crystal X-ray powder diffraction, as well as solid-state NMR, thermogravimetric analyses (TGA) and differential scanning calorimetry (DSC).

\section{B. Synthesis of the Imidazole Ligands}

Utilizing Mannich-type reactions, imidazole compounds could be synthesized in good yields through the modification of a previously reported procedure (see Scheme 19) (Driessen, W. L. et al., 2003). The general procedure involved the mixing of the appropriate disubstituted imidazole compound with the adequate molar equivalents of various primary amines and formaldehyde in water. The reaction was usually stirred at 
room temperature for five to ten days, after which the desired product was isolated as a white precipitate. Vacuum filtration of the solid followed by acetonitrile and ether washes generally yielded compounds $\mathbf{4 6 - 5 1}$ in 40 to $70 \%$ yield.

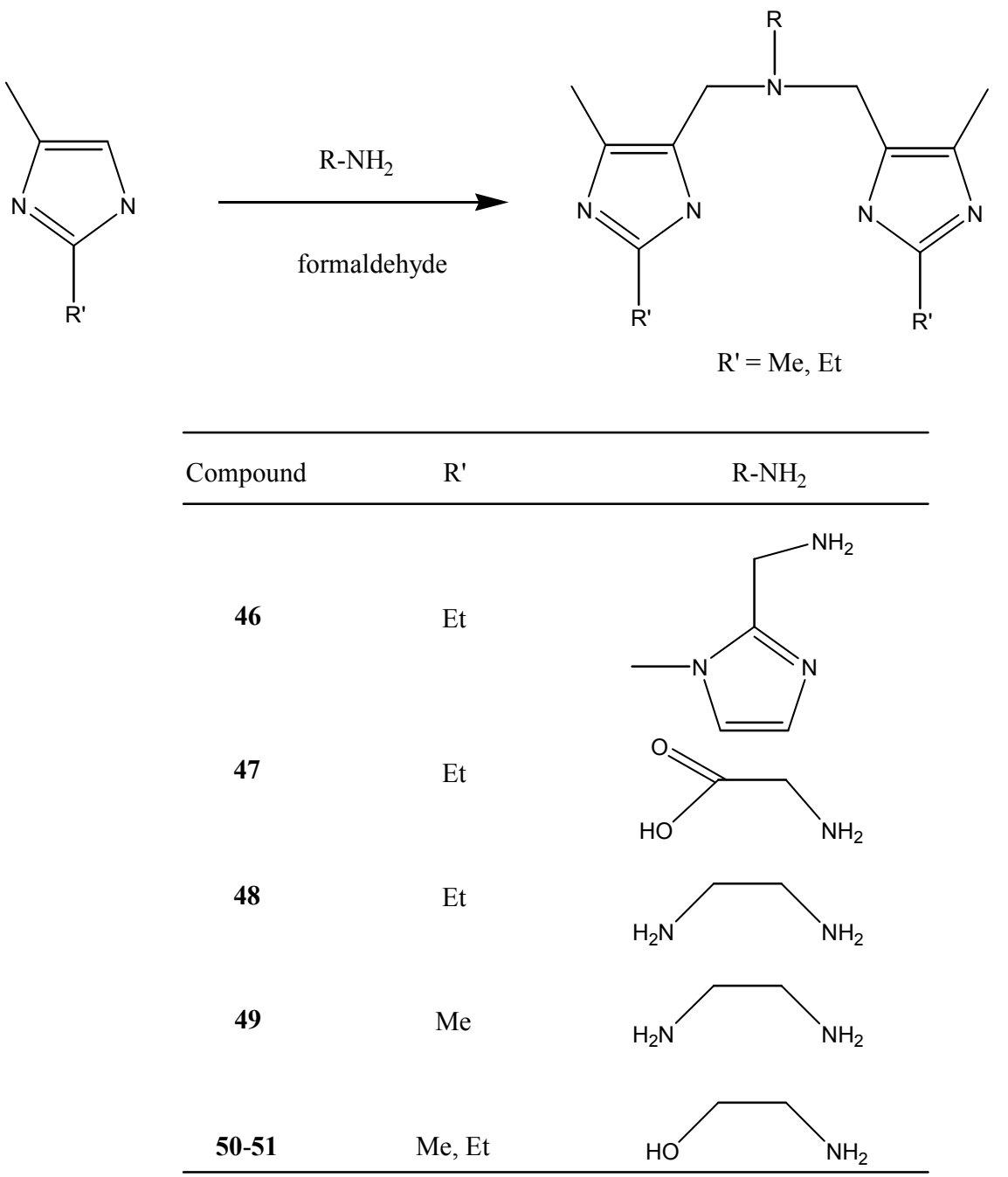

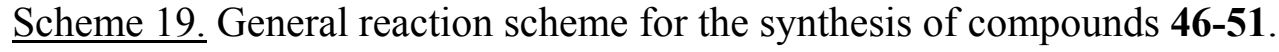

C. Synthesis and Characterization of Compounds 46-51

1. (Bis(2-ethyl-5-methylimidazol-4-yl)methyl)((1-methylimidazol-2yl)methyl)amine (46)

2-Aminomethyl-1-methylimidazole (Chen, S. et al., 1994) was used as the source of primary amine in the reaction. The amine hydrochloride salt, $0.85 \mathrm{~g}(4.66 \mathrm{mmol})$, was dissolved in water and the $\mathrm{pH}$ of the solution was adjusted to 11 . To this mixture was 
added $1.02 \mathrm{~g}(9.32 \mathrm{mmol})$ of 2-ethyl-4-methylimidazole and $0.81 \mathrm{~g}(9.99 \mathrm{mmol})$ of $37 \%$ formaldehyde dissolved in water. The reaction was then stirred for a week at room temperature where upon a white powder precipitated. Isolation of the compound by vacuum filtration yielded compound 46 in 55\% yield ( $0.91 \mathrm{~g})$.

$\mathrm{MP}=149-152{ }^{\circ} \mathrm{C} ;{ }^{1} \mathrm{H}$ NMR $\mathrm{CD}_{3} \mathrm{OD} \delta 6.94(1, \mathrm{~s}, \mathrm{H} 5), 6.82(1, \mathrm{~s}, \mathrm{H} 4), 3.55\left(2, \mathrm{~s},-\mathrm{CH}_{2}-\right)$, $3.44\left(4, \mathrm{~s},-\mathrm{CH}_{2}-\right), 3.43\left(3, \mathrm{~s}, \mathrm{~N}-\mathrm{CH}_{3}\right), 2.64\left(4, \mathrm{q},-\mathrm{CH}_{2}-\right), 2.03\left(6, \mathrm{~s},-\mathrm{CH}_{3}-\right), 1.25(6, \mathrm{t},-$ $\left.\mathrm{CH}_{3^{-}}\right) .{ }^{13} \mathrm{C} \mathrm{NMR} \mathrm{CD}_{3} \mathrm{OD} \delta 148.3\left(\mathrm{~s},{ }^{\mathrm{Im}} \mathrm{C} 2\right), 145.8\left(\mathrm{~s},{ }^{\mathrm{NIm}} \mathrm{C} 2\right), 125.6(\mathrm{~s}, \mathrm{C} 4), 121.2(\mathrm{~s}, \mathrm{C} 5)$, $49.1\left(\mathrm{~s},-\mathrm{CH}_{2}-\right), 48.6\left(\mathrm{~s},-\mathrm{CH}_{2}-\right), 31.8\left(\mathrm{~s}, \mathrm{~N}-\mathrm{CH}_{3}\right), 21.2\left(\mathrm{~s},-\mathrm{CH}_{2}-\right), 12.3\left(\mathrm{~s}, \quad-\mathrm{CH}_{3}\right), 9.3(-$ $\mathrm{CH}_{3}$ ). ESI-MS m/z $356.3\left[\mathrm{M}+\mathrm{H}^{+}\right]$. Anal. Calc. for $\mathrm{C}_{19} \mathrm{H}_{29} \mathrm{~N}_{7} \cdot \mathrm{H}_{2} \mathrm{O}$ C, 61.10; H, 8.37; N, 26.25; Found C, 61.35; H, 8.01; N, 26.64.

2. N,N-Bis(2-ethyl-5-methylimidazol-4-methyl)glycine (47)

The hydrochloride salt of glycine methyl ester, $1.17 \mathrm{~g}(9.32 \mathrm{mmol})$, was dissolved in water and the $\mathrm{pH}$ of the solution was adjusted to 10.5. 2-Ethyl-4(5)-methylimidazole, $2.05 \mathrm{~g}(18.6 \mathrm{mmol})$, was added along with $1.51 \mathrm{~g}(18.6 \mathrm{mmol})$ of formaldehyde $(37 \%)$ in water. After a week of stirring at room temperature, a white solid precipitated and was recovered by vacuum filtration. It should be noted that during the reaction, the ester was saponified and the yield of compound 47 was $65 \%$ (1.94 g).

$\mathrm{MP}=168-170{ }^{\circ} \mathrm{C} ;{ }^{1} \mathrm{H}$ NMR $\mathrm{CD}_{3} \mathrm{OD} \delta 3.95\left(4, \mathrm{~s},-\mathrm{CH}_{2}-\right), 3.30\left(2, \mathrm{~s},-\mathrm{CH}_{2}-\right), 2.73$ (4, q, $\left.\mathrm{CH}_{2}-\right), 2.20\left(6, \mathrm{~s},-\mathrm{CH}_{3}-\right), 1.30\left(6, \mathrm{t},-\mathrm{CH}_{3}-\right) .{ }^{13} \mathrm{C} \mathrm{NMR} \mathrm{CD}_{3} \mathrm{OD} \delta 173.6(\mathrm{COOH}), 148.9$ (s, $\left.{ }^{\mathrm{Im}} \mathrm{C} 2\right), 128.8\left(\mathrm{~s},{ }^{\mathrm{Im}} \mathrm{C} 4\right), 124.7\left(\mathrm{~s},{ }^{\mathrm{Im}} \mathrm{C} 5\right), 55.7\left(\mathrm{~s},-\mathrm{CH}_{2}-\right), 49.7\left(\mathrm{~s},-\mathrm{CH}_{2^{-}}\right) 20.7\left(\mathrm{~s},-\mathrm{CH}_{2^{-}}\right)$, $11.5\left(\mathrm{~s},-\mathrm{CH}_{3}\right), 8.6\left(\mathrm{~s},-\mathrm{CH}_{3}\right)$. ESI-MS m/z $320.1\left[\mathrm{M}+\mathrm{H}^{+}\right]$. Elem. Anal. Calc. for $\mathrm{C}_{16} \mathrm{H}_{25} \mathrm{~N}_{5} \mathrm{O}_{2} \cdot \mathrm{H}_{2} \mathrm{O}$ C, 56.95; H, 8.07; N, 20.49; Found C, 56.67; H, 7.97; N, 20.46. 
3. $\mathrm{N}, \mathrm{N}, \mathrm{N}^{\prime}, \mathrm{N}^{\prime}$-Tetrakis((2-ethyl-4-methylimidazolyl-5-)methyl)ethylene diamine (48)

In $10 \mathrm{~mL}$ of water, $3.28 \mathrm{~g}(29.8 \mathrm{mmol})$ of 4(5)ethyl-2-methylimidazole was treated with $0.45 \mathrm{~g}(7.45 \mathrm{mmol})$ of ethylenediamine and $3.28 \mathrm{~g}(40.4 \mathrm{mmol})$ of $37 \%$ formaldehyde. After five days of stirring, a white precipitate could be isolated by vacuum filtration in $45 \%$ yield $(1.84 \mathrm{~g})$.

$\mathrm{MP}=96-98{ }^{\circ} \mathrm{C} ;{ }^{1} \mathrm{H}$ NMR $\mathrm{CD}_{3} \mathrm{OD} \delta 3.42\left(4, \mathrm{~s},-\mathrm{CH}_{2}-\right), 2.63$ (4, q, $\left.-\mathrm{CH}_{2}-\right), 2.58(2, \mathrm{~s},-$ $\left.\mathrm{CH}_{2}-\right), 2.05\left(6, \mathrm{~s},-\mathrm{CH}_{3}-\right), 1.24\left(6, \mathrm{t},-\mathrm{CH}_{3}-\right) .{ }^{13} \mathrm{C}^{\mathrm{NMR}} \mathrm{CD}_{3} \mathrm{OD} \delta 148.4\left(\mathrm{~s},{ }^{\mathrm{Im}} \mathrm{C} 2\right), 128.9(\mathrm{~s}$, $\left.{ }^{\mathrm{Im}} \mathrm{C} 4\right), 126.3\left(\mathrm{~s},{ }^{\mathrm{Im}} \mathrm{C} 5\right), 50.0\left(\mathrm{~s},-\mathrm{CH}_{2^{-}}\right), 48.3\left(\mathrm{~s},-\mathrm{CH}_{2^{-}}\right), 21.3\left(\mathrm{~s},-\mathrm{CH}_{2}-\right), 12.2\left(\mathrm{~s},-\mathrm{CH}_{3}\right), 9.6$ (s, - $\mathrm{CH}_{3}$ ). ESI-MS m/z $549.3\left[\mathrm{M}+\mathrm{H}^{+}\right]$. Elem. Anal. Calc. for $\mathrm{C}_{30} \mathrm{H}_{48} \mathrm{~N}_{10} \cdot 2 \mathrm{H}_{2} \mathrm{O}$ C, 61.61; H, 8.96; N, 23.95; Found C.61.19; H.8.75; N 24.41;

4. $\quad \mathrm{N}, \mathrm{N}, \mathrm{N}^{\prime}, \mathrm{N}^{\prime}$-tetrakis((2,5-dimethylimidazolyl-4-)methyl)ethylene diamine (49)

The procedure used to prepare compound $\mathbf{4 8}$ was followed with the exception that 2,4(5)-dimethylimidazole was substituted for 4(5)-ethyl-2-methylimidazole. $\mathrm{MP}=104-105{ }^{\circ} \mathrm{C} ;{ }^{1} \mathrm{H}$ NMR $\mathrm{CD}_{3} \mathrm{OD} \delta 3.47\left(4, \mathrm{~s},-\mathrm{CH}_{2}-\right), 2.66\left(2, \mathrm{~s},-\mathrm{CH}_{2}-\right), 2.29(6, \mathrm{~s},-$ $\left.\mathrm{CH}_{3}-\right), 2.06\left(6, \mathrm{t},-\mathrm{CH}_{3}-\right) .{ }^{13} \mathrm{C}$ NMR $\mathrm{CD}_{3} \mathrm{OD} \delta 143.1\left(\mathrm{~s},{ }^{\mathrm{Im}} \mathrm{C} 2\right), 128.6\left(\mathrm{~s},{ }^{\mathrm{Im}} \mathrm{C} 4\right), 126.5(\mathrm{~s}$, $\left.{ }^{\mathrm{Im}} \mathrm{C} 4\right), 49.4\left(\mathrm{~s},-\mathrm{CH}_{2}-\right), 48.4\left(\mathrm{~s},-\mathrm{CH}_{2}-\right), 12.3\left(\mathrm{~s},-\mathrm{CH}_{3}\right), 9.3\left(\mathrm{~s},-\mathrm{CH}_{3}\right)$. ESI-MS m/z 493.2 $\left[\mathrm{M}+\mathrm{H}^{+}\right]$. Elem. Anal. Calc. for $\mathrm{C}_{26} \mathrm{H}_{40} \mathrm{~N}_{10} \cdot 2 \mathrm{H}_{2} \mathrm{O} \mathrm{C}, 59.07$; H, 8.39; N, 26.49; Found C, 59.31; H, 8.14; N, 26.31.

For the synthesis, characterization and crystallization of compounds $\mathbf{5 0}$ and $\mathbf{5 1}$, see Matt Cecil's thesis. X-ray quality crystals of all other compounds were obtained by slow evaporation of a saturated methanol/water (50/50) solution in presence of drying agent (ethylene glycol or Drierite $\left.{ }^{\circledR}\right)$. 


\section{X-ray Crystallographic Analysis of Compounds 46 and 47 Monohydrates}

Compounds 46 and 47 are similar tripodal ligands containing two identical imidazole pendants and a different third pendant group. For compound 46, the third pendant is a N-methylated imidazole moiety, while for compound $\mathbf{4 7}$, it is a carboxylic acid group. Nevertheless, both groups have the ability to form strong hydrogen bond interactions.

Both compounds crystallize with two independent organic molecules and a water molecule per asymmetric unit. In addition, compound $\mathbf{4 7}$ is isolated as a Zwitterion with carboxylic acid deprotonated and one of the imidazole rings fully protonated. The waters in both compounds are chelated between two conserved non-alkylated unfunctionalized imidazoles as shown in Figure 68.

a)

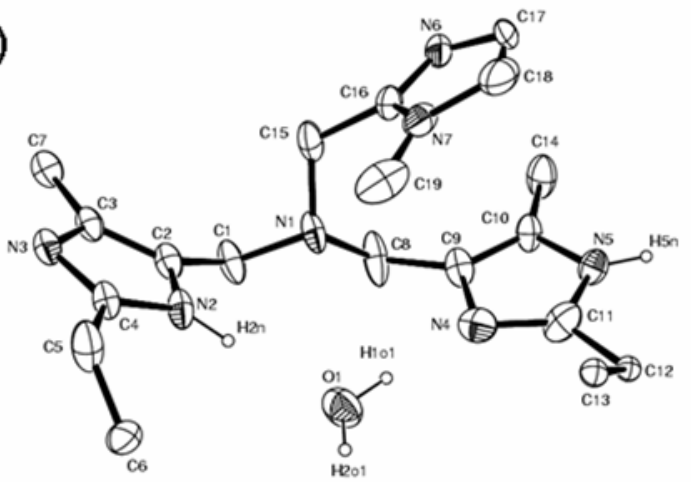

b)

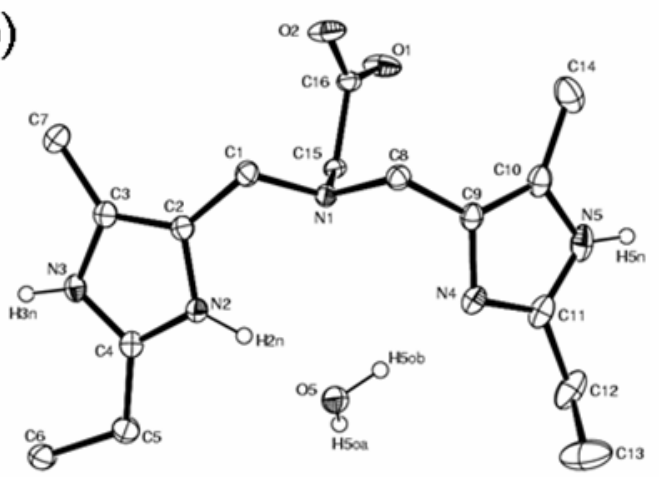

Figure 68. ORTEP view of hydrate structure of compounds $\mathbf{4 6}$ (a) and $\mathbf{4 7}$ (b). Ellipsoids are drawn at $40 \%$ probability levels. Methylene and methyl hydrogens have been omitted for clarity.

In compound 46, the water molecule forms donor and acceptor hydrogen bonds with N4 and N2, respectively. The third, less bulky, 1-methylimidazole pendant is hydrogen bonded to the $\mathrm{H} 2 \mathrm{O} 1$ hydrogen atom of a water molecule associated with a symmetry related tripod resulting in the formation of a one-dimensional array of hydrogen bonds along the crystallographic $\mathrm{b}$ axis, as illustrated in Figure 69. The N2--- 
O1 separation is $2.869 \AA$ and the $\mathrm{N} 2-\mathrm{H} 2 \mathrm{~N}---\mathrm{O} 1$ angle is $172.00^{\circ}$. A hydrogen atom associated with the water molecule is hydrogen bonded with the other imidazole nitrogen (O1---N4 separation of $2.876 \AA$ with O1-H1O1---N4 angle of $\left.174.55^{\circ}\right)$. Finally, the second hydrogen of the water interacts with the 1-methylimidazole pendant from a symmetry related molecule (O1---N6 separation of $2.930 \AA$ and O1-H2O1---N6 angle of $\left.167.94^{\circ}\right)$

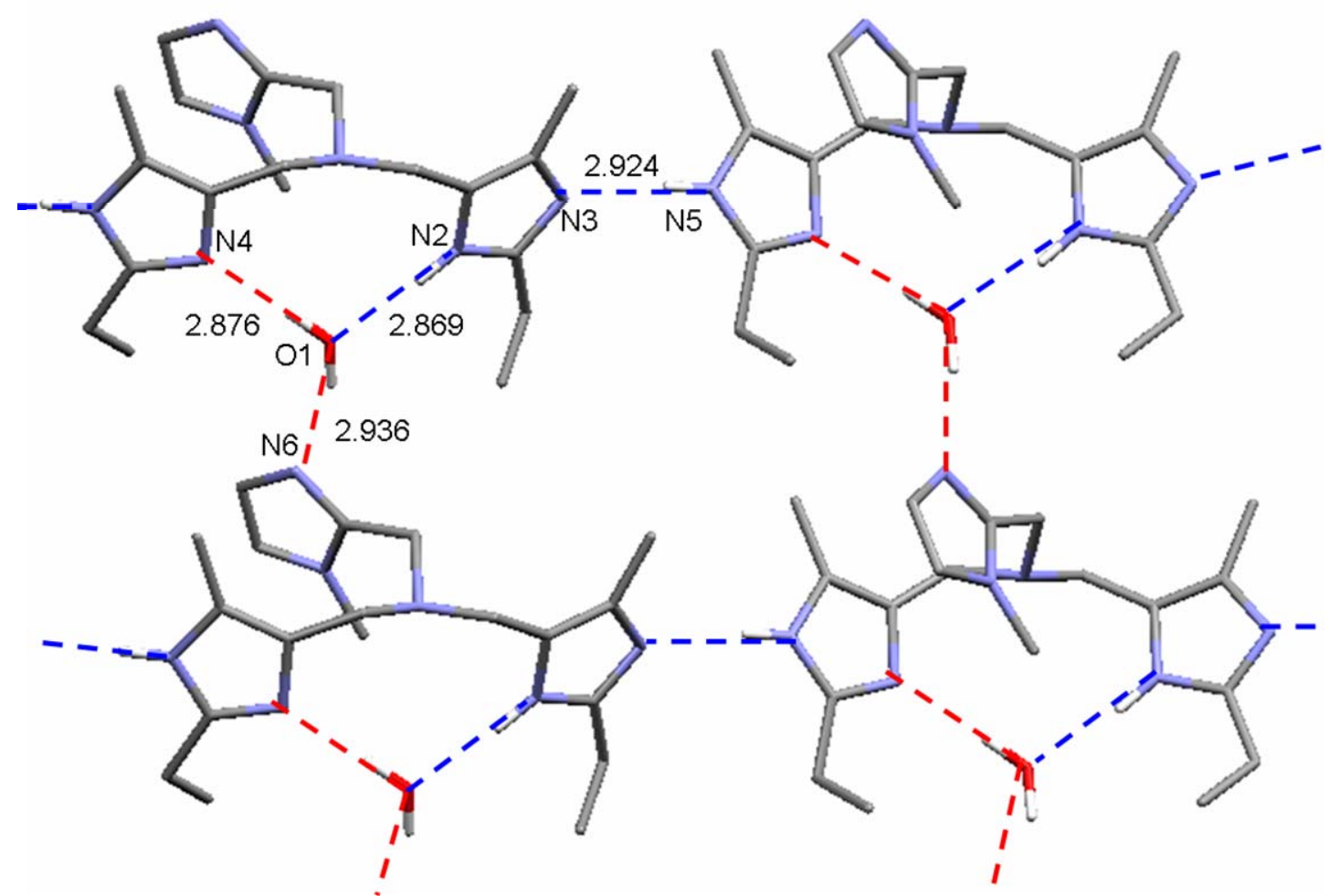

Figure 69. Illustration of the network of hydrogen bonds between water molecules and imidazole nitrogens found in the packing diagram of compound $\mathbf{4 6}$.

As with compound $\mathbf{4 6}$, the water molecule of $\mathbf{4 7}$ acts as a proton acceptor to one of the imidazole nitrogen atoms (N2---O5 separation of $2.718 \AA$ with $\mathrm{N} 2-\mathrm{H} 2 \mathrm{~N}---\mathrm{O} 5$ angles of $\left.171.22^{\circ}\right)$ and as a proton donor to a nitrogen atom of the second imidazole (O5--N4 separation of $2.812 \AA$ with O5-H5OB---N4 angles of $176.50^{\circ}$ ). The remaining $\mathrm{H}$ atom of the water ( $\mathrm{H} 5 \mathrm{OA})$ is hydrogen bonded to one of the carboxylic acid oxygens 
(O1---O5 separation of $2.756 \AA$ and O5-H5OA---O1 angle of $177.14^{\circ}$ ). The hydrogen bonding interactions in compound $\mathbf{4 7}$ are significantly stronger than in compound $\mathbf{4 6}$ due in part to the Zwitterionic nature of $\mathbf{4 7 .}$

Figure 69 also shows the extended hydrogen bonding between neighboring imidazoles of compound 46. The N3---N5 separation of $2.924 \AA$ and the N5-H5N---N3 angle of $169.82^{\circ}$ are consistent with the presence of strong hydrogen bonding along the crystallographic c axis.

Compound 47, on the other hand, displays an interesting packing diagram with each football-like dimeric unit (Figure 70) hydrogen bonded to four neighboring dimers through the carboxylate oxygen and imidazole nitrogen atoms (Figure 71). Both carboxylate oxygens of one dimer unit are hydrogen bonded to two adjacent backbone imidazole N-Hs (average O---N separation of $2.739 \AA$ and N-H---O angle of $173.0^{\circ}$ ).

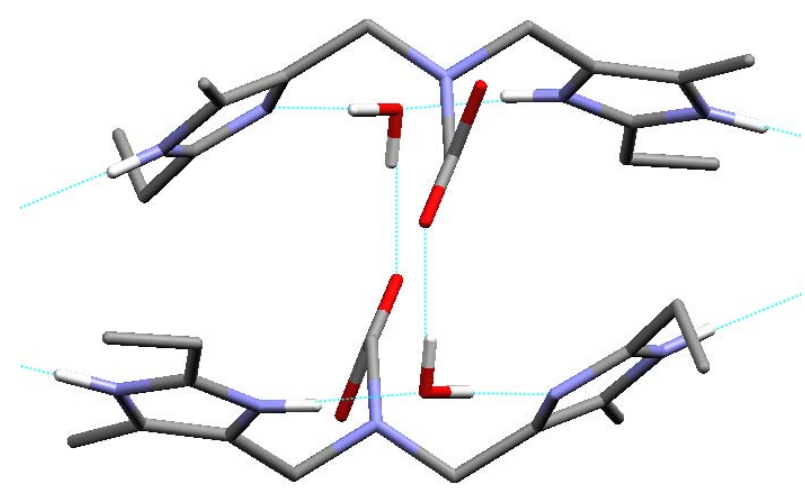

Figure 70. Capped-stick representation of the dimeric structure of compound 47. 


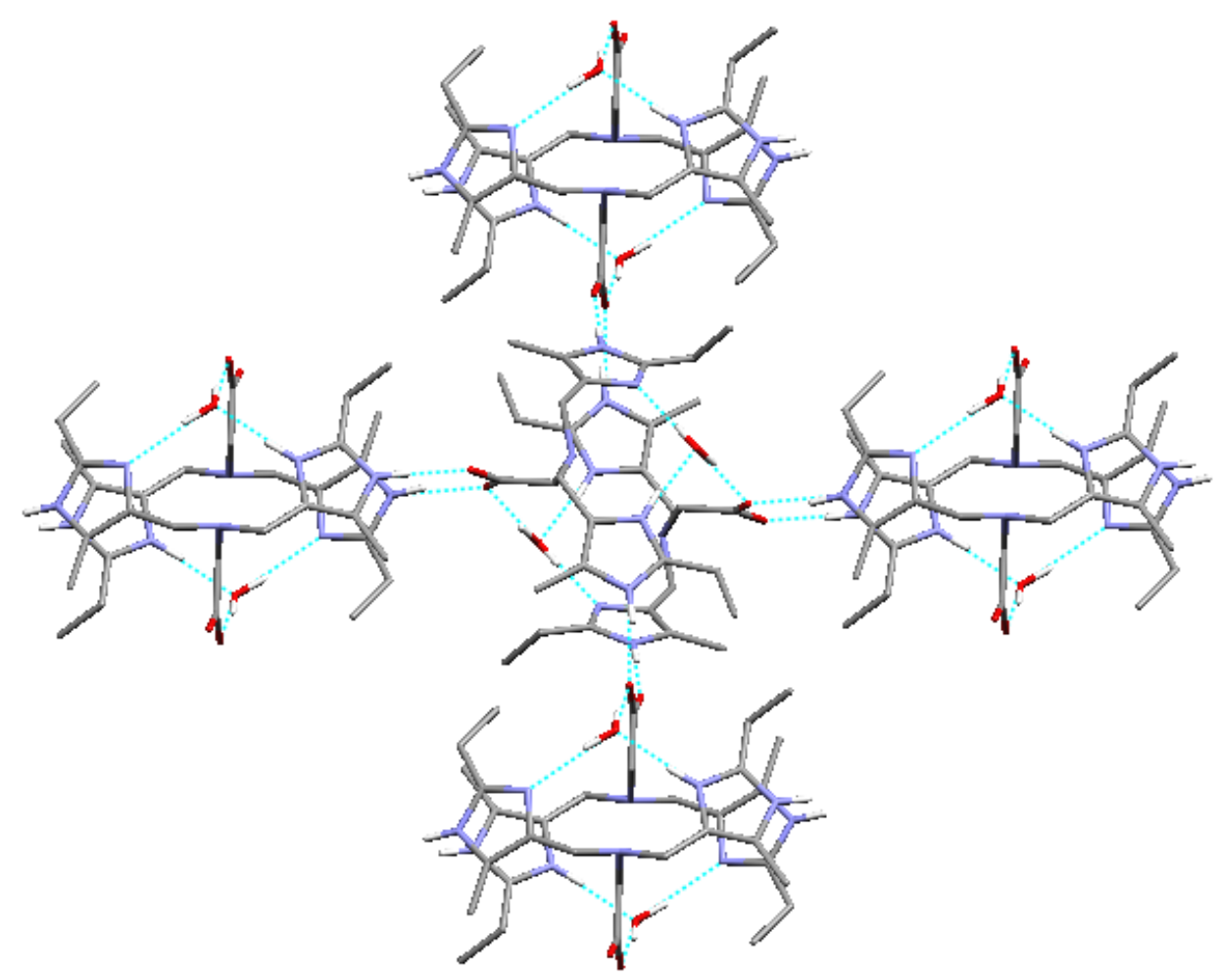

Figure 71. Capped-stick representation of the supramolecular assembly resulting from the interactions of dimers of compound 47.

Interestingly, the crystal structure of a compound similar to 47 has been reported. 3,3-Bis(2-imidazolyl)propionic acid (HBIP) crystallizes as both a monohydrate and hemihydrate zwitterion (Gimeno, B. et al., 1992; Gimeno, B. et al., 1996). Both crystal structures have features similar to compound $\mathbf{4 7}$, with the water hydrogen bonded to an imidazole nitrogen and a carboxylic acid oxygen atom. In addition, the imidazole nitrogen and the carboxylic acid form strong hydrogen bonds. The main difference between HBIP and compound 47 is HBIP does not have the appropriate spacing to support chelation of the water molecule as observed in 47 , which contains a tertiary amine nitrogen atom as part of the molecular framework. 
From this study, imidazole and also carboxylic acid moieties display affinity for water molecules in the solid-state, and form strong hydrogen bonds. It appears that simple tripodal compounds favor the encapsulation of water molecules within the ligand framework, thus isolating them and preventing them from forming chains of hydrogen bonded hydrates.

\section{E. Extended Hydrate Structures}

The study was then extended to include less hindered imidazole compounds to evaluate their interactions with water in the solid-state and to promote greater waterwater interactions and less water-ligand interactions. Described in this next section is the characterization of two imidazole hydrates that stabilize one-dimensional water chain structures in the solid-state.

Many fundamental biological processes appear to depend on the unique properties of water chains (Cukierman, S., 2000; Jude, K. M. et al., 2002; Kandori, H., 2000; Lanyi, J. K., 2000; Law, R. J. et al., 2000; Zaslavsky, D. \& Gennis, R. B., 2000; Zhong, Q. F. et al., 1998). Curiously, little is known of the structural constraints required in stabilizing 1D water chains. Unlike bulk water or ice (Mishima, O. \& Stanley, H. E., 1998), 1-D water chains appear to be stabilized by strong H-bonding between neighboring waters along the chain as well as H-bonding between water molecules and donor-acceptor groups associated with channels (Cukierman, S., 2000). Recently, we have discovered that certain imidazole compounds stabilize infinite 1-D water chains relevant to the biological structures mentioned above (Cheruzel, L. E. et al., 2003). Herein we describe the crystal structures of the hydrated compounds and preliminary data from solid-state ${ }^{2} \mathrm{H}$ 
NMR studies and calorimetric analyses that establish the possibility of reorientation dynamics of the water chain nanostructures.
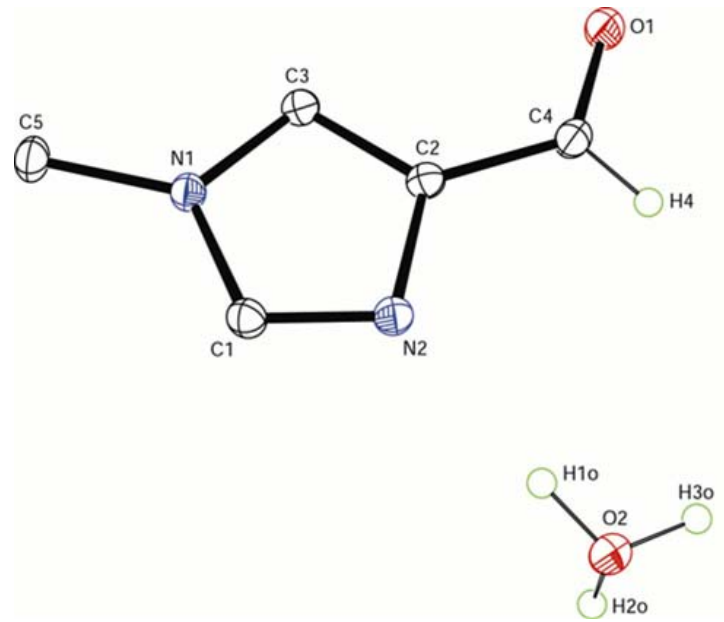

Compound $\mathbf{5 2} \cdot \mathrm{H}_{2} \mathrm{O}$
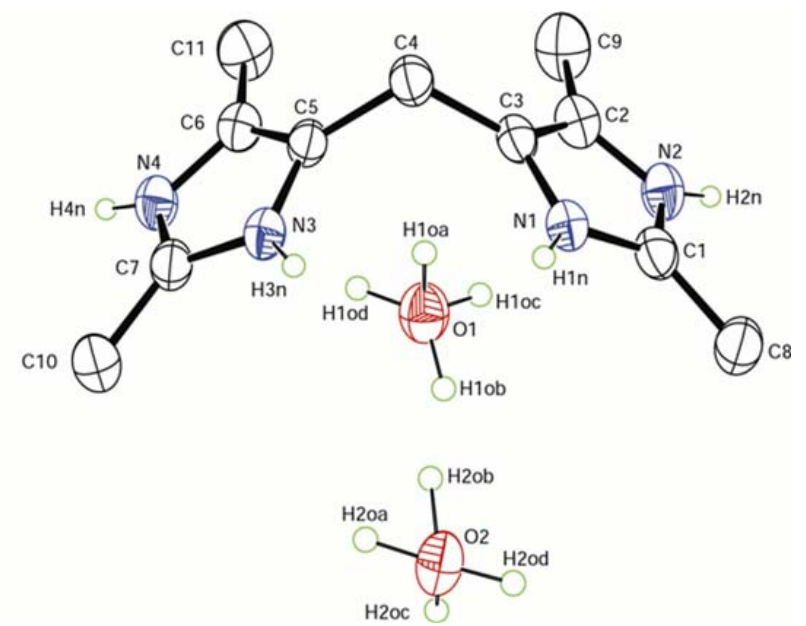

Compound $2 \cdot 2 \mathrm{H}_{2} \mathrm{O}$

Figure 72. ORTEP views of the molecular structures of compounds $\mathbf{5 2}$ and $\mathbf{2}$. Thermal ellipsoids are drawn at $40 \%$ probability level. Hydrates in both structures are disordered and form strong $\mathrm{N}-\mathrm{H}---\mathrm{O}$ and $\mathrm{O}-\mathrm{H}---\mathrm{O}$ hydrogen bonds. In compound 2 , the methyl and methylene $\mathrm{H}$ atoms are omitted for clarity.

The crystal structures of hydrates of 1-methylimidazole-4-carboxaldehyde (52)

(Chen, S. et al., 1994) and 4,4'-methylene-bis(2,5-dimethylimidazole) (2) are shown in

Figure 72, along with their respective packing representations in Figure 73 (which also display the arrangement of imidazole $\mathrm{N}$ atoms in both compounds in relation to their infinite 1-D water chains). The water channels in $\mathbf{5 2}$ are generated by weak $\pi$ interactions between imidazole molecules in alternating layers along the crystallographic $\mathrm{c}$ axis. The closest intermolecular interactions between layers are $3.282 \AA$ (C1'-C3), $3.297 \AA$ (C1'$\mathrm{N} 1)$ and $3.323 \AA\left(\mathrm{C} 3-\mathrm{N} 1^{\prime}\right)$, and individual channels are linked together by weak interactions (C3---O1" $3.273 \AA$ ) between neighboring imidazole molecules (Figure 74). The approximate dimension of the water channels in compound $\mathbf{5 2}$ is $6.62 \times 3.44 \AA^{2}$. 
a)

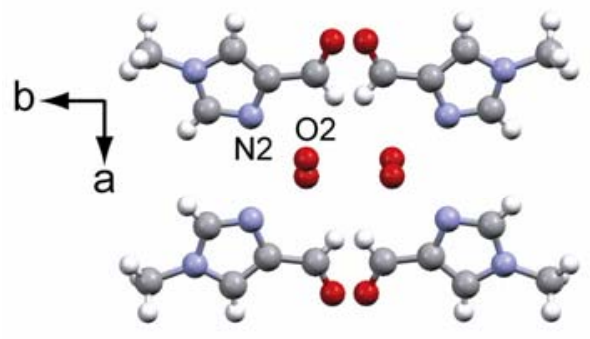

c)

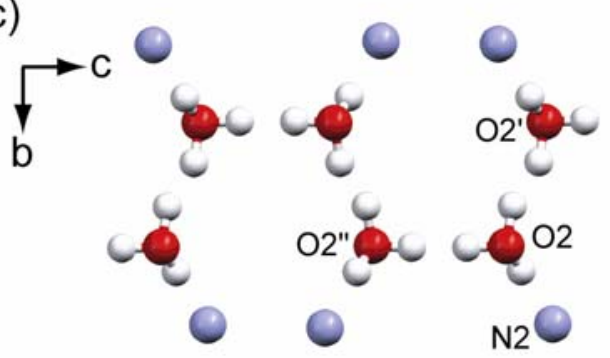

b)

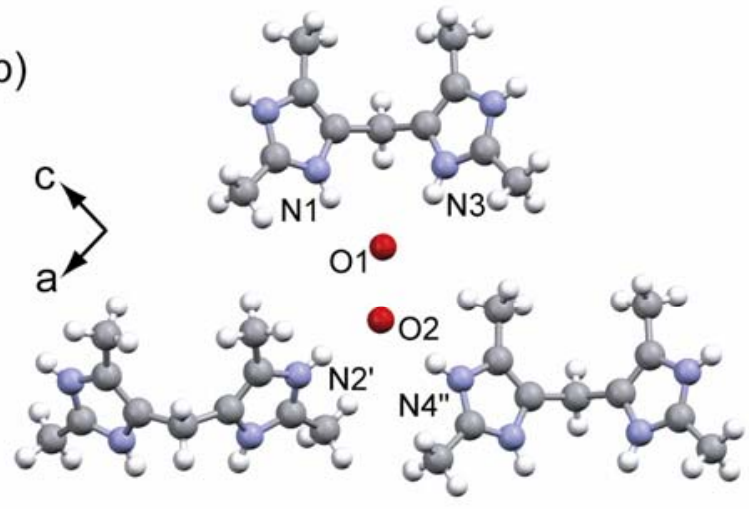

d)

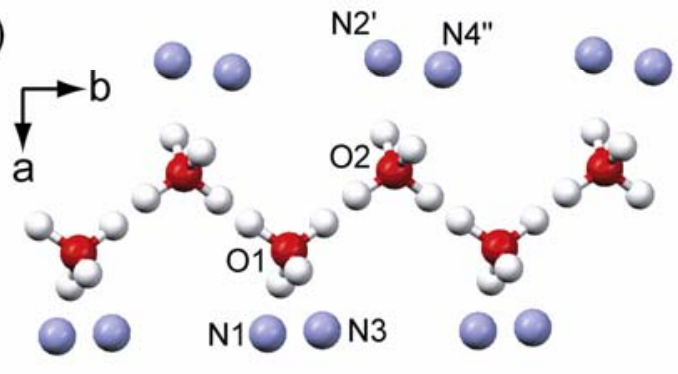

Figure 73. Packing representations viewed down the water channel of compound $\mathbf{5 2}$ and 2 are shown in frames a) and b), respectively. In both representations water $\mathrm{H}$ atoms have been omitted for clarity. In addition, hydrogen-bonding representations illustrating the nanostructure of the water chains of $\mathbf{5 2}$ and $\mathbf{2}$ are shown in frames c) and d), respectively with each channel oriented along the horizontal axis of the illustration. Imidazole nitrogen atoms involved in hydrogen bonding are included in frames c) and d). Imidazole N-H atoms are omitted in frame d) for clarity.

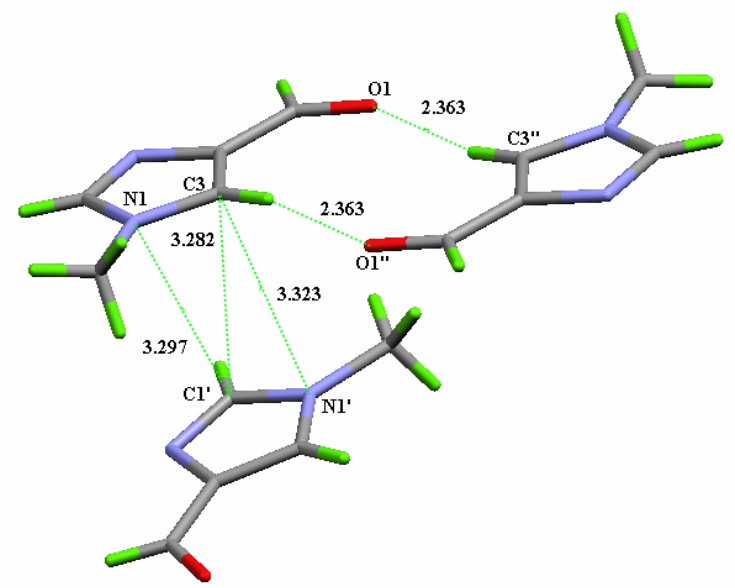

Figure 74. Closest interatomic contacts between imidazole molecules associated with the water channel and weak intermolecular interactions between adjacent channels. 
The water molecules in $\mathbf{5 2}$ are trigonally distorted and form strong hydrogen bonds with symmetry related molecules in the chain as well as with imidazole nitrogen atoms directed towards the channel. Each water molecule has a full-occupancy H-atom (H1o) that is strongly hydrogen bonded to N2 (N2---O2 2.8424(16) $\AA$ ). The other Hatoms ( $\mathrm{H} 2 \mathrm{o}$ and $\mathrm{H} 3 \mathrm{o})$ are positionally disordered and were treated as half-occupancy atoms during refinement. Both $\mathrm{H} 2 \mathrm{Oa}$ and $\mathrm{H} 2 \mathrm{Ob}$ are hydrogen bonded to symmetry related waters, and the $\mathrm{O} 2---\mathrm{O} 22^{\prime}(-\mathrm{x}+1,-\mathrm{y},-\mathrm{z}+1)$ and $\mathrm{O} 2---\mathrm{O} 2 "(-\mathrm{x}+1, \mathrm{y},-\mathrm{z}+3 / 2)$ separations are 2.763(2) and 2.783(2) $\AA$, respectively, indicating the presence of strong hydrogen bonding between water molecules in the chain (see Table 18). Overall, the shape of the water chain resembles an "arm chair" motif.

Table 18. Selected O---O separations and O-H---O angles for compounds $\mathbf{2}$ and $\mathbf{5 2}$.

\begin{tabular}{ccc}
\hline & O---O separation $(\AA)$ & O-H---O angle $\left(^{\circ}\right)$ \\
\hline Compound 52 & & \\
O2-H1O2---N2 & $2.8424(16)$ & $176(2)$ \\
O2-H2AO---O2\#1 & $2.783(2)$ & $173(4)$ \\
O2-H2BO---O2\#2 & $2.763(2)$ & $167(4)$ \\
& O---O---O angle: $107.5^{\circ}$ \\
Compound 2 & \multicolumn{2}{c}{} \\
O2-H2OD---N4\#1 & $2.786(2)$ & $164(3)$ \\
O2-H2OC---O1\#2 & $2.776(2)$ & $161(3)$ \\
O2-H2OB---N2\#3 & $2.828(2)$ & $168(3)$ \\
O1-H1OD---N3 & $2.855(2)$ & $168(3)$ \\
O1-H1OA---O2 \#4 & $2.776(2)$ & $171(3)$ \\
O1-H1OB---O2 & $2.778(2)$ & $174(3)$ \\
O1-H1OC---N1 & $2.825(2)$ & $148(3)$ \\
N4-H4N---O2 \#5 & $2.786(2)$ & $166(3)$ \\
N3-H3N---O1 & $2.855(2)$ & $158(3)$ \\
N2-H2N--O2 \#6 & $2.828(2)$ & $169(3)$ \\
N1-H1N---O1 & $2.825(2)$ & $158(3)$ \\
O2-H2AO---O1 & $2.778(2)$ & $174(3)$ \\
& O---O---O angle: $110.0^{\circ}$ \\
\hline
\end{tabular}

Symmetry transformations used to generate equivalent atoms $\# 1-x+1, y,-z+3 / 2 \# 2-x+1,-y,-z+1 \# 3 x+1 / 2, y+1 / 2, z$ \#4 x, y-1, z \#5 x, -y+1, z+1/2 \#6 x-1/2, y-1/2, z 
Compound $\mathbf{2}$ has a different packing arrangement of imidazole molecules (Figure 73) that results in water channels oriented along the crystallographic b axis. The imidazole $(\mathrm{N}-\mathrm{H})$ and water hydrogen atoms were located and refined as half-occupancy atoms. Both water molecules associated with the asymmetric unit were found to be tetrahedrally disordered. The first water molecule containing $\mathrm{O} 1$ forms strong hydrogen bonds (Table 18) with imidazole N1 (O1---N1 2.828(2) $\AA$ ) and N3 (O1---N3 2.854(2) $\AA$ ) atoms, while the second water, containing $\mathrm{O} 2$, is hydrogen bonded to $\mathrm{N} 2^{\prime}(\mathrm{x}+1 / 2, \mathrm{y}+1 / 2$,

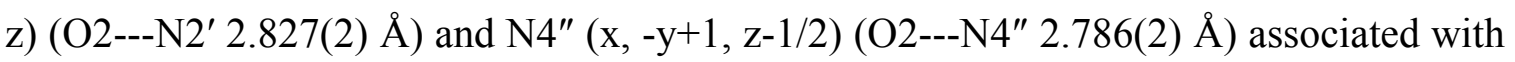
different imidazole molecules on opposite sides of the water channel. In addition, both waters are strongly hydrogen bonded to each other (O1---O2 2.778(2) Å) forming a "zigzag" motif, a possible proton wire structure proposed by Nagle and Morowitz (Nagle, J. F. \& Morowitz, H. J., 1978). The water channel formed by the stacking of 2 has an approximate rectangular shape $\left(\sim 4.80 \times 3.02 \AA^{2}\right)$ and a smaller pore size compared to $\mathbf{5 2}$ $\left(\sim 6.62 \times 3.44 \AA^{2}\right)$. The apparent smaller pore diameter of 2 appears better suited for stabilizing the "zig-zag" arrangement of water molecules over the "arm-chair" motif observed for $\mathbf{5 2}$.

In conclusion, the X-ray crystal structures suggest that compound $\mathbf{5 2}$ and $\mathbf{2}$ are potential models of biologically relevant proton wires. Curiously, there have been no comprehensive studies of water dynamics in systems containing infinite water chain structures. This may be due in part to the limited number of well-characterized continuous water chain structures involving small molecules (Cheng, D. P. et al., 2001; Fois, E. et al., 2001; Kim, S. A. \& Kuppers, H., 1994; Lee, Y. et al., 2002; Stahl, K. et al., 1989; Sun, C. Q. et al., 2002). In order to determine if $\mathbf{5 2}$ and $\mathbf{2}$ serve as models of 
biological proton wires, we have studied the dynamics of the water chains using solidstate ${ }^{2} \mathrm{H}$ and ${ }^{17} \mathrm{O}$ NMR spectroscopy and examined the calorimetric behavior of the compounds by thermogravimetric analysis (TGA) and differential scanning calorimetry (DSC). The results from these studies will be discussed later in this Chapter (Sections J and L). Future studies on these and related 1-D water chain structures will include proton conductivity measurements, detailed examination of deuterium exchange and hydrate reorientation dynamics in crystalline and powdered samples, as well as molecular modeling.

\section{F. Evaluation of the Crystal Structure of Compound 1}

Compound 2 was found to co-crystallize with two water molecules per asymmetric unit as detailed above. However, under the same recrystallization conditions compound 1 crystallizes without waters of hydration. Apparently, the presence of the ethyl substituents in the 2-position of the imidazole ring causes rotation around $\mathrm{C} 4$ (methylene backbone atom). As a result, one of the rings is rotated by $180^{\circ}$ relative to the other (Figure 75), and imidazole N-Hs are strongly interacting with symmetry related molecules (Figure 76).

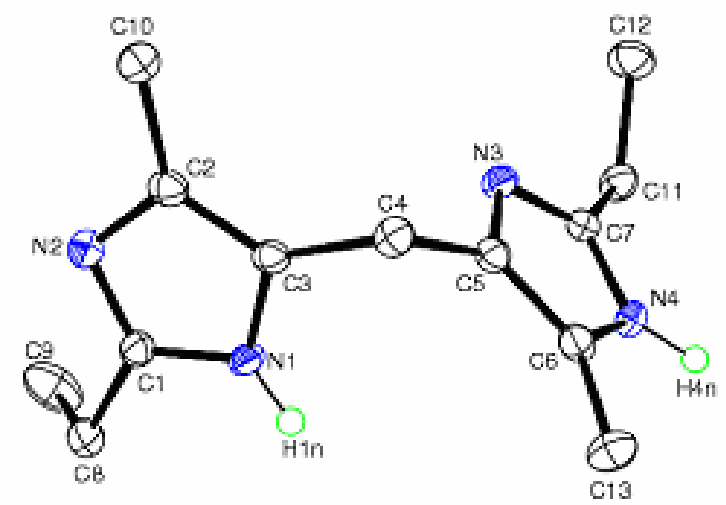

Figure 75. ORTEP view of compound 1. Ellipsoids are drawn at 40\% probability. Methyl and methylene hydrogens have been omitted for clarity. 

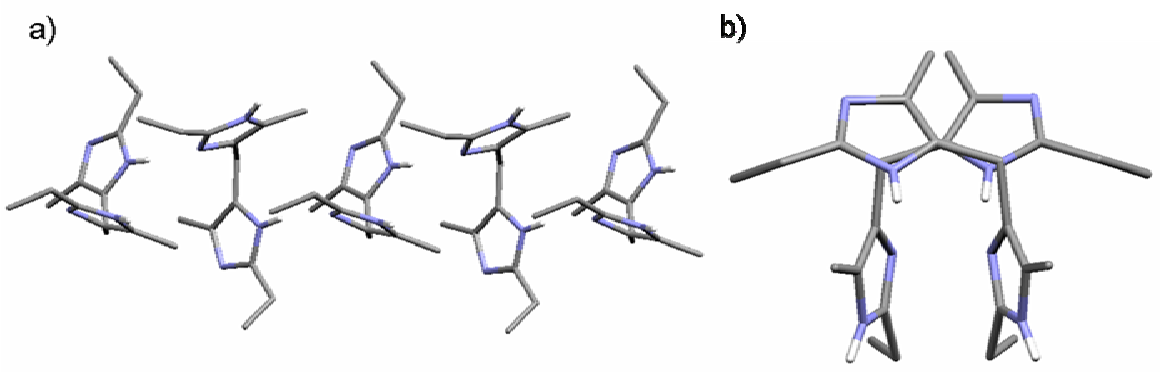

Figure 76. Side- (a) and top-views (b) of the one-dimensional strong hydrogen bonded arrangements of compound 1. All carbon hydrogens have been omitted for clarity.

One set of hydrogen bonds (N1---N3 separation of $2.881 \AA$, N1-H1n---N3 angle of $164.60^{\circ}$ ) creates a chain of stacked imidazoles along the crystallographic c axis, while hydrogen bonds involving N4 and N2 (N4---N2 separations of $2.819 \AA \AA$, N4-H4n---N2 angle of $172.49^{\circ}$ ) link neighboring chains together (Figure 77 ).

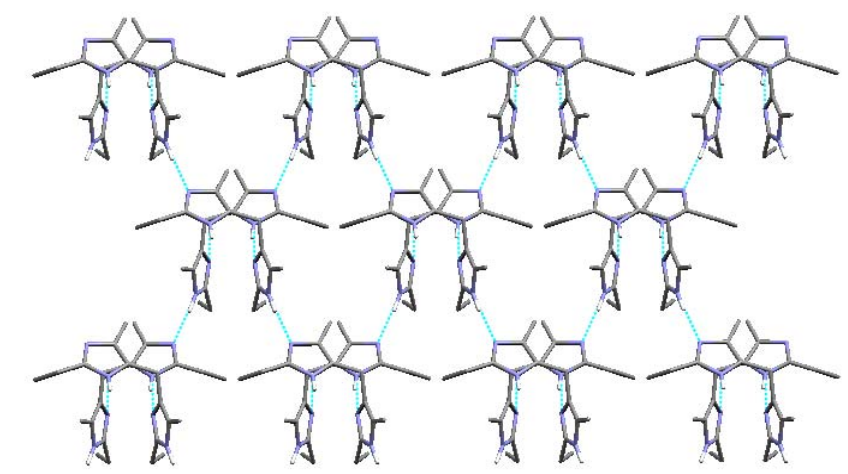

Figure 77. Packing arrangement of the one dimensional chains of $\mathrm{L}^{\mathrm{Et}, \mathrm{Me}}$ and their intermolecular hydrogen bonding with symmetry related chains. All carbon hydrogens have been omitted.

Hydrogen bonding interactions observed in $\mathbf{1}$ and related compounds are of interest as proton conductors in fuel cells (Kreuer, K. D., 2001; Munch, W. et al., 2001). The resulting assembly is also stabilized by the interlocking of the ethyl chain residues, as 
illustrated in Figure 77 (C9---C8' and C9---C9' separations of 3.905 and $4.488 \AA$, respectively). The packing of the imidazole chains forms a continuous channel with dimensions of $6.01 \times 7.63 \AA^{2}$.

Similar hydrogen bond interactions have also been observed for other simple imidazole compounds that are of interest as proton wires and may be useful in fuel cells (Munch, W. et al., 2001)

\section{G. Evaluation of the Crystal Structures of Compounds 48 and 49}

The study was expanded to evaluate the interactions between water molecules and imidazole groups separated by alkyl chain spacers (compound 48 and 49). The crystal structures of compounds $\mathbf{4 8}$ and $\mathbf{4 9}$ are shown in Figure 78 and illustrate the four and thirteen waters of hydration found per imidazole compounds, respectively. Both imidazole compounds are very similar and differ only in the substituents in the 2-position of the imidazole ring (ethyl for $\mathbf{4 8}$ versus a methyl group for $\mathbf{4 9}$ ). As a result, the packing arrangements of the organic molecules in the crystals are very similar for both compounds (Figure 79). The packing of the host imidazole molecules creates channels (with dimensions of $5.1 \times 4.5 \AA^{2}$ ) throughout the crystals and a unique intersection involving four imidazole groups of neighboring molecules which are reminiscent of the influenza A M2 virus channel (Figure 80). 

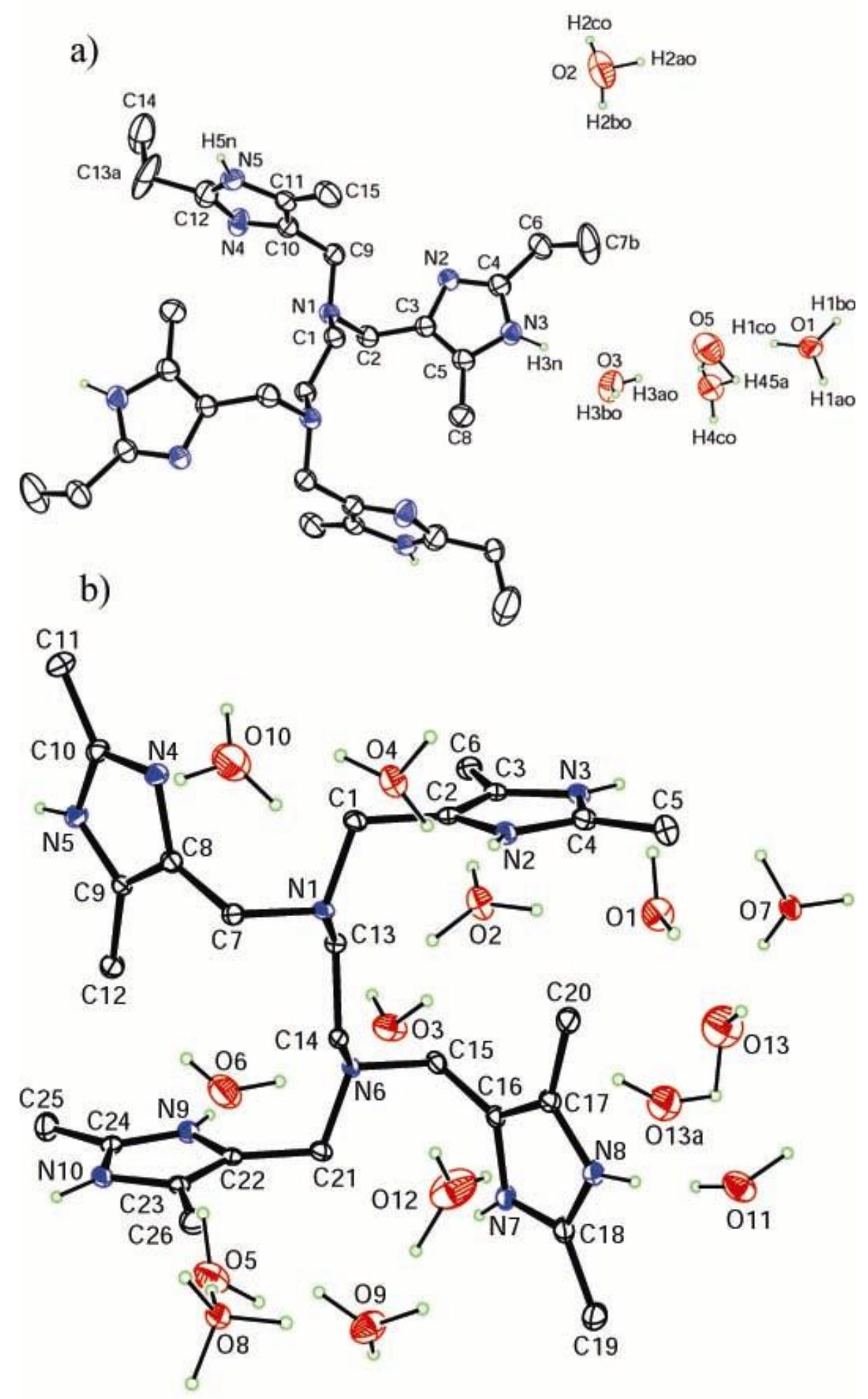

Figure 78. ORTEP views of the hydrates of compounds 48 (a) and 49 (b). Methylene and methyl hydrogens have been omitted for clarity. 
a)

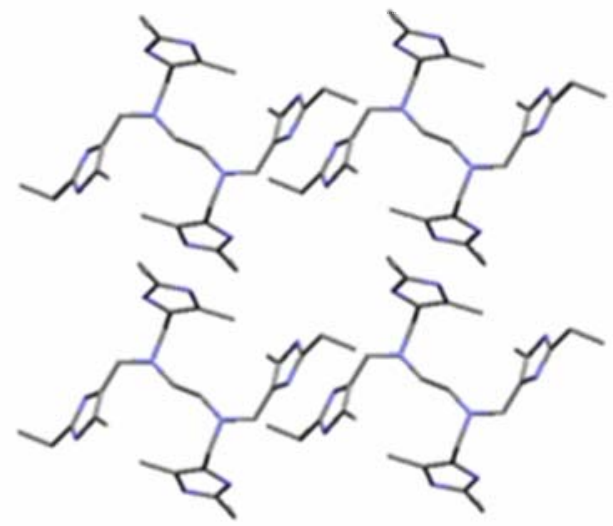

b)

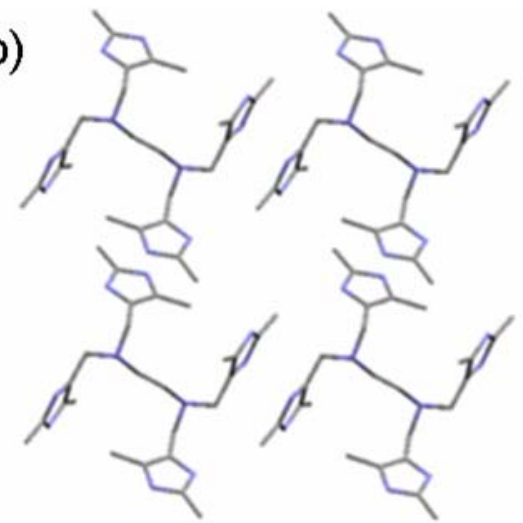

Figure 79. Imidazole packing diagrams of compounds 48 (a) and 49 (b).

In both compounds, the cluster of four imidazoles interacts with two conserved water molecules (Figure 81). The remaining water molecules are assembled in different clustered arrangements (see further discussion below). In compound 48, the water molecules in the void space of the organic host form a distorted chair-like water cluster, which appears to contain a four-membered water ring (a result of positional disordering of two water molecules in the cluster). The replacement of the ethyl group by a methyl group in compound 49 opens another dimension for the expansion of the water network, and for the first time, fused five- and six-membered water rings are observed, as well as larger fourteen-, sixteen- and seventeen-membered water rings. In both compounds, attempts were made to locate the hydrogens on the waters. These representations are discussed separately below. 


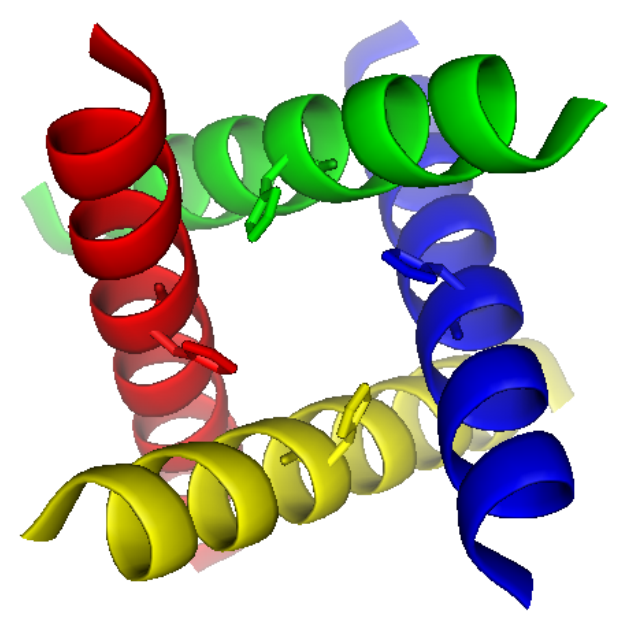

Figure 80. Four-helix bundle of the Influenza A M2 domain from the PDB coordinate (PDB: 1MP6) (Wang, J. F. et al., 2001).

$\pi$-Stacking interactions between the His residues and Trp from one neighboring helix has been postulated to play a role in the proton-gating process (Okada, A. et al., 2001). Indeed, in both compounds, a similar $\pi$-stacking interaction is observed in both model structures with the shortest interaction of $3.345 \AA$ (Figure 81).

a)

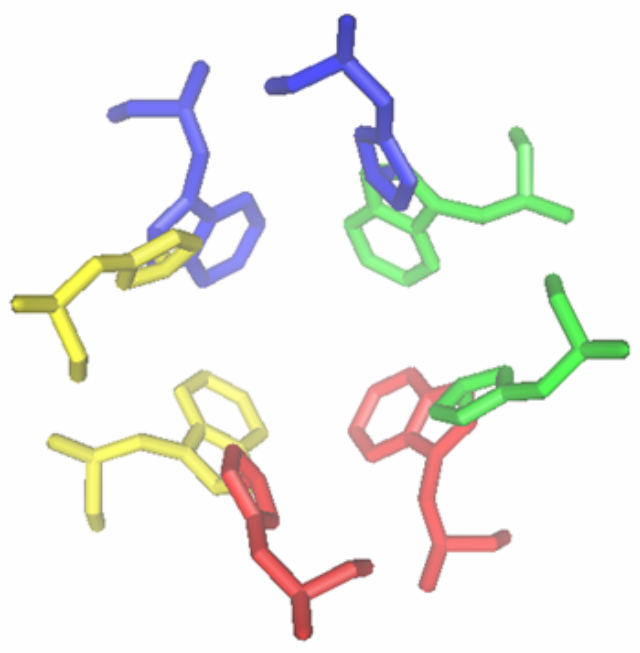

b)

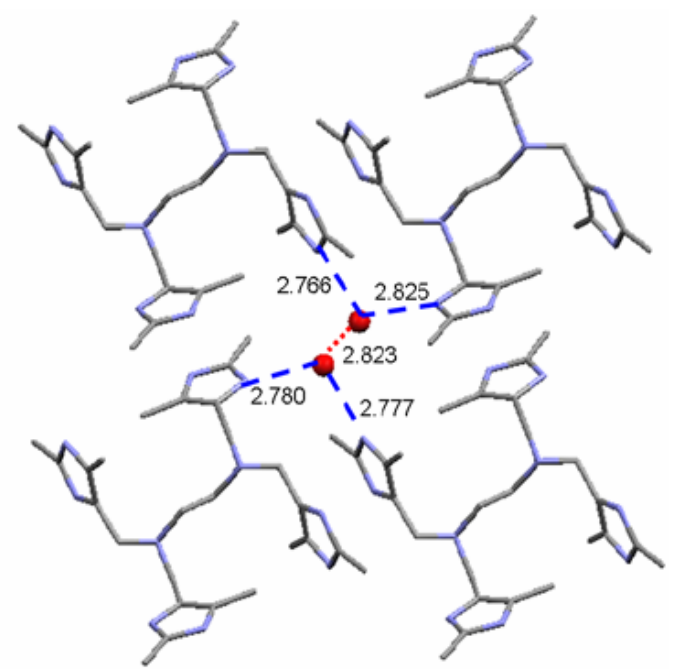

Figure 81. (a) His-Trp $\pi$-stacking from the PDB coordinates; (b) imidazole arrangements found in both compounds that interact with two structural waters.

Interestingly, as described above, both compounds have four imidazole moieties that strongly interact with two unique water molecules localized between layers of host 
molecules. The presence of these waters in $\mathbf{4 8}$ and $\mathbf{4 9}$ models the molecular arrangement of the proposed histidine gate in the influenza A M2 virus. In addition, similar water arrangements have been proposed to act as bridges during helix-helix assembly (Popot, J. L. \& Engelman, D. M., 2000). The influenza A M2 virus contains a water channel formed by four helices that are bundled together. In compound $\mathbf{4 8 ,} \mathrm{O} 1$ and its symmetry related (-x, -y, -z) neighbor interact with each other through a strong hydrogen bond (O--O separation of $2.851 \AA$ and $\mathrm{O} 1-\mathrm{H} 1 \mathrm{BO}----\mathrm{O} 1^{\prime}$ angle of $167.21^{\circ}$ ). $\mathrm{O} 1$ is also strongly interacting with two imidazole nitrogen atoms (N5 and N2) of the organic host. The O1--N2 and O1---N5 separations of 2.787 and $2.858 \AA$, respectively, as well as linear angles of 177.49 and $178.43^{\circ}$ for $\mathrm{O} 1-\mathrm{H} 1 \mathrm{AO}---\mathrm{N} 2$ and $\mathrm{N} 5-\mathrm{H} 5 \mathrm{~N}---\mathrm{O} 1$, respectively is indicative of strong hydrogen bonding between these waters and imidazole nitrogen atoms.

In compound 49, $\mathrm{O} 7$ and $\mathrm{O} 8$ are strongly hydrogen bonded to the cluster of four imidazoles containing N4, N10 with $\mathrm{O} 7$ and N3, N7 with O8. O7 has one full-occupancy hydrogen, H7AO, which is hydrogen bonded with N4 (O7---N4 separation of $2.781 \AA$ and $\mathrm{O} 7-\mathrm{H} 7 \mathrm{AO}---\mathrm{N} 4$ angle of $144.15^{\circ}$ ) and two half-occupancy hydrogens, H7BO and $\mathrm{H} 7 \mathrm{CO}$. The latter hydrogen, $\mathrm{H7CO}$, is bonded to N10 which also has a half-occupancy hydrogen, H10N (O7---N10 separation of $2.775 \AA$ and the non-parallel N10-H10N---O7 and $\mathrm{O} 7-\mathrm{H} 7 \mathrm{CO}---\mathrm{N} 10$ angles of 150.19 and $141.96^{\circ}$, respectively). O8 was modeled with four half-occupancy hydrogen atoms, which interact with two half-occupancy imidazole nitrogens H7N and H3N (O8---N3 and O8---N7 separations of 2.766 and $2.825 \AA$, respectively). The O8-H8CO---N3 and O8-H8AO---N7 angles are 164.11 and $169.08^{\circ}$, respectively, and are very similar to the N3-H3N---O8 and N7-H7N---O8 angles of 165.87 and $163.43^{\circ}$, respectively. These parameters indicate the strong interactions 
between lattice waters and the imidazole host. The presence of the waters in both compounds is potentially relevant to the bridging arrangement of waters in helix-helix assemblies (Popot, J. L. \& Engelman, D. M., 2000). In both compounds, the two waters (O1 and its symmetry related for $\mathbf{4 8}$, and $\mathrm{O} 7$ and $\mathrm{O} 8$ for 49 ) are also involved in hydrogen bonding with other waters associated with water rings. In compound $\mathbf{4 8}$, the two water molecules are bridging a cluster of six water molecules along the diagonal of the unit cell. In compound 49, the formation of novel fused five- and six-membered water rings as well as larger fourteen-, sixteen- and seventeen-membered rings were observed. A detailed description of the structures of the water rings are given in the following sections.

\section{H. Arrangement of Waters in Compound $\mathbf{4 8}$}

In compound 48, a cluster of six water molecules is isolated within the void space of the organic host. The organic host forms a hourglass-like channel where the cluster of six water molecules is linked together by the two bridging water molecules $\mathrm{O} 1$ and its symmetry related atom, $\mathrm{O1}^{\prime}$ (Figure 82 ) forming a unique one-dimensional water chain. Interestingly, an isolated water cluster composed of dimeric and hexameric structures has been observed in a matrix of Ce(III) complex (Ghosh, S. K. \& Bharadwaj, P. K., 2003). 
a)

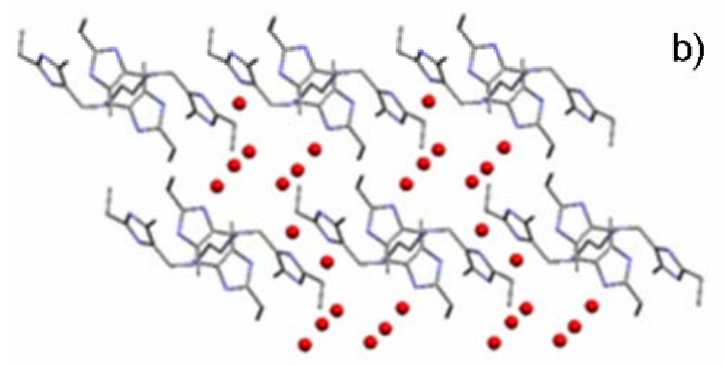

b)

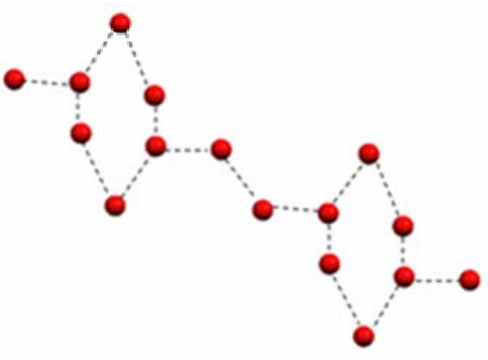

Figure 82. Water organization in compound 48. Clusters of six water molecules in a distorted chair conformation are confined in an hourglass-like channel and isolated from each other by hydrophobic barriers composed of the ethyl groups.

A closer examination of the water cluster in $\mathbf{4 8}$ reveals that the six-membered ring is severally distorted from the typical chair or boat conformation observed in other compounds (Rodriguez-Cuamatzi, P. et al., 2004), and the six-water cluster contains two long O---O contacts (O2---O3 separation of $3.294 \AA$ ) (Figure 83).

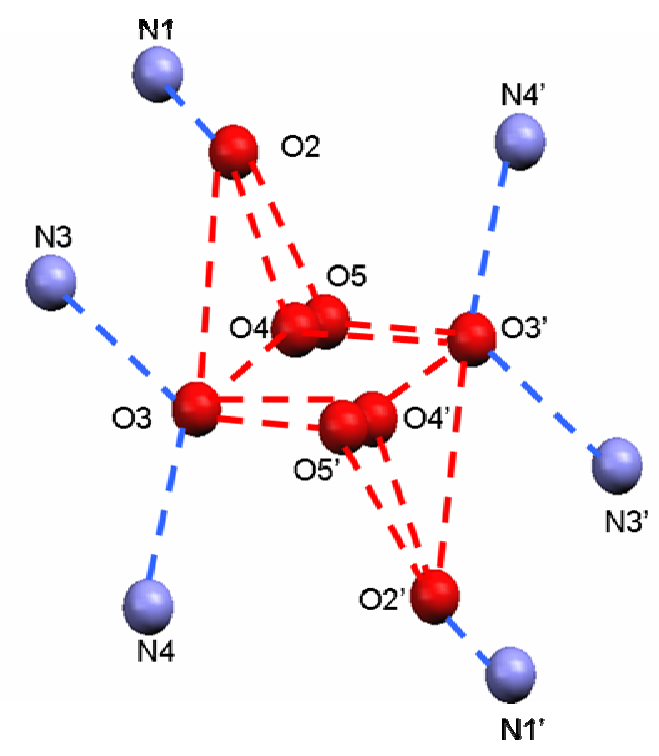

Figure 83. Illustration of the six-water cluster of compound $\mathbf{4 8}$ with the positionally disordered water molecule $(\mathrm{O} 4 / \mathrm{O} 5)$.

In fact, the wingtip oxygen atoms, $\mathrm{O} 2$ and $\mathrm{O} 2$ ', are strongly interacting with $\mathrm{O} 4$ and $\mathrm{O}^{\prime}$, as well as $\mathrm{O} 5$ and $\mathrm{O5}^{\prime}$, which are the disordered atom positions. The wingtip 
oxygens also weakly interact with $\mathrm{O} 3$. The presence of the positionally disordered water molecule $(\mathrm{O} 4, \mathrm{O} 5)$ seems to imply that the ring may interconvert between a distorted sixmembered ring in a chair-like conformation that includes atoms $\mathrm{O} 2, \mathrm{O} 3, \mathrm{O} 5, \mathrm{O}^{\prime}, \mathrm{O}^{\prime}$ 'and $\mathrm{O}^{\prime}$, and a four-membered water ring, including $\mathrm{O} 3, \mathrm{O} 4, \mathrm{O}^{\prime}$ and $\mathrm{O}^{\prime}$ ' with two wingtip water molecules, $\mathrm{O} 2$ and $\mathrm{O} 2$ '.

There are several examples of discrete six-water clusters in both boat and chair conformations (Custelcean, R. et al., 2000; Ghosh, S. K. \& Bharadwaj, P. K., 2003; Infantes, L. \& Motherwell, S., 2002; Michaelides, A. et al., 2003; Rodriguez-Cuamatzi, P. et al., 2004), but only two examples of four-membered water rings (Long, L. S. et al., 2004; Tao, J. et al., 2004). Theoretical calculations indicate five possible arrangements of six-membered water rings that are virtually isoenergetic: ring, book, bag, cage and prism structures (Ludwig, R., 2001) and also five possible arrangements of four-water clusters: ring, star, lasso, tetrahedron and chain (Ludwig, R., 2001).

In this study, hydrogen atoms on the water molecules were located by difference electron maps. During the refinement, positions of the hydrogens were fixed as well as their thermal parameters. The hydrogen atom model generated is consistent with the Bernal and Fowler's "ice rule", which globally states that every oxygen atoms is covalently bonded to two hydrogen atoms, and that exactly one hydrogen atom is found between two oxygen atoms (Bernal, J. D. \& Fowler, R. H., 1933). The second part of the statement can be modified by having half hydrogen atoms on oxygen atoms facing each other. The four- and six-membered ring models of the water clusters in $\mathbf{4 8}$ are discussed separately below. 
1. Chair-like Conformation of the Six-membered Water Ring (O2, O3, O5, $\mathrm{O} 2{ }^{\prime}, \mathrm{O}^{\prime}, \mathrm{O}^{\prime}$ )

Figure 84 illustrates the arrangement of waters in the chair-like six-membered ring conformation, as well as the position of the hydrogen atoms involved in hydrogen bonding. Close examination of the bond distances reveals that one of the O---O separations is significantly longer than the others (O2---O3 separation is $3.294 \AA$ ), resulting in a distorted chair conformation compared to other reported structures (Custelcean, R. et al., 2000; Ghosh, S. K. \& Bharadwaj, P. K., 2003; Michaelides, A. et al., 2003). This distortion occurs because $\mathrm{O} 2$ interacts more strongly with the tertiary nitrogen, N1, (O2---N1 separation of $2.781 \AA$ and O2-H2AO---N1 angle of $\left.174.58^{\circ}\right)$ than with $\mathrm{O} 3 . \mathrm{O} 3$ is also strongly hydrogen bonded to two imidazole nitrogen atoms $\mathrm{N} 3$ and N4 (O3---N3 and O3---N4 separations of 2.884 and $2.851 \AA$, respectively). As a result, it appears that the water pocket is too large to accommodate the water cluster in a regular chair-like conformation and that $\mathrm{O} 2$ behaves more like a structural water (bound to the organic host) instead of an integral part of the water ring. See Table 19 for a complete list of important hydrogen bonding parameters of the water ring in compound $\mathbf{4 8 .}$

Table 19. Selected O---O separations and O---O---O, O-H---O angles for the sixmembered water rings.

\begin{tabular}{cccc}
\hline \multicolumn{2}{c}{ O---O separations $(\AA)$} & O---O---O angles $\left(^{\circ}\right)$ \\
\hline O3---O5 & 2.873 & O3---O5---O2 & 105.38 \\
O5---O2 & 2.823 & O5---O2---O3 & 79.88 \\
O2---O3 & 3.294 & O2---O3---O5 & 113.93 \\
\hline \multicolumn{4}{c}{ O-H---O angles $\left(^{\circ}\right)$} \\
\hline \multicolumn{4}{c}{161.19} \\
\hline O3-H3AO---O5 & 159.29 \\
O5-H45B---O2 & 160.66 \\
O2-H2CO---O3 & 123.92 \\
O2-H2BO---O5
\end{tabular}



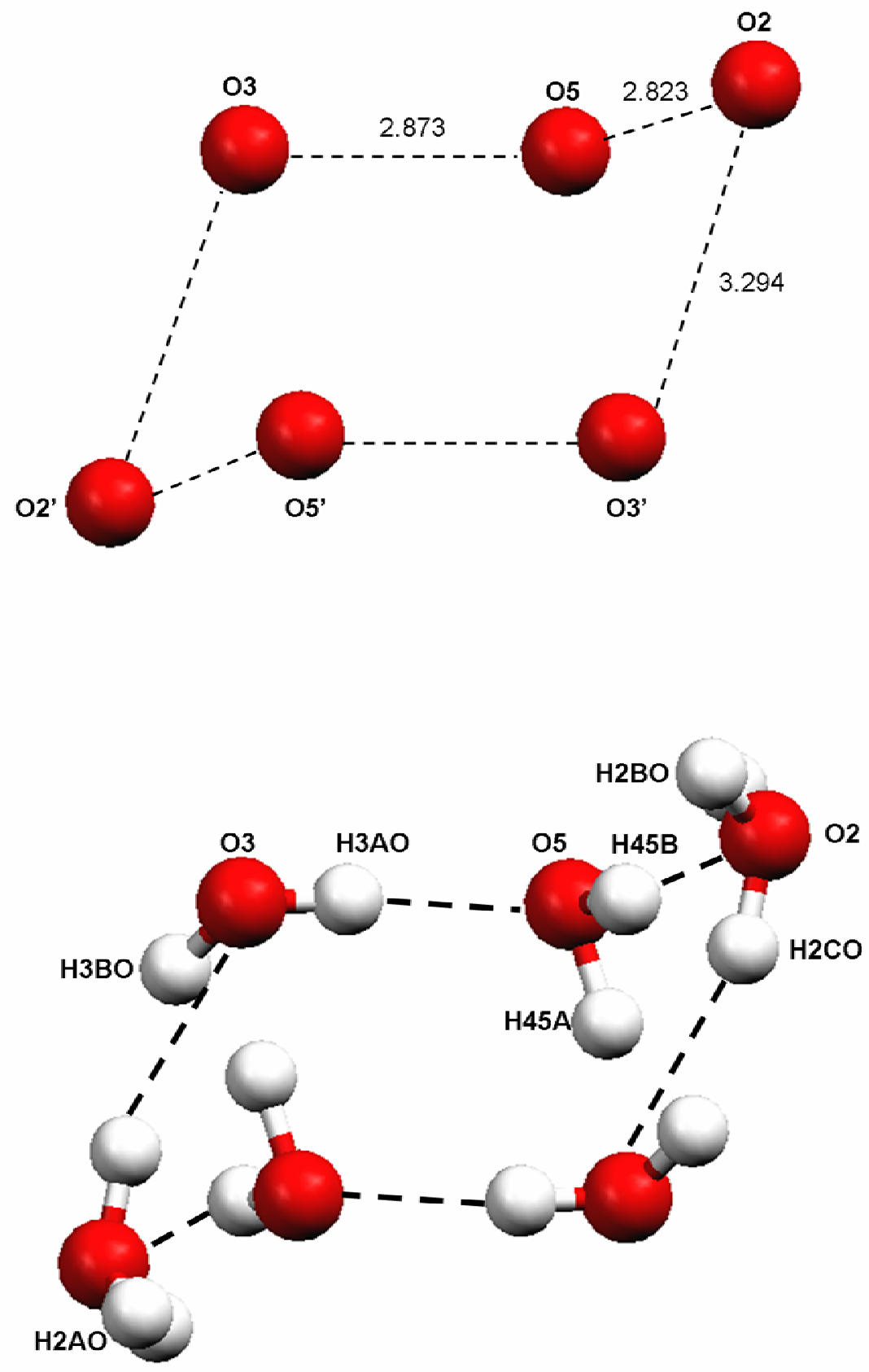

Figure 84. Ball-and-stick representations of the six-membered water ring found in $\mathbf{4 8 .}$ 
The presence of the two long O---O separations and the disordering of $\mathrm{O} 4 / \mathrm{O} 5$ waters in the plane of the ring suggests that the cluster has a tendency to interconvert between the distorted chair conformation and a structure that is best described as a fourmembered ring. The model of the latter ring structure is described below.

\section{2. $\quad$ Four-membered Water Ring $\left(\mathrm{O} 3, \mathrm{O} 4, \mathrm{O}^{\prime}, \mathrm{O}^{\prime}\right)$}

During the refinement of the crystal structure, one of the water molecules was found to be positionally disordered between two positions (O4 and O5). While the O5--O3 separation $(3.943 \AA)$ was too long to be considered an important contact, the separation of $2.983 \AA$ between $\mathrm{O} 4$ and $\mathrm{O} 3$ suggests that the arrangement of the six oxygen atoms in this form resembles a four-membered water cluster with two wingtips water oxygens (O2) (Figure 85). There have been numerous theoretical calculations performed on water tetramers and five conformations are predicted which differ by the position of the hydrogen atoms not involved in the hydrogen bonding within the ring. Interestingly, the three positionally disordered hydrogen atoms found on $\mathrm{O} 4$ are indicative of the possible existence of uudd or uuud conformers for the water tetramer. Two well-resolved uudd water tetramers present in inorganic matrix have been characterized recently (Long, L. S. et al., 2004; Tao, J. et al., 2004). In compound 48, the O4---O3' separation of $2.983 \AA$ is slightly longer than the 2.896 and $2.810 \AA \AA$ observed for the uudd structures, but still reflective of a strong hydrogen bonding between these water molecules. Selected hydrogen bonding parameters associated with the 4-membered ring are listed in Table 20. 

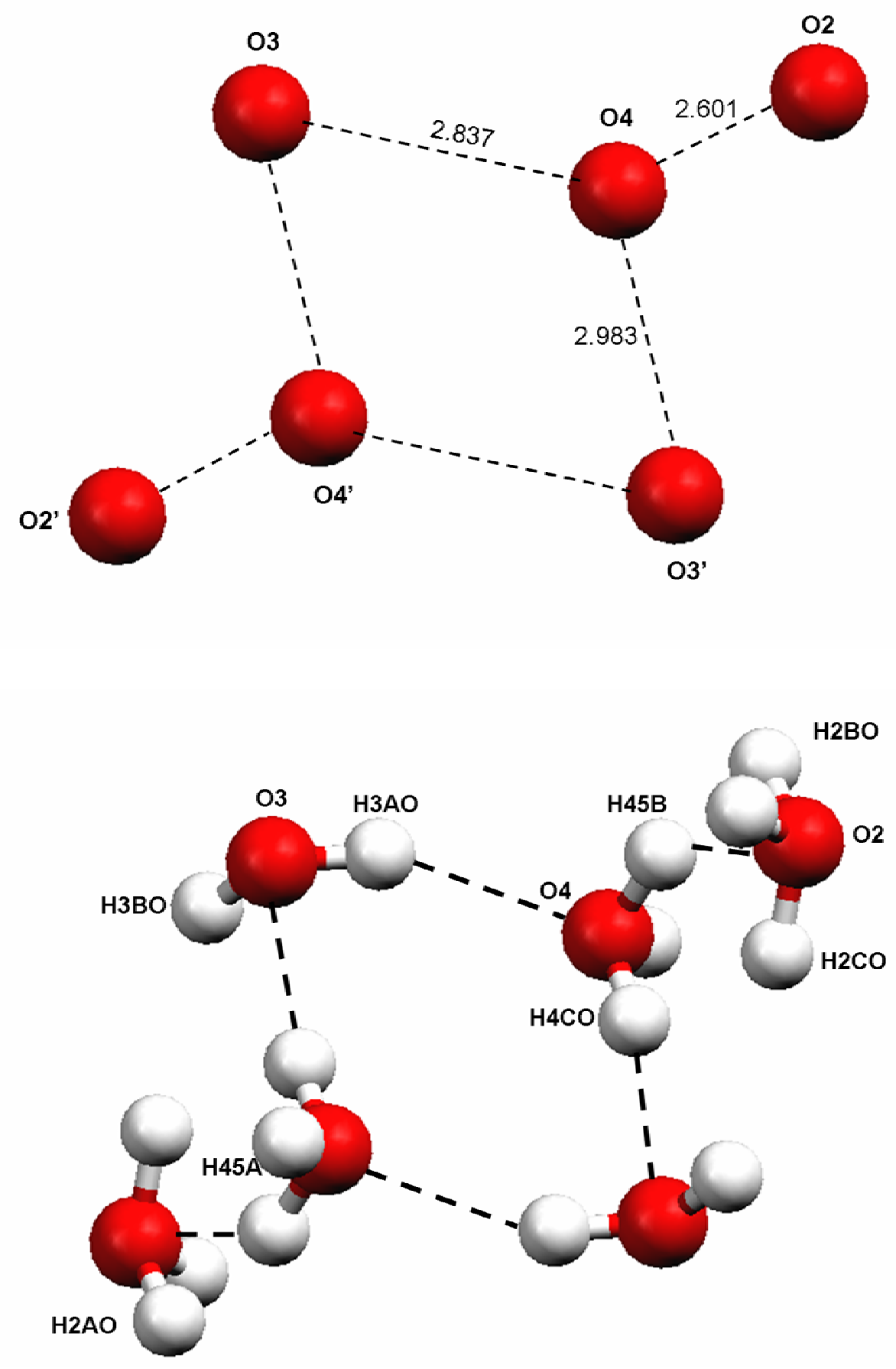

Figure 85. Ball-and-stick representations of the four-membered water ring with two wingtip water molecules (O2 and $\left.\mathrm{O}_{2}^{\prime}\right)$ found in $\mathbf{4 8}$. 
Table 20. Selected O---O separations and O---O---O, O-H---O angles for the four membered water ring with two wingtip water molecules.

\begin{tabular}{cccc}
\hline \multicolumn{2}{c}{ O---O separations $(\AA)$} & \multicolumn{2}{c}{ O---O---O angles $\left(^{\circ}\right)$} \\
\hline O3---O4 & 2.837 & O3---O4---O3' & 101.88 \\
O4---O3' & 2.983 & O4---O3---O4' & 78.12 \\
O4---O2 & 2.601 & O3---O4---O2 & 112.79 \\
O2---O3' & 3.294 & O4---O2---O3' & 59.43 \\
& O2---O3'---O4' & 96.85 \\
\hline \multicolumn{3}{c}{ O-H---O angles $\left(^{\circ}\right)$} \\
\hline \multicolumn{3}{c}{155.54} \\
O3-H3AO---O4 172.71 \\
O4-H4CO---O3' $345 B---O 2$ & 137.97 \\
O2-H2BO---O4 & 98.21 \\
O2-H2CO---O3 & 160.31 \\
\hline
\end{tabular}

As illustrated earlier (Figure 82), the ethyl groups of the organic host of $\mathbf{4 8}$ form hydrophobic barriers between water chains that confine the clusters in well-defined cavities. Individual cavities are linked together forming isolated one-dimensional water chains throughout the crystal. Simple modification of the structure of the organic hosts (substitution of a methyl group for an ethyl group in the 2-position) produces a drastic change in the water organization in the crystal structure of compound 49. The smaller methyl groups cannot interlock to form hydrophobic barriers as in $\mathbf{4 8}$. As a result, 49 has an extended 2-D structure of water clusters (Figure 86). The observation of fused fiveand six-membered hydrogen-bonded water rings in 49 is unique and may provide useful insight into the structure of water clusters present on the surface of proteins in the solidstate. Molecular dynamic simulations have proposed similar structures to be present in phase transitions between liquid and solid forms of water (Koga, K. et al., 2000). 


\section{Analysis of the Crystal Structure of Compound 49}

As indicated above, the substitution of the ethyl group for a methyl group in $\mathbf{4 9}$ did not alter the $\pi$-stacking of the imidazole moieties of the host, but rather altered the organization of the water molecules in the crystal lattice. Compound 49 crystallizes with thirteen water molecules per asymmetric unit. The organization of the water molecules reveals the presence of two five- and one six-membered water rings that are fused together (Figure 86).

a)

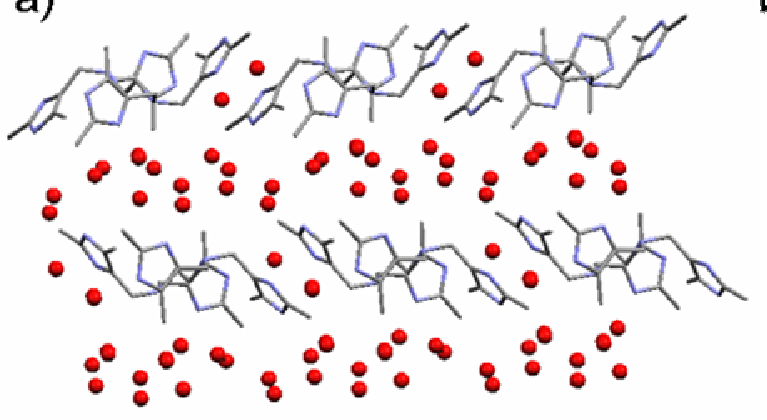

b)

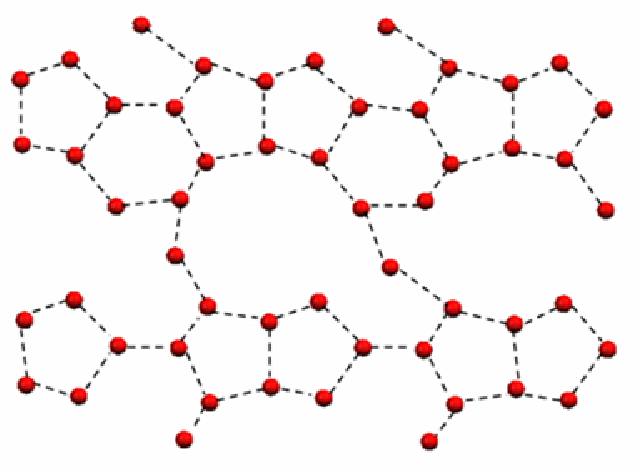

Figure 86. Organization of water molecules in compound 49 (a) showing the twodimensional layer of water molecules (b).

The two five-membered rings containing $\mathrm{O} 9, \mathrm{O} 5, \mathrm{O} 6, \mathrm{O} 3, \mathrm{O} 12$ and $\mathrm{O} 1, \mathrm{O} 2, \mathrm{O} 4$, O5, O9 share two common oxygen atoms, 09 and 05 . The two fused five-membered rings are also fused with a six-membered ring containing $\mathrm{O} 2, \mathrm{O} 3, \mathrm{O} 6, \mathrm{O} 11, \mathrm{O} 10, \mathrm{O} 4$ through oxygen atoms, $\mathrm{O} 2$ and O4, as illustrated in Figure 87. 


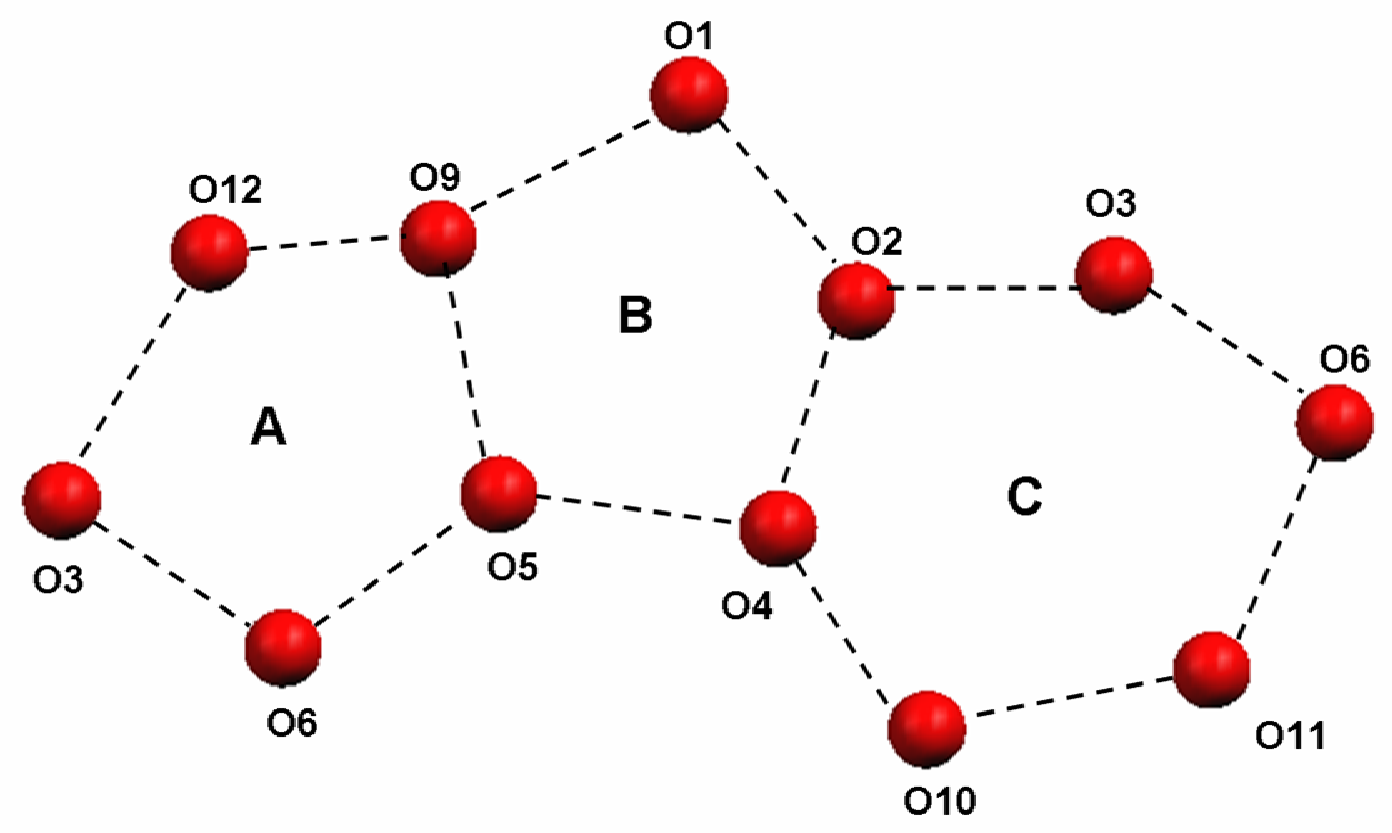

Figure 87. Ball-and-stick representation of the fused five- and six-membered ring observed in the crystal structure of compound 49.

The 5-5-6 fused ring structure is very novel and has not been observed previously (Infantes, L. et al., 2003). The three-ring unit is fused further to other repeating units through $\mathrm{O} 3$ and $\mathrm{O} 6$ to form continuous ribbons of water clusters. These ribbons are connected to each other through $\mathrm{O} 13$ forming larger fourteen-membered ring units (see Figure 98). Larger sixteen- and seventeen-membered rings involving the two bridging water molecules $\mathrm{O} 7$ and $\mathrm{O} 8$ encapsulate the organic frame (see Figure 99). A more detailed description of the water-water interactions involved in these large water ring structures is given below as well as a detailed evaluation of the hydrogen bond network, and the illustrations of possible violations of the Bernal and Fowler's rule. 
1. Five-membered Water Ring A (O1, O2, O4, O5, O9)

The pentameric arrangement of water molecules in ring A is illustrated in Figure 88. Four oxygen atoms $(\mathrm{O} 2, \mathrm{O} 4, \mathrm{O} 5, \mathrm{O} 9)$ are located in the plane while $\mathrm{O} 1$ lies out of the plane by $1.88 \AA$. The overall shape of the five-membered ring resembles the envelope conformation of cyclopentadiene. The observed O---O separations ranging from 2.752$2.821 \AA$ are longer than expected from theoretical calculations, which predicts that the O--O separation should range from 2.724 to $2.731 \AA$ (Xantheas, S. S., 1995). Nevertheless, the bond distances and angles are consistent with strong hydrogen bond interactions between neighboring water molecules. Pertinent $\mathrm{O}---\mathrm{O}$ separations and $\mathrm{O}---\mathrm{O}---\mathrm{O}$ angles are summarized in Table 21, as well as other hydrogen bonding parameters associated with the other water ring in $\mathbf{4 9}$.

There are several structural features of ring A worth discussing. The O9---O1--O2 angle of $98.26^{\circ}$ is a fairly acute angle but consistent with the puckered conformation of the ring. Three of the five water oxygens, $\mathrm{O} 1, \mathrm{O} 2$ and $\mathrm{O} 4$, are interacting with nitrogen atoms of host molecules and the remaining waters are interacting only with each other. O1 is strongly hydrogen bonded to one of the two tertiary amine nitrogens, N6, with an O1---N6 separation of $2.805 \AA$ and O1-H1AO---N6 angle of $156.73^{\circ}$. The halfoccupancy hydrogen $\mathrm{H} 2 \mathrm{CO}$ of $\mathrm{O} 2$ is interacting with the $\mathrm{N} 2$ nitrogen atom of an imidazole ring that also carries a half-occupancy hydrogen, H2N. A similar argument was used above to explain the positional disordering of hydrogen atoms in compound $\mathbf{5 2}$ (see section $\mathrm{E}$ in this Chapter). The O2-H2CO---N2 angle of $150.03^{\circ}$ and the N2-H2N---O2 angle of $140.41^{\circ}$, as well as the O2---N2 separation of $2.852 \AA$ are indicative of strong 
hydrogen bonding. $\mathrm{O} 4$ is the acceptor atom in the hydrogen bond with $\mathrm{H} 5 \mathrm{~N}$ and the $\mathrm{O} 4---$ N5 separation is $2.829 \AA$ and N5-H5N---O4 angle is $165.89^{\circ}$.
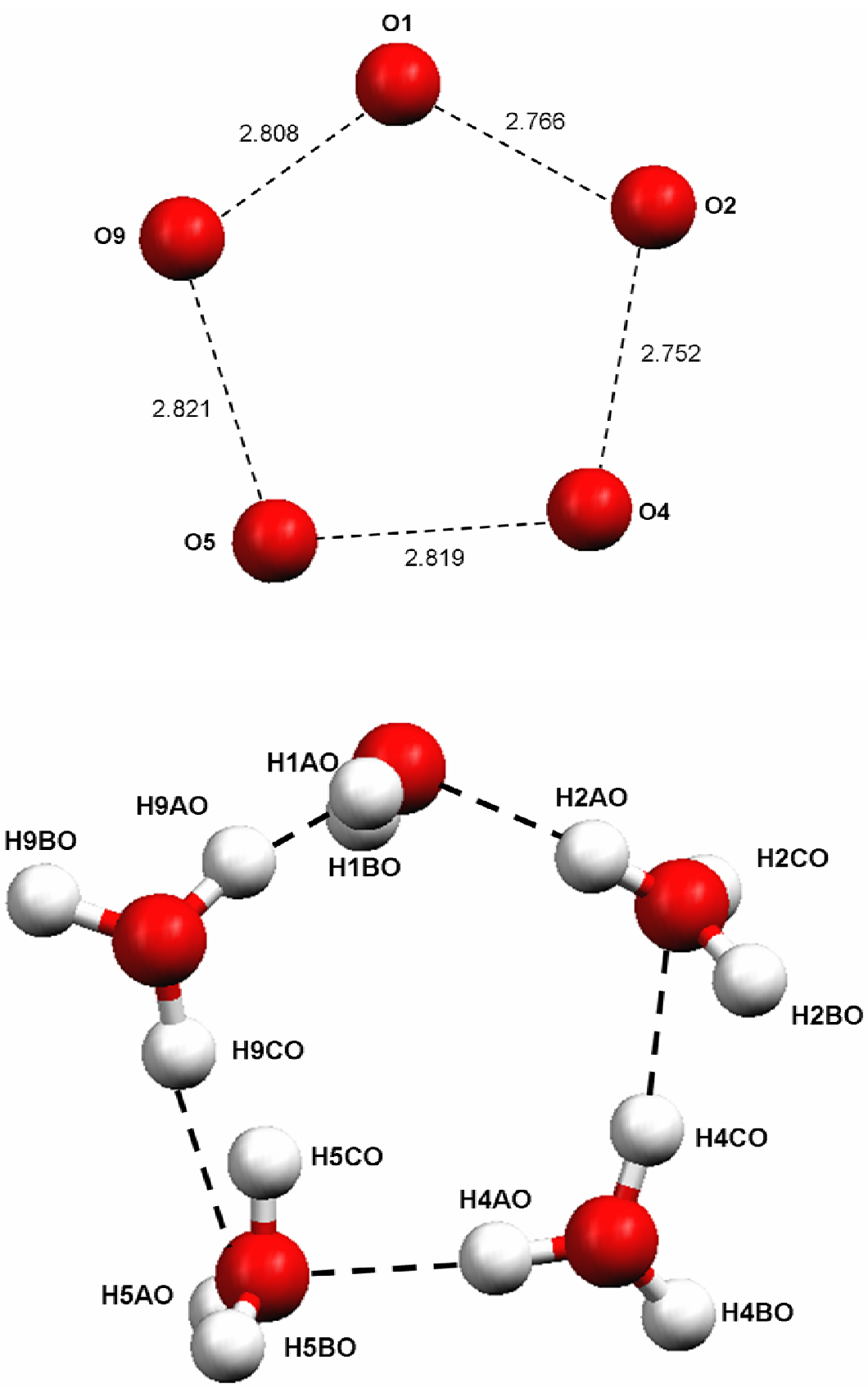

Figure 88. Ball-and-stick representations of one of the five-membered rings observed in the crystal structure of compound 49. 


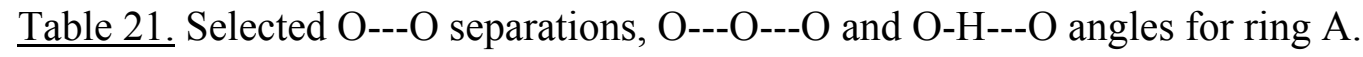

\begin{tabular}{cccc}
\hline O---O separations $(\AA)$ & \multicolumn{2}{c}{ O---O---O angles $\left(^{\circ}\right)$} \\
\hline O1---O2 & 2.766 & O1---O2---O4 & 102.94 \\
O2---O4 & 2.752 & O2---O4---O5 & 107.68 \\
O4---O5 & 2.819 & O4---O5---O9 & 101.41 \\
O5---O9 & 2.821 & O5---O9---O1 & 104.25 \\
O9---O1 & 2.808 & O9---O1---O2 & 98.26 \\
\hline \multicolumn{5}{c}{ O-H---O angles $\left(^{\circ}\right)$} \\
\hline \multicolumn{3}{c}{123.95} \\
O9-H9AO---O1 141.54 \\
O1-H1BO---O9 170.18 \\
O2-H2AO---O1 3 BO---O4 \\
O4-H4CO---O2 \\
O4-H4AO---O5
\end{tabular}

Overall, the O-H---O angles in the pentameric ring $\mathrm{A}$ are in agreement with the presence of strong hydrogen bonds. However, they disagree with the Bernal and Fowler's rule and lead to a Bjerrum D type defect (Figure 89) (Kirschgen, T. M. et al., 2003).

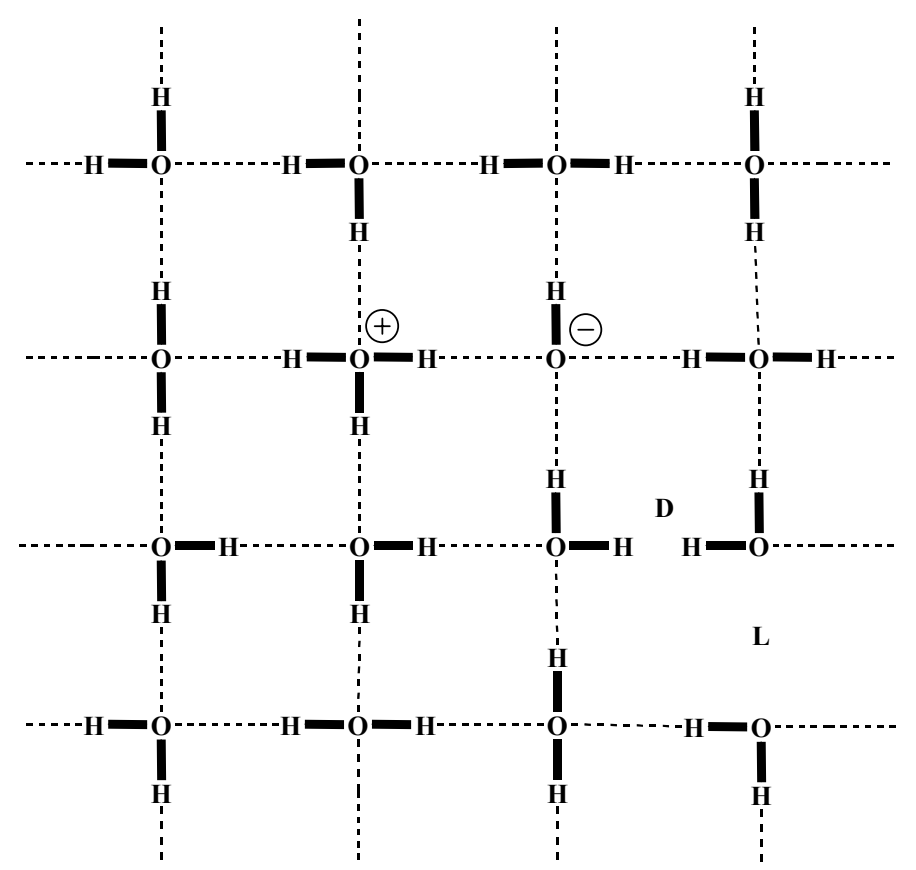

Figure 89. Illustration of the point defects in ice-like structures associated with water hydrogens. Ionic defects are represented with + and -, Bjerrum defects with L for empty and D for doubly occupied, respectively (reproduced from (Kirschgen, T. M. et al., 2003)). 
More specifically, the hydrogen atoms on $\mathrm{O} 9$ and $\mathrm{O} 1$ were refined as full occupancy atoms with the vertex between the two oxygen atoms. Usually this type of defect is necessary for proton transport to occur (Kirschgen, T. M. et al., 2003).

2. Five-membered Water Ring B (O9, O5, O6, O3, O12)

The pentameric arrangement of water molecules in ring B is illustrated in Figure 90. Ring B is formed by the water molecules containing $\mathrm{O} 9, \mathrm{O} 5, \mathrm{O} 6, \mathrm{O} 3$ and $\mathrm{O} 12$ and has a different structure than ring $\mathrm{A}$. While ring $\mathrm{A}$ has an envelope conformation, ring $\mathrm{B}$ is quasi planar (rms deviation of the atoms in ring B is 0.148). Also, the O---O separations in ring $B$ are different from the previously described five-membered ring (A) (Table 22).

Table 22. Selected O---O separations, O---O---O and O-H---O angles found in ring B.

\begin{tabular}{|c|c|c|c|}
\hline \multicolumn{2}{|c|}{ O---O separations $(\AA)$} & \multicolumn{2}{|c|}{ O---O---O angles $\left({ }^{\circ}\right)$} \\
\hline O9---O5 & 2.821 & O9---O5---O6 & 99.31 \\
\hline O5---O6 & 2.765 & O5---O6---O3 & 116.05 \\
\hline O6---O3 & 2.771 & O6---O3---O12 & 96.03 \\
\hline O3---O12 & 2.834 & O3---O12---O9 & 113.97 \\
\hline O12---O9 & 2.555 & O12---O9----O5 & 110.17 \\
\hline \multicolumn{4}{|c|}{$\mathrm{O}-\mathrm{H}---\mathrm{O}$ angles $\left(^{\circ}\right)$} \\
\hline $\mathrm{O} 12-\mathrm{H} 1$ & & 163. & \\
\hline O6-H6A & & 143. & \\
\hline $\mathrm{O} 5-\mathrm{H} 5 \mathrm{~A}$ & & 164. & \\
\hline $\mathrm{O} 5-\mathrm{H} 5 \mathrm{C}$ & & 137. & \\
\hline O9-H9C & & 153. & \\
\hline O9-H9B & & 155. & \\
\hline $\mathrm{O} 12-\mathrm{H} 1$ & & 137. & \\
\hline
\end{tabular}



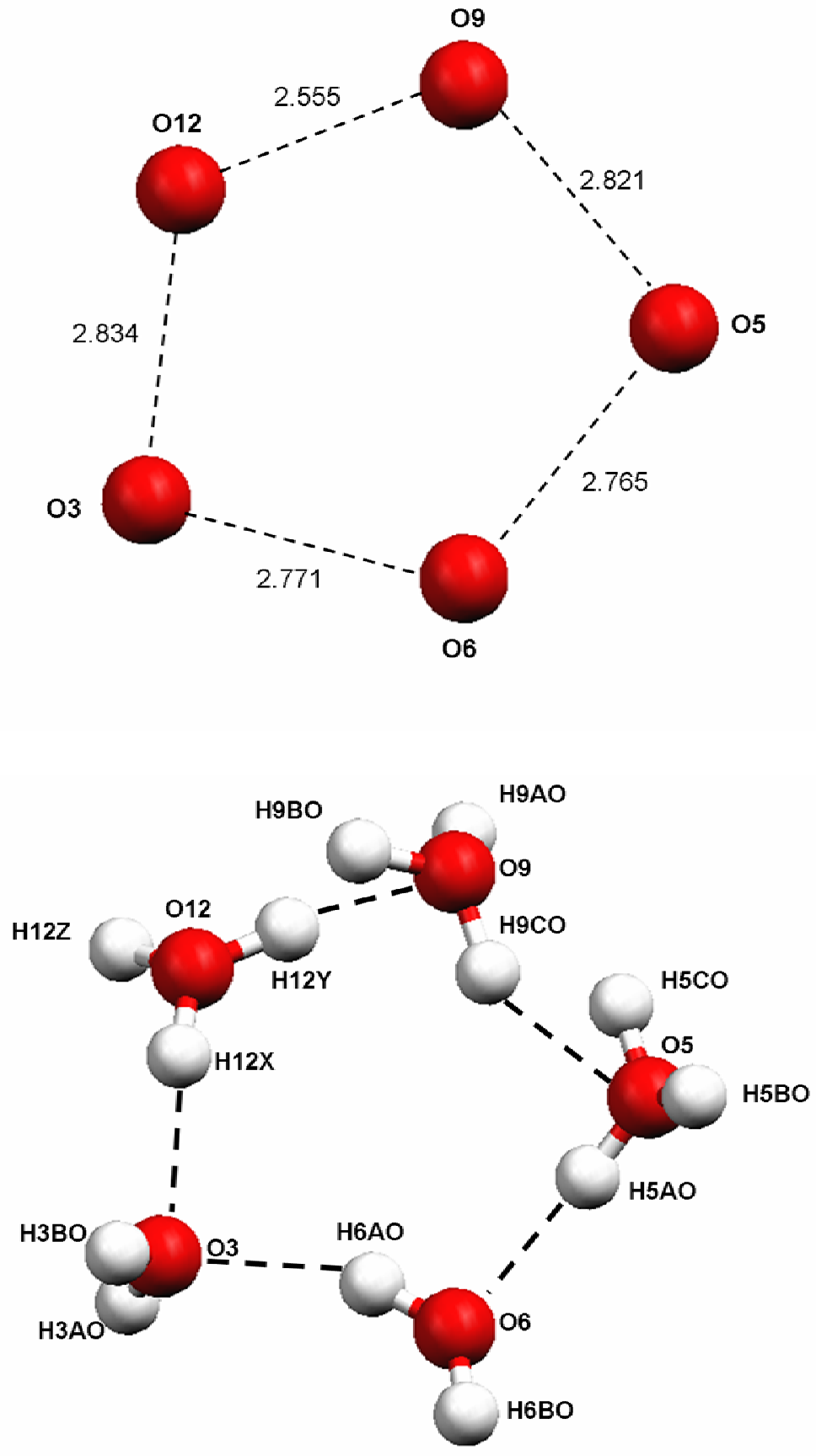

Figure 90. Ball-and-stick representations of the second five-membered water ring observed in compound 49. 
A very short O---O interaction of $2.555 \AA$ is found between the $\mathrm{O} 9$ and $\mathrm{O} 12$ oxygen atoms (Table 22). Such short contacts have been proposed for the Zundel ion, $\mathrm{H}_{2} \mathrm{O}_{5}{ }^{+}$ (Zundel, G. \& Metzger, H., 1967). However, in our case, compound 49 is clearly neutral. If charged sites are present they may be delocalized through the $\pi$-stack of the imidazole units of the host molecules. For example, the O12-N7 separation of $3.166 \AA$ indicates a strong point-to-face $\pi$-stacking interaction (Figure 91) (Gallivan, J. P. \& Dougherty, D. A., 1999; Zundel, G. \& Metzger, Z., 1968), which could be the origin of charge separation.

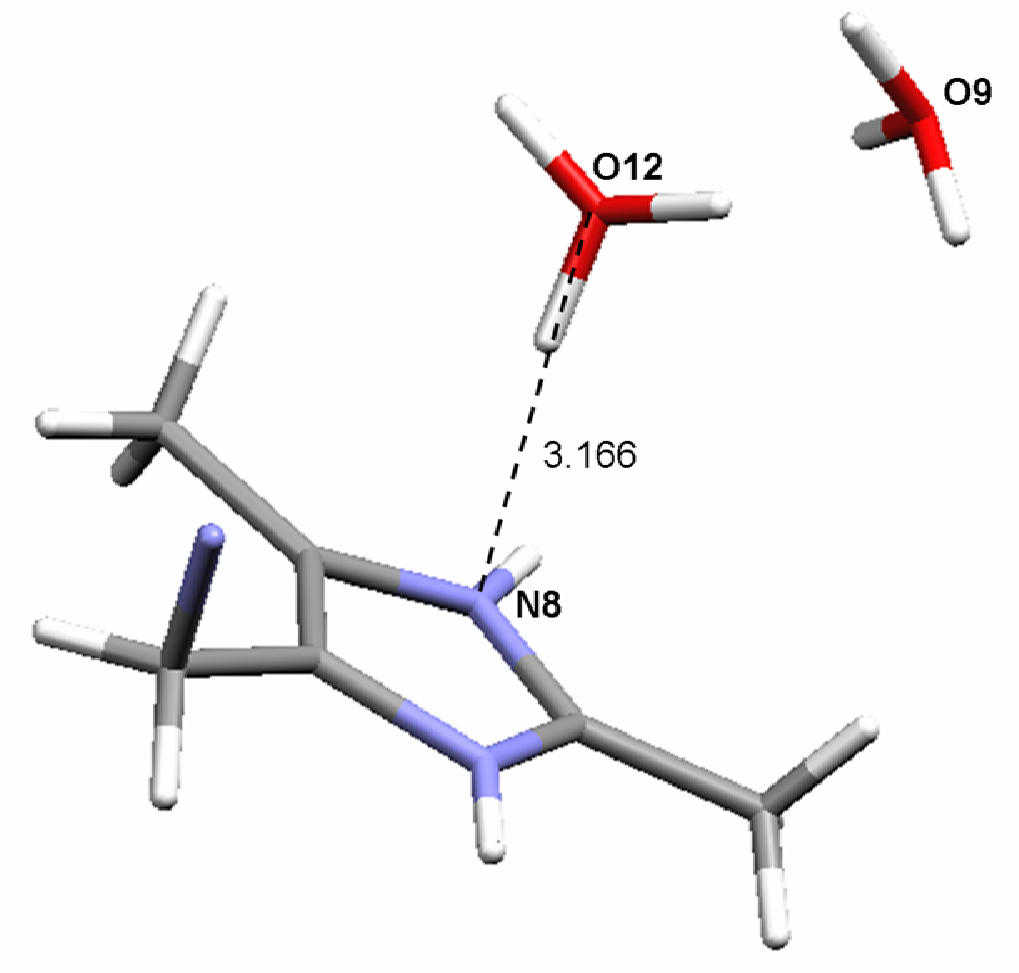

Figure 91. Capped-stick representation of the point-to-face $\pi$ stacked interaction between water molecule, $\mathrm{O} 12$, and the imidazole ring containing $\mathrm{N} 8$.

In ring $\mathrm{B}$, only $\mathrm{O} 3$ is interacting with the organic frame via the second tertiary amine nitrogen atom, N1, with an O3---N1 separation of $2.828 \AA$ and O3-H3AO---N1 
angle of $152.35^{\circ}$ (see Table 22 for others hydrogen bonding parameters). This fivemembered water ring $\mathrm{B}$ is fused to the previous ring A through $\mathrm{O} 9$ and $\mathrm{O} 5$ and to the sixmembered water ring $\mathrm{C}$ through $\mathrm{O} 2$ and $\mathrm{O} 4$. In contrast to ring $\mathrm{A}$, the water hydrogens in ring B follow the Bernal and Fowler's rule.

\section{Six-membered Water Ring C (O2, O3, O6, O11, O10, O4)}

Figure 92 illustrates the arrangement of waters in the six-membered ring $\mathrm{C}$, as well as the position of the hydrogen atoms involved in hydrogen bonding. The sixmembered ring $\mathrm{C}$ is flatter than the one observed in the structure of compound $\mathbf{4 8}$, and is reminiscent of the near planar six-membered ring proposed to be present in liquid water (Ludwig, R., 2001). A closer inspection of the structure of ring $\mathrm{C}$ shows that it is ruffled, where $\mathrm{O} 6$ and $\mathrm{O} 10$ are puckered out of a plane defined by $\mathrm{O} 4, \mathrm{O} 2, \mathrm{O} 3, \mathrm{O} 11$ by 1.53 and $0.78 \AA$, respectively, compared to a $2.30 \AA$ displacement observed for O2 in the chair conformation of 48. Only one of the six O---O separations is slightly longer than the other $(2.855 \AA$ between $\mathrm{O} 10$ and O11 compared to the more normal $2.773 \AA$ average separation for the other oxygens) (Table 23). 

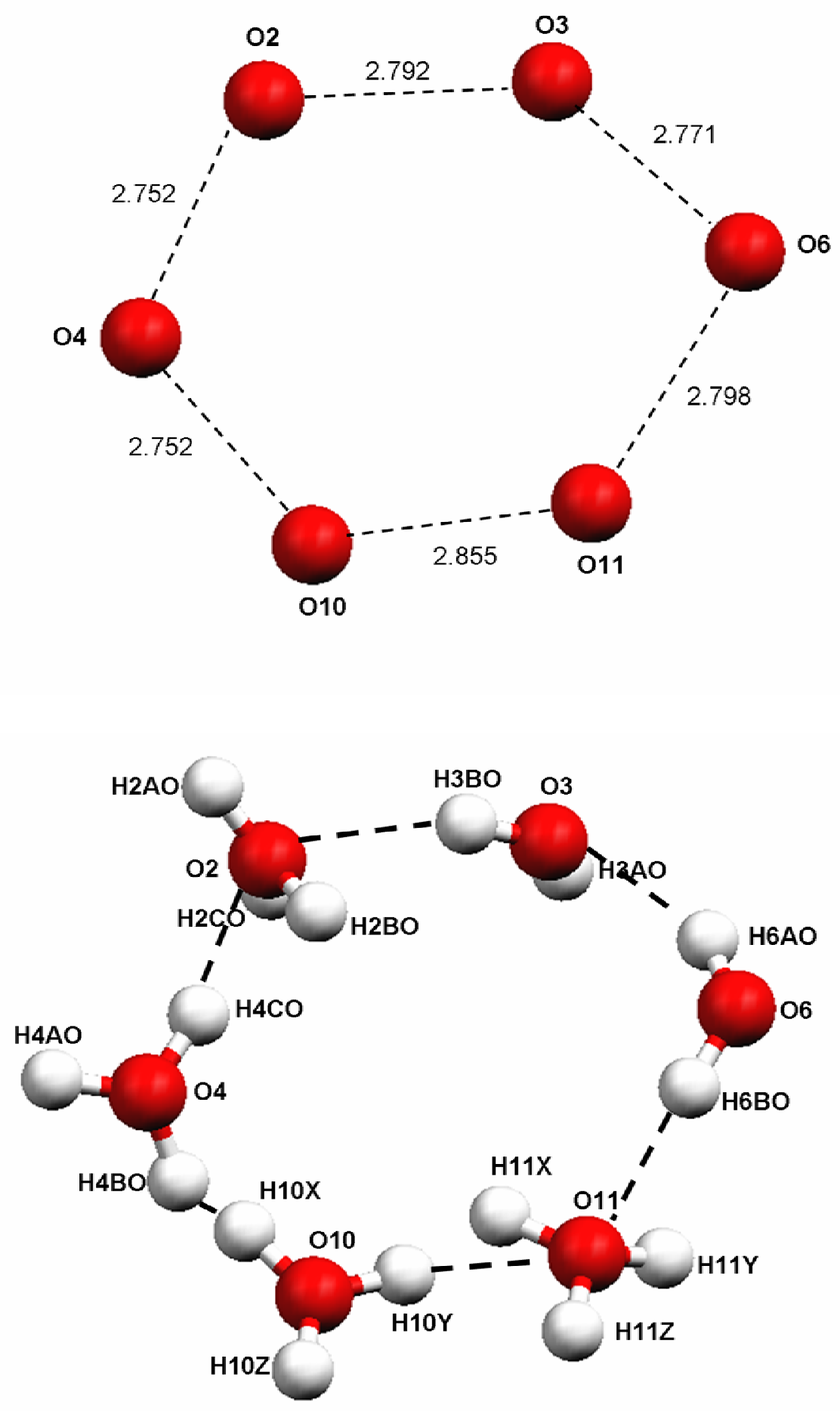

Figure 92. Ball-and-stick representations of the six-membered water ring $\mathrm{C}$ observed in compound 49. 
Table 23. Selected O---O separations, O---O---O and $\mathrm{O}-\mathrm{H}---\mathrm{O}$ angles in the sixmembered water ring $\mathrm{C}$.

\begin{tabular}{|c|c|c|c|}
\hline \multicolumn{2}{|c|}{ O---O separations $(\AA)$} & \multicolumn{2}{|c|}{ O---O---O angles $\left(^{\circ}\right)$} \\
\hline O2---O3 & 2.792 & O2---O3---O6 & 119.23 \\
\hline O3---O6 & 2.771 & O3---O6---O11 & 102.52 \\
\hline O6---O11 & 2.798 & O6---O11---O10 & 112.95 \\
\hline O11---O10 & 2.855 & O11---O10---O4 & 107.26 \\
\hline O10---O4 & 2.752 & O10---O4----O2 & 100.11 \\
\hline $\mathrm{O} 4---\mathrm{O} 2$ & 2.752 & O4---O2---O3 & 123.36 \\
\hline \multicolumn{4}{|c|}{ O-H---O angles $\left(^{\circ}\right)$} \\
\hline $\mathrm{O} 3-\mathrm{H} 3 \mathrm{~B}$ & & \multicolumn{2}{|c|}{146.93} \\
\hline O6-H6A & & \multicolumn{2}{|c|}{143.93} \\
\hline O6-H6BC & 11 & \multicolumn{2}{|c|}{160.44} \\
\hline O11-H112 & 10 & \multicolumn{2}{|c|}{137.32} \\
\hline $\mathrm{O} 10-\mathrm{H} 10$ & 011 & \multicolumn{2}{|c|}{136.03} \\
\hline $\mathrm{O} 4-\mathrm{H} 4 \mathrm{BC}$ & 10 & \multicolumn{2}{|c|}{147.06} \\
\hline $\mathrm{O} 10-\mathrm{H} 10$ & $\mathrm{O} 4$ & \multicolumn{2}{|c|}{130.75} \\
\hline $\mathrm{O} 4-\mathrm{H} 4 \mathrm{C}$ & & \multicolumn{2}{|c|}{165.98} \\
\hline $\mathrm{O} 2-\mathrm{H} 2 \mathrm{~B}$ & & \multicolumn{2}{|c|}{108.12} \\
\hline
\end{tabular}

In addition to the two previously described hydrogen bonding interactions between O4---N5 and O3---N1 (Section I.1 in this Chapter), O11 is also hydrogen bonded to the imidazole nitrogen atom, N8, which also carries a half-occupancy hydrogen (N8---O11 separation of $2.783 \AA$ with N8-H8N---O11 and O11-H11Y---N8 angles of 159.47 and $122.47^{\circ}$, respectively).

Finally, the resulting fused $\mathrm{A}, \mathrm{B}$ and $\mathrm{C}$ rings extend along the crystallographic $\mathrm{c}$ axis, while along the crystallographic a axis the resulting ribbons are linked together via O13 forming a fourteen-membered ring water cluster. A detailed description of this structure is presented in the next section. 


\section{4. $\quad$ Fourteen-membered Water Ring}

Larger water clusters have been observed in the crystal structures of a few small molecule hydrates (Barbour, L. J. et al., 2000; Ghosh, S. K. \& Bharadwaj, P. K., 2004; Raghuraman, K. et al., 2003). They have also been observed crystallographically near the surface of proteins where they are thought to play an important role in protein hydration and protein/protein interactions (Pal, S. K. \& Zewail, A. H., 2004; Papoian, G. A. et al., 2003; Zhao, L. et al., 2004). For example, in the crystal structure of hemoglobin, a wellordered water cluster (19 water molecules) has been shown to play an integral role in the cooperative function of the dimeric hemoglobin (Royer, W. E. et al., 1996). On the other hand, large water clusters have been identified in the crystals of the plant protein crambin (Teeter, M. M. \& Heo, N. H., 1988) and in human lysozymes (Blake, C. C. F. et al., 1983). Water clusters, especially pentameric rings (Teeter, M. M., 1984), are found mainly near hydrophobic sites of the proteins and are thought to play an important role in the protein hydration by maximizing van der Waals contacts between hydrophobic entities and water molecules, without disrupting the hydrogen bonding network (Cameron, I. L. et al., 1997a).

Related to this, compound $\mathbf{4 9}$ has an interesting supramolecular arrangements of waters that are connected throughout the crystal lattice via fourteen-, sixteen- and seventeen-membered rings. The organic molecule of $\mathbf{4 9}$ is embedded in a water cage formed by the small water rings (A, B and C) described above, and forms a larger water cluster as illustrated in Figure 93. 


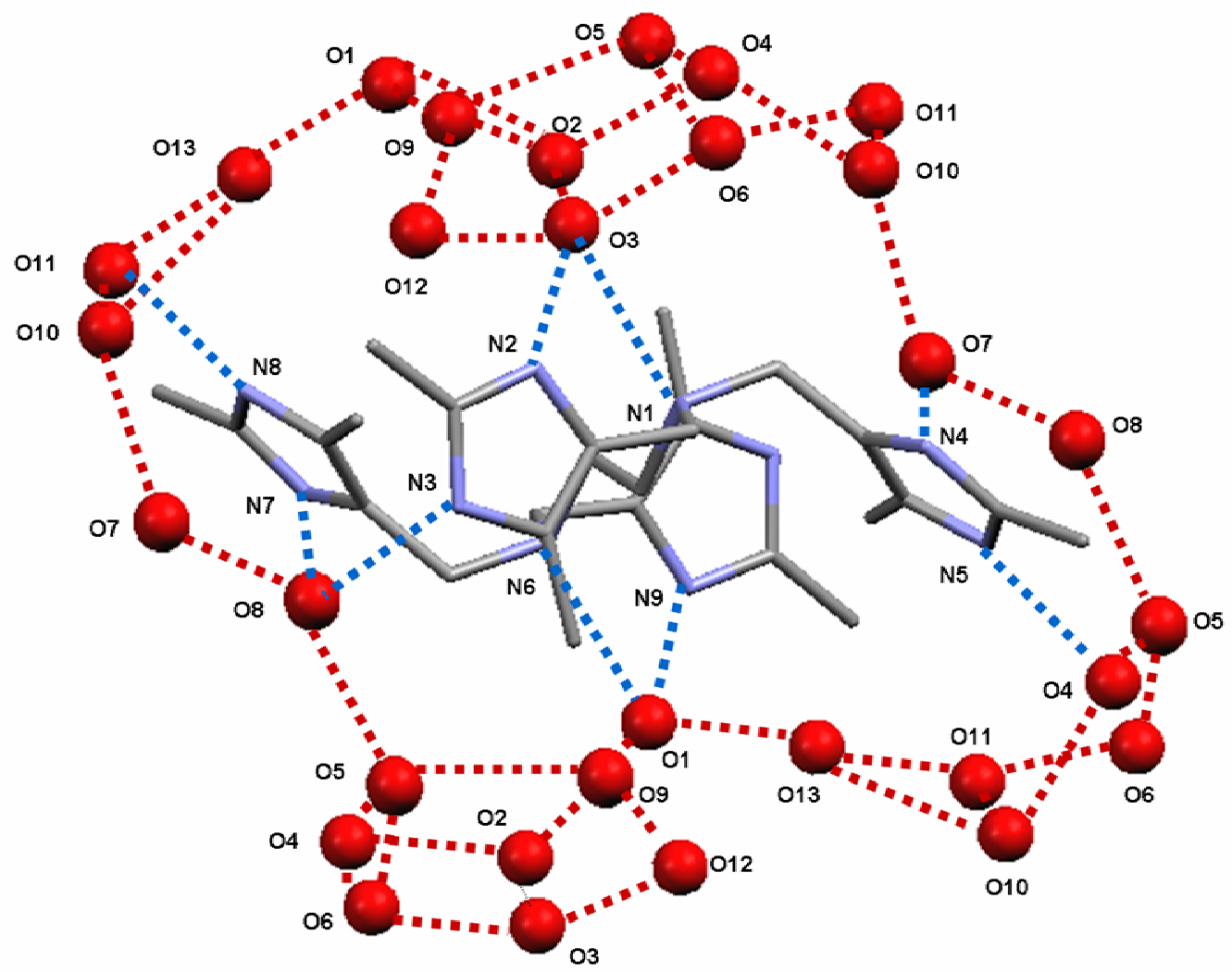

Figure 93. Supramolecular packing of the hydrate lattice encapsulating the polyimidazole compound 49.

The lattice is composed of the $\mathrm{A}, \mathrm{B}$ and $\mathrm{C}$ ring ribbons, illustrated on the top and bottom of the diagram. The ribbons on a same face (parallel to the ac plane) are connected to each other through O13, forming a fourteen-membered ring (Figure 94). The top and bottom layers are connected via the $\mathrm{O} 7$ and $\mathrm{O} 8$ water molecules forming a larger sixteen-membered ring (Figure 99) in the bc plane. Finally, in the ac plane, a seventeen-membered water ring is formed involving the bridging waters (O7 and 08$)$ and the water molecules of the $\mathrm{A}, \mathrm{B}$ and $\mathrm{C}$ ring ribbons.

Figure 94 illustrates the fourteen-membered water ring found in compound $\mathbf{4 9}$. Pertinent hydrogen bonding parameters associated with this water ring are summarized in Table 24 . 

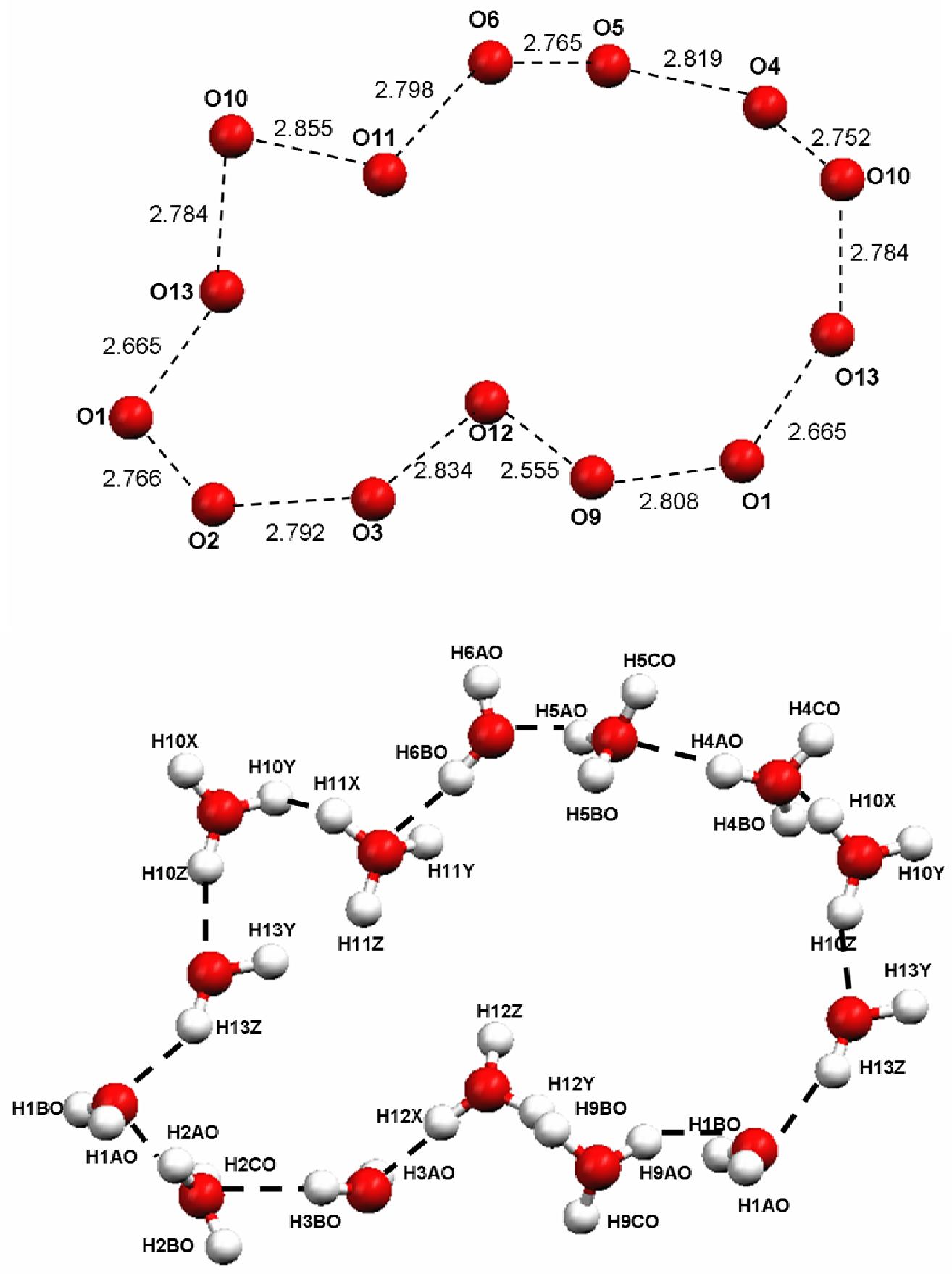

Figure 94. Ball-and-stick representations of the fourteen-membered water ring found in the crystal structure of compound 49. 
Table 24. Selected O---O separations, O---O---O and $\mathrm{O}-\mathrm{H}---\mathrm{O}$ angles found in the fourteen-membered water ring.

\begin{tabular}{|c|c|c|c|}
\hline \multicolumn{2}{|c|}{ O---O separations $(\AA)$} & \multicolumn{2}{|c|}{ O---O---O angles $\left(^{\circ}\right)$} \\
\hline O1---O2 & 2.766 & O1---O2---O3 & 128.42 \\
\hline $\mathrm{O} 2---\mathrm{O} 3$ & 2.792 & O2---O3---O12 & 126.69 \\
\hline O3---O12 & 2.834 & O3---O12---O9 & 113.97 \\
\hline O12---O9 & 2.555 & O12---O9---O1 & 142.26 \\
\hline O9---O1 & 2.808 & O9---O1---O13 & 129.14 \\
\hline O1---O13 & 2.665 & O1---O13---O10 & 142.59 \\
\hline O13---O10 & 2.784 & O13---O10---O4 & 100.17 \\
\hline O10---O4 & 2.752 & O10---O4---O5 & 134.88 \\
\hline O4---O5 & 2.819 & O4---O5---O6 & 125.06 \\
\hline O5---O6 & 2.765 & O5---O6---O11 & 133.26 \\
\hline O6---O11 & 2.798 & O11---O10---O13 & 74.84 \\
\hline O11---O10 & 2.855 & O10---O13---O1 & 142.59 \\
\hline & & O13---O1---O2 & 99.94 \\
\hline \multicolumn{4}{|c|}{$\mathrm{O}-\mathrm{H}---\mathrm{O}$ angles $\left(^{\circ}\right)$} \\
\hline $\mathrm{O} 2-\mathrm{H} 2 \mathrm{~A}$ & -O1 & 170.18 & \\
\hline O3-H3B & $\mathrm{O} 2$ & 146.93 & \\
\hline $\mathrm{O} 12-\mathrm{H} 12$ & $-\mathrm{O} 3$ & 163.54 & \\
\hline $\mathrm{O} 12-\mathrm{H} 12$ & -09 & 137.53 & \\
\hline O9-H9BC & $\mathrm{O} 12$ & 155.87 & \\
\hline O9-H9A & $-\mathrm{O} 1$ & 123.95 & \\
\hline O13-H13 & $-\mathrm{O} 1$ & 151.61 & \\
\hline $\mathrm{O} 10-\mathrm{H} 10$ & 013 & 141.24 & \\
\hline $\mathrm{O} 13-\mathrm{H} 13$ & $\mathrm{O} 10$ & 82.37 & \\
\hline $\mathrm{O} 10-\mathrm{H} 10$ & $-\mathrm{O} 4$ & 130.75 & \\
\hline $\mathrm{O} 4-\mathrm{H} 4 \mathrm{~A}$ & -05 & 176.39 & \\
\hline O5-H5A & -O6 & 164.87 & \\
\hline O6-H6BC & O11 & 160.44 & \\
\hline O11-H11 & $\mathrm{O} 10$ & 137.32 & \\
\hline
\end{tabular}

For the sake of brevity, this section will focus only on the new interaction involving the $\mathrm{O} 13$, which has been modeled as a positionally disordered oxygen atom with $70 \%$ of its occupancy in the $\mathrm{O} 13$ position and the remaining $30 \%$ occupancy in the O13A position. This defect can be rationalized similarly to compound $\mathbf{4 8}$ where the water O13 oscillates between two positions interacting with $\mathrm{O} 11$ and $\mathrm{O} 10$ (O13a---O11 and O13---O10 separations of 2.976 and 2.784 Å, respectively) and O1 (O13---O1 and O13a- 
--O1 separations of 2.665 and $3.309 \AA$ ), forming a distorted lasso-type structure (see Figure 96) (Ludwig, R., 2001). The near-perfect fused 6-4-6 water ring pattern is disrupted by the displacement of O13A. O13A appears to be out of position disrupting the fusion of four- and six-membered rings (Scheme 20). The crystal structure of a 6-4-6 fused ring tape has been reported previously (Infantes, L. \& Motherwell, S., 2002).

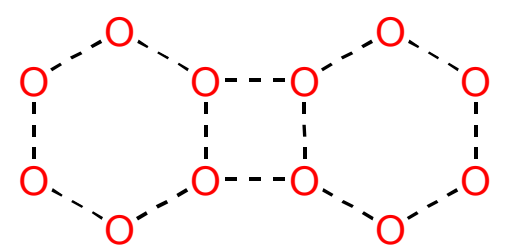

Ideal fused 6-4-4 membered water ring. versus

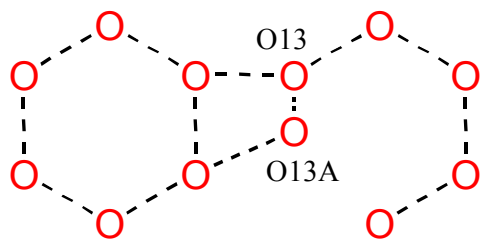

Water arrangement observed in $\mathbf{4 9}$, with the positionally disordered water molecule, $\mathrm{O} 13$.

Scheme 20. Water arrangement observed in 49 with the positionally disordered O13 water, disrupting the ideal fused 6-4-6 membered ring.

Disruption of the arrangement is due to the fact that the 4-position imidazole methyl groups, C6 and C20, impede O13A and O12 from completing a six-membered ring containing $\mathrm{O} 1, \mathrm{O} 2, \mathrm{O} 3, \mathrm{O} 12, \mathrm{O} 13 \mathrm{~A}$ and $\mathrm{O} 13$ (Figure 95). The O---C separations of 3.574 and 3.621 reflects a short contact between the hydrophobic methyl groups, C6 and $\mathrm{C} 20$, and the water molecules, $\mathrm{O} 12$ and $\mathrm{O} 13 \mathrm{~A}$, respectively. In addition, the water molecules containing $\mathrm{O} 10, \mathrm{O} 11, \mathrm{O} 13$ and $\mathrm{O} 13 \mathrm{~A}$ do not form an ideal four-membered water ring but form instead a distorted lasso-type structure, as detailed below. 


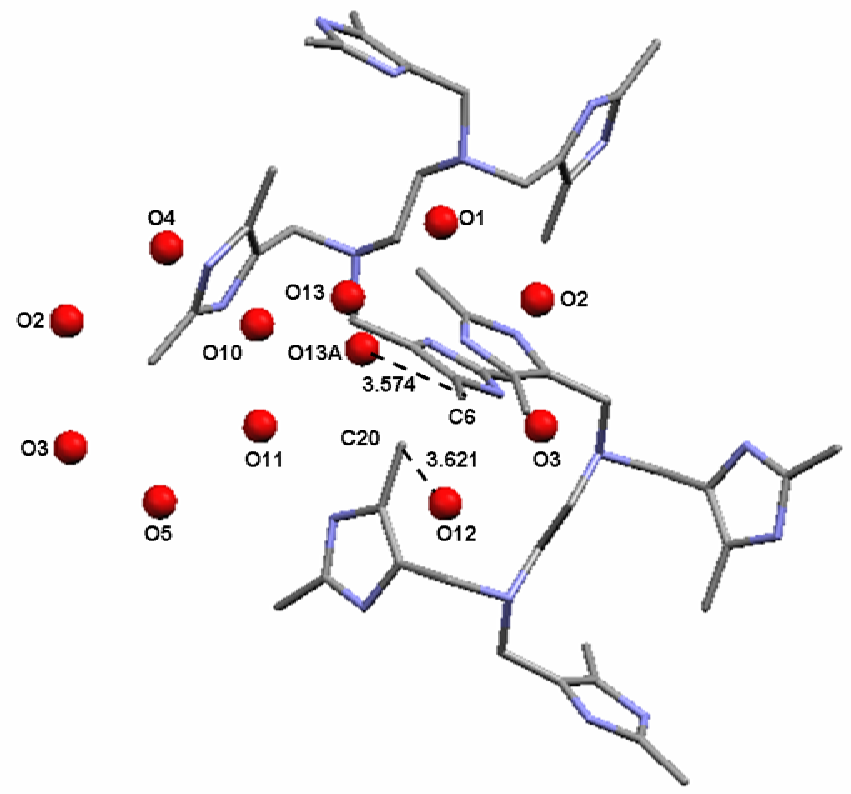

Figure 95. Ball-and-stick representation of the incomplete 6-4-6 water rings in compound 49.

\section{Lasso-type Structure (O10, O11, O13, O13A, O1)}

As mentioned previously, instead of forming a perfect four-membered ring with $\mathrm{O} 11$ and $\mathrm{O} 10$, the water ring structure $(\mathrm{O} 10, \mathrm{O} 11, \mathrm{O} 13, \mathrm{O} 13 \mathrm{~A}, \mathrm{O} 1)$ is closer to a lassotype structure (Figure 96) where the O13 and O13A water molecules oscillate between the averaged middle position of the atom (Scheme 21). Pertinent hydrogen bonding parameters associated with the lasso structure of $\mathbf{4 9}$ are listed in Table 25.<smiles></smiles>

Proposed lasso-type water structure. versus

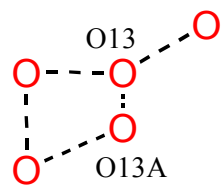

Water arrangement observed in $\mathbf{4 9}$, with the positionally disordered water molecule, $\mathrm{O} 13$.

Scheme 21. Representations of the proposed lasso-type water structure and the water arrangement resulting from the positionally disordered $\mathrm{O} 13$ water. 

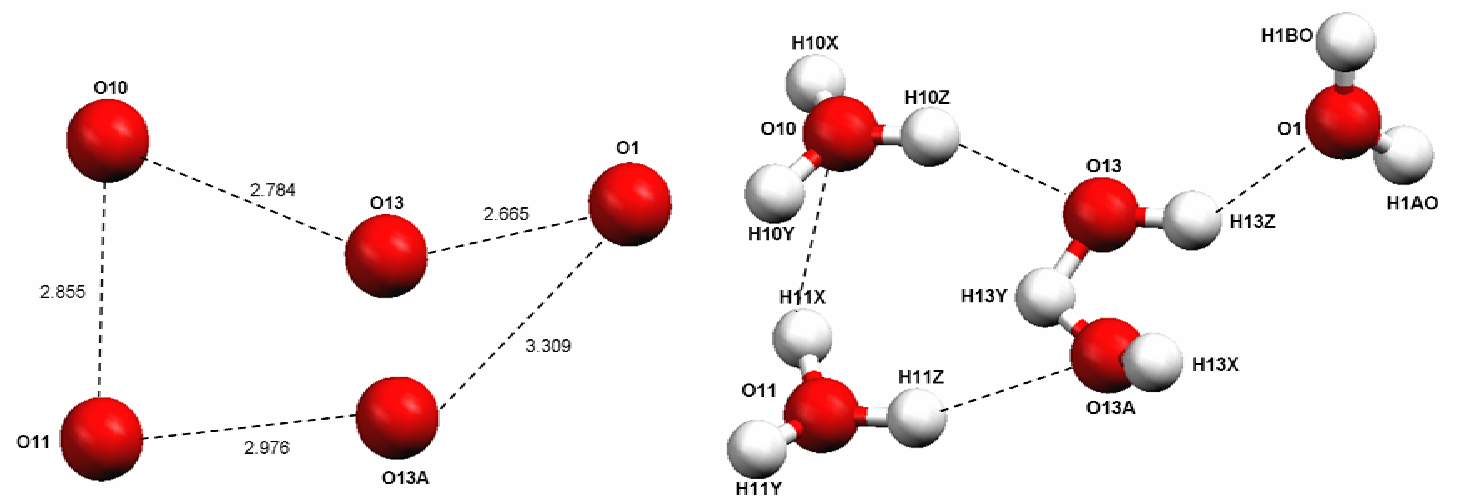

Figure 96. Ball-and-stick representations of the lasso-type structure found in compound 49.

Table 25. Selected O---O separations, O---O---O and O-H---O angles found in the lassotype structure.

\begin{tabular}{cccc}
\hline \multicolumn{2}{c}{ O---O separations $(\AA)$} & O----O---O angles $\left(^{\circ}\right)$ \\
\hline O1---O13 & 2.659 & O10---O11---O13A & 76.92 \\
O13---O10 & 2.796 & O11---O13A---O1 & 146.08 \\
O10---O11 & 2.856 & O11---O10---O13 & 74.84 \\
O11---O13A & 2.969 & O10---O13---O1 & 142.59 \\
O13A---O1 & 3.32 & & \\
\hline \multicolumn{5}{c}{ O-H---O angles $\left(^{\circ}\right)$} \\
\hline \multicolumn{5}{c}{141.24} \\
O10-H10Z---O13 & 136.03 \\
O10-H10Y---O11 & 137.32 \\
O11-H11X---O10 & 157.47 \\
O11-H11Z---O13A & 110.55 \\
O13A-H13Y---O11 & 151.61 \\
O13-H13Z---O1
\end{tabular}

Like O12 (Section 2), the O13 water molecule is also involved in a similar type of $\pi$-stacking with the imidazole ring containing N5 (Figure 97). 


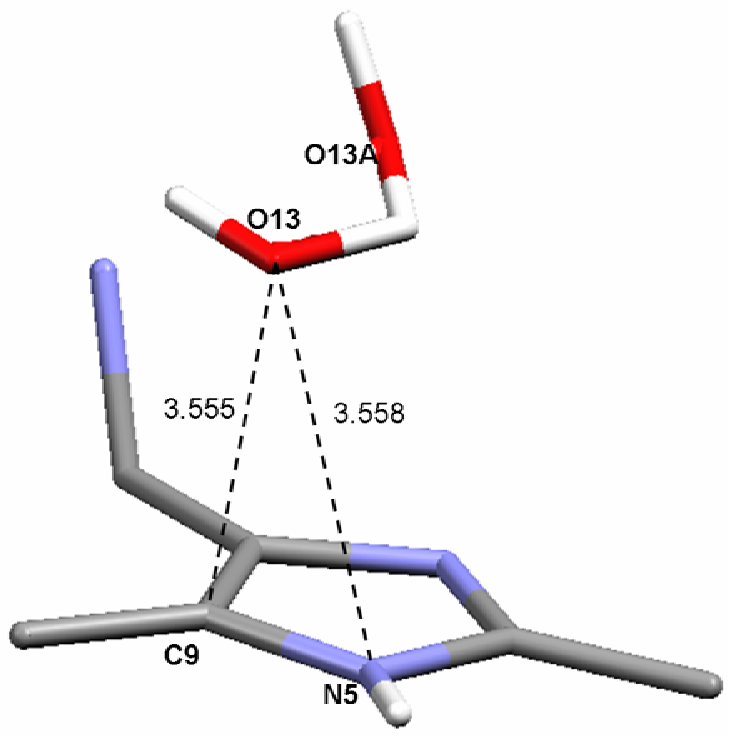

Figure 97. Capped-stick representation of the pi-stack interaction between the water molecule and the imidazole ring.

The lasso ring is only interacting with the organic frame at N8 through O11 (O11H11Y---N8 and N8-H8N---O11 angles of 122.47 and $159.47^{\circ}$, respectively, with an O11N8 separation of $2.783 \AA$ ). The metric parameters reflects a strong hydrogen bonding interaction between the imidazole nitrogen N8 and the water molecule $\mathrm{O} 11$.

\section{Sixteen-membered Water Ring}

The sixteen-membered ring is composed of two ribbon water layers bridged via O7 and O8 (Figure 98). Most of the interactions have been described previously for the other ring structures, and the pertinent O---O separations; O---O---O and O-H---O angles are summarized in Table 26. 

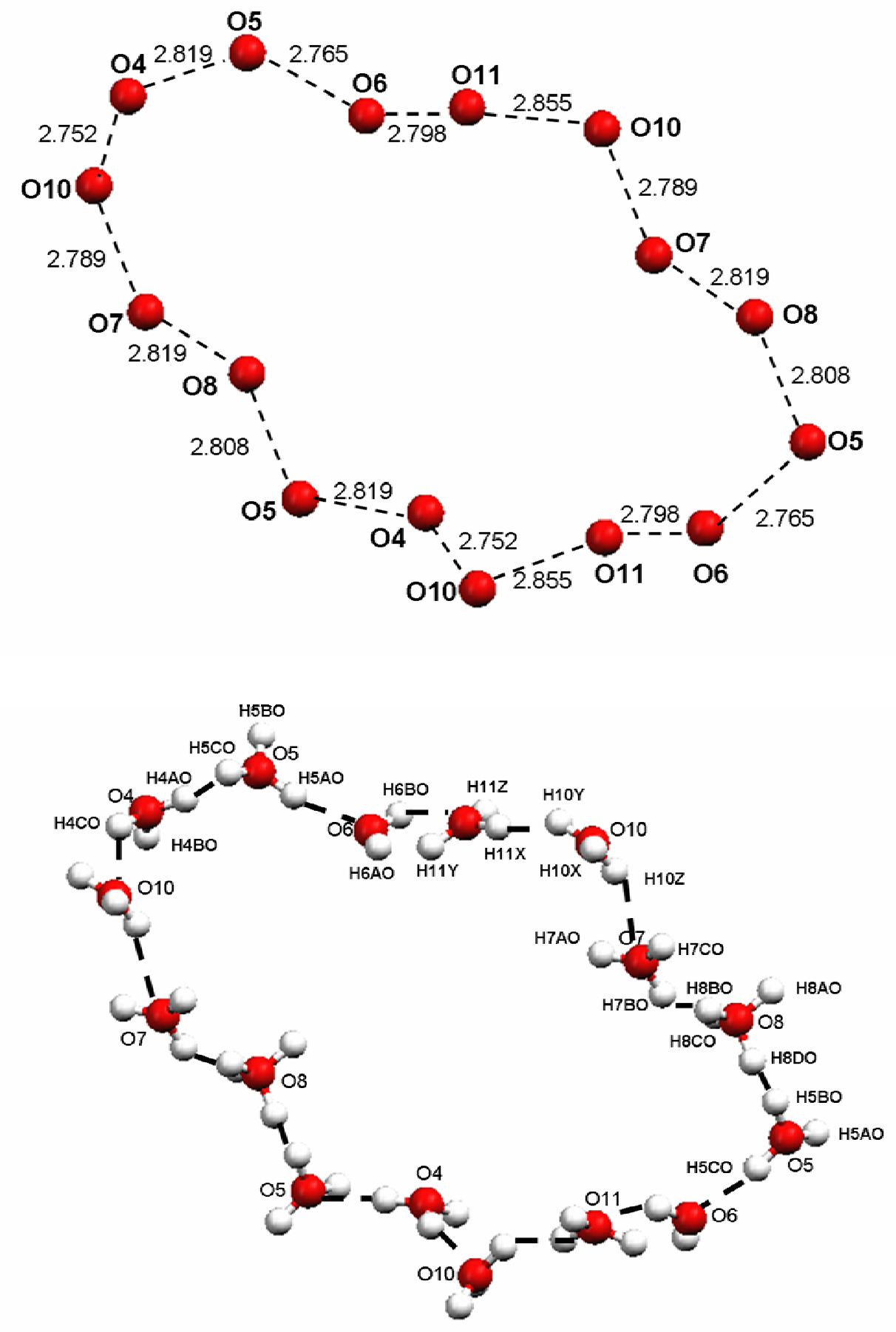

Figure 98. Ball-and-stick representations of the sixteen-membered water ring found in the crystal structure of compound 49. 
Table 26. Selected O---O separations, O---O---O and $\mathrm{O}-\mathrm{H}---\mathrm{O}$ angles found in the sixteen-membered water ring.

\begin{tabular}{|c|c|c|c|}
\hline \multicolumn{2}{|c|}{ O---O separations $(\AA)$} & \multicolumn{2}{|c|}{ O---O---O angles $\left({ }^{\circ}\right)$} \\
\hline O4---O5 & 2.819 & O4---O5---O6 & 125.08 \\
\hline O5---06 & 2.765 & O5---O6---O11 & 133.28 \\
\hline O6---O11 & 2.798 & O6---O11---O10 & 122.9 \\
\hline O11---O10 & 2.855 & O11---O10---O7 & 120.34 \\
\hline O10---O7 & 2.789 & O10---O7----O8 & 134.12 \\
\hline O7---O8 & 2.819 & O7---O8---O5 & 139.69 \\
\hline O8---O5 & 2.808 & O8---O5---O6 & 105.64 \\
\hline \multirow[t]{5}{*}{ O10---O4 } & 2.752 & O11---O10---O4 & 107.21 \\
\hline & & O10---O4---O5 & 134.74 \\
\hline & & O4---O5---O8 & 112.71 \\
\hline & & O5---O8---O7 & 139.69 \\
\hline & & O7---O10---O4 & 122.05 \\
\hline \multicolumn{4}{|c|}{$\mathrm{O}-\mathrm{H}---\mathrm{O}$ angles $\left(^{\circ}\right)$} \\
\hline \multicolumn{2}{|c|}{ O4-H4AO---O5 } & \multicolumn{2}{|l|}{176.39} \\
\hline \multicolumn{2}{|c|}{ O5-H5AO---O6 } & \multicolumn{2}{|l|}{164.87} \\
\hline \multicolumn{2}{|c|}{ O6-H6BO---O11 } & \multicolumn{2}{|l|}{160.44} \\
\hline \multicolumn{2}{|c|}{ O11-H11X---O10 } & \multicolumn{2}{|l|}{137.32} \\
\hline \multicolumn{2}{|c|}{ O10-H10Z---O7 } & \multicolumn{2}{|l|}{126.81} \\
\hline \multicolumn{2}{|c|}{ O7-H7BO---O8 } & \multicolumn{2}{|l|}{165.08} \\
\hline \multicolumn{2}{|c|}{ O8-H8BO---O7 } & \multicolumn{2}{|l|}{148.92} \\
\hline \multicolumn{2}{|c|}{ O8-H8DO---O5 } & \multicolumn{2}{|l|}{158.46} \\
\hline \multicolumn{2}{|c|}{ O5-H5BO---O8 } & \multicolumn{2}{|l|}{159.25} \\
\hline \multicolumn{2}{|c|}{ O10-H10X---O4 } & \multicolumn{2}{|l|}{130.75} \\
\hline \multicolumn{2}{|c|}{ O4-H4BO---O10 } & \multicolumn{2}{|l|}{147.06} \\
\hline
\end{tabular}

The sixteen-membered ring interacts with the organic molecule through the O10--N7, O8---N7, O4---N5 and O11---N8 contacts; all of which were previously described.

\section{Seventeen-membered Water Ring}

The water cage that encapsulates the imidazole compound is composed of the fourteen-membered water ring in the ac plane, the sixteen-membered ring in the bc plane and a novel seventeen-membered water ring in the ac plane (Figure 93). The seventeenmembered ring contains the bridging water molecules (O7 and $\mathrm{O} 8)$ and the water molecules of the ribbon layers (O2, O4, O10, O1, O13, O9, O5) (Figure 99). Most of the 
interactions have been described previously for the other ring structures, and the pertinent O---O separations, O---O----O and O-H---O angles are summarized in Table 27.
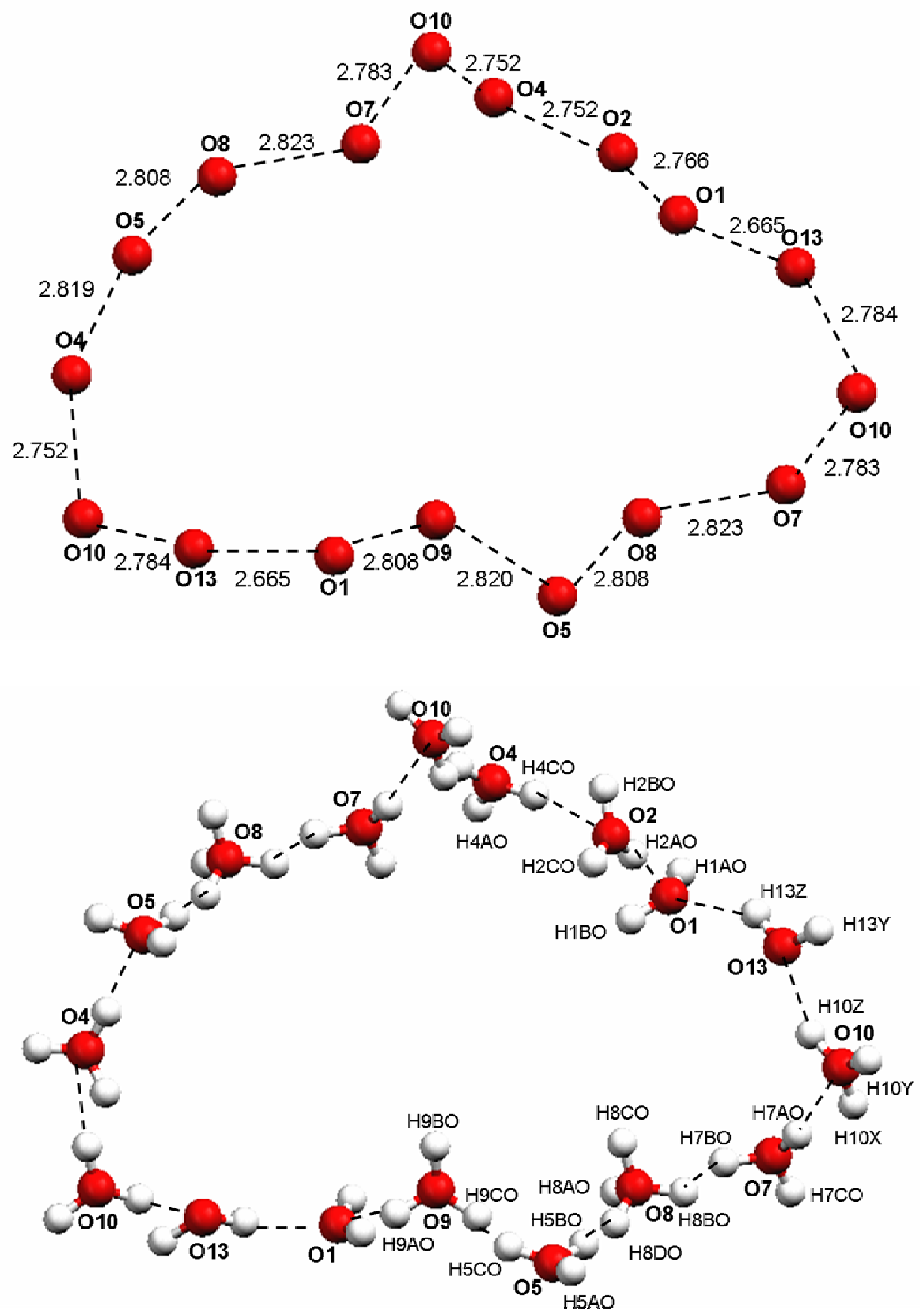

Figure 99. Ball-and-stick representations of the seventeen-membered water ring found in the crystal structure of compound 49. 
Table 27. Selected O---O separations, O---O---O and O-H---O angles found in the seventeen-membered water ring.

\begin{tabular}{cccc}
\hline \multicolumn{2}{c}{ O---O separations $(\AA)$} & \multicolumn{2}{c}{ O---O---O angles $\left(^{\circ}\right)$} \\
\hline O1---O2 & 2.766 & O1---O2---O4 & 102.94 \\
O2---O4 & 2.752 & O2---O4---O10 & 100.11 \\
O4---O10 & 2.752 & O4---O10---O7 & 121.95 \\
O10---O7 & 2.783 & O10---O7---O8 & 134.24 \\
O7---O8 & 2.823 & O7---O8---O5 & 139.71 \\
O8---O5 & 2.808 & O8---O5---O4 & 112.69 \\
O5---O4 & 2.819 & O5---O4---O10 & 134.88 \\
O10---O13 & 2.784 & O4---O10---O13 & 100.17 \\
O13---O1 & 2.665 & O10---O13---O1 & 142.59 \\
O1---O9 & 2.808 & O13---O1---O9 & 123.14 \\
O9---O5 & 2.82 & O1---O9---O5 & 104.25 \\
& & O9---O5---O8 & 11.46 \\
& & O5---O8---O7 & 139.71 \\
& & O8---O7---O10 & 134.24 \\
& & O7---O10---O13 & 121.76 \\
& & O13---O1---O2 & 99.94 \\
\hline
\end{tabular}

\begin{tabular}{cc}
\hline \multicolumn{2}{c}{ O-H---O angles $\left(^{\circ}\right)$} \\
\hline O2-H2AO---O1 & 174.76 \\
O4-H4CO---O2 & 168.64 \\
O4-H4BO---O10 & 149.38 \\
O10-H10X---O4 & 132.32 \\
O10-H10Z---O7 & 126.81 \\
O7-H7BO---O8 & 169.5 \\
O8-H8BO---O7 & 151.05 \\
O8-H8DO---O5 & 156.92 \\
O5-H5BO---O8 & 165.79 \\
O4-H4AO---O5 & 174.01 \\
O4-H4BO---O10 & 149.38 \\
O10-H10X---O4 & 132.32 \\
O10-H10Z---O13 & 156.31 \\
O13-H13Z---O1 & 143.74 \\
O1-H1BO---O9 & 140.08 \\
O5-H5CO---O9 & 145.09 \\
O9-H9CO---O6 & 146.08 \\
\hline
\end{tabular}

The seventeen-membered ring is also interacting with the organic molecule through the O4---N5, O7---N10, O9---N9, O1---N6 interactions; all of which were previously described. 


\section{Summary}

In conclusion, the crystal structures of compounds 48 and 49 display unique hydrogen bonding features that are potentially relevant to biological systems such as the influenza A virus and more importantly to the formation and stabilization of water ring clusters presumed to be present near the surface of proteins. The unique arrangement of the imidazole groups in both compounds is very similar to that found for the histidine residues in the influenza A M2 virus. Also, the $\pi$-stackings of the imidazoles in both compounds are reminiscent to the $\pi$-stacking of the Trp and His residues observed in the crystal structure of the influenza A M2 virus, which is thought to act as a gate and control the proton flux. In addition, the presence of the two bridging water molecules interacting with the imidazole cluster can be of importance in the helix-helix interactions as well as in the mechanism of proton transport.

This study also illustrates for the first time, fused five- and six-water rings within a single crystal structure. Some incomplete or distorted water rings were observed, which highlight the role of the organic host in disrupting the water arrangements. In compound 48, the six-membered ring is distorted from the regular chair conformation mainly because the wingtip water molecules are strongly interacting with the tertiary nitrogen atoms of the host molecule. In compound 49, the potential 6-4-6 fused water ring structure was disrupted by the presence of hydrophobic methyl groups.

Finally, the polyimidazole molecule is embedded in a water cage which contains the fused $\mathrm{A}, \mathrm{B}$ and $\mathrm{C}$ ring ribbons and larger fourteen-, sixteen- and seventeen-membered water ring clusters. The characterizations of the first fused five- and six-membered water 
ring cluster is of importance in the understanding of the properties of water and its interactions with organic molecules.

J. Thermogravimetric Analyses (TGA) and Differential Scanning Calorimetry (DSC) Studies

Crystalline samples of all hydrated compounds were examined by TGA and DSC under open conditions. TGA analyses show total weight loss for each compound consistent with the water content observed in the X-ray crystal structures (Table 28). A typical TGA plot is illustrated in Figure 100. Other TGA data can be found in Appendix 3.

TGA

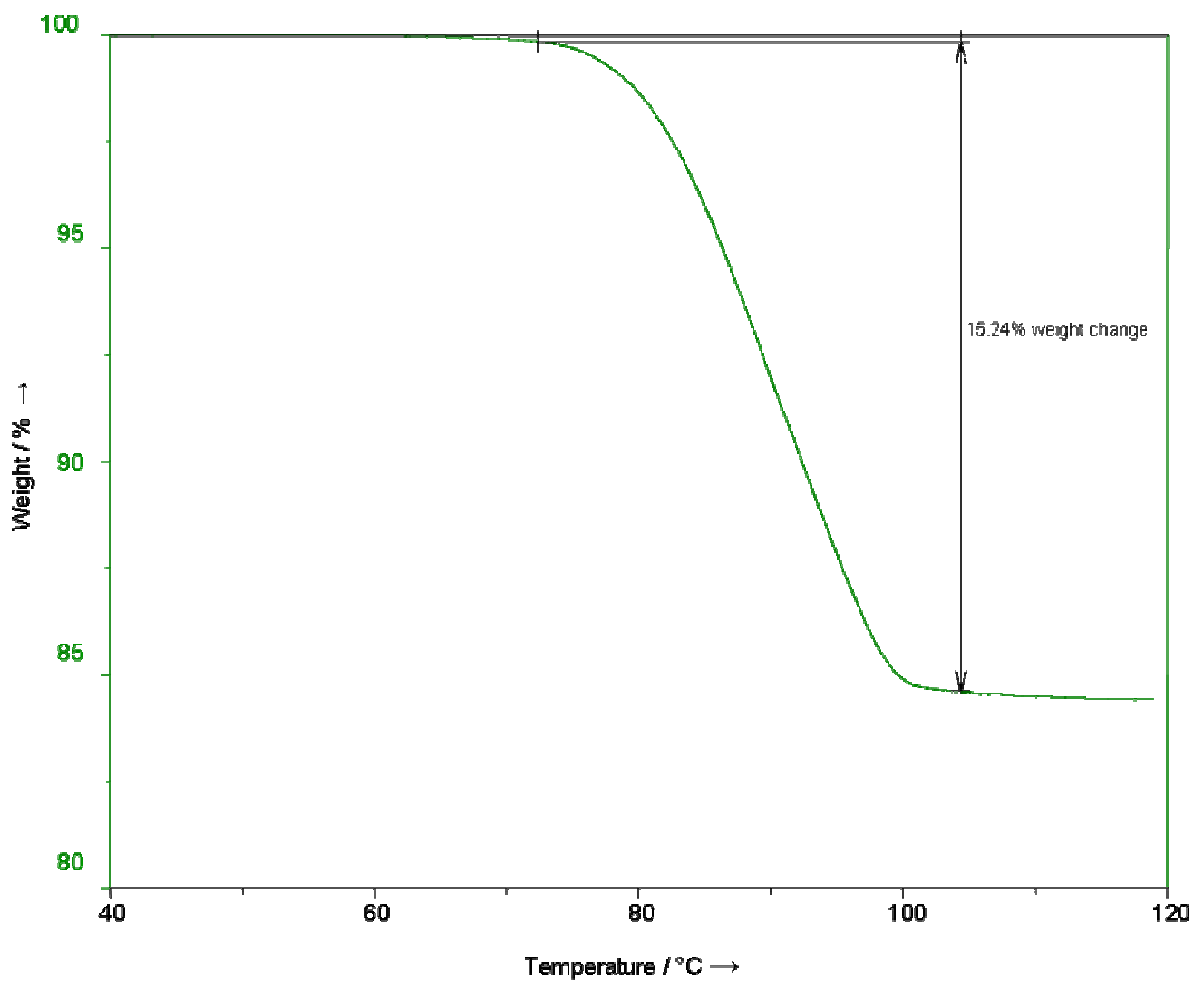

Figure 100. Typical TGA plot illustrated for compound 2 (equilibrated to $30^{\circ} \mathrm{C}$ and then heated at a rate of $1{ }^{\circ} \mathrm{C} / \mathrm{min}$ in flowing $\mathrm{N}_{2}$ ). 
Table 28. TGA experiment results illustrating the weight lost corresponding to the lost of water molecules for all hydrate compounds.

\begin{tabular}{ccc}
\hline Compound & Theoretical Water Weight Percentage & Observed Weight Lost Percentage \\
\hline $\mathbf{5 2}$ & $14.1 \%$ & $14.2 \%$ \\
$\mathbf{2}$ & $15.0 \%$ & $15.2 \%$ \\
$\mathbf{4 6}$ & $4.8 \%$ & Not performed \\
$\mathbf{4 7}$ & $5.3 \%$ & $12.9 \% \mathrm{o}^{\mathrm{a}}$ \\
$\mathbf{4 8}$ & $11.6 \%$ & $17.2 \% \mathrm{o}^{\mathrm{a}}$ \\
$\mathbf{4 9}$ & $32.2 \%$ & $32.3 \%$ \\
\hline
\end{tabular}

${ }^{\mathrm{a}}$ The difference between the theoretical and observed weight lost is probably due to residual solvent water molecules at the surface of the crystalline sample.

In general, the dehydration temperature as well as the hydrogen bond strength per water molecule could be determined from the DSC plot (Figure 101). All DSC results are summarized in Table 29. For compound 2, 48 and 49, the dehydration endotherms display two peaks indicative of different environments around the waters in each compound. The hydrogen bond strengths found for each compound are consistent with the water arrangement in each compound. Lower values of the hydrogen bond strengths indicate weaker water interactions in the crystal lattice. The strongest interaction is found for compound 47, which has waters hydrogen bonded to charged ionic groups. The results found by DSC are similar to those reported previously for hydrated tripeptides (Pometun, M. S. et al., 2002) and theophylline monohydrate (Suihko, E. et al., 1997) and are in good agreement with the strength of a hydrogen bond. 


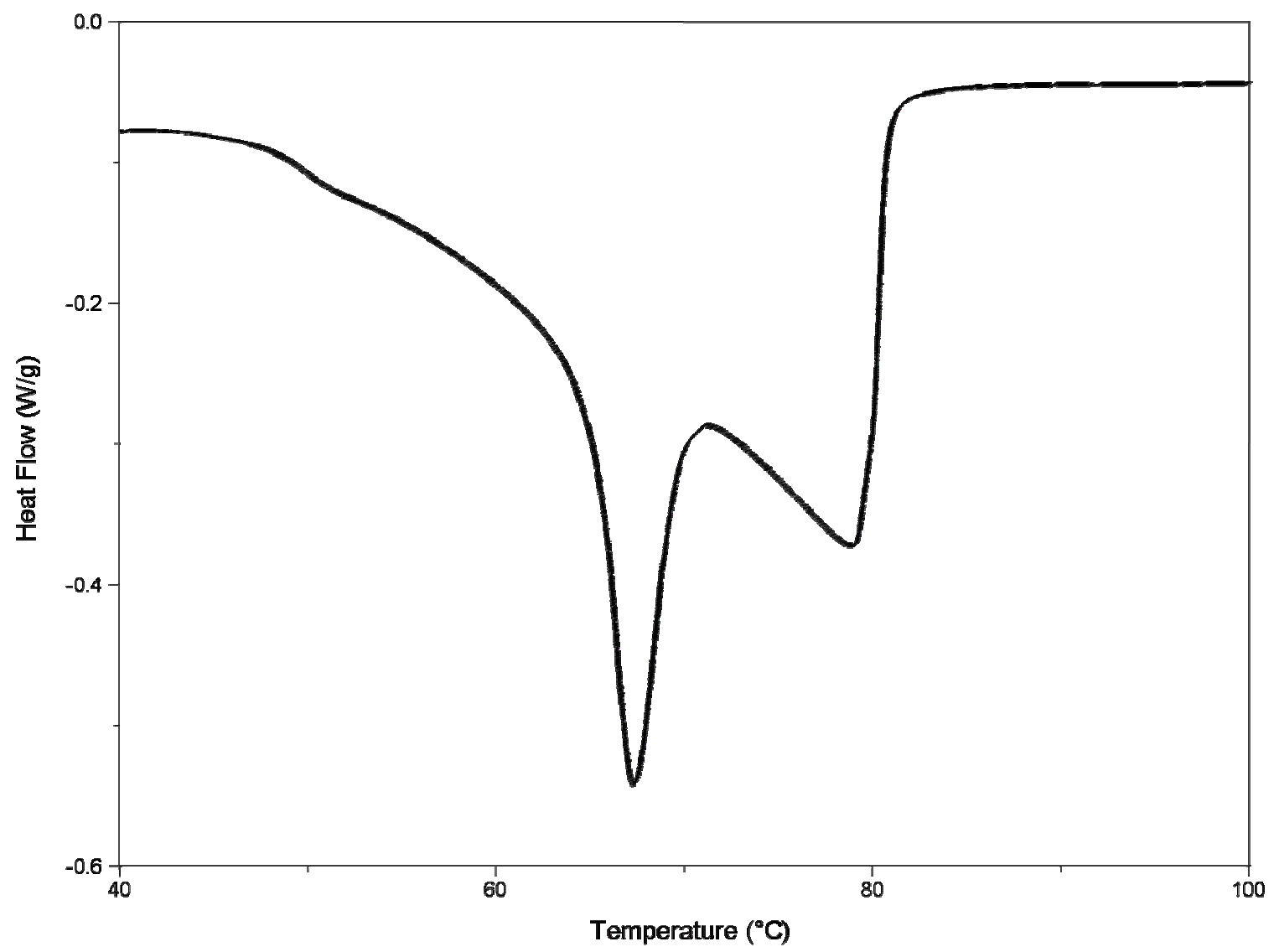

Figure 101. Typical DSC plot illustrated for compound 2 (equilibrated to $30^{\circ} \mathrm{C}$ and then heated at a rate of $1{ }^{\circ} \mathrm{C} / \mathrm{min}$ in flowing $\mathrm{N}_{2}$ ).

Table 29. DSC results showing the dehydration temperatures and the corresponding hydrogen bond strength per water molecule for all hydrated compounds.

\begin{tabular}{ccc}
\hline Compound & $\begin{array}{c}\text { Dehydration } \\
\text { Temperature }\left({ }^{\circ} \mathrm{C}\right)\end{array}$ & $\begin{array}{c}\text { Hydrogen Bond Strength in } \mathrm{kJ} / \mathrm{mol} \\
\text { of water }\end{array}$ \\
\hline $\mathbf{5 2}$ & 37 & 16 \\
$\mathbf{2}$ & 68 and 79 & 44 \\
$\mathbf{4 6}$ & 37 & Not measured \\
$\mathbf{4 7}$ & 96 & 126 \\
$\mathbf{4 8}$ & 83 and 93 & 19 \\
$\mathbf{4 9}$ & 59 and 76 & 60 \\
\hline
\end{tabular}

(a) The hydrogen bond strength was calculated as followed (Area under the dehydration peaks $x$ Molecular weight of the compound/number of water molecules per compound). 


\section{K. Powder X-ray Diffraction Study}

Compound 2 was studied by powder diffraction methods to determine if the microcrystalline structure is maintained upon dehydration and rehydration. In Figure 102, the blue trace corresponds to the powder diffraction pattern of hydrated compound $\mathbf{2}$. Compound 2 was then dehydrated under vacuum at $60{ }^{\circ} \mathrm{C}$ until constant weight was established. Its powder diffraction pattern (red trace) is very different from the hydrated starting material. Exposure of the dehydrated sample to water vapor regenerated the initial powder pattern (green trace). Similar behavior has been observed for theophylline (Suihko, E. et al., 1997).

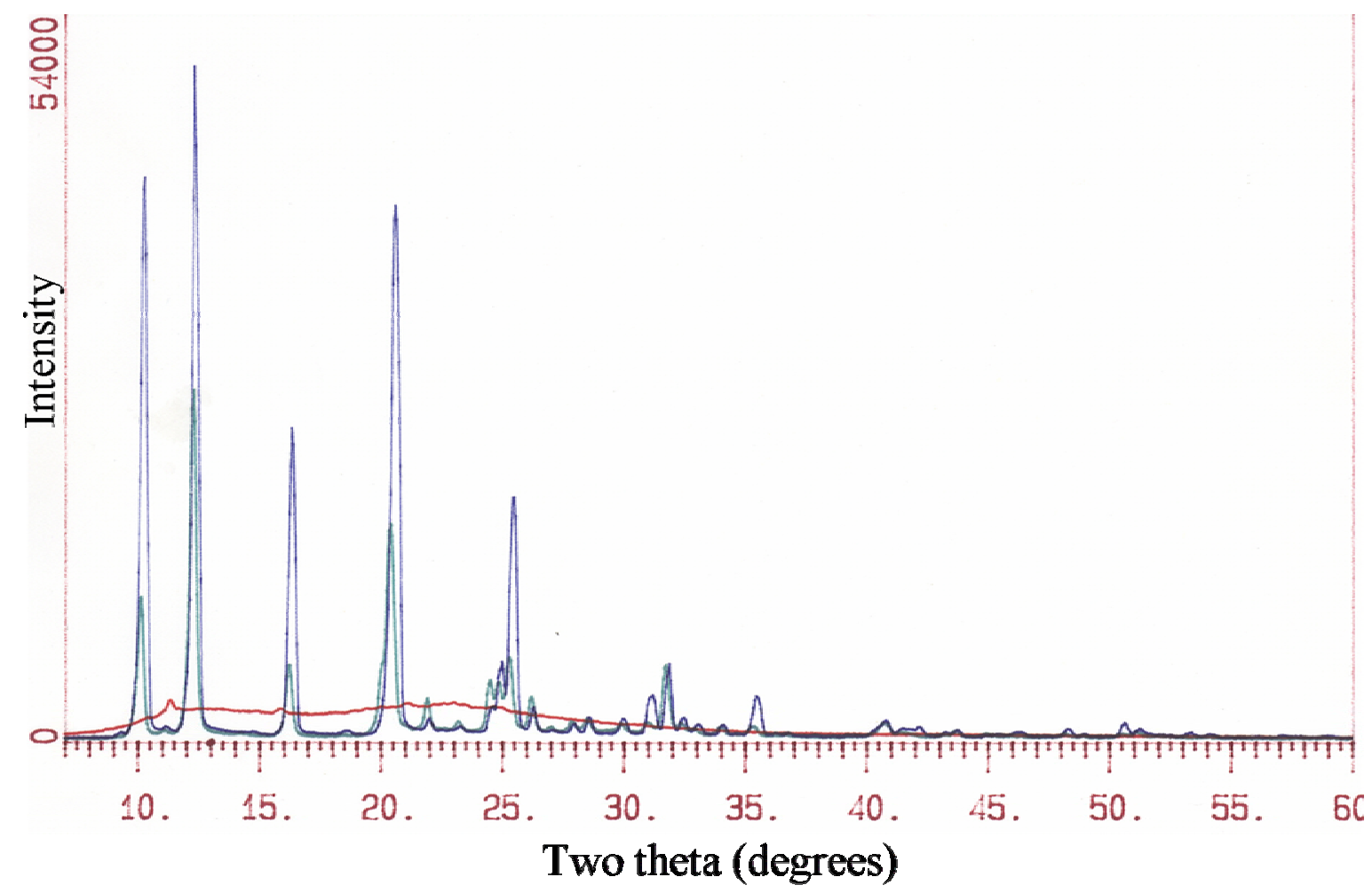

Figure 102. X-ray powder diffractograms of hydrated (green trace), dehydrated (red trace) and rehydrated (blue trace) compound $\mathbf{2}$. 


\section{L. $\quad$ Solid-state ${ }^{2}$ H NMR Spectroscopy}

As mentioned previously, the translocation of protons in biological systems is important and yet little is known about the mode of action due to the limited number of studies reported. Solid-state NMR has been shown to be an efficient tool to explore reorientational dynamics of structural hydrate compounds in the crystalline state (Pometun, M. S. et al., 2002). In general, the ${ }^{2} \mathrm{H}$ NMR width of spectrum reflects the dynamics of the deuterium disorder in the solid-state. Static deuterons have large quadrupole coupling (around $220 \mathrm{kHz}$ ) and give rise to broad spectra, while more dynamic deuterons have averaged quadrupole couplings which results in narrower spectral widths. In hydrated compounds, solid-state spectra are usually obtained when either deuterium transfer occurs between non-parallel bonds or water deuteriums undergo rotation or "flip", which in both cases will average the ${ }^{2} \mathrm{H}$ quadrupole coupling. In the intermediate state when deuterons reorient on the time-scale of the experiment, the ${ }^{2} \mathrm{H}$ NMR spectra are usually attenuated, and hence typically not observed (Wittebort, R. J. et al., 1988). In these cases, variable temperature experiments are required to either slow down or speed up the deuteron dynamics.

In the following studies, all compounds were recrystallized from a $\mathrm{CD}_{3} \mathrm{OD} / \mathrm{D}_{2} \mathrm{O}$ mixture to efficiently exchange deuterio for protio atoms. In most of the compounds, imidazole N-D could possibly contribute to the overall ${ }^{2} \mathrm{H}$ NMR spectrum. Therefore, it was necessary to establish the dynamics and behavior of hydrogen bonded imidazole N-D atoms in the solid-state independent of the water molecules. The dynamical behavior of 4(5)methyl-2-phenylimidazole (53) was evaluated as a model compound. 


\section{Crystal Structure of 4(5)-Methyl-2-phenylimidazole}

Recrystallization of $\mathbf{5 3}$ from a methanol/water solution yielded colorless crystals suitable for X-ray crystallographic analysis (Figure 103). The crystal structure of $\mathbf{5 3}$ indicates that the imidazole moieties are hydrogen bonded to neighboring molecules in a one-dimensional chain along the crystallographic c axis (Figure 104). Such arrangements have also been observed for other simple imidazole compounds that are of interest as proton wires and may be useful in fuel cells (Munch, W. et al., 2001).

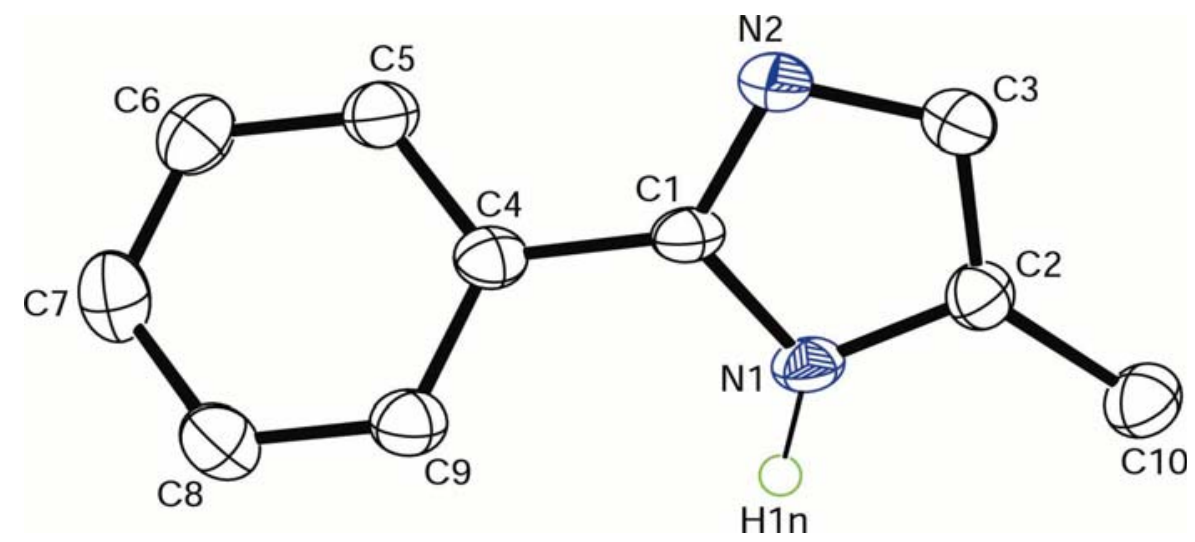

Figure 103. ORTEP view of 4(5)methyl-2-phenylimidazole. Ellipsoids are drawn with $50 \%$ probability. Carbon hydrogens have been omitted for clarity.

This imidazole compound is involved in strong hydrogen bonding interactions between $\mathrm{H} 1 \mathrm{n}$ of $\mathrm{N} 1$ atom and $\mathrm{N}^{\prime}$ ' atom associated with symmetry related molecules forming one-dimensional chains of hydrogen bond or "proton wires" along the crystallographic c axis, as illustrated in Figure 104. 

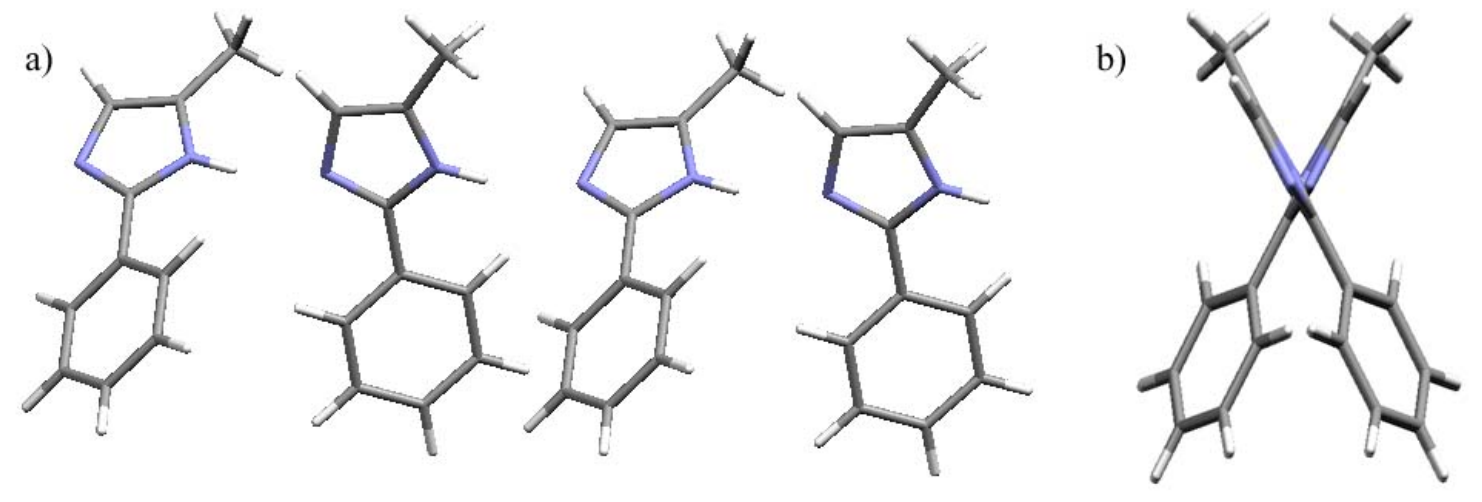

Figure 104. Capped-stick representations of side and top view of the hydrogen bonding chain of 4(5)methyl-2-phenylimidazole in the solid-state.

The ${ }^{2} \mathrm{H}$ spectrum of $\mathbf{5 3}$ is shown in Figure 105. The spectrum was only observed using a long relaxation delay, $\mathrm{T}_{1}(>60 \mathrm{~s})$. The quadrupole coupling of $160 \mathrm{kHz}$ (compared to $220 \mathrm{kHz}$ for static N-D deuteron) is indicative of either slow deuterium transfer or low amplitude motion of the N-D in solid- state.

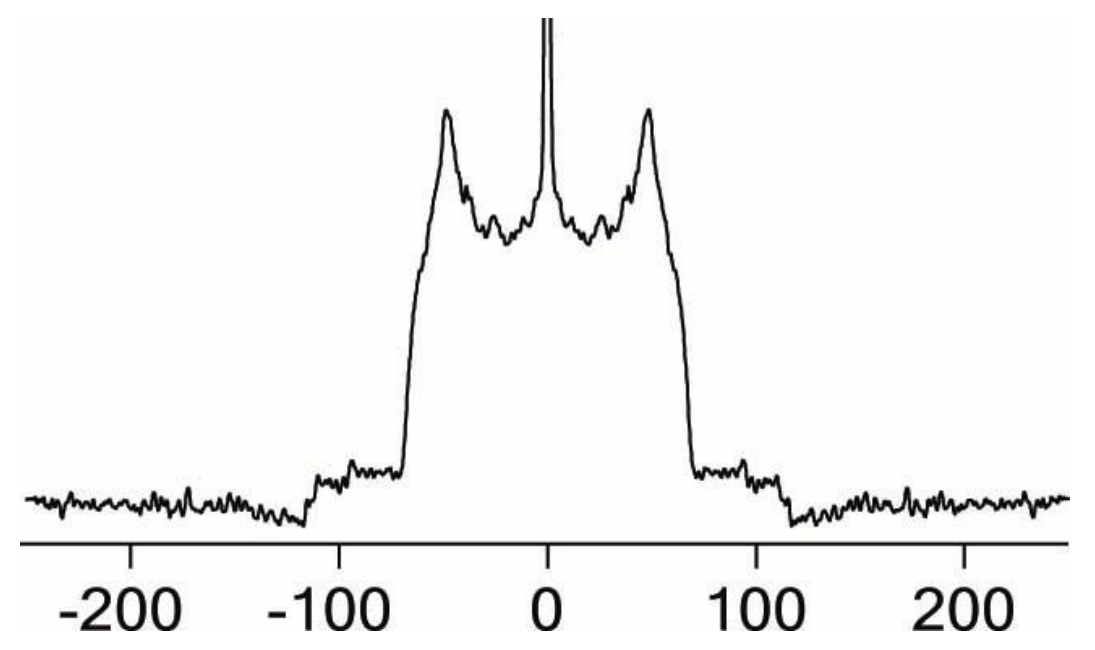

Figure 105. Solid-state ${ }^{2} \mathrm{H}$ NMR powder spectrum of compound $\mathbf{5 3}$.

2. Reorientational Behavior of the Water Molecules in the Solid-state

All spectra were observed with a short relaxation time $(\mathrm{t}<10 \mathrm{~s})$ and were unambiguously attributed to the water deuteriums and not to N-D signals, which were saturated under these experimental conditions. 


\section{a) Mono Hydrate Compound 47}

The ${ }^{2} \mathrm{H}$ NMR spectrum of $\mathbf{4 7}$ is indicative of a quasi-stationary behavior of the water in this structure, with a quadrupole coupling of $188 \mathrm{kHz}$ (Figure 106). Indeed, in the crystal structure of $\mathbf{4 7}$, the water is strongly interacting with the negatively charged carboxylic acid oxygen and the two imidazole nitrogens.

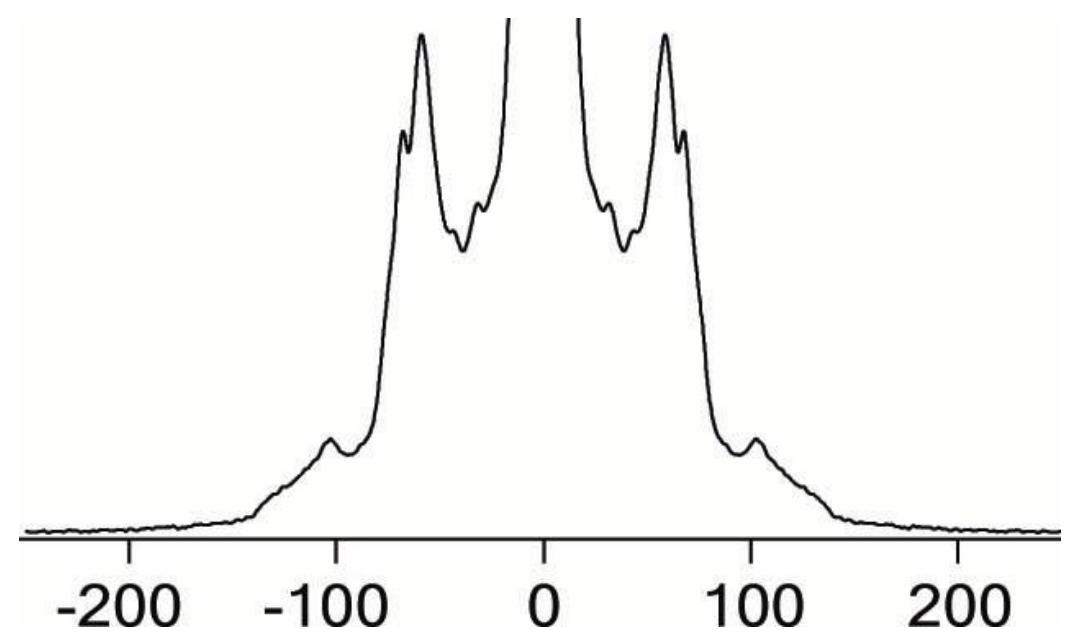

Figure 106. Solid-state ${ }^{2} \mathrm{H}$ NMR powder spectrum of compound 47.

b) One-dimensional Water Chains in Compounds $\mathbf{2}$ and $\mathbf{5 2}$

In the context of proton transfer along an H-bonded chain of waters, dynamical disorder plays a central role. Reorientation of O-H bonds in both $\mathbf{5 2}$ and $\mathbf{2}$ occurs not only if waters reorient but also if a proton is transferred because, in contrast to the ice structure, the half-occupied $\mathrm{O}-\mathrm{H}$ bonds observed in the crystal structure for adjacent waters in $\mathbf{5 2}$ and $\mathbf{2}$ are not antiparallel. ${ }^{2} \mathrm{H}$ spectra of $\mathbf{2}$ and $\mathbf{5 2}$ are shown in Figure 107 and clearly display different water dynamics. The room temperature spectrum of $\mathbf{2}$ is dominated by features for stationary deuterons (quadrupole coupling of $183 \mathrm{kHz}$ ), supported on a lower time-scale by the ${ }^{17} \mathrm{O}$ spectrum of 2 (Figure 109) (Cheruzel, L. E. et al., 2003). In contrast, the spectrum of $\mathbf{5 2}$ has a different shape with substantially reduced breadth and intensity indicative of intermediate exchange dynamics (quadrupole coupling 
of $100 \mathrm{kHz}$ ). Similar spectra were observed for ice where they could be uniquely attributed to molecular rotation.

Interestingly, on lowering the temperature of 2 to $183 \mathrm{~K}$, the spectrum shows the appearance of a narrow central feature indicative of a dynamic water. This suggests that one of the two waters in $\mathbf{2}$ is dynamically disordered and not seen in the ${ }^{2} \mathrm{H}$ spectrum at $298 \mathrm{~K}$ due to intermediate exchange. Upon lowering the temperature, water motion slows and approaches slow exchange resulting in increased signal intensity. Similar proton dynamics are observed for other small molecule proton wire models, which include discontinuous water chain structures (Terao, H. et al., 2001) and hydrated tripeptide crystals (Pometun, M. S. et al., 2002). In the latter system, for example, Pometun et al. have demonstrated the presence of dynamic deuterium exchange consistent with the Grotthuss mechanism (Agmon, N., 1995).

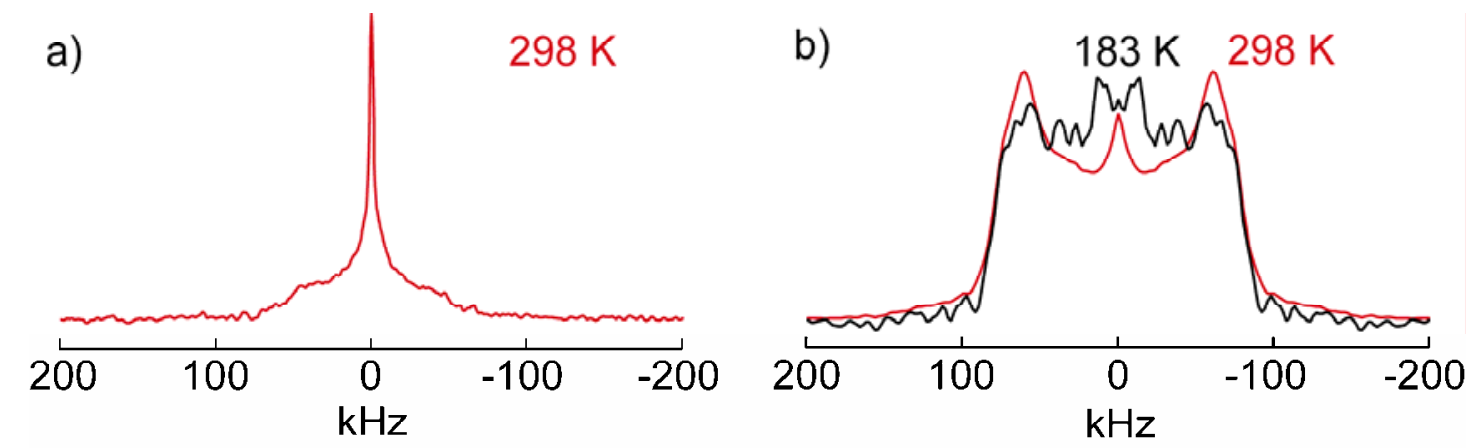

Figure 107. Solid-state ${ }^{2}$ H NMR powder spectra of a) compound $\mathbf{5 2}$ and b) compound 2.

\section{c) Compounds 48 and 49}

The ${ }^{2} \mathrm{H}$ powder spectra of $\mathbf{4 8}$ and $\mathbf{4 9}$ are strikingly similar and indicative of a quasi-static behavior of the waters at room temperature (quadrupole coupling of $180 \mathrm{kHz}$ ) (Figure 108). This result implies that the waters in both compounds have librational dynamics with small amplitude motion. Upon cooling the temperature to $-80{ }^{\circ} \mathrm{C}$, the 
dynamics of the waters is slowed, which corresponds to an increase in the spectrum width. The spectrum at $-80{ }^{\circ} \mathrm{C}$ shows the overlapping of two similar spectra corresponding to two sets of water molecules with different librational dynamics. These results are somewhat surprising because in the crystal structures of both compounds the waters are mainly interacting with each other and have only a few interactions with the organic frame (see Sections H and I), which should lead to a spectrum similar to ice. However, a slower dynamic of the waters in $\mathbf{4 8}$ and $\mathbf{4 9}$ is potentially consistent with the ordered hydration shell layer surrounding proteins. In fact, a thin layer of water molecules at the surface of the proteins is thought to be quasi-stationary with low translational and reorientational motion (Pal, S. K. et al., 2002a).
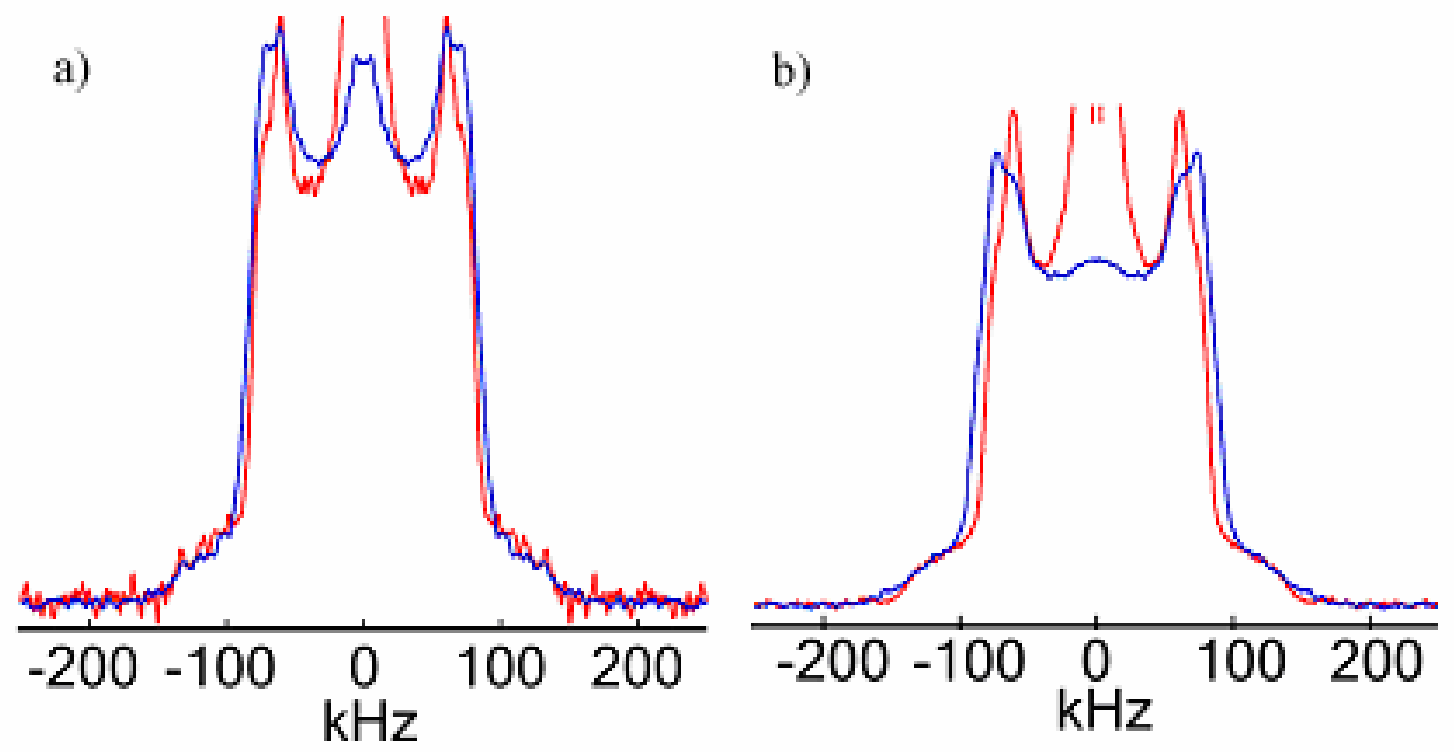

Figure 108. ${ }^{2} \mathrm{H}$ solid-state NMR spectra for compounds 48 (a) and $\mathbf{4 9}$ (b) consistent with a slow reorientational dynamic behavior of the water molecules in the solidstate.

M. Solid-state ${ }^{17} \mathrm{O}$ NMR Experiment

Because the ${ }^{2} \mathrm{H}$ NMR spectra of compounds 2,48 and 49 are consistent with slow reorientational dynamics and poor proton transport, ${ }^{17} \mathrm{O}$ NMR experiments were 
conducted to probe the exchange of the crystal lattice waters with ${ }^{17} \mathrm{O}$ water vapor. Agre et al. has demonstrated the selectivity of aquapore proteins towards the transport of waters (not protons) and other cations (Agre, P. et al., 2002). In these experiments, crystalline powder samples of the hydrated compounds were exposed to ${ }^{17} \mathrm{O}$ water vapor in sealed tubes. After five days, the detection of ${ }^{17} \mathrm{O}$ spectrum confirmed the incorporation of ${ }^{17} \mathrm{O}$ water into the crystal lattice (Figure 109).

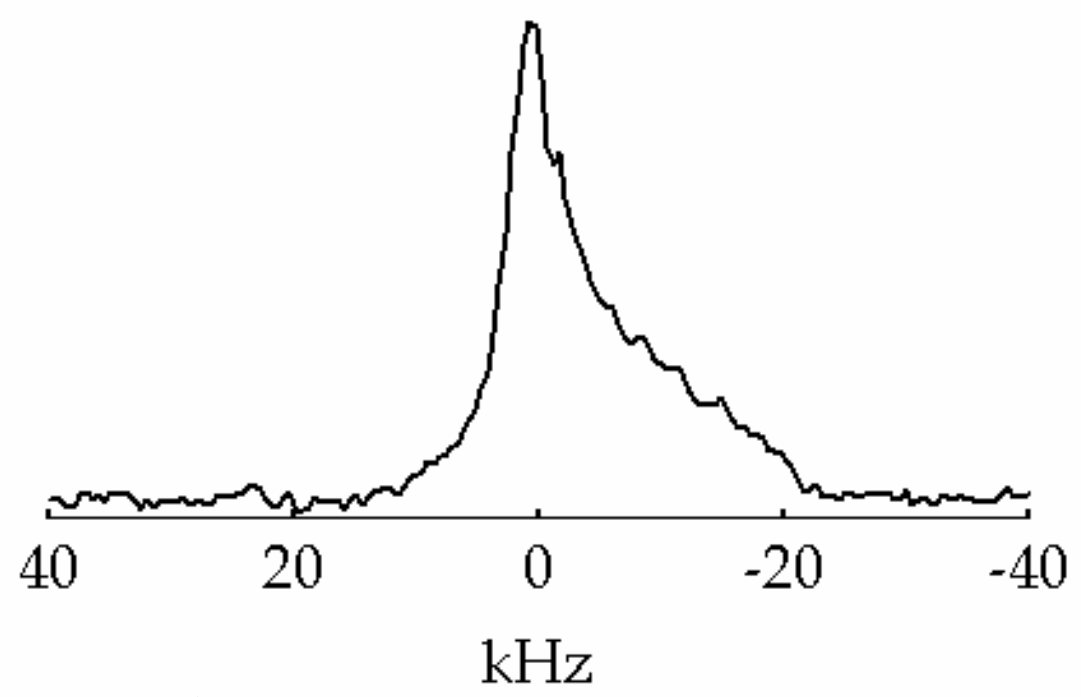

Figure 109. Solid-state ${ }^{17} \mathrm{O}$ NMR powder spectrum for both compound 2 and $\mathbf{4 8}$ indicating the exchange of ${ }^{17} \mathrm{O}$ water vapor with lattice water in the solidstate.

In summary, the study of the imidazole hydrates lead to the characterization of biologically important water arrangements. The stabilization of one-dimensional water chains and the study of their solid-state dynamic are of importance in the further design of proton wire models. In addition to the characterization of novel fused four-, five- and six-membered water clusters, as well as larger water ring systems. The study offers some insights into the possible formation or interconversion of water rings and in the role of the imidazole framework in stabilizing water ring structures. 


\section{REFERENCES}

AbdelMagid, A. F., Carson, K. G., Harris, B. D., Maryanoff, C. A., Shah, R. D. Reductive amination of aldehydes and ketones with sodium triacetoxyborohydride. Studies on direct and indirect reductive amination procedures. Journal of Organic Chemistry 1996, 61, 3849-3862.

Abuskhuna, S., McCann, M., Briody, J., Devereux, M., Mckee, V. Synthesis and structure of $\mathrm{Mn}(\mathrm{II}), \mathrm{Cu}(\mathrm{II})$ and $\mathrm{Zn}(\mathrm{II})$ complexes containing bis-imidazole ligands. Polyhedron 2004, 23, 1731-1737.

Addison, A. W., Rao, T. N., Reedijk, J., Vanrijn, J., Verschoor, G. C. Synthesis, Structure, and spectroscopic properties of copper(II) compounds containing nitrogen sulfur donor ligands - the crystal and molecular-structure of aqua[1,7bis(N-methylbenzimidazol-2'-yl)-2,6-dithiaheptane]copper(II) perchlorate. Journal of the Chemical Society-Dalton Transactions 1984, 1349-1356.

Agmon, N. The Grotthuss Mechanism. Chemical Physics Letters 1995, 244, 456-462.

Agre, P., King, L. S., Yasui, M., Guggino, W. B., Ottersen, O. P., Fujiyoshi, Y., Engel, A., Nielsen, S. Aquaporin water channels - from atomic structure to clinical medicine. Journal of Physiology-London 2002, 542, 3-16.

Andrews, S. J., Robb, D. A., Welch, A. J. Structure of Bis(triphenylphosphoranediyl)ammonium chloride boric-acid adduct (1-1), $\mathrm{C}_{36} \mathrm{H}_{30} \mathrm{NP}^{2+} \cdot \mathrm{Cl}^{-} \cdot \mathrm{BH}_{3} \mathrm{O}_{3}$. Acta Crystallographica Section C-Crystal Structure Communications 1983, 39, 880-882.

Armstrong, W. H. , Lippard, S. J. Convenient, high-yield synthesis of $\left(\mathrm{Et}_{4} \mathrm{~N}\right)_{2}\left[\mathrm{Fe}_{2} \mathrm{OCl}_{6}\right]$. Inorganic Chemistry 1985, 24, 981-982.

Baird, E. E. , Dervan, P. B. Solid phase synthesis of polyamides containing imidazole and pyrrole amino acids. Journal of the American Chemical Society 1996, 118, 61416146.

Barbour, L. J., Orr, G. W., Atwood, J. L. Characterization of a well resolved supramolecular ice-like $\left(\mathrm{H}_{2} \mathrm{O}\right)(10)$ cluster in the solid state. Chemical Communications 2000, 859-860.

Bard, A. J. , Faulkner, L. R. Electrochemical Methods, Fundamentals and Applications 1980, Chapter 6. 
Barety, D., Resibois, B., Vergoten, G., Moschetto, Y. Electrochemical-behavior of nitroimidazole derivatives in dimethylsulfoxide. Journal of Electroanalytical Chemistry 1984, 162, 335-341.

Bernal, J. D. , Fowler, R. H. A theory of water and ionic solution, with particular reference to hydrogen and hydroxyl ions. Journal of Chemical Physics 1933, 1, $515-548$.

Bhalla, R., Helliwell, M., Garner, C. D. Synthesis and coordination chemistry of the bis(imidazole) ligand, bis(1-methyl-4,5-diphenylimidaze-2oyl)(benzyloxy)methane. Inorganic Chemistry 1997, 36, 2944-2949.

Bhattacharyya, S. M., Wang, Z. G., Zewail, A. H. Dynamics of water near a protein surface. Journal of Physical Chemistry B 2003, 107, 13218-13228.

Bizzarri, A. R., Cannistraro, S. Molecular dynamics of water at the protein-solvent interface. Journal of Physical Chemistry B 2002, 106, 6617-6633.

Blake, C. C. F., Pulford, W. C. A., Artymiuk, P. J. X-Ray studies of water in crystals of lysozyme. Journal of Molecular Biology 1983, 167, 693-723.

Bloemink, M. J., Engelking, H., Karentzopoulos, S., Krebs, B., Reedijk, J. Synthesis, crystal structure, antitumor activity, and DNA-binding properties of the new active platinum compound (bis( $\mathrm{N}$-methylimidazol-2-yl)carbinol) dichloroplatinum(II), lacking a NH moiety, and of the inactive analog dichloro(N1, N-1'-dimethyl-2,2'-biimidazole)platinum(II). Inorganic Chemistry 1996, 35, 619-627.

Boncheva, M., Bruzewicz, D. A., Whitesides, G. M. Formation of chiral, threedimensional aggregates by self-assembly of helical components. Langmuir 2003, 19, 6066-6071.

Brammer, L., Bruton, E. A., Sherwood, P. Understanding the behavior of halogens as hydrogen bond acceptors. Crystal Growth \& Design 2001, 1, 277-290.

Broomhead, J. A., Camm, G., Sterns, M., Webster, L. Dinuclear complexes of first transition series metals with 4,4'-dipyrazolylmethane: characterisation, DNA binding and anticancer properties. Inorganica Chimica Acta 1998, 271, 151-159.

Brown, P. H., Bellaloui, N., Wimmer, M. A., Bassil, E. S., Ruiz, J., Hu, H., Pfeffer, H., Dannel, F., Romheld, V. Boron in plant biology. Plant Biology 2002, 4, 205-223.

Brownback, M. A., Murmann, R. K., Barnes, C. L. Kinetic, thermodynamic and X-ray crystal studies on $\mathrm{N}$-alkyl-alpha-amineoxime ligand exchange between planar nickel(II) complexes. Polyhedron 2001, 20, 2505-2515.

Bruker Advanced X-ray Solutions, Inc. Saint, V. 6.22 2001a, Madison, WI. 
Bruker Advanced X-ray Solutions, Inc. Smart, V.5.625 2001b, Madison, WI.

Buchanan, R. M., Chen, S., Richardson, J. F., Bressan, M., Forti, L., Morvillo, A., Fish, R. H. Biomimetic oxidation studies .8. Structure of a new MMO active-site Model, $\left.\left[\mathrm{Fe}_{2} \mathrm{O}\left(\mathrm{H}_{2} \mathrm{O}\right)_{2} \text { (tris(1-methylimidazol-2-yl)methyl)amine }\right)_{2}\right]^{4+}$, and role of the aqua ligand in alkane functionalization reactions. Inorganic Chemistry 1994, 33, 3208-3209.

Buchanan, R. M., Obrien, R. J., Richardson, J. F., Latour, J. M. Synthesis and properties of a binuclear ( $\mu$-oxo) diiron(III) complex containing a tripodal polybenzimidazole ligand. Inorganica Chimica Acta 1993, 214, 33-40.

Buchman, R., Heinstei, P. F., Wells, J. N. Imidazole derivatives as inhibitors of cyclic nucleotide phosphodiesterases. Journal of Medicinal Chemistry 1974, 17, 11681173 .

Burnham, C. J., Xantheas, S. S., Miller, M. A., Applegate, B. E., Miller, R. E. The formation of cyclic water complexes by sequential ring insertion: Experiment and theory. Journal of Chemical Physics 2002, 117, 1109-1122.

Cameron, I. L., Kanal, K. M., Keener, C. R., Fullerton, G. D. A mechanistic view of the non-ideal osmotic and motional behavior of intracellular water Cell Biology International 1997, 21, 99-113.

Carrozzo, R., Rizza, T., Lucioli, S., Pierini, R., Bertini, E., Santorelli, F. A mitochondrial ATPase 6 mutation is associated with Leigh syndrome in a family and affects proton flow and adenosine triphosphate output when modeled in Escherichia coli. Acta Paediatrica 2004, 93, 65-67.

Cavalcanti, J. C. M., de Abreu, F. C., Oliveira, N. V., de Moura, M. A. B. F., Chaves, J. G., Alves, R. J., Bertinaria, M., Fruttero, R., Goulart, M. O. F. Effect of the leaving group on the electrodic reduction mechanism of anti-Helicobacter pylori metronidazole derivatives, in aprotic and protic media. Bioelectrochemistry 2004, $63,353-357$.

Chaplin, M. F. A proposal for the structuring of water. Biophysical Chemistry 2000, 83, 211-221.

Chen, P., Fujisawa, K., Solomon, E. I. Spectroscopic and theoretical studies of mononuclear copper(II) alkyl- and hydroperoxo complexes: Electronic structure contributions to reactivity. Journal of the American Chemical Society 2000, 122, 10177-10193.

Chen, P. , Solomon, E. I. Oxygen activation by the noncoupled binuclear copper site in peptidylglycine $\alpha$-hydroxylating monooxygenase. Reaction mechanism and role of the noncoupled nature of the active site. Journal of the American Chemical Society 2004, 126, 4991-5000. 
Chen, S., Richardson, J. F., Buchanan, R. M. Synthesis and characterization of Copper(II) complexes of new tripodal polyimidazole ligands. Inorganic Chemistry 1994, 33, 2376-2382.

Cheng, D. P., Khan, M. A., Houser, R. P. Coordination polymers composed of copper(II), trimesic acid, and imidazole: 3D architecture stabilized by hydrogen bonding. Inorganic Chemistry 2001, 40, 6858-6861.

Cheruzel, L. E., Pometun, M. S., Cecil, M. R., Mashuta, M. S., Wittebort, R. J., Buchanan, R. M. Structures and solid-state dynamics of one-dimensional water chains stabilized by imidazole channels. Angewandte Chemie-International Edition 2003, 42, 5452-5455.

Cheruzel, L. E., Wang, J. P., Mashuta, M. S., Buchanan, R. M. Structure and properties of an $\mathrm{Fe}(\mathrm{III})$ complex containing a novel amide functionalized polyimidazole ligand. Chemical Communications 2002, 2166-2167.

Cho, C. H., Singh, S., Robinson, G. W. Understanding all of water's anomalies with a nonlocal potential. Journal of Chemical Physics 1997, 107, 7979-7988.

Choma, C., Gratkowski, H., Lear, J. D., DeGrado, W. F. Asparagine-mediated selfassociation of a model transmembrane helix. Nature Structural Biology 2000, 7, $161-166$.

Cole, A. P., Root, D. E., Mukherjee, P., Solomon, E. I., Stack, T. D. P. Trinuclear intermediate in the copper-mediated reduction of $\mathrm{O}_{2}$ : Four electrons from three coppers. Science 1996, 273, 1848-1850.

Collman, J. P., Boulatov, R., Sunderland, C. J., Fu, L. Functional analogues of cytochrome c oxidase, myoglobin, and hemoglobin. Chemical Reviews 2004, 104, $561-588$.

Collman, J. P., Zhong, M., Zhang, C., Costanzo, S. Catalytic activities of $\mathrm{Cu}(\mathrm{II})$ complexes with nitrogen-chelating bidentate ligands in the coupling of imidazoles with arylboronic acids. Journal of Organic Chemistry 2001, 66, 7892-7897.

Crossnoe, C. R., Germanas, J. P., LeMagueres, P., Mustata, G., Krause, K. L. The crystal structure of Trichomonas vaginalis ferredoxin provides insight into metronidazole activation. Journal of Molecular Biology 2002, 318, 503-518.

Cukierman, S. Proton mobilities in water and in different stereoisomers of covalently linked gramicidin A channels. Biophysical Journal 2000, 78, 1825-1834.

Custelcean, R., Afloroaei, C., Vlassa, M., Polverejan, M. Formation of extended tapes of cyclic water hexamers in an organic molecular crystal host. Angewandte ChemieInternational Edition 2000, 39, 3094-3096. 
Decoursey, T. E. Voltage-gated proton channels and other proton transfer pathways. Physiological Reviews 2003, 83, 475-579.

Derewenda, Z. S., Lee, L., Derewenda, U. The occurrence of C-H---O hydrogen-bonds in proteins Journal of Molecular Biology 1995, 252, 248-262.

Desiraju, G. R. Supramolecular synthons in crystal engineering - A new organicsynthesis. Angewandte Chemie-International Edition in English 1995, 34, 23112327.

Desiraju, G. R. The C-H---O hydrogen bond: Structural implications and supramolecular design. Accounts of Chemical Research 1996, 29, 441-449.

Dougherty, R. C. , Howard, L. N. Equilibrium structural model of liquid water: Evidence from heat capacity, spectra, density, and other properties. Journal of Chemical Physics 1998, 109, 7379-7393.

Driessen, W. L., Rehorst, D., Reedijk, J., Mutikainen, P., Turpeinen, U. Copper(II) compounds of some Mannich-condensation amine-bis-imidazole ligands. Inorganica Chimica Acta 2003, 355, 64-68.

Dutzler, R., Campbell, E. B., Cadene, M., Chait, B. T., MacKinnon, R. X-ray structure of a CIC chloride channel at $3.0 \AA$ reveals the molecular basis of anion selectivity. Nature 2002, 415, 287-294.

Eigen, M. Proton transfer, acid-base catalysis, and enzymatic hydrolysis. I. Elementary processes. Angewandte Chemie 1963, 75, 489-508.

Elgafi, S., Field, L. D., Messerle, B. A., Hambley, T. W., Turner, P. Synthesis of novel ruthenium complexes containing bidentate imidazole-based ligands. Journal of the Chemical Society-Dalton Transactions 1997, 2341-2345.

Elgafi, S., Field, L. D., Messerle, B. A., Turner, P., Hambley, T. W. Rhodium complexes containing bidentate imidazolyl ligands: Synthesis and structure. Journal of Organometallic Chemistry 1999, 588, 69-77.

FergusonMiller, S. , Babcock, G. T. Heme/copper terminal oxidases. Chemical Reviews 1996, 96, 2889-2907.

Firouzabadi, H., Iranpoor, N., Hazarkhani, H. Iodine catalyzes efficient and chemoselective thioacetalization of carbonyl functions, transthioacetalization of O,O- and S,O-acetals and acylals. Journal of Organic Chemistry 2001, 66, 75277529 .

Fleming, J. S., Mann, K. L. V., Carraz, C. A., Psillakis, E., Jeffery, J. C., McCleverty, J. A., Ward, M. D. Anion-templated assembly of a supramolecular cage complex. Angewandte Chemie-International Edition 1998, 37, 1279-1281. 
Fois, E., Gamba, A., Tabacchi, G., Quartieri, S., Vezzalini, G. On the collective properties of water molecules in one-dimensional zeolitic channels. Physical Chemistry Chemical Physics 2001, 3, 4158-4163.

Futai, M., Omote, H., Sambongi, Y., Wada, Y. Synthase ( $\mathrm{H}^{+}$ATPase): Coupling between catalysis, mechanical work, and proton translocation. Biochimica et Biophysica Acta-Bioenergetics 2000, 1458, 276-288.

Gagne, R. R., Koval, C. A., Lisensky, G. C. Ferrocene as an internal standard for electrochemical measurements. Inorganic Chemistry 1980, 19, 2854-2855.

Gallivan, J. P. , Dougherty, D. A. Cation- $\pi$ interactions in structural biology. Proceedings of the National Academy of Sciences of the United States of America 1999, 96, 9459-9464.

Galvan-Tejada, N., Bernes, S., Castillo-Blum, S. E., Noth, H., Vicente, R., BarbaBehrens, N. Supramolecular structures of metronidazole and its copper(II), cobalt(II) and zinc(II) coordination compounds. Journal of Inorganic Biochemistry 2002, 91, 339-348.

Garribba, E., Micera, G., Sanna, D., Strinna-Erre, L. The Cu(II)-2,2 '-bipyridine system revisited. Inorganica Chimica Acta 2000, 299, 253-261.

Ghosh, S. K. , Bharadwaj, P. K. Coexistence of water dimer and hexamer clusters in 3D metal-organic framework structures of $\mathrm{Ce}(\mathrm{III})$ and $\operatorname{Pr}(\mathrm{III})$ with pyridine-2,6dicarboxylic acid. Inorganic Chemistry 2003, 42, 8250-8254.

Ghosh, S. K. , Bharadwaj, P. K. A dodecameric water cluster built around a cyclic quasiplanar hexameric core in an organic supramolecular complex of a cryptand. Angewandte Chemie-International Edition 2004, 43, 3577-3580.

Gimeno, B., Sancho, A., Soto, L., Legros, J. P. 3,3-bis(2-imidazolyl)propionic acid hemihydrate. Acta Crystallographica Section C-Crystal Structure Communications 1996, 52, 1226-1228.

Gimeno, B., Soto, L., Sancho, A., Dahan, F., Legros, J. P. Structure of 3,3-bis(2imidazolyl)propionic acid monohydrate. Acta Crystallographica Section CCrystal Structure Communications 1992, 48, 1671-1673.

Graziano, G. On the size dependence of hydrophobic hydration. Journal of the Chemical Society-Faraday Transactions 1998, 94, 3345-3352.

Groziak, M. P. , Wei, L. L. Multifunctionalization of imidazole via sequential halogenmetal exchange - A new route to purine-ring analogs. Journal of Organic Chemistry 1992, 57, 3776-3780. 
Gunther, M. R., Peters, J. A., Sivaneri, M. K. Histidinyl radical formation in the selfperoxidation reaction of bovine copper-zinc superoxide dismutase. Journal of Biological Chemistry 2002, 277, 9160-9166.

Gupta, R., MacBeth, C. E., Young, V. G., Borovik, A. S. Isolation of monomeric $\mathrm{Mn}(\mathrm{III} / \mathrm{II}) \mathrm{OH}$ and $\mathrm{Mn}(\mathrm{III}) \mathrm{O}$ complexes from water: Evaluation of $\mathrm{O}-\mathrm{H}$ bond dissociation energies. Journal of the American Chemical Society 2002, 124, 11361137.

Harata, M., Hasegawa, K., Jitsukawa, K., Masuda, H., Einaga, H. Preparations, structures, and properties of copper(II) complexes with a new tripodal tetradentate ligand, N-(2-pyridylmethyl)bis(6-pivalamido-2-pyridylmethyl)amine, and reactivities of the $\mathrm{Cu}(\mathrm{I})$ complex with dioxygen. Bulletin of the Chemical Society of Japan 1998a, 71, 1031-1038.

Harata, M., Jitsukawa, K., Masuda, H., Einaga, H. Preparations, structures, and properties of $\mathrm{Cu}(\mathrm{II})$ complexes with tripodal tetradentate ligand, tris(6-pivaloylamino-2pyridylmethyl)amine (Htppa), and reaction of its $\mathrm{Cu}(\mathrm{I})$ complex with dioxygen Bulletin of the Chemical Society of Japan 1998b, 71, 637-645.

Haselhorst, G., Wieghardt, K., Keller, S., Schrader, B. The ( $\mu$-oxo)bis [trichloroferrate(III)] dianion revisited. Inorganic Chemistry 1993, 32, 520-525.

Hawkins, C. A., Baird, E. E., Dervan, P. B., Wemmer, D. E. Analysis of hairpin polyamide complexes having DNA binding sites in close proximity. Journal of the American Chemical Society 2002, 124, 12689-12696.

Hawkins, C. A., de Clairac, R. P., Dominey, R. N., Baird, E. E., White, S., Dervan, P. B., Wemmer, D. E. Controlling binding orientation in hairpin polyamide DNA complexes. Journal of the American Chemical Society 2000, 122, 5235-5243.

Hayashi, H., Fujinami, S., Nagatomo, S., Ogo, S., Suzuki, M., Uehara, A., Watanabe, Y., Kitagawa, T. A bis( $\mu$-oxo)dicopper(III) complex with aromatic nitrogen donors: Structural characterization and reversible conversion between copper(I) and bis $(\mu-$ oxo)dicopper(III) species. Journal of the American Chemical Society 2000, 122, 2124-2125.

Henson, M. J., Vance, M. A., Zhang, C. X., Liang, H. C., Karlin, K. D., Solomon, E. I. Resonance Raman investigation of equatorial ligand donor effects on the $\mathrm{Cu}_{2} \mathrm{O}_{2}{ }^{2+}$ core in end-on and side-on $\mu$-peroxo-dicopper(II) and bis( $\mu$-oxo)dicopper(III) complexes. Journal of the American Chemical Society 2003, 125, 5186-5192.

Hille, B. Ionic channels in excitable membranes.Current problems and biophysical approaches. Biophysical Journal 1978, 22, 283-294.

Holm, R. H., Kennepohl, P., Solomon, E. I. Structural and functional aspects of metal sites in biology. Chemical Reviews 1996, 96, 2239-2314. 
Hong, B. H., Lee, J. Y., Lee, C. W., Kim, J. C., Bae, S. C., Kim, K. S. Self-assembled arrays of organic nanotubes with infinitely long one-dimensional H-bond chains. Journal of the American Chemical Society 2001, 123, 10748-10749.

Hoss, H. , Elias, H. Mechanism of associatively controlled ligand substitution in squareplanar bis(N-alkylsalicylaldiminato)nickel(II) complexes - Kinetic, spectroscopic, and thermodynamic characterization of adducts and intermediates. Inorganic Chemistry 1993, 32, 317-323.

Hu, Z. Z., Takami, S., Kimura, M., Tachi, Y., Naruta, Y. 2,4,5-Triphenyl-4H-imidazol-4yl hydroperoxide-dichloromethane (2/1). Acta Crystallographica Section CCrystal Structure Communications 2000, 56, E465-E466.

Hummer, G., Rasaiah, J. C., Noworyta, J. P. Water conduction through the hydrophobic channel of a carbon nanotube. Nature 2001, 414, 188-190.

Infantes, L., Chisholm, J., Motherwell, S. Extended motifs from water and chemical functional groups in organic molecular crystals. Crystengcomm 2003, 5, 480-486.

Infantes, L. , Motherwell, S. Water clusters in organic molecular crystals. Crystengcomm 2002, 454-461.

Jain, M. L., Tsao, Y. P., Ho, N. L., Cheng, J. W. A facile synthesis of $\left[\mathrm{N} 1, \mathrm{NH}_{2}-\mathrm{N}^{15}(2)\right]-$, $\left[\mathrm{N} 3, \mathrm{NH}_{2}-\mathrm{N}^{15}(2)\right]-$, and $\left[\mathrm{N} 1, \mathrm{~N} 3, \mathrm{NH}_{2}-\mathrm{N}-15(3)\right]$-labeled adenine. Journal of Organic Chemistry 2001, 66, 6472-6475.

Janiak, C. A critical account on $\pi-\pi$ stacking in metal complexes with aromatic nitrogencontaining ligands. Journal of the Chemical Society-Dalton Transactions 2000, 3885-3896.

Janiak, C., Scharmann, T. G., Mason, S. A. Two-dimensional water and ice layers: Neutron diffraction studies at 278, 263, and $20 \mathrm{~K}$. Journal of the American Chemical Society 2002, 124, 14010-14011.

Jude, K. M., Wright, S. K., Tu, C., Silverman, D. N., Viola, R. E., Christianson, D. W. Crystal structure of F65A/Y 131C-methylimidazole carbonic anhydrase V reveals architectural features of an engineered proton shuttle. Biochemistry 2002, 41, 2485-2491.

Kandori, H. Role of internal water molecules in bacteriorhodopsin. Biochimica et Biophysica Acta-Bioenergetics 2000, 1460, 177-191.

Karlin, S., Zhu, Z. Y., Karlin, K. D. The extended environment of mononuclear metal centers in protein structures. Proceedings of the National Academy of Sciences of the United States of America 1997, 94, 14225-14230. 
Kavallieratos, K., Bertao, C. M., Crabtree, R. H. Hydrogen bonding in anion recognition: A family of versatile, nonpreorganized neutral and acyclic receptors. Journal of Organic Chemistry 1999, 64, 1675-1683.

Kim, S. A. , Kuppers, H. Proton disorder of water-molecules in the structure of lithium hydrogen cis-4-cyclohexene-1,2-dicarboxylate dihydrate, $\mathrm{LiHC}_{8} \mathrm{H}_{8} \mathrm{O}_{4} \cdot 2 \mathrm{H}_{2} \mathrm{O}$. Zeitschrift fur Kristallographie 1994, 209, 789-793.

Kirschgen, T. M., Zeidler, M. D., Geil, B., Fujara, F. A deuteron NMR study of the tetrahydrofuran clathrate hydrate - Part II: Coupling of rotational and translational dynamics of water. Physical Chemistry Chemical Physics 2003, 5, 5247-5252.

Kitajima, N., Fujisawa, K., Fujimoto, C., Morooka, Y., Hashimoto, S., Kitagawa, T., Toriumi, K., Tatsumi, K., Nakamura, A. A new model for dioxygen binding in hemocyanin - Synthesis, characterization, and molecular-structure of the $\mu-\eta^{2}: \eta^{2}$ -peroxo dinuclear copper(II) complexes, $\left[\mathrm{Cu}\left(\mathrm{Hb}\left(3,5-\mathrm{R}_{2} \mathrm{Pz}\right)_{3}\right)\right]_{2}\left(\mathrm{O}_{2}\right)(\mathrm{R}=\mathrm{Iso}-\mathrm{Pr}$ and $\mathrm{Ph}$ ). Journal of the American Chemical Society 1992, 114, 1277-1291.

Kitajima, N. , Morooka, Y. Copper-dioxygen complexes - Inorganic and bioinorganic perspectives. Chemical Reviews 1994, 94, 737-757.

Klinman, J. P. Mechanisms whereby mononuclear copper proteins functionalize organic substrates. Chemical Reviews 1996, 96, 2541-2561.

Kodera, M., Kajita, Y., Tachi, Y., Katayama, K., Kano, K., Hirota, S., Fujinami, S., Suzuki, M. Synthesis, structure, and greatly improved reversible $\mathrm{O}_{2}$ binding in a structurally modulated $\mu-\eta^{2}: \eta^{2}$-peroxodicopper(II) complex with roomtemperature stability. Angewandte Chemie-International Edition 2004, 43, 334337.

Kodera, M., Kita, T., Miura, I., Nakayama, N., Kawata, T., Kano, K., Hirota, S. Hydroperoxo-copper(II) complex stabilized by $\mathrm{N}_{3} \mathrm{~S}$-type ligand having a phenyl thioether. Journal of the American Chemical Society 2001, 123, 7715-7716.

Koga, K., Tanaka, H., Zeng, X. C. First-order transition in confined water between highdensity liquid and low-density amorphous phases. Nature 2000, 408, 564-567.

Kojima, T., Leising, R. A., Yan, S. P., Que, L. Alkane functionalization at nonheme iron centers - Stoichiometric transfer of metal-bound ligands to alkane. Journal of the American Chemical Society 1993, 115, 11328-11335.

Kopka, M. L., Goodsell, D. S., Han, G. W., Chiu, T. K., Lown, J. W., Dickerson, R. E. Defining GC-specificity in the minor groove: Side-by-side binding of the diimidazole lexitropsin to C-A-T-G-G-C-C-A-T-G. Structure 1997, 5, 1033-1046.

Kowalski, A. 1-(p-methoxyphenyl)-2-methyl-4-nitroimidazole and 1-(p-acetylphenyl)-2methyl-4-nitroimidazole. Acta Crystallographica Section C-Crystal Structure Communications 1996, 52, 1784-1787. 
Kresge, C. T., Leonowicz, M. E., Roth, W. J., Vartuli, J. C., Beck, J. S. Ordered mesoporous molecular-sieves synthesized by a liquid-crystal template mechanism. Nature 1992, 359, 710-712.

Kreuer, K. D. On the development of proton conducting polymer membranes for hydrogen and methanol fuel cells. Journal of Membrane Science 2001, 185, 2939.

Krische, M. J., Lehn, J. M. The utilization of persistent H-bonding motifs in the selfassembly of supramolecular architectures. Molecular Self-Assembly 2000, 96, 329.

Lanyi, J. K. Bacteriorhodopsin. Biochimica et Biophysica Acta-Bioenergetics 2000, 1460, $1-3$.

Law, R. J., Forrest, L. R., Ranatunga, K. M., La Rocca, P., Tieleman, D. P., Sansom, M. S. P. Structure and dynamics of the pore-lining helix of the nicotinic receptor: MD simulations in water, lipid bilayers, and transbilayer bundles. ProteinsStructure Function and Genetics 2000, 39, 47-55.

Lee, Y., Vogt, T., Hriljac, J. A., Parise, J. B., Hanson, J. C., Kim, S. J. Non-framework cation migration and irreversible pressure-induced hydration in a zeolite. Nature 2002, 420, 485-489.

Lehn, J. M. Perspectives in supramolecular chemistry - from molecular recognition towards molecular information-processing and self-organization. Angewandte Chemie-International Edition in English 1990, 29, 1304-1319.

Li, Q., Xue, F., Mak, T. C. W. Crystalline inclusion compounds of urea with oxoboron components. Stabilization of the elusive dihydrogen borate anion in a hydrogenbonded host lattice. Inorganic Chemistry 1999, 38, 4142-4148.

Liang, H. C., Dahan, M., Karlin, K. D. Dioxygen-activating bio-inorganic model complexes. Current Opinion in Chemical Biology 1999, 3, 168-175.

Lipscomb, W. N. , Strater, N. Recent advances in zinc enzymology. Chemical Reviews 1996, 96, 2375-2433.

Liu, C. L., Zhou, J. Y., Li, Q. X., Wang, L. J., Liao, Z. R., Xu, H. B. DNA damage by copper(II) complexes: Coordination-structural dependence of reactivities. Journal of Inorganic Biochemistry 1999, 75, 233-240.

London, R. E. , Gabel, S. A. Formation of a trypsin-borate-4-aminobutanol ternary complex. Biochemistry 2002, 41, 5963-5967.

Long, L. S., Wu, Y. R., Huang, R. B., Zheng, L. S. A well-resolved uudd cyclic water tetramer in the crystal host of $\left[\mathrm{Cu}\right.$ (adipate)(4,4-bipyridine)] $\left(\mathrm{H}_{2} \mathrm{O}\right)_{2}$. Inorganic Chemistry 2004, 43, 3798-3800. 
Ludwig, R. Water: From clusters to the bulk. Angewandte Chemie International Edition 2001, 40, 1809-1827.

Lythgoe, D. J. , Ramsden, C. A. 4-Unsubstituted, 5-Amino and 5-Unsubstituted, 4Aminoimidazoles. Advances in Heterocyclic Chemistry, Vol 61 1994, 61, 1-58.

MacBeth, C. E., Hammes, B. S., Young, V. G., Borovik, A. S. Hydrogen-bonding cavities about metal ions: Synthesis, structure, and physical properties for a series of monomeric $\mathrm{M}-\mathrm{OH}$ complexes derived from water. Inorganic Chemistry 2001, 40, 4733-4741.

MacDonald, J. C., Dorrestein, P. C., Pilley, M. M., Foote, M. M., Lundburg, J. L., Henning, R. W., Schultz, A. J., Manson, J. L. Design of layered crystalline materials using coordination chemistry and hydrogen bonds. Journal of the American Chemical Society 2000, 122, 11692-11702.

Manzur, J. New Complexes of Iron(II), Cobalt(II), Nickel(II) and Copper(II) with 2,2'Dipyridylmethane. Transition Metal Chemistry 1986, 11, 220-223.

Maret, W. , Vallee, B. L. Cobalt as probe and label of proteins. Metallobiochemistry, Part C 1993, 226, 52-71.

Mashuta, M. S., Cheruzel, L., Buchanan, R. M. Tris[(1-methylimidazol-2-yl)methyl]amine-boric acid (1/1). Acta Crystallographica Section C-Crystal Structure Communications 2002, 58, O629-O631.

Meissner, R. S., Rebek, J., Demendoza, J. Autoencapsulation through intermolecular forces - A synthetic self-assembling spherical complex. Science 1995, 270, 14851488.

Mendz, G. L. , Megraud, F. Is the molecular basis of metronidazole resistance in microaerophilic organisms understood? Trends in Microbiology 2002, 10, 370375.

Michaelides, A., Skoulika, S., Bakalbassis, E. G., Mrozinski, J. Cyclic water hexamers and decamers in a porous lanthanide-organic framework: Correlation between some physical properties and crystal structure. Crystal Growth \& Design 2003, 3, 487-492.

Mirica, L. M., Vance, M., Rudd, D. J., Hedman, B., Hodgson, K. O., Solomon, E. I., Stack, T. D. P. A stabilized $\mu-\eta^{2}: \eta^{2}$-peroxodicopper(II) complex with a secondary diamine ligand and its tyrosinase-like reactivity. Journal of the American Chemical Society 2002, 124, 9332-9333.

Mishima, O. , Stanley, H. E. The relationship between liquid, supercooled and glassy water. Nature 1998, 396, 329-335. 
Modig, K., Liepinsh, E., Otting, G., Halle, B. Dynamics of protein and peptide hydration. Journal of the American Chemical Society 2004, 126, 102-114.

Munch, W., Kreuer, K. D., Silvestri, W., Maier, J., Seifert, G. The diffusion mechanism of an excess proton in imidazole molecule chains: First results of an $a b$ initio molecular dynamics study. Solid State Ionics 2001, 145, 437-443.

Nagle, J. F. , Morowitz, H. J. Molecular mechanisms for proton transport in membranes. Proceedings of the National Academy of Sciences of the United States of America 1978, 75, 298-302.

Nakashima, K. Lophine derivatives as versatile analytical tools. Biomedical Chromatography 2003, 17, 83-95.

Navarro, J. A. R. , Lippert, B. Simple 1:1 and 1:2 complexes of metal ions with heterocycles as building blocks for discrete molecular as well as polymeric assemblies. Coordination Chemistry Reviews 2001, 222, 219-250.

Nguyen, B., Tardy, C., Bailly, C., Colson, P., Houssier, C., Kumar, A., Boykin, D. W., Wilson, W. D. Influence of compound structure on affinity, sequence selectivity, and mode of binding to DNA for unfused aromatic dications related to furamidine. Biopolymers 2002, 63, 281-297.

Noguchi, K., Dannel, F., Pfeffer, H., Romheld, V., Hayashi, H., Fujiwara, T. Defect in root-shoot translocation of boron in Arabidopsis thaliana mutant bor1-1. Journal of Plant Physiology 2000, 156, 751-755.

Novak, A., Blake, A. J., Wilson, C., Love, J. B. Titanium and zirconium complexes supported by dipyrrolide ligands. Chemical Communications 2002, 2796-2797.

O'Hare, C. C., Mack, D., Tandon, M., Sharma, S. K., Lown, J. W., Kopka, M. L., Dickerson, R. E., Hartley, J. A. DNA sequence recognition in the minor groove by crosslinked polyamides: The effect of N-terminal head group and linker length on binding affinity and specificity. Proceedings of the National Academy of Sciences of the United States of America 2002, 99, 72-77.

Oberhausen, K. J., Obrien, R. J., Richardson, J. F., Buchanan, R. M. New tripodal Cu(II) complexes containing imidazole ligands. Inorganica Chimica Acta 1990, 173, 145-154.

Ohtsu, H., Itoh, S., Nagatomo, S., Kitagawa, T., Ogo, S., Watanabe, Y., Fukuzumi, F. Characterization of imidazolate-bridged dinuclear and mononuclear hydroperoxo complexes. Inorganic Chemistry 2001, 40, 3200-3207.

Okada, A., Miura, T., Takeuchi, H. Protonation of histidine and histidine-tryptophan interaction in the activation of the M2 ion channel from influenza A virus. Biochemistry 2001, 40, 6053-6060. 
Osako, T., Nagatomo, S., Tachi, Y., Kitagawa, T., Itoh, S. Low-temperature stopped-flow studies on the reactions of copper(II) complexes and $\mathrm{H}_{2} \mathrm{O}_{2}$ : The first detection of a mononuclear copper(II)-peroxo intermediate. Angewandte Chemie-International Edition 2002, 41, 4325-4328.

Pal, S. K., Peon, J., Zewail, A. H. Biological water at the protein surface: Dynamical solvation probed directly with femtosecond resolution. Proceedings of the National Academy of Sciences of the United States of America 2002a, 99, 17631768 .

Pal, S. K., Peon, J., Zewail, A. H. Ultrafast surface hydration dynamics and expression of protein functionality: $\alpha$-Chymotrypsin. Proceedings of the National Academy of Sciences of the United States of America 2002b, 99, 15297-15302.

Pal, S. K. , Zewail, A. H. Dynamics of water in biological recognition. Chemical Reviews 2004, 104, 2099-2123.

Papoian, G. A., Ulander, J., Eastwood, M. P., Luthey-Schulten, Z., Wolynes, P. G. Water in protein structure prediction. Proceedings of the National Academy of Sciences of the United States of America 2004, 101, 3352-3357.

Papoian, G. A., Ulander, J., Wolynes, P. G. Role of water mediated interactions in protein-protein recognition landscapes. Journal of the American Chemical Society 2003, 125, 9170-9178.

Pardanani, A., Gambacurta, A., Ascoli, F., Royer, W. E. Mutational destabilization of the critical interface water cluster in Scapharca dimeric hemoglobin: Structural basis for altered allosteric activity. Journal of Molecular Biology 1998, 284, 729-739.

Parker, M. J. , Clarke, A. R. Amide backbone and water-related H/D isotope effects on the dynamics of a protein folding reaction. Biochemistry 1997, 36, 5786-5794.

Place, C., Zimmermann, J. L., Mulliez, E., Guillot, G., Bois, C., Chottard, E. C. Crystallographic, electrochemical, and pulsed EPR study of copper(II) polyimidazole complexes relevant to the metal sites of copper proteins. Inorganic Chemistry 1998, 37, 4030-4039.

Pohl, P., Saparov, S. M., Borgnia, M. J., Agre, P. Highly selective water channel activity measured by voltage clamp: Analysis of planar lipid bilayers reconstituted with purified AqpZ. Proceedings of the National Academy of Sciences of the United States of America 2001, 98, 9624-9629.

Pomes, R. , Roux, B. Molecular mechanism of $\mathrm{H}^{+}$conduction in the single-file water chain of the gramicidin channel. Biophysical Journal 2002, 82, 2304-2316.

Pometun, M. S., Gundusharma, U. M., Richardson, J. F., Wittebort, R. J. Solid-state NMR and calorimetry of structural waters in helical peptides. Journal of the American Chemical Society 2002, 124, 2345-2351. 
Popot, J. L. , Engelman, D. M. Helical membrane protein folding, stability, and evolution. Annual Review of Biochemistry 2000, 69, 881-922.

Preston, G. M., Carroll, T. P., Guggino, W. B., Agre, P. Appearance of Water Channels in Xenopus Oocytes Expressing Red-Cell Chip28 Protein. Science 1992, 256, 385-387.

Qiao, X. L., Chen, S. M., Tan, L., Zheng, H., Ding, Y. D., Ping, Z. H. Investigation of formation of superoxide anion radical in DMSO by ESR: Part 1. Influence of $\mathrm{Fe}^{2+}$ and $\mathrm{Cu}^{2+}$. Magnetic Resonance in Chemistry 2001, 39, 207-211.

Quant, L. D., Shearer, J., Liang, H. C., Zhang, C. X., Karlin, K. D., Vance, M., Henson, M. J., Solomon, E. I. Dioxygen activation by copper(I) complexes: Electronic effects on the formation and substrate reactivity of the $\mathrm{Cu}_{2} \mathrm{O}_{2}$ core. Journal of Inorganic Biochemistry 2003, 96, 214-214.

Que, L. Physical methods in bioinorganic chemistry: Spectroscopy and magnetism 2000, University Science Book, Sausalito, CA.

Que, L. , Tolman, W. B. Bis( $\mu$-oxo)dimetal "Diamond" cores in copper and iron complexes relevant to biocatalysis. Angewandte Chemie-International Edition 2002, 41, 1114-1137.

Raghuraman, K., Katti, K. K., Barbour, L. J., Pillarsetty, N., Barnes, C. L., Katti, K. V. Characterization of supramolecular $\left(\mathrm{H}_{2} \mathrm{O}\right)_{18}$ water morphology and watermethanol $\left(\mathrm{H}_{2} \mathrm{O}\right)_{15}\left(\mathrm{CH}_{3} \mathrm{OH}\right)_{3}$ clusters in a novel phosphorus functionalized trimeric amino acid host Journal of the American Chemical Society 2003, 125, 6955-6961.

Rao, P. , Benner, S. A. Fluorescent charge-neutral analogue of xanthosine: Synthesis of a 2'-deoxyribonucleoside bearing a 5-aza-7-deazaxanthine base. Journal of Organic Chemistry 2001, 66, 5012-5015.

Richardson, J. F., Wilsonblumenberg, C. A., Oberhausen, K. J., Mashuta, M. S., Buchanan, R. M. Structure of bis[(N-methyl-2-imidazolyl)methyl]amine. Acta Crystallographica Section C-Crystal Structure Communications 1988, 44, 22172218.

Riggio, I., van Albada, G. A., Ellis, D. D., Mutikainen, I., Spek, A. L., Turpeinen, U., Reedijk, J. X-ray crystal structures, spectroscopic and magnetic measurements of copper(II) and cobalt(II) halide compounds with bis(2-benzimidazolyl)alkane ligands. Polyhedron 2001, 20, 2659-2666.

Robinson, J. M. A., Philp, D., Harris, K. D. M., Kariuki, B. M. Weak interactions in crystal engineering - Understanding the recognition properties of the nitro group. New Journal of Chemistry 2000, 24, 799-806.

Rodriguez-Cuamatzi, P., Vargas-Diaz, G., Hopfl, H. Modification of 2-D water that contains hexameric units in chair and boat conformations - A contribution to the 
structural elucidation of bulk water. Angewandte Chemie International Edition 2004, 43, 3041-3044.

Roelfes, G., Vrajmasu, V., Chen, K., Ho, R. Y. N., Rohde, J. U., Zondervan, C., La Crois, R. M., Schudde, E. P., Lutz, M., Spek, A. L., Hage, R., Feringa, B. L., Munck, E., Que, L. End-on and side-on peroxo derivatives of non-heme iron complexes with pentadentate ligands: Models for putative intermediates in biological iron/dioxygen chemistry. Inorganic Chemistry 2003, 42, 2639-2653.

Roffia, S., Gottardi, C., Vianello, E. Electrochemical-behavior of 4-nitroimidazole and 2-methyl-5-nitroimidazole - autoprotonation of anion radical and redox-catalyzed reduction of the supporting electrolyte cation. Journal of Electroanalytical Chemistry 1982, 142, 263-275.

Roy, A., Choudhury, A., Rao, C. N. R. Supramolecular hydrogen-bonded structure of a 1:2 adduct of melamine with boric acid. Journal of Molecular Structure 2002, 613, 61-66.

Royer, W. E., Pardanani, A., Gibson, Q. H., Peterson, E. S., Friedman, J. M. Ordered water molecules as key allosteric mediators in a cooperative dimeric hemoglobin. Proceedings of the National Academy of Sciences of the United States of America 1996, 93, 14526-14531.

Sawyer, D. T., Sobkowiak, A., Matsushita, T. Metal $\left[\mathrm{ML}_{\mathrm{x}} ; \mathrm{M}=\mathrm{Fe}, \mathrm{Cu}, \mathrm{Co}\right.$, $\mathrm{Mn}$ /hydroperoxide-induced activation of dioxygen for the oxygenation of hydrocarbons: Oxygenated Fenton chemistry. Accounts of Chemical Research 1996, 29, 409-416.

Seio, K., Mizuta, M., Terada, T., Sekine, M. Synthesis and properties of a pyrroleimidazole polyamide having a ferrocene dicarboxylic amide linker. Tetrahedron Letters 2004, 45, 6783-6786.

Sheldrick, G. M. SADABS V. 2.02, Area Detector Absorption Correction 1997a, University of Göttingen, Göttingen, Germany.

Sheldrick, G. M. SHELX-6.12, Program library for structure solution and molecular graphics 2001, Bruker Advanced X-ray Solutions, Inc., Madison, WI.

Sheldrick, G. M. SHELX-97, Program for the refinement of Crystal Structures 1997b, University of Göttingen, Göttingen, Germany.

Shikoku Chemicals Corp. 4,4'-Methylene-bis(2-ethyl-5-methylimidazole). 1984, JP 59,190,972 CA 102: 149268a.

Siddiqui, A. Q., Merson-Davies, L., Cullis, P. M. The synthesis of novel polyaminenitroimidazole conjugates designed to probe the structural specificities of the polyamine uptake system in A549 lung carcinoma cells. Journal of the Chemical Society-Perkin Transactions 1 1999, 3243-3252. 
Silvestri, R., Artico, M., Massa, S., Marceddu, T., De Montis, F., La Colla, P. 1-[2(Diphenylmethoxy)ethyl]-2-methyl-5-nitroimidazole: A potent lead for the design of novel NNRTIs. Bioorganic \& Medicinal Chemistry Letters 2000, 10, 253-256.

Sobott, F., Wattenberg, A., Barth, H. D., Brutschy, B. Ionic clathrates from aqueous solutions detected with laser induced liquid beam ionization/desorption mass spectrometry. International Journal of Mass Spectrometry 1999, 187, 271-279.

Solomon, E. I., Baldwin, M. J., Lowery, M. D. Electronic-Structures of Active-Sites in Copper Proteins - Contributions to Reactivity. Chemical Reviews 1992, 92, 521542.

Solomon, E. I., Chen, P., Metz, M., Lee, S. K., Palmer, A. E. Oxygen binding, activation, and reduction to water by copper proteins. Angewandte Chemie-International Edition 2001, 40, 4570-4590.

Solomon, E. I., Sundaram, U. M., Machonkin, T. E. Multicopper oxidases and oxygenases. Chemical Reviews 1996, 96, 2563-2605.

Solomon, E. I., Tuczek, F., Root, D. E., Brown, C. A. spectroscopy of binuclear dioxygen complexes. Chemical Reviews 1994, 94, 827-856.

Son, S. U., Park, K. H., Kim, B. Y., Chung, Y. K. Construction of cylindrical nanotubular materials by self-assembly of $\mathrm{Co}(\mathrm{NCS})_{2}$ with bent-building blocks having diimidazole rings. Crystal Growth \& Design 2003, 3, 507-512.

Speedy, R. J. Waterlike anomalies from repulsive interactions. Journal of Chemical Physics 1997, 107, 3222-3229.

Sreenivasan, U. , Axelsen, P. H. Buried water in homologous serine proteases. Biochemistry 1992, 31, 12785-12791.

Stahl, K., Kvick, A., Ghose, S. One-dimensional water chain in the zeolite bikitaite Neutron-diffraction study at $13 \mathrm{~K}$ and $295 \mathrm{~K}$. Zeolites 1989, 9, 303-311.

Stillinger, F. H. Water revisited. Science 1980, 209, 451-457.

Suihko, E., Ketolainen, J., Poso, A., Ahlgren, M., Gynther, J., Paronen, P. Dehydration of theophylline monohydrate - A two step process. International Journal of Pharmaceutics 1997, 158, 47-55.

Sun, C. Q., Zhou, D. L., Grant, D. J. W., Young, V. G. Theophylline monohydrate. Acta Crystallographica Section E-Structure Reports Online 2002, 58, O368-O370.

Sundberg, R. J., Martin, R. B. Interactions of histidine and other imidazole derivatives with transition-metal ions in chemical and biological-systems. Chemical Reviews 1974, 74, 471-517. 
Tadokoro, M. , Nakasuji, K. Hydrogen bonded 2,2'-biimidazolate transition metal complexes as a tool of crystal engineering. Coordination Chemistry Reviews 2000, 198, 205-218.

Taki, M., Itoh, S., Fukuzumi, S. Oxo-transfer reaction from a bis( $\mu$-oxo)dicopper(III) complex to sulfides. Journal of the American Chemical Society 2002, 124, 9981002.

Tanaka, H. Simple physical explanation of the unusual thermodynamic behavior of liquid water. Physical Review Letters 1998, 80, 5750-5753.

Tao, J., Ma, Z. J., Huang, R. B., Zheng, L. S. Synthesis and characterization of a tetrazolate-bridged coordination framework encapsulating $\mathrm{D}_{2 \mathrm{~h}}$-symmetric cyclic $(\mathrm{H} 2 \mathrm{O})_{4}$ cluster arrays. Inorganic Chemistry 2004, 43, 6133-6135.

Teeter, M. M. Water-structure of a hydrophobic protein at atomic resolution - Pentagon rings of water-molecules in crystals of crambin. Proceedings of the National Academy of Sciences of the United States of America-Biological Sciences 1984, 81, 6014-6018.

Teeter, M. M. , Heo, N. H. Crambin water-structure at atomic resolution from X-Ray and neutron data. Biophysical Journal 1988, 53, A249-A249.

Teeter, M. M., Yamano, A., Stec, B., Mohanty, U. On the nature of a glassy state of matter in a hydrated protein: Relation to protein function. Proceedings of the National Academy of Sciences of the United States of America 2001, 98, 1124211247.

Terao, H., Sugawara, T., Kita, Y., Sato, N., Kaho, E., Takeda, S. Proton relay in a onedimensional hydrogen-bonded chain composed of water molecules and a squaric acid derivative. Journal of the American Chemical Society 2001, 123, 1046810474.

Thorhauge, J., Roberson, M., Hazell, R. G., Jorgensen, K. A. On the intermediates in chiral bis(oxazoline)copper(II)-catalyzed enantioselective reactions Experimental and theoretical investigations. Chemistry-A European Journal 2002, 8, 1888-1898.

Tieleman, D. P., Biggin, P. C., Smith, G. R., Sansom, M. S. P. Simulation approaches to ion channel structure-function relationships. Quarterly Reviews of Biophysics 2001, 34, 473-561.

Tocher, J. H. , Edwards, D. I. Electrochemical characteristics of nitroheterocyclic compounds of biological interest .8. Stability of nitro radical-anions from cyclic voltammetric studies. Free Radical Research Communications 1992, 16, 19-25.

Tshuva, E. Y., Lippard, S. J. Synthetic models for non-heme carboxylate-bridged diiron metalloproteins: Strategies and tactics. Chemical Reviews 2004, 104, 987-1011. 
Tsukaguchi, H., Shayakul, C., Berger, U. V., Mackenzie, B., Devidas, S., Guggino, W. B., van Hoek, A. N., Hediger, M. A. Molecular characterization of a broad selectivity neutral solute channel. Journal of Biological Chemistry 1998, 273, 24737-24743.

Tubbs, K. J., Fuller, A. L., Bennett, B., Arif, A. M., Berreau, L. M. Mononuclear $\mathrm{N}_{3} \mathrm{~S}$ (thioether)-ligated copper(II) methoxide complexes: Synthesis, characterization, and hydrolytic reactivity Inorganic Chemistry 2003a, 42, 47904791.

Tubbs, K. J., Fuller, A. L., Bennett, B., Arif, A. M., Makowska-Grzyska, M. M., Berreau, L. M. Evaluation of the influence of a thioether substituent on the solid state and solution properties of $\mathrm{N}_{3} \mathrm{~S}$-ligated copper(II) complexes. Dalton Transactions 2003b, 3111-3116.

Tyeklar, Z. , Karlin, K. D. Copper dioxygen chemistry - A bioinorganic challenge. Accounts of Chemical Research 1989, 22, 241-248.

Vandermeer, K. , Mulder, J. J. C. Ab-initio calculations on 1-imidazolyl radical. Chemical Physics Letters 1975, 34, 189-191.

Vandersluis, P., Spek, A. L. Bypass - An effective method for the refinement of crystalstructures containing disordered solvent regions. Acta Crystallographica Section A 1990, 46, 194-201.

Varfolomeev, S. D. , Gurevich, K. G. Enzyme active sites: bioinformatics, architecture, and mechanisms of action. Russian Chemical Bulletin 2001, 50, 1709-1717.

VidenovaAdrabinska, V. , Etter, M. C. Urea-glutaric acid (2:1) structural aggregates as building blocks for crystal engineering. Journal of Chemical Crystallography 1995, 25, 823-829.

Vilar, R., Mingos, D. M. P., White, A. J. P., Williams, D. J. Anion control in the selfassembly of a cage coordination complex. Angewandte Chemie-International Edition 1998, 37, 1258-1261.

Wada, A., Harata, M., Hasegawa, K., Jitsukawa, K., Masuda, H., Mukai, M., Kitagawa, T., Einaga, H. Structural and spectroscopic characterization of a mononuclear hydroperoxo-copper(II) complex with tripodal pyridylamine ligands. Angewandte Chemie-International Edition 1998, 37, 798-799.

Wada, A., Honda, Y., Yamaguchi, S., Nagatomo, S., Kitagawa, T., Jitsukawa, K., Masuda, H. Steric and hydrogen-bonding effects on the stability of copper complexes with small complexes. Inorganic Chemistry 2004, 43, 5725-5735.

Wang, C., Lamb, R. A., Pinto, L. H. Activation of the M2 ion-channel of influenza-virus - A role for the transmembrane domain histidine residue. Biophysical Journal 1995, 69, 1363-1371. 
Wang, C., Takeuchi, K., Holsinger, L. J., Lamb, R. A., Pinto, L. H. Ion channel activity of the M2 protein of influenza A virus. Biophysical Journal 1993, 64, A94-A94.

Wang, J. F., Kim, S., Kovacs, F., Cross, T. A. Structure of the transmembrane region of the M2 protein $\mathrm{H}^{+}$channel. Protein Science 2001, 10, 2241-2250.

Wikstrom, M., Verkhovsky, M. I., Hummer, G. Water-gated mechanism of proton translocation by cytochrome $\mathrm{c}$ oxidase. Biochimica et Biophysica ActaBioenergetics 2003, 1604, 61-65.

Wittebort, R. J., Usha, M. G., Ruben, D. J., Wemmer, D. E., Pines, A. Observation of molecular-reorientation in ice by proton and deuterium magnetic resonance. Journal of the American Chemical Society 1988, 110, 5668-5671.

Xantheas, S. S. Ab initio studies of cyclic water clusters $(\mathrm{H} 2 \mathrm{O})_{\mathrm{n}}, \mathrm{n}=1-6.3$. Comparison of density-functional with MP2 results. Journal of Chemical Physics 1995, 102, 4505-4517.

Xing, W. L. , He, X. W. Kinetic determination of organic vapor mixtures with single piezoelectric quartz crystal sensor using artificial neural networks. Talanta 1997, 44, 959-965.

Xu, Q., Axelrod, H. L., Abresch, E. C., Paddock, M. L., Okamura, M. Y., Feher, G. Xray structure determination of three mutants of the bacterial photosynthetic reaction centers from $\mathrm{Rb}$. sphaeroides: Altered proton transfer pathways. Structure 2004, 12, 703-715.

Yamaguchi, S., Nagatomo, S., Kitagawa, T., Funahashi, Y., Ozawa, T., Jitsukawa, K., Masuda, H. Copper hydroperoxo species activated by hydrogen-bonding interaction with its distal oxygen. Inorganic Chemistry 2003, 42, 6968-6970.

Yang, X. L., Kaenzig, C., Lee, M., Wang, A. H. J. Binding of AR-1-144, a tri-imidazole DNA minor groove binder, to CCGG sequence analyzed by NMR spectroscopy. European Journal of Biochemistry 1999, 263, 646-655.

Yin, Z. M., Jiang, L., He, J. Q., Cheng, J. P. The first observation of nitrogen-carbonyl bonding: self-assembly of N-oxalyl 2,4-dinitroanilide assisted by a weak $\mathrm{N}---\mathrm{O}=\mathrm{C}$ interaction. Chemical Communications 2003, 2326-2327.

Zaslavsky, D. , Gennis, R. B. Proton pumping by cytochrome oxidase: progress, problems and postulates. Biochimica et Biophysica Acta-Bioenergetics 2000, $1458,164-179$.

Zhang, P. J., Toyoshima, C., Yonekura, K., Green, N. M., Stokes, D. L. Structure of the calcium pump from sarcoplasmic reticulum at $8 \AA$ resolution. Nature 1998, 392, 835-839. 
Zhao, L., Pal, S. K., Xia, T. B., Zewail, A. H. Dynamics of ordered water in interfacial enzyme recognition: Bovine pancreatic phospholipase A2. Angewandte ChemieInternational Edition 2004, 43, 60-63.

Zhong, Q. F., Husslein, T., Moore, P. B., Newns, D. M., Pattnaik, P., Klein, M. L. The M2 channel of influenza A virus: A molecular dynamics study. Febs Letters 1998, 434, 265-271.

Zundel, G. , Metzger, H. Infrared spectroscopic study of the nature of the $\mathrm{H}_{9} \mathrm{O}_{4}{ }^{+}$group in acid solutions. Zeitschrift fuer Naturforschung, Teil A: Astrophysik, Physik und Physikalische Chemie 1967, 22, 1412-1414. 


\section{APPENDIX 1}

\section{CRYSTALLOGRAPHIC DATA}

Table S1. Crystal data and structure refinement for compound $\mathbf{1}$.

Identification code

Empirical formula

Formula weight

Temperature

Wavelength

Crystal system

Space group

Unit cell dimensions

Volume

Z

Density (calculated)

Absorption coefficient

$\mathrm{F}(000)$

Crystal size

Crystal color, habit

Theta range for data collection

Index ranges

Reflections collected

Independent reflections

Completeness to theta $=28.22^{\circ}$

Absorption correction

Max. and min. transmission

Refinement method

Data/restraints/parameters
$\mathrm{L}^{\mathrm{Et}, \mathrm{Me}}$

$\mathrm{C}_{13} \mathrm{H}_{20} \mathrm{~N}_{4}$

232.33

100(2) K

$0.71073 \AA$

Monoclinic

$\mathrm{Cc}$

$$
\begin{array}{ll}
\mathrm{a}=15.184(3) \AA & \alpha=90^{\circ} . \\
\mathrm{b}=10.002(2) \AA & B=98.370(3)^{\circ} . \\
\mathrm{c}=8.856(1) \AA & \gamma=90^{\circ} .
\end{array}
$$

$1330.7(4) \AA^{3}$

4

$1.160 \mathrm{Mg} / \mathrm{m}^{3}$

$0.072 \mathrm{~mm}^{-1}$

504

$0.42 \times 0.05 \times 0.04 \mathrm{~mm}^{3}$

colorless needle

2.45 to $28.22^{\circ}$.

$-19<=\mathrm{h}<=19,-12<=\mathrm{k}<=13,-11<=\mathrm{l}<=11$

5596

$2853[\mathrm{R}($ int $)=0.028]$

$93.8 \%$

SADABS

0.837 and 0.983

Full-matrix least-squares on $\mathrm{F}^{2}$

$2853 / 2 / 234$ 
Goodness-of-fit on $\mathrm{F}^{2}$

Final $\mathrm{R}$ indices [I $>2 \operatorname{sigma}(\mathrm{I})]$

$\mathrm{R}$ indices (all data)

Largest diff. peak and hole
1.042

$\mathrm{R}_{1}=0.037, \mathrm{wR}_{2}=0.069$

$\mathrm{R}_{1}=0.047, \mathrm{wR}_{2}=0.072$

0.186 and -0.156 e. $\AA^{-3}$ 
Table S2. Atomic coordinates $\left(\mathrm{x} 10^{4}\right)$ and equivalent isotropic displacement parameters $\left(\AA^{2} \times 10^{3}\right)$ for compound 1.

\begin{tabular}{lrrrr}
\hline & $\mathrm{x}$ & $\mathrm{y}$ & $\mathrm{z}$ & $\mathrm{U}(\mathrm{eq})$ \\
\hline $\mathrm{N}(1)$ & $7388(1)$ & $1078(2)$ & $9871(2)$ & $18(1)$ \\
$\mathrm{N}(2)$ & $8452(1)$ & $2112(1)$ & $8873(2)$ & $21(1)$ \\
$\mathrm{N}(3)$ & $6147(1)$ & $-1114(1)$ & $7067(2)$ & $18(1)$ \\
$\mathrm{N}(4)$ & $5093(1)$ & $-1773(2)$ & $8387(2)$ & $19(1)$ \\
$\mathrm{C}(1)$ & $7796(1)$ & $2256(2)$ & $9705(2)$ & $18(1)$ \\
$\mathrm{C}(2)$ & $8458(1)$ & $764(2)$ & $8486(2)$ & $19(1)$ \\
$\mathrm{C}(3)$ & $7803(1)$ & $112(2)$ & $9098(2)$ & $17(1)$ \\
$\mathrm{C}(4)$ & $7512(1)$ & $-1326(2)$ & $9063(2)$ & $19(1)$ \\
$\mathrm{C}(5)$ & $6527(1)$ & $-1481(2)$ & $8544(2)$ & $18(1)$ \\
$\mathrm{C}(7)$ & $5283(1)$ & $-1312(2)$ & $7031(2)$ & $18(1)$ \\
$\mathrm{C}(6)$ & $5888(1)$ & $-1894(2)$ & $9364(2)$ & $19(1)$ \\
$\mathrm{C}(8)$ & $7531(1)$ & $3545(2)$ & $10383(2)$ & $24(1)$ \\
$\mathrm{C}(9)$ & $7294(2)$ & $4634(2)$ & $9204(3)$ & $40(1)$ \\
$\mathrm{C}(10)$ & $9133(1)$ & $211(2)$ & $7578(2)$ & $24(1)$ \\
$\mathrm{C}(11)$ & $4570(1)$ & $-1057(2)$ & $5697(2)$ & $23(1)$ \\
$\mathrm{C}(12)$ & $4822(2)$ & $-1588(2)$ & $4209(2)$ & $30(1)$ \\
$\mathrm{C}(13)$ & $5926(2)$ & $-2396(2)$ & $10965(2)$ & $27(1)$ \\
& & & & \\
\hline
\end{tabular}


Table S3. Crystal data and structure refinement for compound 2.

Identification code

$\mathrm{L}^{\mathrm{Me}, \mathrm{Me}}$

Empirical formula

$\mathrm{C}_{11} \mathrm{H}_{20} \mathrm{~N}_{4} \mathrm{O}_{2}$

Formula weight

240.31

Temperature

296(2) K

Wavelength

$0.71073 \AA$

Crystal system

monoclinic

Space group

Unit cell dimensions

$\mathrm{Cc}$

Unit cell dimensions

$\mathrm{a}=17.9264(19) \AA$

$\alpha=90^{\circ}$.

$\mathrm{b}=4.5526(5) \AA$

$\beta=105.623(2)^{\circ}$.

$\mathrm{c}=17.8364(19) \AA$

$\gamma=90^{\circ}$.

Volume

1401.9(3) $\AA^{3}$

Z

4

Density (calculated)

$1.139 \mathrm{Mg} / \mathrm{m}^{3}$

Absorption coefficient

$0.081 \mathrm{~mm}^{-1}$

$\mathrm{F}(000)$

520

Crystal size

$0.36 \times 0.28 \times 0.25 \mathrm{~mm}^{3}$

Crystal color (habit)

colorless block

Theta range for data collection

2.36 to $28.19^{\circ}$.

Index ranges

$-20<=\mathrm{h}<=22,-6<=\mathrm{k}<=6,-22<=\mathrm{l}<=23$

Reflections collected

5678

Independent reflections

$2962[\mathrm{R}($ int $)=0.015]$

Completeness to theta $=28.19^{\circ}$

$94.1 \%$

Refinement method

Full-matrix least-squares on $\mathrm{F}^{2}$

Data/restraints/parameters

$2962 / 2 / 160$

Goodness-of-fit on $\mathrm{F}^{2}$

1.055

Final $R$ indices $[\mathrm{I}>2 \operatorname{sigma}(\mathrm{I})]$

$\mathrm{R}_{1}=0.0422, \mathrm{wR}_{2}=0.0944$

$\mathrm{R}$ indices (all data)

$\mathrm{R}_{1}=0.0451, \mathrm{wR}_{2}=0.0962$

Largest diff. peak and hole

0.186 and -0.123 e. $\AA^{-3}$ 
Table S4. Atomic coordinates (x 104) and equivalent isotropic displacement parameters $\left(\AA^{2} \mathrm{x} 10^{3}\right)$ for compound 2.

\begin{tabular}{lrrrr}
\hline & $\mathrm{x}$ & $\mathrm{y}$ & $\mathrm{z}$ & $\mathrm{U}(\mathrm{eq})$ \\
\hline $\mathrm{C}(1)$ & $1316(1)$ & $3074(4)$ & $461(1)$ & $52(1)$ \\
$\mathrm{C}(2)$ & $1118(1)$ & $172(5)$ & $1355(1)$ & $55(1)$ \\
$\mathrm{C}(3)$ & $1882(1)$ & $96(4)$ & $1391(1)$ & $45(1)$ \\
$\mathrm{C}(4)$ & $2527(1)$ & $-1637(4)$ & $1917(1)$ & $51(1)$ \\
$\mathrm{C}(5)$ & $3016(1)$ & $47(4)$ & $2596(1)$ & $45(1)$ \\
$\mathrm{C}(6)$ & $3021(1)$ & $27(5)$ & $3357(1)$ & $51(1)$ \\
$\mathrm{C}(7)$ & $3936(1)$ & $2973(4)$ & $3234(1)$ & $51(1)$ \\
$\mathrm{C}(8)$ & $1181(2)$ & $5207(5)$ & $-199(1)$ & $68(1)$ \\
$\mathrm{C}(9)$ & $668(2)$ & $-1395(8)$ & $1826(2)$ & $84(1)$ \\
$\mathrm{C}(10)$ & $4591(1)$ & $5114(6)$ & $3412(1)$ & $66(1)$ \\
$\mathrm{C}(11)$ & $2532(2)$ & $-1577(7)$ & $3769(2)$ & $75(1)$ \\
$\mathrm{N}(1)$ & $1999(1)$ & $1966(4)$ & $823(1)$ & $47(1)$ \\
$\mathrm{N}(2)$ & $766(1)$ & $2067(4)$ & $762(1)$ & $56(1)$ \\
$\mathrm{N}(3)$ & $3599(1)$ & $1940(4)$ & $2518(1)$ & $47(1)$ \\
$\mathrm{N}(4)$ & $3612(1)$ & $1917(4)$ & $3750(1)$ & $54(1)$ \\
$\mathrm{O}(1)$ & $3587(1)$ & $2798(3)$ & $931(1)$ & $53(1)$ \\
$\mathrm{O}(2)$ & $4137(1)$ & $7787(3)$ & $368(1)$ & $52(1)$ \\
\hline & & & &
\end{tabular}


Table S5. Crystal data and structure refinement for compound $\mathbf{3}$.

Identification code

Empirical formula

Formula weight

Temperature

Wavelength

Crystal system

Space group

Unit cell dimensions

Volume

Z

Density (calculated)

Absorption coefficient

$\mathrm{F}(000)$

Crystal size

Crystal color (habit)

Theta range for data collection

Index ranges

Reflections collected

Independent reflections

Completeness to theta $=28.23^{\circ}$

Absorption correction

Refinement method

Data/restraints/parameters

Goodness-of-fit on $\mathrm{F}^{2}$

Final $\mathrm{R}$ indices [I $>2 \operatorname{sigma}(\mathrm{I})]$

$\mathrm{R}$ indices (all data)

Largest diff. peak and hole
$\mathrm{Co}\left(\mathrm{L}^{\mathrm{Et}, \mathrm{Me}}\right) \mathrm{Cl}_{2}$

$\mathrm{C}_{13} \mathrm{H}_{20} \mathrm{Cl}_{2} \mathrm{CoN}_{4}$

362.16

100(2) K

$0.71073 \AA$

Orthorhombic

$\mathrm{P} 2{ }_{1}{ }_{1} 2_{1}$

$$
\begin{array}{ll}
\mathrm{a}=8.0619(11) \AA & \alpha=90^{\circ} . \\
\mathrm{b}=14.0248(19) \AA & \beta=90^{\circ} . \\
\mathrm{c}=14.597(2) \AA & \gamma=90^{\circ} .
\end{array}
$$

$1650.4(4) \AA^{3}$

4

$1.458 \mathrm{Mg} / \mathrm{m}^{3}$

$1.359 \mathrm{~mm}^{-1}$

748

$0.36 \times 0.20 \times 0.17 \mathrm{~mm}^{3}$

bight-blue block

2.01 to $28.23^{\circ}$.

$-10<=\mathrm{h}<=10,-18<=\mathrm{k}<=18,-19<=\mathrm{l}<=19$

13794

$3789[\mathrm{R}(\mathrm{int})=0.047]$

$95.4 \%$

None

Full-matrix least-squares on $\mathrm{F}^{2}$

$3789 / 0 / 187$

1.094

$\mathrm{R}_{1}=0.056, \mathrm{wR}_{2}=0.136$

$\mathrm{R}_{1}=0.058, \mathrm{wR}_{2}=0.137$

2.283 and -0.405 e. $\AA^{-3}$ 
Table S6. Atomic coordinates $\left(\mathrm{x} 10^{4}\right)$ and equivalent isotropic displacement parameters $\left(\AA^{2} \times 10^{3}\right)$ for compound 3 .

\begin{tabular}{|c|c|c|c|c|}
\hline & $\mathrm{x}$ & $\mathrm{y}$ & $\mathrm{z}$ & $\mathrm{U}(\mathrm{eq})$ \\
\hline $\operatorname{Co}(1)$ & $2182(1)$ & 8803(1) & $1533(1)$ & $17(1)$ \\
\hline $\mathrm{Cl}(1)$ & $4547(2)$ & $9386(1)$ & $2172(1)$ & $26(1)$ \\
\hline $\mathrm{Cl}(2)$ & $-65(2)$ & $9400(1)$ & $2242(1)$ & $24(1)$ \\
\hline $\mathrm{N}(1)$ & $2323(5)$ & $7376(3)$ & $1490(3)$ & $18(1)$ \\
\hline $\mathrm{N}(2)$ & $3235(5)$ & $5922(3)$ & 1691(3) & $23(1)$ \\
\hline $\mathrm{N}(3)$ & $2299(6)$ & $8976(3)$ & $164(2)$ & $19(1)$ \\
\hline $\mathrm{N}(4)$ & $3170(5)$ & $9389(3)$ & $-1205(3)$ & $19(1)$ \\
\hline $\mathrm{C}(1)$ & $3036(7)$ & $6780(3)$ & $2078(3)$ & $22(1)$ \\
\hline $\mathrm{C}(2)$ & $2658(6)$ & $5964(3)$ & 794(3) & $20(1)$ \\
\hline $\mathrm{C}(3)$ & $2056(6)$ & $6862(3)$ & $676(3)$ & $17(1)$ \\
\hline $\mathrm{C}(4)$ & $1233(6)$ & $7315(4)$ & $-127(3)$ & $20(1)$ \\
\hline$C(5)$ & 1997(6) & $8222(3)$ & $-442(3)$ & $16(1)$ \\
\hline$C(6)$ & $2541(6)$ & $8467(3)$ & $-1293(3)$ & $19(1)$ \\
\hline$C(7)$ & $3011(7)$ & $9668(3)$ & $-329(3)$ & $21(1)$ \\
\hline$C(8)$ & $3423(7)$ & $6974(4)$ & $3060(4)$ & $29(1)$ \\
\hline$C(9)$ & $1867(8)$ & $6934(4)$ & $3643(4)$ & $36(2)$ \\
\hline$C(10)$ & $2798(10)$ & $5135(4)$ & $154(4)$ & $35(1)$ \\
\hline $\mathrm{C}(11)$ & $3468(8)$ & 10641(4) & $18(4)$ & $29(1)$ \\
\hline$C(12)$ & $2013(8)$ & $11227(4)$ & $317(4)$ & $35(1)$ \\
\hline$C(13)$ & $2617(8)$ & 7948(4) & $-2184(3)$ & $31(1)$ \\
\hline
\end{tabular}


Table S7. Crystal data and structure refinement for compound 4.

Identification code

Empirical formula

Formula weight

Temperature

Wavelength

Crystal system

Space group

Unit cell dimensions

Volume

Z

Density (calculated)

Absorption coefficient

$\mathrm{F}(000)$

Crystal size

Crystal color (habit)

Theta range for data collection

Index ranges

Reflections collected

Independent reflections

Completeness to theta $=24.85^{\circ}$

Absorption correction

Refinement method

Data/restraints/parameters

Goodness-of-fit on $\mathrm{F}^{2}$

Final $R$ indices $[\mathrm{I}>2 \operatorname{sigma}(\mathrm{I})]$

$\mathrm{R}$ indices (all data)

Largest diff. peak and hole

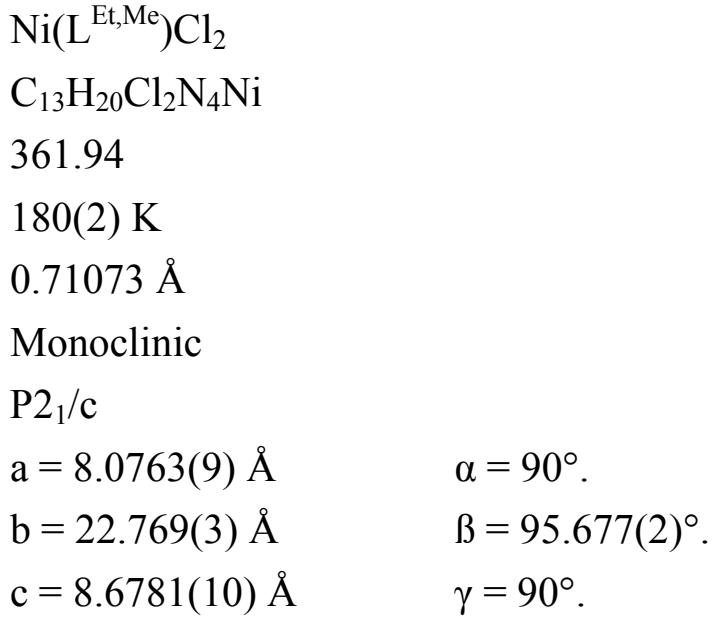

None

Full-matrix least-squares on $\mathrm{F}^{2}$

$2278 / 0 / 182$

1.03

$\mathrm{R}_{1}=0.033, \mathrm{wR}_{2}=0.089$

$\mathrm{R}_{1}=0.033, \mathrm{wR}_{2}=0.089$

0.749 and -0.646 e. $\AA^{-3}$ 
Table S8. Atomic coordinates $\left(\mathrm{x}^{1} 0^{4}\right)$ and equivalent isotropic displacement parameters $\left(\AA^{2} \times 10^{3}\right)$ for compound 4 .

\begin{tabular}{|c|c|c|c|c|}
\hline & $\mathrm{X}$ & $\mathrm{y}$ & $\mathrm{z}$ & $\mathrm{U}(\mathrm{eq})$ \\
\hline $\mathrm{Ni}(1)$ & $2107(1)$ & $3746(1)$ & $3307(1)$ & $16(1)$ \\
\hline $\mathrm{Cl}(1)$ & $4638(1)$ & $3658(1)$ & $3911(1)$ & $30(1)$ \\
\hline $\mathrm{Cl}(2)$ & $751(1)$ & $4157(1)$ & $1032(1)$ & $20(1)$ \\
\hline $\mathrm{N}(1)$ & $1116(3)$ & $4129(1)$ & $5129(3)$ & $16(1)$ \\
\hline $\mathrm{N}(2)$ & $416(3)$ & $4672(1)$ & $7140(3)$ & $17(1)$ \\
\hline $\mathrm{N}(3)$ & $1033(3)$ & 2989(1) & $3538(3)$ & $18(1)$ \\
\hline $\mathrm{N}(4)$ & $375(3)$ & $2079(1)$ & $3934(3)$ & $21(1)$ \\
\hline $\mathrm{C}(1)$ & $1569(3)$ & $4547(1)$ & $6212(4)$ & $16(1)$ \\
\hline$C(2)$ & $-843(3)$ & $4320(1)$ & $6656(4)$ & $18(1)$ \\
\hline $\mathrm{C}(3)$ & $-403(3)$ & $3984(1)$ & $5400(4)$ & $17(1)$ \\
\hline$C(4)$ & $-1297(3)$ & $3537(1)$ & $4344(4)$ & $20(1)$ \\
\hline$C(5)$ & $-426(3)$ & $2980(1)$ & $4125(4)$ & $18(1)$ \\
\hline$C(6)$ & $-845(4)$ & $2417(1)$ & $4379(4)$ & 19(1) \\
\hline $\mathrm{C}(7)$ & $1478(4)$ & $2432(1)$ & $3435(4)$ & $18(1)$ \\
\hline$C(8)$ & $3124(4)$ & $4841(1)$ & $6429(4)$ & $21(1)$ \\
\hline $\mathrm{C}(9)$ & $3561(4)$ & $5070(2)$ & $8175(4)$ & $30(1)$ \\
\hline$C(10)$ & $-2309(4)$ & $4349(2)$ & $7472(4)$ & $22(1)$ \\
\hline $\mathrm{C}(11)$ & $2942(4)$ & $2217(1)$ & $2815(4)$ & $23(1)$ \\
\hline$C(12)$ & $3602(4)$ & $1670(2)$ & $3672(5)$ & $30(1)$ \\
\hline$C(13)$ & $-2282(4)$ & $2156(2)$ & $4923(4)$ & $28(1)$ \\
\hline
\end{tabular}


Table S9. Crystal data and structure refinement for compound $\mathbf{5}$.

\begin{tabular}{|c|c|c|}
\hline Identification code & \multicolumn{2}{|l|}{$\mathrm{Cu}\left(\mathrm{L}^{\mathrm{Et}, \mathrm{Me}}\right) \mathrm{Cl}_{2}$} \\
\hline Empirical formula & \multicolumn{2}{|l|}{$\mathrm{C}_{26} \mathrm{H}_{40} \mathrm{Cl}_{4} \mathrm{Cu}_{2} \mathrm{~N}_{8}$} \\
\hline Formula weight & \multicolumn{2}{|l|}{733.54} \\
\hline Temperature & \multicolumn{2}{|l|}{ 293(2) K } \\
\hline Wavelength & \multicolumn{2}{|l|}{$0.71073 \AA$} \\
\hline Crystal system & \multicolumn{2}{|l|}{ Monoclinic } \\
\hline Space group & \multicolumn{2}{|l|}{$\mathrm{P} 2(1) / \mathrm{c}$} \\
\hline \multirow[t]{3}{*}{ Unit cell dimensions } & $a=14.4342(10) \AA$ & $\alpha=90^{\circ}$ \\
\hline & $\mathrm{b}=14.7860(10) \AA$ & $\beta=107.569(10)^{\circ}$. \\
\hline & $c=16.2327(10) \AA$ & $\gamma=90^{\circ}$ \\
\hline Volume & \multicolumn{2}{|l|}{$3302.8(4) \AA^{3}$} \\
\hline Z & \multicolumn{2}{|l|}{4} \\
\hline Density (calculated) & \multicolumn{2}{|l|}{$1.475 \mathrm{Mg} / \mathrm{m}^{3}$} \\
\hline Absorption coefficient & \multicolumn{2}{|l|}{$1.641 \mathrm{~mm}^{-1}$} \\
\hline $\mathrm{F}(000)$ & \multicolumn{2}{|l|}{1512} \\
\hline Crystal size & \multicolumn{2}{|c|}{$0.40 \times 0.33 \times 0.30 \mathrm{~mm}^{3}$} \\
\hline Crystal color & \multicolumn{2}{|l|}{ dark red block } \\
\hline Theta range for data collection & \multicolumn{2}{|l|}{2.02 to $25.0^{\circ}$} \\
\hline Index ranges & \multicolumn{2}{|c|}{$-17<=\mathrm{h}<=0,-17<=\mathrm{k}<=0,-18<=\mathrm{l}<=19$} \\
\hline Reflections collected & \multicolumn{2}{|l|}{6036} \\
\hline Independent reflections & \multicolumn{2}{|c|}{$5791[\mathrm{R}(\mathrm{int})=0.011]$} \\
\hline Completeness to theta $=25.00^{\circ}$ & \multicolumn{2}{|l|}{$99.7 \%$} \\
\hline Absorption correction & \multicolumn{2}{|l|}{ Empirical $\omega$-scan } \\
\hline Max. and min. transmission & \multicolumn{2}{|l|}{0.897 and 0.800} \\
\hline Refinement method & \multicolumn{2}{|c|}{ Full-matrix least-squares on $\mathrm{F}^{2}$} \\
\hline Data/restraints/parameters & \multicolumn{2}{|l|}{$5791 / 0 / 398$} \\
\hline Goodness-of-fit on $\mathrm{F}^{2}$ & \multicolumn{2}{|l|}{1.073} \\
\hline Final $R$ indices $[\mathrm{I}>2 \operatorname{sigma}(\mathrm{I})]$ & \multicolumn{2}{|c|}{$\mathrm{R}_{1}=0.052, \mathrm{wR}_{2}=0.116$} \\
\hline $\mathrm{R}$ indices (all data) & \multicolumn{2}{|c|}{$\mathrm{R}_{1}=0.081, \mathrm{wR}_{2}=0.128$} \\
\hline Extinction coefficient & \multicolumn{2}{|l|}{$0.0079(4)$} \\
\hline Largest diff. peak and hole & \multicolumn{2}{|l|}{0.72 and -0.52 e. $\AA^{-3}$} \\
\hline
\end{tabular}


Table S10. Atomic coordinates $\left(\times 10^{4}\right)$ and equivalent isotropic displacement parameters $\left(\AA^{2} \times 10^{3}\right)$ for compound 5 .

\begin{tabular}{|c|c|c|c|c|}
\hline & $\mathrm{x}$ & $\mathrm{y}$ & $\mathrm{z}$ & $\mathrm{U}(\mathrm{eq})$ \\
\hline $\mathrm{Cu}(1)$ & $3971(1)$ & 1851(1) & $5834(1)$ & $54(1)$ \\
\hline $\mathrm{Cl}(1)$ & 4499(1) & 2551(1) & $4862(1)$ & $88(1)$ \\
\hline $\mathrm{Cl}(2)$ & $4917(1)$ & $2459(1)$ & $7125(1)$ & $93(1)$ \\
\hline $\mathrm{N}(1)$ & $3899(3)$ & $562(2)$ & $6074(3)$ & $51(1)$ \\
\hline $\mathrm{N}(2)$ & $4270(3)$ & $-771(3)$ & $6631(3)$ & $61(1)$ \\
\hline $\mathrm{N}(3)$ & $2583(3)$ & $2062(2)$ & $5591(3)$ & $53(1)$ \\
\hline $\mathrm{N}(4)$ & $1284(3)$ & $2728(3)$ & $5682(3)$ & $63(1)$ \\
\hline$C(1)$ & $4627(4)$ & $20(4)$ & $6497(3)$ & $59(1)$ \\
\hline$C(2)$ & $3273(4)$ & $-750(3)$ & $6305(3)$ & $54(1)$ \\
\hline$C(3)$ & $3045(3)$ & $77(3)$ & $5948(3)$ & $45(1)$ \\
\hline$C(4)$ & $2066(3)$ & $430(3)$ & $5438(3)$ & $52(1)$ \\
\hline$C(5)$ & $1885(3)$ & $1406(3)$ & $5565(3)$ & $46(1)$ \\
\hline$C(6)$ & $1072(3)$ & 1813(3) & $5627(3)$ & $53(1)$ \\
\hline$C(7)$ & 2191(4) & $2852(3)$ & $5661(4)$ & $64(1)$ \\
\hline$C(8)$ & $5698(4)$ & $215(4)$ & $6764(4)$ & $78(2)$ \\
\hline$C(9)$ & $6088(5)$ & $233(6)$ & $6022(5)$ & $102(2)$ \\
\hline$C(10)$ & $2658(4)$ & $-1536(4)$ & 6394(4) & $82(2)$ \\
\hline $\mathrm{C}(11)$ & $2684(5)$ & $3749(4)$ & $5695(6)$ & $103(3)$ \\
\hline$C(12)$ & $2126(6)$ & $4535(4)$ & $5657(7)$ & $136(4)$ \\
\hline$C(13)$ & 107(4) & $1470(4)$ & $5622(4)$ & $75(2)$ \\
\hline $\mathrm{Cu}(2)$ & $1096(1)$ & $5323(1)$ & $3022(1)$ & $64(1)$ \\
\hline $\mathrm{Cl}(3)$ & $232(2)$ & $5736(1)$ & $1682(1)$ & $104(1)$ \\
\hline $\mathrm{Cl}(4)$ & $369(2)$ & $6094(2)$ & $3851(2)$ & $125(1)$ \\
\hline $\mathrm{N}(5)$ & $2501(3)$ & $5442(3)$ & $3426(3)$ & $72(1)$ \\
\hline $\mathrm{N}(6)$ & $3973(3)$ & $5957(3)$ & $3952(4)$ & $82(2)$ \\
\hline $\mathrm{N}(7)$ & $1150(3)$ & $4021(3)$ & $3071(3)$ & $68(1)$ \\
\hline $\mathrm{N}(8)$ & $797(3)$ & $2617(3)$ & $3192(4)$ & $81(2)$ \\
\hline$C(14)$ & $3029(5)$ & $6152(4)$ & $3788(6)$ & 103(3) \\
\hline$C(15)$ & $4069(3)$ & $5088(3)$ & $3688(3)$ & $54(1)$ \\
\hline$C(16)$ & $3150(3)$ & $4771(3)$ & $3368(3)$ & $48(1)$ \\
\hline$C(17)$ & $2827(4)$ & $3893(3)$ & $2928(3)$ & $54(1)$ \\
\hline
\end{tabular}




$\begin{array}{lcllr}\mathrm{C}(18) & 1940(3) & 3493(3) & 3064(3) & 48(1) \\ \mathrm{C}(19) & 1720(4) & 2615(3) & 3134(3) & 56(1) \\ \mathrm{C}(20) & 463(4) & 3464(4) & 3151(5) & 92(2) \\ \mathrm{C}(21 \mathrm{~A}) & 2640(11) & 7093(9) & 3684(13) & 73(4) \\ \mathrm{C}(21 \mathrm{~B}) & 2712(13) & 7001(12) & 4371(16) & 88(5) \\ \mathrm{C}(22 \mathrm{~A}) & 2757(17) & 7340(16) & 4683(14) & 114(8) \\ \mathrm{C}(22 \mathrm{~B}) & 2537(18) & 7653(16) & 3800(20) & 155(10) \\ \mathrm{C}(23) & 5028(4) & 4674(4) & 3775(4) & 72(2) \\ \mathrm{C}(24 \mathrm{~A}) & -553(12) & 3764(12) & 3004(19) & 82(6) \\ \mathrm{C}(24 \mathrm{~B}) & -470(16) & 3647(16) & 3627(19) & 105(7) \\ \mathrm{C}(25 \mathrm{~A}) & -983(14) & 3312(12) & 3646(15) & 99(6) \\ \mathrm{C}(25 \mathrm{~B}) & -1089(18) & 3859(18) & 2781(17) & 144(10) \\ \mathrm{C}(26) & 2274(4) & 1771(3) & 3143(4) & 75(2)\end{array}$


Table S11. Crystal data and structure refinement for compound 6.

\begin{tabular}{|c|c|c|}
\hline Identification code & \multicolumn{2}{|l|}{$\mathrm{Zn}\left(\mathrm{L}^{\mathrm{Et}, \mathrm{Me}}\right) \mathrm{Cl}_{2}$} \\
\hline Empirical formula & \multicolumn{2}{|l|}{$\mathrm{C}_{13} \mathrm{H}_{20} \mathrm{Cl}_{2} \mathrm{~N}_{4} \mathrm{Zn}$} \\
\hline Formula weight & \multicolumn{2}{|l|}{368.60} \\
\hline Temperature & \multicolumn{2}{|l|}{$296(2) \mathrm{K}$} \\
\hline Wavelength & \multicolumn{2}{|l|}{$0.71073 \AA$} \\
\hline Crystal system & \multicolumn{2}{|l|}{ orthorhombic } \\
\hline Space group & \multicolumn{2}{|l|}{$\mathrm{P} 2(1) 2(1) 2(1)$} \\
\hline \multirow[t]{3}{*}{ Unit cell dimensions } & $\mathrm{a}=14.477(3) \AA$ & $\alpha=90^{\circ}$ \\
\hline & $\mathrm{b}=14.477(3) \AA$ & $\beta=90^{\circ}$ \\
\hline & $\mathrm{c}=8.1266(18) \AA$ & $\gamma=90^{\circ}$ \\
\hline Volume & \multicolumn{2}{|l|}{$1703.2(7) \AA^{3}$} \\
\hline $\mathrm{Z}$ & \multicolumn{2}{|l|}{4} \\
\hline Density (calculated) & \multicolumn{2}{|l|}{$1.437 \mathrm{Mg} / \mathrm{m}^{3}$} \\
\hline Absorption coefficient & \multicolumn{2}{|l|}{$1.751 \mathrm{~mm}^{-1}$} \\
\hline $\mathrm{F}(000)$ & \multicolumn{2}{|l|}{760} \\
\hline Crystal size & \multicolumn{2}{|c|}{$0.19 \times 0.13 \times 0.09 \mathrm{~mm}^{3}$} \\
\hline Crystal color & \multicolumn{2}{|l|}{ colorless } \\
\hline Theta range for data collection & \multicolumn{2}{|l|}{2.81 to $28.31^{\circ}$. } \\
\hline Index ranges & \multicolumn{2}{|c|}{$-19<=\mathrm{h}<=17,-17<=\mathrm{k}<=18,-7<=\mathrm{l}<=10$} \\
\hline Reflections collected & \multicolumn{2}{|l|}{10534} \\
\hline Independent reflections & \multicolumn{2}{|c|}{$3906[\mathrm{R}(\mathrm{int})=0.0515]$} \\
\hline Completeness to theta $=28.31^{\circ}$ & \multicolumn{2}{|l|}{$94.7 \%$} \\
\hline Refinement method & \multicolumn{2}{|c|}{ Full-matrix least-squares on $\mathrm{F}^{2}$} \\
\hline Data/restraints/parameters & \multicolumn{2}{|c|}{$3906 / 0 / 182$} \\
\hline Goodness-of-fit on $\mathrm{F}^{2}$ & \multicolumn{2}{|l|}{1.010} \\
\hline Final $R$ indices $[\mathrm{I}>2 \operatorname{sigma}(\mathrm{I})]$ & \multicolumn{2}{|c|}{$\mathrm{R}_{1}=0.0749, \mathrm{wR}_{2}=0.1477$} \\
\hline $\mathrm{R}$ indices (all data) & \multicolumn{2}{|c|}{$\mathrm{R}_{1}=0.1064, \mathrm{wR}_{2}=0.1536$} \\
\hline Largest diff. peak and hole & \multicolumn{2}{|c|}{2.311 and -0.602 e..$\AA^{-3}$} \\
\hline
\end{tabular}


Table S12. Atomic coordinates $\left(\times 10^{4}\right)$ and equivalent isotropic displacement parameters $\left(\AA^{2} \times 10^{3}\right)$ for compound 6 .

\begin{tabular}{|c|c|c|c|c|}
\hline & $\mathrm{x}$ & $\mathrm{y}$ & $\mathrm{z}$ & $\mathrm{U}(\mathrm{eq})$ \\
\hline $\mathrm{Cl}(1)$ & $4385(2)$ & $7248(2)$ & $7(3)$ & $80(1)$ \\
\hline $\mathrm{Cl}(2)$ & $4366(2)$ & $7212(2)$ & $4587(3)$ & $90(1)$ \\
\hline $\mathrm{N}(1)$ & $2409(3)$ & $6548(4)$ & $2364(9)$ & $63(2)$ \\
\hline $\mathrm{N}(6)$ & $4366(5)$ & $3823(5)$ & $3167(9)$ & $69(2)$ \\
\hline $\mathrm{N}(7)$ & $3970(3)$ & $5191(4)$ & $2348(10)$ & $65(2)$ \\
\hline $\mathrm{N}(2)$ & $1002(4)$ & $6768(5)$ & 3192(9) & $76(2)$ \\
\hline$C(12)$ & $6156(7)$ & $5276(8)$ & $1968(18)$ & $127(5)$ \\
\hline $\mathrm{C}(3)$ & $1908(5)$ & $5729(5)$ & $2172(9)$ & $51(2)$ \\
\hline$C(2)$ & $1036(4)$ & $5869(5)$ & $2746(11)$ & $62(2)$ \\
\hline$C(5)$ & $3227(5)$ & $4593(5)$ & $2126(10)$ & $55(2)$ \\
\hline$C(6)$ & $3470(5)$ & $3744(5)$ & $2649(12)$ & $63(2)$ \\
\hline$C(7)$ & $4636(5)$ & $4704(6)$ & $3022(13)$ & $71(3)$ \\
\hline $\mathrm{C}(8)$ & $2042(7)$ & $8150(6)$ & $3390(17)$ & $110(4)$ \\
\hline $\mathrm{C}(1)$ & $1838(5)$ & $7148(5)$ & $3014(12)$ & $72(2)$ \\
\hline$C(11)$ & $5597(6)$ & $5033(7)$ & $3465(16)$ & $104(4)$ \\
\hline$C(13)$ & $2955(6)$ & $2846(5)$ & $2700(15)$ & $96(3)$ \\
\hline C(9) & 1839(9) & $8724(7)$ & $2040(20)$ & $154(6)$ \\
\hline$C(10)$ & $228(5)$ & $5219(7)$ & $2860(18)$ & $104(4)$ \\
\hline$C(4)$ & $2325(6)$ & $4902(6)$ & $1395(12)$ & 71(3) \\
\hline $\mathrm{Zn}(1)$ & $3802(1)$ & $6566(1)$ & $2245(1)$ & $63(1)$ \\
\hline
\end{tabular}


Table S13. Crystal data and structure refinement for compound 7.

Identification code

Empirical formula

Formula weight

Temperature

Wavelength

Crystal system

Space group

Unit cell dimensions

Volume

Z

Density (calculated)

Absorption coefficient

$\mathrm{F}(000)$

Crystal size

Crystal color (habit)

Theta range for data collection

Index ranges

Reflections collected

Independent reflections

Completeness to theta $=23.25^{\circ}$

Absorption correction

Refinement method

Data/restraints/parameters

Goodness-of-fit on $\mathrm{F}^{2}$

Final $R$ indices $[\mathrm{I}>2 \operatorname{sigma}(\mathrm{I})]$

$\mathrm{R}$ indices (all data)

Largest diff. peak and hole
$\mathrm{Cu}\left(\mathrm{L}^{\mathrm{Me}, \mathrm{Me}}\right) \mathrm{Cl}_{2}$

$\mathrm{C}_{11} \mathrm{H}_{16} \mathrm{Cl}_{2} \mathrm{CuN}_{4}$

338.72

293(2) K

$0.71073 \AA$

Triclinic

P-1

$\mathrm{a}=7.0082(6) \AA$

$\alpha=78.8990(10)^{\circ}$.

$\mathrm{b}=8.4633(7) \AA$

$\beta=76.1840(10)^{\circ}$.

$\mathrm{c}=12.2972(10) \AA$

$\gamma=79.8480(10)^{\circ}$.
2

$1.634 \mathrm{Mg} / \mathrm{m}^{3}$

$1.961 \mathrm{~mm}^{-1}$

346

$0.23 \times 0.15 \times 0.11 \mathrm{~mm}^{3}$

dark brown

1.73 to $23.25^{\circ}$.

$-6<=\mathrm{h}<=7,-9<=\mathrm{k}<=9,-13<=\mathrm{l}<=13$

4339

$1970[\mathrm{R}(\mathrm{int})=0.012]$

$99.6 \%$

\section{SADABS}

Full-matrix least-squares on $\mathrm{F}^{2}$

1970/0/168

1.036

$\mathrm{R}_{1}=0.023, \mathrm{wR}_{2}=0.059$

$\mathrm{R}_{1}=0.023, \mathrm{wR}_{2}=0.059$

0.423 and -0.316 e. $\AA^{-3}$ 
Table S14. Atomic coordinates $\left(\mathrm{x}_{10} 0^{4}\right.$ ) and equivalent isotropic displacement parameters $\left(\AA^{2} \times 10^{3}\right)$ for compound 7 .

\begin{tabular}{|c|c|c|c|c|}
\hline & $\mathrm{x}$ & $\mathrm{y}$ & $\mathrm{z}$ & $\mathrm{U}(\mathrm{eq})$ \\
\hline $\mathrm{Cu}(1)$ & $7264(1)$ & $-2047(1)$ & $7442(1)$ & $14(1)$ \\
\hline $\mathrm{Cl}(1)$ & $9778(1)$ & $-1665(1)$ & $8295(1)$ & $20(1)$ \\
\hline $\mathrm{Cl}(2)$ & $7786(1)$ & $-4646(1)$ & $7322(1)$ & $24(1)$ \\
\hline $\mathrm{N}(1)$ & $5155(3)$ & $-605(2)$ & $8218(2)$ & $15(1)$ \\
\hline $\mathrm{N}(2)$ & 2691(3) & $463(2)$ & $9415(2)$ & $16(1)$ \\
\hline $\mathrm{N}(3)$ & $7259(3)$ & $-693(2)$ & $5943(2)$ & $14(1)$ \\
\hline $\mathrm{N}(4)$ & $7719(3)$ & $373(2)$ & $4154(2)$ & $16(1)$ \\
\hline $\mathrm{C}(1)$ & $3813(3)$ & $-932(3)$ & $9167(2)$ & $15(1)$ \\
\hline$C(2)$ & $3327(3)$ & $1747(3)$ & $8602(2)$ & $16(1)$ \\
\hline$C(3)$ & $4865(3)$ & $1064(3)$ & $7859(2)$ & $16(1)$ \\
\hline$C(4)$ & $6302(3)$ & $1830(3)$ & $6884(2)$ & $17(1)$ \\
\hline$C(5)$ & $6836(3)$ & $999(3)$ & $5855(2)$ & $14(1)$ \\
\hline$C(6)$ & $7129(3)$ & $1669(3)$ & $4748(2)$ & $15(1)$ \\
\hline$C(7)$ & 7791(3) & $-1024(3)$ & $4886(2)$ & $15(1)$ \\
\hline$C(8)$ & $3552(4)$ & $-2568(3)$ & $9838(2)$ & $20(1)$ \\
\hline C(9) & $2392(4)$ & $3465(3)$ & $8647(2)$ & $21(1)$ \\
\hline$C(10)$ & $8366(3)$ & $-2644(3)$ & $4522(2)$ & $19(1)$ \\
\hline$C(11)$ & $6928(4)$ & $3380(3)$ & $4167(2)$ & $21(1)$ \\
\hline
\end{tabular}


Table S15. Crystal data and structure refinement for compound $\mathbf{8}$.

Identification code

Empirical formula

Formula weight

Temperature

Wavelength

Crystal system

Space group

Unit cell dimensions

Volume

Z

Density (calculated)

Absorption coefficient

$\mathrm{F}(000)$

Crystal size

Crystal color, habit

Theta range for data collection

Index ranges

Reflections collected

Independent reflections

Completeness to theta $=28.20^{\circ}$

Refinement method

Data/restraints/parameters

Goodness-of-fit on F2

Final R indices $[\mathrm{I}>2 \operatorname{sigma}(\mathrm{I})]$

$\mathrm{R}$ indices (all data)

Largest diff. peak and hole
$\left[\mathrm{Co}\left(\mathrm{L}^{\mathrm{Et}, \mathrm{Me}}\right)_{2}\right] \mathrm{Cl}_{2}$

$\mathrm{C}_{26} \mathrm{H}_{40} \mathrm{Cl}_{2} \mathrm{CoN}_{8}$

594.49

296(2) K

$0.71073 \AA$

monoclinic

$\mathrm{C} 2 / \mathrm{c}$

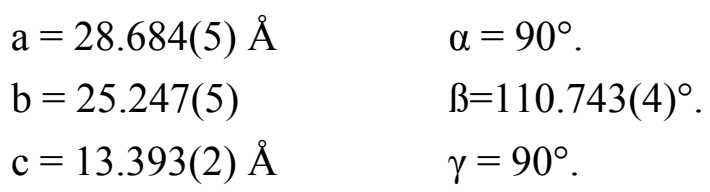

9070(3) ^3

12

$1.306 \mathrm{Mg} / \mathrm{m} 3$

$0.774 \mathrm{~mm}-1$

3756

$0.35 \times 0.23 \times 0.14 \mathrm{~mm} 3$

deep violet

1.11 to $28.20^{\circ}$.

$-38<=\mathrm{h}<=19,-31<=\mathrm{k}<=31,-16<=\mathrm{l}<=17$

27664

$10245[\mathrm{R}(\mathrm{int})=0.1092]$

$91.8 \%$

Full-matrix least-squares on F2

10245/0/509

1.012

$\mathrm{R}_{1}=0.0571, \mathrm{wR}_{2}=0.1183$

$\mathrm{R}_{1}=0.1794, \mathrm{wR}_{2}=0.1368$

0.844 and -0.397 e. $\AA \AA-3$ 
Table S16. Atomic coordinates (x 104) and equivalent isotropic displacement parameters $\left(\AA^{2} \times 10^{3}\right)$ for compound $\mathbf{1 0}$.

\begin{tabular}{|c|c|c|c|c|}
\hline & $\mathrm{x}$ & $\mathrm{y}$ & $\mathrm{z}$ & $\mathrm{U}(\mathrm{eq})$ \\
\hline $\operatorname{Co}(1)$ & $1666(1)$ & $1318(1)$ & $835(1)$ & $35(1)$ \\
\hline $\mathrm{N}(1)$ & 1197(3) & $1732(3)$ & $-399(6)$ & $38(2)$ \\
\hline $\mathrm{N}(2)$ & $706(3)$ & $2317(3)$ & $-1472(6)$ & $44(2)$ \\
\hline $\mathrm{N}(3)$ & $1975(3)$ & $915(3)$ & $-60(6)$ & $38(2)$ \\
\hline $\mathrm{N}(4)$ & $2480(3)$ & 491(3) & $-663(7)$ & $48(2)$ \\
\hline $\mathrm{N}(5)$ & $2134(3)$ & $1721(3)$ & $2087(6)$ & $36(2)$ \\
\hline $\mathrm{N}(6)$ & $2629(3)$ & $2312(3)$ & $3160(7)$ & $48(2)$ \\
\hline $\mathrm{N}(7)$ & $1362(3)$ & $910(3)$ & $1739(6)$ & $36(2)$ \\
\hline $\mathrm{N}(8)$ & $850(3)$ & $495(3)$ & $2351(6)$ & $43(2)$ \\
\hline $\mathrm{Cl}(1)$ & $3334(1)$ & $3269(1)$ & $4170(3)$ & $57(1)$ \\
\hline $\mathrm{Cl}(2)$ & 0 & $3268(1)$ & 7500 & $58(1)$ \\
\hline $\mathrm{C}(1)$ & $968(3)$ & $2202(4)$ & $-419(9)$ & $45(3)$ \\
\hline$C(2)$ & $756(3)$ & $1915(4)$ & $-2135(8)$ & $38(3)$ \\
\hline$C(3)$ & $1063(3)$ & $1561(4)$ & $-1443(8)$ & $37(3)$ \\
\hline$C(4)$ & $1222(3)$ & $1025(3)$ & $-1738(7)$ & $39(3)$ \\
\hline$C(5)$ & $1748(3)$ & $851(4)$ & $-1164(8)$ & $33(2)$ \\
\hline$C(6)$ & $2062(3)$ & $595(4)$ & $-1544(8)$ & $36(3)$ \\
\hline$C(7)$ & $2428(4)$ & $687(4)$ & $227(8)$ & $45(3)$ \\
\hline$C(8)$ & $969(4)$ & $2507(4)$ & $521(9)$ & $74(4)$ \\
\hline$C(9 A)$ & $822(7)$ & $3054(7)$ & $366(14)$ & $44(5)$ \\
\hline$C(9 B)$ & $1040(8)$ & $3155(9)$ & $155(18)$ & $77(8)$ \\
\hline$C(10)$ & $487(3)$ & 1901(4) & $-3321(7)$ & $56(3)$ \\
\hline$C(11)$ & $2795(3)$ & $644(5)$ & $1356(9)$ & $77(4)$ \\
\hline$C(12)$ & $3288(4)$ & $842(4)$ & $1375(8)$ & $93(4)$ \\
\hline$C(13)$ & 2011(3) & $435(4)$ & $-2657(7)$ & $50(3)$ \\
\hline$C(14)$ & $2365(3)$ & $2184(4)$ & $2148(8)$ & $40(3)$ \\
\hline$C(15)$ & $2568(3)$ & $1902(4)$ & $3786(8)$ & $38(3)$ \\
\hline$C(16)$ & $2258(3)$ & $1534(4)$ & $3155(7)$ & $38(3)$ \\
\hline$C(17)$ & $2126(3)$ & 1011(3) & $3450(8)$ & $47(3)$ \\
\hline$C(18)$ & 1601(3) & $856(4)$ & $2840(7)$ & $33(3)$ \\
\hline C(19) & $1286(4)$ & $596(4)$ & $3232(8)$ & $38(3)$ \\
\hline
\end{tabular}




\begin{tabular}{|c|c|c|c|c|}
\hline$C(20)$ & $908(3)$ & $687(4)$ & 1471(8) & $43(3)$ \\
\hline$C(21)$ & $2358(3)$ & $2528(4)$ & $1258(8)$ & $70(4)$ \\
\hline$C(22 A)$ & $2678(8)$ & $3005(10)$ & $1410(20)$ & $116(10)$ \\
\hline $\mathrm{C}(22 \mathrm{~B})$ & $2366(6)$ & $3125(6)$ & $1365(12)$ & $34(4)$ \\
\hline $\mathrm{C}(23)$ & $2838(3)$ & $1902(4)$ & $4974(7)$ & $57(3)$ \\
\hline $\mathrm{C}(24)$ & $530(3)$ & 643(4) & $370(8)$ & $54(3)$ \\
\hline$C(25)$ & $36(4)$ & $844(4)$ & $284(9)$ & $101(5)$ \\
\hline$C(26)$ & $1324(3)$ & $436(4)$ & $4322(7)$ & $47(3)$ \\
\hline $\operatorname{Co}(2)$ & 5000 & $1318(1)$ & 7500 & $35(1)$ \\
\hline $\mathrm{N}(9)$ & $4529(3)$ & $1736(3)$ & $6270(6)$ & $36(2)$ \\
\hline $\mathrm{N}(10)$ & $4042(3)$ & $2316(3)$ & $5188(6)$ & $40(2)$ \\
\hline $\mathrm{N}(11)$ & $4692(3)$ & 913(3) & $8389(6)$ & $37(2)$ \\
\hline $\mathrm{N}(12)$ & $4188(3)$ & 494(3) & $9018(6)$ & $44(2)$ \\
\hline $\mathrm{Cl}(3)$ & 0 & $9761(2)$ & 2500 & $49(1)$ \\
\hline $\mathrm{Cl}(4)$ & $3332(1)$ & $9760(1)$ & $9167(3)$ & $48(1)$ \\
\hline$C(27)$ & $4300(3)$ & $2200(4)$ & $6221(8)$ & $40(3)$ \\
\hline$C(28)$ & 4093(3) & $1917(4)$ & $4528(8)$ & $40(3)$ \\
\hline$C(29)$ & $4401(3)$ & $1562(4)$ & $5214(8)$ & $31(2)$ \\
\hline$C(30)$ & $4552(3)$ & $1028(4)$ & $4896(7)$ & $43(3)$ \\
\hline$C(31)$ & $4918(3)$ & $854(4)$ & $9487(8)$ & $34(2)$ \\
\hline$C(32)$ & $4611(4)$ & $593(4)$ & $9905(8)$ & $38(3)$ \\
\hline$C(33)$ & $4249(3)$ & $686(4)$ & $8153(7)$ & $43(3)$ \\
\hline$C(34)$ & $4308(4)$ & $2509(4)$ & $7174(8)$ & $64(3)$ \\
\hline$C(35 A)$ & $4354(8)$ & $3151(10)$ & $6940(20)$ & $67(8)$ \\
\hline$C(35 B)$ & 4101(9) & $3043(10)$ & $6960(20)$ & $78(8)$ \\
\hline$C(36)$ & $3825(3)$ & $1906(4)$ & $3348(7)$ & $59(3)$ \\
\hline$C(37)$ & $3845(3)$ & $666(4)$ & $7052(7)$ & $60(3)$ \\
\hline$C(38)$ & $3330(3)$ & $835(4)$ & $6966(8)$ & $89(4)$ \\
\hline C(39) & $4659(3)$ & $443(3)$ & $10983(7)$ & $49(3)$ \\
\hline
\end{tabular}


Table S17. Crystal data and structure refinement for compound 9.

Identification code

Empirical formula

Formula weight

Temperature

Wavelength

Crystal system

Space group

Unit cell dimensions

Volume

Z

Density (calculated)

Absorption coefficient

$\mathrm{F}(000)$

Crystal size

Theta range for data collection

Index ranges

Reflections collected

Independent reflections

Completeness to theta $=28.25^{\circ}$

Absorption correction

Refinement method

Data/restraints/parameters

Goodness-of-fit on $\mathrm{F}^{2}$

Final $\mathrm{R}$ indices $[\mathrm{I}>2 \operatorname{sigma}(\mathrm{I})]$

$\mathrm{R}$ indices (all data)

Largest diff. peak and hole
$\left[\mathrm{Zn}\left(\mathrm{L}^{\mathrm{Et}, \mathrm{Me}}\right)_{2}\right] \mathrm{Cl}_{2}$

$\mathrm{C}_{26} \mathrm{H}_{40} \mathrm{Cl}_{2} \mathrm{~N}_{8} \mathrm{O}_{8} \mathrm{Zn}$

728.93

293(2) K

$0.71073 \AA$

Triclinic

P-1

$\mathrm{a}=12.5583(15) \AA$

$\alpha=86.131(2)^{\circ}$.

$\mathrm{b}=14.3503(17) \AA$

$\beta=78.475(2)^{\circ}$.

$\mathrm{c}=18.531(2) \AA$

$\gamma=85.065(2)^{\circ}$.
$3255.8(7) \AA^{3}$

4

$1.487 \mathrm{Mg} / \mathrm{m}^{3}$

$0.978 \mathrm{~mm}^{-1}$

1520

$0.258 \times 0.236 \times 0.059 \mathrm{~mm}^{3}$

1.12 to $28.25^{\circ}$.

$-15<=\mathrm{h}<=16,-18<=\mathrm{k}<=18,-23<=\mathrm{l}<=24$

28850

$14592[\mathrm{R}($ int $)=0.0240]$

$90.6 \%$

None

Full-matrix least-squares on $\mathrm{F}^{2}$

14592/0/779

1.111

$\mathrm{R}_{1}=0.0764, \mathrm{wR}_{2}=0.1940$

$\mathrm{R}_{1}=0.0948, \mathrm{wR}_{2}=0.2030$

4.580 and -1.384 e. $\AA^{-3}$ 
Table S18. Atomic coordinates (x 104) and equivalent isotropic displacement parameters $\left(\AA^{2} \mathrm{x} 10^{3}\right)$ for compound 9.

\begin{tabular}{|c|c|c|c|c|}
\hline & $\mathrm{x}$ & $\mathrm{y}$ & $\mathrm{z}$ & $\mathrm{U}(\mathrm{eq})$ \\
\hline $\mathrm{Cl}(3)$ & $7782(1)$ & $2601(1)$ & $6136(1)$ & $23(1)$ \\
\hline $\mathrm{Cl}(4)$ & $2633(1)$ & $664(1)$ & $7252(1)$ & $24(1)$ \\
\hline $\mathrm{Cl}(5)$ & $8427(1)$ & $4703(1)$ & $2076(1)$ & $27(1)$ \\
\hline $\mathrm{N}(1)$ & $2576(4)$ & $3631(3)$ & $6517(3)$ & $22(1)$ \\
\hline $\mathrm{N}(2)$ & $2944(3)$ & $3225(3)$ & $5378(2)$ & $21(1)$ \\
\hline $\mathrm{N}(3)$ & $4075(3)$ & $1916(3)$ & $4264(2)$ & $21(1)$ \\
\hline $\mathrm{N}(4)$ & $5199(4)$ & 711(3) & $3928(3)$ & $24(1)$ \\
\hline $\mathrm{N}(5)$ & $2834(4)$ & $5279(3)$ & $3088(2)$ & $25(1)$ \\
\hline $\mathrm{N}(6)$ & $2760(3)$ & $3894(3)$ & $3644(2)$ & $22(1)$ \\
\hline $\mathrm{N}(7)$ & $1386(3)$ & $2383(3)$ & $4341(2)$ & $21(1)$ \\
\hline $\mathrm{N}(8)$ & $-254(4)$ & $1923(3)$ & $4680(2)$ & $22(1)$ \\
\hline $\mathrm{N}(9)$ & $1731(4)$ & $8402(3)$ & $-1882(3)$ & $24(1)$ \\
\hline $\mathrm{N}(10)$ & $1914(3)$ & $7657(3)$ & $-846(2)$ & $21(1)$ \\
\hline $\mathrm{N}(11)$ & $824(3)$ & $7519(3)$ & $740(2)$ & $22(1)$ \\
\hline $\mathrm{N}(12)$ & $-626(4)$ & $7711(3)$ & $1599(3)$ & $26(1)$ \\
\hline $\mathrm{N}(13)$ & $3234(3)$ & $6334(3)$ & $421(2)$ & $21(1)$ \\
\hline $\mathrm{N}(14)$ & $3845(4)$ & $4898(3)$ & $638(3)$ & $31(1)$ \\
\hline $\mathrm{N}(15)$ & $3245(3)$ & $8378(3)$ & $420(2)$ & $22(1)$ \\
\hline $\mathrm{N}(16)$ & $3807(4)$ & $9665(3)$ & $715(3)$ & $26(1)$ \\
\hline $\mathrm{O}(1)$ & $7006(3)$ & $2679(3)$ & $6827(2)$ & $32(1)$ \\
\hline $\mathrm{O}(2)$ & $7973(3)$ & $1627(3)$ & $5968(2)$ & $36(1)$ \\
\hline $\mathrm{O}(3)$ & $7338(4)$ & $3110(3)$ & $5561(2)$ & $39(1)$ \\
\hline $\mathrm{O}(4)$ & $8780(3)$ & $2966(3)$ & $6203(2)$ & $34(1)$ \\
\hline $\mathrm{O}(5)$ & $8855(4)$ & 4694(4) & $2740(3)$ & $51(1)$ \\
\hline $\mathrm{O}(6)$ & $7828(6)$ & $3883(5)$ & $2115(4)$ & $79(2)$ \\
\hline $\mathrm{O}(7)$ & $7670(5)$ & $5497(4)$ & $2052(3)$ & $72(2)$ \\
\hline $\mathrm{O}(8)$ & $9257(5)$ & $4668(4)$ & $1440(3)$ & $66(2)$ \\
\hline $\mathrm{O}(9)$ & $3759(3)$ & $806(3)$ & $6939(2)$ & $33(1)$ \\
\hline $\mathrm{O}(10)$ & $2488(3)$ & $529(3)$ & $8036(2)$ & $33(1)$ \\
\hline $\mathrm{O}(11)$ & $2340(3)$ & $-162(3)$ & $6946(2)$ & $28(1)$ \\
\hline $\mathrm{O}(12)$ & $1959(3)$ & $1471(3)$ & $7061(2)$ & $30(1)$ \\
\hline
\end{tabular}




\begin{tabular}{|c|c|c|c|c|}
\hline$C(1)$ & $-4(4)$ & $7198(4)$ & $-348(3)$ & $24(1)$ \\
\hline $\mathrm{C}(2)$ & $3830(4)$ & 2921(3) & $5712(3)$ & $19(1)$ \\
\hline$C(3)$ & 1991(4) & $3995(3)$ & $3185(3)$ & $22(1)$ \\
\hline$C(4)$ & 2194(4) & $3643(3)$ & $5892(3)$ & $22(1)$ \\
\hline$C(5)$ & $2445(4)$ & $8082(4)$ & $-1456(3)$ & $24(1)$ \\
\hline$C(6)$ & $728(4)$ & $1922(3)$ & $4868(3)$ & $21(1)$ \\
\hline$C(7)$ & $-244(4)$ & $2420(3)$ & $4015(3)$ & $20(1)$ \\
\hline$C(8)$ & $696(4)$ & $8179(3)$ & $-1544(3)$ & $23(1)$ \\
\hline$C(9)$ & $1301(4)$ & $3218(4)$ & $3097(3)$ & $23(1)$ \\
\hline$C(10)$ & $4824(4)$ & $1795(3)$ & $4730(3)$ & $22(1)$ \\
\hline $\mathrm{C}(11)$ & $3739(4)$ & $1107(4)$ & $3178(3)$ & $26(1)$ \\
\hline$C(12)$ & $1004(4)$ & $1477(4)$ & $5563(3)$ & $25(1)$ \\
\hline$C(13)$ & $4324(4)$ & $5440(4)$ & $1050(3)$ & $25(1)$ \\
\hline$C(14)$ & $3206(4)$ & $9302(3)$ & 298(3) & $22(1)$ \\
\hline$C(15)$ & $-1005(4)$ & $7548(3)$ & 973(3) & $24(1)$ \\
\hline$C(16)$ & $813(4)$ & $7708(3)$ & $-899(3)$ & 21(1) \\
\hline$C(17)$ & $6514(4)$ & $630(4)$ & $4788(3)$ & $26(1)$ \\
\hline$C(18)$ & $4221(4)$ & $3038(4)$ & $7030(3)$ & $26(1)$ \\
\hline$C(19)$ & $3911(4)$ & $8156(3)$ & 933(3) & $21(1)$ \\
\hline$C(20)$ & $780(4)$ & $2705(3)$ & $3803(3)$ & $21(1)$ \\
\hline $\mathrm{C}(21)$ & $4884(4)$ & $2488(4)$ & $5294(3)$ & $24(1)$ \\
\hline$C(22)$ & $5536(4)$ & $1047(3)$ & $4518(3)$ & $22(1)$ \\
\hline$C(23)$ & $3202(4)$ & $5444(3)$ & $268(3)$ & $25(1)$ \\
\hline$C(24)$ & $3604(4)$ & $3178(3)$ & $6419(3)$ & $21(1)$ \\
\hline$C(25)$ & $2038(4)$ & $4857(4)$ & $2835(3)$ & $25(1)$ \\
\hline$C(26)$ & $3949(4)$ & $6338(3)$ & 913(3) & $22(1)$ \\
\hline$C(27)$ & $-2184(4)$ & $7495(4)$ & $969(3)$ & $30(1)$ \\
\hline$C(28)$ & $1124(5)$ & $7866(4)$ & $2003(3)$ & $31(1)$ \\
\hline C(29) & $4322(4)$ & $1247(3)$ & $3785(3)$ & $22(1)$ \\
\hline$C(30)$ & $457(4)$ & $7691(3)$ & $1448(3)$ & $24(1)$ \\
\hline$C(31)$ & $-93(4)$ & $7430(3)$ & $437(3)$ & $22(1)$ \\
\hline$C(32)$ & $3247(4)$ & $4692(3)$ & $3574(3)$ & $23(1)$ \\
\hline C(33) & $4118(4)$ & $4906(4)$ & $3968(3)$ & $28(1)$ \\
\hline$C(34)$ & $1124(4)$ & $4115(4)$ & $5785(3)$ & $27(1)$ \\
\hline$C(35)$ & $-268(5)$ & $8423(4)$ & $-1895(3)$ & $31(1)$ \\
\hline$C(36)$ & $1433(5)$ & $5337(4)$ & $2286(3)$ & $33(1)$ \\
\hline
\end{tabular}




\begin{tabular}{|c|c|c|c|c|}
\hline$C(37)$ & $4254(4)$ & $8959(3)$ & 1127(3) & $23(1)$ \\
\hline$C(38)$ & $606(5)$ & $500(4)$ & $5748(3)$ & $33(1)$ \\
\hline C(39) & $3638(4)$ & $8138(4)$ & $-1669(3)$ & $30(1)$ \\
\hline$C(40)$ & $5228(4)$ & $4387(4)$ & $3682(3)$ & $33(1)$ \\
\hline$C(41)$ & $-1239(4)$ & $2538(4)$ & $3682(3)$ & $26(1)$ \\
\hline$C(42)$ & $4197(5)$ & $7196(4)$ & $1251(3)$ & $35(1)$ \\
\hline$C(43)$ & $2608(5)$ & $9880(4)$ & $-214(3)$ & $29(1)$ \\
\hline$C(44)$ & $2506(5)$ & $5100(4)$ & $-204(3)$ & $33(1)$ \\
\hline$C(45)$ & $4132(5)$ & $7488(4)$ & $-2289(3)$ & $35(1)$ \\
\hline$C(46)$ & $5061(5)$ & $5010(4)$ & $1545(3)$ & $33(1)$ \\
\hline$C(47)$ & $4934(5)$ & $9131(4)$ & $1668(3)$ & $35(1)$ \\
\hline$C(48)$ & $1409(5)$ & $10039(5)$ & $61(4)$ & $49(2)$ \\
\hline$C(49)$ & $2907(6)$ & $378(5)$ & $3363(4)$ & $44(2)$ \\
\hline$C(50)$ & $1215(5)$ & $5105(4)$ & $5458(4)$ & $39(1)$ \\
\hline$C(51)$ & $1434(6)$ & $4825(5)$ & $244(4)$ & $51(2)$ \\
\hline$C(52)$ & $1144(6)$ & $8903(4)$ & $2135(4)$ & $40(1)$ \\
\hline $\mathrm{Zn}(1)$ & $2809(1)$ & $2853(1)$ & 4393(1) & $20(1)$ \\
\hline $\mathrm{Zn}(2)$ & $2342(1)$ & $7446(1)$ & 131(1) & $20(1)$ \\
\hline $\mathrm{Cl}(1)$ & $3590(1)$ & $2288(1)$ & $941(1)$ & $27(1)$ \\
\hline $\mathrm{O}(13)$ & $4260(8)$ & $2897(7)$ & $529(5)$ & $123(3)$ \\
\hline $\mathrm{O}(14)$ & $2680(8)$ & $1930(7)$ & $750(5)$ & 117(3) \\
\hline $\mathrm{O}(15)$ & $2710(20)$ & $2870(20)$ & $1109(15)$ & $366(12)$ \\
\hline $\mathrm{O}(16)$ & $4283(8)$ & $1474(7)$ & $1065(6)$ & $132(3)$ \\
\hline
\end{tabular}


Table S19. Crystal data and structure refinement for compound $\mathbf{1 0 .}$

\begin{tabular}{|c|c|c|}
\hline Identification code & \multicolumn{2}{|l|}{$\left[\mathrm{Ni}\left(\mathrm{L}^{\mathrm{Et}, \mathrm{Me}}\right)_{2}\right] \mathrm{Cl}_{2}$} \\
\hline Empirical formula & \multicolumn{2}{|l|}{$\mathrm{C}_{26} \mathrm{H}_{39} \mathrm{Cl}_{2} \mathrm{~N}_{8} \mathrm{NiO}_{2}$} \\
\hline Formula weight & \multicolumn{2}{|l|}{617.26} \\
\hline Temperature & \multicolumn{2}{|l|}{$296(2) \mathrm{K}$} \\
\hline Wavelength & \multicolumn{2}{|l|}{$0.71073 \AA$} \\
\hline Crystal system & \multicolumn{2}{|l|}{ Triclinic } \\
\hline Space group & \multicolumn{2}{|l|}{$\mathrm{P}-1$} \\
\hline \multirow[t]{3}{*}{ Unit cell dimensions } & $\mathrm{a}=11.0683(13) \AA$ & $\alpha=102.790(2)^{\circ}$. \\
\hline & $\mathrm{b}=14.2200(16) \AA$ & $\beta=107.434(2)^{\circ}$. \\
\hline & $\mathrm{c}=10.7852(13) \AA$ & $\gamma=84.570(2)^{\circ}$ \\
\hline Volume & \multicolumn{2}{|l|}{$1578.6(3) \AA^{3}$} \\
\hline $\mathrm{Z}$ & \multicolumn{2}{|l|}{2} \\
\hline Density (calculated) & \multicolumn{2}{|l|}{$1.299 \mathrm{Mg} / \mathrm{m}^{3}$} \\
\hline Absorption coefficient & \multicolumn{2}{|l|}{$0.818 \mathrm{~mm}^{-1}$} \\
\hline $\mathrm{F}(000)$ & \multicolumn{2}{|l|}{650} \\
\hline Crystal size & \multicolumn{2}{|c|}{$0.43 \times 0.27 \times 0.20 \mathrm{~mm}^{3}$} \\
\hline Crystal color (habit) & \multicolumn{2}{|l|}{ yellow prism } \\
\hline Theta range for data collection & \multicolumn{2}{|l|}{1.93 to $28.24^{\circ}$. } \\
\hline Index ranges & \multicolumn{2}{|c|}{$-6<=\mathrm{h}<=14,-18<=\mathrm{k}<=17,-14<=\mathrm{k}<=14$} \\
\hline Reflections collected & \multicolumn{2}{|l|}{8087} \\
\hline Independent reflections & \multicolumn{2}{|c|}{$6401[\mathrm{R}($ int $)=0.0352]$} \\
\hline Completeness to theta $=28.24^{\circ}$ & \multicolumn{2}{|l|}{$82.0 \%$} \\
\hline Absorption correction & \multicolumn{2}{|l|}{ SADABS } \\
\hline Max. and min. transmission & \multicolumn{2}{|l|}{0.753 and 0.996} \\
\hline Refinement method & \multicolumn{2}{|c|}{ Full-matrix least-squares on $\mathrm{F}^{2}$} \\
\hline Data/restraints/parameters & \multicolumn{2}{|l|}{$6401 / 4 / 389$} \\
\hline Goodness-of-fit on $\mathrm{F}^{2}$ & \multicolumn{2}{|l|}{1.043} \\
\hline Final $R$ indices $[\mathrm{I}>2 \operatorname{sigma}(\mathrm{I})]$ & \multicolumn{2}{|c|}{$\mathrm{R}_{1}=0.046, \mathrm{wR}_{2}=0.123$} \\
\hline $\mathrm{R}$ indices (all data) & \multicolumn{2}{|c|}{$\mathrm{R}_{1}=0.055, \mathrm{wR}_{2}=0.127$} \\
\hline Largest diff. peak and hole & \multicolumn{2}{|c|}{0.811 and -0.303 e..$\AA^{-3}$} \\
\hline
\end{tabular}


Table S20. Atomic coordinates (x 104) and equivalent isotropic displacement parameters $\left(\AA^{2} \times 10^{3}\right)$ for compound $\mathbf{1 0}$.

\begin{tabular}{|c|c|c|c|c|}
\hline & $\mathrm{x}$ & $\mathrm{y}$ & $\mathrm{z}$ & $\mathrm{U}(\mathrm{eq})$ \\
\hline $\mathrm{Ni}(1)$ & 0 & 5000 & 10000 & $23(1)$ \\
\hline $\mathrm{Ni}(2)$ & 5000 & 0 & 0 & $23(1)$ \\
\hline $\mathrm{N}(1)$ & $5723(2)$ & $-263(2)$ & $1716(2)$ & $25(1)$ \\
\hline $\mathrm{N}(2)$ & $6808(3)$ & $-304(2)$ & $3748(2)$ & $31(1)$ \\
\hline $\mathrm{N}(3)$ & $5376(2)$ & $1326(2)$ & $567(2)$ & $26(1)$ \\
\hline $\mathrm{N}(4)$ & $5464(3)$ & $2855(2)$ & $1466(3)$ & $32(1)$ \\
\hline $\mathrm{N}(5)$ & $810(2)$ & $4921(2)$ & $8658(2)$ & $26(1)$ \\
\hline $\mathrm{N}(6)$ & 1909(3) & $4573(2)$ & $7243(3)$ & $35(1)$ \\
\hline $\mathrm{N}(7)$ & $-339(2)$ & $3668(2)$ & $9509(2)$ & $26(1)$ \\
\hline $\mathrm{N}(8)$ & $-813(3)$ & $2178(2)$ & $8549(3)$ & $33(1)$ \\
\hline$C(1)$ & $6802(3)$ & $-7(2)$ & $2647(3)$ & $28(1)$ \\
\hline$C(2)$ & $5709(3)$ & $-776(2)$ & $3519(3)$ & $29(1)$ \\
\hline$C(3)$ & $5038(3)$ & $-751(2)$ & $2254(3)$ & $26(1)$ \\
\hline$C(4)$ & $7889(3)$ & $471(3)$ & $2525(3)$ & $39(1)$ \\
\hline$C(5)$ & $8247(4)$ & $1398(3)$ & $3552(5)$ & $71(1)$ \\
\hline$C(6)$ & $5438(4)$ & $-1212(2)$ & $4543(3)$ & $41(1)$ \\
\hline$C(7)$ & $3841(3)$ & $-1230(2)$ & 1389(3) & $30(1)$ \\
\hline$C(8)$ & $5120(3)$ & 1994(2) & $1531(3)$ & $28(1)$ \\
\hline$C(9)$ & $5959(3)$ & $2746(2)$ & 411(3) & $31(1)$ \\
\hline$C(10)$ & $5901(3)$ & $1793(2)$ & $-144(3)$ & $27(1)$ \\
\hline$C(11)$ & $4450(3)$ & $1856(2)$ & 2489(3) & $35(1)$ \\
\hline$C(12)$ & $3066(4)$ & $1657(4)$ & $1822(4)$ & $63(1)$ \\
\hline$C(13)$ & $6383(4)$ & $3576(2)$ & $26(4)$ & $45(1)$ \\
\hline$C(14)$ & $-813(3)$ & $3078(2)$ & $8345(3)$ & $30(1)$ \\
\hline$C(15)$ & $-330(3)$ & $2181(2)$ & $9886(3)$ & $30(1)$ \\
\hline$C(16)$ & $-40(3)$ & $3110(2)$ & 10481(3) & $26(1)$ \\
\hline$C(17)$ & $-1334(3)$ & $3340(3)$ & $7010(3)$ & $40(1)$ \\
\hline$C(18 A)$ & $-2731(7)$ & $3039(6)$ & $6323(7)$ & $42(2)$ \\
\hline $\mathrm{C}(18 \mathrm{~B})$ & $-2731(12)$ & $3540(10)$ & $6658(13)$ & $94(4)$ \\
\hline$C(19)$ & $-217(3)$ & 1291(2) & $10431(4)$ & $43(1)$ \\
\hline$C(20)$ & $1688(3)$ & $4321(2)$ & $8291(3)$ & $31(1)$ \\
\hline
\end{tabular}




$\begin{array}{lllll}\mathrm{C}(21) & 479(3) & 5583(2) & 7828(3) & 27(1) \\ \mathrm{C}(22) & 1162(3) & 5371(2) & 6944(3) & 32(1) \\ \mathrm{C}(23) & 2428(4) & 3542(3) & 8968(4) & 45(1) \\ \mathrm{C}(24 \mathrm{~A}) & 2290(9) & 2520(6) & 8051(8) & 48(2) \\ \mathrm{C}(24 \mathrm{~B}) & 2750(11) & 2669(8) & 8057(11) & 66(3) \\ \mathrm{C}(25) & -421(3) & 6404(2) & 8087(3) & 30(1) \\ \mathrm{C}(26) & 1230(4) & 5852(3) & 5869(3) & 45(1) \\ \mathrm{Cl}(1) & 8497(1) & 148(1) & 6704(1) & 45(1) \\ \mathrm{Cl}(2) & 3514(1) & 3804(1) & 5207(1) & 67(1) \\ \mathrm{O}(1) & 4770(5) & 4428(2) & 3154(4) & 61(1) \\ \mathrm{O}(2) & 1217(4) & 2265(3) & 4409(5) & 59(1) \\ \end{array}$


Table S21. Crystal data and structure refinement for compound 13.

Identification code

$\left[\mathrm{Cu}\left(\mathrm{L}^{\mathrm{Et}, \mathrm{Me}}\right)_{2} \mathrm{Cl}\right] \mathrm{Cl}$

Empirical formula

Formula weight

$\mathrm{C}_{26} \mathrm{H}_{41} \mathrm{Cl}_{2} \mathrm{CuN}_{8} \cdot \mathrm{CH}_{3} \mathrm{OH}$

Temperature

631.14

Wavelength

100(2) K

Crystal system

$0.71073 \AA$

Space group

Unit cell dimensions

Monoclinic

$\mathrm{P} 21 / \mathrm{c}$

Volume

$\mathrm{a}=9.4891(7) \AA$

$\alpha=90^{\circ}$

$\mathrm{b}=15.5874(11) \AA$

$\beta=96.916(1)^{\circ}$

$\mathrm{c}=21.5318(15) \AA$

$\gamma=90^{\circ}$

Z

3161.6(4) $\AA^{3}$

Density (calculated)

4

Absorption coefficient

$1.326 \mathrm{Mg} / \mathrm{m}^{3}$

$0.894 \mathrm{~mm}^{-1}$

$\mathrm{F}(000)$

1332

Crystal size

$0.04 \times 0.08 \times 0.33 \mathrm{~mm}^{3}$

Crystal color, habit

green plate

Theta range for data collection

1.62 to $28.26^{\circ}$.

Index ranges

$-12<=\mathrm{h}<=12,-20<=\mathrm{k}<=20,-28<=\mathrm{l}<=27$

Reflections collected

27461

Independent reflections

$7365[\mathrm{R}($ int $)=0.033]$

Completeness to theta $=28.26^{\circ}$

Absorption correction

$93.9 \%$

Max. and min. transmission

SADABS

Refinement method

0.889 and 0.992

Full-matrix least-squares on $\mathrm{F}^{2}$

Data/restraints/parameters

$7365 / 0 / 418$

Goodness-of-fit on $\mathrm{F}^{2}$

1.05

Final $\mathrm{R}$ indices $[\mathrm{I}>2 \operatorname{sigma}(\mathrm{I})]$

$\mathrm{R}_{1}=0.036, \mathrm{wR}_{2}=0.093$

$\mathrm{R}$ indices (all data)

$\mathrm{R}_{1}=0.051, \mathrm{wR}_{2}=0.096$

Largest diff. peak and hole

0.706 and -0.346 e. $\AA^{-3}$ 
Table S22. Atomic coordinates (x 104) and equivalent isotropic displacement parameters $\left(\AA^{2} \times 10^{3}\right)$ for compound 13.

\begin{tabular}{|c|c|c|c|c|}
\hline & $\mathrm{x}$ & $\mathrm{y}$ & $\mathrm{z}$ & $\mathrm{U}(\mathrm{eq})$ \\
\hline $\mathrm{Cu}(1)$ & $2397(1)$ & $8474(1)$ & $7469(1)$ & $12(1)$ \\
\hline $\mathrm{Cl}(1)$ & $2632(1)$ & $6964(1)$ & $7348(1)$ & $29(1)$ \\
\hline $\mathrm{N}(1)$ & $1001(2)$ & $9386(1)$ & $7739(1)$ & $16(1)$ \\
\hline $\mathrm{N}(2)$ & $-252(2)$ & $10545(1)$ & $7839(1)$ & $21(1)$ \\
\hline $\mathrm{N}(3)$ & $3186(2)$ & $8323(1)$ & $8355(1)$ & $14(1)$ \\
\hline $\mathrm{N}(4)$ & $4582(2)$ & $8031(1)$ & $9212(1)$ & $19(1)$ \\
\hline $\mathrm{N}(5)$ & $3958(2)$ & $9363(1)$ & $7220(1)$ & $17(1)$ \\
\hline $\mathrm{N}(6)$ & $5215(2)$ & $10522(1)$ & $7120(1)$ & $23(1)$ \\
\hline $\mathrm{N}(7)$ & $1499(2)$ & $8460(1)$ & $6592(1)$ & $14(1)$ \\
\hline $\mathrm{N}(8)$ & $-70(2)$ & 8444(1) & $5764(1)$ & $22(1)$ \\
\hline $\mathrm{C}(1)$ & $511(2)$ & 10104(1) & $7456(1)$ & $19(1)$ \\
\hline $\mathrm{C}(2)$ & $-271(2)$ & $10095(1)$ & $8389(1)$ & $20(1)$ \\
\hline$C(3)$ & $520(2)$ & 9379(1) & $8325(1)$ & $16(1)$ \\
\hline$C(4)$ & $873(2)$ & $8649(1)$ & $8767(1)$ & $17(1)$ \\
\hline$C(5)$ & $2426(2)$ & $8432(1)$ & $8864(1)$ & $15(1)$ \\
\hline$C(6)$ & $3288(2)$ & $8256(1)$ & 9401(1) & $19(1)$ \\
\hline$C(7)$ & $4482(2)$ & $8070(1)$ & $8584(1)$ & $16(1)$ \\
\hline$C(8)$ & $758(2)$ & $10417(1)$ & $6819(1)$ & $27(1)$ \\
\hline $\mathrm{C}(9)$ & $727(3)$ & 11379(1) & $6749(1)$ & $38(1)$ \\
\hline$C(10)$ & $-1036(2)$ & $10417(1)$ & $8907(1)$ & $29(1)$ \\
\hline$C(11)$ & $5684(2)$ & $7842(1)$ & $8224(1)$ & $20(1)$ \\
\hline$C(12)$ & $6974(2)$ & $8423(1)$ & $8358(1)$ & $26(1)$ \\
\hline$C(13)$ & $3057(2)$ & $8279(2)$ & $10073(1)$ & $29(1)$ \\
\hline$C(14)$ & $4537(2)$ & $10048(1)$ & $7516(1)$ & $20(1)$ \\
\hline$C(15)$ & $5080(2)$ & $10134(1)$ & $6543(1)$ & $22(1)$ \\
\hline$C(16)$ & $4292(2)$ & $9421(1)$ & $6608(1)$ & $18(1)$ \\
\hline$C(17)$ & $3763(2)$ & $8757(1)$ & $6135(1)$ & $21(1)$ \\
\hline$C(18)$ & $2180(2)$ & $8647(1)$ & $6070(1)$ & $17(1)$ \\
\hline$C(19)$ & $1207(2)$ & $8648(1)$ & $5553(1)$ & $22(1)$ \\
\hline$C(20)$ & $143(2)$ & $8328(1)$ & $6387(1)$ & $16(1)$ \\
\hline$C(21)$ & $4442(2)$ & $10319(1)$ & $8178(1)$ & $27(1)$ \\
\hline
\end{tabular}




$\begin{array}{lrrrr}\mathrm{C}(22) & 3913(3) & 11220(2) & 8235(1) & 48(1) \\ \mathrm{C}(23) & 5736(2) & 10499(2) & 6005(1) & 34(1) \\ \mathrm{C}(24) & 1321(3) & 8818(2) & 4879(1) & 39(1) \\ \mathrm{C}(25) & -983(2) & 8035(1) & 6766(1) & 23(1) \\ \mathrm{C}(26) & -2291(2) & 8599(2) & 6700(1) & 34(1) \\ \mathrm{Cl}(2) & 7059(1) & 6942(1) & 9924(1) & 47(1) \\ \mathrm{C}(30) & 7666(4) & 9242(2) & 232(2) & 68(1) \\ \mathrm{O}(30) & 8636(2) & 8704(1) & -27(1) & 55(1) \\ \end{array}$


Table S23. Crystal data and structure refinement for compound $\mathbf{1 4 .}$

Identification code

$\left[\mathrm{Cu}\left(\mathrm{L}^{\mathrm{Et}, \mathrm{Me}}\right)_{2} \mathrm{ClO}_{4}\right] \mathrm{ClO}_{4}$

Empirical formula

$\mathrm{C}_{26} \mathrm{H}_{40} \mathrm{~N}_{8} \mathrm{Cu} \bullet 2 \mathrm{ClO}_{4}$

Formula weight

727.10

Temperature

$100(2) \mathrm{K}$

Wavelength

$0.71073 \AA$

Crystal system

Monoclinic

Space group

Unit cell dimensions

$\mathrm{P} 2{ }_{1} / \mathrm{c}$

$\mathrm{a}=19.977(3) \AA \quad \alpha=90^{\circ}$.

$\mathrm{b}=8.3943(12) \AA$

$\beta=104.187(2)^{\circ}$.

$\mathrm{c}=19.867(3) \AA$

$\gamma=90^{\circ}$.

Volume

$3229.8(8) \AA^{3}$

Z

4

Density (calculated)

$1.495 \mathrm{Mg} / \mathrm{m}^{3}$

Absorption coefficient

$0.901 \mathrm{~mm}^{-1}$

$\mathrm{F}(000)$

1516

Crystal size

$0.15 \times 0.06 \times 0.02 \mathrm{~mm}^{3}$

Crystal color, habit

red-brown needle

Theta range for data collection

2.10 to $27.12^{\circ}$.

Index ranges

$-25<=\mathrm{h}<=25,-10<=\mathrm{k}<=10,-25<=\mathrm{l}<=25$

Reflections collected

24533

Independent reflections

$6598[\mathrm{R}($ int $)=0.099]$

Completeness to theta $=27.12^{\circ}$

Absorption correction

$92.3 \%$

Max. and min. transmission

SADABS

Refinement method

0.817 and 0.991

Full-matrix least-squares on $\mathrm{F}^{2}$

Data/restraints/parameters

$6598 / 0 / 415$

Goodness-of-fit on $\mathrm{F}^{2}$

1.06

Final $R$ indices $[\mathrm{I}>2 \operatorname{sigma}(\mathrm{I})]$

$\mathrm{R}_{1}=0.056, \mathrm{wR}_{2}=0.108$

$\mathrm{R}$ indices (all data)

$\mathrm{R}_{1}=0.122, \mathrm{wR}_{2}=0.123$

Largest diff. peak and hole

1.05 and -0.65 e. $\AA^{-3}$ 
Table S24. Atomic coordinates (x 104) and equivalent isotropic displacement parameters $\left(\AA^{2} \times 10^{3}\right)$ for compound 14.

\begin{tabular}{|c|c|c|c|c|}
\hline & $\mathrm{X}$ & $\mathrm{y}$ & $\mathrm{z}$ & $\mathrm{U}(\mathrm{eq})$ \\
\hline $\mathrm{Cu}(1)$ & $2002(1)$ & $7962(1)$ & $2923(1)$ & $18(1)$ \\
\hline $\mathrm{N}(1)$ & $2675(2)$ & $9713(4)$ & $2772(2)$ & 21(1) \\
\hline $\mathrm{N}(2)$ & $3429(2)$ & $10947(4)$ & $2330(2)$ & $28(1)$ \\
\hline $\mathrm{N}(3)$ & $2654(2)$ & $7233(4)$ & $3762(2)$ & $16(1)$ \\
\hline $\mathrm{N}(4)$ & $3362(2)$ & $5738(4)$ & $4508(2)$ & $20(1)$ \\
\hline $\mathrm{N}(5)$ & $2179(2)$ & $6141(4)$ & $2283(2)$ & $19(1)$ \\
\hline $\mathrm{N}(6)$ & $2652(2)$ & $4794(4)$ & $1576(2)$ & $23(1)$ \\
\hline $\mathrm{N}(7)$ & $1206(2)$ & $8744(4)$ & $2222(2)$ & $16(1)$ \\
\hline $\mathrm{N}(8)$ & $479(2)$ & $10240(4)$ & 1492(2) & $19(1)$ \\
\hline $\mathrm{C}(1)$ & $2831(2)$ & $10107(5)$ & $2180(2)$ & $26(1)$ \\
\hline $\mathrm{C}(2)$ & $3671(2)$ & $11071(5)$ & $3047(2)$ & $22(1)$ \\
\hline$C(3)$ & $3194(2)$ & $10299(5)$ & $3310(2)$ & $19(1)$ \\
\hline C(4) & $3182(2)$ & $9942(5)$ & $4045(2)$ & $21(1)$ \\
\hline$C(5)$ & $3173(2)$ & $8187(5)$ & $4169(2)$ & $18(1)$ \\
\hline$C(6)$ & $3620(2)$ & $7277(5)$ & $4633(2)$ & $19(1)$ \\
\hline$C(7)$ & $2783(2)$ & $5746(5)$ & $3994(2)$ & $18(1)$ \\
\hline $\mathrm{C}(8)$ & $2431(2)$ & $9801(6)$ & $1456(2)$ & $35(1)$ \\
\hline $\mathrm{C}(9)$ & $2819(3)$ & $8962(6)$ & $1009(2)$ & $42(1)$ \\
\hline$C(10)$ & $4336(2)$ & $11874(5)$ & $3383(2)$ & $32(1)$ \\
\hline $\mathrm{C}(11)$ & $2370(2)$ & $4290(5)$ & $3747(2)$ & $22(1)$ \\
\hline$C(12)$ & $2120(2)$ & $3478(5)$ & $4330(2)$ & $26(1)$ \\
\hline$C(13)$ & $4253(2)$ & $7621(5)$ & $5177(2)$ & $25(1)$ \\
\hline$C(14)$ & $2779(2)$ & $5627(5)$ & $2174(2)$ & $20(1)$ \\
\hline$C(15)$ & $1955(2)$ & $4769(5)$ & $1282(2)$ & $21(1)$ \\
\hline$C(16)$ & $1661(2)$ & $5595(5)$ & $1722(2)$ & $21(1)$ \\
\hline$C(17)$ & $935(2)$ & $6027(5)$ & $1681(2)$ & $25(1)$ \\
\hline$C(18)$ & $823(2)$ & $7789(5)$ & $1684(2)$ & $18(1)$ \\
\hline C(19) & $375(2)$ & $8720(5)$ & $1230(2)$ & $19(1)$ \\
\hline $\mathrm{C}(20)$ & $978(2)$ & $10219(5)$ & $2088(2)$ & $16(1)$ \\
\hline $\mathrm{C}(21)$ & $3480(2)$ & $5904(6)$ & $2642(2)$ & $29(1)$ \\
\hline$C(22)$ & $4064(3)$ & $5921(7)$ & $2285(3)$ & $50(2)$ \\
\hline
\end{tabular}




\begin{tabular}{lrrrr}
$\mathrm{C}(23)$ & $1646(3)$ & $4002(6)$ & $592(2)$ & $38(1)$ \\
$\mathrm{C}(24)$ & $-150(2)$ & $8319(5)$ & $580(2)$ & $26(1)$ \\
$\mathrm{C}(25)$ & $1216(2)$ & $11686(4)$ & $2512(2)$ & $20(1)$ \\
$\mathrm{C}(26)$ & $644(2)$ & $12381(5)$ & $2807(2)$ & $24(1)$ \\
$\mathrm{Cl}(1)$ & $1044(1)$ & $7896(1)$ & $4021(1)$ & $21(1)$ \\
$\mathrm{O}(1)$ & $1104(2)$ & $6799(4)$ & $3475(1)$ & $33(1)$ \\
$\mathrm{O}(2)$ & $1369(2)$ & $7268(3)$ & $4680(1)$ & $30(1)$ \\
$\mathrm{O}(3)$ & $1365(2)$ & $9378(3)$ & $3914(2)$ & $36(1)$ \\
$\mathrm{O}(4)$ & $316(1)$ & $8164(3)$ & $3973(2)$ & $26(1)$ \\
$\mathrm{Cl}(2)$ & $4213(1)$ & $2511(1)$ & $859(1)$ & $27(1)$ \\
$\mathrm{O}(5)$ & $4139(2)$ & $1926(4)$ & $178(2)$ & $48(1)$ \\
$\mathrm{O}(6)$ & $4728(2)$ & $3719(4)$ & $999(2)$ & $54(1)$ \\
$\mathrm{O}(7)$ & $3543(2)$ & $3123(5)$ & $881(3)$ & $50(2)$ \\
$\mathrm{O}(8)$ & $4383(2)$ & $1273(6)$ & $1346(2)$ & $73(2)$ \\
& & & & \\
\hline
\end{tabular}


Table S25. Crystal data and structure refinement for compound $\mathbf{1 5 .}$

Identification code

Empirical formula

Formula weight

Temperature

Wavelength

Crystal system

Space group

Unit cell dimensions

Volume

Z

Density (calculated)

Absorption coefficient

$\mathrm{F}(000)$

Crystal size

Crystal color, habit

Theta range for data collection

Index ranges

Reflections collected

Independent reflections

Completeness to theta $=28.26^{\circ}$

Absorption correction

Max. and min. transmission

Refinement method

Data/restraints/parameters

Goodness-of-fit on $\mathrm{F}^{2}$

Final R indices [I $>2 \operatorname{sigma}(\mathrm{I})]$

$\mathrm{R}$ indices (all data)

Extinction coefficient

Largest diff. peak and hole
1-Methyl-4-nitroimidazole-2-

carboxaldehyde.

$\mathrm{C}_{5} \mathrm{H}_{5} \mathrm{~N}_{3} \mathrm{O}_{3}$

155.12

$100(2) \mathrm{K}$

$0.71073 \AA$

Monoclinic

$\mathrm{P} 2{ }_{1} / \mathrm{c}$

$\mathrm{a}=11.4305(15) \AA \quad \alpha=90^{\circ}$.

$\mathrm{b}=10.4593(14) \AA \quad \beta=96.462(2)^{\circ}$.

$\mathrm{c}=11.0941(15) \AA \quad \gamma=90^{\circ}$.

$1317.9(3) \AA^{3}$

8

$1.564 \mathrm{Mg} / \mathrm{m}^{3}$

$0.132 \mathrm{~mm}^{-1}$

640

$0.39 \times 0.25 \times 0.14 \mathrm{~mm}^{3}$

colorless needle

1.79 to $28.26^{\circ}$.

$-14<=\mathrm{h}<=14,-13<=\mathrm{k}<=13,-14<=\mathrm{l}<=14$

11015

$3050[\mathrm{R}(\mathrm{int})=0.016]$

$93.2 \%$

\section{SADABS}

0.915 and 0.996

Full-matrix least-squares on $\mathrm{F}^{2}$

$3050 / 0 / 206$

1.04

$\mathrm{R}_{1}=0.035, \mathrm{wR}_{2}=0.080$

$\mathrm{R}_{1}=0.038, \mathrm{wR}_{2}=0.081$

0.0055(9)

0.314 and -0.234 e. $\AA^{-3}$ 
Table S26. Atomic coordinates (x 104) and equivalent isotropic displacement parameters $\left(\AA^{2} \times 10^{3}\right)$ for compound 15.

\begin{tabular}{|c|c|c|c|c|}
\hline & $\mathrm{x}$ & $\mathrm{y}$ & $\mathrm{z}$ & $\mathrm{U}(\mathrm{eq})$ \\
\hline $\mathrm{O}(1)$ & $1300(1)$ & $6317(1)$ & $4002(1)$ & $27(1)$ \\
\hline $\mathrm{O}(2)$ & $1144(1)$ & $11167(1)$ & $7324(1)$ & $23(1)$ \\
\hline $\mathrm{O}(3)$ & $-658(1)$ & $10749(1)$ & $7659(1)$ & $26(1)$ \\
\hline $\mathrm{N}(1)$ & $-336(1)$ & $7739(1)$ & $5371(1)$ & $17(1)$ \\
\hline $\mathrm{N}(2)$ & 1192(1) & $9039(1)$ & $5908(1)$ & $18(1)$ \\
\hline $\mathrm{N}(3)$ & $248(1)$ & $10511(1)$ & $7190(1)$ & $19(1)$ \\
\hline $\mathrm{C}(1)$ & $825(1)$ & $8014(1)$ & $5270(1)$ & $18(1)$ \\
\hline $\mathrm{C}(2)$ & $233(1)$ & $9400(1)$ & $6429(1)$ & $17(1)$ \\
\hline$C(3)$ & $-721(1)$ & $8624(1)$ & $6117(1)$ & $18(1)$ \\
\hline$C(4)$ & $1600(1)$ & $7282(1)$ & $4556(1)$ & $22(1)$ \\
\hline$C(5)$ & $-1049(1)$ & $6682(1)$ & $4813(1)$ & $21(1)$ \\
\hline $\mathrm{O}(4)$ & $6272(1)$ & $-690(1)$ & $8921(1)$ & $30(1)$ \\
\hline $\mathrm{O}(5)$ & $5410(1)$ & $2638(1)$ & $4202(1)$ & $30(1)$ \\
\hline $\mathrm{O}(6)$ & $3537(1)$ & $2205(1)$ & $3975(1)$ & $25(1)$ \\
\hline $\mathrm{N}(4)$ & $4325(1)$ & 229(1) & $7158(1)$ & $18(1)$ \\
\hline $\mathrm{N}(5)$ & $5739(1)$ & $1188(1)$ & $6244(1)$ & $19(1)$ \\
\hline $\mathrm{N}(6)$ & $4532(1)$ & $2133(1)$ & $4534(1)$ & $20(1)$ \\
\hline$C(6)$ & $5506(1)$ & $469(1)$ & $7171(1)$ & $18(1)$ \\
\hline$C(7)$ & $4665(1)$ & $1401(1)$ & $5636(1)$ & $18(1)$ \\
\hline$C(8)$ & $3773(1)$ & $825(1)$ & $6172(1)$ & $19(1)$ \\
\hline$C(9)$ & $6432(1)$ & $5(1)$ & $8084(1)$ & $25(1)$ \\
\hline$C(10)$ & $3733(1)$ & $-489(1)$ & $8053(1)$ & $25(1)$ \\
\hline
\end{tabular}


Table S27. Crystal data and structure refinement for compound 21.

Identification code

Empirical formula

Formula weight

Temperature

Wavelength

Crystal system

Space group

Unit cell dimensions

Volume

Z

Density (calculated)

Absorption coefficient

$\mathrm{F}(000)$

Crystal size

Crystal color

Theta range for data collection

Index ranges

Reflections collected

Independent reflections

Completeness to theta $=28.22^{\circ}$

Absorption correction

Max. and min. transmission

Refinement method

Data/restraints/parameters

Goodness-of-fit on $\mathrm{F}^{2}$

Final R indices $[\mathrm{I}>2 \operatorname{sigma}(\mathrm{I})]$

$\mathrm{R}$ indices (all data)

Largest diff. peak and hole
1-Methyl-4-nitroimidazole-2-acetal.

$\mathrm{C}_{7} \mathrm{H}_{9} \mathrm{~N}_{3} \mathrm{O}_{4}$

199.17

100(2) K

$0.71073 \AA$

Monoclinic

$\mathrm{P} 2(1) / \mathrm{c}$

$\mathrm{a}=4.3538(5) \AA$

$\alpha=90^{\circ}$.

$\mathrm{b}=10.1323(11) \AA$

$\beta=93.994(2)^{\circ}$.

$\mathrm{c}=19.605(2) \AA$ $\gamma=90^{\circ}$.

862.78(16) $\AA^{3}$

4

$1.533 \mathrm{Mg} / \mathrm{m}^{3}$

$0.127 \mathrm{~mm}^{-1}$

416

$0.41 \times 0.21 \times 0.02 \mathrm{~mm}^{3}$

colorless

2.08 to $28.22^{\circ}$.

$-5<=\mathrm{h}<=5,-13<=\mathrm{k}<=12,-24<=\mathrm{l}<=25$

7265

$2005[\mathrm{R}(\mathrm{int})=0.0255]$

$94.2 \%$

None

0.9975 and 0.9496

Full-matrix least-squares on $\mathrm{F}^{2}$

2005/0/152

1.012

$\mathrm{R}_{1}=0.0329, \mathrm{wR}_{2}=0.0728$

$\mathrm{R}_{1}=0.0394, \mathrm{wR}_{2}=0.0757$

0.288 and -0.188 e. $\AA^{-3}$ 
Table S28. Atomic coordinates (x 104) and equivalent isotropic displacement parameters $\left(\AA^{2} \times 10^{3}\right)$ for compound 21.

\begin{tabular}{lrrrr}
\hline & $\mathrm{x}$ & $\mathrm{y}$ & $\mathrm{z}$ & $\mathrm{U}(\mathrm{eq})$ \\
\hline $\mathrm{O}(1)$ & $6904(3)$ & $7353(1)$ & $3886(1)$ & $43(1)$ \\
$\mathrm{O}(2)$ & $4444(2)$ & $5585(1)$ & $4142(1)$ & $26(1)$ \\
$\mathrm{O}(3)$ & $194(2)$ & $8062(1)$ & $1160(1)$ & $18(1)$ \\
$\mathrm{O}(4)$ & $3364(2)$ & $6482(1)$ & $780(1)$ & $22(1)$ \\
$\mathrm{N}(1)$ & $1304(2)$ & $5648(1)$ & $2131(1)$ & $17(1)$ \\
$\mathrm{N}(2)$ & $4644(2)$ & $7177(1)$ & $2543(1)$ & $18(1)$ \\
$\mathrm{N}(3)$ & $5188(2)$ & $6426(1)$ & $3731(1)$ & $22(1)$ \\
$\mathrm{C}(1)$ & $3003(3)$ & $6747(1)$ & $1997(1)$ & $17(1)$ \\
$\mathrm{C}(2)$ & $1904(3)$ & $5355(1)$ & $2804(1)$ & $18(1)$ \\
$\mathrm{C}(3)$ & $3931(3)$ & $6308(1)$ & $3038(1)$ & $18(1)$ \\
$\mathrm{C}(4)$ & $60(3)$ & $8202(1)$ & $426(1)$ & $22(1)$ \\
$\mathrm{C}(5)$ & $-751(3)$ & $4884(1)$ & $1654(1)$ & $17(1)$ \\
$\mathrm{C}(6)$ & $3021(3)$ & $7411(1)$ & $1316(1)$ & $22(1)$ \\
$\mathrm{C}(7)$ & $1316(3)$ & $6884(1)$ & $206(1)$ & \\
\hline
\end{tabular}


Table S29. Crystal data and structure refinement for compound $\mathbf{2 6 .}$

Identification code

Empirical formula

Formula weight

Temperature

Wavelength

Crystal system

Space group

Unit cell dimensions

Volume

Z

Density (calculated)

Absorption coefficient

$\mathrm{F}(000)$

Crystal size

Crystal color

Theta range for data collection

Index ranges

Reflections collected

Independent reflections

Completeness to theta $=28.29^{\circ}$

Absorption correction

Refinement method

Data/restraints/parameters

Goodness-of-fit on $\mathrm{F}^{2}$

Final $R$ indices $[\mathrm{I}>2 \operatorname{sigma}(\mathrm{I})]$

$\mathrm{R}$ indices (all data)

Largest diff. peak and hole
1-Methyl-4-pivaloylamido-imidazole-2carboxaldehyde.

$\mathrm{C}_{10} \mathrm{H}_{15} \mathrm{~N}_{3} \mathrm{O}_{2}$

209.25

100(2) K

$0.71073 \AA$

Orthorhombic

P2(1)2(1)2(1)

$\mathrm{a}=9.3723(8) \AA$

$\alpha=90^{\circ}$.

$\mathrm{b}=21.4013(19) \AA$

$\beta=90^{\circ}$.

$c=21.9764(19) \AA$

$\gamma=90^{\circ}$.

4408.0(7) $\AA^{3}$

16

$1.261 \mathrm{Mg} / \mathrm{m}^{3}$

$0.090 \mathrm{~mm}^{-1}$

1792

$0.367 \times 0.119 \times 0.047 \mathrm{~mm}^{3}$

colorless

1.33 to $28.29^{\circ}$

$-12<=\mathrm{h}<=12,-28<=\mathrm{k}<=28,-29<=\mathrm{l}<=29$

39223

$10314[\mathrm{R}($ int $)=0.0415]$

$96.7 \%$

None

Full-matrix least-squares on $\mathrm{F}^{2}$

$10314 / 0 / 574$

1.011

$\mathrm{R}_{1}=0.0434, \mathrm{wR}_{2}=0.0847$

$\mathrm{R}_{1}=0.0668, \mathrm{wR}_{2}=0.0925$

0.233 and -0.188 e. $\AA^{-3}$ 
Table S30. Atomic coordinates (x 104) and equivalent isotropic displacement parameters $\left(\AA^{2} \times 10^{3}\right)$ for compound 26.

\begin{tabular}{|c|c|c|c|c|}
\hline & $\mathrm{x}$ & $\mathrm{y}$ & $\mathrm{z}$ & $\mathrm{U}(\mathrm{eq})$ \\
\hline $\mathrm{O}(1)$ & $1353(1)$ & 2093(1) & $11055(1)$ & $26(1)$ \\
\hline $\mathrm{O}(2)$ & $4929(2)$ & $663(1)$ & $8609(1)$ & $31(1)$ \\
\hline $\mathrm{N}(1)$ & $2929(2)$ & $1241(1)$ & 10211(1) & $20(1)$ \\
\hline $\mathrm{N}(2)$ & $3221(2)$ & $2090(1)$ & $9639(1)$ & $20(1)$ \\
\hline $\mathrm{N}(3)$ & $4542(2)$ & $1678(1)$ & $8809(1)$ & $22(1)$ \\
\hline$C(1)$ & $2658(2)$ & $1863(1)$ & $10154(1)$ & $19(1)$ \\
\hline $\mathrm{C}(2)$ & $3857(2)$ & $1593(1)$ & $9368(1)$ & $19(1)$ \\
\hline$C(3)$ & $3684(2)$ & $1061(1)$ & $9711(1)$ & $21(1)$ \\
\hline$C(4)$ & $1862(2)$ & $2256(1)$ & $10569(1)$ & $22(1)$ \\
\hline $\mathrm{C}(5)$ & $2477(2)$ & 819(1) & $10696(1)$ & $28(1)$ \\
\hline$C(6)$ & $5023(2)$ & $1207(1)$ & $8449(1)$ & $20(1)$ \\
\hline$C(7)$ & $5704(2)$ & $1405(1)$ & $7845(1)$ & $20(1)$ \\
\hline $\mathrm{C}(8)$ & $7248(2)$ & 1591(1) & $7986(1)$ & $26(1)$ \\
\hline $\mathrm{C}(9)$ & $4916(2)$ & $1955(1)$ & $7547(1)$ & $28(1)$ \\
\hline$C(10)$ & $5695(2)$ & $845(1)$ & $7415(1)$ & $28(1)$ \\
\hline $\mathrm{O}(3)$ & $6142(2)$ & $2815(1)$ & $12210(1)$ & $29(1)$ \\
\hline $\mathrm{O}(4)$ & $3913(2)$ & $4534(1)$ & $9690(1)$ & $30(1)$ \\
\hline $\mathrm{N}(4)$ & $5580(2)$ & $3751(1)$ & 11251(1) & $20(1)$ \\
\hline $\mathrm{N}(5)$ & $4560(2)$ & $2970(1)$ & $10738(1)$ & $20(1)$ \\
\hline $\mathrm{N}(6)$ & $3799(2)$ & $3496(1)$ & $9838(1)$ & $20(1)$ \\
\hline$C(11)$ & $5243(2)$ & $3133(1)$ & $11250(1)$ & $19(1)$ \\
\hline$C(12)$ & $4469(2)$ & $3507(1)$ & $10411(1)$ & $19(1)$ \\
\hline$C(13)$ & $5093(2)$ & 3998(1) & $10720(1)$ & $22(1)$ \\
\hline$C(14)$ & $5528(2)$ & 2693(1) & $11738(1)$ & $23(1)$ \\
\hline$C(15)$ & $6281(2)$ & $4110(1)$ & $11733(1)$ & $27(1)$ \\
\hline$C(16)$ & $3532(2)$ & $4021(1)$ & $9506(1)$ & $22(1)$ \\
\hline$C(17)$ & $2701(2)$ & $3937(1)$ & $8908(1)$ & $22(1)$ \\
\hline$C(18)$ & $1128(2)$ & $3856(1)$ & $9077(1)$ & $33(1)$ \\
\hline$C(19)$ & $2865(3)$ & $4530(1)$ & $8528(1)$ & $38(1)$ \\
\hline$C(20)$ & $3221(2)$ & $3375(1)$ & $8541(1)$ & $26(1)$ \\
\hline $\mathrm{O}(5)$ & $3737(2)$ & $6353(1)$ & $12115(1)$ & $31(1)$ \\
\hline
\end{tabular}




\begin{tabular}{|c|c|c|c|c|}
\hline $\mathrm{O}(6)$ & $-126(2)$ & $5395(1)$ & $9575(1)$ & $29(1)$ \\
\hline N(7) & $2432(2)$ & $5699(1)$ & $11085(1)$ & $21(1)$ \\
\hline $\mathrm{N}(8)$ & $1962(2)$ & $6639(1)$ & $10698(1)$ & $21(1)$ \\
\hline $\mathrm{N}(9)$ & $719(2)$ & $6358(1)$ & 9791(1) & $20(1)$ \\
\hline$C(21)$ & $2576(2)$ & $6326(1)$ & $11157(1)$ & $20(1)$ \\
\hline$C(22)$ & $1428(2)$ & $6189(1)$ & $10330(1)$ & $20(1)$ \\
\hline$C(23)$ & $1703(2)$ & $5602(1)$ & $10559(1)$ & $22(1)$ \\
\hline$C(24)$ & $3239(2)$ & $6625(1)$ & $11680(1)$ & $26(1)$ \\
\hline$C(25)$ & $2957(2)$ & $5204(1)$ & 11491(1) & $28(1)$ \\
\hline$C(26)$ & $-43(2)$ & $5950(1)$ & $9442(1)$ & $20(1)$ \\
\hline$C(27)$ & $-759(2)$ & $6224(1)$ & $8879(1)$ & $21(1)$ \\
\hline$C(28)$ & $-1882(2)$ & $6704(1)$ & $9073(1)$ & $30(1)$ \\
\hline$C(29)$ & $356(2)$ & $6534(1)$ & $8472(1)$ & $39(1)$ \\
\hline$C(30)$ & $-1501(3)$ & $5701(1)$ & $8528(1)$ & $37(1)$ \\
\hline $\mathrm{O}(7)$ & $-1500(1)$ & $7726(1)$ & $11068(1)$ & $23(1)$ \\
\hline $\mathrm{O}(8)$ & $1447(1)$ & $9436(1)$ & $8698(1)$ & $25(1)$ \\
\hline $\mathrm{N}(10)$ & $-238(2)$ & $8662(1)$ & $10252(1)$ & $18(1)$ \\
\hline $\mathrm{N}(11)$ & $540(2)$ & $7861(1)$ & $9694(1)$ & $18(1)$ \\
\hline $\mathrm{N}(12)$ & $1699(2)$ & $8407(1)$ & $8885(1)$ & $19(1)$ \\
\hline$C(31)$ & $-171(2)$ & $8031(1)$ & $10197(1)$ & $17(1)$ \\
\hline$C(32)$ & $932(2)$ & $8406(1)$ & $9430(1)$ & $18(1)$ \\
\hline C(33) & $461(2)$ & $8909(1)$ & $9768(1)$ & $19(1)$ \\
\hline$C(34)$ & $-848(2)$ & $7590(1)$ & $10603(1)$ & $20(1)$ \\
\hline$C(35)$ & $-847(2)$ & $9030(1)$ & $10748(1)$ & $24(1)$ \\
\hline$C(36)$ & $1910(2)$ & $8927(1)$ & $8538(1)$ & $19(1)$ \\
\hline$C(37)$ & $2775(2)$ & $8838(1)$ & $7953(1)$ & $20(1)$ \\
\hline$C(38)$ & $2572(3)$ & $9411(1)$ & $7552(1)$ & $38(1)$ \\
\hline C(39) & $4353(2)$ & 8783(1) & $8133(1)$ & $38(1)$ \\
\hline$C(40)$ & $2297(2)$ & $8255(1)$ & $7609(1)$ & $31(1)$ \\
\hline
\end{tabular}


Table S31. Crystal data and structure refinement for compound $\mathbf{2 8 .}$

Identification code

Empirical formula

Formula weight

Temperature

Wavelength

Crystal system

Space group

Unit cell dimensions

Volume

$\mathrm{Z}$

Density (calculated)

Absorption coefficient

$\mathrm{F}(000)$

Crystal size

Crystal color, habit

Theta range for data collection

Index ranges

Reflections collected

Independent reflections

Completeness to theta $=28.23^{\circ}$

Absorption correction

Max. and min. transmission

Refinement method

Data/restraints/parameters

Goodness-of-fit on $\mathrm{F}^{2}$

Final $\mathrm{R}$ indices $[\mathrm{I}>2 \operatorname{sigma}(\mathrm{I})]$

$\mathrm{R}$ indices (all data)

Largest diff. peak and hole
1-Methyl-4-pivaloylamidoimidazole-2-

oxime.

$\mathrm{C}_{10} \mathrm{H}_{16} \mathrm{~N}_{4} \mathrm{O}_{2}$

224.27

100(2) K

$0.71073 \AA$

Monoclinic

$\mathrm{P} 2{ }_{1} / \mathrm{c}$

$\mathrm{a}=10.822(3) \AA \quad \alpha=90^{\circ}$

$\mathrm{b}=9.155(3) \AA \quad \beta=95.511(4)^{\circ}$

$\mathrm{c}=11.861(3) \AA \quad \gamma=90^{\circ}$

$1169.7(5) \AA^{3}$

4

$1.274 \mathrm{Mg} / \mathrm{m}^{3}$

$0.092 \mathrm{~mm}^{-1}$

480

$0.119 \times 0.085 \times 0.061 \mathrm{~mm}^{3}$

colorless plate

1.89 to $28.23^{\circ}$

$-14<=\mathrm{h}<=14,-12<=\mathrm{k}<=12,-15<=\mathrm{l}<=15$

9899

$2707[\mathrm{R}(\mathrm{int})=0.0418]$

$93.8 \%$

\section{SADABS}

0.986 and 0.871

Full-matrix least-squares on $\mathrm{F}^{2}$

2707/0/165

1.024

$\mathrm{R}_{1}=0.057, \mathrm{wR}_{2}=0.121$

$\mathrm{R}_{1}=0.089, \mathrm{wR}_{2}=0.131$

0.277 and -0.201 e. $\AA^{-3}$ 
Table S32. Atomic coordinates (x 104) and equivalent isotropic displacement parameters $\left(\AA^{2} \times 10^{3}\right)$ for compound 28.

\begin{tabular}{|c|c|c|c|c|}
\hline & $\mathrm{x}$ & $\mathrm{y}$ & $\mathrm{z}$ & $\mathrm{U}(\mathrm{eq})$ \\
\hline $\mathrm{O}(1)$ & $8460(2)$ & $10279(2)$ & $3059(1)$ & $37(1)$ \\
\hline $\mathrm{O}(2)$ & $4261(1)$ & $12019(2)$ & $8450(1)$ & $28(1)$ \\
\hline $\mathrm{N}(1)$ & $6402(2)$ & $12099(2)$ & $5528(1)$ & $22(1)$ \\
\hline $\mathrm{N}(2)$ & $6364(2)$ & $9705(2)$ & $5761(1)$ & $21(1)$ \\
\hline $\mathrm{N}(3)$ & $7544(2)$ & $8897(2)$ & $4297(2)$ & $23(1)$ \\
\hline $\mathrm{N}(4)$ & $4953(2)$ & $12274(2)$ & $7530(2)$ & $23(1)$ \\
\hline$C(1)$ & $6010(2)$ & $10987(2)$ & $6152(2)$ & $20(1)$ \\
\hline$C(2)$ & $7035(2)$ & $11502(2)$ & $4692(2)$ & $22(1)$ \\
\hline$C(3)$ & $7007(2)$ & $10036(2)$ & $4865(2)$ & $19(1)$ \\
\hline$C(4)$ & $6243(2)$ & $13670(2)$ & $5702(2)$ & $28(1)$ \\
\hline$C(5)$ & $5285(2)$ & $11068(2)$ & $7117(2)$ & $23(1)$ \\
\hline$C(6)$ & $8299(2)$ & $9069(2)$ & $3458(2)$ & $23(1)$ \\
\hline$C(7)$ & $8974(2)$ & $7705(2)$ & $3091(2)$ & $25(1)$ \\
\hline$C(8)$ & $8353(2)$ & $6275(2)$ & $3398(2)$ & $29(1)$ \\
\hline$C(9)$ & $10293(2)$ & $7781(3)$ & $3692(2)$ & $33(1)$ \\
\hline$C(10)$ & $9027(2)$ & $7784(3)$ & $1806(2)$ & $31(1)$ \\
\hline
\end{tabular}


Table S33. Crystal data and structure refinement for $\mathbf{L 2}$.

Identification code

Empirical formula

Formula weight

Temperature

Wavelength

Crystal system

Space group

Unit cell dimensions

Volume

Z

Density (calculated)

Absorption coefficient

$\mathrm{F}(000)$

Crystal size

Crystal color

Theta range for data collection

Index ranges

Reflections collected

Independent reflections

Completeness to theta $=28.04^{\circ}$

Refinement method

Data/restraints/parameters

Goodness-of-fit on $\mathrm{F}^{2}$

Final R indices $[\mathrm{I}>2 \operatorname{sigma}(\mathrm{I})]$

$\mathrm{R}$ indices (all data)

Largest diff. peak and hole
Bis((1-methyl-4-pivaloylamidoimidazol-2methyl))(1-methylimidazol-2-methyl)amine.

$\mathrm{C}_{25} \mathrm{H}_{41} \mathrm{~N}_{9} \mathrm{O}_{3}$

515.67

$100(2) \mathrm{K}$

$0.71073 \AA$

monoclinic

$\mathrm{C} 2 / \mathrm{c}$

$$
\begin{array}{ll}
\mathrm{a}=29.757(6) \AA & \alpha=90^{\circ} . \\
\mathrm{b}=11.358(2) \AA & \beta=97.948(3)^{\circ} . \\
\mathrm{c}=19.493(4) \AA & \gamma=90^{\circ} .
\end{array}
$$

$6525(2) \AA^{3}$

8

$1.050 \mathrm{Mg} / \mathrm{m}^{3}$

$0.072 \mathrm{~mm}^{-1}$

2224

$0.45 \times 0.25 \times 0.15 \mathrm{~mm}^{3}$

colorless

1.92 to $28.04^{\circ}$.

$-39<=\mathrm{h}<=37,-14<=\mathrm{k}<=14,-25<=\mathrm{l}<=25$

27922

$7543[\mathrm{R}($ int $)=0.0231]$

$95.5 \%$

Full-matrix least-squares on $\mathrm{F}^{2}$

$7543 / 0 / 359$

1.025

$\mathrm{R}_{1}=0.0677, \mathrm{wR}_{2}=0.1261$

$\mathrm{R}_{1}=0.0862, \mathrm{wR}_{2}=0.1324$

0.790 and -0.388 e. $\AA^{-3}$ 
Table S34. Atomic coordinates (x 104) and equivalent isotropic displacement parameters $\left(\AA^{2} \times 10^{3}\right)$ for compound $\mathbf{L} 2$.

\begin{tabular}{|c|c|c|c|c|}
\hline & $\mathrm{X}$ & $\mathrm{y}$ & $\mathrm{z}$ & $\mathrm{U}(\mathrm{eq})$ \\
\hline $\mathrm{N}(1)$ & $640(1)$ & $6204(2)$ & $-1089(1)$ & $41(1)$ \\
\hline $\mathrm{N}(2)$ & $1434(1)$ & $5014(2)$ & $44(1)$ & $43(1)$ \\
\hline $\mathrm{N}(3)$ & $1667(1)$ & $6607(2)$ & $-461(1)$ & $42(1)$ \\
\hline $\mathrm{N}(4)$ & $1872(1)$ & $5124(2)$ & $1160(1)$ & $43(1)$ \\
\hline $\mathrm{N}(5)$ & $-388(1)$ & $6497(2)$ & $-448(1)$ & $48(1)$ \\
\hline $\mathrm{N}(6)$ & $216(1)$ & $7384(2)$ & 101(1) & $76(1)$ \\
\hline $\mathrm{N}(7)$ & $-987(1)$ & $7613(2)$ & $-79(1)$ & $60(1)$ \\
\hline $\mathrm{N}(8)$ & $866(1)$ & $7411(2)$ & $-2551(1)$ & $61(1)$ \\
\hline $\mathrm{N}(9)$ & $517(1)$ & $8614(2)$ & $-1910(1)$ & $61(1)$ \\
\hline $\mathrm{O}(1)$ & 2493(1) & $6229(1)$ & $1459(1)$ & $55(1)$ \\
\hline $\mathrm{O}(2)$ & $-921(1)$ & $9405(2)$ & $415(1)$ & $105(1)$ \\
\hline $\mathrm{O}(3)$ & $1034(1)$ & $5614(2)$ & $6549(1)$ & $75(1)$ \\
\hline $\mathrm{C}(1)$ & $1755(1)$ & $5595(2)$ & 497(1) & $40(1)$ \\
\hline$C(2)$ & $1906(1)$ & $6575(2)$ & $198(1)$ & $42(1)$ \\
\hline$C(3)$ & $2235(1)$ & $5468(2)$ & $1610(1)$ & $40(1)$ \\
\hline$C(4)$ & $1389(1)$ & $5662(2)$ & $-527(1)$ & $40(1)$ \\
\hline$C(5)$ & $378(1)$ & $6465(2)$ & $-1766(1)$ & $42(1)$ \\
\hline$C(6)$ & $2305(1)$ & $4851(2)$ & $2315(1)$ & $45(1)$ \\
\hline$C(7)$ & $362(1)$ & $5640(2)$ & $-619(1)$ & $49(1)$ \\
\hline$C(8)$ & $1043(1)$ & $5481(2)$ & $-1151(1)$ & $44(1)$ \\
\hline$C(9)$ & $63(1)$ & $6496(2)$ & $-330(1)$ & $53(1)$ \\
\hline$C(10)$ & $579(1)$ & $7487(2)$ & $-2091(1)$ & $46(1)$ \\
\hline$C(11)$ & $1687(1)$ & $7538(2)$ & $-971(1)$ & $53(1)$ \\
\hline$C(12)$ & $2195(1)$ & $3537(2)$ & $2251(1)$ & $55(1)$ \\
\hline$C(13)$ & $1996(1)$ & $5440(2)$ & $2779(1)$ & $59(1)$ \\
\hline$C(14)$ & $-521(1)$ & $7408(2)$ & $-68(1)$ & $60(1)$ \\
\hline$C(15)$ & $-1162(1)$ & $8611(3)$ & $156(1)$ & $70(1)$ \\
\hline$C(16)$ & $-1680(1)$ & $8746(3)$ & $74(1)$ & $68(1)$ \\
\hline$C(17)$ & $-1930(1)$ & $7831(2)$ & $-399(2)$ & $71(1)$ \\
\hline$C(18)$ & $2802(1)$ & $5014(2)$ & $2632(1)$ & $61(1)$ \\
\hline$C(19)$ & $-1821(1)$ & 8799(3) & $770(2)$ & $91(1)$ \\
\hline
\end{tabular}




\begin{tabular}{lrrrr}
$\mathrm{C}(20)$ & $-155(1)$ & $7988(3)$ & $271(1)$ & $88(1)$ \\
$\mathrm{C}(21)$ & $782(1)$ & $9296(3)$ & $-2269(2)$ & $88(1)$ \\
$\mathrm{C}(22)$ & $223(1)$ & $9048(3)$ & $-1428(2)$ & $82(1)$ \\
$\mathrm{C}(23)$ & $695(1)$ & $7678(3)$ & $340(2)$ & $104(1)$ \\
$\mathrm{C}(24)$ & $991(1)$ & $8555(3)$ & $-2655(2)$ & $84(1)$ \\
$\mathrm{C}(25)$ & $-1794(1)$ & $9975(3)$ & $-293(2)$ & $99(1)$ \\
\hline
\end{tabular}




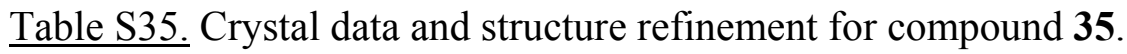

Identification code

Empirical formula

Formula weight

Temperature

Wavelength

Crystal system

Space group

Unit cell dimensions

Volume

Z

Density (calculated)

Absorption coefficient

$\mathrm{F}(000)$

Crystal size

Crystal color, habit

Theta range for data collection

Index ranges

Reflections collected

Independent reflections

Completeness to theta $=28.31^{\circ}$

Absorption correction

Min. and max. transmission

Refinement method

Data/restraints/parameters

Goodness-of-fit on $\mathrm{F}^{2}$

Final $\mathrm{R}$ indices $[\mathrm{I}>2 \operatorname{sigma}(\mathrm{I})]$

$\mathrm{R}$ indices (all data)

Largest diff. peak and hole
$\left[\mathrm{Fe}(\mathbf{L 1}) \mathrm{Cl}_{2}\right]^{+}$

$2\left(\mathrm{C}_{20} \mathrm{H}_{30} \mathrm{~N}_{8} \mathrm{Cl}_{2} \mathrm{Fe}\right) \bullet \mathrm{Fe}_{2} \mathrm{O}_{1} \mathrm{Cl}_{6}$

1390.94

$100(2) \mathrm{K}$

$0.71073 \AA$

Monoclinic

$\mathrm{P} 2{ }_{1} / \mathrm{c}$

$\mathrm{a}=11.2811(12) \AA \quad \alpha=90^{\circ}$.

$\mathrm{b}=17.749(2) \AA$

$\beta=104.619(2)^{\circ}$.

$c=14.7148(16) \AA$

$\gamma=90^{\circ}$.
4

$1.620 \mathrm{Mg} / \mathrm{m}^{3}$

$1.519 \mathrm{~mm}^{-1}$

1420

$0.15 \times 0.13 \times 0.06 \mathrm{~mm}^{3}$

orange plate

1.83 to $28.31^{\circ}$.

$-14<=\mathrm{h}<=15,-23<=\mathrm{k}<=23,-18<=\mathrm{l}<=19$

24973

$6672[\mathrm{R}(\mathrm{int})=0.043]$

$94.2 \%$

\section{SADABS}

0.710 and 0.998

Full-matrix least-squares on $\mathrm{F}^{2}$

$6672 / 0 / 344$

1.042

$\mathrm{R}_{1}=0.036, \mathrm{wR}_{2}=0.079$

$\mathrm{R}_{1}=0.053, \mathrm{wR}_{2}=0.084$

0.457 and -0.329 e. $\AA^{-3}$ 
Table S36. Atomic coordinates (x 104) and equivalent isotropic displacement parameters $\left(\AA^{2} \times 10^{3}\right)$ for compound 35.

\begin{tabular}{|c|c|c|c|c|}
\hline & $\mathrm{x}$ & $\mathrm{y}$ & $\mathrm{z}$ & $\mathrm{U}(\mathrm{eq})$ \\
\hline $\mathrm{Fe}(1)$ & $3311(1)$ & $1720(1)$ & $5859(1)$ & $14(1)$ \\
\hline $\mathrm{Cl}(1)$ & $4878(1)$ & $958(1)$ & $6540(1)$ & $21(1)$ \\
\hline $\mathrm{Cl}(2)$ & $3180(1)$ & $2440(1)$ & $7138(1)$ & $20(1)$ \\
\hline $\mathrm{O}(1)$ & $1150(2)$ & $-1115(1)$ & $6538(1)$ & $24(1)$ \\
\hline $\mathrm{N}(1)$ & $1681(2)$ & 2381(1) & $4916(1)$ & $15(1)$ \\
\hline $\mathrm{N}(2)$ & $1740(2)$ & $1117(1)$ & $5976(1)$ & $16(1)$ \\
\hline $\mathrm{N}(3)$ & $-238(2)$ & $1073(1)$ & $5826(1)$ & $17(1)$ \\
\hline $\mathrm{N}(4)$ & $4131(2)$ & $2580(1)$ & $5281(1)$ & $17(1)$ \\
\hline $\mathrm{N}(5)$ & $3997(2)$ & $3593(1)$ & $4411(1)$ & $21(1)$ \\
\hline $\mathrm{N}(6)$ & $2975(2)$ & $1139(1)$ & $4569(1)$ & $15(1)$ \\
\hline $\mathrm{N}(7)$ & $1844(2)$ & 901(1) & $3149(1)$ & $16(1)$ \\
\hline $\mathrm{N}(8)$ & $2388(2)$ & $-117(1)$ & $6539(2)$ & $19(1)$ \\
\hline$C(1)$ & $644(2)$ & $2284(1)$ & $5354(2)$ & $17(1)$ \\
\hline$C(2)$ & $692(2)$ & $1496(1)$ & $5716(2)$ & $15(1)$ \\
\hline$C(3)$ & $1455(2)$ & $412(1)$ & $6249(2)$ & $16(1)$ \\
\hline$C(4)$ & $231(2)$ & $374(1)$ & $6160(2)$ & $19(1)$ \\
\hline$C(5)$ & $-1514(2)$ & $1302(1)$ & $5674(2)$ & $22(1)$ \\
\hline$C(6)$ & $2113(2)$ & $3174(1)$ & $4933(2)$ & $18(1)$ \\
\hline$C(7)$ & $3399(2)$ & $3127(1)$ & $4857(2)$ & $17(1)$ \\
\hline$C(8)$ & $5259(2)$ & $2707(1)$ & $5101(2)$ & $22(1)$ \\
\hline$C(9)$ & $5180(2)$ & $3331(2)$ & $4564(2)$ & $25(1)$ \\
\hline$C(10)$ & $3505(3)$ & $4241(1)$ & $3829(2)$ & $31(1)$ \\
\hline $\mathrm{C}(11)$ & $1373(2)$ & 2089(1) & $3930(2)$ & $17(1)$ \\
\hline$C(12)$ & $2058(2)$ & $1380(1)$ & $3881(2)$ & $15(1)$ \\
\hline$C(13)$ & $3363(2)$ & $473(1)$ & $4263(2)$ & $17(1)$ \\
\hline$C(14)$ & $2677(2)$ & $320(1)$ & $3384(2)$ & $19(1)$ \\
\hline$C(15)$ & $915(2)$ & $982(1)$ & $2260(2)$ & $19(1)$ \\
\hline$C(16)$ & 2193(2) & $-867(1)$ & $6678(2)$ & $19(1)$ \\
\hline$C(17)$ & $3345(2)$ & $-1343(1)$ & $7024(2)$ & $21(1)$ \\
\hline$C(18)$ & $4202(3)$ & $-1258(2)$ & $6374(2)$ & $31(1)$ \\
\hline C(19) & $4048(3)$ & $-1067(2)$ & $7995(2)$ & $30(1)$ \\
\hline
\end{tabular}




\begin{tabular}{lllll}
$\mathrm{C}(20)$ & $2971(3)$ & $-2165(2)$ & $7072(3)$ & $42(1)$ \\
$\mathrm{Fe}(2)$ & $8767(1)$ & $4397(1)$ & $4493(1)$ & $17(1)$ \\
$\mathrm{Cl}(3)$ & $8415(1)$ & $3562(1)$ & $5522(1)$ & $23(1)$ \\
$\mathrm{Cl}(4)$ & $9239(1)$ & $3794(1)$ & $3299(1)$ & $27(1)$ \\
$\mathrm{Cl}(5)$ & $7039(1)$ & $5046(1)$ & $3978(1)$ & $22(1)$ \\
$\mathrm{O}(2)$ & 10000 & 5000 & 5000 & $25(1)$ \\
\hline
\end{tabular}


Table S37. Crystal data and structure refinement for compound $\mathbf{3 8 .}$

Identification code

Empirical formula

Formula weight

Temperature

Wavelength

Crystal system

Space group

Unit cell dimensions

Volume

Z

Density (calculated)

Absorption coefficient

$\mathrm{F}(000)$

Crystal size

Crystal color

Theta range for data collection

Index ranges

Reflections collected

Independent reflections

Completeness to theta $=25.18^{\circ}$

Refinement method

Data/restraints/parameters

Goodness-of-fit on $\mathrm{F}^{2}$

Final $\mathrm{R}$ indices $[\mathrm{I}>2 \operatorname{sigma}(\mathrm{I})]$

$\mathrm{R}$ indices (all data)

Largest diff. peak and hole
$[\mathrm{Cu}(\mathbf{L 3}) \mathrm{Cl}]^{+}$

$2\left(\mathrm{C}_{30} \mathrm{H}_{48} \mathrm{ClCuN}_{10} \mathrm{O}_{3}\right) \bullet \mathrm{CuCl}_{4}$

673.39

100(2) K

$0.71073 \AA$

Monoclinic

$\mathrm{P} 2(1) / \mathrm{n}$

$\begin{array}{ll}\mathrm{a}=21.653(10) \AA & \alpha=90^{\circ} . \\ \mathrm{b}=10.260(5) \AA & \beta=93.766(8)^{\circ} . \\ \mathrm{c}=31.194(15) \AA & \gamma=90^{\circ} .\end{array}$

6915(6) $\AA^{3}$

8

$1.294 \mathrm{Mg} / \mathrm{m}^{3}$

$0.760 \mathrm{~mm}^{-1}$

2818

$0.32 \times 0.25 \times 0.11 \mathrm{~mm}^{3}$

brown

1.89 to $25.18^{\circ}$.

$-25<=\mathrm{h}<=25,-12<=\mathrm{k}<=12,-37<=\mathrm{l}<=37$

49657

$12328[\mathrm{R}(\mathrm{int})=0.1149]$

$99.1 \%$

Full-matrix least-squares on $\mathrm{F}^{2}$

$12328 / 0 / 758$

1.060

$\mathrm{R}_{1}=0.0864, \mathrm{wR}_{2}=0.1667$

$\mathrm{R}_{1}=0.1952, \mathrm{wR}_{2}=0.1819$

1.596 and -0.615 e. $\AA^{-3}$ 
Table S38. Atomic coordinates (x 104) and equivalent isotropic displacement parameters $\left(\AA^{2} \times 10^{3}\right)$ for compound 38.

\begin{tabular}{|c|c|c|c|c|}
\hline & $\mathrm{X}$ & $\mathrm{y}$ & z & $\mathrm{U}(\mathrm{eq})$ \\
\hline $\mathrm{Cu}(1)$ & $10038(1)$ & $5516(1)$ & $3838(1)$ & $50(1)$ \\
\hline $\mathrm{N}(1)$ & 10919(3) & $4549(6)$ & $4016(2)$ & $50(2)$ \\
\hline $\mathrm{N}(2)$ & $9814(3)$ & $4582(6)$ & $4365(2)$ & $48(2)$ \\
\hline $\mathrm{N}(3)$ & $10030(3)$ & $3042(6)$ & $4846(2)$ & $47(2)$ \\
\hline $\mathrm{N}(4)$ & 10591(3) & $7090(6)$ & $3963(2)$ & $47(2)$ \\
\hline $\mathrm{N}(5)$ & $11487(3)$ & $7908(7)$ & $4209(2)$ & $56(2)$ \\
\hline $\mathrm{N}(6)$ & 10164(3) & $4603(6)$ & $3289(2)$ & $49(2)$ \\
\hline $\mathrm{N}(7)$ & $10687(3)$ & $3188(6)$ & $2928(3)$ & $54(2)$ \\
\hline $\mathrm{N}(8)$ & $8758(3)$ & $4921(6)$ & $4404(2)$ & $52(2)$ \\
\hline $\mathrm{N}(9)$ & $9926(3)$ & $8876(6)$ & $3913(2)$ & $57(2)$ \\
\hline $\mathrm{C}(1)$ & $10920(4)$ & $4036(8)$ & $4460(3)$ & $64(2)$ \\
\hline$C(2)$ & $10252(4)$ & $3835(8)$ & $4558(3)$ & $49(2)$ \\
\hline$C(3)$ & $9277(4)$ & $4252(8)$ & $4554(2)$ & $46(2)$ \\
\hline$C(4)$ & $9410(4)$ & $3304(7)$ & $4858(2)$ & $48(2)$ \\
\hline$C(5)$ & $10388(4)$ & $2103(7)$ & $5117(2)$ & $61(2)$ \\
\hline$C(6)$ & $11423(3)$ & $5490(8)$ & 3994(3) & $62(2)$ \\
\hline$C(7)$ & $11176(4)$ & $6818(8)$ & $4070(2)$ & $46(2)$ \\
\hline$C(8)$ & $10517(4)$ & $8384(8)$ & $4028(2)$ & $46(2)$ \\
\hline $\mathrm{C}(9)$ & $11057(4)$ & $8903(8)$ & $4190(2)$ & $52(2)$ \\
\hline$C(10)$ & $12140(3)$ & $7952(8)$ & $4360(3)$ & $67(3)$ \\
\hline $\mathrm{C}(11)$ & $10987(4)$ & $3458(8)$ & $3713(3)$ & $66(3)$ \\
\hline$C(12)$ & $10626(4)$ & $3776(8)$ & $3301(3)$ & $44(2)$ \\
\hline$C(13)$ & $9923(4)$ & $4559(9)$ & 2871(3) & $75(3)$ \\
\hline$C(14)$ & $10246(5)$ & $3719(10)$ & $2653(3)$ & $85(3)$ \\
\hline$C(15)$ & $11162(4)$ & $2258(8)$ & $2813(3)$ & $69(3)$ \\
\hline$C(16)$ & $8187(4)$ & $4752(9)$ & $4550(3)$ & $64(3)$ \\
\hline$C(17)$ & $7661(4)$ & $5532(11)$ & $4319(3)$ & $74(3)$ \\
\hline$C(18)$ & $7097(4)$ & $5478(10)$ & $4584(3)$ & $91(3)$ \\
\hline C(19) & $7533(4)$ & $4813(10)$ & $3886(3)$ & $102(4)$ \\
\hline$C(20)$ & $7830(4)$ & $6943(9)$ & $4243(3)$ & $88(3)$ \\
\hline $\mathrm{C}(21)$ & $9777(4)$ & $10213(9)$ & $3938(3)$ & $65(3)$ \\
\hline
\end{tabular}




\begin{tabular}{|c|c|c|c|c|}
\hline$C(22)$ & $9108(4)$ & $10557(8)$ & $3802(3)$ & $66(2)$ \\
\hline$C(23)$ & $8815(4)$ & $9710(9)$ & $3463(3)$ & $119(4)$ \\
\hline$C(24)$ & $8756(4)$ & 10465(9) & $4217(4)$ & $106(4)$ \\
\hline$C(25)$ & $9116(4)$ & 11998(8) & $3664(3)$ & $88(3)$ \\
\hline $\mathrm{O}(1)$ & $8130(2)$ & $3980(6)$ & $4854(2)$ & $80(2)$ \\
\hline $\mathrm{O}(2)$ & $10176(3)$ & 10973(6) & $4066(2)$ & $83(2)$ \\
\hline $\mathrm{O}(3)$ & $9272(2)$ & $6455(4)$ & $3749(2)$ & $55(2)$ \\
\hline $\mathrm{Cu}(2)$ & $332(1)$ & $6676(1)$ & $1485(1)$ & $74(1)$ \\
\hline $\mathrm{N}(10)$ & $1216(3)$ & $7570(7)$ & $1671(2)$ & $60(2)$ \\
\hline $\mathrm{N}(11)$ & $868(3)$ & $5069(8)$ & $1537(2)$ & $64(2)$ \\
\hline $\mathrm{N}(12)$ & $1803(3)$ & $4238(8)$ & $1672(2)$ & $60(2)$ \\
\hline $\mathrm{N}(13)$ & $155(4)$ & $7362(6)$ & $2065(2)$ & $60(2)$ \\
\hline $\mathrm{N}(14)$ & $508(4)$ & $8191(7)$ & $2684(3)$ & $65(2)$ \\
\hline $\mathrm{N}(15)$ & $471(4)$ & $7782(7)$ & $973(2)$ & $84(1)$ \\
\hline $\mathrm{N}(16)$ & $981(4)$ & $9357(8)$ & $679(2)$ & $84(1)$ \\
\hline $\mathrm{N}(17)$ & $234(3)$ & $3199(7)$ & $1531(2)$ & $70(2)$ \\
\hline $\mathrm{N}(18)$ & $-834(5)$ & $6962(9)$ & $2182(3)$ & $111(3)$ \\
\hline$C(26)$ & $1699(4)$ & $6641(9)$ & $1540(3)$ & $67(3)$ \\
\hline$C(27)$ & $1463(5)$ & $5292(8)$ & $1589(3)$ & $58(2)$ \\
\hline$C(28)$ & $832(4)$ & $3738(10)$ & 1581(3) & $63(3)$ \\
\hline$C(29)$ & $1388(4)$ & $3201(9)$ & $1671(2)$ & $63(2)$ \\
\hline$C(30)$ & 2481(3) & $4118(8)$ & $1770(3)$ & $67(3)$ \\
\hline$C(31)$ & $1266(4)$ & 7742(9) & 2137(3) & $73(3)$ \\
\hline$C(32)$ & $640(4)$ & $7789(8)$ & $2298(3)$ & $59(2)$ \\
\hline$C(33)$ & $-291(4)$ & $7463(10)$ & $2330(4)$ & $80(3)$ \\
\hline$C(34)$ & $-103(5)$ & 7958(9) & $2716(3)$ & $80(3)$ \\
\hline$C(35)$ & $928(4)$ & $8692(8)$ & $3024(3)$ & $74(3)$ \\
\hline$C(36)$ & $1242(4)$ & $8812(9)$ & $1446(3)$ & $71(3)$ \\
\hline$C(37)$ & $919(5)$ & $8667(10)$ & $1033(3)$ & $84(1)$ \\
\hline$C(38)$ & 191(4) & $7830(9)$ & $545(3)$ & $84(1)$ \\
\hline C(39) & $563(4)$ & $8852(9)$ & $375(3)$ & $84(1)$ \\
\hline$C(40)$ & $1419(4)$ & 10437(9) & $621(3)$ & $101(3)$ \\
\hline$C(41)$ & $93(5)$ & $1939(10)$ & $1627(3)$ & $81(3)$ \\
\hline$C(42)$ & $-570(5)$ & $1457(11)$ & $1558(5)$ & $127(5)$ \\
\hline$C(43)$ & $-575(4)$ & $310(12)$ & $1295(5)$ & $183(7)$ \\
\hline$C(44)$ & $-985(4)$ & $2526(11)$ & $1375(5)$ & $181(7)$ \\
\hline
\end{tabular}




$\begin{array}{lrlrr}\mathrm{C}(45) & -789(7) & 1056(19) & 2012(6) & 79(6) \\ \mathrm{C}(46) & -1351(7) & 6720(12) & 2413(4) & 119(5) \\ \mathrm{C}(47) & -1946(6) & 6232(14) & 2186(8) & 225(10) \\ \mathrm{C}(48) & -1878(7) & 4904(17) & 2137(7) & 254(6) \\ \mathrm{C}(49) & -2231(7) & 7170(16) & 1945(6) & 254(6) \\ \mathrm{C}(50) & -2457(8) & 6086(16) & 2552(7) & 254(6) \\ \mathrm{O}(4) & 510(3) & 1202(6) & 1772(2) & 87(2) \\ \mathrm{O}(5) & -1300(3) & 7014(7) & 2821(3) & 114(2) \\ \mathrm{O}(6) & -447(3) & 5765(8) & 1343(3) & 135(3) \\ \mathrm{Cl}(1) & 2330(1) & 1816(2) & 4394(1) & 74(1) \\ \mathrm{O}(7) & 1894(3) & 1524(6) & 4701(2) & 91(2) \\ \mathrm{O}(8) & 2122(3) & 1172(6) & 3996(2) & 101(2) \\ \mathrm{O}(9) & 2346(3) & 3171(6) & 4299(2) & 92(2) \\ \mathrm{O}(10) & 2929(3) & 1372(8) & 4529(3) & 144(3) \\ \mathrm{Cl}(2) & 2324(1) & 5405(2) & 2962(1) & 61(1) \\ \mathrm{O}(11) & 2406(3) & 4035(6) & 2976(2) & 103(2) \\ \mathrm{O}(12) & 1695(3) & 5718(6) & 2909(2) & 94(2) \\ \mathrm{O}(13) & 2674(3) & 6000(7) & 2662(2) & 112(3) \\ \mathrm{O}(14) & 2542(3) & 5917(6) & 3384(2) & 80(2)\end{array}$


Table S39. Crystal data and structure refinement for compound 39.

Identification code

Empirical formula

Formula weight

Temperature

Wavelength

Crystal system

Space group

Unit cell dimensions

Volume

Z

Density (calculated)

Absorption coefficient

$\mathrm{F}(000)$

Crystal size

Crystal color

Theta range for data collection

Index ranges

Reflections collected

Independent reflections

Completeness to theta $=28.02^{\circ}$

Refinement method

Data/restraints/parameters

Goodness-of-fit on $\mathrm{F}^{2}$

Final $R$ indices $[\mathrm{I}>2 \operatorname{sigma}(\mathrm{I})]$

$\mathrm{R}$ indices (all data)

Largest diff. peak and hole
$[\mathrm{Cu}(\mathbf{L 2}) \mathrm{OH}]^{+}$

$\mathrm{C}_{25} \mathrm{H}_{40} \mathrm{CuN}_{9} \mathrm{O}_{2} \bullet \mathrm{ClO}_{4}$

731.22

$100(2) \mathrm{K}$

$0.71073 \AA$

Monoclinic

$\mathrm{C} 2 / \mathrm{c}$

$$
\begin{array}{ll}
\mathrm{a}=31.507(4) \AA & \alpha=90^{\circ} . \\
\mathrm{b}=10.2599(12) \AA & \beta=117.812(2)^{\circ} . \\
\mathrm{c}=27.068(3) \AA & \gamma=90^{\circ} .
\end{array}
$$

8

$1.255 \mathrm{Mg} / \mathrm{m}^{3}$

$0.745 \mathrm{~mm}^{-1}$

3080

$0.31 \times 0.20 \times 0.05 \mathrm{~mm}^{3}$

green

1.46 to $28.02^{\circ}$.

$-41<=\mathrm{h}<=41,-13<=\mathrm{k}<=13,-34<=\mathrm{l}<=35$

32877

$8950[\mathrm{R}(\mathrm{int})=0.0499]$

$95.5 \%$

Full-matrix least-squares on $\mathrm{F}^{2}$

$8950 / 21 / 505$

1.056

$\mathrm{R}_{1}=0.0626, \mathrm{wR}_{2}=0.1399$

$\mathrm{R}_{1}=0.0930, \mathrm{wR}_{2}=0.1493$

1.126 and -1.878 e. $\AA^{-3}$ 
Table S40. Atomic coordinates (x 104) and equivalent isotropic displacement parameters $\left(\AA^{2} \times 10^{3}\right)$ for compound 39.

\begin{tabular}{|c|c|c|c|c|}
\hline & $\mathrm{x}$ & $\mathrm{y}$ & $\mathrm{z}$ & $\mathrm{U}(\mathrm{eq})$ \\
\hline $\mathrm{Cu}(1)$ & $1357(1)$ & $1920(1)$ & 4893(1) & $20(1)$ \\
\hline $\mathrm{Cl}(1)$ & $1597(1)$ & $1065(2)$ & $5762(1)$ & $23(1)$ \\
\hline $\mathrm{N}(1)$ & $1140(2)$ & $2751(5)$ & 4099(2) & $21(1)$ \\
\hline $\mathrm{N}(2)$ & $1233(2)$ & $227(5)$ & $4443(2)$ & $21(1)$ \\
\hline $\mathrm{N}(3)$ & $1048(2)$ & $-652(5)$ & $3627(2)$ & $23(1)$ \\
\hline $\mathrm{N}(4)$ & $740(2)$ & $2815(5)$ & $4794(2)$ & $21(1)$ \\
\hline $\mathrm{N}(5)$ & $145(2)$ & $4126(5)$ & $4276(2)$ & $25(1)$ \\
\hline $\mathrm{N}(6)$ & $1955(2)$ & $3035(5)$ & $5086(2)$ & $20(1)$ \\
\hline $\mathrm{N}(7)$ & $2273(2)$ & $4517(5)$ & $4772(2)$ & $21(1)$ \\
\hline $\mathrm{N}(8)$ & $1462(2)$ & $-1617(5)$ & $5042(2)$ & $22(1)$ \\
\hline $\mathrm{N}(9)$ & $502(2)$ & $2087(6)$ & $5469(2)$ & $24(1)$ \\
\hline $\mathrm{N}(10)$ & $2435(2)$ & $3231(6)$ & $6071(2)$ & $23(1)$ \\
\hline $\mathrm{O}(1)$ & $1467(2)$ & $-3714(4)$ & $4806(2)$ & $31(1)$ \\
\hline $\mathrm{O}(2)$ & $-224(2)$ & $2370(5)$ & $5413(2)$ & $33(1)$ \\
\hline $\mathrm{O}(3)$ & $3074(2)$ & $4531(5)$ & $6513(2)$ & $32(1)$ \\
\hline$C(1)$ & $874(2)$ & $1755(6)$ & $3659(3)$ & $24(1)$ \\
\hline$C(2)$ & $1062(2)$ & $445(6)$ & $3899(3)$ & $21(1)$ \\
\hline$C(3)$ & $1324(2)$ & $-1096(6)$ & $4512(3)$ & $21(1)$ \\
\hline$C(4)$ & $1216(2)$ & $-1653(6)$ & $4013(3)$ & $24(1)$ \\
\hline$C(5)$ & $869(3)$ & $-808(7)$ & $3023(3)$ & $29(2)$ \\
\hline$C(6)$ & $832(2)$ & $3902(6)$ & $4042(3)$ & $25(1)$ \\
\hline$C(7)$ & $561(2)$ & $3607(6)$ & $4356(3)$ & $21(1)$ \\
\hline $\mathrm{C}(8)$ & $416(2)$ & $2827(6)$ & $5003(3)$ & $21(1)$ \\
\hline $\mathrm{C}(9)$ & $46(2)$ & $3635(6)$ & $4688(3)$ & $25(1)$ \\
\hline$C(10)$ & $-170(3)$ & $5009(7)$ & $3827(3)$ & $34(2)$ \\
\hline$C(11)$ & $1581(2)$ & $3164(7)$ & $4065(3)$ & $24(1)$ \\
\hline$C(12)$ & $1934(2)$ & $3607(6)$ & $4634(3)$ & $22(1)$ \\
\hline$C(13)$ & $2329(2)$ & $3623(6)$ & $5534(3)$ & $19(1)$ \\
\hline$C(14)$ & $2536(2)$ & $4541(6)$ & $5348(3)$ & $23(1)$ \\
\hline$C(15)$ & $2349(2)$ & 5392(7) & 4391(3) & $28(2)$ \\
\hline$C(16)$ & $1483(2)$ & $-2918(6)$ & $5151(3)$ & $24(1)$ \\
\hline
\end{tabular}




\begin{tabular}{|c|c|c|c|c|}
\hline$C(17)$ & $1537(2)$ & $-3290(6)$ & $5726(3)$ & $23(1)$ \\
\hline$C(18)$ & $1368(3)$ & $-4695(6)$ & $5699(3)$ & $31(2)$ \\
\hline C(19) & $2074(2)$ & $-3174(7)$ & $6148(3)$ & $32(2)$ \\
\hline$C(20)$ & $1244(3)$ & $-2396(7)$ & $5907(3)$ & $28(2)$ \\
\hline$C(21)$ & $173(2)$ & $1859(6)$ & $5648(3)$ & $24(1)$ \\
\hline$C(22)$ & $309(2)$ & $899(6)$ & $6129(3)$ & $26(1)$ \\
\hline$C(23)$ & $109(3)$ & $-424(8)$ & $5852(4)$ & $47(2)$ \\
\hline$C(24)$ & $64(3)$ & $1304(8)$ & $6476(3)$ & $37(2)$ \\
\hline$C(25)$ & $848(3)$ & 773(9) & $6510(3)$ & $42(2)$ \\
\hline$C(26)$ & $2802(2)$ & $3726(7)$ & $6543(3)$ & $26(1)$ \\
\hline$C(27)$ & $2860(3)$ & $3197(8)$ & $7101(3)$ & $37(2)$ \\
\hline$C(28)$ & $2344(5)$ & $3270(20)$ & $7084(7)$ & $48(5)$ \\
\hline$C(28 \mathrm{~A})$ & $3430(6)$ & $2644(19)$ & $7405(7)$ & $49(5)$ \\
\hline C(29) & $2969(8)$ & $1773(19)$ & $7132(8)$ & $59(6)$ \\
\hline$C(29 A)$ & $2580(8)$ & $2020(20)$ & $7071(7)$ & $62(6)$ \\
\hline$C(30)$ & $3189(9)$ & $4070(20)$ & $7565(7)$ & $61(6)$ \\
\hline$C(30 A)$ & $2869(7)$ & $4331(18)$ & $7452(7)$ & $39(4)$ \\
\hline $\mathrm{Cu}(2)$ & 5191(1) & $897(2)$ & $7517(1)$ & $28(1)$ \\
\hline $\mathrm{Cu}(2 \mathrm{~A})$ & 5000 & $1400(13)$ & 7500 & $173(4)$ \\
\hline $\mathrm{Cl}(2)$ & $4702(2)$ & $2134(6)$ & $7760(2)$ & $45(1)$ \\
\hline $\mathrm{Cl}(3)$ & $5432(2)$ & $2575(4)$ & $7167(2)$ & $34(1)$ \\
\hline $\mathrm{Cl}(4)$ & $4753(2)$ & $-906(4)$ & $7299(2)$ & $56(1)$ \\
\hline $\mathrm{Cl}(5)$ & $5900(2)$ & $-178(5)$ & $7917(2)$ & $54(1)$ \\
\hline $\mathrm{O}(4)$ & $6314(4)$ & $-674(12)$ & $8142(5)$ & $57(4)$ \\
\hline
\end{tabular}


Table S41. Crystal data and structure refinement for compound $\mathbf{4 0 .}$

Identification code

Empirical formula

Formula weight

Temperature

Wavelength

Crystal system

Space group

Unit cell dimensions

Volume

Z

Density (calculated)

Absorption coefficient

$\mathrm{F}(000)$

Crystal size

Crystal color, habit

Theta range for data collection

Index ranges

Reflections collected

Independent reflections

Completeness to theta $=25.12^{\circ}$

Absorption correction

Max. and min. transmission

Refinement method

Data/restraints/parameters

Goodness-of-fit on $\mathrm{F}^{2}$

Final $\mathrm{R}$ indices $[\mathrm{I}>2 \operatorname{sigma}(\mathrm{I})]$

$\mathrm{R}$ indices (all data)

Largest diff. peak and hole
$\left[\mathrm{Cu}(\mathbf{L 2}) \mathrm{N}_{3}\right] \mathrm{ClO}_{4}$

$\mathrm{C}_{25} \mathrm{H}_{39} \mathrm{CuN}_{12} \mathrm{O}_{2} \bullet \mathrm{ClO}_{4}$

702.67

293(2) K

$0.71073 \AA$

Triclinic

P-1

$\mathrm{a}=12.003(3) \AA$

$\alpha=116.114(4)^{\circ}$

$\mathrm{b}=12.133(3) \AA$

$\beta=103.539(4)^{\circ}$

$\mathrm{c}=13.327(3) \AA$

$\gamma=99.520(4)^{\circ}$
2

$1.447 \mathrm{Mg} / \mathrm{m}^{3}$

$0.819 \mathrm{~mm}^{-1}$

734

$0.166 \times 0.077 \times 0.037 \mathrm{~mm}^{3}$

green plate

1.81 to $25.12^{\circ}$

$-14<=\mathrm{h}<=14,-14<=\mathrm{k}<=14,-15<=\mathrm{l}<=15$

12004

$5712[\mathrm{R}($ int $)=0.0486]$

$99.3 \%$

\section{SADABS}

0.976 and 0.658

Full-matrix least-squares on $\mathrm{F}^{2}$

$5712 / 6 / 417$

1.013

$\mathrm{R}_{1}=0.0645, \mathrm{wR}_{2}=0.1130$

$\mathrm{R}_{1}=0.0863, \mathrm{wR}_{2}=0.1239$

0.515 and -0.461 e. $\AA^{-3}$ 
Table S42. Atomic coordinates (x 104) and equivalent isotropic displacement parameters $\left(\AA^{2} \times 10^{3}\right)$ for compound 40.

\begin{tabular}{|c|c|c|c|c|}
\hline & $\mathrm{X}$ & $\mathrm{y}$ & $\mathrm{z}$ & $\mathrm{U}(\mathrm{eq})$ \\
\hline $\mathrm{Cu}(1)$ & $8210(1)$ & $5159(1)$ & $7347(1)$ & $47(1)$ \\
\hline $\mathrm{O}(1)$ & $6376(4)$ & $8136(4)$ & $5328(4)$ & $71(1)$ \\
\hline $\mathrm{O}(2)$ & $12048(4)$ & $8774(4)$ & $11670(4)$ & $82(2)$ \\
\hline $\mathrm{N}(1)$ & 6794(4) & $4070(5)$ & 7611(4) & $41(1)$ \\
\hline $\mathrm{N}(2)$ & $6858(4)$ & $5887(5)$ & $6912(4)$ & $48(1)$ \\
\hline $\mathrm{N}(3)$ & 4984(4) & $5924(5)$ & $6741(4)$ & $50(1)$ \\
\hline $\mathrm{N}(4)$ & $7870(4)$ & $3487(4)$ & $5970(4)$ & $51(1)$ \\
\hline $\mathrm{N}(5)$ & $6614(4)$ & $1553(5)$ & $4642(5)$ & $49(1)$ \\
\hline $\mathrm{N}(6)$ & $8948(4)$ & $5889(5)$ & $9086(4)$ & $47(1)$ \\
\hline $\mathrm{N}(7)$ & $8910(5)$ & $5814(5)$ & $10696(5)$ & $51(1)$ \\
\hline $\mathrm{N}(8)$ & $7443(4)$ & $7199(5)$ & $6109(5)$ & $54(2)$ \\
\hline $\mathrm{N}(9)$ & $10632(5)$ & $7722(5)$ & $9852(5)$ & $57(2)$ \\
\hline $\mathrm{N}(10)$ & $9450(5)$ & $6252(5)$ & $7132(5)$ & $56(2)$ \\
\hline $\mathrm{N}(11)$ & $10201(5)$ & $5825(5)$ & $6761(5)$ & $55(2)$ \\
\hline $\mathrm{N}(12)$ & $10939(5)$ & $5479(6)$ & $6421(5)$ & $79(2)$ \\
\hline $\mathrm{C}(1)$ & $5890(5)$ & $4798(6)$ & $7782(6)$ & $54(2)$ \\
\hline$C(2)$ & $5868(6)$ & $5500(6)$ & $7115(5)$ & $45(2)$ \\
\hline$C(3)$ & $6536(5)$ & $6584(6)$ & $6384(5)$ & $45(2)$ \\
\hline$C(4)$ & $5401(5)$ & $6614(6)$ & $6243(5)$ & $50(2)$ \\
\hline$C(5)$ & $3787(5)$ & $5729(6)$ & $6869(6)$ & $74(2)$ \\
\hline$C(6)$ & $7356(5)$ & $4053(6)$ & $8707(5)$ & $54(2)$ \\
\hline$C(7)$ & $8367(6)$ & $5249(6)$ & $9523(6)$ & $48(2)$ \\
\hline$C(8)$ & $9871(6)$ & $6899(6)$ & $10056(6)$ & $46(2)$ \\
\hline $\mathrm{C}(9)$ & $9863(6)$ & $6871(6)$ & $11068(6)$ & $55(2)$ \\
\hline$C(10)$ & $8525(6)$ & $5385(6)$ & $11468(5)$ & $74(2)$ \\
\hline$C(11)$ & $6252(5)$ & $2757(6)$ & $6568(5)$ & $58(2)$ \\
\hline$C(12)$ & $6925(6)$ & $2587(6)$ & $5696(6)$ & $46(2)$ \\
\hline$C(13)$ & $8194(6)$ & $2992(7)$ & $4924(6)$ & $67(2)$ \\
\hline$C(14)$ & $7432(7)$ & $1789(7)$ & $4124(6)$ & $69(2)$ \\
\hline$C(15)$ & $5617(6)$ & $352(6)$ & $4042(5)$ & $69(2)$ \\
\hline$C(16)$ & $7349(6)$ & $7984(6)$ & $5667(5)$ & $45(2)$ \\
\hline
\end{tabular}




\begin{tabular}{lccrr}
$\mathrm{C}(17)$ & $8492(6)$ & $8642(6)$ & $5552(6)$ & $57(2)$ \\
$\mathrm{C}(18)$ & $9587(6)$ & $9102(7)$ & $6651(7)$ & $107(3)$ \\
$\mathrm{C}(19)$ & $8648(7)$ & $7692(7)$ & $4460(8)$ & $137(4)$ \\
$\mathrm{C}(20)$ & $8329(6)$ & $9810(7)$ & $5481(7)$ & $91(3)$ \\
$\mathrm{C}(21)$ & $11688(7)$ & $8627(6)$ & $10673(7)$ & $60(2)$ \\
$\mathrm{C}(22)$ & $12390(6)$ & $9442(6)$ & $10270(6)$ & $55(2)$ \\
$\mathrm{C}(23)$ & $11796(7)$ & $10437(8)$ & $10275(9)$ & $139(4)$ \\
$\mathrm{C}(24)$ & $12469(8)$ & $8631(8)$ & $9096(7)$ & $146(4)$ \\
$\mathrm{C}(25)$ & $13637(7)$ & $10171(8)$ & $11166(7)$ & $118(3)$ \\
$\mathrm{Cl}(1)$ & $6008(2)$ & $7557(2)$ & $1091(2)$ & $94(1)$ \\
$\mathrm{O}(3 \mathrm{~A})$ & $5883(12)$ & $7393(10)$ & $2070(10)$ & $99(4)$ \\
$\mathrm{O}(4 \mathrm{~A})$ & $4784(11)$ & $6776(13)$ & $68(11)$ & $117(4)$ \\
$\mathrm{O}(5 \mathrm{~A})$ & $6883(10)$ & $7107(10)$ & $710(10)$ & $90(4)$ \\
$\mathrm{O}(6 \mathrm{~A})$ & $6189(9)$ & $8922(9)$ & $1432(9)$ & $70(3)$ \\
$\mathrm{O}(4 \mathrm{~B})$ & $5509(17)$ & $7398(17)$ & $29(18)$ & $231(8)$ \\
$\mathrm{O}(5 \mathrm{~B})$ & $6434(13)$ & $6529(15)$ & $928(13)$ & $181(6)$ \\
$\mathrm{O}(3 \mathrm{~B})$ & $5216(11)$ & $7525(10)$ & $1681(10)$ & $117(4)$ \\
$\mathrm{O}(6 \mathrm{~B})$ & $6922(12)$ & $8809(12)$ & $1881(11)$ & $142(4)$ \\
\hline
\end{tabular}


Table S43. Crystal data and structure refinement for compound $4 \mathbf{4 1}$

Identification code

Empirical formula

Formula weight

Temperature

Wavelength

Crystal system

Space group

Unit cell dimensions

Volume

$\mathrm{Z}$

Density (calculated)

Absorption coefficient

$\mathrm{F}(000)$

Crystal size

Theta range for data collection

Index ranges

Reflections collected

Independent reflections

Completeness to theta $=28.35^{\circ}$

Absorption correction

Refinement method

Data/restraints/parameters

Goodness-of-fit on $\mathrm{F}^{2}$

Final $R$ indices $[\mathrm{I}>2 \operatorname{sigma}(\mathrm{I})]$

$\mathrm{R}$ indices (all data)

Largest diff. peak and hole
2-Hydroxymethyl-1-methyl-4-

nitroimidazole.

$\mathrm{C}_{5} \mathrm{H}_{7} \mathrm{~N}_{3} \mathrm{O}_{3}$

157.14

568(2) K

$0.71073 \AA$

Orthorhombic

Pccn

$\begin{array}{ll}\mathrm{a}=8.8943(7) \AA & \alpha=90^{\circ} . \\ \mathrm{b}=18.5639(15) \AA & \beta=90^{\circ} . \\ \mathrm{c}=8.3351(7) \AA & \gamma=90^{\circ} .\end{array}$

$1376.23(19) \AA^{3}$

8

$1.517 \mathrm{Mg} / \mathrm{m}^{3}$

$0.127 \mathrm{~mm}^{-1}$

656

$0.33 \times 0.14 \times 0.07 \mathrm{~mm}^{3}$

2.19 to $28.35^{\circ}$.

$-11<=\mathrm{h}<=8,-24<=\mathrm{k}<=24,-11<=\mathrm{l}<=10$

7838

$1638[\mathrm{R}(\mathrm{int})=0.0360]$

$95.0 \%$

None

Full-matrix least-squares on $\mathrm{F}^{2}$

$1638 / 0 / 103$

0.993

$\mathrm{R}_{1}=0.0493, \mathrm{wR}_{2}=0.1463$

$\mathrm{R}_{1}=0.0708, \mathrm{wR}_{2}=0.1546$

0.358 and -0.148 e. $\AA^{-3}$ 
Table S44. Atomic coordinates $\left(\times 10^{4}\right)$ and equivalent isotropic displacement parameters $\left(\AA^{2} \times 10^{3}\right)$ for compound 41.

\begin{tabular}{lrrrr}
\hline & $\mathrm{x}$ & $\mathrm{y}$ & $\mathrm{z}$ & $\mathrm{U}(\mathrm{eq})$ \\
\hline $\mathrm{N}(2)$ & $2266(2)$ & $6492(1)$ & $604(2)$ & $42(1)$ \\
$\mathrm{C}(1)$ & $862(2)$ & $6680(1)$ & $870(2)$ & $40(1)$ \\
$\mathrm{C}(2)$ & $2157(2)$ & $5954(1)$ & $-500(2)$ & $40(1)$ \\
$\mathrm{N}(3)$ & $3458(2)$ & $5600(1)$ & $-1110(2)$ & $52(1)$ \\
$\mathrm{O}(1)$ & $-244(2)$ & $7855(1)$ & $1301(2)$ & $58(1)$ \\
$\mathrm{N}(1)$ & $-109(2)$ & $6287(1)$ & $-51(2)$ & $45(1)$ \\
$\mathrm{C}(3)$ & $730(2)$ & $5819(1)$ & $-933(2)$ & $46(1)$ \\
$\mathrm{O}(2)$ & $4700(2)$ & $5808(1)$ & $-686(2)$ & $73(1)$ \\
$\mathrm{O}(3)$ & $3254(2)$ & $5103(1)$ & $-2061(2)$ & $72(1)$ \\
$\mathrm{C}(5)$ & $347(2)$ & $7238(1)$ & $2035(2)$ & $51(1)$ \\
$\mathrm{C}(4)$ & $-1740(2)$ & $6358(1)$ & $-116(3)$ & $68(1)$ \\
\hline
\end{tabular}


Table S45. Crystal data and structure refinement for compound $\mathbf{4 2}$.

Identification code

Empirical formula

Formula weight

Temperature

Wavelength

Crystal system

Space group

Unit cell dimensions

Volume

Z

Density (calculated)

Absorption coefficient

$\mathrm{F}(000)$

Crystal size

Crystal color, habit

Theta range for data collection

Index ranges

Reflections collected

Independent reflections

Completeness to theta $=28.21^{\circ}$

Absorption correction

Max. and min. transmission

Refinement method

Data/restraints/parameters

Goodness-of-fit on $\mathrm{F}^{2}$

Final R indices $[\mathrm{I}>2 \operatorname{sigma}(\mathrm{I})]$

$\mathrm{R}$ indices (all data)

Largest diff. peak and hole
1-Methyl-4-nitroimidazole-2-carboxylic acid.

$\mathrm{C}_{5} \mathrm{H}_{5} \mathrm{~N}_{3} \mathrm{O}_{4} \bullet \mathrm{CH}_{3} \mathrm{OH}$

203.16

$100(2) \mathrm{K}$

$0.71073 \AA$

Triclinic

P-1

$\begin{array}{ll}\mathrm{a}=7.4017(11) \AA & \alpha=85.221(2)^{\circ} \\ \mathrm{b}=7.7853(12) \AA & \beta=83.158(2)^{\circ} \\ \mathrm{c}=7.7852(11) \AA & \gamma=75.744(2)^{\circ}\end{array}$

431.03(11) $\AA^{3}$

2

$1.565 \mathrm{Mg} / \mathrm{m}^{3}$

$0.137 \mathrm{~mm}^{-1}$

212

$0.174 \times 0.111 \times 0.047 \mathrm{~mm}^{3}$

colorless plate

2.64 to $28.21^{\circ}$

$-9<=\mathrm{h}<=9,-9<=\mathrm{k}<=10,-10<=\mathrm{l}<=10$

3783

$1916[\mathrm{R}($ int $)=0.0150]$

$90.2 \%$

\section{SADABS}

0.956 and 0.885

Full-matrix least-squares on $\mathrm{F}^{2}$

1916/0/135

1.013

$\mathrm{R}_{1}=0.034, \mathrm{wR}_{2}=0.077$

$\mathrm{R}_{1}=0.039, \mathrm{wR}_{2}=0.079$

0.266 and -0.286 e. $\AA^{-3}$ 
Table S46. Atomic coordinates (x 104) and equivalent isotropic displacement parameters $\left(\AA^{2} \times 10^{3}\right)$ for compound 42.

\begin{tabular}{lrrrr}
\hline & $\mathrm{x}$ & $\mathrm{y}$ & $\mathrm{z}$ & $\mathrm{U}(\mathrm{eq})$ \\
\hline $\mathrm{O}(1)$ & & & \\
$\mathrm{O}(2)$ & $2975(1)$ & $5297(1)$ & $3190(1)$ & $23(1)$ \\
$\mathrm{O}(3)$ & $1442(1)$ & $4741(1)$ & $1054(1)$ & $24(1)$ \\
$\mathrm{O}(4)$ & $5755(1)$ & $402(1)$ & $-3098(1)$ & $25(1)$ \\
$\mathrm{N}(1)$ & $8559(1)$ & $-445(1)$ & $-2277(1)$ & $25(1)$ \\
$\mathrm{N}(2)$ & $6276(2)$ & $2793(1)$ & $1714(1)$ & $17(1)$ \\
$\mathrm{N}(3)$ & $4552(2)$ & $2458(1)$ & $-343(1)$ & $17(1)$ \\
$\mathrm{C}(1)$ & $6919(2)$ & $414(2)$ & $-2103(1)$ & $19(1)$ \\
$\mathrm{C}(2)$ & $4551(2)$ & $3250(2)$ & $1098(2)$ & $17(1)$ \\
$\mathrm{C}(3)$ & $6334(2)$ & $1476(2)$ & $-625(2)$ & $17(1)$ \\
$\mathrm{C}(4)$ & $7426(2)$ & $1652(2)$ & $614(2)$ & $19(1)$ \\
$\mathrm{C}(5)$ & $2903(2)$ & $4538(2)$ & $1918(2)$ & $17(1)$ \\
$\mathrm{O}(5)$ & $6846(2)$ & $3383(2)$ & $3272(2)$ & $24(1)$ \\
$\mathrm{C}(6)$ & $1205(1)$ & $2628(1)$ & $8018(1)$ & $22(1)$ \\
& $1524(2)$ & $2128(2)$ & $6255(2)$ & $24(1)$ \\
\hline
\end{tabular}


Table S47. Crystal data and structure refinement for compound 43.

Identification code

Empirical formula

Formula weight

Temperature

Wavelength

Crystal system

Space group

Unit cell dimensions

Volume

Z

Density (calculated)

Absorption coefficient

$\mathrm{F}(000)$

Crystal size

Crystal color

Theta range for data collection

Index ranges

Reflections collected

Independent reflections

Completeness to theta $=28.29^{\circ}$

Refinement method

Data/restraints/parameters

Goodness-of-fit on $\mathrm{F}^{2}$

Final R indices $[\mathrm{I}>2 \operatorname{sigma}(\mathrm{I})]$

$\mathrm{R}$ indices (all data)

Largest diff. peak and hole tmima : boric acid (1/1).

$\mathrm{C}_{15} \mathrm{H}_{21} \mathrm{~N}_{7} \bullet \mathrm{B}(\mathrm{OH})_{3}$

361.22

$100(2) \mathrm{K}$

$0.71073 \AA$

monoclinic

$\mathrm{P} 2{ }_{1} / \mathrm{c}$

$\mathrm{a}=16.2812(17) \AA \quad \alpha=90^{\circ}$.

$\mathrm{b}=10.0010(10) \AA \quad \beta=110.719(2)^{\circ}$.

$\mathrm{c}=12.2564(13) \AA \quad \gamma=90^{\circ}$.

$1866.6(3) \AA^{3}$

4

$1.285 \mathrm{Mg} / \mathrm{m}^{3}$

$0.092 \mathrm{~mm}^{-1}$

768

$0.24 \times 0.21 \times 0.08 \mathrm{~mm}^{3}$

colorless

2.44 to $28.29^{\circ}$.

$-21<=\mathrm{h}<=20,-13<=\mathrm{k}<=13,-15<=\mathrm{l}<=16$

16065

$4361[\mathrm{R}($ int $)=0.029]$

$94.0 \%$

Full-matrix least-squares on $\mathrm{F}^{2}$

$4361 / 0 / 251$

1.03

$\mathrm{R}_{1}=0.041, \mathrm{wR}_{2}=0.098$

$\mathrm{R}_{1}=0.054, \mathrm{wR}_{2}=0.105$

0.309 and -0.206 e. $\AA^{-3}$ 
Table S48. Atomic coordinates $\left(\times 10^{4}\right)$ and equivalent isotropic displacement parameters $\left(\AA^{2} \times 10^{3}\right)$ for compound 43.

\begin{tabular}{|c|c|c|c|c|}
\hline & $\mathrm{x}$ & $\mathrm{y}$ & $\mathrm{Z}$ & $\mathrm{U}(\mathrm{eq})$ \\
\hline $\mathrm{N}(1)$ & $3794(1)$ & $5730(1)$ & $4334(1)$ & $22(1)$ \\
\hline $\mathrm{N}(2)$ & $4582(1)$ & $6035(1)$ & $3213(1)$ & $22(1)$ \\
\hline $\mathrm{N}(3)$ & $1757(1)$ & $7825(1)$ & $1342(1)$ & $21(1)$ \\
\hline $\mathrm{N}(4)$ & $1160(1)$ & $6813(1)$ & $-368(1)$ & $24(1)$ \\
\hline $\mathrm{N}(5)$ & $1075(1)$ & $3555(1)$ & $2549(1)$ & $20(1)$ \\
\hline $\mathrm{N}(6)$ & $1825(1)$ & 1790(1) & $2344(1)$ & $19(1)$ \\
\hline $\mathrm{N}(8)$ & $2521(1)$ & $4902(1)$ & $1817(1)$ & $18(1)$ \\
\hline $\mathrm{C}(1)$ & 3929(1) & $5353(1)$ & $3350(1)$ & $18(1)$ \\
\hline$C(2)$ & $4876(1)$ & $6885(1)$ & $4155(1)$ & $26(1)$ \\
\hline$C(3)$ & 4399(1) & $6707(1)$ & $4852(1)$ & $27(1)$ \\
\hline$C(4)$ & $3139(1)$ & $5206(2)$ & $4780(1)$ & $32(1)$ \\
\hline$C(5)$ & $3386(1)$ & $4342(1)$ & $2512(1)$ & $20(1)$ \\
\hline$C(6)$ & $1836(1)$ & $6835(1)$ & $625(1)$ & $19(1)$ \\
\hline$C(7)$ & $623(1)$ & $7839(1)$ & $-276(1)$ & $26(1)$ \\
\hline$C(8)$ & $982(1)$ & $8473(1)$ & $765(1)$ & $25(1)$ \\
\hline $\mathrm{C}(9)$ & $2351(1)$ & $8116(1)$ & $2529(1)$ & $27(1)$ \\
\hline$C(10)$ & $2598(1)$ & $5900(1)$ & 969(1) & $20(1)$ \\
\hline$C(11)$ & $1611(1)$ & $3045(1)$ & $2022(1)$ & $17(1)$ \\
\hline$C(12)$ & $1403(1)$ & $1492(1)$ & $3110(1)$ & $21(1)$ \\
\hline$C(13)$ & $937(1)$ & $2567(1)$ & $3242(1)$ & $24(1)$ \\
\hline$C(14)$ & $666(1)$ & $4874(1)$ & $2355(1)$ & $28(1)$ \\
\hline$C(15)$ & $1914(1)$ & $3828(1)$ & $1202(1)$ & $19(1)$ \\
\hline $\mathrm{B}(1)$ & $4057(1)$ & $613(1)$ & $3466(1)$ & $18(1)$ \\
\hline $\mathrm{O}(1)$ & $3487(1)$ & $1007(1)$ & $2405(1)$ & $21(1)$ \\
\hline $\mathrm{O}(2)$ & $3767(1)$ & $378(1)$ & $4366(1)$ & $23(1)$ \\
\hline $\mathrm{O}(3)$ & $4926(1)$ & $458(1)$ & $3619(1)$ & $22(1)$ \\
\hline
\end{tabular}


Table S49. Crystal data and structure refinement for compound 44.

Identification code

Empirical formula

Formula weight

Temperature

Wavelength

Crystal system

Space group

Unit cell dimensions

Volume

$\mathrm{Z}$

Density (calculated)

Absorption coefficient

$\mathrm{F}(000)$

Crystal size

Crystal color

Theta range for data collection

Index ranges

Reflections collected

Independent reflections

Completeness to theta $=28.30^{\circ}$

Absorption correction

Refinement method

Data/restraints/parameters

Goodness-of-fit on $\mathrm{F}^{2}$

Final $\mathrm{R}$ indices $[\mathrm{I}>2$ sigma(I)]

$\mathrm{R}$ indices (all data)

Largest diff. peak and hole
Compound 16 : boric acid (2/1)

$2\left(\mathrm{C}_{15} \mathrm{H}_{20} \mathrm{~N}_{8} \mathrm{O}_{2}\right) \bullet \mathrm{B}(\mathrm{OH})_{3}$

750.61

100(2) K

$0.71073 \AA$

Monoclinic

$\mathrm{P} 2(1) / \mathrm{n}$

$\begin{array}{ll}\mathrm{a}=15.7997(18) \AA & \alpha=90^{\circ} \\ \mathrm{b}=8.2540(9) \AA & \beta=92.861(2)^{\circ} \\ \mathrm{c}=27.530(3) \AA & \gamma=90^{\circ}\end{array}$ $3585.7(7) \AA^{3}$

4

$1.390 \mathrm{Mg} / \mathrm{m}^{3}$

$0.103 \mathrm{~mm}^{-1}$

1584

$0.301 \times 0.173 \times 0.081 \mathrm{~mm}^{3}$

colorless

1.52 to $28.30^{\circ}$.

$-20<=\mathrm{h}<=21,-10<=\mathrm{k}<=10,-34<=\mathrm{l}<=35$

29945

$8345[\mathrm{R}(\mathrm{int})=0.0273]$

$93.8 \%$

Sadabs

Full-matrix least-squares on $\mathrm{F}^{2}$

$8345 / 0 / 540$

1.097

$\mathrm{R}_{1}=0.043, \mathrm{wR}_{2}=0.107$

$\mathrm{R}_{1}=0.058, \mathrm{wR}_{2}=0.113$

0.556 and -0.203 e. $\AA^{-3}$ 
Table S50. Atomic coordinates (x 104) and equivalent isotropic displacement parameters $\left(\AA^{2} \times 10^{3}\right)$ for compound 44.

\begin{tabular}{|c|c|c|c|c|}
\hline & $\mathrm{x}$ & $\mathrm{y}$ & $\mathrm{z}$ & $\mathrm{U}(\mathrm{eq})$ \\
\hline $\mathrm{O}(1)$ & $1760(1)$ & $-3080(1)$ & $2339(1)$ & $29(1)$ \\
\hline $\mathrm{O}(2)$ & $798(1)$ & $-4396(1)$ & $2713(1)$ & $36(1)$ \\
\hline $\mathrm{O}(3)$ & $6850(1)$ & $12771(1)$ & $2303(1)$ & $27(1)$ \\
\hline $\mathrm{O}(4)$ & $5796(1)$ & $14128(1)$ & $2570(1)$ & $34(1)$ \\
\hline $\mathrm{N}(1)$ & $1371(1)$ & $396(1)$ & $3362(1)$ & $19(1)$ \\
\hline $\mathrm{N}(2)$ & $627(1)$ & $-1890(1)$ & $3351(1)$ & $18(1)$ \\
\hline $\mathrm{N}(3)$ & $-1506(1)$ & $3120(1)$ & $3240(1)$ & $19(1)$ \\
\hline $\mathrm{N}(4)$ & $-2272(1)$ & $2589(1)$ & $3871(1)$ & $18(1)$ \\
\hline $\mathrm{N}(5)$ & $256(1)$ & $4876(1)$ & $4361(1)$ & $21(1)$ \\
\hline $\mathrm{N}(6)$ & $1000(1)$ & $3166(1)$ & $4831(1)$ & $23(1)$ \\
\hline $\mathrm{N}(7)$ & $1241(1)$ & $-3196(1)$ & $2659(1)$ & $23(1)$ \\
\hline $\mathrm{N}(8)$ & $-243(1)$ & $1336(1)$ & $3967(1)$ & $15(1)$ \\
\hline $\mathrm{N}(9)$ & $6448(1)$ & $9799(1)$ & $3454(1)$ & $17(1)$ \\
\hline $\mathrm{N}(10)$ & $5623(1)$ & 11953(1) & $3312(1)$ & $19(1)$ \\
\hline $\mathrm{N}(11)$ & $5632(1)$ & $5891(1)$ & $4589(1)$ & $21(1)$ \\
\hline $\mathrm{N}(12)$ & $5920(1)$ & $8035(1)$ & $5053(1)$ & $22(1)$ \\
\hline N(13) & $3734(1)$ & $6689(2)$ & $3297(1)$ & $23(1)$ \\
\hline $\mathrm{N}(14)$ & $2823(1)$ & $7404(1)$ & $3842(1)$ & $20(1)$ \\
\hline $\mathrm{N}(15)$ & $6279(1)$ & $12972(1)$ & 2591(1) & $21(1)$ \\
\hline $\mathrm{N}(16)$ & $4814(1)$ & $8890(1)$ & $4002(1)$ & $17(1)$ \\
\hline $\mathrm{C}(1)$ & 763(1) & $-504(2)$ & $3578(1)$ & $17(1)$ \\
\hline$C(2)$ & $1171(1)$ & $-1860(2)$ & $2985(1)$ & $18(1)$ \\
\hline$C(3)$ & $1643(1)$ & $-476(2)$ & $2982(1)$ & $20(1)$ \\
\hline$C(4)$ & 1694(1) & 1978(2) & $3525(1)$ & $26(1)$ \\
\hline$C(5)$ & $373(1)$ & $18(2)$ & $4035(1)$ & $17(1)$ \\
\hline$C(6)$ & $-1630(1)$ & 2099(2) & $3617(1)$ & $17(1)$ \\
\hline$C(7)$ & $-2565(1)$ & $3983(2)$ & $3646(1)$ & $20(1)$ \\
\hline$C(8)$ & $-2101(1)$ & $4327(2)$ & $3258(1)$ & $21(1)$ \\
\hline$C(9)$ & $-844(1)$ & $2989(2)$ & 2891(1) & $26(1)$ \\
\hline$C(10)$ & $-1055(1)$ & $716(2)$ & $3748(1)$ & $17(1)$ \\
\hline $\mathrm{C}(11)$ & $302(1)$ & $3357(2)$ & $4553(1)$ & $19(1)$ \\
\hline
\end{tabular}




\begin{tabular}{lrrrl}
$\mathrm{C}(12)$ & $1410(1)$ & $4641(2)$ & $4817(1)$ & $23(1)$ \\
$\mathrm{C}(13)$ & $964(1)$ & $5691(2)$ & $4532(1)$ & $24(1)$ \\
$\mathrm{C}(14)$ & $-430(1)$ & $5551(2)$ & $4049(1)$ & $27(1)$ \\
$\mathrm{C}(15)$ & $-360(1)$ & $2097(2)$ & $4447(1)$ & $17(1)$ \\
$\mathrm{C}(16)$ & $5787(1)$ & $10720(2)$ & $3605(1)$ & $18(1)$ \\
$\mathrm{C}(17)$ & $6728(1)$ & $10494(2)$ & $3047(1)$ & $18(1)$ \\
$\mathrm{C}(18)$ & $6209(1)$ & $11800(2)$ & $2968(1)$ & $18(1)$ \\
$\mathrm{C}(19)$ & $6824(1)$ & $8398(2)$ & $3708(1)$ & $23(1)$ \\
$\mathrm{C}(20)$ & $5350(1)$ & $10343(2)$ & $4061(1)$ & $20(1)$ \\
$\mathrm{C}(21)$ & $5390(1)$ & $7411(2)$ & $4715(1)$ & $18(1)$ \\
$\mathrm{C}(22)$ & $6521(1)$ & $6854(2)$ & $5146(1)$ & $26(1)$ \\
$\mathrm{C}(23)$ & $6353(1)$ & $5526(2)$ & $4867(1)$ & $25(1)$ \\
$\mathrm{C}(24)$ & $5215(1)$ & $4851(2)$ & $4223(1)$ & $29(1)$ \\
$\mathrm{C}(25)$ & $4632(1)$ & $8237(2)$ & $4489(1)$ & $18(1)$ \\
$\mathrm{C}(26)$ & $3506(1)$ & $7843(2)$ & $3618(1)$ & $19(1)$ \\
$\mathrm{C}(27)$ & $2602(1)$ & $5906(2)$ & $3655(1)$ & $23(1)$ \\
$\mathrm{C}(28)$ & $3159(1)$ & $5450(2)$ & $3321(1)$ & $25(1)$ \\
$\mathrm{C}(29)$ & $4441(1)$ & $6781(2)$ & $2978(1)$ & $33(1)$ \\
$\mathrm{C}(30)$ & $4016(1)$ & $9323(2)$ & $3731(1)$ & $20(1)$ \\
& & & & \\
\hline
\end{tabular}


Table S51. Crystal data and structure refinement for compound $\mathbf{4 6 .}$

Identification code

Empirical formula

Formula weight

Temperature

Wavelength

Crystal system

Space group

Unit cell dimensions

Volume

Z

Density (calculated)

Absorption coefficient

$\mathrm{F}(000)$

Crystal size

Crystal color

Theta range for data collection

Index ranges

Reflections collected

Independent reflections

Completeness to theta $=28.30^{\circ}$

Refinement method

Data/restraints/parameters

Goodness-of-fit on $\mathrm{F}^{2}$

Final R indices $[\mathrm{I}>2 \operatorname{sigma}(\mathrm{I})]$

$\mathrm{R}$ indices (all data)

Largest diff. peak and hole
Bis(2-ethyl-5-methylimidazol-4-methyl)(1methylimidazol-2-methyl)amine,

monohydrate.

$\mathrm{C}_{19} \mathrm{H}_{21} \mathrm{~N}_{7} \mathrm{O}$

363.43

100(2) K

$0.71073 \AA$

Monoclinic

$\mathrm{C} 2$

$$
\begin{aligned}
& \mathrm{a}=21.149(13) \AA \quad \alpha=90^{\circ} \text {. } \\
& \mathrm{b}=8.343(4) \AA \quad \beta=114.698(16)^{\circ} \text {. } \\
& \mathrm{c}=25.174(14) \AA \quad \gamma=90^{\circ} .
\end{aligned}
$$$$
\text { 4036(4) } \AA^{3}
$$

8

$1.196 \mathrm{Mg} / \mathrm{m}^{3}$

$0.080 \mathrm{~mm}^{-1}$

1536

$0.22 \times 0.18 \times 0.11 \mathrm{~mm}^{3}$

colorless

1.93 to $28.30^{\circ}$.

$-26<=\mathrm{h}<=27,-10<=\mathrm{k}<=10,-31<=\mathrm{l}<=33$

17567

$8769[\mathrm{R}(\mathrm{int})=0.0347]$

$92.7 \%$

Full-matrix least-squares on $\mathrm{F}^{2}$

$8769 / 7 / 509$

1.047

$\mathrm{R}_{1}=0.0682, \mathrm{wR}_{2}=0.1297$

$\mathrm{R}_{1}=0.1068, \mathrm{wR}_{2}=0.1386$

0.384 and -0.314 e. $\AA^{-3}$ 
Table S52. Atomic coordinates $\left(\times 10^{4}\right)$ and equivalent isotropic displacement parameters $\left(\AA^{2} \times 10^{3}\right)$ for compound 46.

\begin{tabular}{|c|c|c|c|c|}
\hline & $\mathrm{x}$ & $\mathrm{y}$ & z & $\mathrm{U}(\mathrm{eq})$ \\
\hline $\mathrm{N}(1)$ & $2970(2)$ & 7819(4) & $9508(1)$ & $41(1)$ \\
\hline $\mathrm{N}(2)$ & $3734(2)$ & $10444(4)$ & $10368(1)$ & $38(1)$ \\
\hline $\mathrm{N}(3)$ & $4370(2)$ & 9880(4) & $11296(1)$ & $35(1)$ \\
\hline $\mathrm{N}(4)$ & 3591(2) & $4795(5)$ & $8872(1)$ & $57(1)$ \\
\hline $\mathrm{N}(5)$ & 4074(2) & $7215(5)$ & $9027(1)$ & $52(1)$ \\
\hline $\mathrm{N}(6)$ & $2258(2)$ & 7952(4) & $7530(1)$ & $40(1)$ \\
\hline $\mathrm{N}(7)$ & $2520(2)$ & 9464(4) & $8313(1)$ & $48(1)$ \\
\hline $\mathrm{N}(8)$ & $1540(2)$ & $5322(4)$ & $4507(1)$ & $40(1)$ \\
\hline N(9) & $-50(2)$ & $4707(5)$ & $4024(1)$ & $52(1)$ \\
\hline $\mathrm{N}(10)$ & $279(2)$ & 2292(4) & $3869(1)$ & $57(1)$ \\
\hline $\mathrm{N}(11)$ & $794(2)$ & 6963(4) & $3314(1)$ & $47(1)$ \\
\hline $\mathrm{N}(12)$ & $274(2)$ & $5451(4)$ & $2530(1)$ & $39(1)$ \\
\hline $\mathrm{N}(13)$ & $1633(2)$ & 7945(4) & $5366(1)$ & $39(1)$ \\
\hline $\mathrm{N}(14)$ & 1927(2) & $7382(4)$ & $6295(1)$ & $34(1)$ \\
\hline $\mathrm{O}(1)$ & $1100(2)$ & $9330(4)$ & $4219(1)$ & $55(1)$ \\
\hline $\mathrm{O}(2)$ & $3120(2)$ & 1834(4) & $9220(1)$ & $54(1)$ \\
\hline $\mathrm{C}(1)$ & $3476(2)$ & $9028(5)$ & $10489(2)$ & $35(1)$ \\
\hline $\mathrm{C}(2)$ & 2013(2) & $6530(5)$ & $5486(2)$ & $37(1)$ \\
\hline$C(3)$ & $2189(2)$ & $6187(5)$ & $6060(2)$ & $34(1)$ \\
\hline $\mathrm{C}(4)$ & $4260(2)$ & $10909(5)$ & $10858(2)$ & $33(1)$ \\
\hline$C(5)$ & $3870(2)$ & $8686(5)$ & $11058(2)$ & $35(1)$ \\
\hline$C(6)$ & $1197(2)$ & $3957(5)$ & $4643(2)$ & $45(1)$ \\
\hline$C(7)$ & $4695(2)$ & $12403(6)$ & $10922(2)$ & $52(1)$ \\
\hline$C(8)$ & $1596(2)$ & $8413(5)$ & $5858(2)$ & $33(1)$ \\
\hline $\mathrm{C}(9)$ & 2181(2) & $6978(5)$ & 7943(2) & $37(1)$ \\
\hline$C(10)$ & $3697(2)$ & $6118(5)$ & $9178(2)$ & $43(1)$ \\
\hline$C(11)$ & $482(2)$ & $3617(5)$ & $4177(2)$ & $44(1)$ \\
\hline$C(12)$ & $3447(2)$ & $6457(5)$ & $9642(2)$ & $46(1)$ \\
\hline$C(13)$ & $762(2)$ & $4473(5)$ & $2942(2)$ & $36(1)$ \\
\hline$C(14)$ & $1222(2)$ & $9902(6)$ & $5921(2)$ & $51(1)$ \\
\hline$C(15)$ & 299(2) & 6914(6) & $2765(2)$ & 49(1) \\
\hline
\end{tabular}




\begin{tabular}{|c|c|c|c|c|}
\hline$C(16)$ & $3840(2)$ & $7312(5)$ & $11425(2)$ & $43(1)$ \\
\hline$C(17)$ & $2466(2)$ & $9411(6)$ & $7765(2)$ & $50(1)$ \\
\hline $\mathrm{C}(18)$ & $1949(2)$ & $5279(5)$ & $7828(2)$ & $56(1)$ \\
\hline C(19) & $2175(2)$ & $5726(6)$ & $5031(2)$ & $47(1)$ \\
\hline$C(20)$ & $2857(2)$ & $8222(6)$ & $10033(2)$ & $48(1)$ \\
\hline $\mathrm{C}(21)$ & $2299(2)$ & $7541(7)$ & $8988(2)$ & $60(2)$ \\
\hline$C(22)$ & $1082(2)$ & $5417(5)$ & $3425(2)$ & $40(1)$ \\
\hline $\mathrm{C}(23)$ & $877(2)$ & $2785(5)$ & $2826(2)$ & $55(1)$ \\
\hline$C(24)$ & $1690(2)$ & $5038(7)$ & $3989(2)$ & $61(2)$ \\
\hline$C(25)$ & $-28(2)$ & $6318(6)$ & $4252(2)$ & $66(2)$ \\
\hline$C(26)$ & $4278(2)$ & $8824(6)$ & $9255(2)$ & $66(2)$ \\
\hline$C(27)$ & $3908(3)$ & $5103(8)$ & $8496(2)$ & $78(2)$ \\
\hline$C(28)$ & $2345(2)$ & $7920(5)$ & $8427(2)$ & $40(1)$ \\
\hline C(29) & $-412(3)$ & 2601(9) & $3495(2)$ & $77(2)$ \\
\hline$C(30)$ & $-612(3)$ & $4067(9)$ & $3577(2)$ & $80(2)$ \\
\hline$C(31 \mathrm{~A})$ & $2440(6)$ & $11068(16)$ & $7517(5)$ & $76(3)$ \\
\hline$C(31 B)$ & $2643(4)$ & $10673(9)$ & $7395(3)$ & $22(1)$ \\
\hline$C(32)$ & $4189(3)$ & $6567(9)$ & $8578(2)$ & $81(2)$ \\
\hline $\mathrm{C}(34 \mathrm{~A})$ & $2966(9)$ & $10830(20)$ & $7345(7)$ & $113(5)$ \\
\hline$C(34 B)$ & $3324(3)$ & $11592(8)$ & $7763(3)$ & $25(1)$ \\
\hline$C(35 \mathrm{~A})$ & $4802(4)$ & $12860(11)$ & $10385(3)$ & $46(2)$ \\
\hline$C(35 B)$ & $4360(4)$ & $13735(10)$ & $10604(3)$ & $41(2)$ \\
\hline$C(36 A)$ & $1244(4)$ & $11233(10)$ & $5607(3)$ & $41(2)$ \\
\hline$C(36 B)$ & $582(4)$ & $10364(12)$ & $5390(3)$ & $50(2)$ \\
\hline$C(41)$ & $2587(2)$ & $4807(5)$ & $6428(2)$ & $43(1)$ \\
\hline$C(42)$ & $-563(3)$ & $9090(8)$ & 2763(3) & $25(1)$ \\
\hline$C(42 A)$ & $-610(9)$ & $8310(20)$ & $2349(7)$ & $114(5)$ \\
\hline$C(43)$ & $-246(4)$ & $8185(9)$ & $2396(3)$ & $22(1)$ \\
\hline$C(43 A)$ & $87(7)$ & $8557(16)$ & $2520(5)$ & $77(3)$ \\
\hline
\end{tabular}


Table S53. Crystal data and structure refinement for compound 47.

Identification code

Empirical formula

Formula weight

Temperature

Wavelength

Crystal system

Space group

Unit cell dimensions

Volume

Z

Density (calculated)

Absorption coefficient

$\mathrm{F}(000)$

Crystal size

Theta range for data collection

Index ranges

Reflections collected

Independent reflections

Completeness to theta $=28.33^{\circ}$

Absorption correction

Refinement method

Data/restraints/parameters

Goodness-of-fit on $\mathrm{F}^{2}$

Final $R$ indices $[\mathrm{I}>2 \operatorname{sigma}(\mathrm{I})]$

$\mathrm{R}$ indices (all data)

Largest diff. peak and hole
N,N-Bis(2-ethyl-5-methylimidazol-4-

methyl)glycine.

$\mathrm{C}_{16} \mathrm{H}_{25} \mathrm{~N}_{5} \mathrm{O}_{2} \bullet \mathrm{H}_{2} \mathrm{O}$

337.43

$100(2) \mathrm{K}$

$0.71073 \AA$

Triclinic

P-1

$\mathrm{a}=12.385(2) \AA \quad \alpha=92.951(3)^{\circ}$.

$\mathrm{b}=15.200(3) \AA \quad \beta=94.820(3)^{\circ}$.

$\mathrm{c}=9.6691(18) \AA \quad \gamma=86.719(3)^{\circ}$.

1808.9(6) $\AA^{3}$

4

$1.239 \mathrm{Mg} / \mathrm{m}^{3}$

$0.088 \mathrm{~mm}^{-1}$

728

$0.19 \times 0.15 \times 0.13 \mathrm{~mm}^{3}$

1.65 to $28.33^{\circ}$.

$-16<=\mathrm{h}<=16,-20<=\mathrm{k}<=19,-12<=\mathrm{l}<=12$

16140

$8148[\mathrm{R}($ int $)=0.024]$

$90.3 \%$

\section{SADABS}

Full-matrix least-squares on $\mathrm{F}^{2}$

$8148 / 0 / 526$

1.01

$\mathrm{R}_{1}=0.047, \mathrm{wR}_{2}=0.100$

$\mathrm{R}_{1}=0.070, \mathrm{wR}_{2}=0.106$

0.333 and -0.239 e. $\AA^{-3}$ 
Table S54. Atomic coordinates (x 104) and equivalent isotropic displacement parameters $\left(\AA^{2} \times 10^{3}\right)$ for compound 47.

\begin{tabular}{|c|c|c|c|c|}
\hline & $\mathrm{x}$ & $\mathrm{y}$ & $\mathrm{z}$ & $\mathrm{U}(\mathrm{eq})$ \\
\hline $\mathrm{O}(1)$ & $12308(1)$ & $1606(1)$ & $228(1)$ & $26(1)$ \\
\hline $\mathrm{O}(2)$ & $11654(1)$ & $2298(1)$ & $2073(1)$ & $40(1)$ \\
\hline $\mathrm{N}(1)$ & 9961(1) & $-657(1)$ & $2912(1)$ & $19(1)$ \\
\hline $\mathrm{N}(2)$ & $11269(1)$ & $-1523(1)$ & $3724(1)$ & $23(1)$ \\
\hline $\mathrm{N}(3)$ & $7855(1)$ & $1477(1)$ & $547(1)$ & $23(1)$ \\
\hline $\mathrm{N}(4)$ & $7716(1)$ & $2628(1)$ & $-773(2)$ & $25(1)$ \\
\hline $\mathrm{N}(5)$ & $10019(1)$ & $1112(1)$ & $2202(1)$ & $19(1)$ \\
\hline$C(1)$ & $10289(1)$ & $-1501(1)$ & $3052(2)$ & $21(1)$ \\
\hline$C(2)$ & $10758(1)$ & $-126(1)$ & $3506(2)$ & $20(1)$ \\
\hline$C(3)$ & $11587(1)$ & $-666(1)$ & $4025(2)$ & $22(1)$ \\
\hline$C(4)$ & $9658(2)$ & $-2273(1)$ & $2573(2)$ & $27(1)$ \\
\hline$C(5)$ & $9577(2)$ & $-2904(1)$ & $3710(2)$ & $47(1)$ \\
\hline$C(6)$ & $12631(1)$ & $-477(1)$ & $4839(2)$ & $30(1)$ \\
\hline$C(7)$ & $10578(1)$ & $854(1)$ & $3515(2)$ & $21(1)$ \\
\hline$C(8)$ & $7328(1)$ & $1844(1)$ & $-551(2)$ & $24(1)$ \\
\hline$C(9)$ & $8617(1)$ & $2075(1)$ & $1036(2)$ & $22(1)$ \\
\hline$C(10)$ & $8545(1)$ & $2789(1)$ & $227(2)$ & $23(1)$ \\
\hline $\mathrm{C}(11)$ & $6384(2)$ & 1491(1) & $-1417(2)$ & $31(1)$ \\
\hline$C(12)$ & $6315(2)$ & $503(1)$ & $-1391(2)$ & $34(1)$ \\
\hline$C(13)$ & $9133(2)$ & $3622(1)$ & $309(2)$ & $29(1)$ \\
\hline$C(14)$ & $9338(1)$ & $1927(1)$ & $2323(2)$ & $23(1)$ \\
\hline$C(15)$ & $10724(1)$ & $1060(1)$ & $1064(2)$ & $19(1)$ \\
\hline$C(16)$ & $11637(1)$ & $1705(1)$ & $1145(2)$ & $22(1)$ \\
\hline $\mathrm{O}(3)$ & $6766(1)$ & $3600(1)$ & $7132(1)$ & $42(1)$ \\
\hline $\mathrm{O}(4)$ & $7562(1)$ & $2905(1)$ & $5393(1)$ & $40(1)$ \\
\hline $\mathrm{N}(6)$ & $6781(1)$ & $6081(1)$ & $3893(2)$ & $27(1)$ \\
\hline $\mathrm{N}(7)$ & $7631(1)$ & $6563(1)$ & $5845(2)$ & $36(1)$ \\
\hline $\mathrm{N}(8)$ & $4764(1)$ & $3974(1)$ & $1518(1)$ & $22(1)$ \\
\hline $\mathrm{N}(9)$ & $3841(1)$ & $2836(1)$ & $969(1)$ & $24(1)$ \\
\hline $\mathrm{N}(10)$ & $6577(1)$ & $4136(1)$ & $3516(1)$ & $19(1)$ \\
\hline$C(17)$ & $6875(2)$ & $6750(1)$ & $4808(2)$ & $33(1)$ \\
\hline
\end{tabular}




\begin{tabular}{lrrrr}
$\mathrm{C}(18)$ & $7527(1)$ & $5430(1)$ & $4383(2)$ & $24(1)$ \\
$\mathrm{C}(19)$ & $8063(2)$ & $5722(1)$ & $5589(2)$ & $30(1)$ \\
$\mathrm{C}(20)$ & $6249(2)$ & $7623(1)$ & $4713(2)$ & $47(1)$ \\
$\mathrm{C}(21)$ & $6421(3)$ & $8094(2)$ & $3440(3)$ & $70(1)$ \\
$\mathrm{C}(22)$ & $8954(2)$ & $5308(2)$ & $6522(2)$ & $45(1)$ \\
$\mathrm{C}(23)$ & $7620(1)$ & $4552(1)$ & $3630(2)$ & $23(1)$ \\
$\mathrm{C}(24)$ & $3826(1)$ & $3711(1)$ & $929(2)$ & $24(1)$ \\
$\mathrm{C}(25)$ & $5408(1)$ & $3250(1)$ & $1951(2)$ & $21(1)$ \\
$\mathrm{C}(26)$ & $4823(1)$ & $2531(1)$ & $1618(2)$ & $23(1)$ \\
$\mathrm{C}(27)$ & $2928(1)$ & $4315(1)$ & $351(2)$ & $32(1)$ \\
$\mathrm{C}(28)$ & $2070(2)$ & $3848(1)$ & $-550(2)$ & $34(1)$ \\
$\mathrm{C}(29)$ & $5075(2)$ & $1577(1)$ & $1845(2)$ & $31(1)$ \\
$\mathrm{C}(30)$ & $6541(1)$ & $3360(1)$ & $2561(2)$ & $23(1)$ \\
$\mathrm{C}(31)$ & $6167(1)$ & $4014(1)$ & $4853(2)$ & $20(1)$ \\
$\mathrm{C}(32)$ & $6890(1)$ & $3454(1)$ & $5867(2)$ & $23(1)$ \\
$\mathrm{O}(5)$ & $5122(1)$ & $5723(1)$ & $1806(1)$ & $30(1)$ \\
$\mathrm{O}(6)$ & $7957(1)$ & $9784(1)$ & $1732(1)$ & $24(1)$ \\
\hline
\end{tabular}


Table S55. Crystal data and structure refinement for compound $\mathbf{4 8 .}$

Identification code

Empirical formula

Formula weight

Temperature

Wavelength

Crystal system

Space group

Unit cell dimensions

Volume

Z

Density (calculated)

Absorption coefficient

$\mathrm{F}(000)$

Crystal size

Crystal color

Theta range for data collection

Index ranges

Reflections collected

Independent reflections

Completeness to theta $=28.38^{\circ}$

Refinement method

Data/restraints/parameters

Goodness-of-fit on $\mathrm{F}^{2}$

Final $\mathrm{R}$ indices $[\mathrm{I}>2 \operatorname{sigma}(\mathrm{I})]$

$\mathrm{R}$ indices (all data)

Largest diff. peak and hole
N,N,N',N'-tetrakis(2-ethyl-5-

methylimidazol-4-methyl) ethylene diamine, tetra hydrate.

$\mathrm{C}_{30} \mathrm{H}_{48} \mathrm{~N}_{10} \bullet 4 \mathrm{H}_{2} \mathrm{O}$

687.87

225(2) K

$0.71073 \AA$

Triclinic

P-1

$\mathrm{a}=10.436(8) \AA \quad \alpha=115.905(12)^{\circ}$.

$\mathrm{b}=10.664(9) \AA \quad \beta=115.341(12)^{\circ}$.

$\mathrm{c}=10.902(9) \AA \quad \gamma=91.916(13)^{\circ}$.

949.4(13) $\AA^{3}$

1

$1.203 \mathrm{Mg} / \mathrm{m}^{3}$

$0.088 \mathrm{~mm}^{-1}$

373

$0.27 \times 0.15 \times 0.11 \mathrm{~mm}^{3}$

colorless

2.21 to $28.38^{\circ}$.

$-13<=\mathrm{h}<=13,-13<=\mathrm{k}<=13,-14<=\mathrm{l}<=14$

8355

$4257[\mathrm{R}(\mathrm{int})=0.0235]$

$89.2 \%$

Full-matrix least-squares on $\mathrm{F}^{2}$

$4257 / 18 / 285$

1.022

$\mathrm{R}_{1}=0.0604, \mathrm{wR}_{2}=0.1085$

$\mathrm{R}_{1}=0.1058, \mathrm{wR}_{2}=0.1206$

0.274 and -0.226 e. $\AA^{-3}$ 
Table S56. Atomic coordinates $\left(\times 10^{4}\right)$ and equivalent isotropic displacement parameters $\left(\AA^{2} \times 10^{3}\right)$ for compound 48.

\begin{tabular}{|c|c|c|c|c|}
\hline & $\mathrm{x}$ & $\mathrm{y}$ & $\mathrm{z}$ & $\mathrm{U}(\mathrm{eq})$ \\
\hline $\mathrm{N}(1)$ & $1476(2)$ & $9224(2)$ & $10919(2)$ & $38(1)$ \\
\hline $\mathrm{N}(2)$ & $3678(2)$ & $7882(2)$ & $9451(2)$ & $42(1)$ \\
\hline $\mathrm{N}(3)$ & $3402(2)$ & $8437(2)$ & $7652(2)$ & $46(1)$ \\
\hline $\mathrm{N}(4)$ & $488(2)$ & $7657(3)$ & $12422(3)$ & $55(1)$ \\
\hline $\mathrm{N}(5)$ & $-1652(3)$ & $6041(2)$ & $10687(3)$ & $53(1)$ \\
\hline $\mathrm{C}(1)$ & $2845(2)$ & $9838(3)$ & $11035(3)$ & $42(1)$ \\
\hline $\mathrm{C}(2)$ & $3101(2)$ & $9071(2)$ & $9678(3)$ & $38(1)$ \\
\hline $\mathrm{C}(3)$ & $2929(2)$ & $9421(3)$ & $8572(3)$ & $42(1)$ \\
\hline$C(4)$ & $3845(3)$ & $7544(3)$ & $8229(3)$ & $45(1)$ \\
\hline $\mathrm{C}(5)$ & $4474(3)$ & $6355(3)$ & $7562(3)$ & $63(1)$ \\
\hline$C(6 A)$ & $3669(18)$ & $5417(15)$ & $5923(15)$ & $137(7)$ \\
\hline$C(6 B)$ & $3940(20)$ & $5659(19)$ & $5905(15)$ & $123(7)$ \\
\hline$C(7)$ & $2385(3)$ & $10583(3)$ & $8265(3)$ & $54(1)$ \\
\hline $\mathrm{C}(8)$ & $1414(3)$ & $7743(3)$ & $10677(3)$ & $42(1)$ \\
\hline $\mathrm{C}(9)$ & 271(3) & $7193(3)$ & $10925(3)$ & $42(1)$ \\
\hline$C(10)$ & $-1050(3)$ & $6201(3)$ & $9841(3)$ & $43(1)$ \\
\hline$C(11)$ & $-703(3)$ & $6937(3)$ & $12222(4)$ & $59(1)$ \\
\hline$C(12 A)$ & $-1130(20)$ & $7000(20)$ & $13430(20)$ & $121(7)$ \\
\hline$C(12 B)$ & $-917(18)$ & $7170(13)$ & $13536(18)$ & $60(3)$ \\
\hline$C(13)$ & $-347(4)$ & $6273(5)$ & $14221(5)$ & $108(1)$ \\
\hline$C(14)$ & $-1817(3)$ & $5404(3)$ & $8112(3)$ & $60(1)$ \\
\hline$C(15)$ & $143(2)$ & $9259(2)$ & $9707(3)$ & $38(1)$ \\
\hline $\mathrm{O}(1)$ & $4349(2)$ & $6046(2)$ & $695(2)$ & $52(1)$ \\
\hline $\mathrm{O}(2)$ & $1935(3)$ & $924(3)$ & $3940(3)$ & $93(1)$ \\
\hline $\mathrm{O}(3)$ & $3347(2)$ & $8660(3)$ & $5083(2)$ & $69(1)$ \\
\hline $\mathrm{O}(4)$ & $5333(5)$ & $8296(6)$ & $3892(5)$ & $58(1)$ \\
\hline $\mathrm{O}(5)$ & $5155(6)$ & $7332(7)$ & $3793(7)$ & $89(2)$ \\
\hline
\end{tabular}


Table S57. Crystal data and structure refinement for compound 49.

Identification code

Empirical formula

Formula weight

Temperature

Wavelength

Crystal system

Space group

Unit cell dimensions

Volume

Z

Density (calculated)

Absorption coefficient

$\mathrm{F}(000)$

Crystal size

Crystal color

Theta range for data collection

Index ranges

Reflections collected

Independent reflections

Completeness to theta $=28.03^{\circ}$

Refinement method

Data/restraints/parameters

Goodness-of-fit on $\mathrm{F}^{2}$

Final $\mathrm{R}$ indices $[\mathrm{I}>2 \operatorname{sigma}(\mathrm{I})]$

$\mathrm{R}$ indices (all data)

Largest diff. peak and hole
N,N,N',N'-tetrakis(2-ethyl-5-

methylimidazole-4-methyl)ethylene diamine, trideca hydrate.

$\mathrm{C}_{26} \mathrm{H}_{46} \mathrm{~N}_{10} \bullet 13 \mathrm{H}_{2} \mathrm{O}$

726.89

$373(2) \mathrm{K}$

$0.71073 \AA$

Monoclinic

$\mathrm{P} 2(1)$

$\mathrm{a}=10.4297(15) \AA \quad \alpha=90^{\circ}$.

$\mathrm{b}=18.138(3) \AA$

$\beta=91.169(2)^{\circ}$.

$\mathrm{c}=10.5320(15) \AA$ $\gamma=90^{\circ}$.
2

$1.212 \mathrm{Mg} / \mathrm{m}^{3}$

$0.096 \mathrm{~mm}^{-1}$

792

$0.35 \times 0.23 \times 0.26 \mathrm{~mm}^{3}$

colorless

1.95 to $28.03^{\circ}$.

$-13<=\mathrm{h}<=13,-23<=\mathrm{k}<=23,-13<=\mathrm{l}<=13$

17439

$8861[\mathrm{R}(\mathrm{int})=0.0380]$

$95.9 \%$

Full-matrix least-squares on $\mathrm{F}^{2}$

$8861 / 81 / 557$

1.048

$\mathrm{R}_{1}=0.0770, \mathrm{wR}_{2}=0.1619$

$\mathrm{R}_{1}=0.0932, \mathrm{wR}_{2}=0.1673$

1.357 and -1.932 e. $\AA^{-3}$ 
Table S58. Atomic coordinates $\left(\times 10^{4}\right)$ and equivalent isotropic displacement parameters $\left(\AA^{2} \times 10^{3}\right)$ for compound 49.

\begin{tabular}{|c|c|c|c|c|}
\hline & $\mathrm{X}$ & $\mathrm{y}$ & $\mathrm{Z}$ & $\mathrm{U}(\mathrm{eq})$ \\
\hline $\mathrm{O}(1)$ & $5790(4)$ & $1409(2)$ & $7823(4)$ & $45(1)$ \\
\hline $\mathrm{O}(2)$ & $3893(3)$ & $2202(2)$ & $6558(3)$ & $30(1)$ \\
\hline $\mathrm{O}(3)$ & $3863(4)$ & $2714(2)$ & $4058(4)$ & $45(1)$ \\
\hline $\mathrm{O}(4)$ & $1713(3)$ & $1818(2)$ & $7830(3)$ & $32(1)$ \\
\hline $\mathrm{O}(5)$ & $2442(4)$ & $1492(2)$ & $360(3)$ & $39(1)$ \\
\hline $\mathrm{O}(6)$ & $1834(4)$ & $2336(3)$ & $2449(4)$ & $51(1)$ \\
\hline $\mathrm{O}(7)$ & $9777(4)$ & $4232(2)$ & $7400(3)$ & $43(1)$ \\
\hline $\mathrm{O}(8)$ & $1897(3)$ & $29(2)$ & $1036(3)$ & $20(1)$ \\
\hline $\mathrm{O}(9)$ & $5107(4)$ & $1751(2)$ & $320(4)$ & $45(1)$ \\
\hline $\mathrm{O}(10)$ & $-30(5)$ & $2759(2)$ & $6690(4)$ & $58(1)$ \\
\hline $\mathrm{O}(11)$ & $9749(4)$ & $2345(2)$ & $4079(3)$ & $43(1)$ \\
\hline $\mathrm{O}(12)$ & $5808(4)$ & $2516(2)$ & $2249(4)$ & $45(1)$ \\
\hline $\mathrm{O}(13)$ & $7831(6)$ & $1843(4)$ & $6537(6)$ & $60(2)$ \\
\hline $\mathrm{O}(13 \mathrm{~A})$ & $7452(13)$ & $1654(7)$ & $5214(12)$ & $41(3)$ \\
\hline $\mathrm{N}(1)$ & $2972(3)$ & $4167(2)$ & $4458(3)$ & $18(1)$ \\
\hline $\mathrm{N}(2)$ & $4694(4)$ & $3694(2)$ & $6903(3)$ & $21(1)$ \\
\hline $\mathrm{N}(3)$ & $6020(4)$ & $4580(2)$ & 7491(3) & $22(1)$ \\
\hline $\mathrm{N}(4)$ & $6(4)$ & $4851(2)$ & $5001(4)$ & $21(1)$ \\
\hline $\mathrm{N}(5)$ & $-517(4)$ & $5634(2)$ & $3478(4)$ & $22(1)$ \\
\hline $\mathrm{N}(6)$ & 4997(3) & $4945(2)$ & $1842(3)$ & $17(1)$ \\
\hline $\mathrm{N}(7)$ & $7887(4)$ & $4241(2)$ & $1263(4)$ & $24(1)$ \\
\hline $\mathrm{N}(8)$ & $8381(4)$ & $3411(2)$ & $2714(4)$ & $27(1)$ \\
\hline $\mathrm{N}(9)$ & $3342(4)$ & $5494(2)$ & $-579(4)$ & $22(1)$ \\
\hline $\mathrm{N}(10)$ & $1946(4)$ & $4654(2)$ & $-1209(3)$ & $23(1)$ \\
\hline $\mathrm{C}(1)$ & $2895(4)$ & $4382(3)$ & $5816(4)$ & $20(1)$ \\
\hline $\mathrm{C}(2)$ & $4174(4)$ & $4352(3)$ & $6480(4)$ & $19(1)$ \\
\hline $\mathrm{C}(3)$ & 4999(4) & 4899(2) & $6864(4)$ & $20(1)$ \\
\hline$C(4)$ & $5811(4)$ & $3856(3)$ & $7509(4)$ & $24(1)$ \\
\hline$C(5)$ & $6667(5)$ & $3299(3)$ & $8116(5)$ & $27(1)$ \\
\hline$C(6)$ & $4930(4)$ & $5715(2)$ & $6662(5)$ & $25(1)$ \\
\hline
\end{tabular}




\begin{tabular}{lrrrr}
$\mathrm{C}(7)$ & $1663(4)$ & $4049(2)$ & $3921(4)$ & $17(1)$ \\
$\mathrm{C}(8)$ & $743(4)$ & $4692(2)$ & $3940(4)$ & $20(1)$ \\
$\mathrm{C}(9)$ & $415(4)$ & $5181(3)$ & $2998(4)$ & $19(1)$ \\
$\mathrm{C}(10)$ & $-738(4)$ & $5417(3)$ & $4680(4)$ & $22(1)$ \\
$\mathrm{C}(11)$ & $-1696(5)$ & $5765(3)$ & $5508(4)$ & $27(1)$ \\
$\mathrm{C}(12)$ & $877(4)$ & $5267(3)$ & $1673(4)$ & $28(1)$ \\
$\mathrm{C}(13)$ & $3684(4)$ & $4725(2)$ & $3743(4)$ & $17(1)$ \\
$\mathrm{C}(14)$ & $4248(4)$ & $4398(2)$ & $2535(4)$ & $18(1)$ \\
$\mathrm{C}(15)$ & $6311(4)$ & $5050(3)$ & $2394(4)$ & $20(1)$ \\
$\mathrm{C}(16)$ & $7202(4)$ & $4408(3)$ & $2344(4)$ & $19(1)$ \\
$\mathrm{C}(17)$ & $7502(4)$ & $3890(3)$ & $3245(4)$ & $22(1)$ \\
$\mathrm{C}(18)$ & $8582(4)$ & $3644(3)$ & $1535(5)$ & $25(1)$ \\
$\mathrm{C}(19)$ & $9472(5)$ & $3284(3)$ & $649(5)$ & $35(1)$ \\
$\mathrm{C}(20)$ & $7079(5)$ & $3799(3)$ & $4589(4)$ & $28(1)$ \\
$\mathrm{C}(21)$ & $5067(4)$ & $4744(3)$ & $483(4)$ & $20(1)$ \\
$\mathrm{C}(22)$ & $3804(4)$ & $4808(2)$ & $-209(4)$ & $18(1)$ \\
$\mathrm{C}(23)$ & $2940(4)$ & $4292(3)$ & $-591(4)$ & $19(1)$ \\
$\mathrm{C}(24)$ & $2219(4)$ & $5375(3)$ & $-1186(4)$ & $22(1)$ \\
$\mathrm{C}(25)$ & $1393(5)$ & $5968(3)$ & $-1739(5)$ & $34(1)$ \\
$\mathrm{C}(26)$ & $2947(5)$ & $3475(3)$ & $-440(5)$ & $28(1)$ \\
\hline
\end{tabular}


Table S59. Crystal data and structure refinement for compound $\mathbf{5 2 .}$

Identification code

Empirical formula

Formula weight

Temperature

Wavelength

Crystal system

Space group

Unit cell dimensions

Volume

Z

Density (calculated)

Absorption coefficient

$\mathrm{F}(000)$

Crystal size

Crystal color (habit)

Theta range for data collection

Index ranges

Reflections collected

Independent reflections

Completeness to theta $=28.26^{\circ}$

Absorption correction

Refinement method

Data/restraints/parameters

Goodness-of-fit on $\mathrm{F}^{2}$

Final $R$ indices $[\mathrm{I}>2 \operatorname{sigma}(\mathrm{I})]$

$\mathrm{R}$ indices (all data)

Extinction coefficient

Largest diff. peak and hole
1-Methylimidazole-4-carboxaldehyde.

$\mathrm{C}_{5} \mathrm{H}_{8} \mathrm{~N}_{2} \mathrm{O}_{2}$

128.13

100(2) K

$0.71073 \AA$

Monoclinic

$\mathrm{C} 2 / \mathrm{c}$

$$
\begin{array}{ll}
\mathrm{a}=20.118(4) \AA & \alpha=90^{\circ} . \\
\mathrm{b}=8.5187(15) \AA & \beta=96.428(3)^{\circ} . \\
\mathrm{c}=7.3338(13) \AA & \gamma=90^{\circ} .
\end{array}
$$

1249.0(4) $\AA^{3}$

8

$1.363 \mathrm{Mg} / \mathrm{m}^{3}$

$0.107 \mathrm{~mm}^{-1}$

544

$0.32 \times 0.25 \times 0.14 \mathrm{~mm}^{3}$

colorless block

2.04 to $28.26^{\circ}$.

$-25<=\mathrm{h}<=25,-10<=\mathrm{k}<=11,-9<=\mathrm{l}<=9$

5325

$1466[\mathrm{R}(\mathrm{int})=0.023]$

$94.6 \%$

\section{SADABS}

Full-matrix least-squares on $\mathrm{F}^{2}$

1466/0/102

1.05

$\mathrm{R}_{1}=0.039, \mathrm{wR}_{2}=0.104$

$\mathrm{R}_{1}=0.044, \mathrm{wR}_{2}=0.107$

$0.0013(8)$

0.340 and -0.195 e. $\AA^{-3}$ 
Table S60. Atomic coordinates (x 104) and equivalent isotropic displacement parameters $\left(\AA^{2} \times 10^{3}\right)$ for compound 52.

\begin{tabular}{lrrrr}
\hline & $\mathrm{x}$ & $\mathrm{y}$ & $\mathrm{z}$ & $\mathrm{U}(\mathrm{eq})$ \\
\hline $\mathrm{O}(1)$ & & & & \\
$\mathrm{N}(1)$ & $3122(1)$ & $586(1)$ & $1062(1)$ & $27(1)$ \\
$\mathrm{N}(2)$ & $3550(1)$ & $5388(1)$ & $2440(1)$ & $17(1)$ \\
$\mathrm{C}(1)$ & $4223(1)$ & $3433(1)$ & $3433(2)$ & $19(1)$ \\
$\mathrm{C}(2)$ & $4133(1)$ & $4954(2)$ & $3439(2)$ & $19(1)$ \\
$\mathrm{C}(3)$ & $3666(1)$ & $2847(2)$ & $2359(2)$ & $18(1)$ \\
$\mathrm{C}(4)$ & $3248(1)$ & $4060(1)$ & $1751(2)$ & $18(1)$ \\
$\mathrm{C}(5)$ & $3592(1)$ & $1178(2)$ & $2007(2)$ & $21(1)$ \\
$\mathrm{O}(2)$ & $3306(1)$ & $6995(2)$ & $2147(2)$ & $22(1)$ \\
& $5125(1)$ & $1495(1)$ & $5675(2)$ & $28(1)$ \\
\hline
\end{tabular}




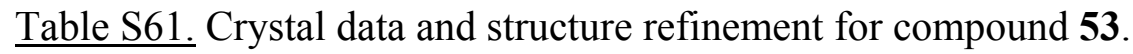

Identification code

Empirical formula

Formula weight

Temperature

Wavelength

Crystal system

Space group

Unit cell dimensions

Volume

Z

Density (calculated)

Absorption coefficient

$\mathrm{F}(000)$

Crystal size

Crystal color, habit

Theta range for data collection

Index ranges

Reflections collected

Independent reflections

Completeness to theta $=28.19^{\circ}$

Absorption correction

Max. and min. transmission

Refinement method

Data/restraints/parameters

Goodness-of-fit on $\mathrm{F}^{2}$

Final $\mathrm{R}$ indices $[\mathrm{I}>2 \operatorname{sigma}(\mathrm{I})]$

$\mathrm{R}$ indices (all data)

Extinction coefficient

Largest diff. peak and hole
4(5)-Methyl-2-phenylimidazole.

$\mathrm{C}_{10} \mathrm{H}_{10} \mathrm{~N}_{2}$

158.20

$100(2) \mathrm{K}$

$0.71073 \AA$

Monoclinic

$\mathrm{P} 2{ }_{1} / \mathrm{c}$

$\mathrm{a}=10.594(3) \AA$

$\alpha=90^{\circ}$.

$\mathrm{b}=8.640(2) \AA$

$\beta=106.755(4)^{\circ}$.

$\mathrm{c}=9.962(2) \AA$

$\gamma=90^{\circ}$.
4

$1.203 \mathrm{Mg} / \mathrm{m}^{3}$

$0.073 \mathrm{~mm}^{-1}$

336

$0.14 \times 0.10 \times 0.03 \mathrm{~mm}^{3}$

colorless plate

2.01 to $28.19^{\circ}$.

$-13<=\mathrm{h}<=13,-11<=\mathrm{k}<=11,-12<=\mathrm{l}<=13$

7238

$2016[\mathrm{R}(\mathrm{int})=0.056]$

$93.8 \%$

\section{SADABS}

0.782 and 0.989

Full-matrix least-squares on $\mathrm{F}^{2}$

2016/0/150

1.04

$\mathrm{R}_{1}=0.049, \mathrm{wR}_{2}=0.102$

$\mathrm{R}_{1}=0.101, \mathrm{wR}_{2}=0.116$

$0.008(3)$

0.187 and -0.180 e. $\AA^{-3}$ 
Table S 62. Atomic coordinates (x 104) and equivalent isotropic displacement parameters $\left(\AA^{2} \times 10^{3}\right)$ for compound 53.

\begin{tabular}{lrrrr}
\hline & $\mathrm{x}$ & $\mathrm{y}$ & $\mathrm{z}$ & $\mathrm{U}(\mathrm{eq})$ \\
\hline $\mathrm{N}(1)$ & $-41(1)$ & $2315(2)$ & $-194(2)$ & $26(1)$ \\
$\mathrm{N}(2)$ & $160(2)$ & $2285(2)$ & $2077(2)$ & $30(1)$ \\
$\mathrm{C}(1)$ & $710(2)$ & $2753(2)$ & $1101(2)$ & $25(1)$ \\
$\mathrm{C}(2)$ & $-1116(2)$ & $1520(2)$ & $-47(2)$ & $28(1)$ \\
$\mathrm{C}(3)$ & $-977(2)$ & $1527(2)$ & $1357(2)$ & $31(1)$ \\
$\mathrm{C}(4)$ & $1960(2)$ & $3581(2)$ & $1370(2)$ & $26(1)$ \\
$\mathrm{C}(5)$ & $2912(2)$ & $3433(2)$ & $2669(2)$ & $31(1)$ \\
$\mathrm{C}(6)$ & $4101(2)$ & $4210(2)$ & $2938(2)$ & $36(1)$ \\
$\mathrm{C}(7)$ & $4361(2)$ & $5150(2)$ & $1917(2)$ & $40(1)$ \\
$\mathrm{C}(8)$ & $3428(2)$ & $5306(2)$ & $627(2)$ & $36(1)$ \\
$\mathrm{C}(9)$ & $2228(2)$ & $4538(2)$ & $355(2)$ & $30(1)$ \\
$\mathrm{C}(10)$ & $-2149(2)$ & $865(3)$ & $-1254(2)$ & $35(1)$ \\
\hline
\end{tabular}


APPENDIX 2

${ }^{1} \mathrm{H}$ AND ${ }^{13} \mathrm{C}$ NMR SPECTRA 


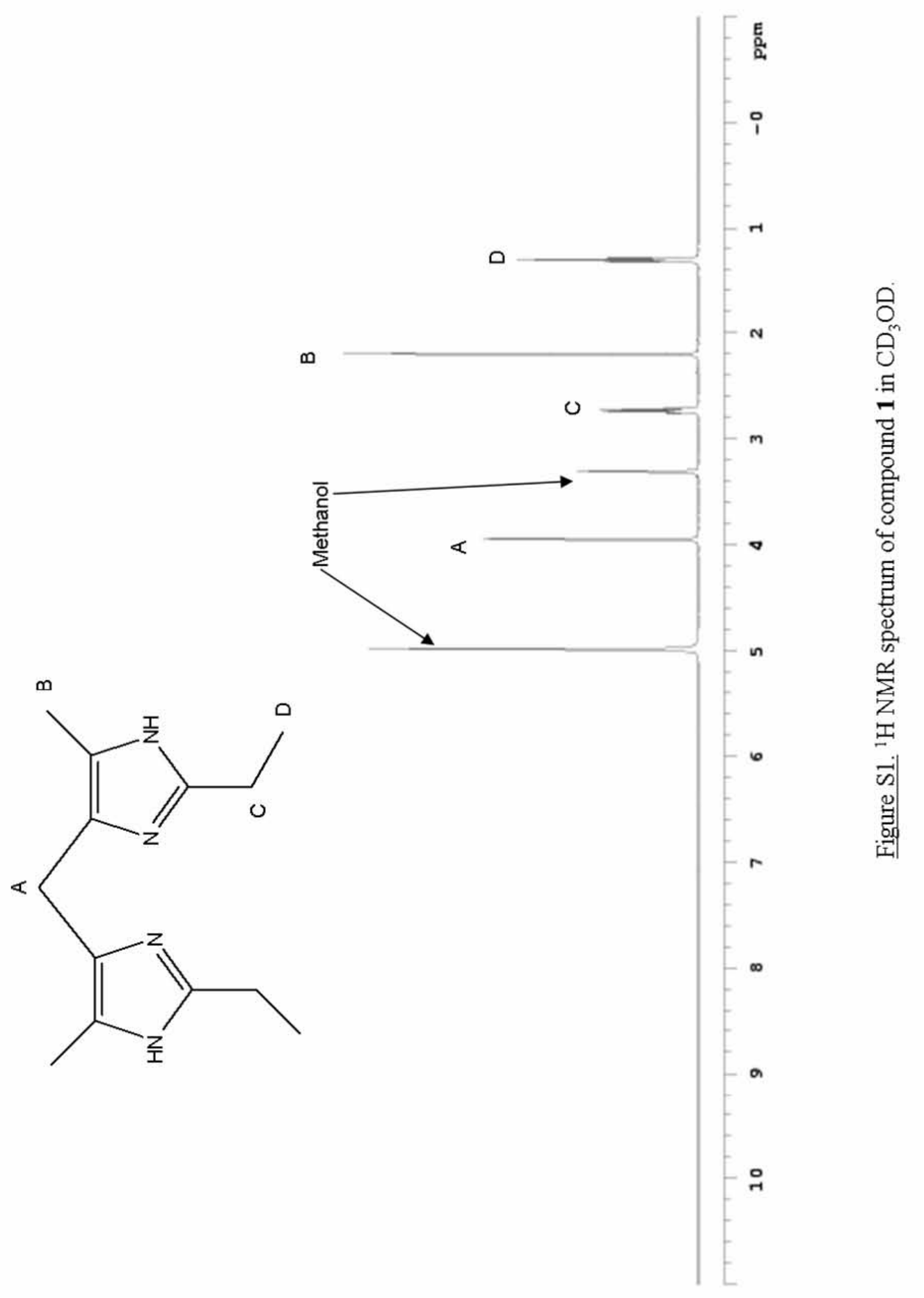




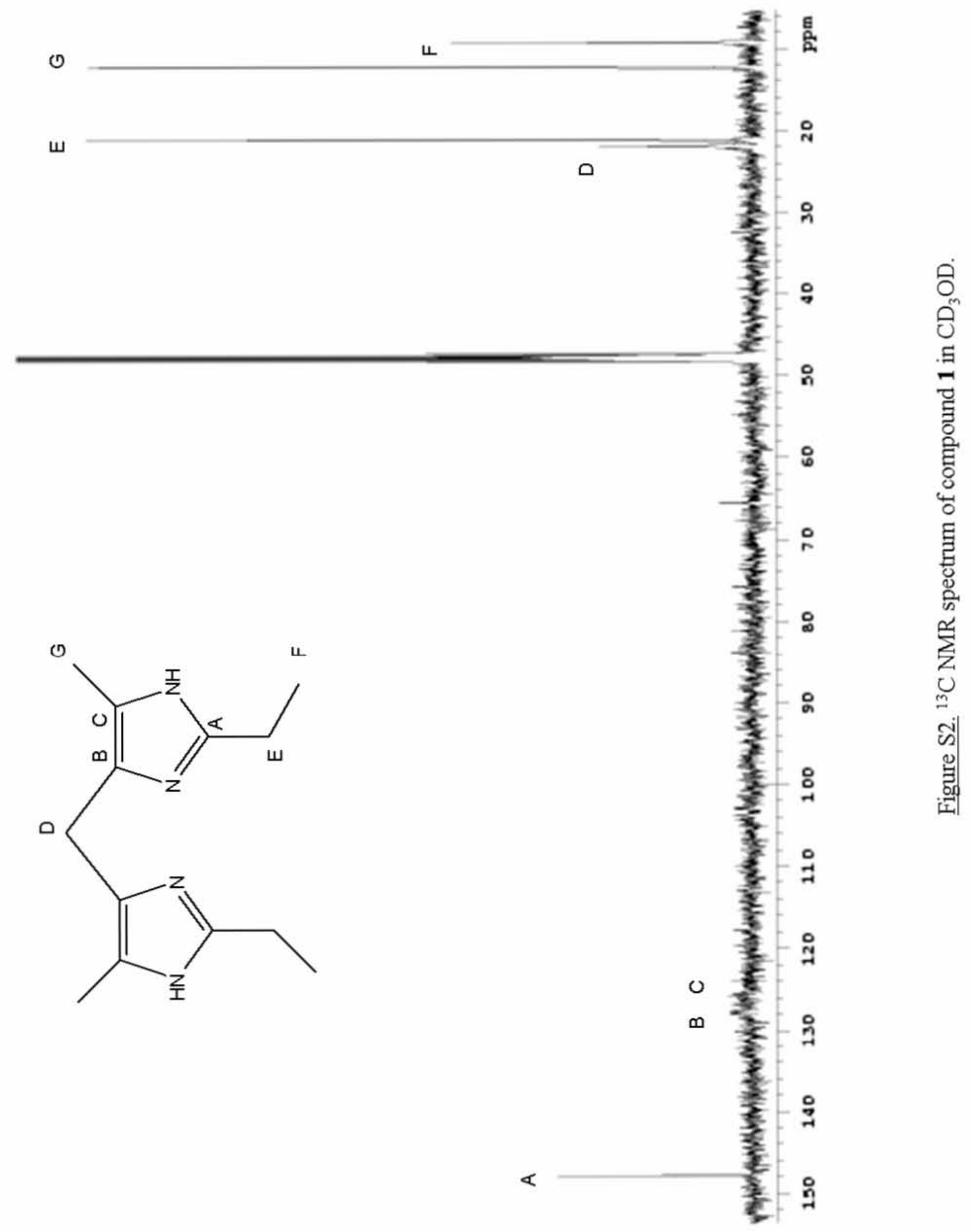




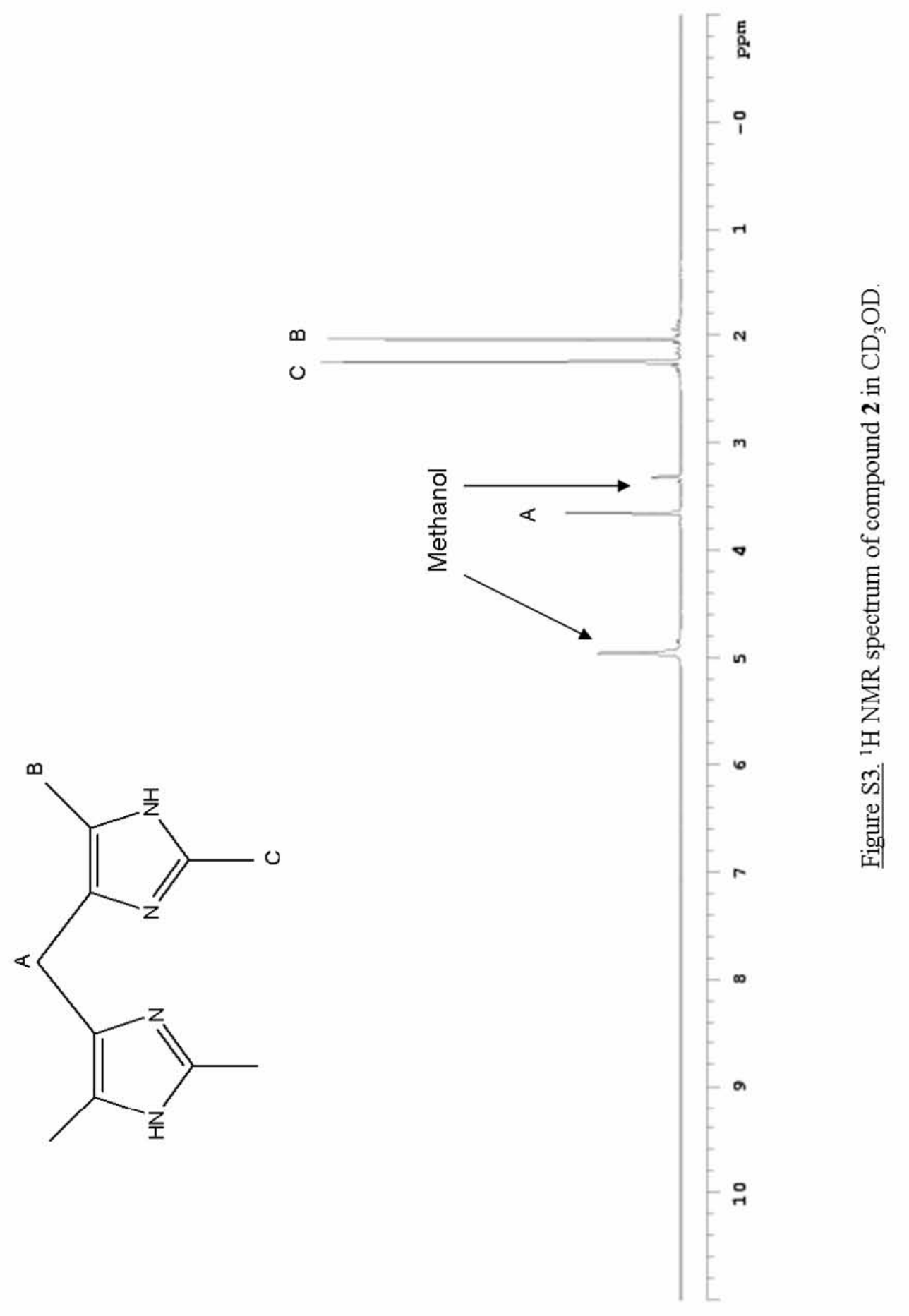




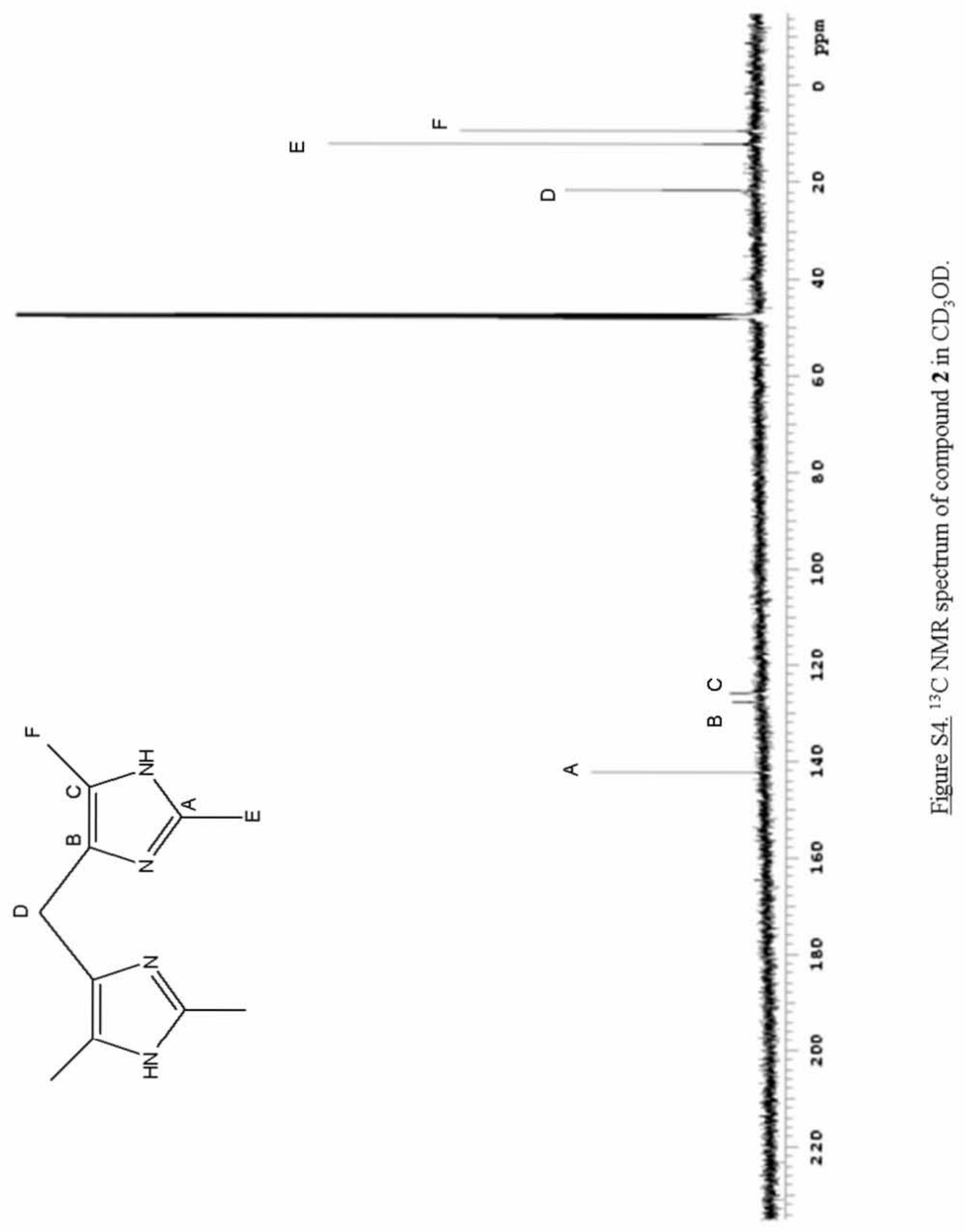




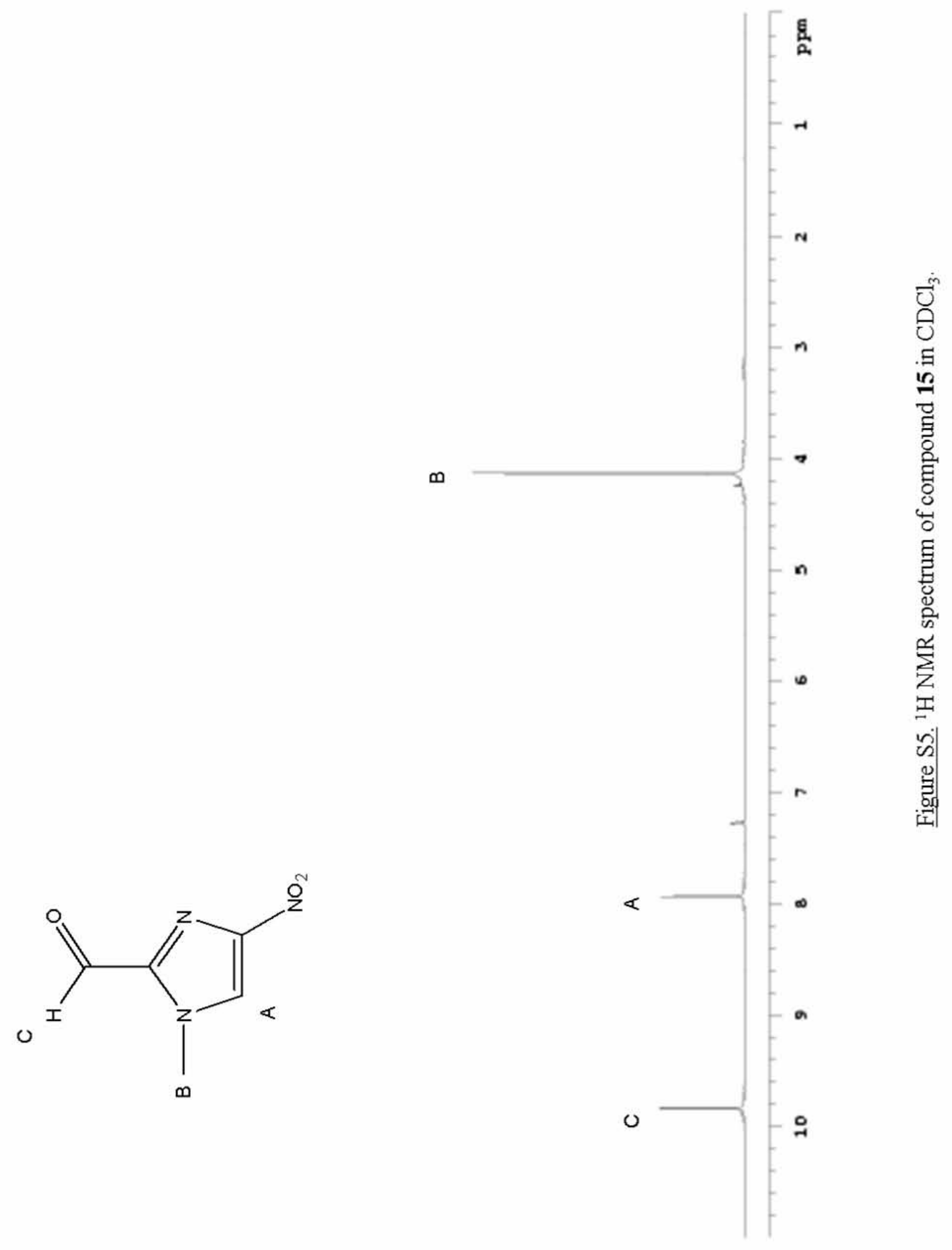




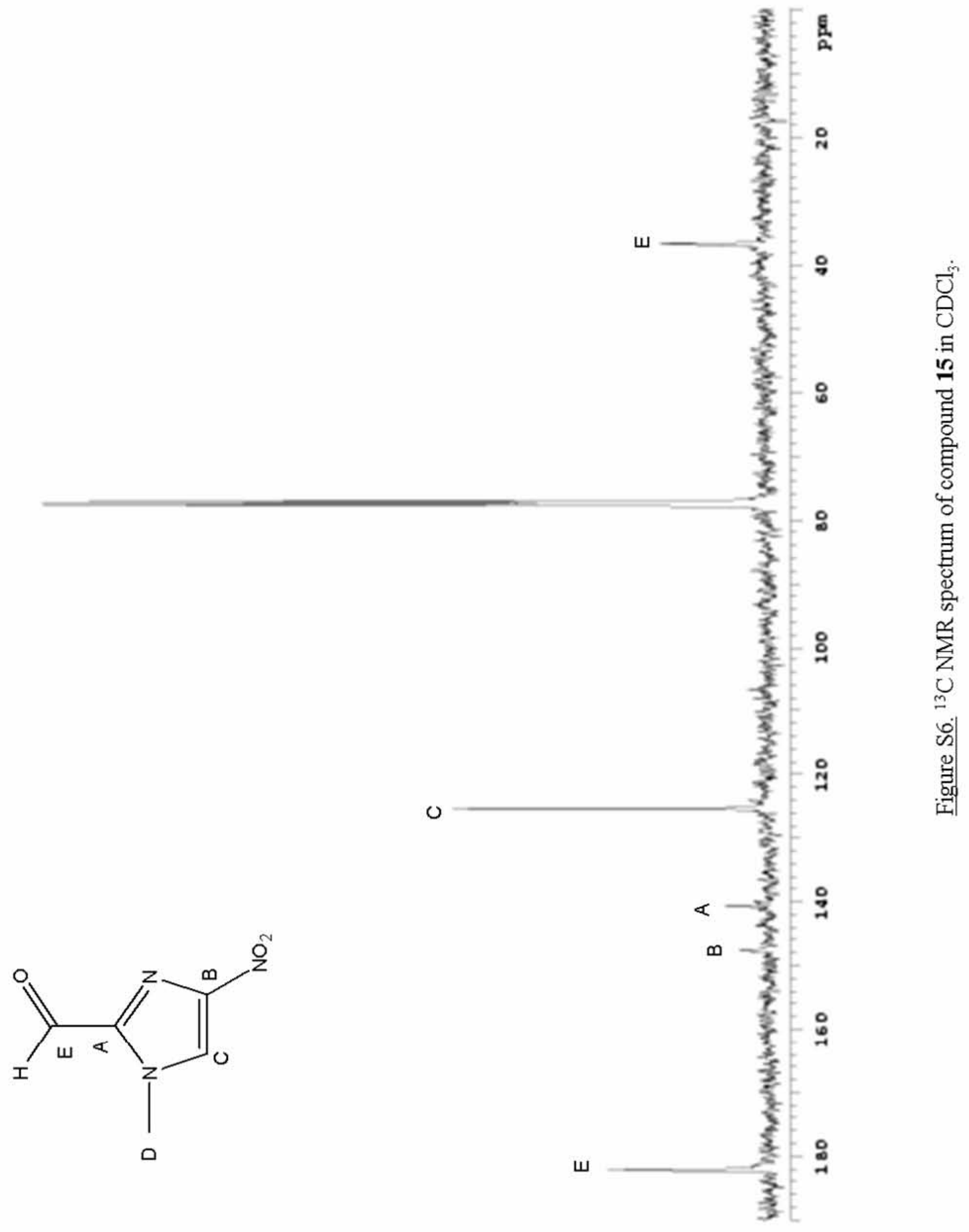




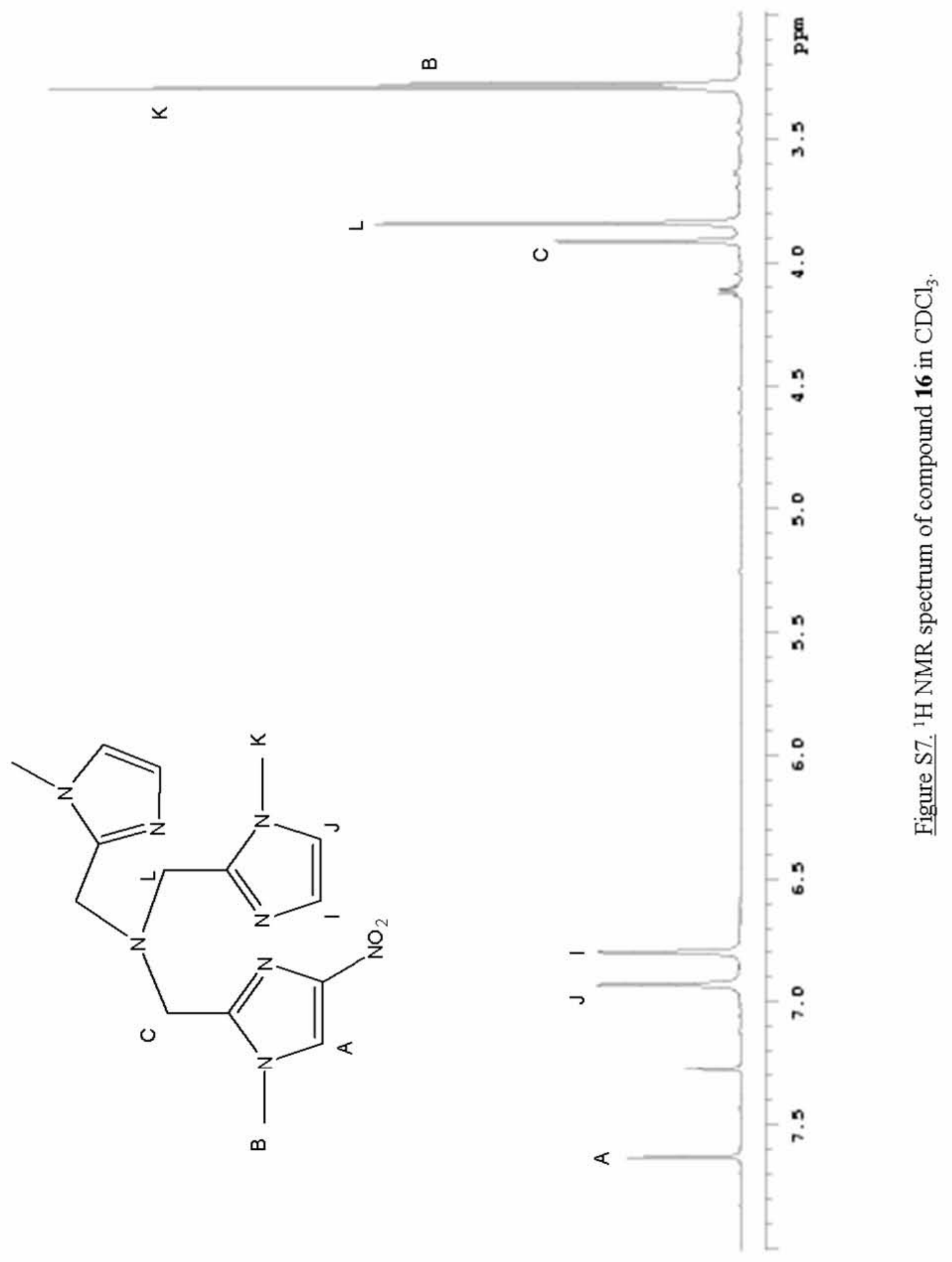




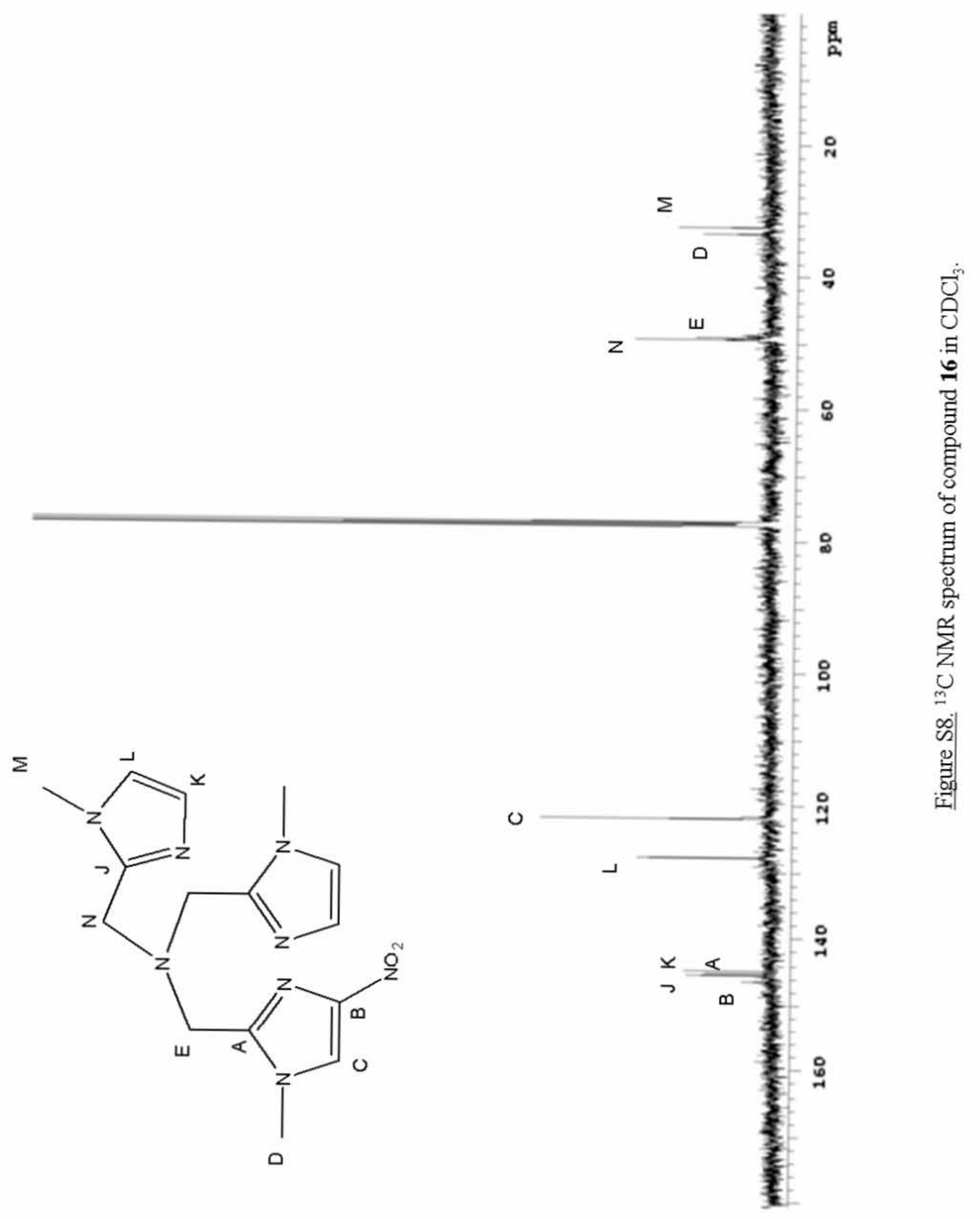




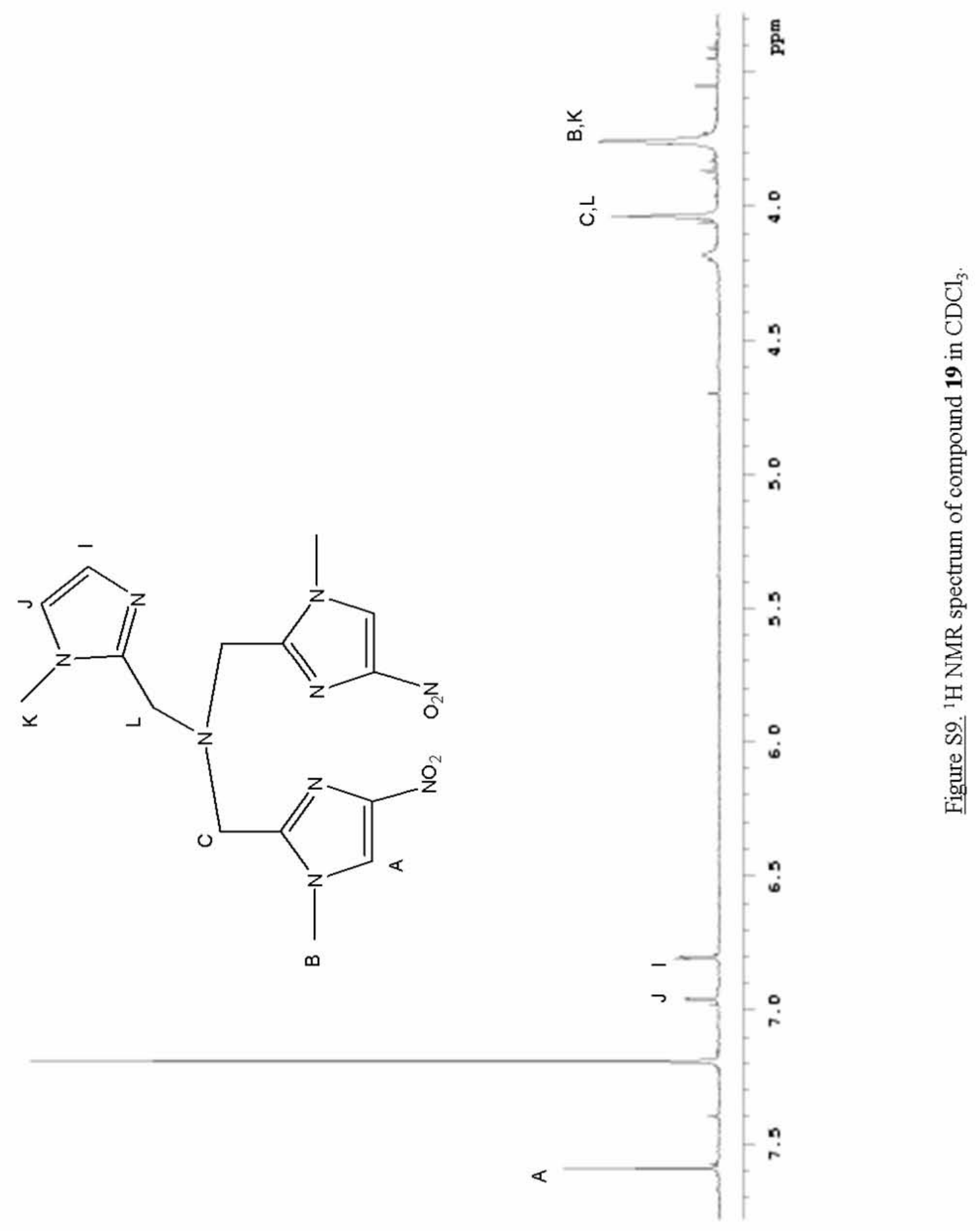




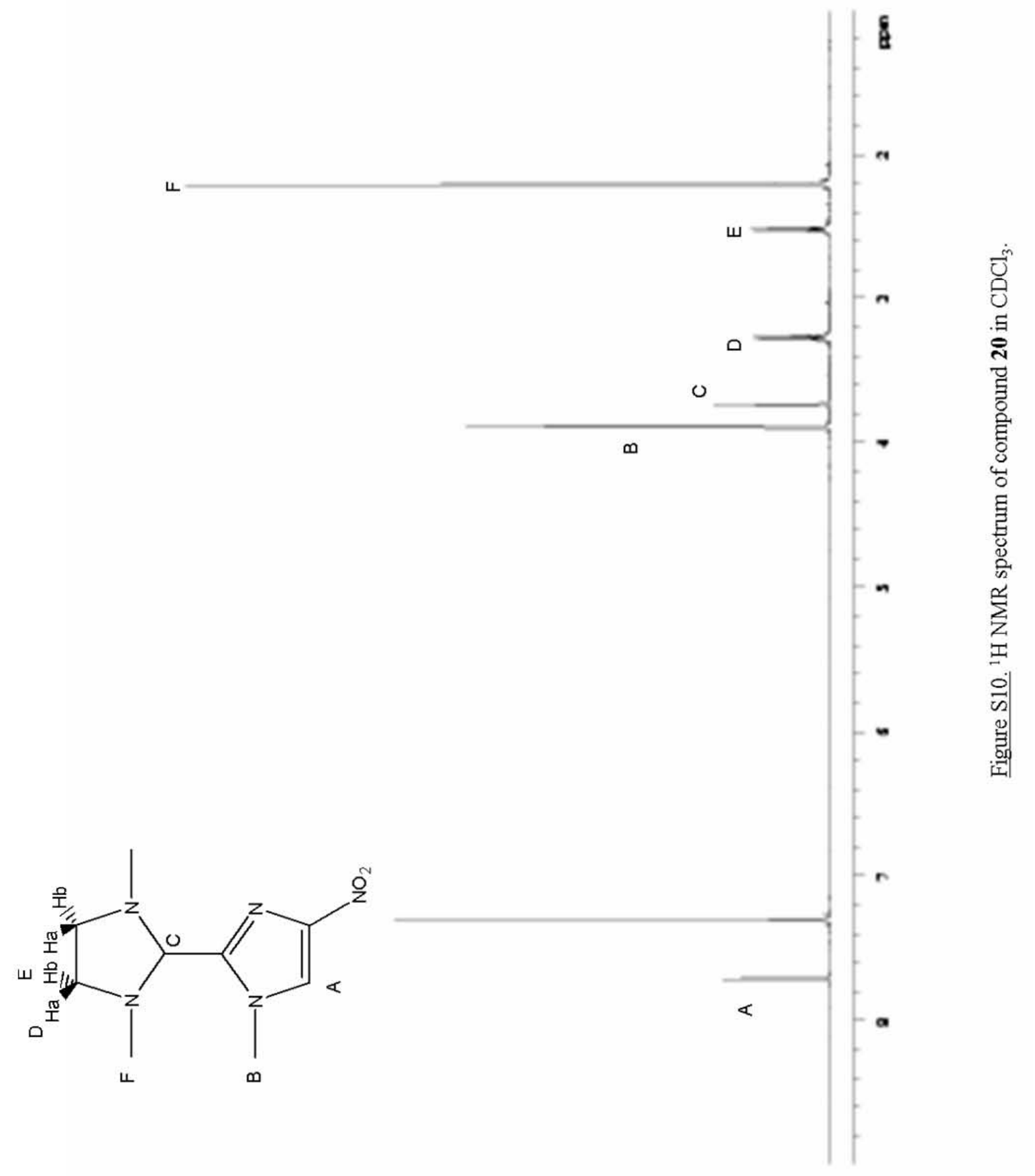




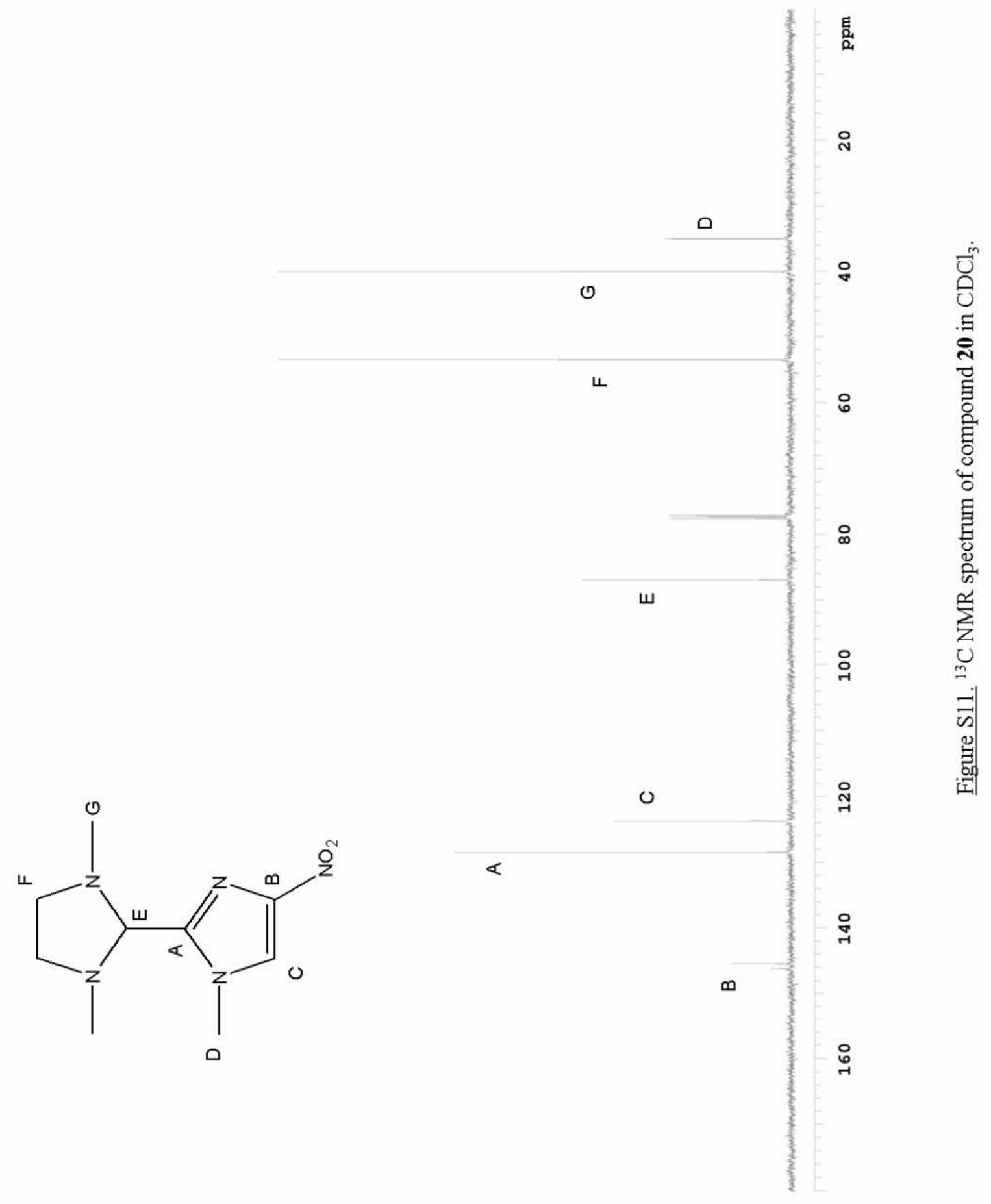




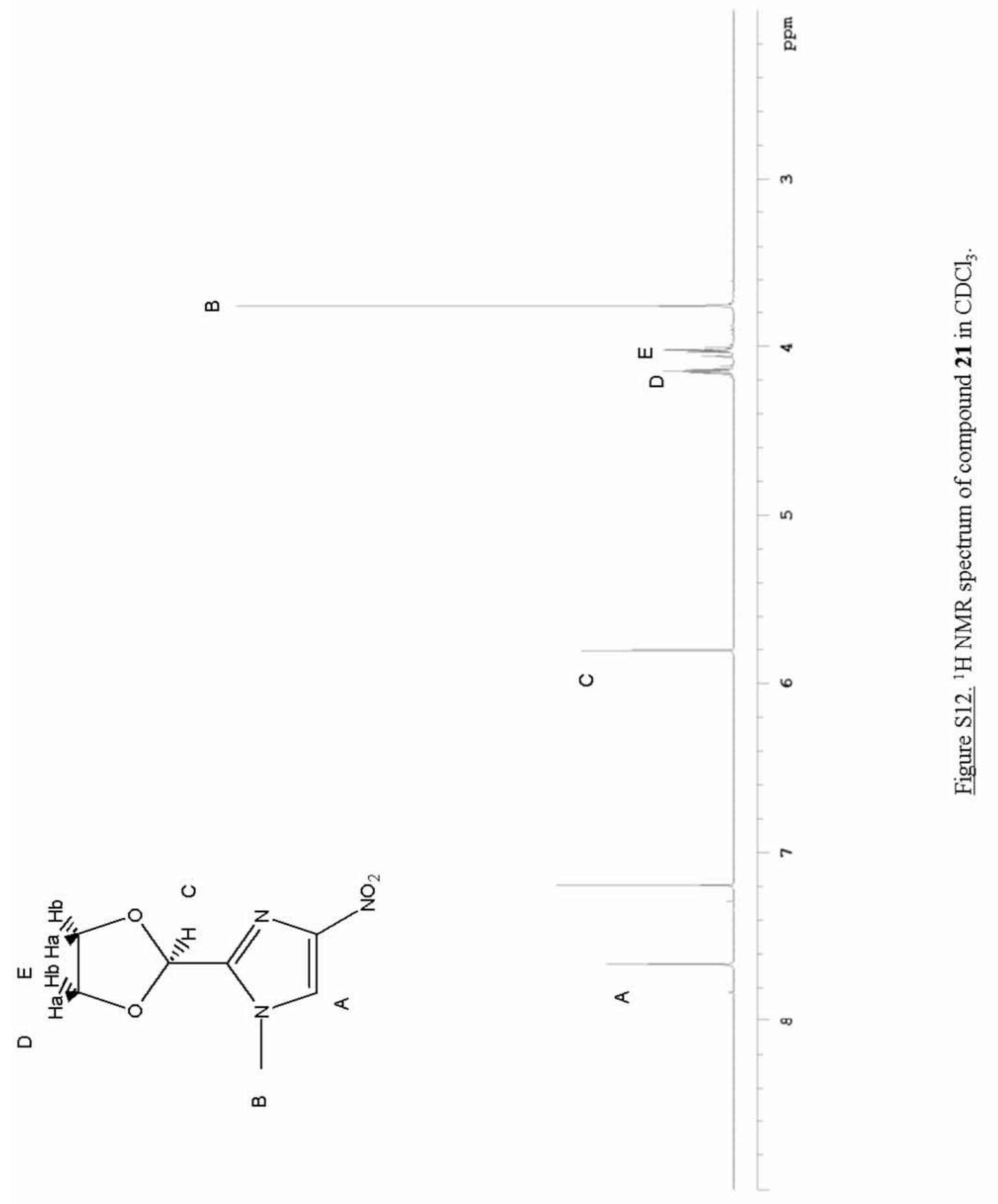




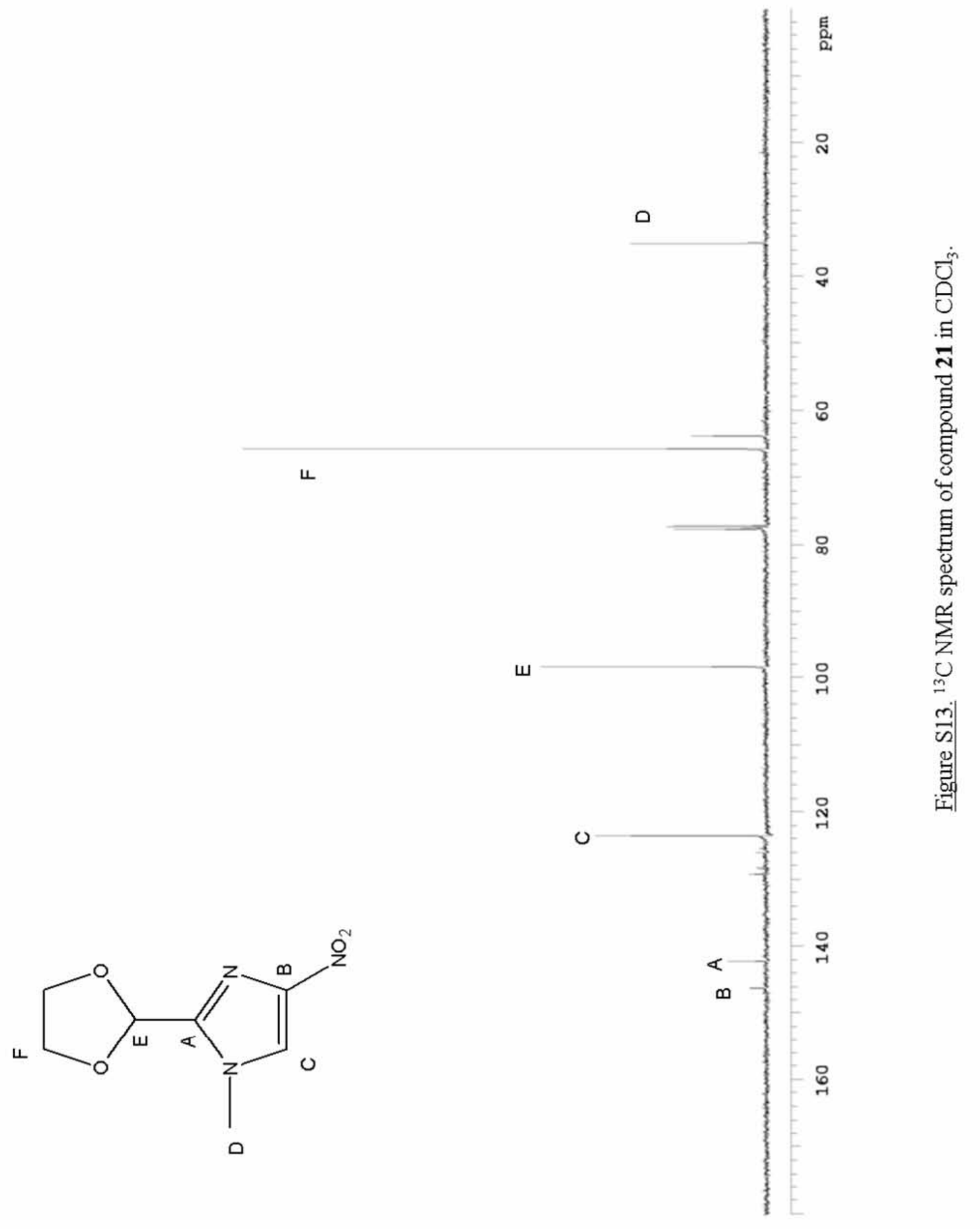




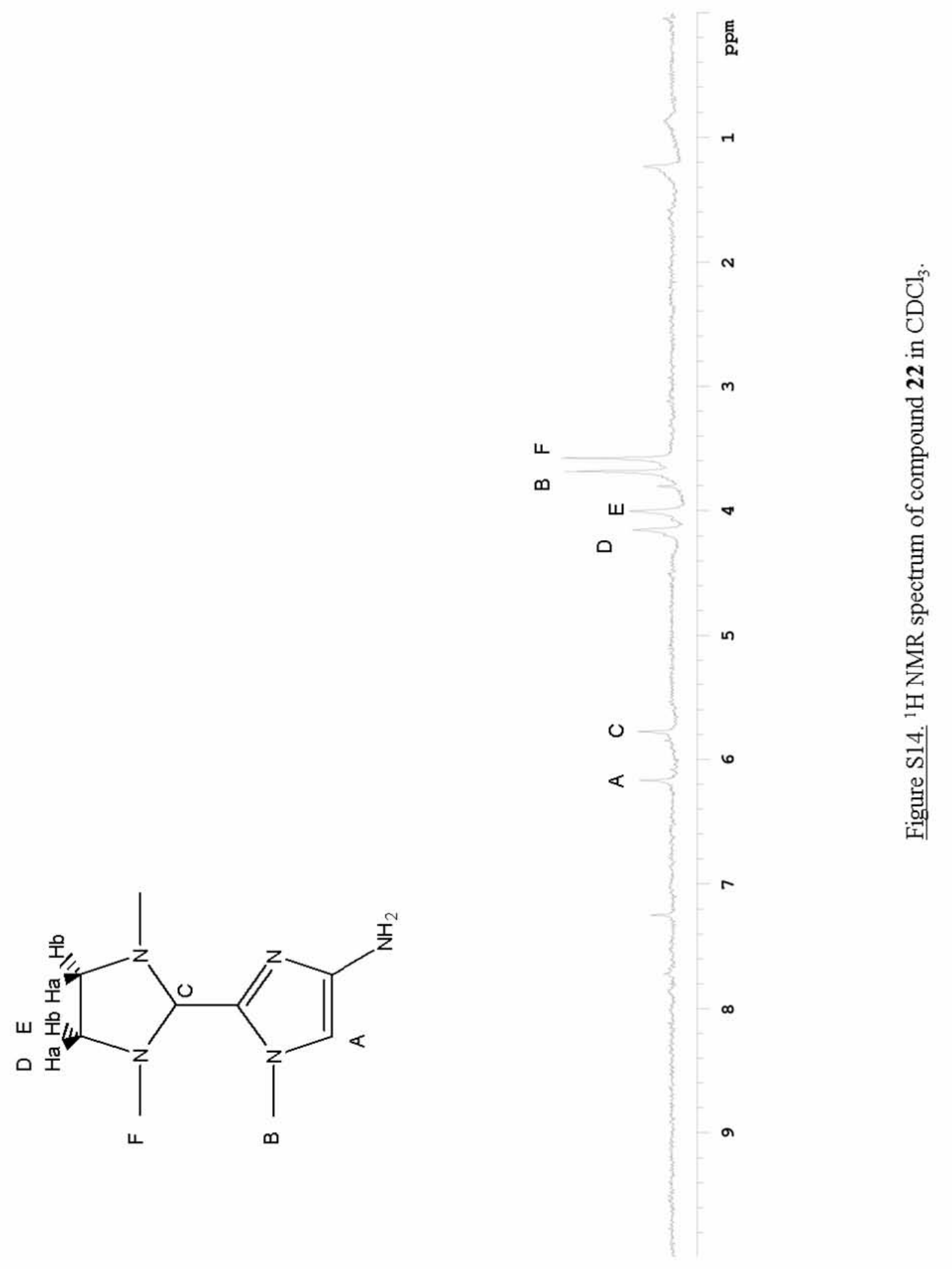




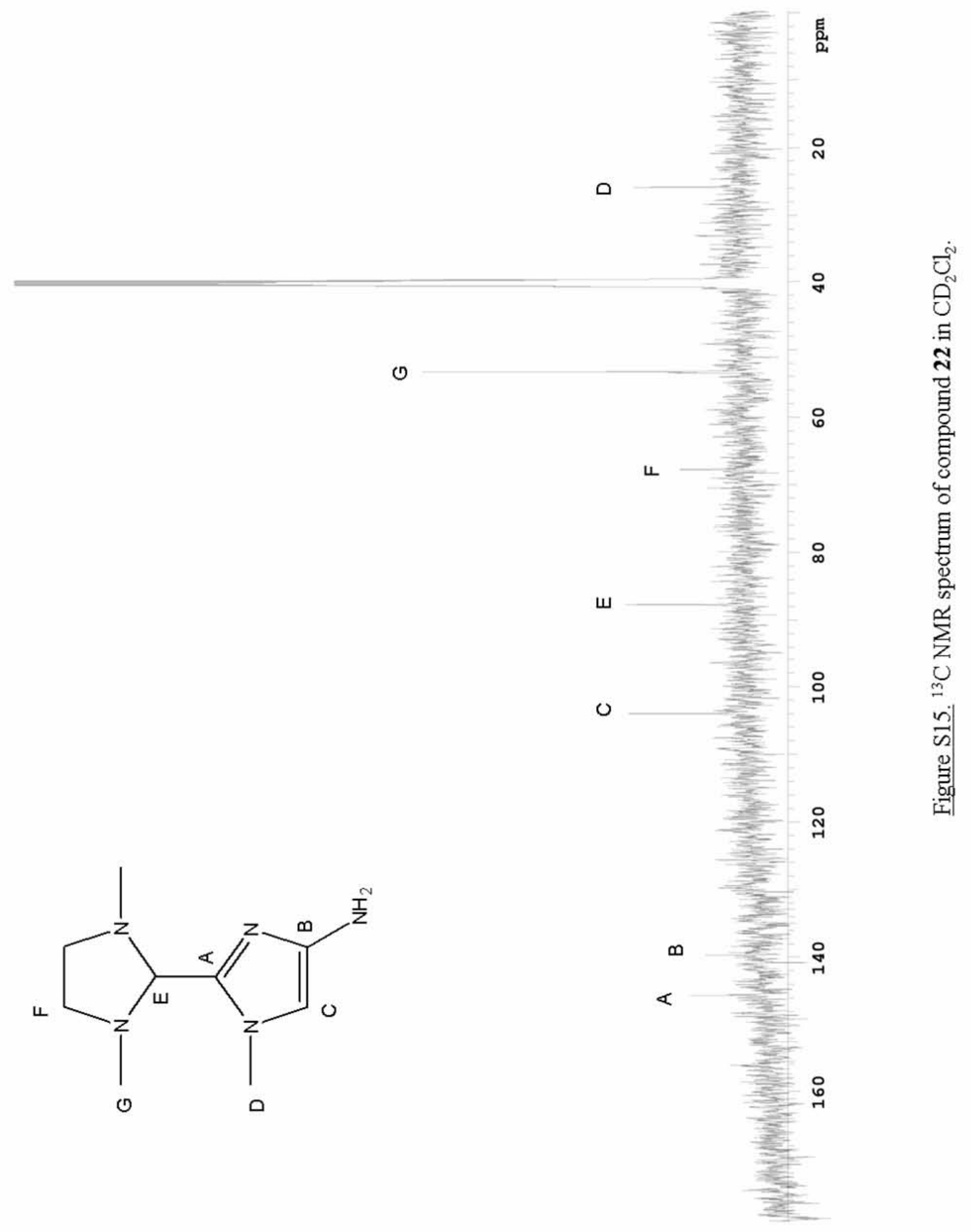




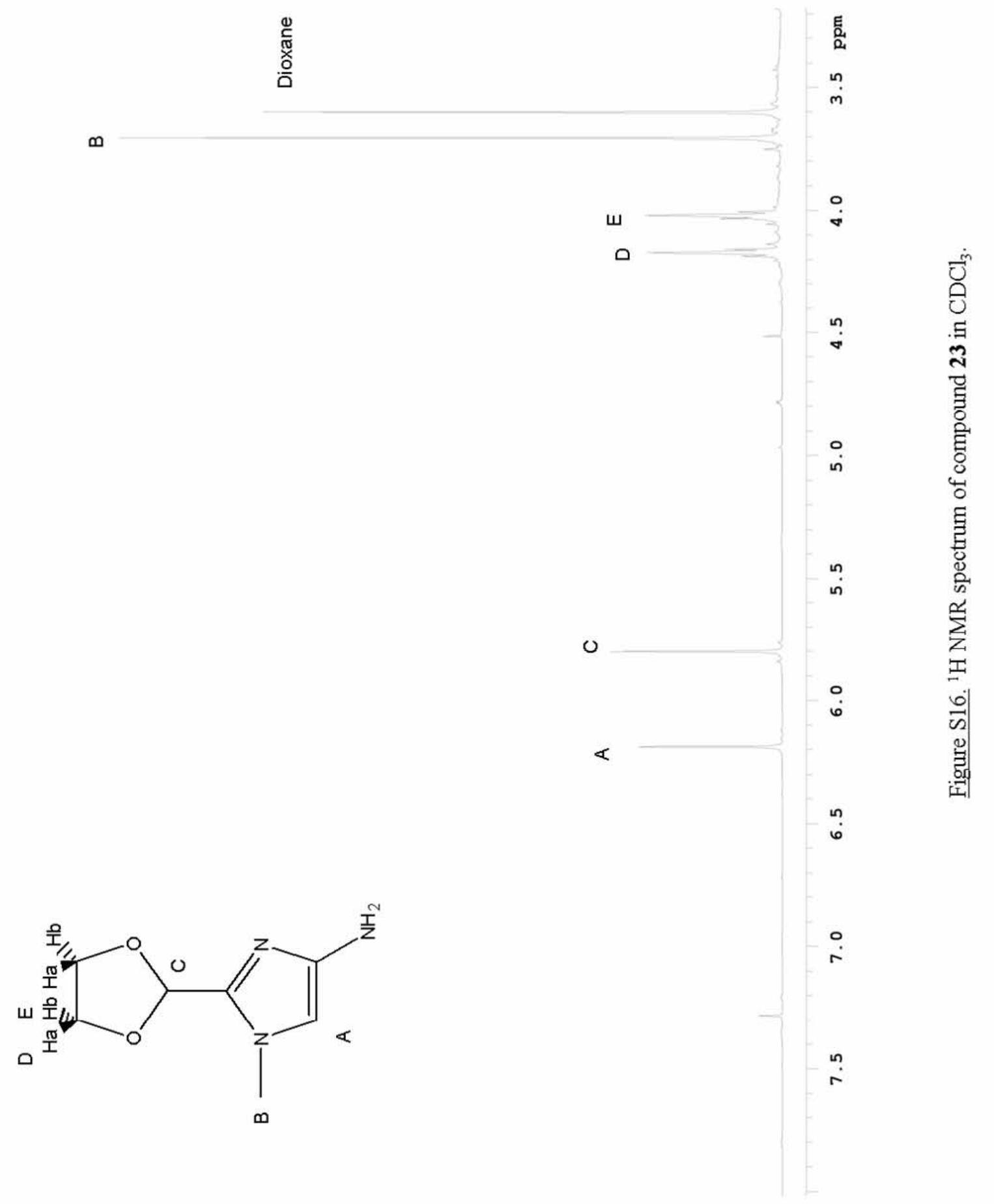




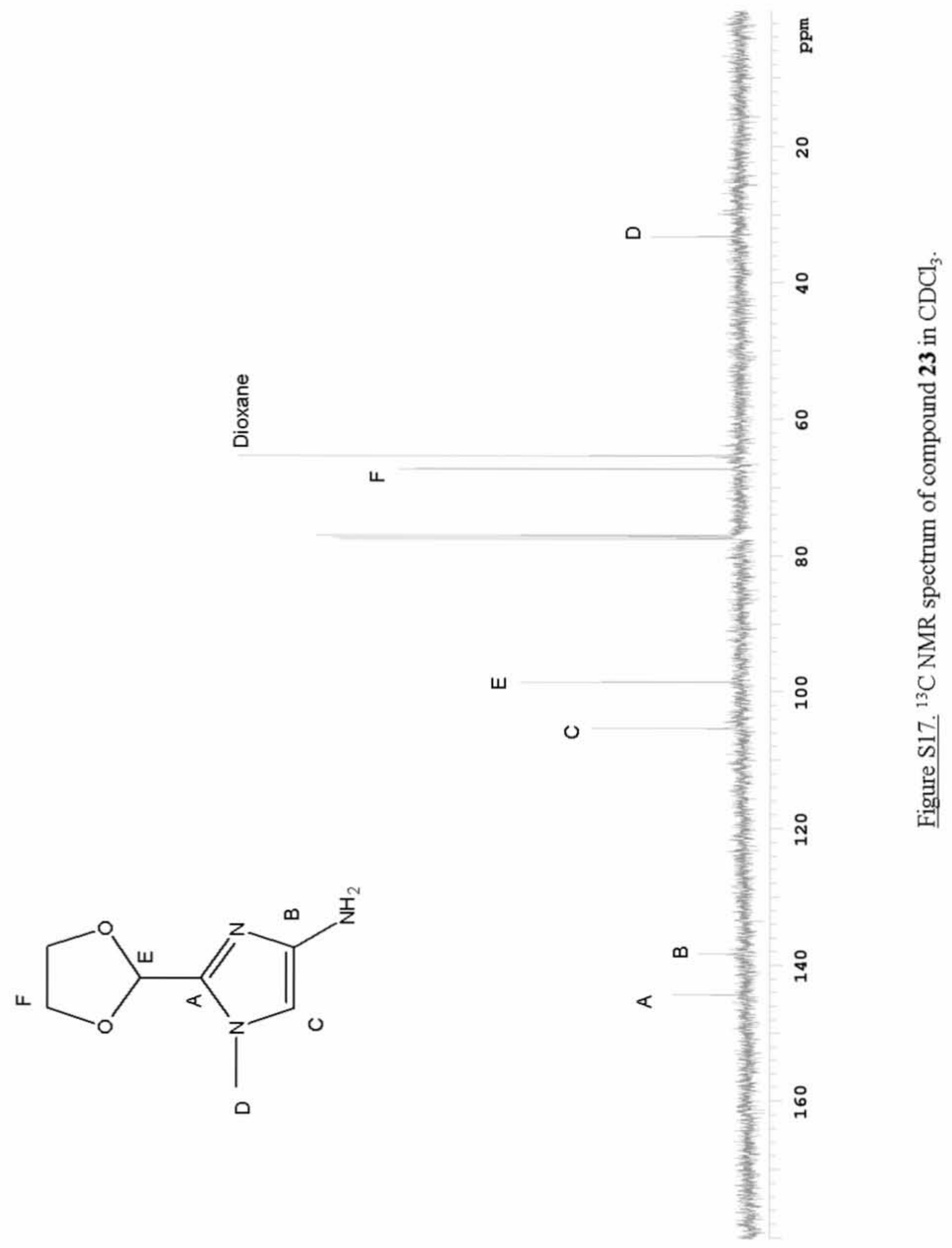




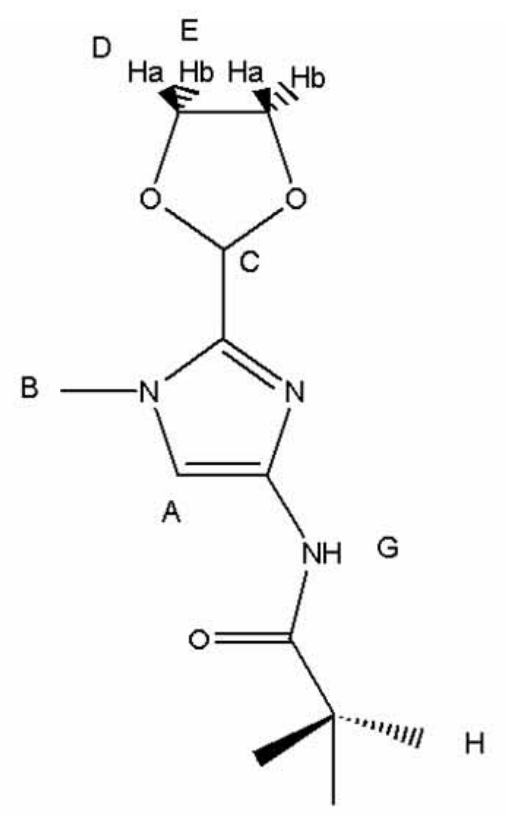




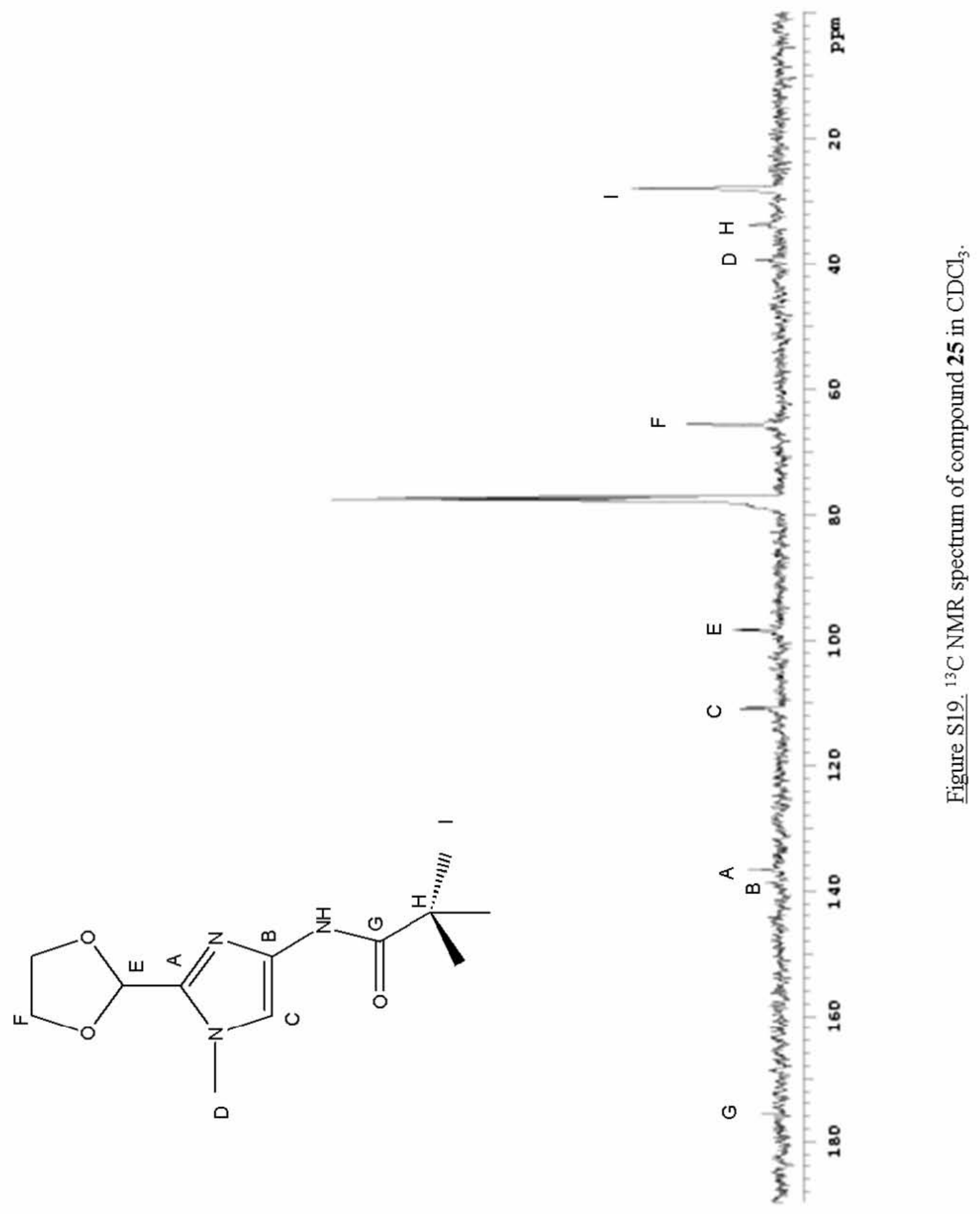




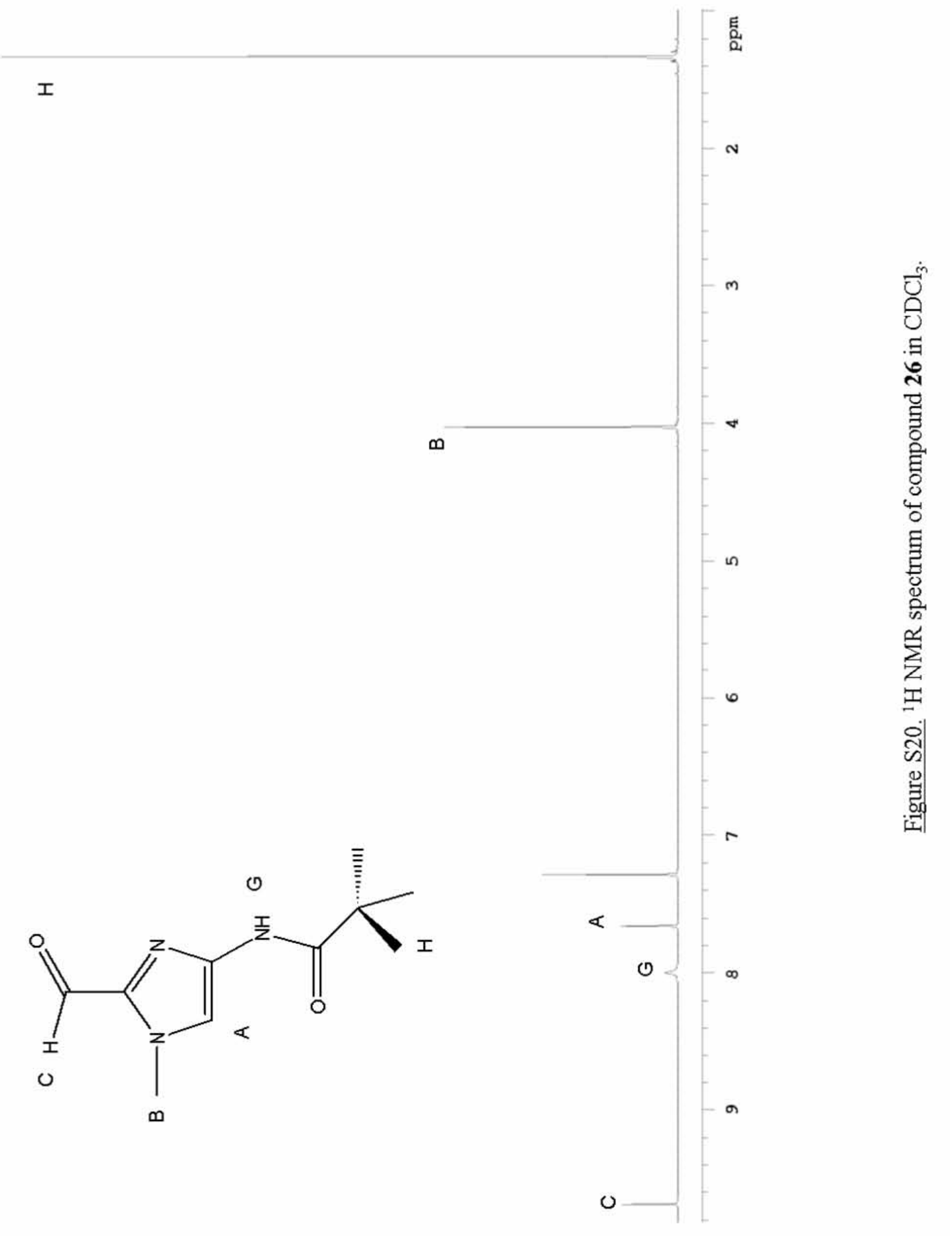




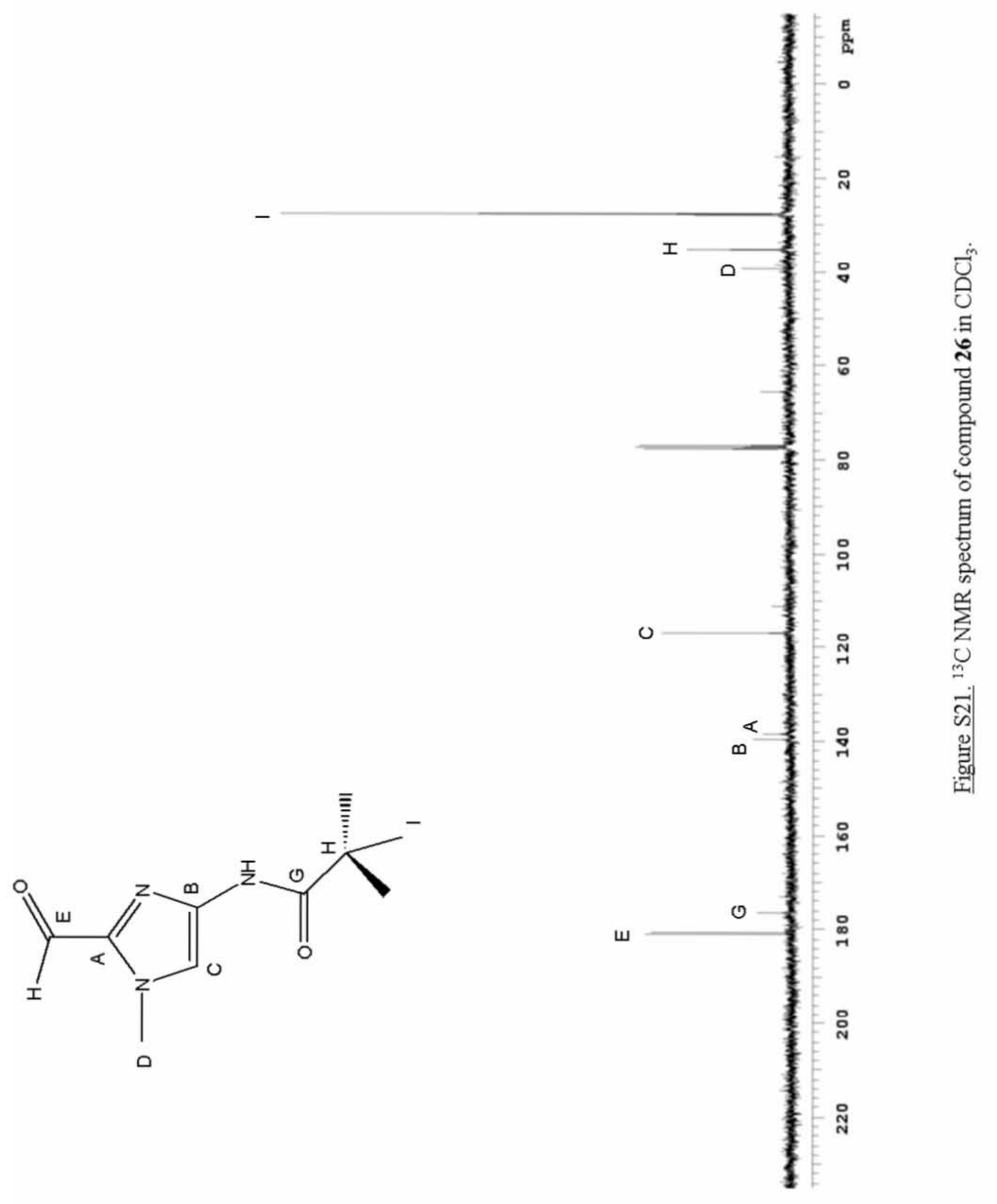




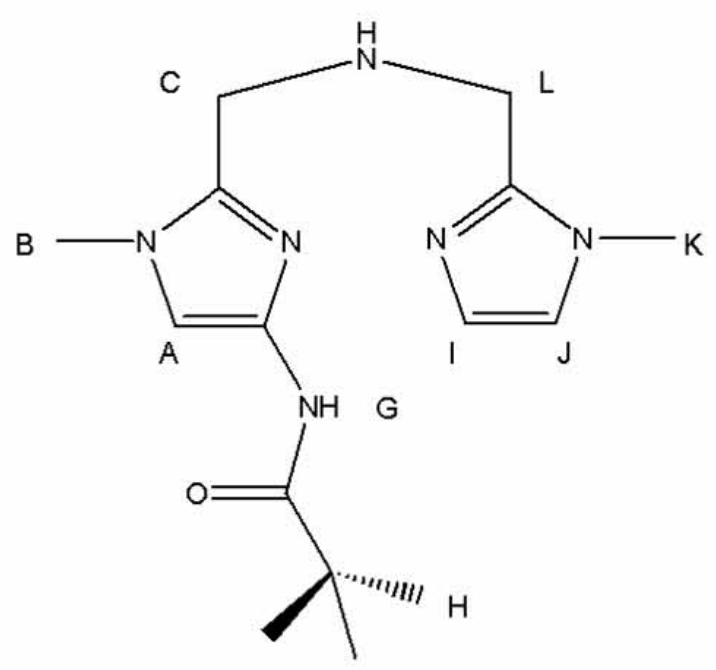

Figure S22. ${ }^{1} \mathrm{H}$ NMR spectrum of compound 27 in $\mathrm{CDCl}_{3}$. 


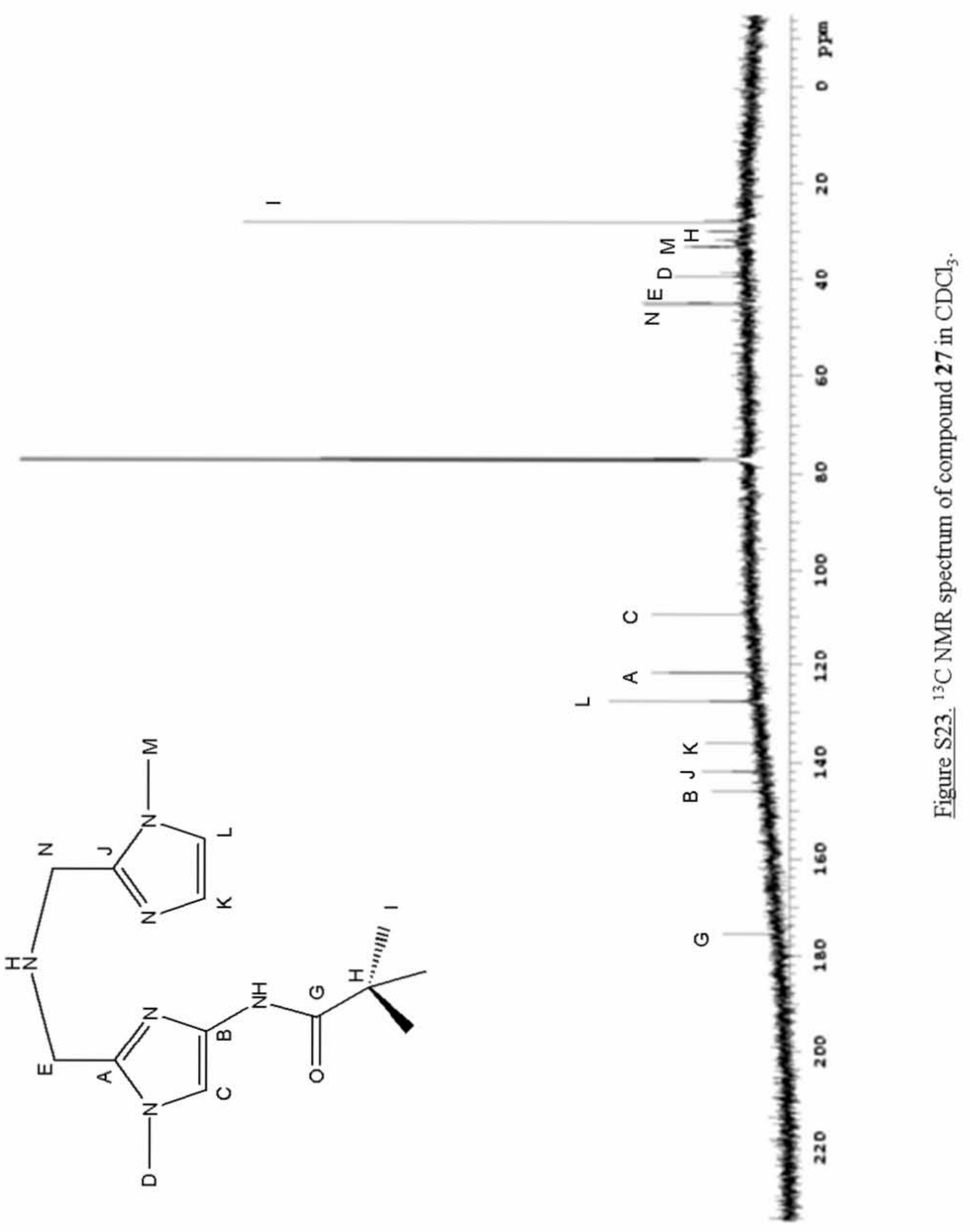




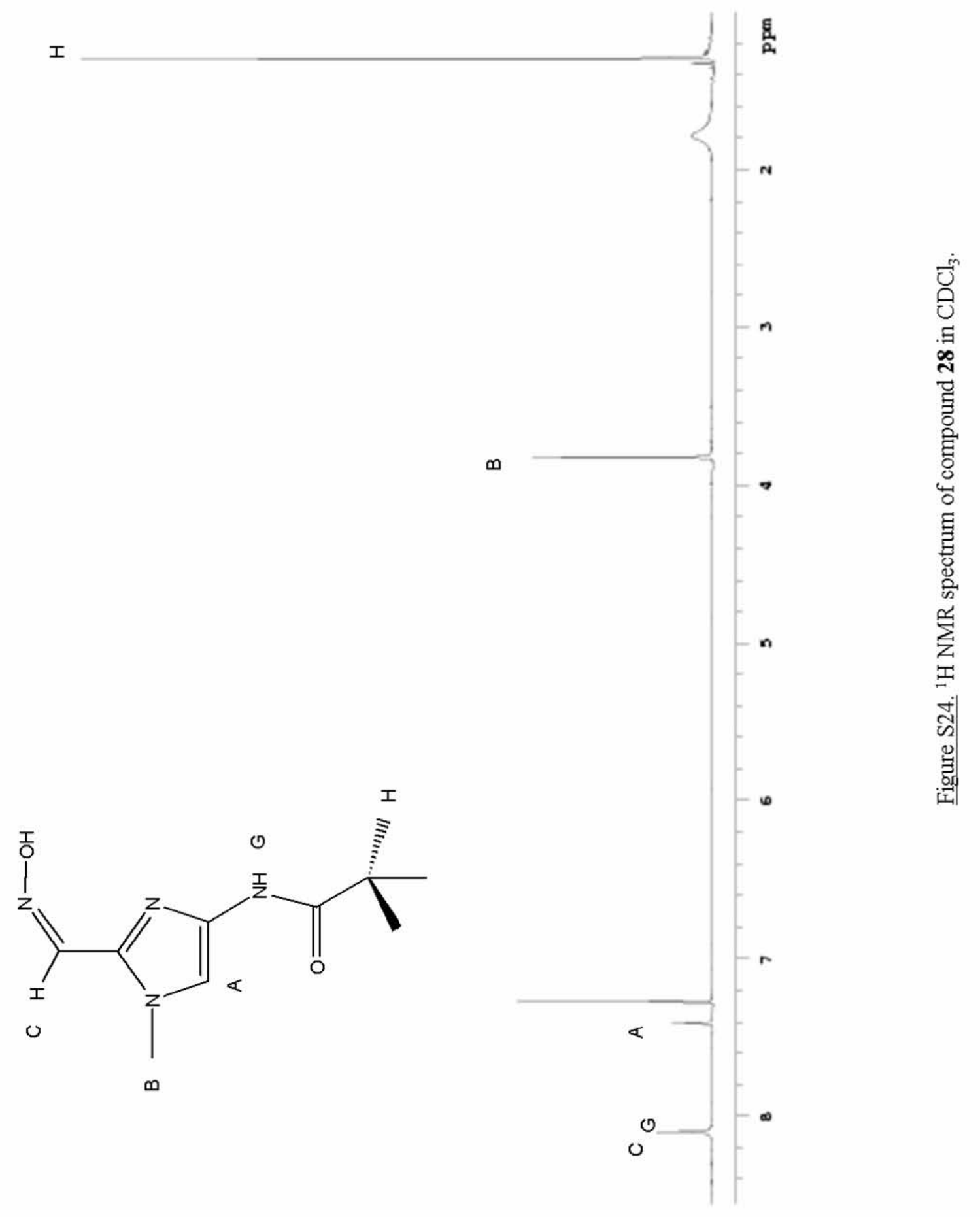




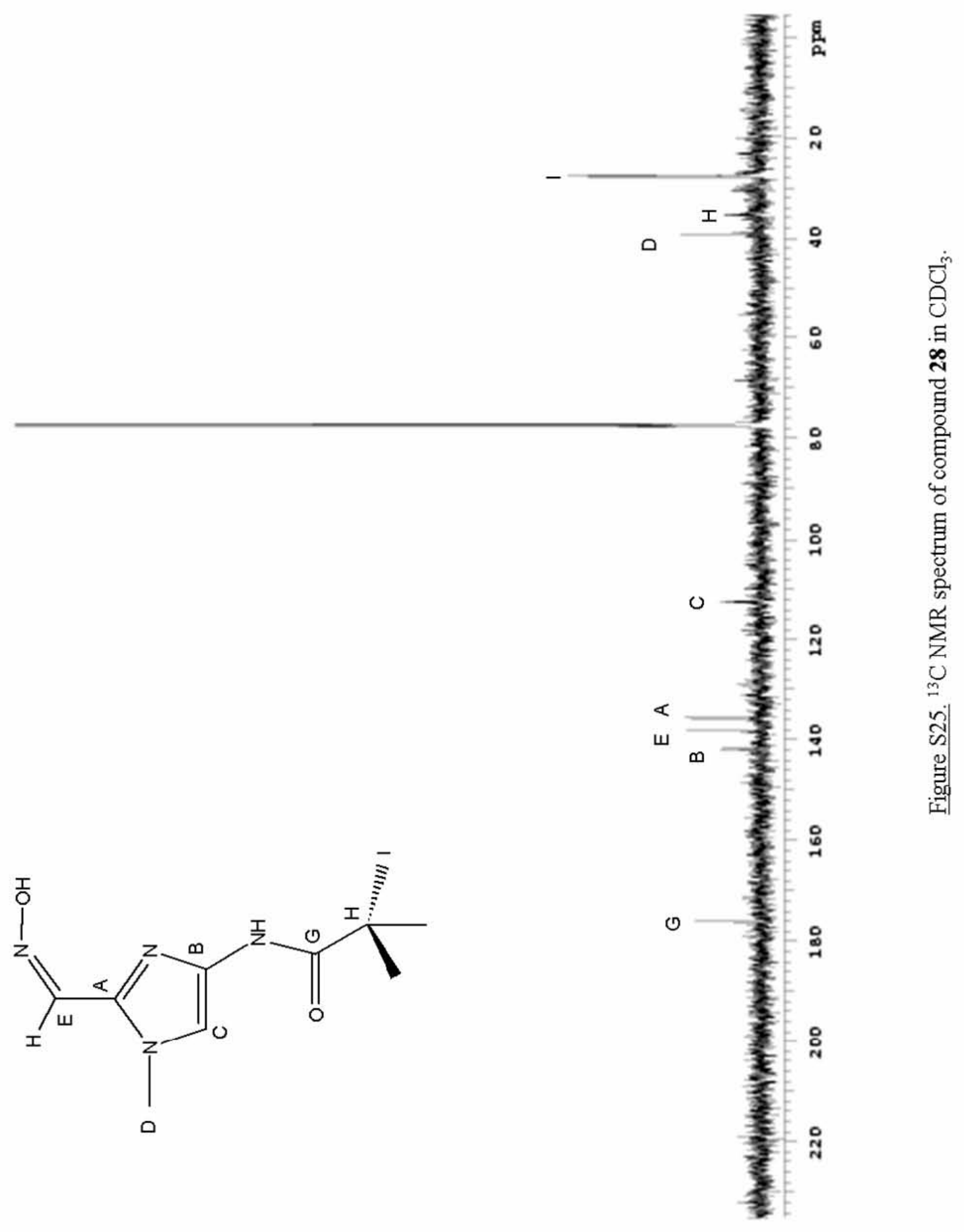




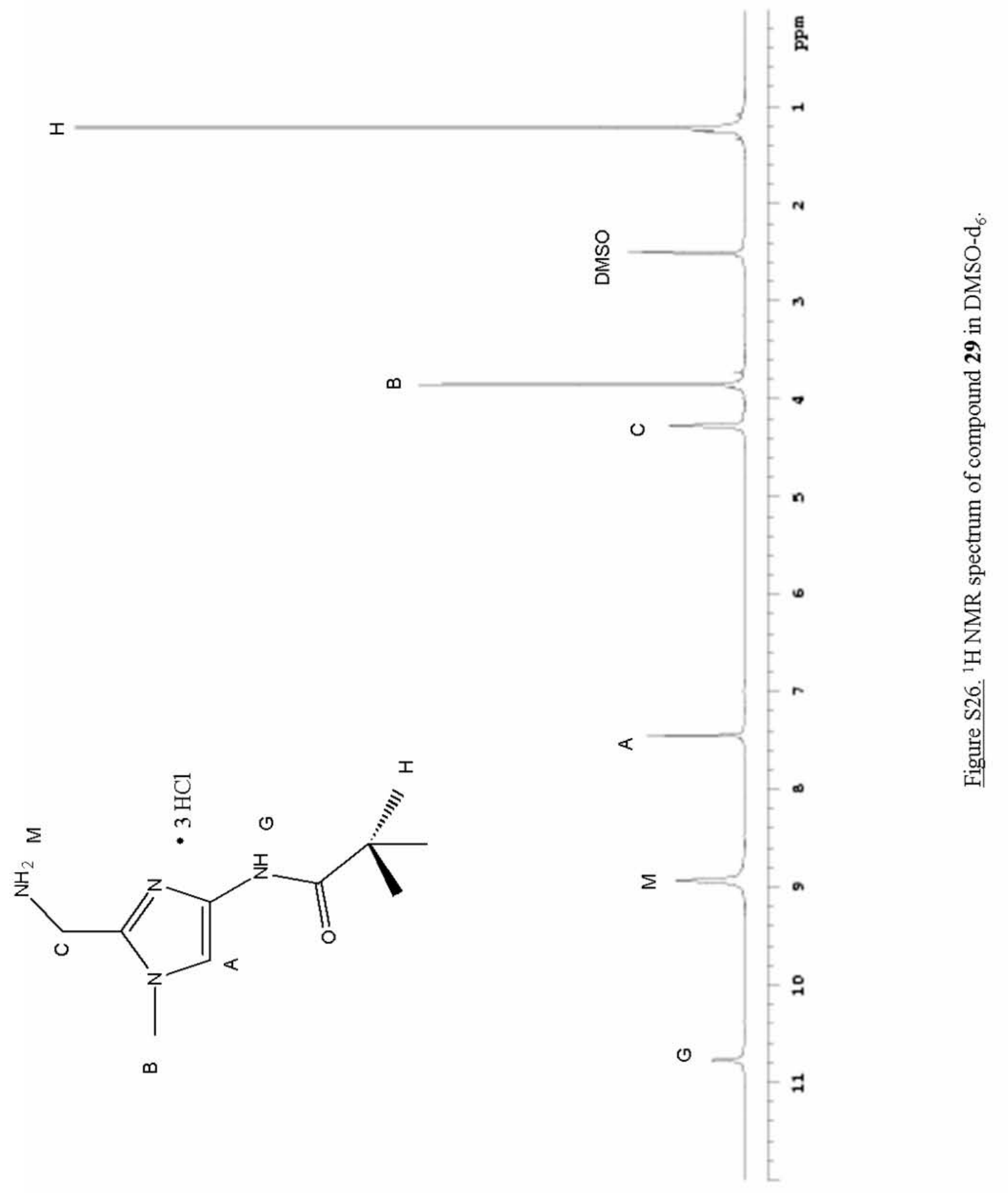




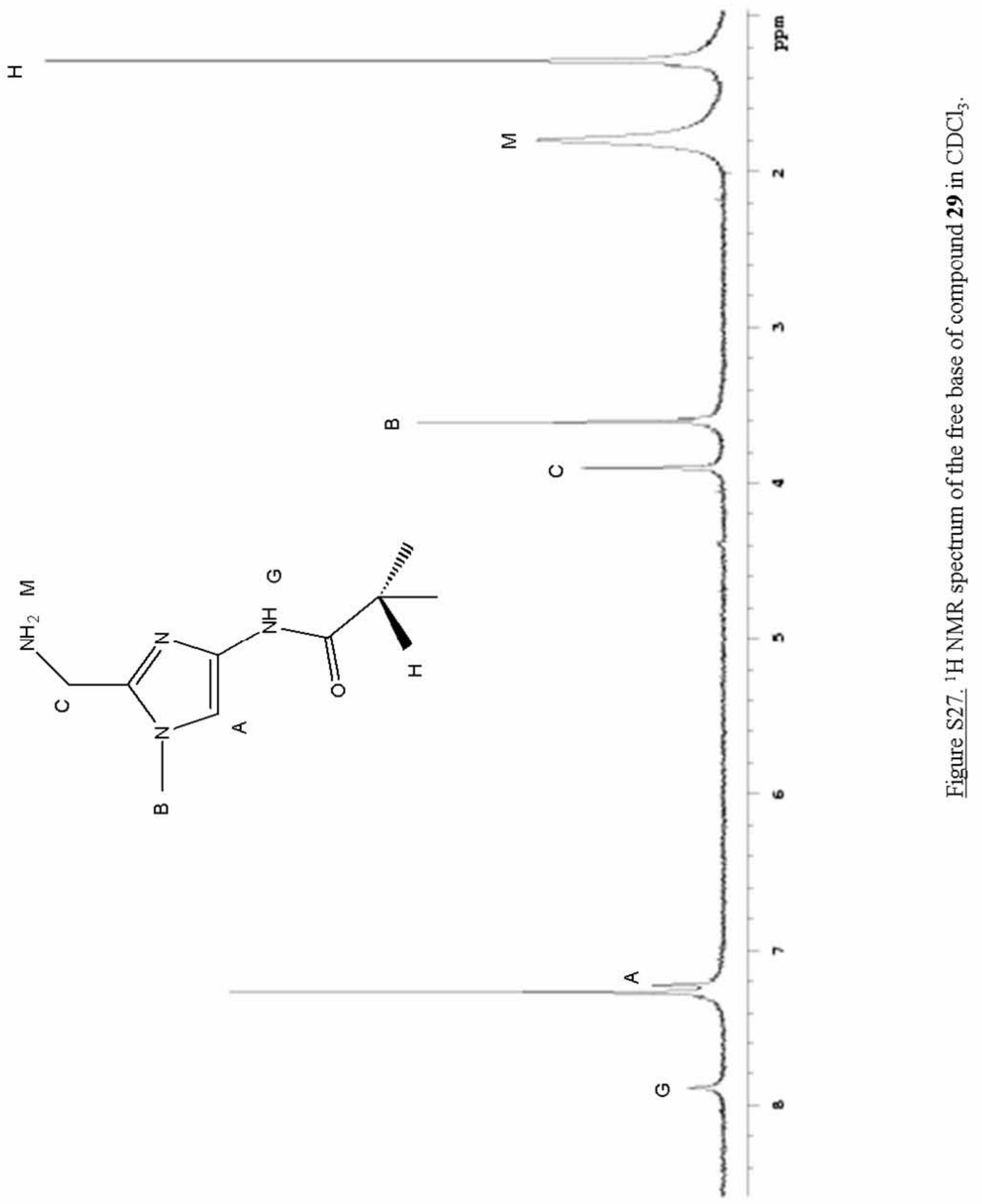




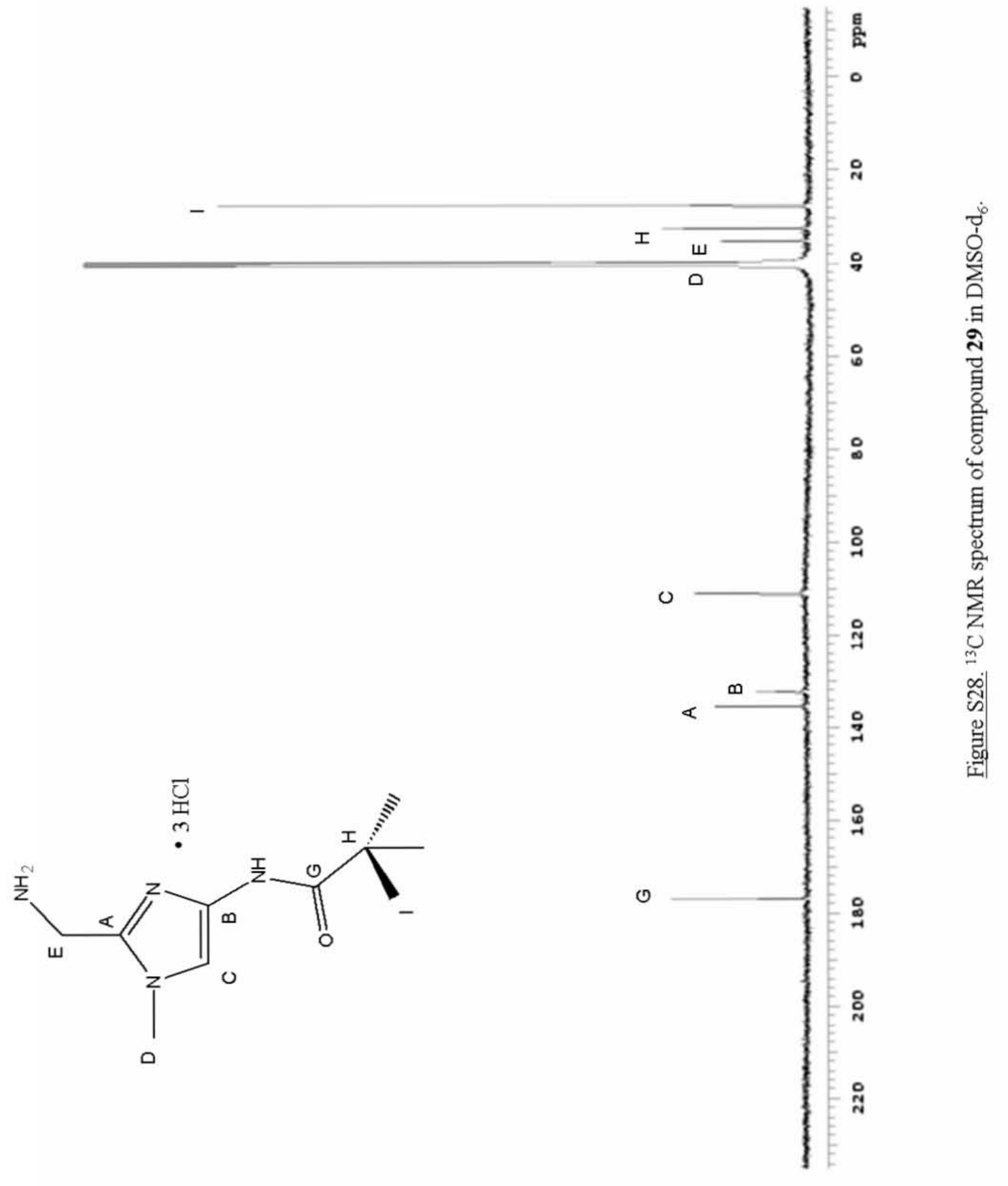




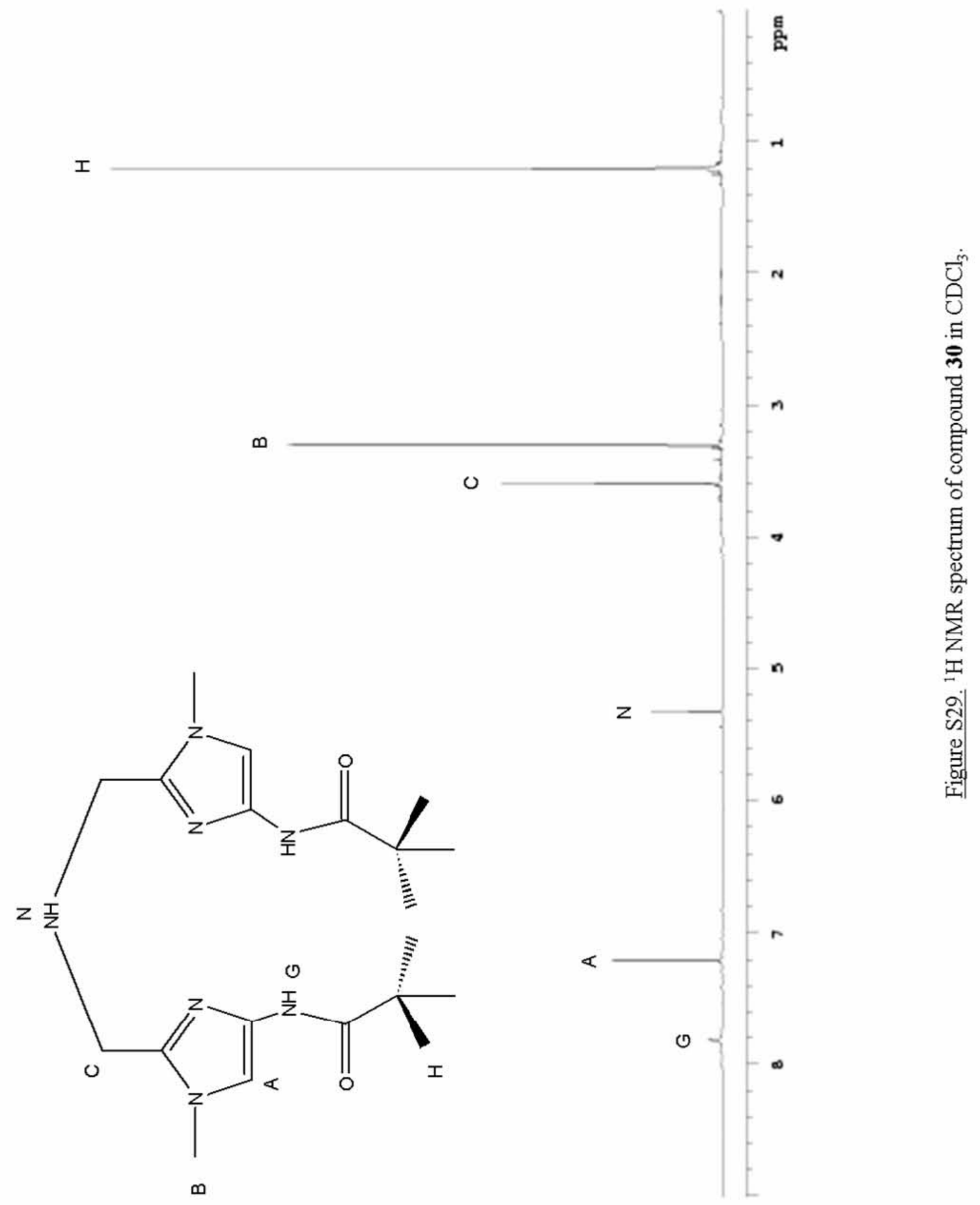




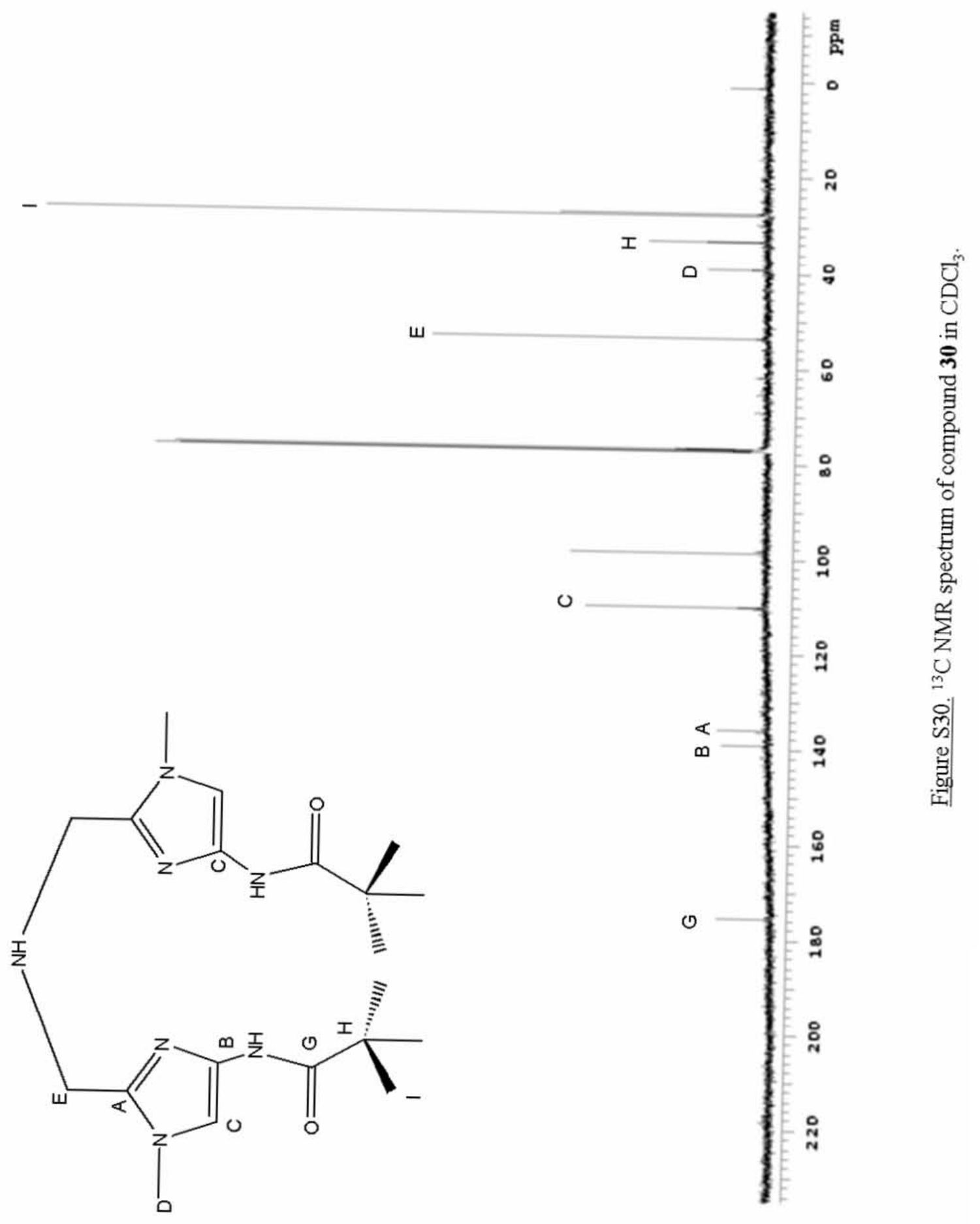



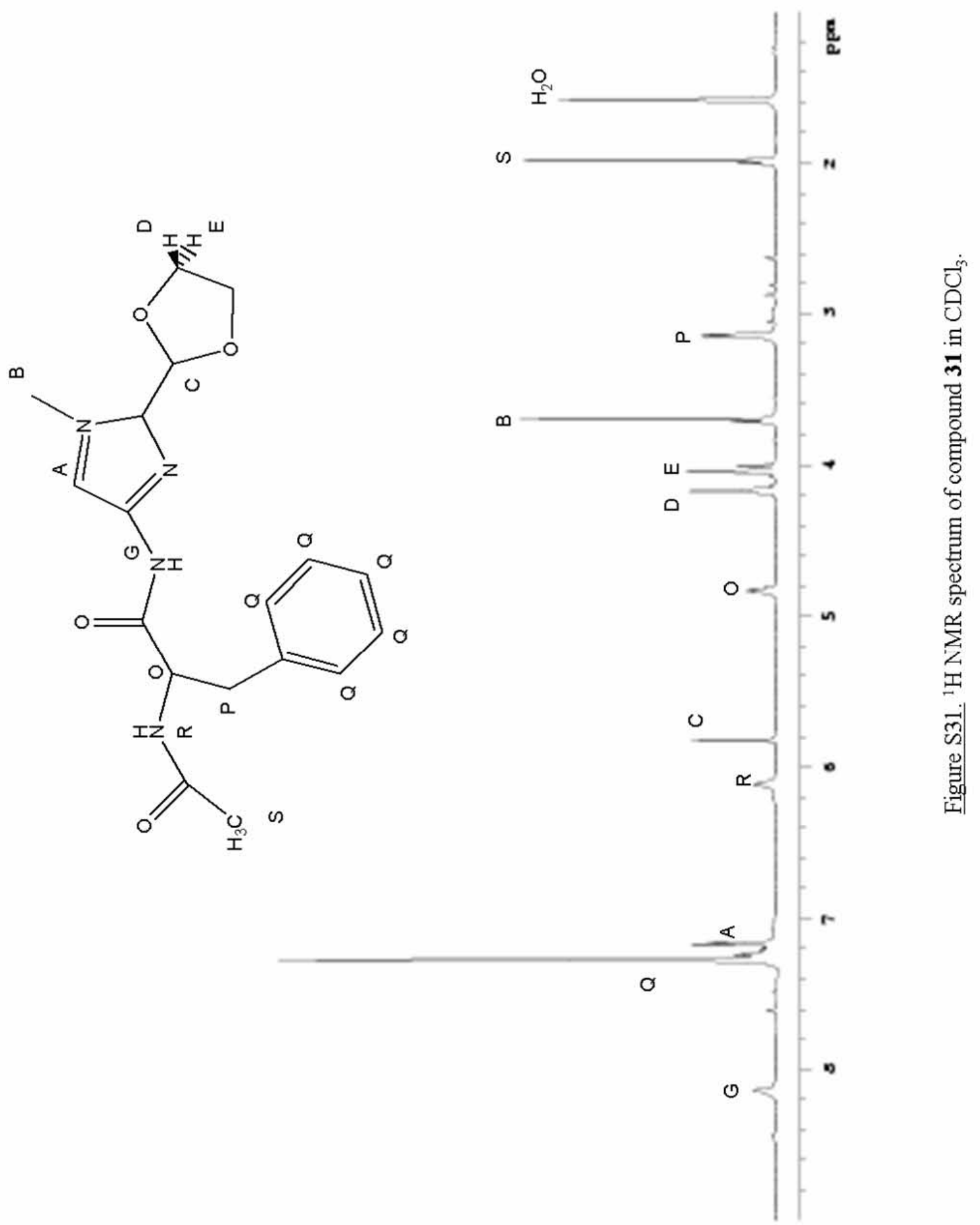


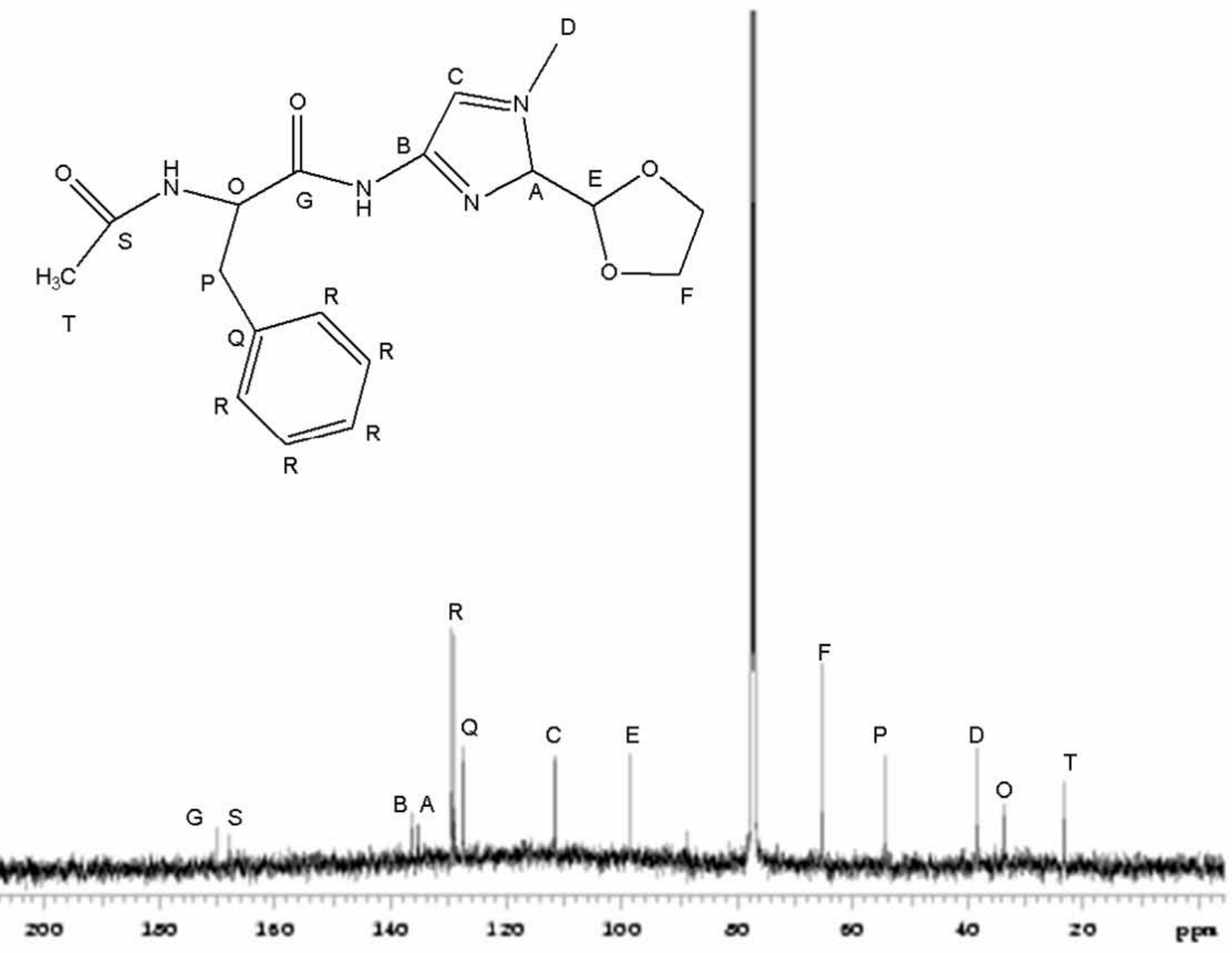

Figure $\mathrm{S} 32 .{ }^{13} \mathrm{C}$ NMR spectrum of compound $\mathbf{3 1}$ in $\mathrm{CDCl}_{3}$. 


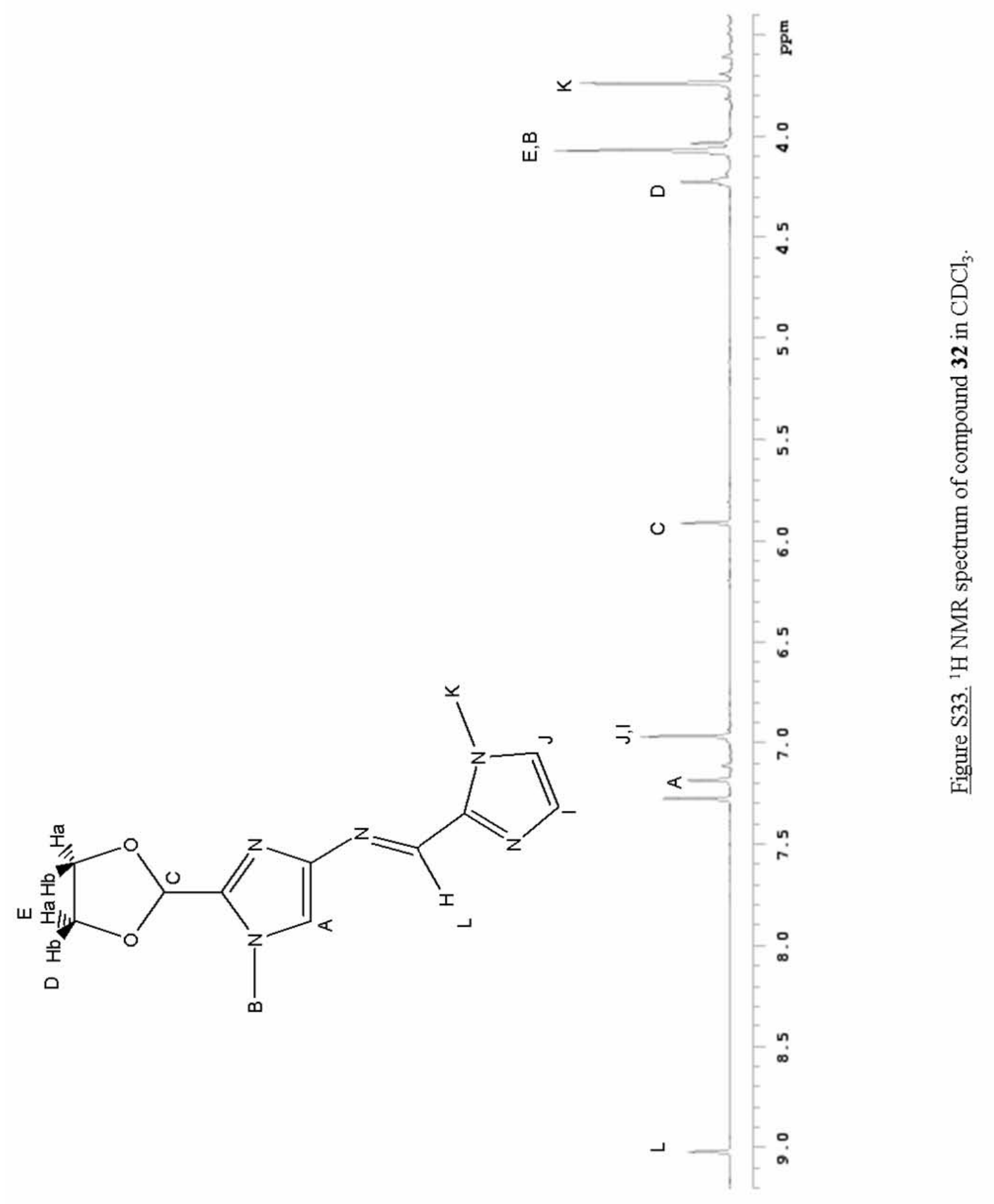




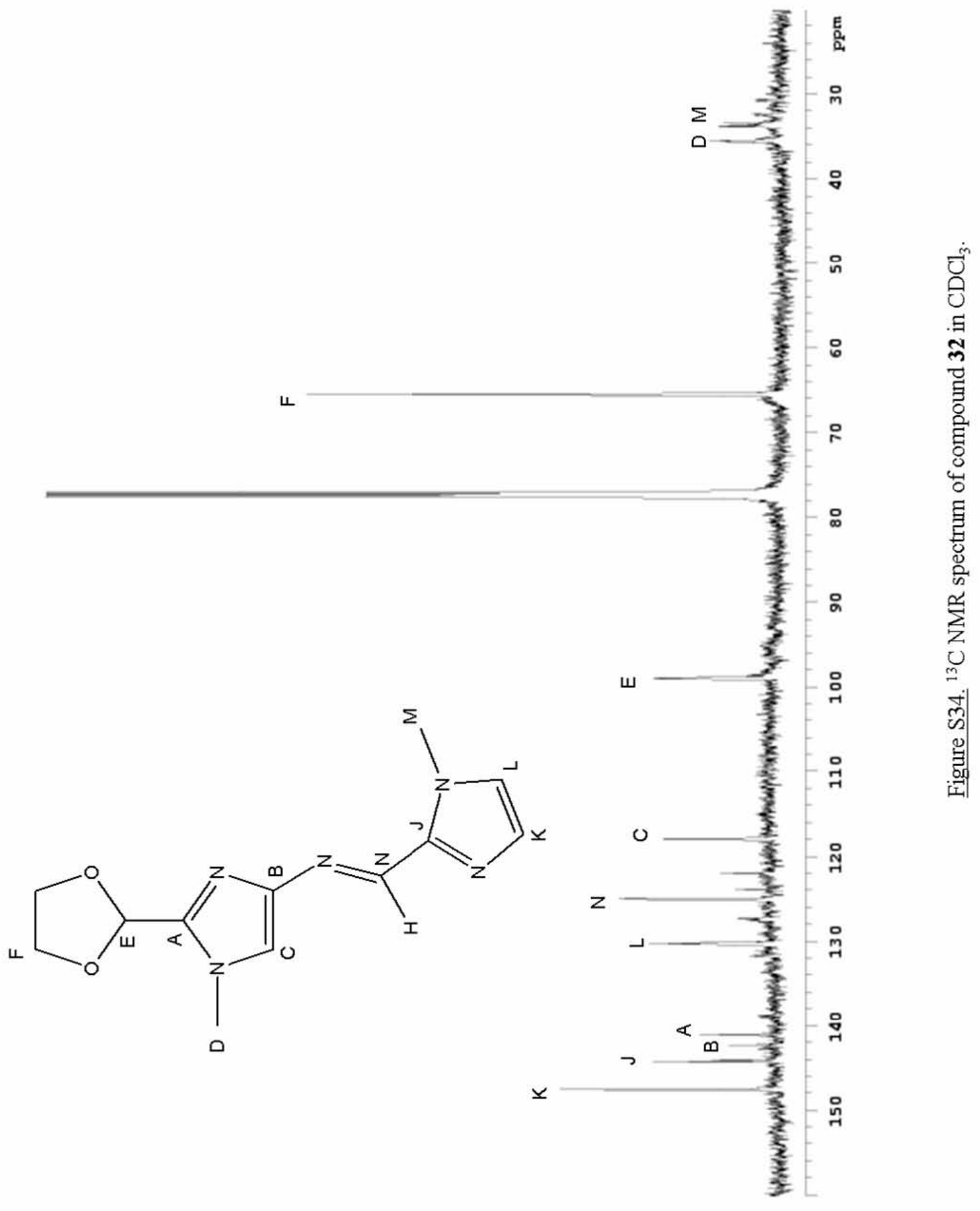



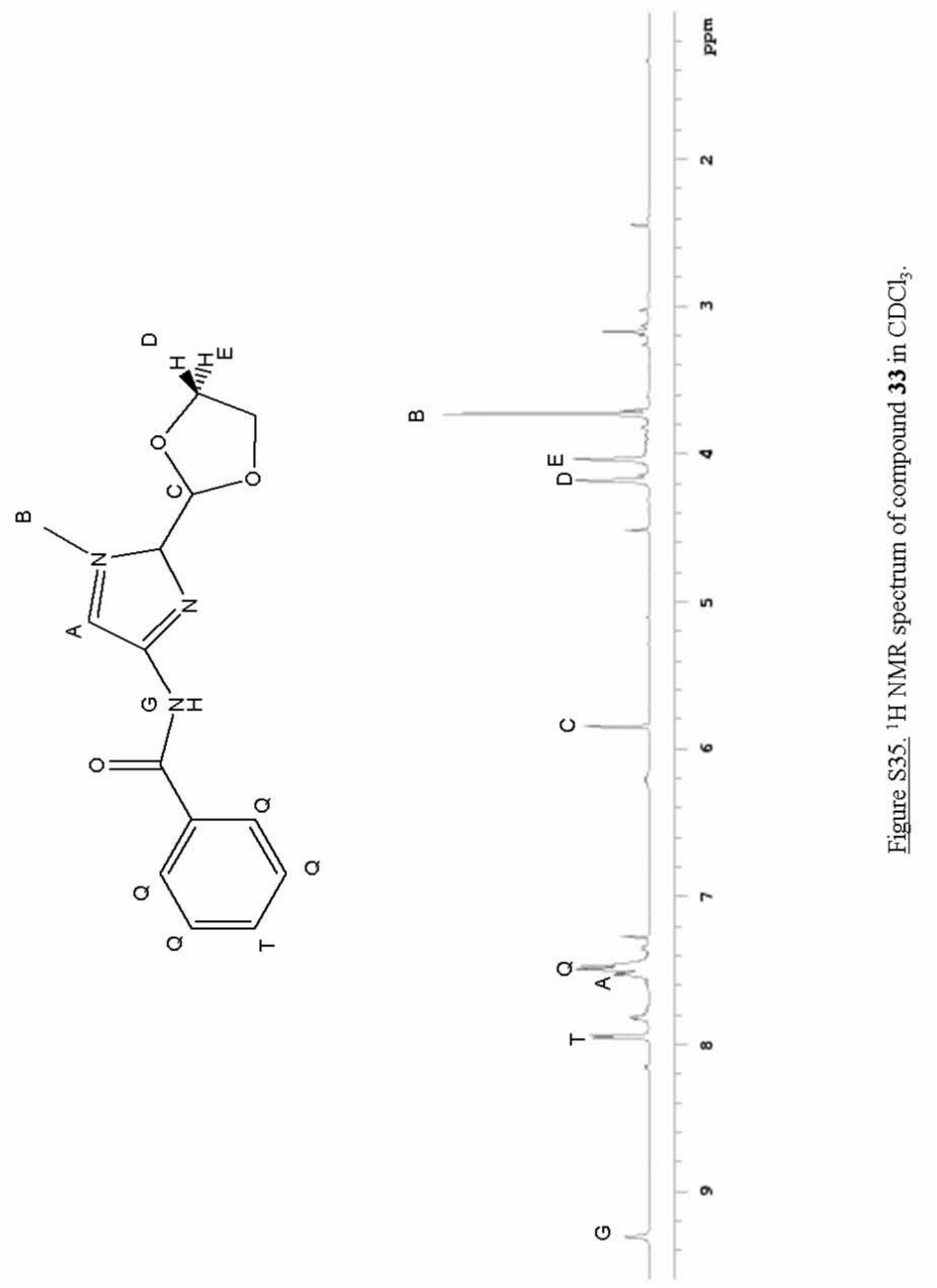


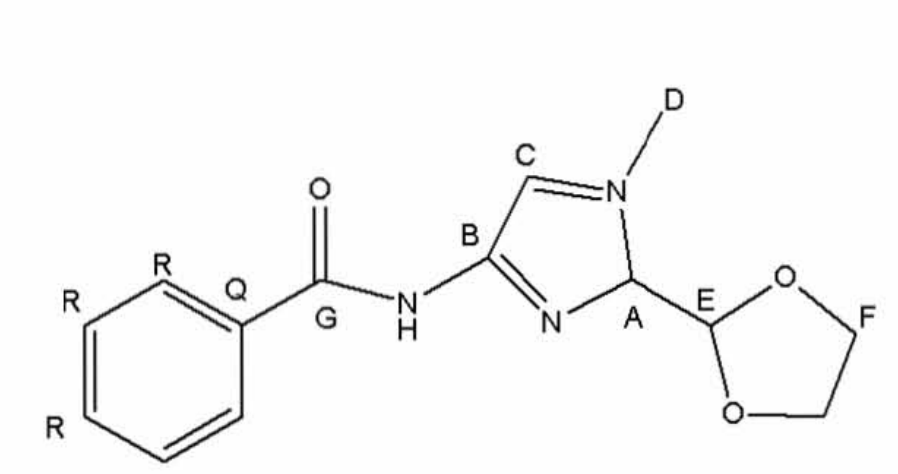

Figure $\mathrm{S} 36 .{ }^{13} \mathrm{C}$ NMR spectrum of compound $\mathbf{3 3}$ in $\mathrm{CDCl}_{3}$. 

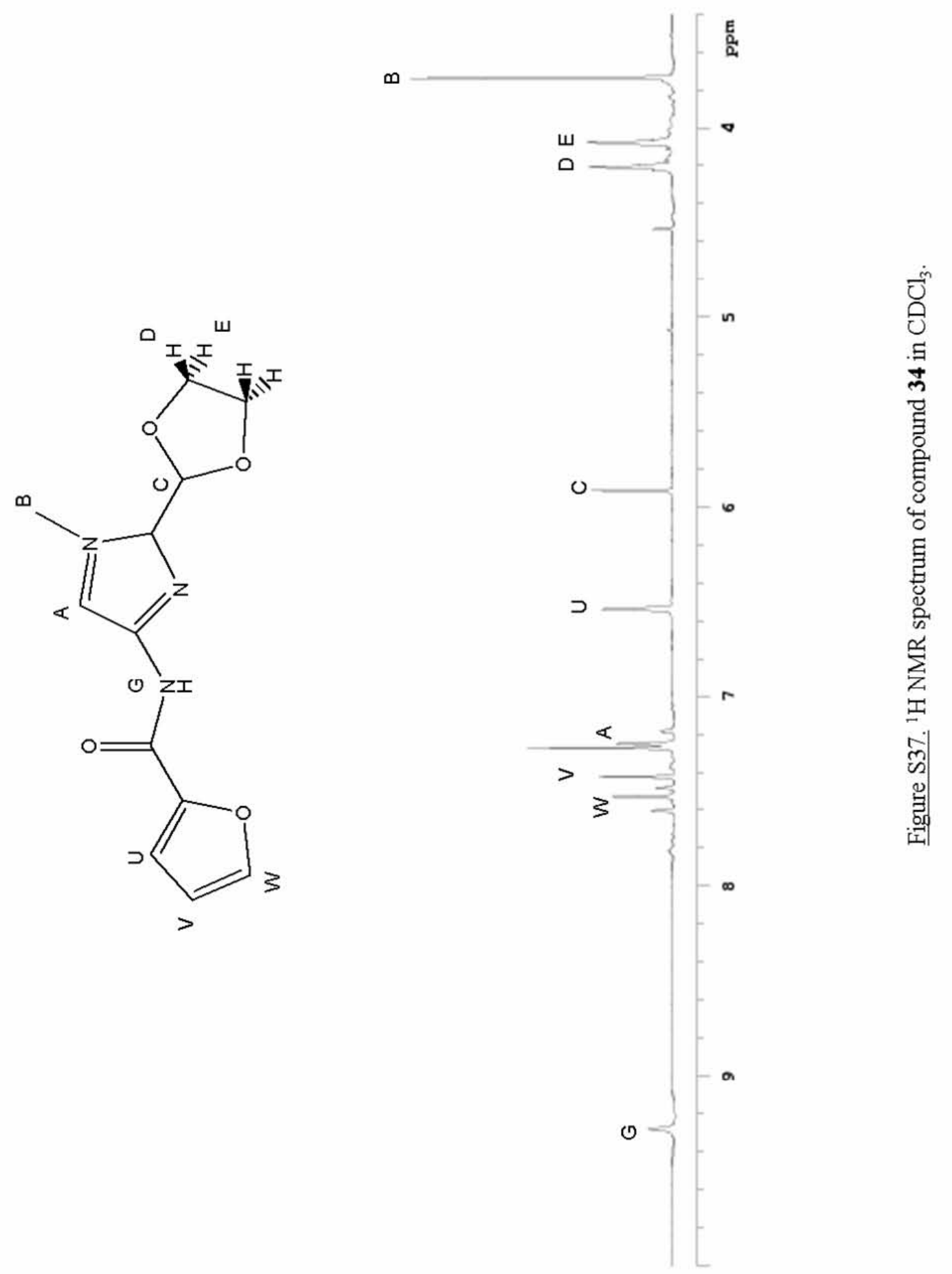


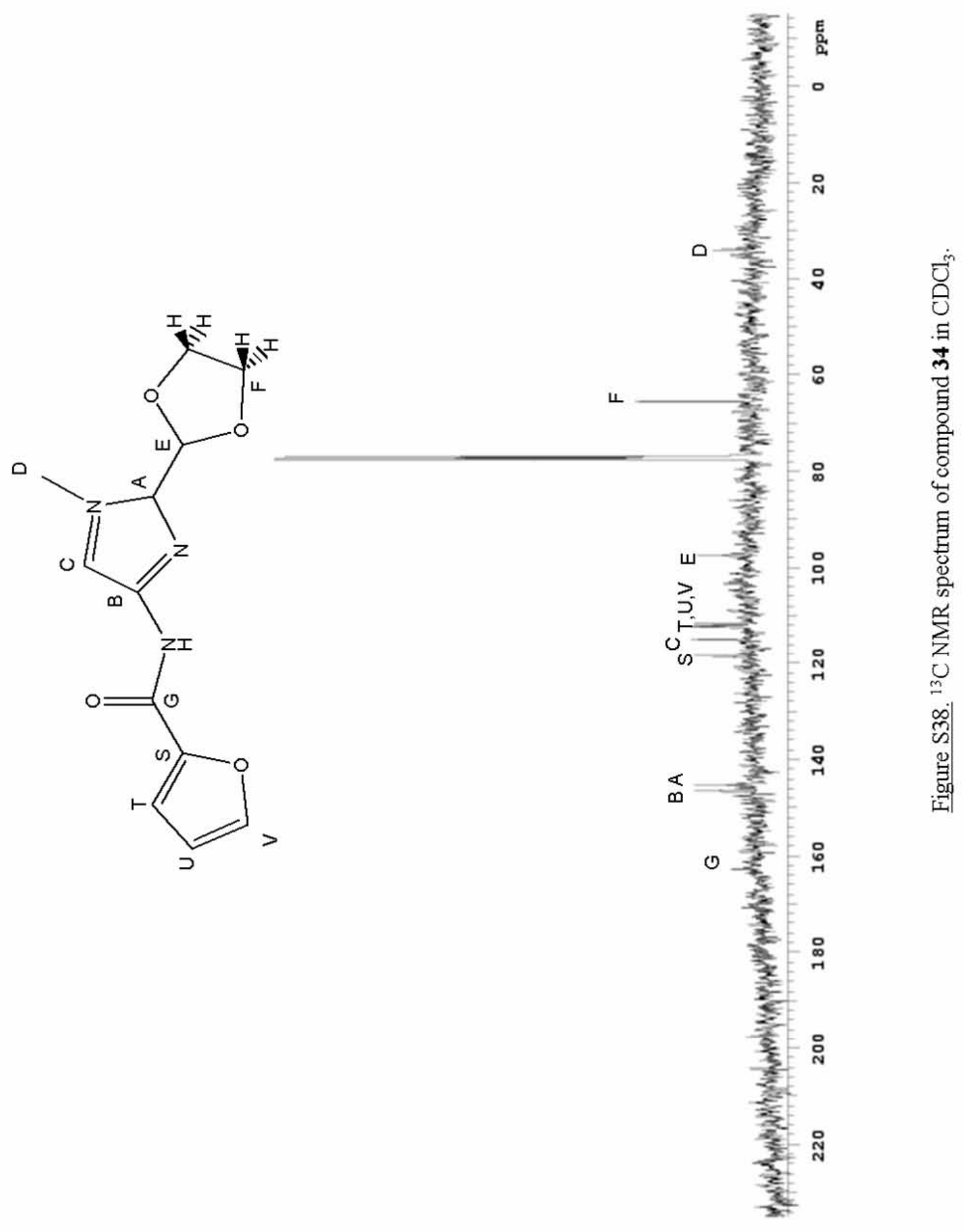




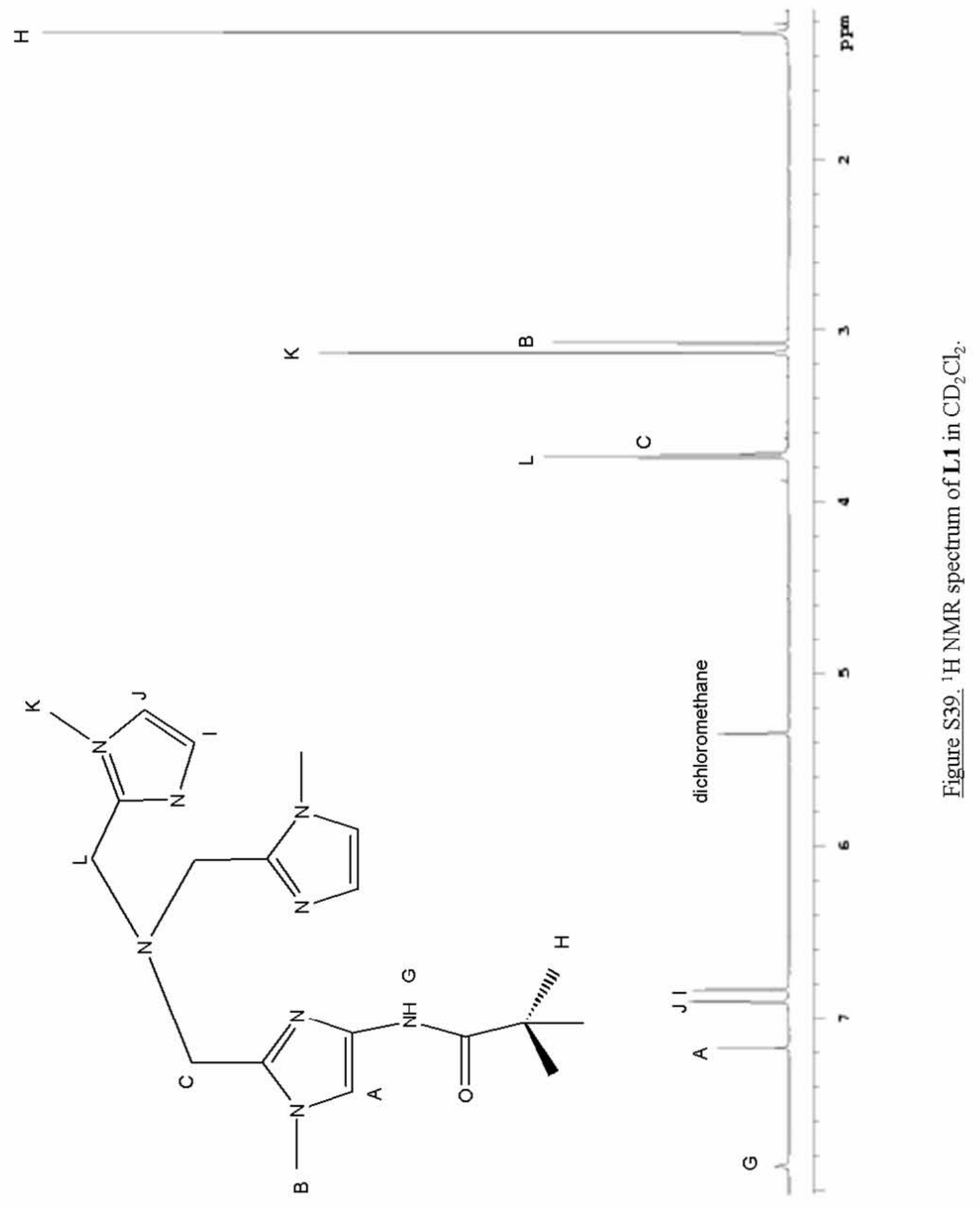




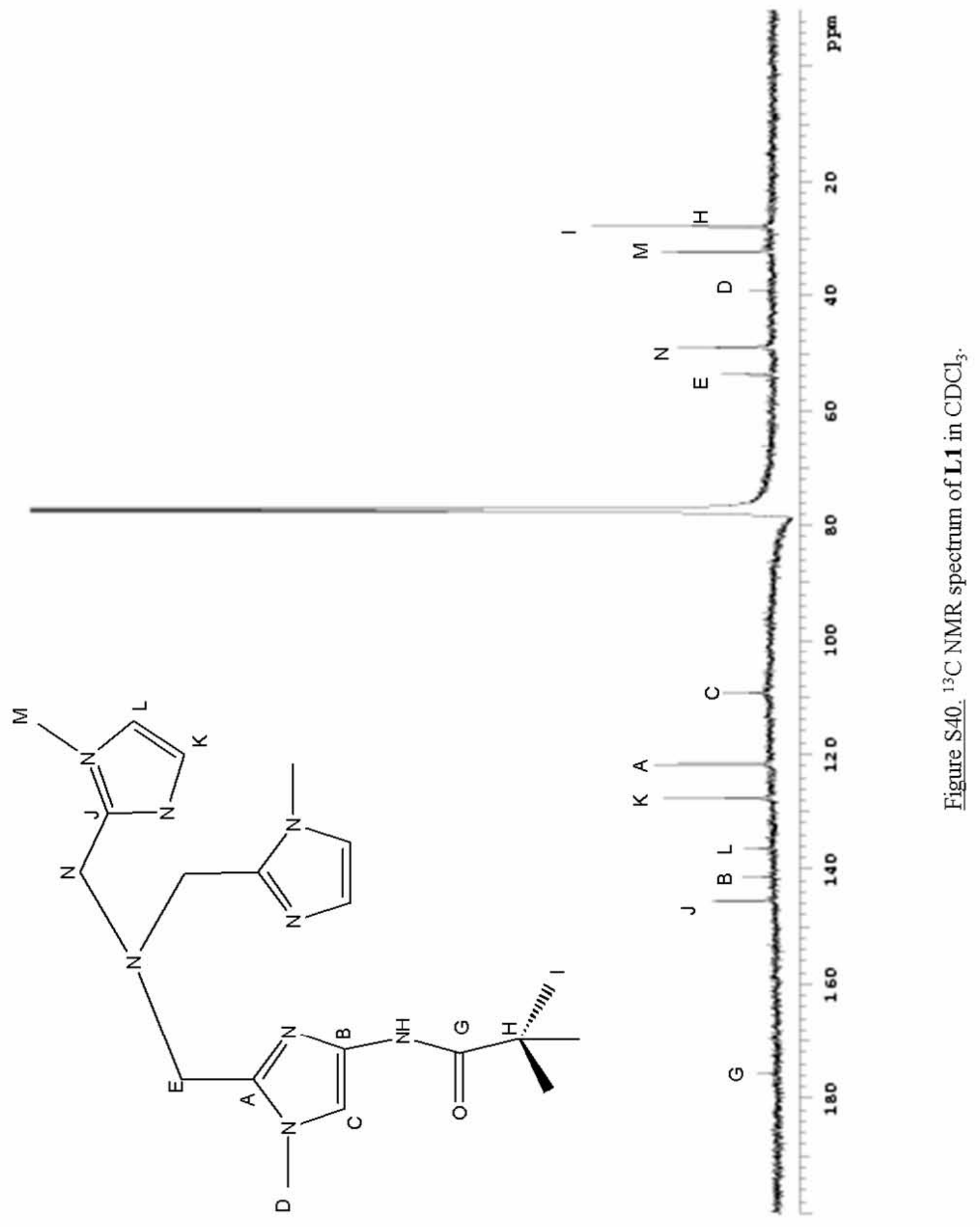




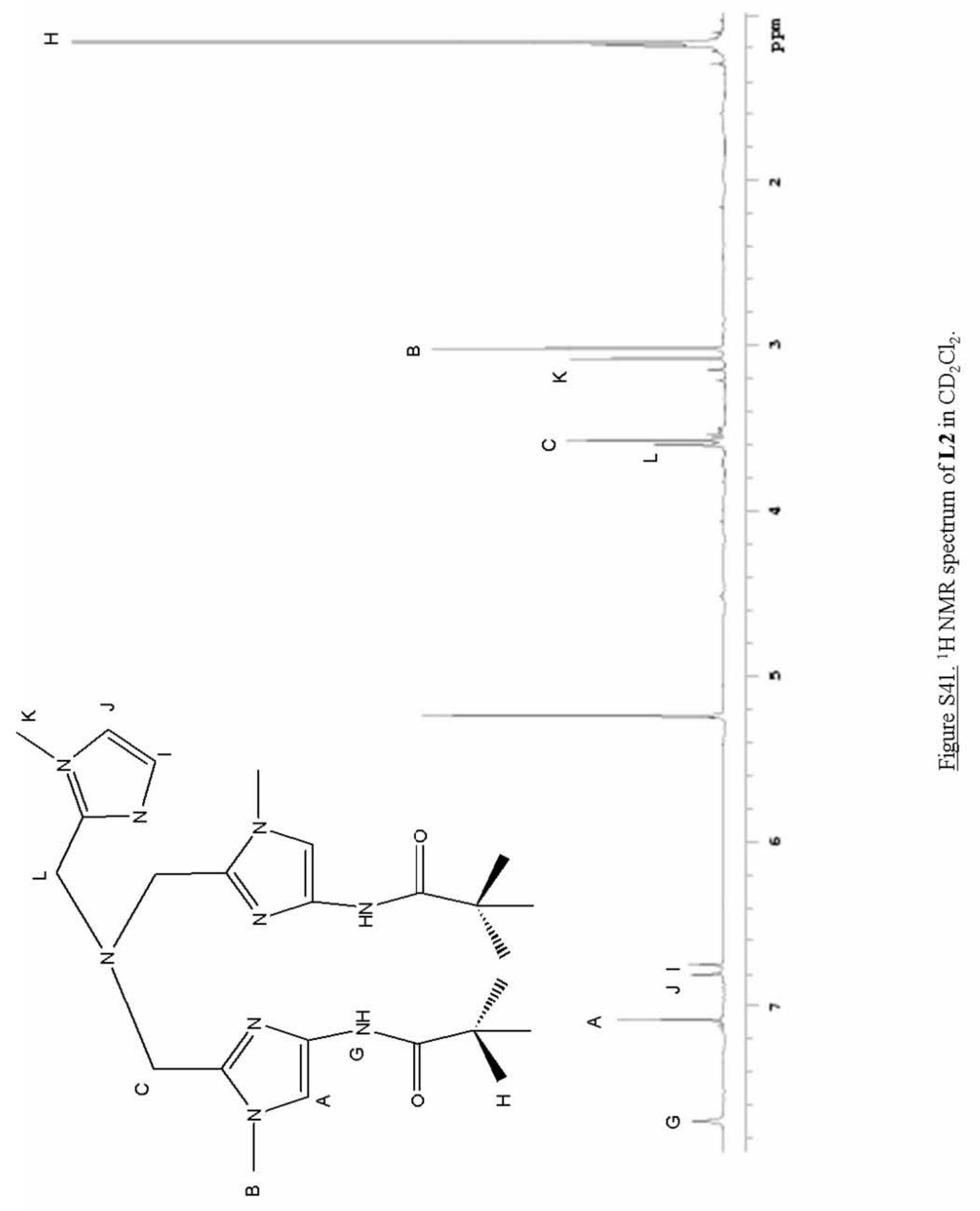




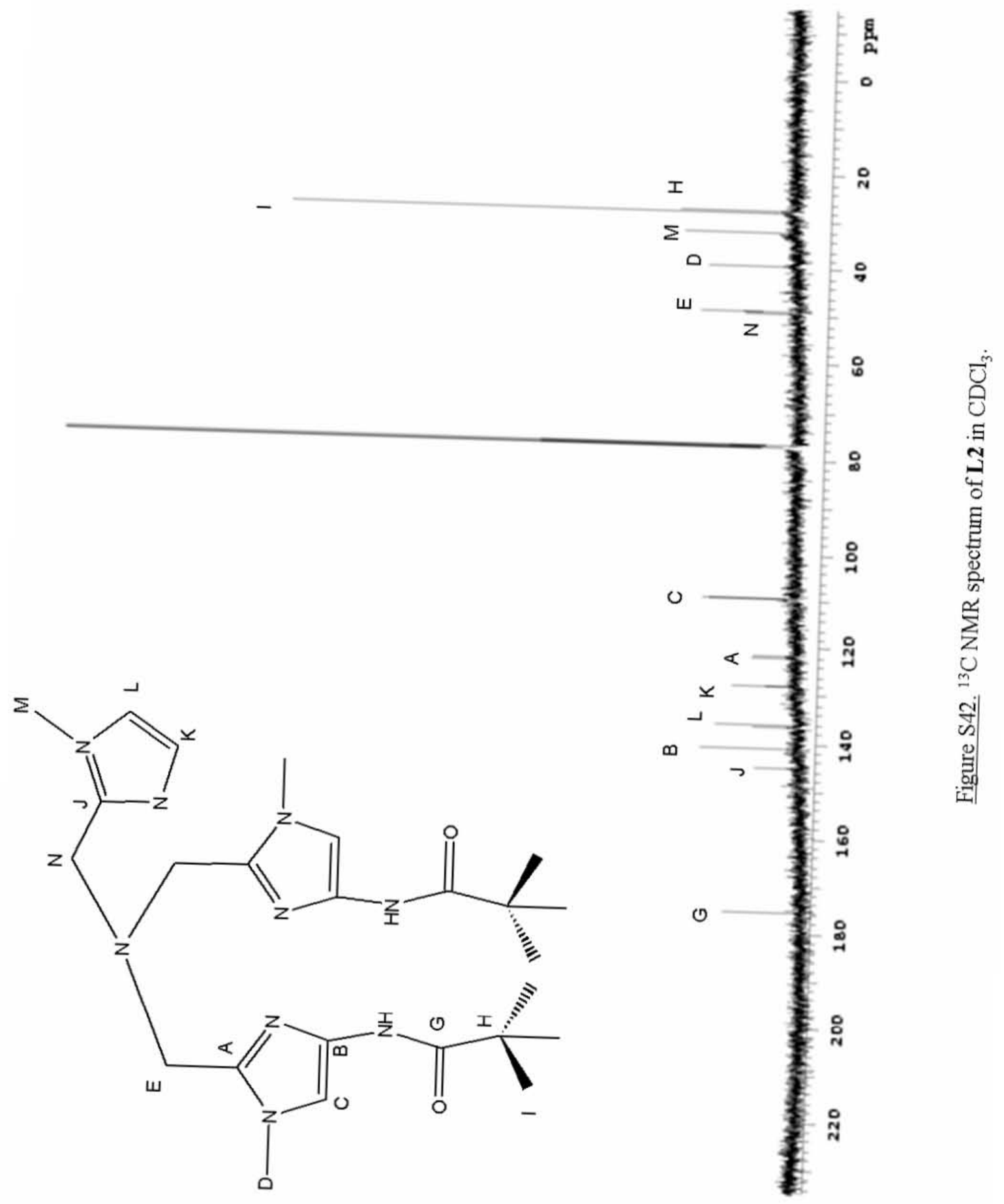




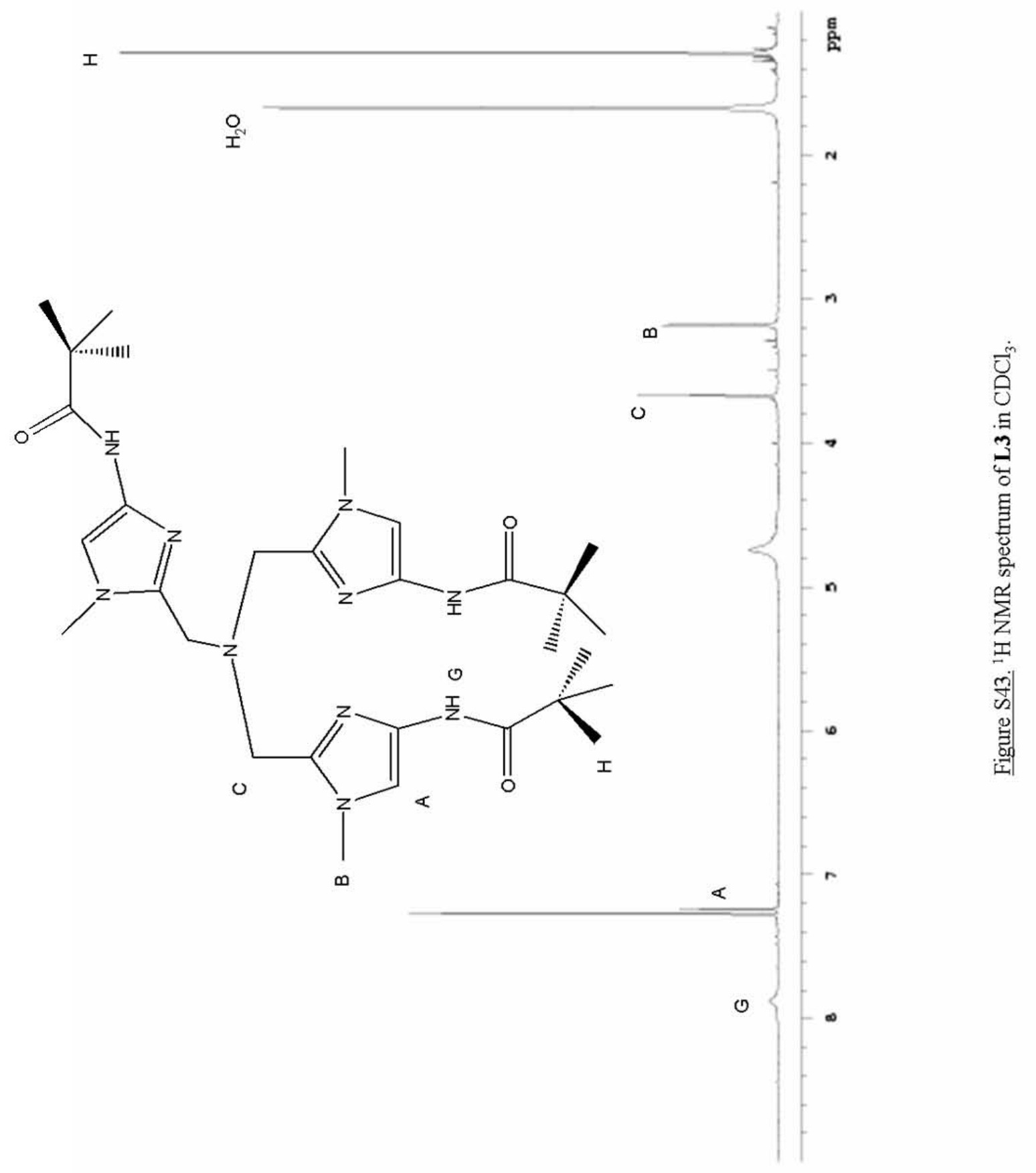




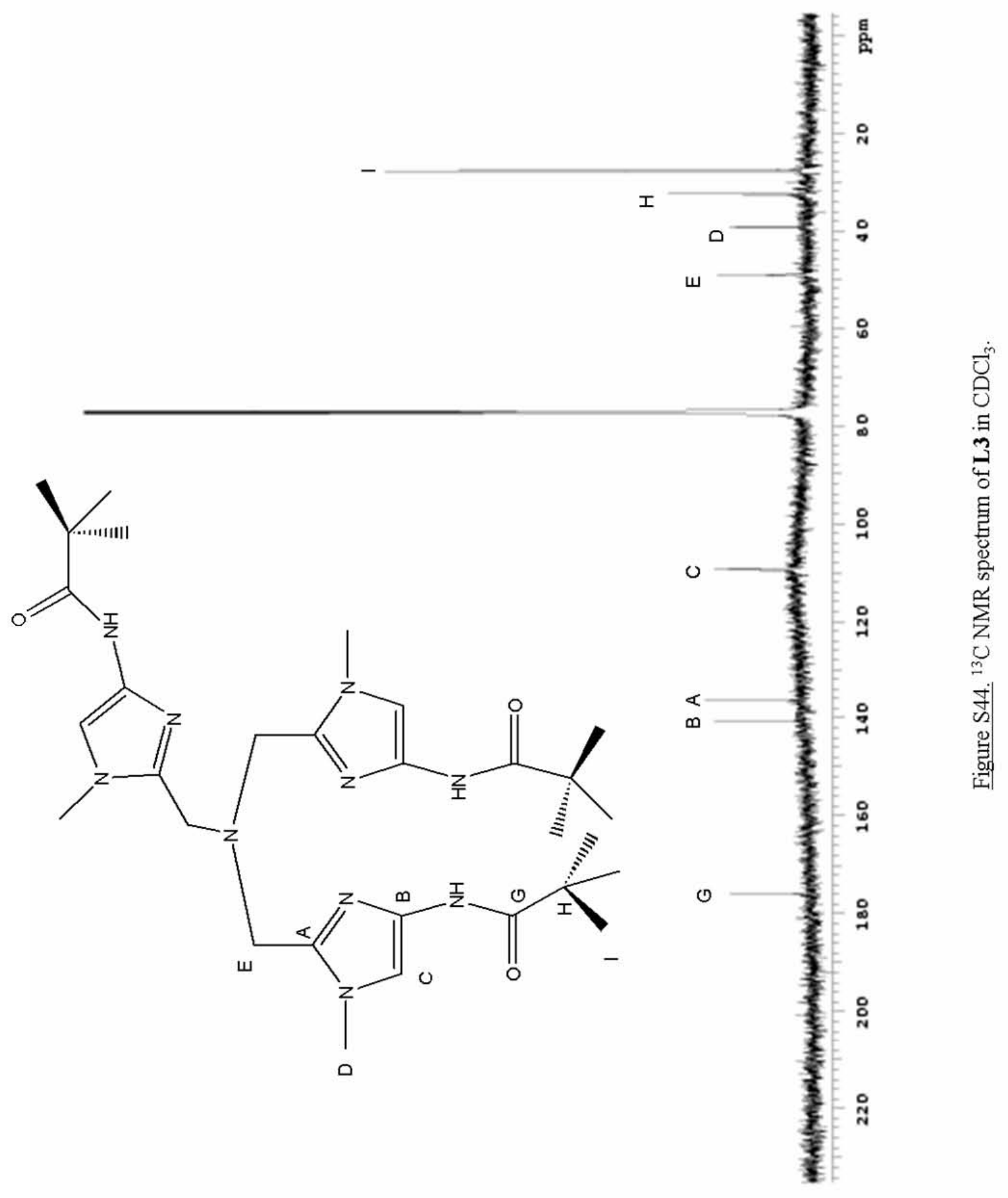




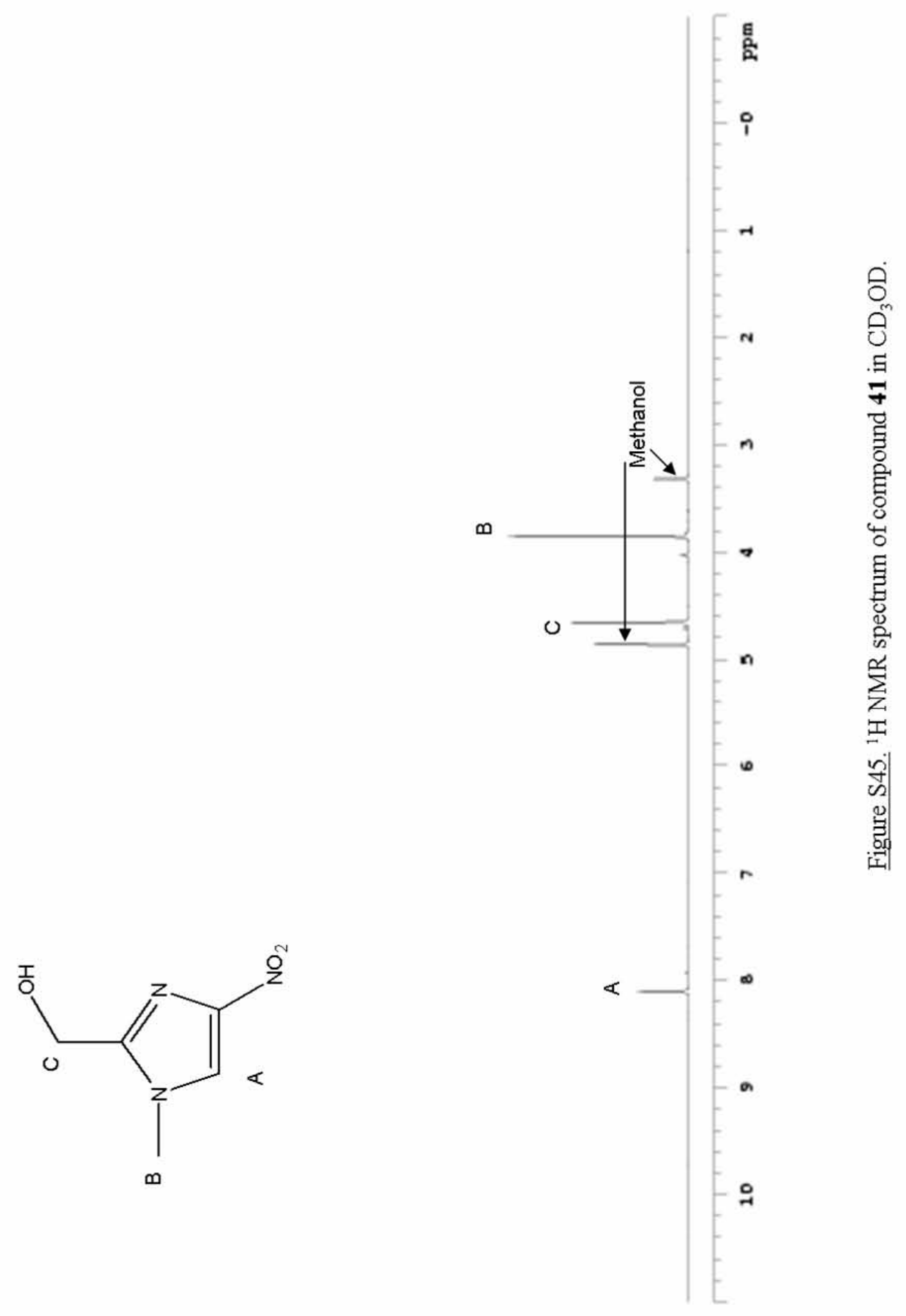




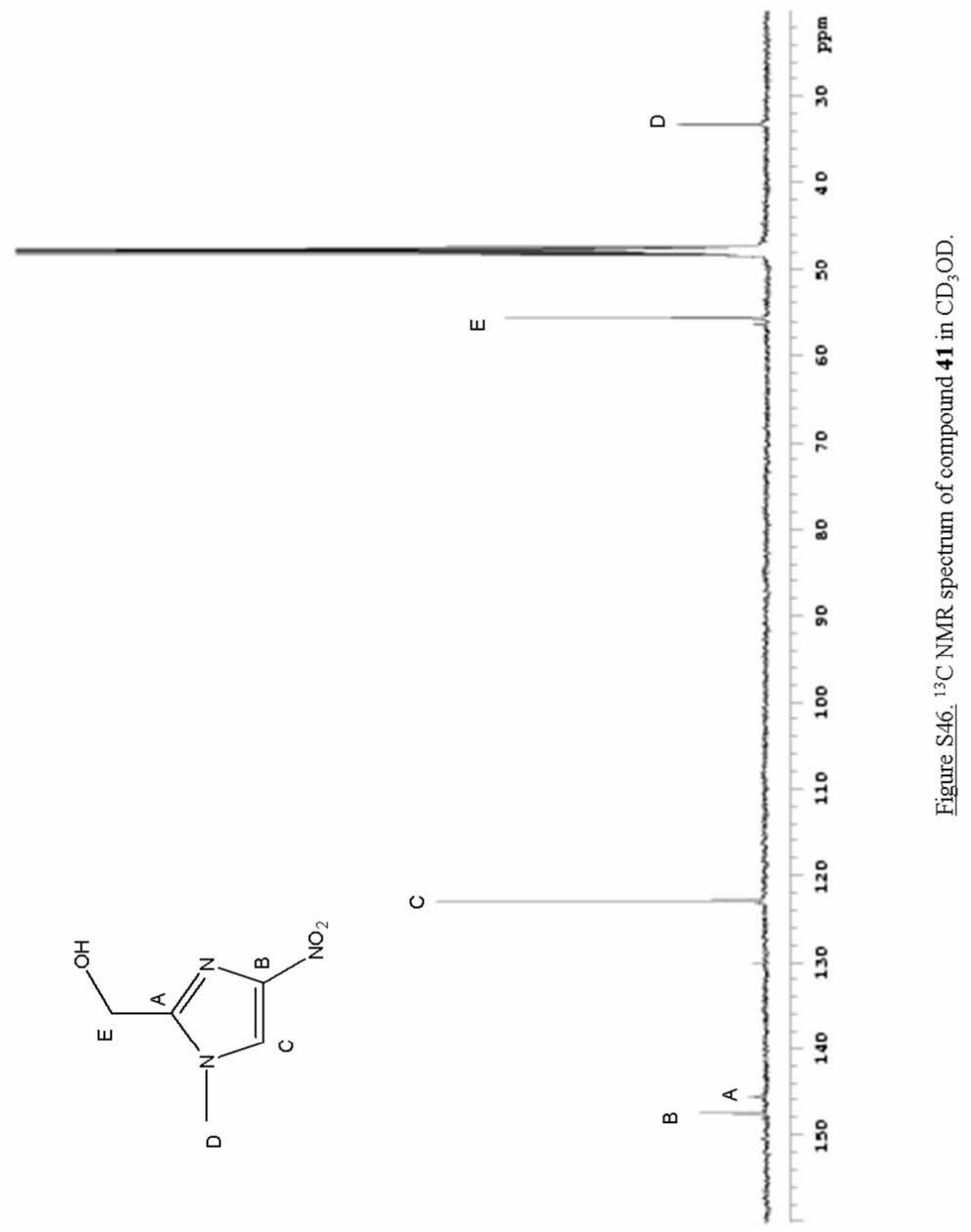




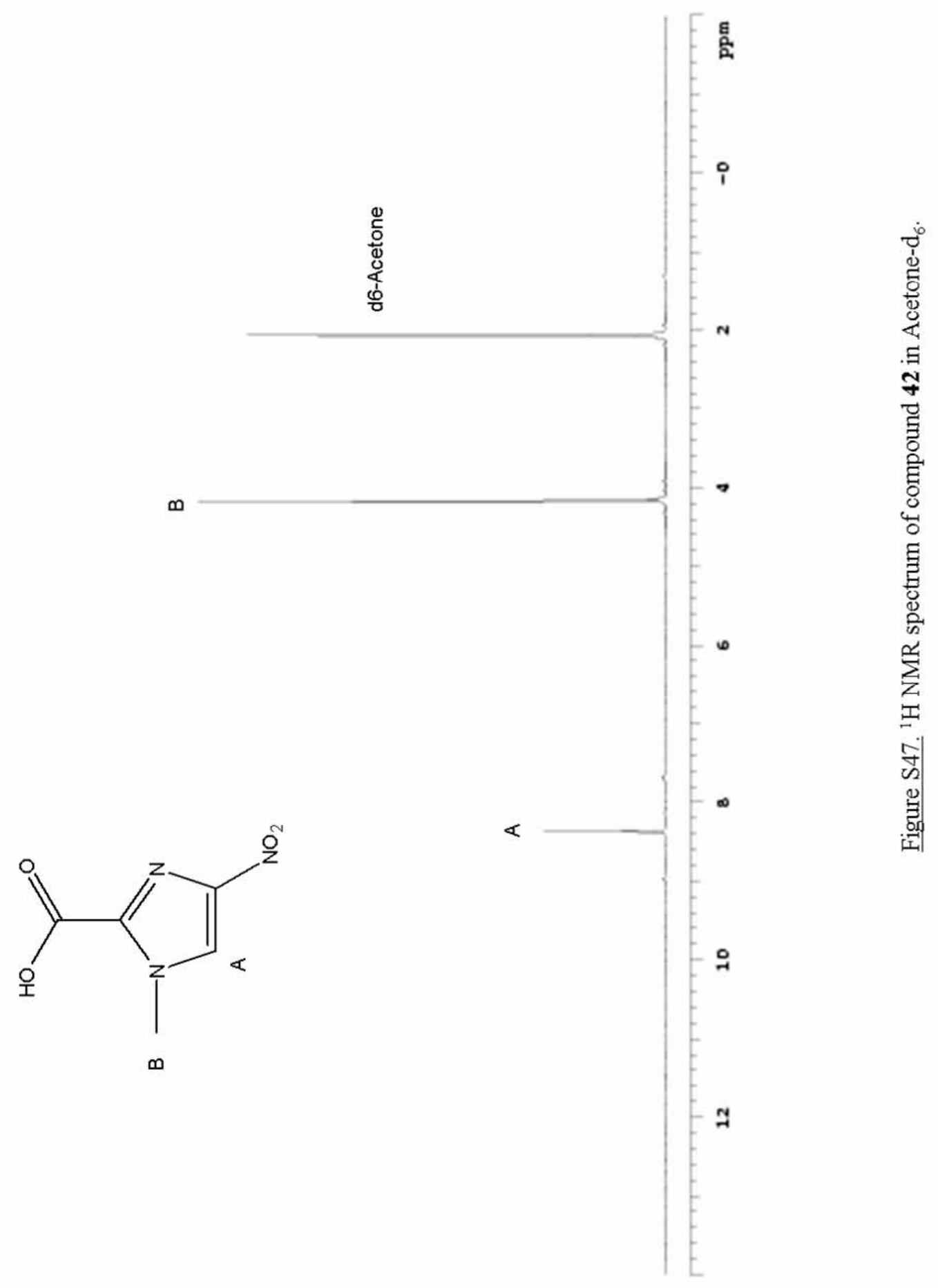




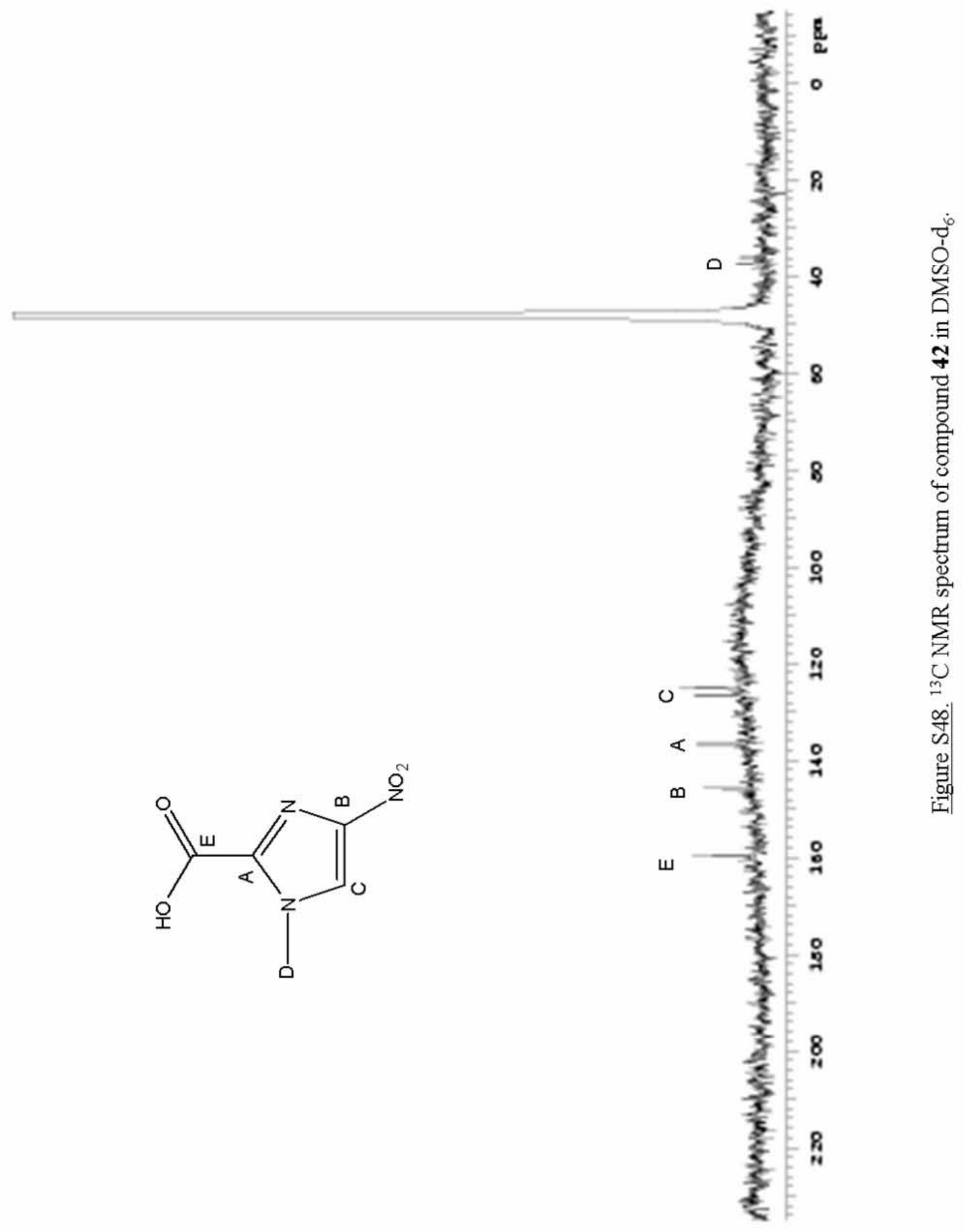




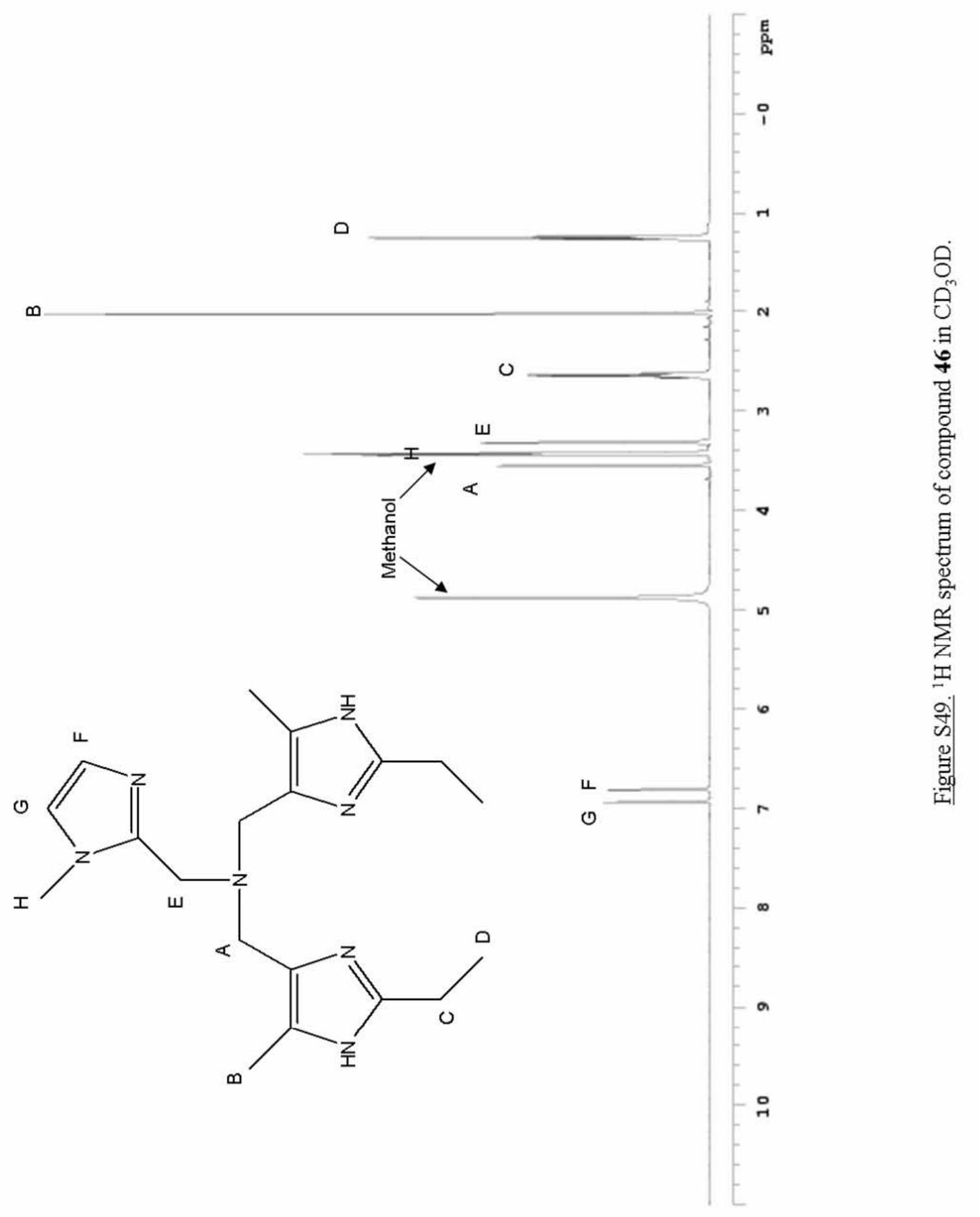




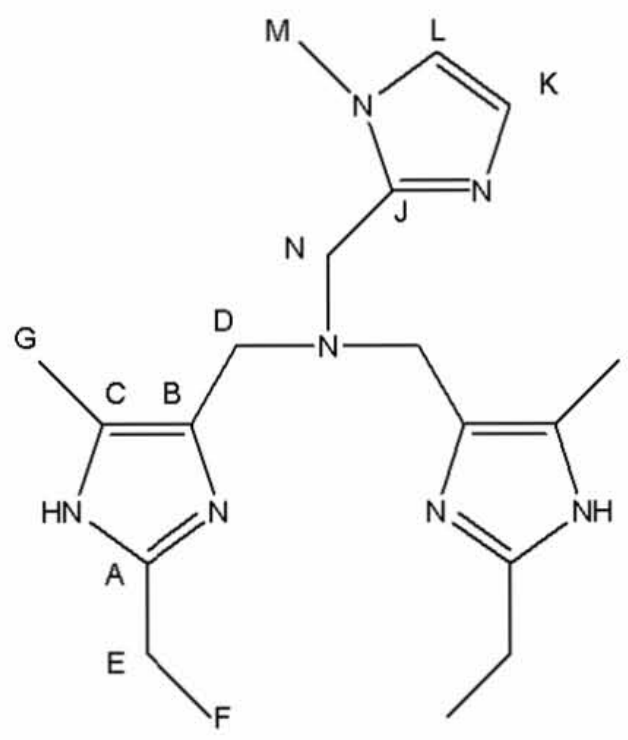

C, L

B, K

A J

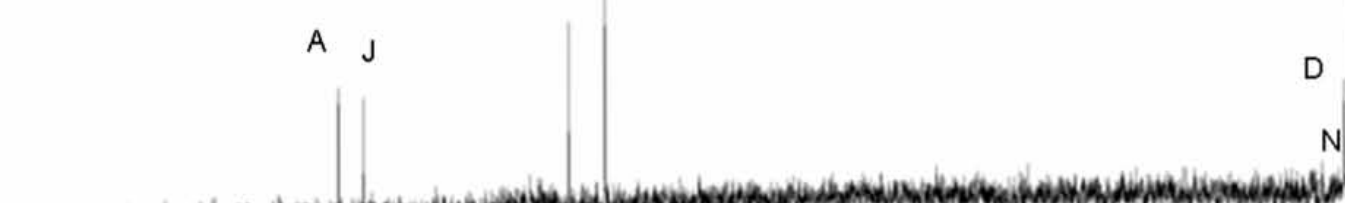

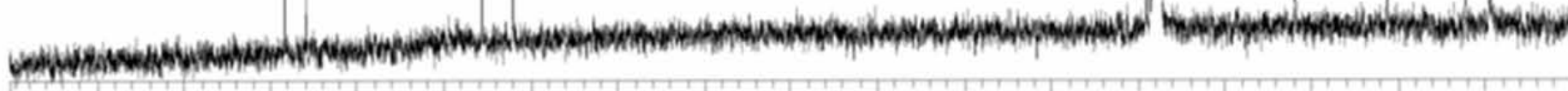

160 


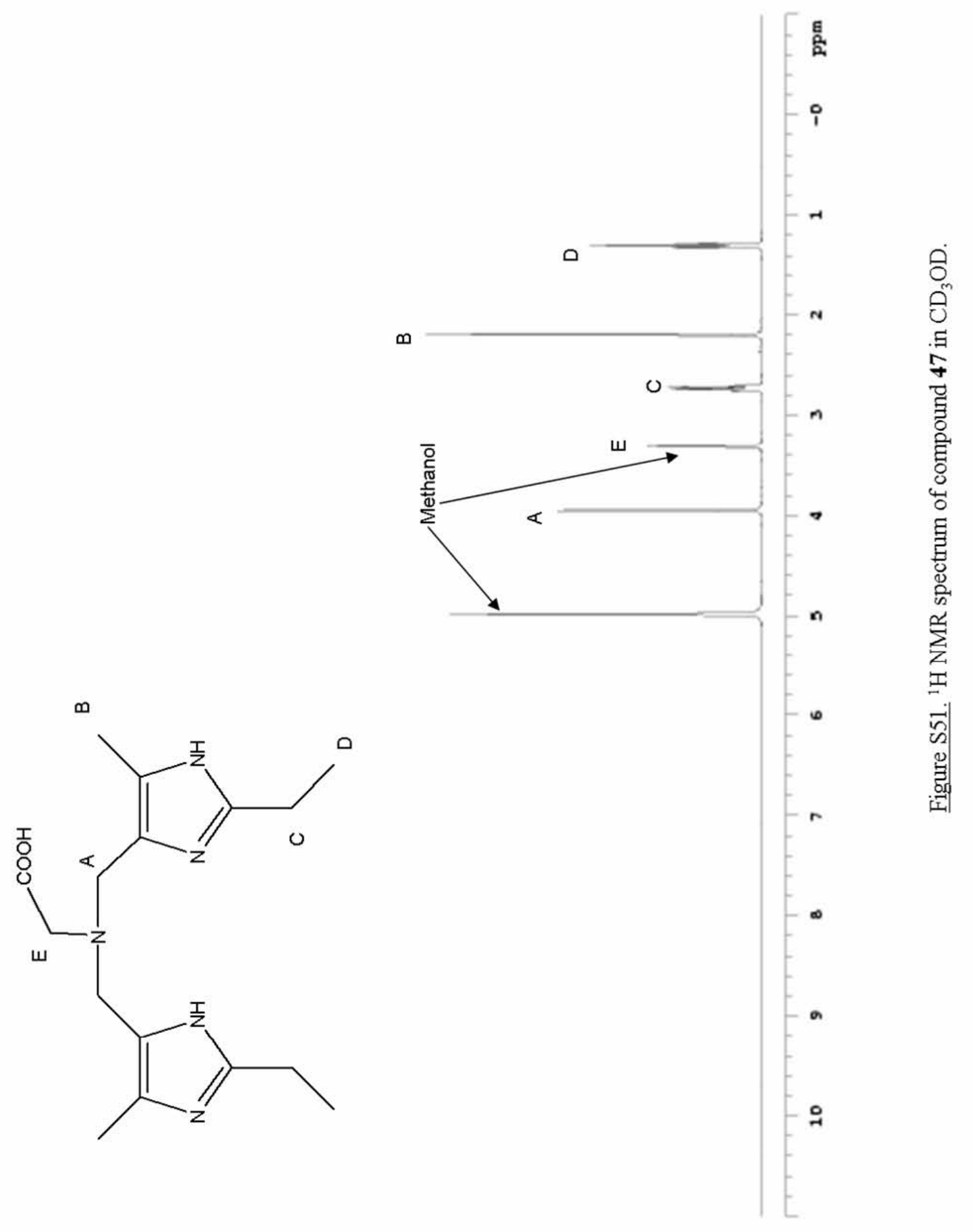




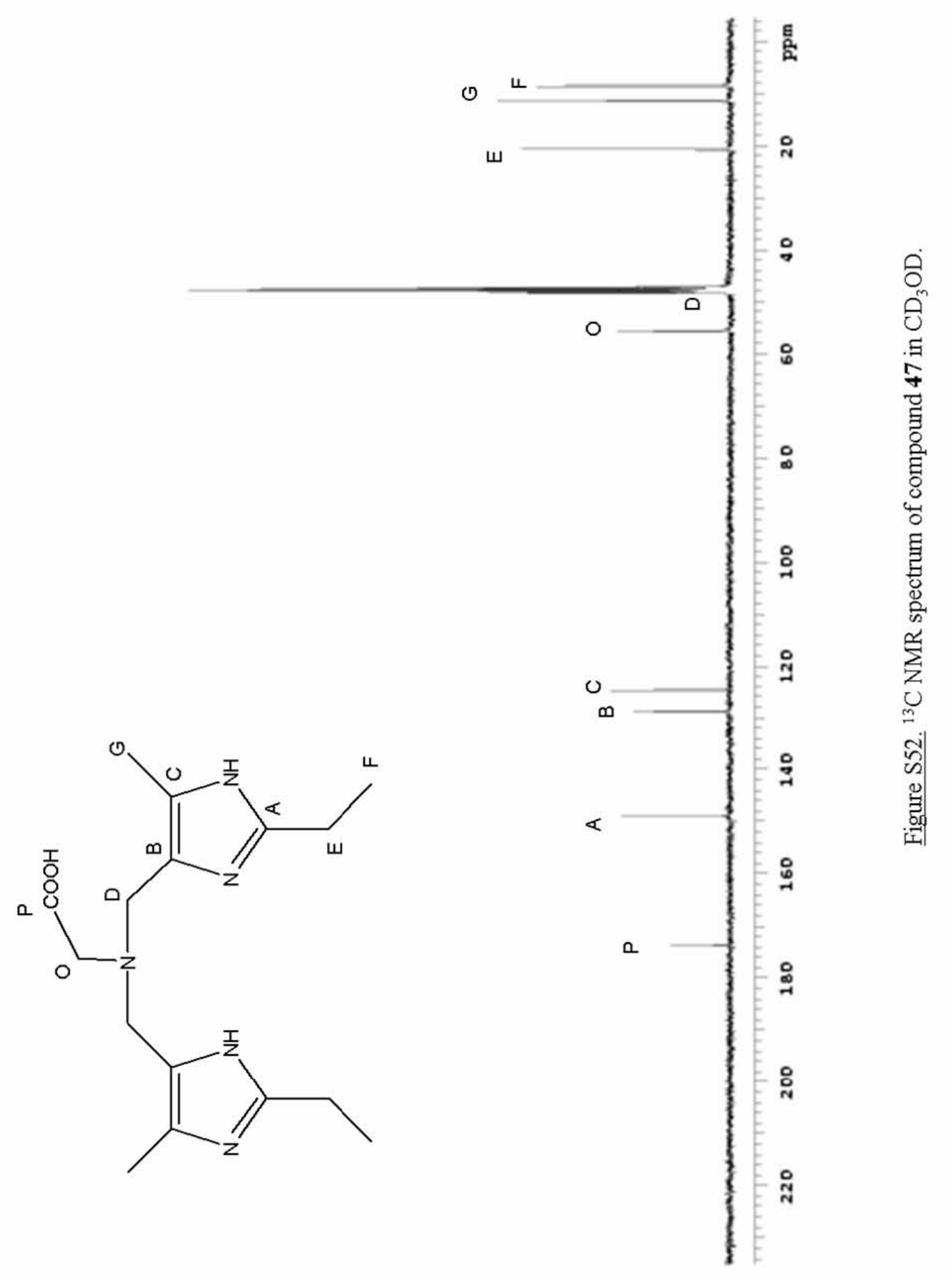




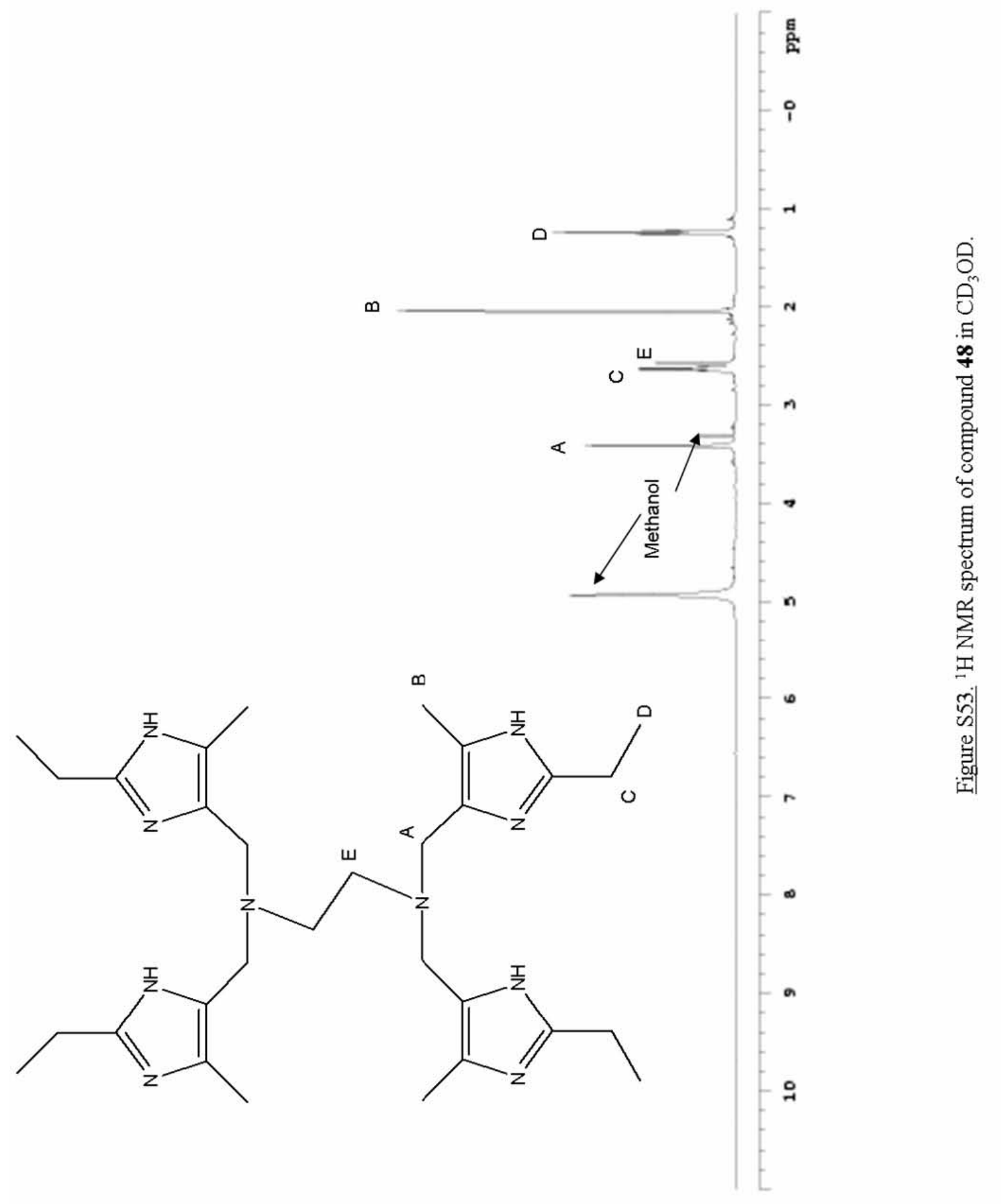




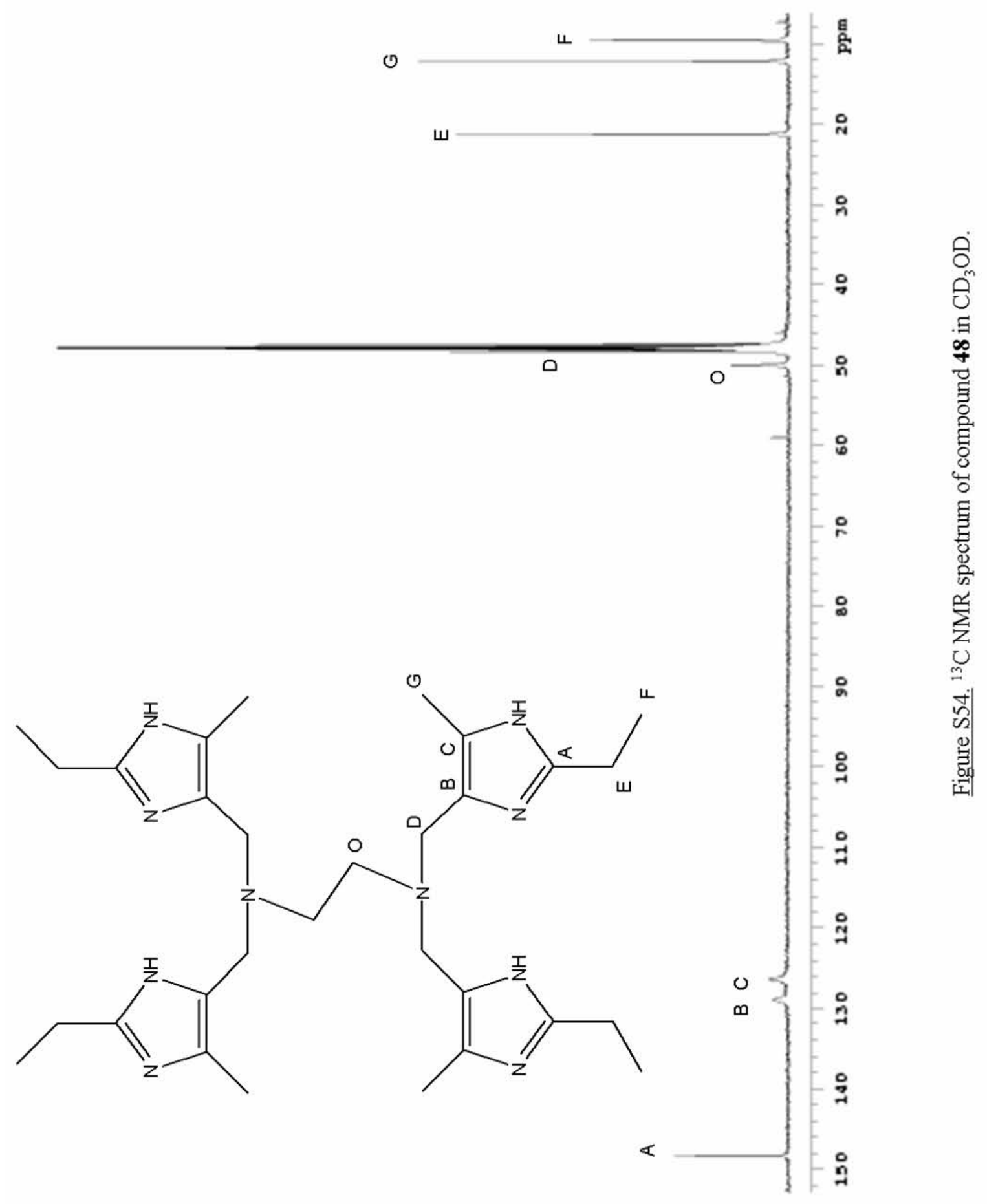




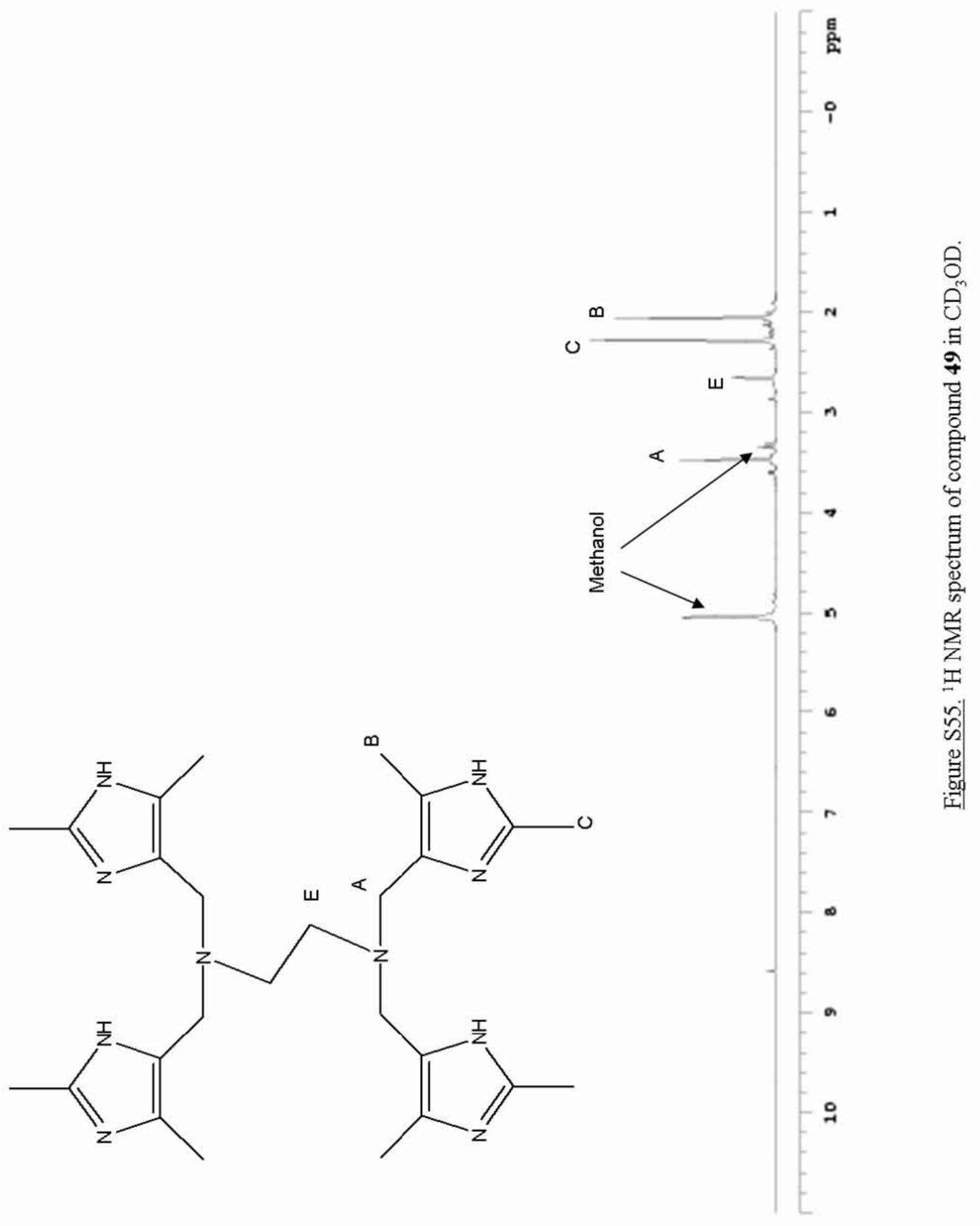




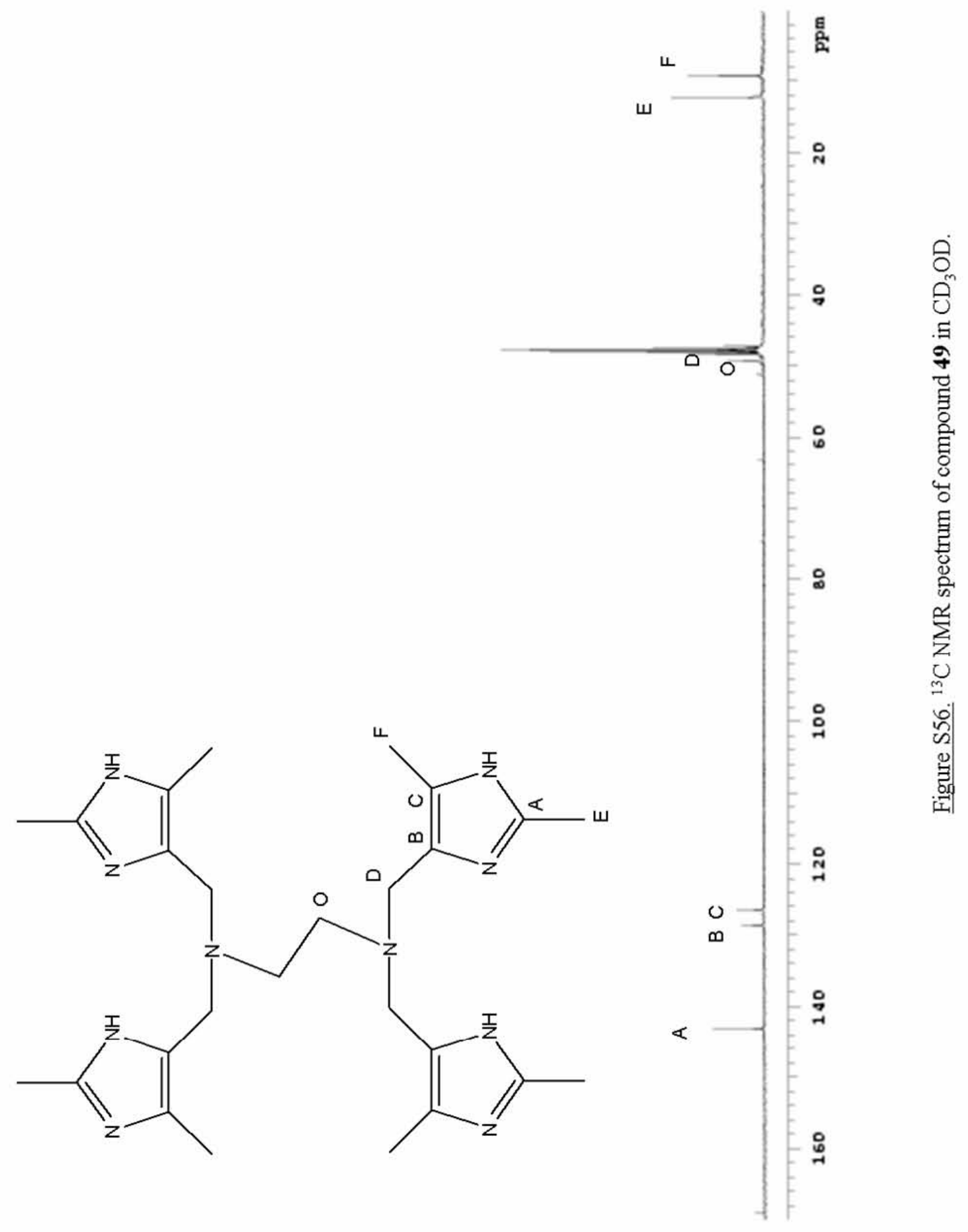


APPENDIX 3

\section{TGA AND DSC PLOTS}

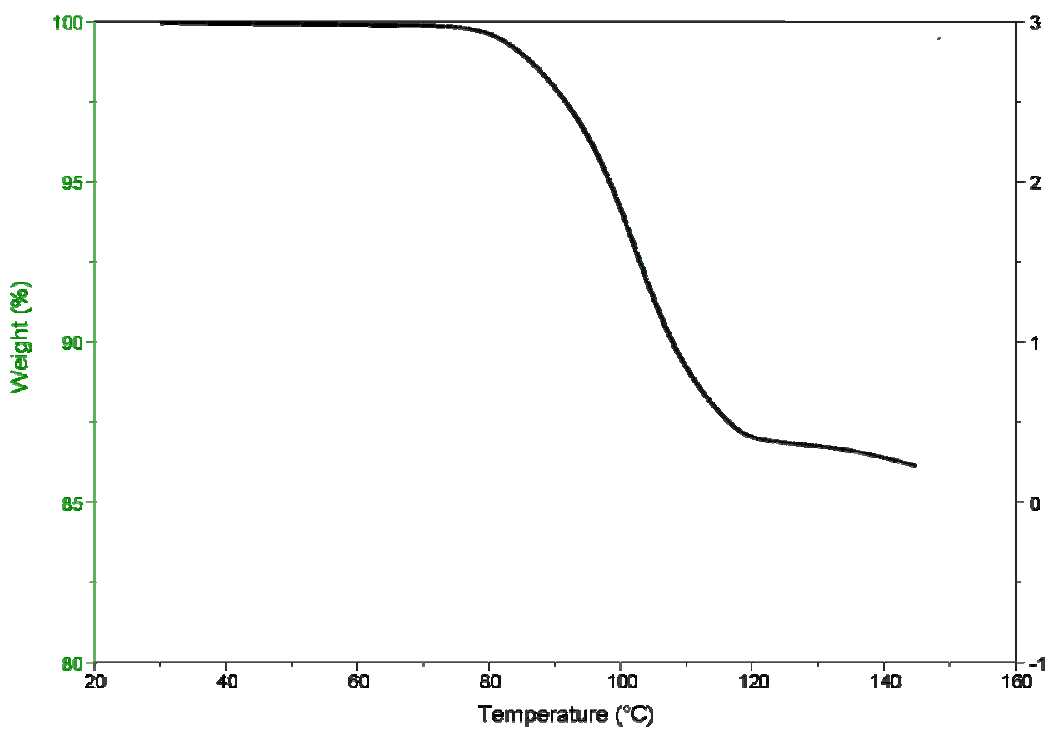

Figure S57. TGA plot for compound 47.

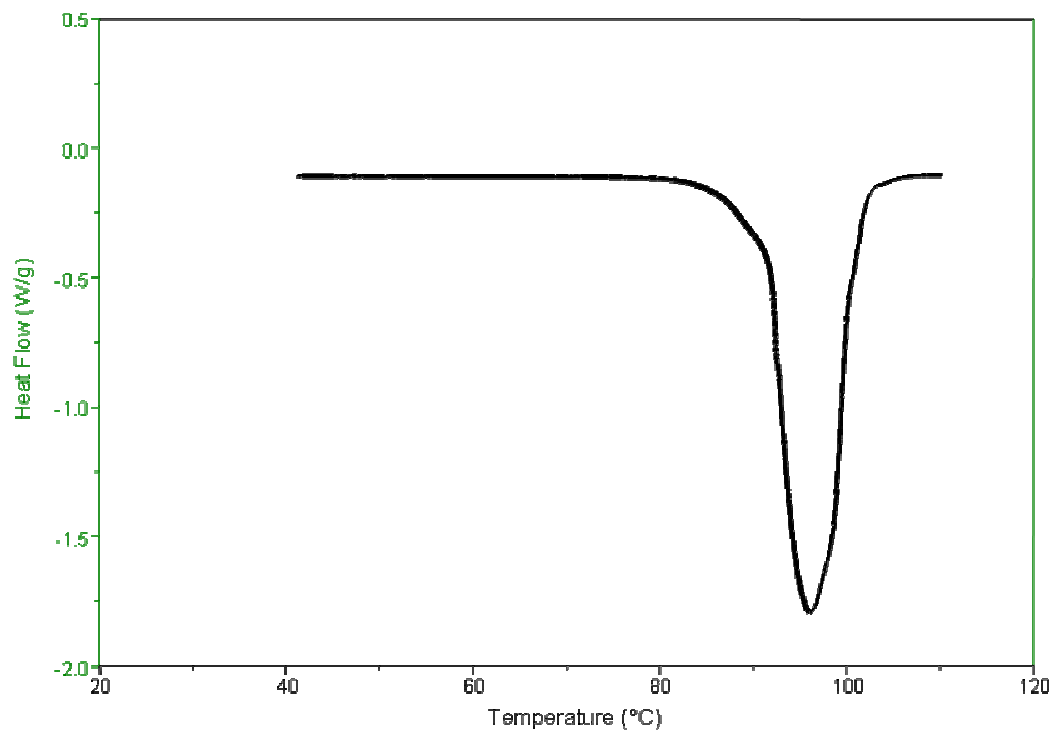

Figure S58. DSC plot for compound 47. 


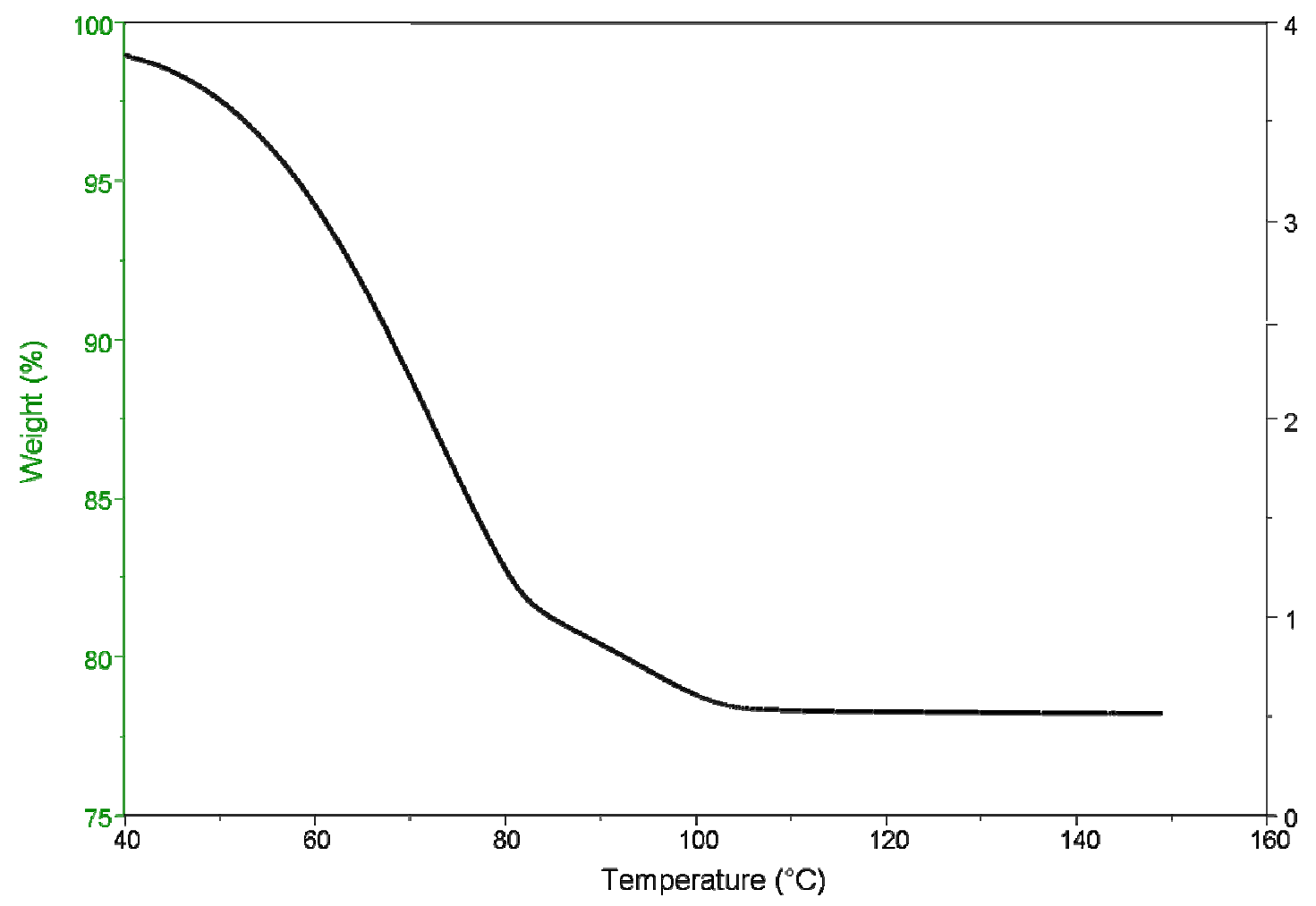

Figure S59. TGA plot for compound 48.

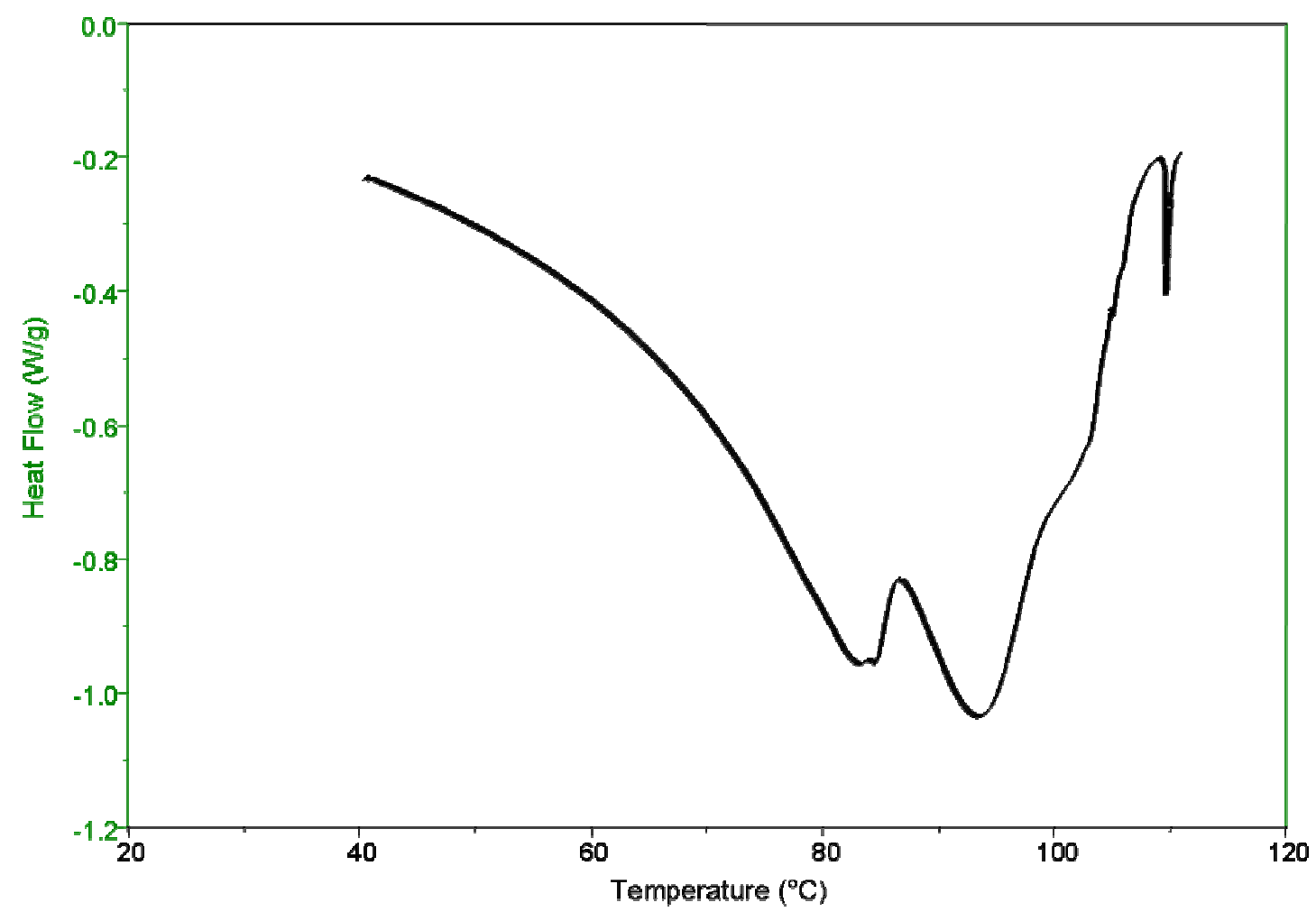

Figure S60. DSC plot for compound 48. 


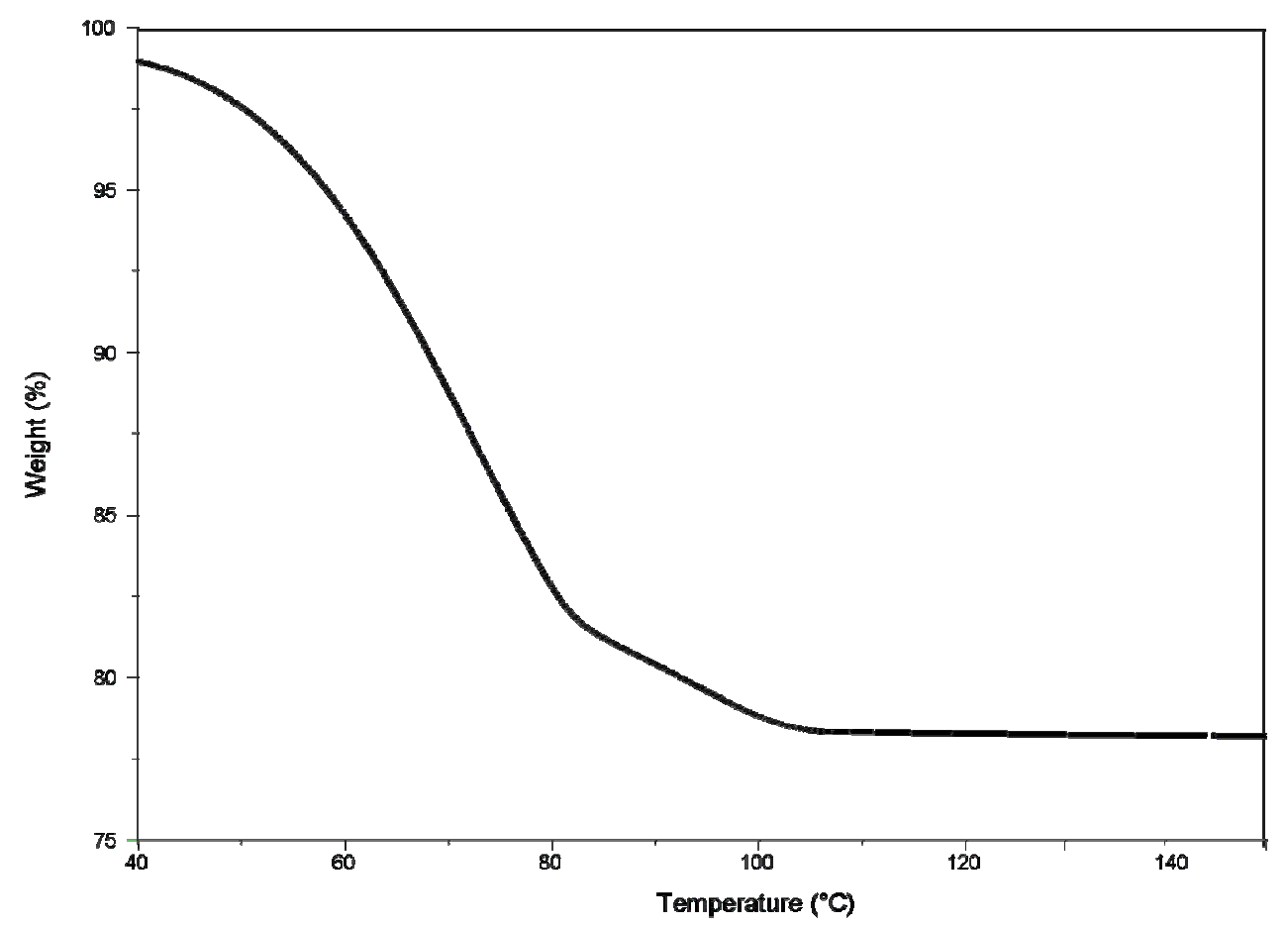

Figure S61. TGA plot for compound 52.

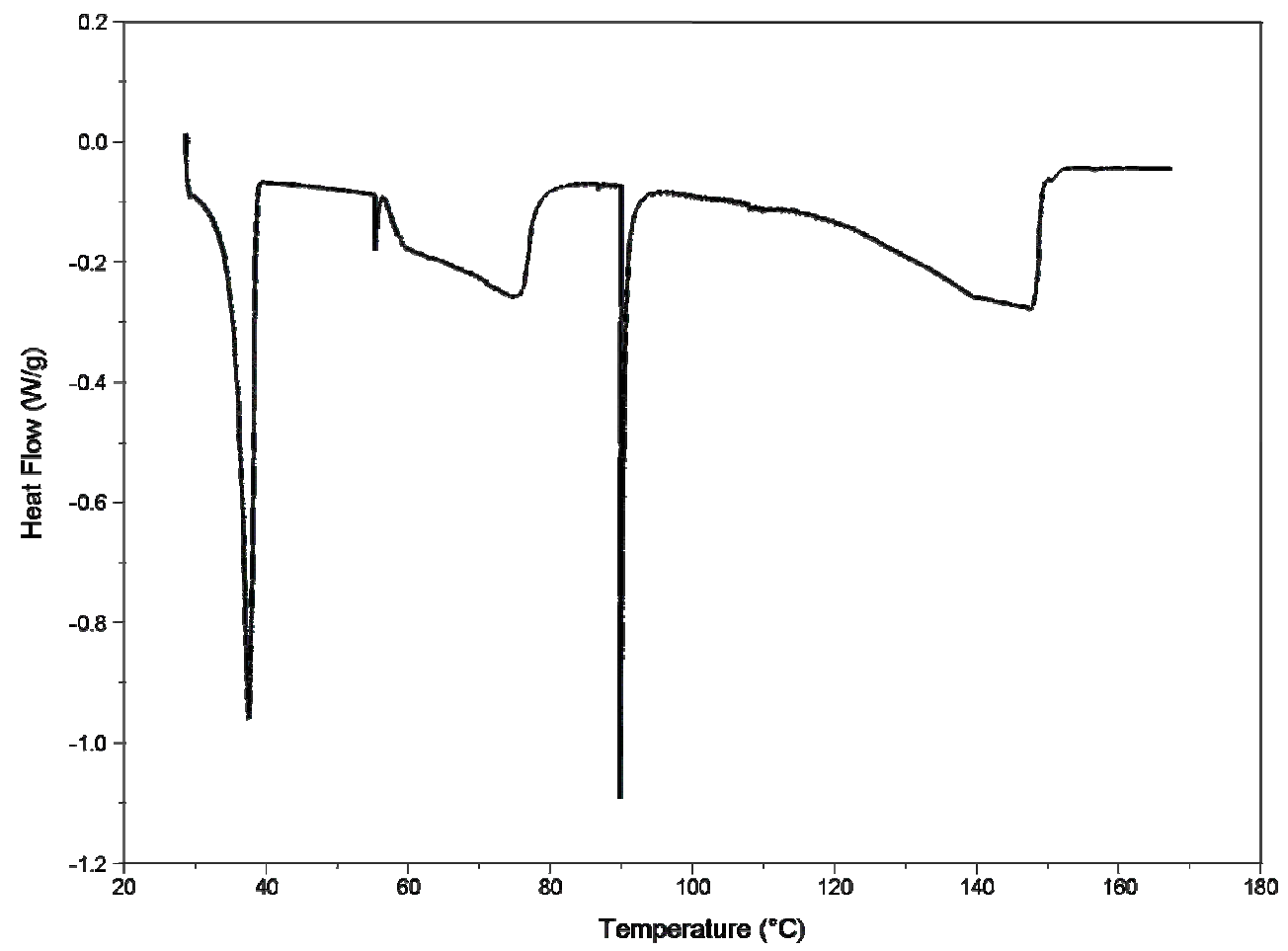

Figure S12. DSC plot for compound 52. 


\section{CURRICULUM VITAE}

NAME: $\quad$ Lionel Emeric Chéruzel

ADDRESS: Department of Chemistry

Univeristy of Louisville

2320 Brook Street, Room 138

Louisville, KY 40292

DOB: $\quad$ Cannes, France - October 23, 1976

EDUCATION:

December 2004 Ph.D., Chemistry, University of Louisville, Louisville, KY.

Research Advisor: Prof. Robert M. Buchanan.

Dissertation: Probing the properties of the second coordination sphere of biologically relevant metal complexes using amide functionalized imidazole ligands and other hydrogen bonding moieties.

2000

French engineer (USA equivalent: Master of Science), Ecole Nationale Superieure de Chimie de Montpellier, Montpellier, France.

PROFESSIONAL EXPERIENCE:

1999-2004 Research Assistant, Dr. Robert M. Buchanan

Synthesis and characterization of metal binding pockets and stabilization of one-dimensional water chains:

Synthesis of ligands and characterization of metal complexes: ${ }^{1} \mathrm{H}$ and

${ }^{13} \mathrm{C}$ NMR, ESI-MS, IR, UV-vis, X-ray crystallography, EPR and solid state NMR.

- Computational chemistry. (have used Gaussian 98, MMII and Insight II).

- Mentored and supervised undergraduate research students and new graduate students.

2003-2004 X-ray crystallography research fellow under the supervision of Dr. Mark S. Mashuta.

1999-2003 Teaching assistant for organic and inorganic laboratory.

- Conducted advanced undergraduate inorganic laboratory sessions. 
- Conducted organic I laboratory sessions.

- Coordinated laboratory materials and graded laboratory reports.

10/1998-07/1999 Engineer internship, Aventis Pharma (ex- Hoescht Marion Roussel), Neuville-sur-Saone, France. (Improved industrial synthetic processes laboratory).

- General laboratory techniques in organic chemistry.

07/1997-10/1998 Engineer training-course, Solvay-Alkali, Rheinberg, Germany; Research and Development laboratory.

- General laboratory techniques in organic chemistry.

09/1996 Technician training-course, Robertet, Grasse, France; (Research/Development laboratory).

- Extraction and characterization of natural products.

\section{PUBLICATIONS:}

"A Supramolecular Assembly of Side-by-Side Polyimidazole Tripod Coils Stabilized by $\pi-\pi$ Stacking and Unique Boric Acid Templated Hydrogen Bonding Interactions". Cheruzel, L. E.; Mashuta, M. S.; Buchanan, R. M. manuscript submitted to Chem. Comm.

"Structures and solid-state dynamics of one-dimensional water chains stabilized by imidazole channels" Cheruzel, L. E.; Pometun, M. S.; Cecil, M. R.; Mashuta, M. S.; Wittebort, R. J.; Buchanan, R. M. Angew. Chem. Int. Ed., 2003, 42, 5452-5456.

"Tris[(1-methylimidazol-2-yl)methyl]-amine-boric acid (1/1)" Mashuta, M. S.; Cheruzel, L. E.; Buchanan, R. M. Acta Cryst. C 2002, 58, O629-O631.

"Structure and properties of an Fe(III) complex containing a novel amide functionalized polyimidazole ligand" Cheruzel, L. E.; Wang, J. P.; Mashuta, M. S.; Buchanan, R. M. Chem. Comm.2002, 2166-2167.

"Synthesis and properties of mononuclear $\mathrm{Cu}(\mathrm{II})$ and $\mathrm{Cu}(\mathrm{I})$ complexes of a new bisamide functionalized polyimidazole ligand" Cheruzel, L. E.; Mashuta, M. S.; Buchanan, R. M. manuscript in preparation.

"Rational design and synthesis of novel amide functionalized imidazole ligands" Cheruzel, L. E.; Mashuta, M. S.; Buchanan, R. M. manuscript in preparation (to be submitted to J. Org. Chem.).

"Synthesis, structures and properties of $\mathrm{LMCl}_{2}$ and $\left[\mathrm{L}_{2} \mathrm{MCl}\right] \mathrm{Cl}$ complexes containing hindered bis-imidazole chelates" Cheruzel, L. E.; Cecil, M. R.; Chung, J.; Turner, C. C.; Mashuta, M. S.; Buchanan, R. M. manuscript in preparation.

\section{PRESENTATION:}

"New Directions in Enzyme Active Site Modeling Using Imidazole Chelates" Cheruzel, L. E.; Mashuta, M. S.; Buchanan, R. M. GRC Graduate Student Session, January $23^{\text {rd }}$ 2004. (oral). 
"Enzyme Active Site Modeling Using Novel Amide Functionalized Imidazole Chelates" Cheruzel, L. E.; Mashuta, M. S.; Buchanan, R. M. Ohio Inorganic Conference, November, 20 $0^{\text {th }}$ 2003. (oral).

"Synthesis, structures, and properties of metal complexes containing novel amidefunctionalized polyimidazole ligands" Cheruzel, L.E.; Mashuta, M. S.; Buchanan, R. M. $225^{\text {th }}$ ACS Meeting in New Orleans, March, 27 $7^{\text {th }}$ 2003. (oral).

"Synthesis, Properties and Dynamics of Novel Water Channel Nano-Assemblies" Cheruzel, L. E.; Pometun, M. S.; Cecil, M. R.; Mashuta, M. S.; Wittebort, R. J.; Buchanan, R. M. Research Louisville, Louisville 2003. (poster)

"Synthesis, Properties and Solid-state Dynamics of One-Dimensional Water Channels" Cheruzel, L. E.; Pometun, M. S.; Cecil, M. R.; Mashuta, M. S.; Wittebort, R. J.; Buchanan, R. M. NanoStrcutures symposium. (poster)

"Towards Stabilizing Cu(III)-oxo Complexes in Water" Cheruzel, L.E.; Cecil M. R.; Petrov, A.S.; Mashuta, M. S.; Pack, G. R.; Buchanan, R. M. 225th ACS Meeting in New Orleans.(poster).

\section{HONORS AND AWARDS:}

- Recipient of the 2004 John Richard Binford Memorial Award for outstanding achievement in graduate studies.

- X-ray crystallography fellowship 2003-2004.

- Research Louisville, Louisville 2003, $2^{\text {nd }}$ prize recipient in poster competition NanoStrcutures symposium, Louisville 2003, $2^{\text {nd }}$ prize recipient in poster competition.

- Chemistry Graduate Student Association officer, 2000-2001.

AFFILIATIONS:

American Chemical Society, Bioinorganic Divisions (2000 to present)

\section{LANGUAGE SKILLS:}

French: native fluency

English: fluent

German: basic knowledge

\section{REFERENCES:}

Professor Robert M. Buchanan

Professor of Chemistry

University of Louisville

bob.buchanan@1ouisville.edu

Professor John O. Trent

Professor of Chemistry

University of Louisville

john.trent@louisville.edu
Professor George R. Pack

Chairman, Chemistry Department

University of Louisville

george.pack@louisville.edu

Professor Craig R. Grapperhaus

Professor of Chemistry

University of Louisville

grapperhaus@louisville.edu 